

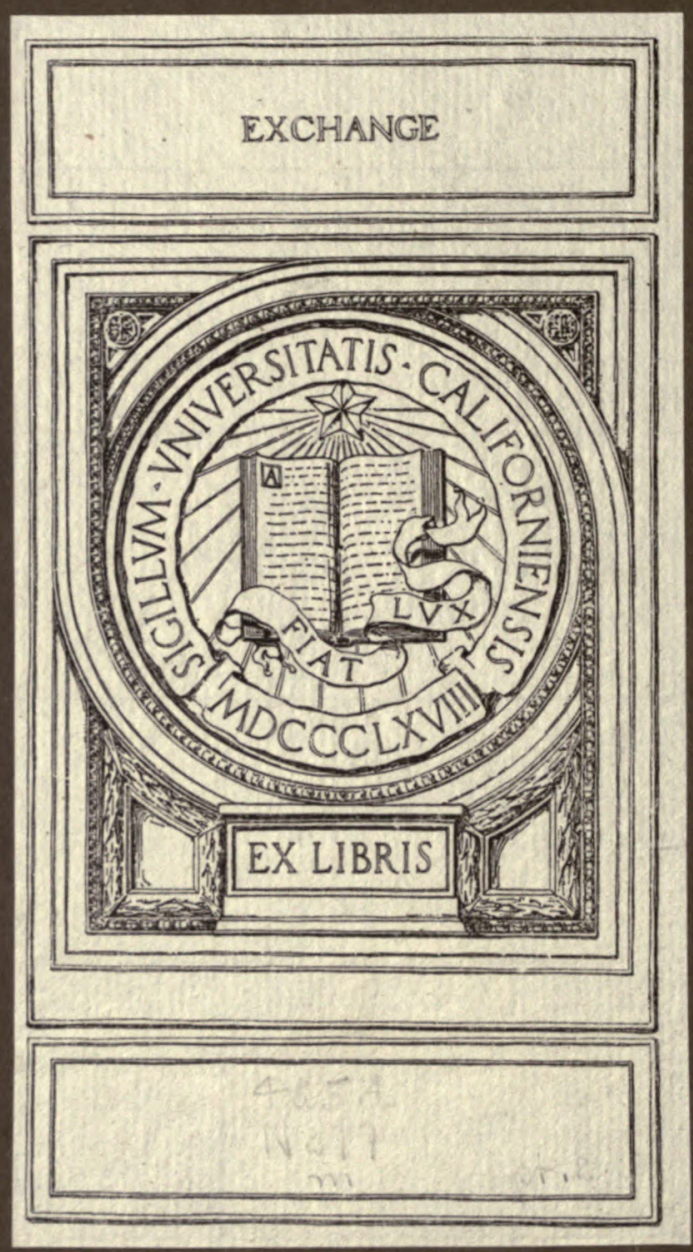







\section{NATIONAL ANTARCTIC EXPEDITION 1901-1904.}

\section{METEOROLOGY \\ PART II}

COMPRISING DAILY SYNCHRONOUS CHARTS 1st OCTOBER, 1901, to 31st MARCH, 1904.

PREPARED IN THE METEOROLOGICAL OFFICE, UNDER THE SUPERINTENDENCE OF

M. W. CAMPBELL HEPWORTH, C.B., R.D., COMMANDER R.N.R. MARINE SUPERINTENDENT.

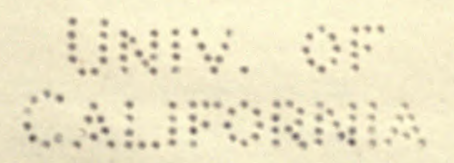

LONDON :

PUBLISHED BY THE ROYAL SOCIETY.

1913. 


\author{
Meteorological Office, \\ South Kensington, \\ LoNDON, S.W. \\ 17th February, 1918.
}

To Sir Archibald Geikie, K.C.B.,

Sir,

President of the Royal Society.

I have now the honour to forward the corrected proof of the "Remarks," introductory to the Daily Synchronous Charts of the Southern Quarter of the Globe, which were prepared, under my direction, to represent the results of the international co-operation in meteorological work for the National Antarctic Expedition, 1901-1904.

These form the last instalment in discharge of the obligation which was undertaken for the Office by the Meteorological Council, in response to a request of the Royal Society, dated 30th September, 1904, and which devolved upon me in 1905 . It would serve no useful purpose now to enter into detailed explanations of the length of time that has been found necessary to complete the work. Of the members of the directing body, under whose guidance it was originally planned, all except myself have passed away —Sir William Wharton, Sir Richard Strachey, Dr. Alexander Buchan, Sir George Darwinand by a coincidence as tragic as it is deplorable, the final touches of the work, designed by international co-operation to elucidate the problems which the discoveries of the Antarctic explorers of 1901-1904 suggest, are delayed by the melancholy news of the loss of their leader, Captain RoBert Falcon ScotT, and of his four companions on their return from his second and successful attempt to reach the South Pole.

$$
\text { I am, Sir, }
$$

Your obedient servant,

W. N. SHAW,

Director. 
PREFACE.

THE present volume completes the publication of all the Physical results of the National Antaretic Expedition of which the supervision was undertaken by the Royal Society. It comprises Part II. of the Meteorology, of which Part I. was issued in 1908. The delay in the appearance of the volume has arisen ehiefly from the labour attending the preparation of the Charts, a task which has been earried through under the superintendence of Commander HzPworth, C.B., Marine Superintendent on the staff of the Meteorological Office, who has supplied the Introductory Text. It will be seen that the volume presents not only the detailed results of the daily observations of the Expedition, but combines also a large number of contemporary observations obtained by other Antaretic explorers, by observatories in various parts of the Southern Hemisphere, and by the Captains of vessels traversing the Antaretic seas. It thus offers a continuous daily picture of the changing meteorological conditions in the whole Antarctic region south of the 30 th parallel of latitude.

An opportunity is afforded here to refer to certain objections made by Captain Scotr to some of the statements contained in Part I. of the Meteorology, which was issued in the summer of the year 1908. Shortly before this distinguished polar explorer was about to sail on the Antaretic Expedition which he is now conducting, in letters addressed to me, he called attention to these statements containing criticisms of the work of his Expedition of 1901-1904. Some of these criticisms, in his opinion, showed a want of appreciation of the practical difficulties of observation in high latitudes, while others involved errors of statement which he wished to correct.

As regards the latter, he maintained, in the first place, that the observations of the directions of wind taken on the land were "true" and not, as was suggested, "magnetic." He pointed out that in a region like that around the Magnetic Pole, where the horizontal magnetic force is very slight and magnetic directions are constantly changing, and where, therefore, it is impracticable to travel by compass, it was necessary that constant attention should be given to keep the course true, and that this necessity was fully realised by himself and his staff. He therefore dissented from the suggestion (text, pp. 489, 490; Preface, p. xii.) that the observations recorded in Lieutenant Royps' important traverse across the icebarrier in the months of November and December, 1903, were probably made by compass. That suggestion occurs in connection with the contention that if a mean correction of $145^{\circ} \mathrm{E}$., which is the deviation at the Winter Quarters, be applied to these observations, the winds recorded as coming from the S.W. to the extent of 68 per cent. are found to be from E. by N. and are thus brought into harmony with those registered at the Winter Quarters. While protesting against this introduction of a magnetic correction, Captain ScoTr pointed out that the correction will not give the desired result, for it has been put in the wrong direction, viz,, westerly instead of easterly, and that even when it is correctly applied, the direction of the 68 per cent. of wind would be N. by E. and not E. by N., as stated in the Table on p. 490.

Captain Soort maintained that, apart from all explanatory theory, the wind observations taken on the sledge-journey in question were perfectly trustworthy, and were in harmony with those made during other sledge-journeys of the Expedition, which combine to indicate a preponderance of southerly and westerly winds in the region under observation, and as he conceives, lend no support to the generalisation that the dominant direction of the surface winds is there from the east.

Another complaint of Captain ScoTt had reference to the insertion of a column (No. 3, pp. 284-363) purporting to give the positions of the sledge-parties at noon each day of their journeys. He remarked that it is difficult to see how the figures in this column were obtained, and that they are constantly in error. Citing in illustration his own sledge-journey of October to December, 1903, he pointed out that 
whereas in the printed table he is stated to have been, on October 30,26 miles from the ship on sea-ice, he was really 80 miles from the ship, elimbing the Ferrar glacier; and, on December 16, when he is represented as being 95 miles from the ship, it is plain from the column of "Remarks," that he had returned to Winter Quarters and was comparing his aneroid with the ship's barometer. Captain ScotT intended to have adjusted these Tables before he sailed on his recent Expedition, but, in the hurry of his departure, seems to have found it impossible to do so.

It shonld be understood that when the Tables of the various sledge-journeys were in eourse of compilation at the Meteorological Office from the records made by the observers, great difficulty was experienced in obtaining information as to the daily positions. Two of the journeys are actually printed without positions, but for the other journeys the positions are printed as supplied to the Meteorological Office by Captain Scorr's instruction, in reply to a request addressed to the Royal Geographical Society. It is matter for regret, however, that after the return of the Expedition, when the staff of observers was dispersed, closer touch with them should not have been maintained.

With regard to the statement that "the explorers bronght back no certain information about the amount of slope of the barrier-surface towards the sea" (Preface, p. xii.), Captain ScotT contended that the staff possessed no means of discriminating between the influence on the barometer of the varying conditions of atmospheric pressure, on the one hand, and of differences in altitude, on the other. While fully realising the importance of distinguishing between these two causes, he knew of no practical means of discriminating them on sledge-journeys over the Antarctic ice-field, and he desired that proper allowance should be made for the apparently insuperable difficulties which have to be encountered. Nevertheless, it must be recognised that the separation of the influence of varying atmospheric pressure from that dependent on height above sea-level, is of such fundamental importance that no polar expedition ean now be regarded as completely equipped for meteorological and physiographical research unless it is provided with the means of conducting levelling operations, independently of barometric variations. The accurate measurement of the slope of the inland ice is required for the determination not only of the atmospheric pressure gradient towards the pole, but also of the flow of the ice-cap.
ARCH. GEIkIE,
24th Junuary, 1918.

\author{
President of the Royal Society.
}

Since the foregoing paragraphs were in type and ready to be printed off, tidings have come of the appalling tragedy of the death of Captain ScoTT and his companions on their return journey from the South Pole. It is not possible to allow this last eontribution from the voyage of the "Discovery" to he published without the addition of a few words expressive of the profound sorrow with which the loss of these brave men has filled the hearts of all those who were associated with them in connection with Antarctic exploration and its problems. We had learnt to appreciate the remarkable gifts of Captain ScoTT and Dr. E. A. WiLson as explorers, and their charm as personal friends. We looked forward to their return home, bringing with them another and still ampler harvest of results. They havo lost their lives in the cause of science, but their names are now imperishably graven on the bede-roll of the heroes of polar discovery.

A. G.

14th February, 1913. 


\title{
REMARKS ON THE CHARTS.
}

\author{
BY \\ M. W. CAMPBELL HEPWORTH, C.B., R.D., COMMANDER R.N.R.
}

The Collection of the Data.

Is connexion with the scheme of International Antaretic Exploration, inaugurated at the beginning of this century, which attained its fulfilment during the years 1901-04, arrangements were made by the British Meteorological Office and the Deutsche Seewarte conjointly, prior to the departure for the Far South of the British and German Expeditions, with a view to obtaining synchronous observations at Noon G.M.T. of barometric pressure, air temperature, and wind frequency, during the period October, 1901, to March, 1903, for Latitudes South of the 30th parallel of South Latitude.

For this country special registers, in a form agreed upon by the British and German Antaretic Committees, were issued to the Ships of H.M. Navy through the Office of the Hydrographer (the late Rear-Admiral Sir W. J. L. Wharton, K.C.B.). A circular letter, issued by the Meteorological Council to marine observers in correspondence with the Office and others engaged on Southern voyages, soliciting their eo-operation in this work, met with a ready response, and a large number of registers were distributed among the Commanders of Ships visiting the Southern Ocean, and numerous contributions resulted. Subsequently the period originally specified was extended to 31st March, 1904, in consequence of the detention of the "Discovery" in MeMurdo Sound, South Victoria Land.

The Observatories of the Colonies in the Southern Hemisphere contributed valuable records and observations in response to an invitation by the Royal Society.

By an arrangement between the Meteorological Office and the Deutsche Seewarte, an exchange of observations, recorded on board ships from which contributions on the special Registers were received by the respective Buresux, was effected. In addition to the data thus collected by the Office a large number of observations at noon G.M.T. were obtained from the "Discovery," "Morning," "Terra Nova," and "Scotia," relating to the passages of these vessels to and from the Antaretic and while cruising in Antaretic Seas; also from many stations in Cape Colony, Australasia, South America, Tierra del Fuego, and Kerguelen Island.

As regards information from stations in, and in the neighbourhood of, Antaretica, in addition to the meteorologieal records kept at Winter Quarters of the "Discovery" in MeMurdo Sound, observations were obtained relating to the "Gauss" station of the German Expedition, near Kaiser Wilhelm II. Land, Laurie Island-South Orkneys, and Snow Hill Island-Palmer Land, through the courtesy of the leaders of the German, Scottish, and Swedish Antaretic Expeditions, Professor von Drygalski, Dr. W. S. Bruck, and Dr. OTTO NoRDENsKJöLD, respectively.

Upon the information thus obtained are based the Daily Synchronous Charts of Sea-Level Pressure for Noon G.M.T., with winds and air temperature, as well as the Charts of mean monthly pressure and air temperature, and the Tables of average wind and gale frequency.

The list of contributors is as follows :-

Strps of the Royal Navy (H.M.S.), Exploring Vessels (E.S.), Steamships (S.S.), and Sailing Veesels (S.) of the Mercantile Marine, from which Observations were Received.

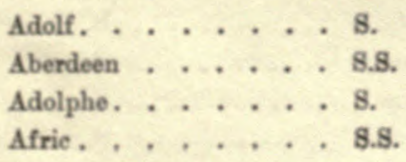

Alauda ........ $\mathbf{8}$.

Aleinous. ......8.

Alexandre . . . . . 8 .

Alliance. . . . . . s.
Alnwick Castle . . . S.8.

Alsterdamm . . . 8.

Altair. . . . . . 8 .

Amphion . . . . H.M.S. 


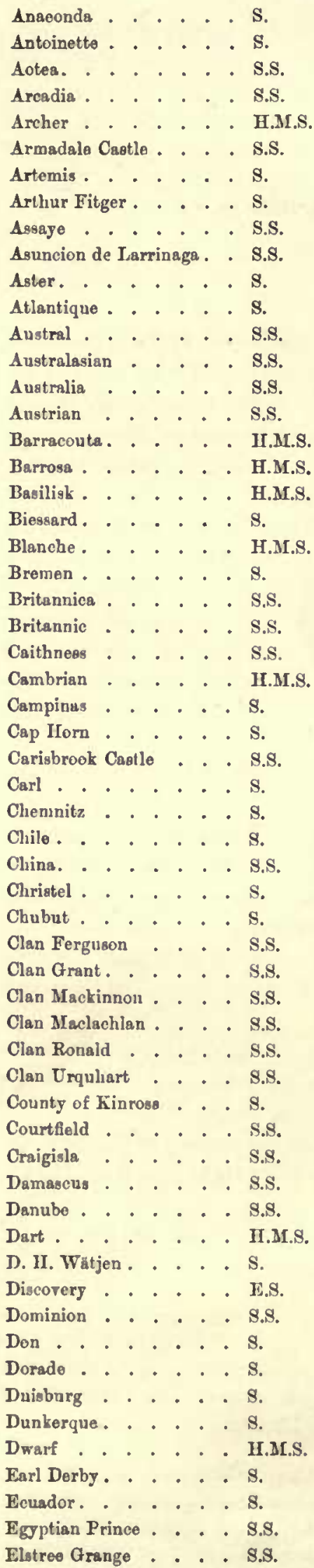

Emilie Siegfried . . . S.

Ems . . . . . . S.

Erne . . . . . S.

European . . . . S.S.

Falls of Iralladalo . . . S.

Forte. . . . . H.M.S.

Gause . . . . S.S.

Général de Sonis . . . S.

General Foy . . . . S.

Gibraltar . . . H.MI S.

Goorkha. . . . . S.S.

Gothic . . . . S.S.

Greta Holme . . . S.S.

Harlech Castie . . . S.S.

Irarold . . . . . $\mathbf{s}$.

IIeliades . . . . S.S.

Hera. . . . . s.

Heraclides . . . . S.S.

Hermione . . . . . S.

Herzogin Cecilie . . . S.

Hibernian . . . . S.S.

Hilarius . . . . . \$.S.

Himalaya . . . . S.S.

Icarus . . . . . H.M.S.

India . . . . . S.S.

Indralema . . . . S.S.

Jacqueline . . . . S.

Jason . . . . . S.S.

Juleo Gommes. . . . S.

Knikoum . . . . . S.S.

Kaipara . . . . . S.S.

Kalliope. . . . . . \$.

Karamea . . . S.S.

Karnak . . . . . S.

Karrakatta . . . . H.M.S.

Kilbride . . . . . . S.S.

Kinfauns Castle . . . S.S.

Knight of St. George . . S.S.

Königin Luise . . . . . \$.

Kumara . . . . . S.S.

Ladye Deria . . . . S.

L'A miral Jauréguiberry . S.

Largo Law . . . . S.

Lisbeth . . . . . S.

Lismore Castle . . . S.S.

Lizard . . . . H.M.S.

Loch Katrine . . . . S.

Loeh Tuy . . . . . S.

Loch Torridon . . . S.

Lutterworth . . . . S.

Lynton . . . . . S.

Macquarie . . . . S.

Madeleine . . . . \$.

Magdalena . . . . S.S.

Magpio . . . . H.M.S.

Mamari . . . . . S.S.

Maori . . . . S.S.

Marthe . . . . . S.

Matatua . . . . S.S.

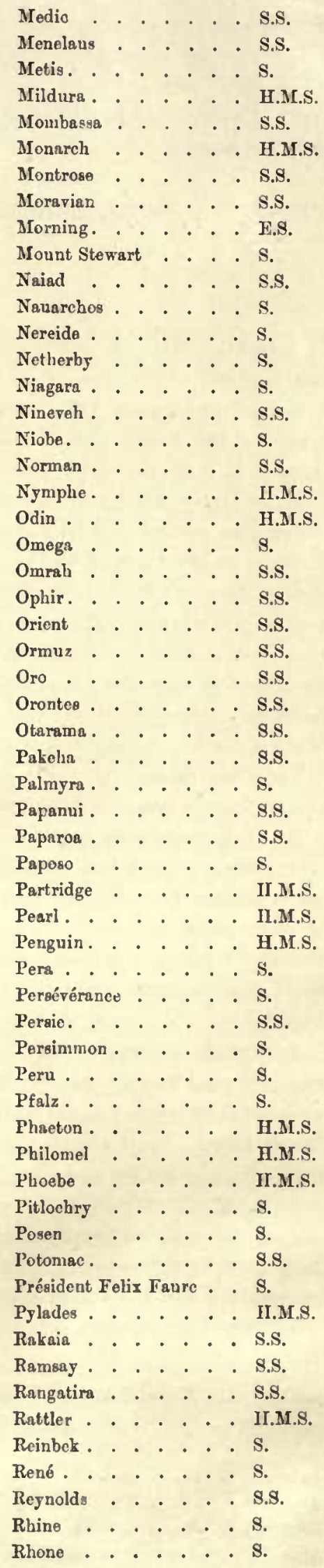


month 24 land observations have been charted. The smallest number of observations for a single day is 19 marine for 9th October, 1903, 10 land thronghout October, 1901, and 10 to 11 throughout March, 1904.

In the Registers issued by the Meteorological Office, observers were requested to give a few readings of their barometer in ports visited in order that the errol of the instrument might be estimated. Facilities were given for recording these readings in the Register by the introduction of a special form.

Some of the observations received from British ships were recorded by trained observers with properly verified instruments provided by the Office; the errors of these instruments were known; but the majority of instrumental observations were derived from barometers and thermometers supplied hy the owners of the vessels in which the observers were serving. The errors of these instruments were ascertained, when possible, by comparison with standards at various ports, and the corrections registered, verified or otherwise, by the comparison of readings noted in the special form of the Register with the corresponding values published in the Daily Weather Reports of the country in which the observations were taken.

Entries in the Registers of doubtful accuracy have been discarded, and it must be admitted that a small percentage of the wind observations charted are not in good agreement with the distribution of barometric pressure to which they are related, particularly as regards direction. The discrepancies may, in nost cases, be attributed to the failure of the observer to realise, or to make sufficient allowance for, tho effects of aberration caused by the vessel's own motion.

\section{The Daily aNd Monthly Charts.}

The result of the work is represented by daily charts for Noon Greenwich Mean Time with charts for monthly pressure and air temperature.

In somo respects the Daily Synchronous Charts are unique. The conditions which they are intended to represent at a given time each day, for a period of thirty months, refer to an area that is far larger than that embraced by any similar set of charts hitherto published. They include localities in the Antarctic, and furnish daily a link between the conditions existing simultaneously in frigid zones and in sub-tropical latitudes, represented on the one hand by three widely separated localities in Antaretica, and on the other by the southern segments of the tropical anticyclones of the Southern Hemisphere. They establish, as a fact, the permanence of these high-pressure areas of the great oceans, and show the gradual seasonal migrations of the South Atlantic, South Pacific, and Indian Ocean anticyclones by the slow oscillations of their southern edges.

Notwithstanding the large number of observations collated, the localities for which data are available for each daily chart are comparatively few, and frequently isolated, owing to the vastnoss of the area to which collectively they are related. Despite the sparseness of the observations charted, and the obvious incompleteness in sequence of the conditions which the charts aro designed to represent, the information they afford is considerable, for not only are the positions of many high- and low-pressure systems over various parts of the regions under notice indicated, but these "Highs" and "Lows" can, for the most part, be identified day after day, the means being thus afforded for tracing the directions in which their centres moved during more or less prolonged periods.

The limits of areas over which cyclonic depressions exercised an influence can, moreover, in a few instances be defined and occasionally the places of their origin or extinction roughly determined.

As regards the charts of monthly pressure and air temperature at sea-level for each of the thirty months under notice, althongh the number of observations upon which they are based is comparatively small, even for those months in which the more ample data are availablo, it may nevertheless bo claimed that they exhibit broadly the more salient features in the distribution of the respective elements they represent during the periods to which they refer. In addition, the charts of mean monthly pressure and air temperature side by side with thoso of normal pressure and air temperature supply the means for comparing the distribution of theso elements, in the several months, with the average distribution.

The tables of monthly average wind and gale frequency introduced assist in the interpretation of the mean monthly chart. 


\section{DISCUSSION OF CERTAIN CONCLUSIONS DRAWN FROM THE STUDY OF THE SYNCHRONOUS CHARTS OF SEA-LEVEL PRESSURE POR NOON G.M.T. WITH WIND AND AIR TEMPERATURE.}

\section{The Paths of the Cyclonic Depressions of the Southern Ocean.}

Hitherto adequate information has been wanting for the purpose of defining the average paths of cyclonic depressions which visit the Southern Ocean and Southern Continents during the several seasons of the year, and this information these circumpolar charts to some extent supply.

An attempt was made by the present writer in the year 1890 to determine, by the aid of observations extracted from a large number of logs relating to voyages between the Cape of Good Hope and Australasia during the three years $1887-9$, the mean paths of the centres of cyclonic systems moving eastward South of the 38th parallel of latitude, ${ }^{*}$ and subsequently to trace the centres of high- and low-pressure systems in transit eastward over Australasia, $\uparrow$ by reference principally to synoptic eharts prepared at the Sydney Observatory under the direetion of the late Mr. H. C. RusselL, then Government Astronomer for New South Wales.

From the information obtained by means of the data contained in the logs referred to it was inferred that East of the 30th meridian of East longitude the centres of atmospherie disturbances appeared to travel to the eastward usually on paths lying South of the 43rd parallel of latitude during winter months and South of the 46 th parallel during summer months. The evidence afforded by the daily synoptic charts of Australasia also appeared to favour this assumption, which is now confirmed by the testimony of the daily eharts under notice.

In a memoir by the writer upon the Climatology of South Vietoria Land and the Neighbouring Seas, which is included in the published results of meteorological observations of the "Discovery" Expedition, during the years 1901 to 1904 , attention is directed to the exceptionally favourable position, regarded as a meteorological station in the Southern Ocean, in which the Winter Quarters of the Explorng Ship "Gauss," of the German Antaretic Expedition, was situated. The value of the data obtained at this station, on the fringe of Antaretica, is, moreover, considerably enhanced by observations recorded at the German station on Kerguelen Island, because together they throw light upon points in connexion with the surface distribution of pressure and wind in eyelonic systems of the Southern Ocean, in regard to which little has hitherto been known.

The following remarks in this connexion, which appear in the memoir referred to, are based upon the data incorporated in the daily charts; it is, therefore, considered admissible to repeat them in these pages.

Lying to the South of the westerly winds of the Southern Ocean, and at the limits of the southern segment of those low-pressure areas which move from West to East with the westerly air current of the Southern Hemisphere, the Winter Quarters of the German Antarctic Expedition were exceptionally well situated as an observing station from a meteorological point of view.

It has been thought by meteorologists, who have attacked the problem, that, associated with the depressions which traverse the Southern Oceans, depressions which are usually elliptical in shape and have their major axes extended in a northerly and southerly direction, the easterly winds in the southern segment of the system are almost always light or moderate in force. Ships running down the easting in

- "Wind Systems and Trade Routes between the Cape of Good Hope and Australin," "Quarterly Journal, Royal Meteorological Society,' Vol. XVII. (1891), pp. 21-27.

+ "The Tracks of Oeean Wind Systems in Transit across Australasis," 'Quarterly Journal, Royal Meteorological Bociety,' Vol. XIX. (1893), pp. 34-38.

₹ "Climatology of Vietoria Land and the Neighbouring Seas," 'National Antaretie Expedition, Meteorology;' Part I. 
high southern latitudes seldom experience strong winds or gales from Lastward, even when there appears to be evidence to show that they are situated well to the south of the central "low" of a cyelonie wind system. It has, therefore, been assumed that in these systems the gradient polewards is normally slight, and that on its southern side the low pressure dominates but a small area.

The results of observations obtained by the German Expedition at Kerguelen Island and at Kaiser Wilhelm II. Land go far to prove that depressions whieh traverse the Southern Ocean cover a much larger area on their southern side than was hitherto supposed, and that although Easterly gales are seldom met with on the trade rontes referred to, nevertheless they occur, considerably further south, it is true, but still within tho limits of the system and forming part of their circulation.

The rise of temperature which was associated with gales from Eastward at the "Gauss" Winter Station and which, as a rule, continued until the wind began to moderate, may be attributed to the circulation of warm air drawn from lower and warmer latitudes about a minimum pressure far north of the station.

Frequently the daily observations at noon G.II.T. of barometer and wind recorcled by the German Antarctic Expedition at Kerguelen Island and at the "Ganss" Winter Quarters respectively-tho former supplemented and confirmed by similar observations made on board ships situated in the neighbourhood of the island-indicate a connexion between the strong winds and gales from Northward and Westwarl associated with diminishing pressure at Kerguelen and the strong winds and gales from eastward experienced at the "Gauss" station. The distance between the meridians of these two stations respectively, on a middle latitude of $57^{\circ} 43^{\prime} \mathrm{S}$., is about 630 miles. As instances in which the common origin of these increases in wind force, experieneed at the two stations, is shown, the following cases are cited. Doubtless the fuller data in the possession of the German meteorologists bring into greater prominence the connexion referred to. It should be understood that noon G.M.T. observations only are cited.

\section{8th to 20th Felruary, 1902.}

At Kerguelen Island on the 18th February, 1902, at noon G.M.T., the larometer stood at $29 \cdot 75$ inches, the thermometer at $45^{\circ} \mathrm{F}$; ; the wind was from West, force 5. Next day the mereury had fallen to 29.43 inches, the temperature had risen $1^{\circ}$; and tho wind, still from West, had increased to a fresh gale, indicating a gradient to the South. On the 20 th the barometer had risen to $29 \cdot 80$ inches, the thermometer showed a drop in the temperature to $42^{\circ} \mathrm{F}$, and the wind had backed to West-south-west. The depression was passing away to the eastward.

By this time, at noon G.M.T., on the 20th, on board the "Ganss," in latitude $65^{\circ} 55^{\prime}$ S., longitude $90^{\circ} 20^{\circ} \mathrm{E}$., the barometer indicated a pressure of $29 \cdot 55$ inches, which was diminishing, the thermometer marked $28^{\circ} \mathrm{F}$, and a fresh breeze was blowing from East. The mercury had fallen to $29 \cdot 28$ inches on the 21st in latitude $66^{\circ} 17^{\prime} \mathrm{S}$., longitude $90^{\circ} 43^{\prime} \mathrm{E}$.; temperaturo had risen to $31^{\circ} \mathrm{F}$., and the direction and force of the wind were the same as on the previous day. On the 22nd, the "Gauss" being then in her Winter Quarters, the mercury had fallen but slightly, to 29.25 inches; the temperature had dropped to $25^{\circ} \mathrm{F}$., and a strong gale was blowing from Vast-by-south. The gale had not abated at noon G.M.T. on the day following, when the direction of the wind had changed to East. The barometer then stood at 29.23 inches, the thermometer at $24^{\circ} \mathrm{F}$. The mercury had fallen to 29.14 inches on the 24 th; temperature had risen to $29^{\circ} \mathrm{F}$., but the gale was abating.

\section{$23 r$ to 28 th April, 1902.}

On the 23rd April of the same year, at noon G.M.T., pressure at Kergitelen Island had fallen $0 \cdot 71$ inch and temperature had risen $8^{\circ} \mathrm{F}$. during the preceding 24 hours. The barometer then read $29 \cdot 20$ inches and the thermometer $48^{\circ} \mathrm{F}$; ; the breeze blew freshly from West-north-west. $\Lambda$ t tho samo G.M.T. a barometer reading of 29.58 inchos was recorded at the "Gauss" station; the temperature was $9^{\circ} \mathrm{F}$., and the wind gentle from East-south-east. On the 24 th the mercury lad risen to $29 \cdot 33$ inches at Kerguclen Island, the temperature had dropped to $34^{\circ} \mathrm{F}$, and the wind had backed to South-west-loy-west and moderaterl. The disturbance, with which the diminution of pressure at the island had been associated, was then passing away to the eastward. At the "Gauss" station tho mercury had by this time fallen to 
$29 \cdot 35$ inches, the thermometer had risen to $17^{*} \mathrm{~F}$, and a strong gale from East-by-north had set in. The mereury continued to fall, on the 25 th it had fallen to $29 \cdot 11$ inches, and the thermometer marked $16^{\circ} \mathrm{F}$.; the direction of the wind had not changed, but the force had inereased to 10 .

Ths barometer was down to 28.49 inches on the 26 th ; the thermometer had risen to $17^{*} \mathrm{~F}$, and the wind still blew with the force of a whole gale from East-by-north. On the day following the mercury had risen to 28.72 inches and was still rising; temperature had dropped to $16^{\circ} \mathrm{F}$, and the gale continued, unabated, from the same point. The wind moderated on the $28 \mathrm{th}$, when the mereury had risen to $29 \cdot 23$ inches.

\section{and to 6th May, 1902.}

Between the 2nd and 6th May, 1902, pressure at Kerguelen Island diminished from 29.92 inches to 28.84 inches, and fresh winds were experienced from North-westward, backing to Westward. The temperature between the 4 th and 5 th had risen from $34^{\circ}$ F. to $42^{\circ}$ F. From the 4 th to the 7 th of the month, inclusive, the "Gauss" station was visited by a strong to whole gale from East-by-north, pressure having diminished from $29 \cdot 24$ inches, on the $3 \mathrm{rd}$, to 28.52 inches on the $6 \mathrm{th}$, and temperature risen during that period from $-4^{\circ} \mathrm{F}$. to $21^{\circ} \mathrm{F}$.

\section{5th to 19th May, 1902.}

Again, between the 15th and 17th of the same month, pressure at Kerguelen Island declined from 29.33 inches to 28.90 inches, and temperature rose from $30^{\circ} \mathrm{F}$. to $42^{\circ} \mathrm{F}$. Strong winds from between West-north-west and West-south-west were recorded at this time and also on the 18 th at the island, and strong winds and gales on board ships in the neighbourhood of the island.

At the German station in the Antaretic the barometer showed a fall from $29 \cdot 23$ inches to 29.09 inches between the 17 th and 18 th, the thermometer a rise from $9^{\circ} \mathrm{F}$. to $13^{\circ} \mathrm{F}$., and the wind, from East-by-north, increased in force to a fresh gale. On the 19th the barometer had risen to $29 \cdot 24$ inches, and the wind inereased from the same point to a whole gale. Next day the mereury had risen to $29 \cdot 43$ inches, temperature had dropped to $8^{\circ} \mathrm{F}$., and the gale was over.

4th to 7th June, 1902.

A rapid diminution of pressure, rise of temperature, and inerease of wind to gale force, which occurred from the 4th to the 6th June at the Antaretic station, was evidently associated with a diminution of pressure and increase of wind to gale force previously recorded (between the 3rd and 5th of the month) at Kerguelen Island and on board the S.S. "Waimate," in a position, on the 4th, rather more than 100 miles south of the island.

Subsequently, between the 6th and 7th of June, the "Waimate," passing the meridian of the "Gauss" station in latitude $50 \frac{1}{2}^{\circ} \mathrm{S}$., experienced a fresh to strong gale from West-south-west, veering to Northwest, while pressure increased at the Antaretie station, and the wind moderated from a whole gale to a strong breeze.

\section{5th to 8th July, 1902.}

On the 5th July a rapid fall of the mercury recorded at Kerguelen Island and on board ships approaching the neighbourhood of the island resulted in an increase of wind on the 6th, which had backed from North-west to West, and blew a fresh gale from the latter direction. During these two days the mercury at the "Gauss" station fell 0.58 inch, and the thermometer rose 11 , and on the 7 th an increasing wind attained the force of a fresh gale. The barometer then commenced to rise; the temperature had risen $5^{\circ}$ since the preceding day, and marked $21^{\circ} \mathrm{F}$. Next day the gale was over.

\section{1th to 18th July, 1902.}

From the 12th to the 13th of the same month barometric pressure at Kerguelen Island declined from 29.82 inches to 28.84 inches, the wind at the same time backing from North-west to West, and freshening. Between the 11th and 12th the thermometer had risen $4^{\circ}$. 
On the 13th a light Sonth-west breeze obtained at the Antarctic station, pressure increasing, the temperature $-11^{\circ} \mathrm{F}$. On the 14 th the barometer there read as high as 29.58 inches; the temperature had risen to $-4^{\circ} \mathrm{F}$., but the wind had backed to East-by-south, and was entered in the record as a fresh breeze. On the 15 th the mereury had fallen half an inch, the thermometer risen $19^{\circ}$, and the wind was blowing with storm force from East-by-north. With a slight recovery of pressure on the 16th, it moderated to a fresh gale, but subsequently inereased to a strong gale, still from the same point, and this continued, pressure the while declining, until the 18 th, when the barometer had fallen to $28 \cdot 61$ inches, and the thermometer marked $17^{\circ} \mathrm{F}$. Pressure recovered next day and the wind moderated, but the temperature had risen to $20^{\circ} \mathrm{F}$; it fell, however, on the 20 th to $1^{\circ} \mathrm{F}$.

\section{Soth July to Sth August, 1902.}

A rapid fall in the barometer from 30.37 inches to 29.62 inches occurred at Kerguelen Island between the 30th and 31 st July, oceasioning an inerease of wind, and associated with a slight rise of temperature. On these days the mereury fell 0.4 inch at the "Gauss" station, and the direction of the wind changed from West-north-west on the 30th to East-by-south on the 3lst, increasing in force at the same time. On the 1st August the mercury had fallen as low as $27 \cdot 82$ inches, and a whole gale was blowing from Eastby-north. The temperature had risen $10^{\circ}$ sinee noon G.M.T. of the preceding day.

A diminution of pressure and decrease in wind force recorded at Kerguelen Island and on board ships in the neighbourhood of the island, on the 6th and 7th August, appear to have been associated with a diminution of pressure, rise of temperature, and inerease of wind from East-by-11orth to gale force, recorded on board the "Ganss" on the 7th and 8th of the month.

\section{5th to 17th August, 1902.}

Reduction of pressure at the island, again, on the 15 th to the 17 th of the samo month, was followed at the "Gauss" station by a rise of temperature between the 16 th and 17 th of $25^{\circ}$, and a fall in the barometer of 0.74 inch between the 17 th and 18th, together with an increase of wind from East-by-11orth on the 18th to storm force.

11th and 12th, 20th and 21st October, 1902.

Diminishing pressure, accompanied by inerease of wind, recorded at Kerguelen Island and by ships in the neighbourbood of the island on the 11 th and 12th October, and again on the 20th and 21 st of that month, was followed at the German Antarctic station by decline of pressure, rise of temperature, and increase of wind to whole gale force.

\section{1th to 14 th December, 1902.}

On the 11th December a fall in the barometer of more than half an inch had been recorded at Kerguelen Island for the previous 24 hours, and the ship "Niagara," some 250 miles north-eastward of the island, was experiencing a strong gale from North-north-west. On the following day the centre of disturbance, progressing eastward, had passed the meridian of the station at Kerguelen, and the S.S. "Salamis," in the immediate neighbourhood of the island, had a strong wind from South-by-west. At the German station in the Antaretic pressure was then giving way, but the wind, from East-north-east, was light. $\Lambda$ bout 1300 miles due north of the "Gauss" the "Loch Torridon" recorded a strong wind from North-by-west and a barometer reading of 29.56 inches, which was 0.28 inch higher than the reading recorded at the same time on board the "Gauss."

The "Niagara," then in about $45^{\circ} \mathrm{S}$. latitude, $811^{\circ} \mathrm{E}$. longitude, still had the wind from Northward, and was therefore in front of the trough of the depression. On the 13 th the "Loch Torridon" and the "Niagara" carried a Westerly wind, and the latter, in about $45^{\circ} \mathrm{S}$. latitude, $86 \frac{1}{2}{ }^{\circ} \mathrm{E}$. longitude, was running before a fresh gale, with the eentral low to the southward of her. 
The Antaretic station, where pressure had continued to give way, was now under the full influence of the disturbance, and a fresh Easterly gale was blowing there, but the wind moderated next day. During this gale temperature appears to have changed very little.

\section{6th to 8th February, 1903.}

A diminution of pressure recorded at Kerguelen Island and on board ships in the neighbourhood of the island between the 6th and 8th February, 1903, which was accompanied by an increase of wind, was followed on the 9 th by a diminution of pressure and a strong gale from East, in $65^{\circ} 53^{\prime} \mathrm{S}$., $89^{\circ} 21^{\prime}$ E., the position in which the "Gauss" was situated.

Other instances furnished by synchronous G.M.T. observations could be cited to show how the gales experienced at Kaiser Wilhelm II. Land, during the sojourn there of the German Exploring Expedition, frequently owed their origin to systems of low pressure travelling eastward, which had previously affected the weather conditions of Kerguelen and ships in the neighbourhood of the island, giving rise to strong winds and gales in those localities.

Studied in connexion with the more ample information in reference to the meteorology of the Antaretie during the same period, which is given in Part I. of this work, considerable light is thrown by these Charts upon problems relating to pressure distribution and wind eireulation in, and in the neighbourhood of, those localities in which the Winter Quarters of the British, German, Scottish, and Swedish Expeditions were situated. They afford additional examples which may be explained by the supposition that the strong winds and gales from polar directions experienced by the "Discovery" Expedition in South Vietoria Land were accompanied by a decided rise of temperature, because they had their origin in lower latitudes over the ocean.

The train of low-pressure areas during their passage eastward in this part of the Southern Ocean frequently follows a more southerly path after passing Cape Adair, the centres of the depressions striking south-eastward and the areas of disturbance spreading over the Ross Sea.

With a cyclonie depression dominating air cireulation over, and in the vicinity of, the Ross Sea, winds are Northerly to North-easterly in the eastern segment of the system, seaward; Easterly to South-easterly in the southern segment, over and immediately to the south of the ice barrier; and Southerly to Southwesterly in the western segment, following the trend of the mountain ranges. It is contended, therefore, that the relative warmth of the winds having a southerly component in South Vietoria Land may reasonably be attributed to the place of origin in lower latitndes over the ocean, though the cold of higher polar regions makes itself felt in the south-westerly segment of the cyclonic depression of that region.

\section{The Weddell Sea Region.}

MeMurdo Sound is situated nearly 400 miles south of North Cape, and west of the easternmost spur of the Admiralty Range. It is, in consequence, sheltered to some extent from northerly winds by this range, and by the east coast ranges, including Prince Albert Mountains, which afford shelter from north-westerly winds also.

Snow Hill, sheltered for the most part from between North-north-east and West by the heights of Joinville Island, which include Mount Percy, by those of Louis Philippe Land, and of Palmer Land, from which rises Mount Haddington, is somewhat similarly situated as regards exposure to winds, so that strong winds and gales from an equatorial quarter are rarely experienced there, while Southerly and South-westerly winds prevail, and frequently attain to gale force.

Because the depressions which exercise the most influence upon the weather conditions of the South Orkneys are those which move to the south-eastward after passing the 60th meridian, the average air circulation in, and in the neighbourhood of, the Weddell Sea, aceruing from a procession of these cyclones, approximates to that which would obtain were an area of low pressure situated over that sea, oceasioning Northerly and North-westerly winds over the eastern side of the sea, Easterly on the southern side; Southerly and South-westerly on the western, and Westerly on the northern side. 
The prevailing winds at Laurie Island, South Orkneys, the station of the Seottish Antaretic Expedition, during the year 1903 were North-westerly, but Northerly and Westerly winds were rather frequent. At Suow Hill, the Swedish station, the average direction of the wind, from March, 1902, to Oetober, 1903, inclusive, was about South-sonth-west, the prevailing winds being from South or Sonth-west. When gales occurred they blew almost exclusively from Southward and Sonth-westward. On board the "Scotia," near the ice barrier bordering the land discovered by the Scottish Expedition in latitnde $74^{\circ} 1^{\prime}$ S., longitude $22^{\circ} \mathrm{W}$., and named by the leader, Mr. BRucE, "Coats Land," the prevailing direction of the wind from the 7th to the 12th of March, 1904, the period of the "Scotia's" stay there, was Easterly; and from the 7 th to the 10th the wind blew with gale force.

It seems probable that between sea and ice barrier in the southern extremity of the Weddell Sea, under normal conditions, there exists a slight pressure gradient for Easterly winds, and that the gales from Eastward which occur there are the result of a steepening of this gradient associated with depressions centred to the north of the barrier, and moving eastward or sonth-eastward.

\section{The Region of Kaiser IVilhelm II. Land.}

At the Winter Quarters of the German Expedition, in latitude $66^{\circ} 2^{\prime} \mathrm{S}$., longitude $89^{\circ} 48^{\prime} \mathrm{W}$., where the "Gauss" lay frozen in during the period March, 1902, to February, 1903, nearly 53 per cent. of all wind observations were of winds from East-by-north, East, and East-by-south; 73 per eent. being from directions in the eastern half of the horizon; 16 per cent. from directions in the western half; and 11 per cent. being noted as calms.* 'The Easterly winds were stronger than those from any other direction; out of 793 hours of strong winds, recorded in the course of twelve months, no less than 90 per cent. were from East-by-north, Last, or Last-by-south.

From the 28th April to the 10th May, and again from the 28th September to the 9th October, periods of 13 and 15 days respectively, meteorological observations were obtained at the foot of the Gaussberg, a mountain situated in latitude $66^{\circ} 48^{\prime} \mathrm{S}$., longitude $89^{\circ} 30^{\prime} \mathrm{E}$., on the verge of the inland iee barrier, 53 miles south from the "Gauss." By comparing the observations of barometric pressure taken at this station with those obtained on board the "Gauss," it was found that pressure was slightly higher at the foot of the mountain than it was on board the ship. During the earlier period the difference announted to $1.7 \mathrm{~mm} .(0.067 \mathrm{inch})$, and during the latter to $0.8 \mathrm{~mm} .(0.031 \mathrm{inch})$.

This slight inerease of pressure landward was thought to be confirmatory of an inference that had been drawn from the direction of the prevailing wind that pressure increased with latitude southward.

Whether this be the case or not, the frequency of winds from Eastward is doubtless due to the existence of a pressure gradient between land and sea, and to the general east and west trend of the coast line.

The steepness of this pressure gradient is increased, and Easterly gales occasioned, by the ineursion of eastward moving low-pressure wind systems. The Easterly gales experienced by the German Expedition at the "Gauss" station were always attended with a steady rise of air temperature, the thermometer continuing to rise until the wind had attained its maximum force. This increase of temperature associated with gales from Eastward may be regarded as a proof that the winds have their origin in lower, warmer, and possibly in tropical latitudes over the ocean, and that they form part of the circulation of eastward moving cyclonic systems, flowing in front of their centres; for during gales from Westward at this station there was always a fall of temperature. The remaining part of the air from the Northward, which, by circulating in rear of these central "lows," had parted with its heat during its passage over the Antaretic, is reinforced by air from polin regions, and occasions a fall of temperature.

The Westerly winds that are shown by the eharts to occur occasionally at Kaiser Wilhelm II. Land immediately after a cyclonic depression has passed eastward to the north of the "Gauss" station, may belong to the wind system of a secondary depression, and the fall of temperature with which it is attended may be due to the introdnction of air of polur origin into the circulation of this secondary.

It will be seen from the foregoing that, as a result of the wind circulation set up during the passage

" "Wind Conditions at the 'Gauss' Winter Quurters," by Dr. WiLr. Meinaledes, Berlin, "The Proceedings of the Fifteenth German Asembly of Geographers at Danzig in 1905.' 
eastward of successive low-pressure systems over the Southern Ocean, relatively warm air is constantly being drawn from lower latitudes in front of central areas of depression, which, after parting with heat in the frigid zone and being still further ehilled by the mixing of air of polar origin, leave the Antaretio as a cold wind.

This exposition of surface wind circulation in high latitudes, which is based on a close examination of the results of observations represented on the daily charts, was offered by the writer in the memoir on the Climatology of South Vietoria Land in Part I. of this work. The proposition has since been elaborated and extended to equatorial regions by Dr. W. J. LocKYER, ${ }^{*}$ who suggests that the warm air currents circulating in front of the barie minima of eastward moving depressions are of equatorial origin, and that after they have traversed the southern and western segments of their eircuit they rejoin the westerly air eurrent, and so return by the trade wind eirculation to the equator on the eastern side of anticyclones.

This, as the writer understands it, is in effect the suggestion put forward, and it is a proposition with which, in the main, he is in accord.

\section{Antioyclones of the Sub-tropical Belt.}

In regard to this subject Dr. LocKYER, in the work already quoted, favours the views held by the late Mr. H. C. RusselL, F.R.S., C.M.G., in regard to these ocean anticyelones and the high-pressure belt. He believes that in latitudes north of the zone of travelling depressions in the Southern Ocean a train of anticyclones moves eastward, following one another in quick succession, and that in charting the mean results of barometer readings recorded in those latitudes the effect is produced on charts relating to average pressure of permanent areas of maximum barometer within a permanent belt where barometer readings are relatively high. Dr. Lockyer thinks that anticyelones make the circuit of the globe, forming, dispersing, and reforming during their passage, and that it is in this manner that the temperate zone is bridged, and the union between tropical and polar air circulation established. He supposes, moreover, that between each of the anticyclones the northern segments of extensive cyclonic depressions, travelling eastward, obtrude, while the anticyclones move with them.

Mr. Russell assumed the rate of translation of these hypothetical systems of high pressure over the Southern Ocean to be about 460 miles per day; were his theory correct, however, a vessel of average speed running eastward between the 30 th and 40 th or even the 45 th parallels of latitude would be overtaken by a succession of anticyclones. On the approach of each the wind would commence to freshen from some point between South and West with a rising barometer, subsequently veering to Northward with a falling barometer and moderating; and a vessel making the passage homeward from Australia vid the Cape of Good Hope in about the 30th parallel would meet these high-pressure systems, moving in the opposite direction, and experience a similar sequence of changes repeated in rapid succession.

Now it is well known that the reverse obtains; winds experienced by vessels running eastward commence to freshen from a northerly or north-westerly direction with a falling barometer; back to the south-westward or southward with a rising barometer and moderate.

To the navigator making the passage between the meridian of Cape Point and that of Cape Leeuwin or of Stewart Island the overtaking depressions are of so marked a character, and the influence they exert upon the progress of his vessel so considerable, that there can be in his mind at least no doubt as to their dominance over the weather.

The evidence afforded by the synehronous daily charts under notice, as well as by charts of average barometrical pressure, is, moreover, in direct contradiction to Mr. Russell's theory, while, on the other hand, it can be proved conclusively by reference to such eharts that the anticyclones of the great oceans are permanent systems of high pressure.

It must be admitted, nevertheless, that the appearance over the extreme west of Australia, on the daily weather charts that are drafted, of these anticyclones, month after month, and their regular progress across the island continent conveys the impression that they are visitors from the Indian Ocean and might have formed, as Mr. RUsselL supposed, thousands of miles to the westward.

\footnotetext{
- 'Bouthern Hemisphere Surface Air Oireulation,' by Wrusras J. 8. Lockrga, M.A. (Cantab.), Ph.D. (Gouttingen), F.R.A.8., Chief Assistant, Bolar Physies Observatory.
} 
The interchange of air between equatorial and polar regions may be effected throngh the intermediary of anticyclonic circulations, albeit these high-pressure systems are permanent; and, in the opinion of the writer, the temperate zones are bridged in this manner. The heat thus transmitted from low to high latitudes, while mitigating in some measure the severity of the climate of northern Antarctica, may also contribute towards the disruption of ice from outlying ice barriers. Similarly the introduction of cool air from high to low latitudes doubtless exereises an ameliorating effect upon tropical regions through the agency of the trade winds.

\section{The Rate of Travel of Cyclonic Depressions.}

To revert to the cyclonic depressions experienced in far southem seas; it has been aseertained* that in the Southern Ocean, between the meridians of $10^{\circ}$ and $140^{\circ} \mathrm{E}$., the strongest gales experienced near the centre of a cyclonic depression blow in its front, from between North-east and North-west, and that the wind moderates when it backs to Westward, as pressure increases; whereas gales that oceur within the northern segment of a cyclonic depression remote from its centre attain their highest velocity in rear of the line of lowest barometer readings, from some point to the South of West, usually from about Southwest, while pressure is rapidly recovering, the wind having been comparatively moderate from Northwestward while pressure was diminishing.

The high velocity of the wind on the outskirts of a depression in rear of its centre may be attributed partly to the proximity of the high-pressure belt situated to the north of the Westerly air current, and partly to the rapid recovery of pressure that takes place by replenishment of air from a polar quarter.

The paths followed by centres of cyclonic depressions vary with the season; the parallels along whieh they move to the eastward depending mainly upon the position of the tropical high-pressure belt which consists, for the most part, of the southern anticyclones of the great oceans; which, in addition to their annual east and west expansion and contraction, have a motion North and South. The amplitude of these seasonal oscillations appears to vary in different years; and it has been suggested that the tropical anticyelones may have a cycle of long period as well as a seasonal movement. This point will be referred to later.

The average paths of the centres of cyclonic depressions depicted on the daily charts under notice have been estimated and grouped. The method employed in their construction was as follows:-The probable positions of the centres of all depressions, that can be identified day after day on four or more consecutive daily charts, were plotted on skeleton charts. Four eharts were used for this purpose, one for each senson of the year; and the several positions allotted to the eentre of each identieal system was joined by a line. Parallel to, and bisecting as nearly as possible the areas covered by the patbs indicated, a line was drawn to represent the average path.

In grouping the paths in seasons, the months of September, October, November are selected to represent Spring; December, January, February : Summer; March, April, May : Autumn; and June, July, August: Winter.

The results obtained are as follow:-The average path of all central areas of depression charted for the entire period, Oetober, 1901, to March, 1904, is found to have been in about the 52nd parallel. Between the mericlians of $20^{\circ} \mathrm{E}$. and $150^{\circ} \mathrm{E}$., that is to say, over the South Indian division of the Southern Ocean, it was between the 49 th and 50 th parallels; and between $150^{\circ} \mathrm{K}$. and $70^{\circ} \mathrm{W}$., the South Pacific division, in about the 55 th.

The Sonth Atlantic division of the ocean, embraced by the meridians $70^{\circ} \mathrm{W}$. and $20^{\circ} \mathrm{E}$., is rarely visited by ships, except on the western side; the observations relating to that portion of the Southern Ocean are, therefore, limited almost exclusively to that side, and to that side only the average paths estimated for this division of the ocean refer.

During each of the seasons the centres of depression after passing the meridian of Joinville Island, abont $56^{\circ} \mathrm{W}$., either struck eastward or south-enstward ; or moved east-north-eastward or north-eastward.

In the Spring of the year the average path taken by centres of depression is foumd to have been between

- 'The Tracks of Oceas Wind Systems in Transit across Australasia,' quoted on p. 9. 
the 49th and 50th parallels in the Indian division, and between the 54th and the 55th in the Pacific. The centres entered the Atlantic division on or near the 58th parallel, thence about one-third of them moved north-eastward, and the remainder passed between Danco Land and the South Orkneys. During the Summer months the 53rd was the average parallel along which the centres travelled eastward in the Indian division, and they followed a path between the 56th and 57th in that of the Pacific. After passing the 56 th meridian of W. longitude, about half the central areas of depression travelled East-south-east between Palmer Land and Danco Land and the South Orkneys, and the other half passed away to the north-eastward. During Autumn and Winter the paths were confined to zones between $48^{\circ} \mathrm{S}$. and $49^{\circ} \mathrm{S}$. in the South Indian division, and between $55^{\circ} \mathrm{S}$. and $56^{\circ} \mathrm{S}$. in the Pacific. After entering the Atlantic division, rather less than one-third of the centres moved east-south-eastward or eastward across Danco Land, or between Danco Land and the South Orkneys, the remainder passing east-north-eastward or north-eastward into the Atlantic. A few erossed Tierra del Fuego or the southern extremity of Patagonia.

The paths of eyclonic centres are found to have been more scattered during the Autumn and Winter months than in Spring and Summer in all parts of the Southern Ocean.

Cyclonic storms, presumably of tropical origin, are represented on each of the charts on which the central positions of Summer and Autumn depressions were plotted, but they are confined to the western portion of the Pacific division of the Southern Ocean. These appear to have moved into the Tasman Sea from the north-westward, one in the Summer of 1901 and one in each of the Autumns of 1902 and 1903.

The centre of the 1902 storm moved south-eastward to the north-west coast of New Zealand, thence south, passing through Cook Strait, and subsequently zigzagged to the eastward. It ean be identified on the daily charts from a position in about $34^{\circ} \mathrm{S}$., $1691^{\circ} \mathrm{E}$., on the 12 th December to a position in about $541_{2}^{\circ}$ S., $1481^{\circ}$ W., on the 19 th of that month, representing a travel of 2187 nautical miles, at an average rate of translation of 312 nautical miles per day.

The cyclones of the Autumns of 1901 and 1903 moved east-south-eastward after crossing the 30th parallel, but cannot be traced to the eastward of the 180th meridian.

The tropical disturbance of December, 1901, above mentioned, is not the only cyclonic depression that ean be traced on the daily charts for a number of days consecutively. Similar instances of identification, day after day, of such systems after their initial location can be cited as follows :-

March 7-15, 1902. From $56^{\circ}$ S., $146^{\circ}$ W. to $55^{\circ} \mathrm{S} ., 80^{\circ} \mathrm{W} .=2243$ miles; 280 miles per day.

May $2-10,1902$. From $53^{\circ} \mathrm{S} ., 102^{\circ}$ E. to $47^{\circ} \mathrm{S} ., 175^{\circ} \mathrm{E}$. $=2840$ miles; 355 miles per day.

May 29-June 5, 1902. From $47 \frac{1}{2}^{\circ}$ S., $17^{\circ}$ E. to $60^{\circ}$ S., $83^{\circ}$ E. $=2433$ miles ; 348 miles per day.

September $2-9,1902$. From $57^{\circ}$ S., $80^{\circ}$ E. to $47^{\circ}$ S., $131 \frac{1}{2}^{\circ}$ E. $=2510$ miles ; 359 miles per day.

May 16-23, 1903. From $54^{\circ}$ S., $131^{\circ}$ W. to $58^{\circ}$ S., $72^{\circ}$ W. $=1995$ miles; 285 miles per day.

September $21-29,1903$. From $47 \frac{1}{2}^{\circ}$ S., $89^{\circ}$ E. to $50 \frac{1}{2}^{\circ}$ S., $130^{\circ}$ E. $=1625$ miles; 203 miles per day.

December $10-17,1903$. From $40^{\circ} \mathrm{S}$., $130^{\circ}$ E. to $55^{\circ} \mathrm{S}$., $171^{\circ} \mathrm{E} .=1890$ miles ; 270 miles per day.

February $8-15,1904$. From $40^{\circ}$ S., $154^{\circ}$ E. to $521^{\circ} \mathrm{S} ., 166^{\circ} \mathrm{W} .=1890$ miles ; 270 miles per day.

If the centres of the respective cyclonic depressions have been correctly located, the average daily rate at which they progressed was nearly 300 miles.

While the number of cyclonic systems that can be identified for four or more days in succession, during their passage over the ocean, is large, the only moving anticyclonic systems that can be traced for more than three consecutive days are :- (1) Those that appear to have their origin to the west of Australia, the centres of which travel eastward, join the Australian "high," and subsequently move across or to the south of Anstralia, over the Tasman Sea and New Zealand or immediately north or south of those islands, and then disappear over the Pacific. (2) Those that move eastwards from the South American Continent, over the sea, and soon after disappear over the Atlantic.

The former appear to originate as secondary high-pressure systems thrown off the South Indian anticyclone; the latter appear to form over the land.

As regards the paths of anticyclones, shown on the charts, the instances are rare in which areas of high barometer, other than those that obviously form part of the permanent anticyclones of the great oceans, 
can be traced over the ocean for more than three consecutive days; and when such areas can be identified for as many as three days, their movements are shown to be erratic and slow.

Over the continents it is otherwise, and in connexion with an investigation, already referred to, the writer found that from November to March inclusive the centres of moving anticyclones that appear over Australia follow paths lying chiefly over the ocean, not far from but to the South of the island Continent, thence over the Tasman Sea, and across or just South of the Middle and South Island of New Zealand; but from May to September inclusive, chiefly over the southern part of Australia, over the Tasman Sea and New Zealand.

He expressed the opinion that these anticyclones form over the cool plains of Western Australia during the winter months, and over the relatively cool sea immediately South-west of the land during the summer, spreading subsequently from the sea northward over the land.

Evidence is not wanting, moreover, to prove that small areas of high pressure, breaking off the Indian Ocean anticyclone, drift eastward and reinforce these high pressure areas that have formed; and that the relatively high-pressure ridges which follow in rear of depressions also are merged in these "highs."

\section{CHARTS OF MEAN PRESSURE AND AIR TEMPERATURE.}

By a close examination of the data exhibited on the charts of mean pressure for Noon G.M.T., montl by month, it is found possible to follow the seasonal oscillations of the tropical high-pressure belt, as represented by the southern margins of the ocean anticyclones: and, by comparing each chart with the accompanying chart illustrating normal pressure distribution, to deteet displacements of the belt from its average southern limit in any month or series of months to which the charts refer. The evidence thus afforded by the pressure charts is in a measure supplemented by a similar comparison of the charted observations of air temperature with average results on the charts accompanying them. Thus it is found that during the last three months of 1901 the southern margins of the South Atlantic, Indian Ocean, and South-castern Pacific permanent high-pressure areas were North and West of their average positions; that of the South-western Pacific was South of the average, and exhibited no departure from the average as regards longitude. In these months the mean air temperature appears to have been above the normal in tho Atlantic and Indian Ocean divisions of the Southern Ocean; but about the normal in the South-eastern and South-westeru Pacific divisions.

During the greater part of 1902 the ocean anticyelones were again North of their average southern limits and the Atlantic antieyclone was West of its average position. The Indian Ocean and South Pacific anticyclones, however, appear in their average positions as regards longitude.

Air temperature over the Southern Ocean, as indicated by the charts, was in each month of this year either about the normal or above it, except in the South-western Pacific division of the occan, where it seems to have been below the normal.

During the year 1903 the southern margin of the high-pressure belt is charted in or near its average parallels; and, while the South Atlantic and Indian Ocean areas of maximum pressure are shown to have been West of their average positions, the two South Pacific areas are located slightly to the East of the average.

As regards mean air temperature during that year, this appears from the position of the isotherms to have been higher than the normal over the South Atlantic and the South-eastern Pacific divisions of the Southern Ocean, slightly above the normal over the Indian Ocean division, and slightly below the normal over the South-western Pacific division.

In the first three months of 1904 the southern margin of the belt is charted in about its average parallels. The air temperature indicated by the isotherms for those months is above normal, except in the South-Western Pacific division, where a slight defect in temperature is indicated.

In a paper contributed to the Royal Metcorological Society in 1908 by Colonel H. E. RAwson, C.B., R.E.,* it was pointed out that when isobaric charts of the Southern Hemisphere relating to any month or months which had been prepared in different years were compared with one another, tho action-centre of the South

" "The Antieyclonic Belt of the Southern Hemisphere," 'Quarterly Journal, Roy. Met. Soe.,' July, 1908. 
Atlantic anticyclone was found to oceupy different positions in the corresponding month or months on the charts of each of these years. He found that if BucHus's charts, published in 1869, are compared with those prepared by the same authority for 1870-84, or if Mors's charts published in 1879, 1883 and 1903 are compared with those prepared by the Meteorological Office, which are based on observations recorded in nearly 3300 logs extending over the period $1855-99$, the mean monthly position of the action-centres will be found to vary very considerably both in latitude and longitude. Colonel Rawson concluded that in addition to the seasonal migration of the high-pressure belt, which has so long been recognised, there is a progressive displacement going on from year to year, in consequence of which the belt is in some years nearer to the Equator than in others. He believed he had found strong evidence of cyclical changes having taken place in the belt's latitude, and of the existence of an interval of $9 \frac{1}{2}$ years between the times of its passing from its extreme northern to its extreme southern positions, and vice versh. If Colonel Ruwsos's theory be correct, the belt should have reached the southern limit of its oscillation in 1903. Now although the southern margin of the high-pressure belt in the several divisions of the ocean, as shown on the monthly charts for that year, appears to be in about its average position as regards latitude, it must be admitted that the monthly charts for both 1901 and 1902 place the margin of the belt in lower parallels.

\section{SUMMARY OF THE OBSERVATIONS OF WIND.}

On Tables I. to IV. are set forth the number of observations of wind from each of eight cardinal and inter-cardinal points of the compass, and of variable winds and calms recorded in the Southern Ocean during the thirty-months period, October 1901 to March 1904; inclusive also of the number of instances on which these winds attained to gale force.

For the purposes of comparison the observations are arranged according to (1) the respective seasons, (2) the divisions of the Ocean, and (3) the zones to which they relate.

In the classification adopted (p. 16), the months of September, October, November are regarded as representing Spring; December, January, February as representing Summer ; March, April, May, Autumn ; and June, July, August, Winter. The following are the meridional boundaries selected for representing the three divisions of the Southern Ocean, $150^{\circ}$ E. to $70^{\circ}$ W., Pacific; $70^{\circ}$ W. to $20^{\circ}$ E., Atlantic; $20^{\circ}$ E. to $150^{\circ} \mathrm{K}$., Indian. The grouping of ocean wind and gale frequency into zones of ten degrees of latitude is adopted for convenience.

Tables V. to IX. state the directions from which the largest and smallest percentages of winds of all forces, and of gales only, were recorded in each of the zones and divisions of the Southern Ocean referred to, in the respective seasons of the year and in all seasons, during the thirty months period.

Table X. furnishes similar information relating to the Southern Ocean as a whole. 


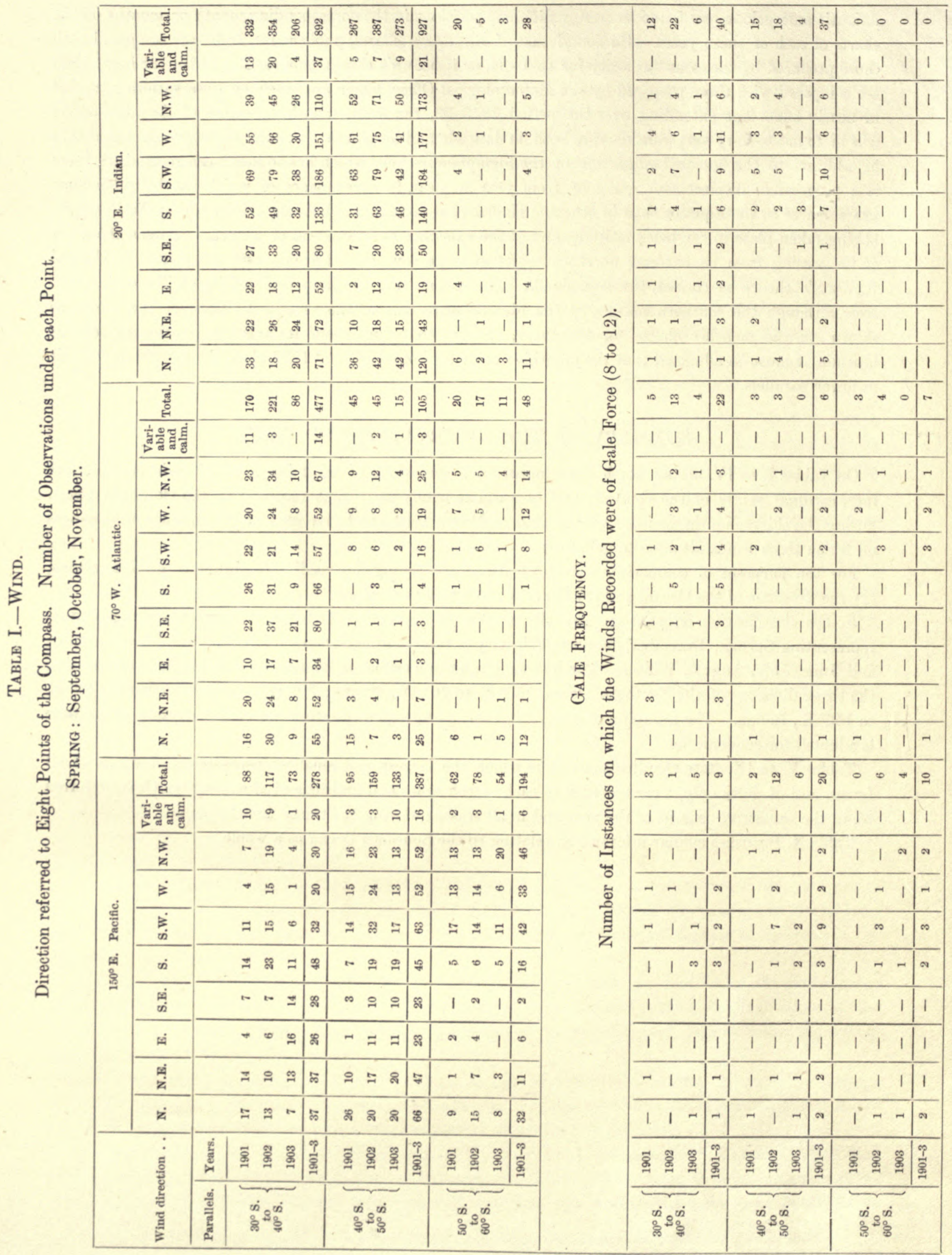




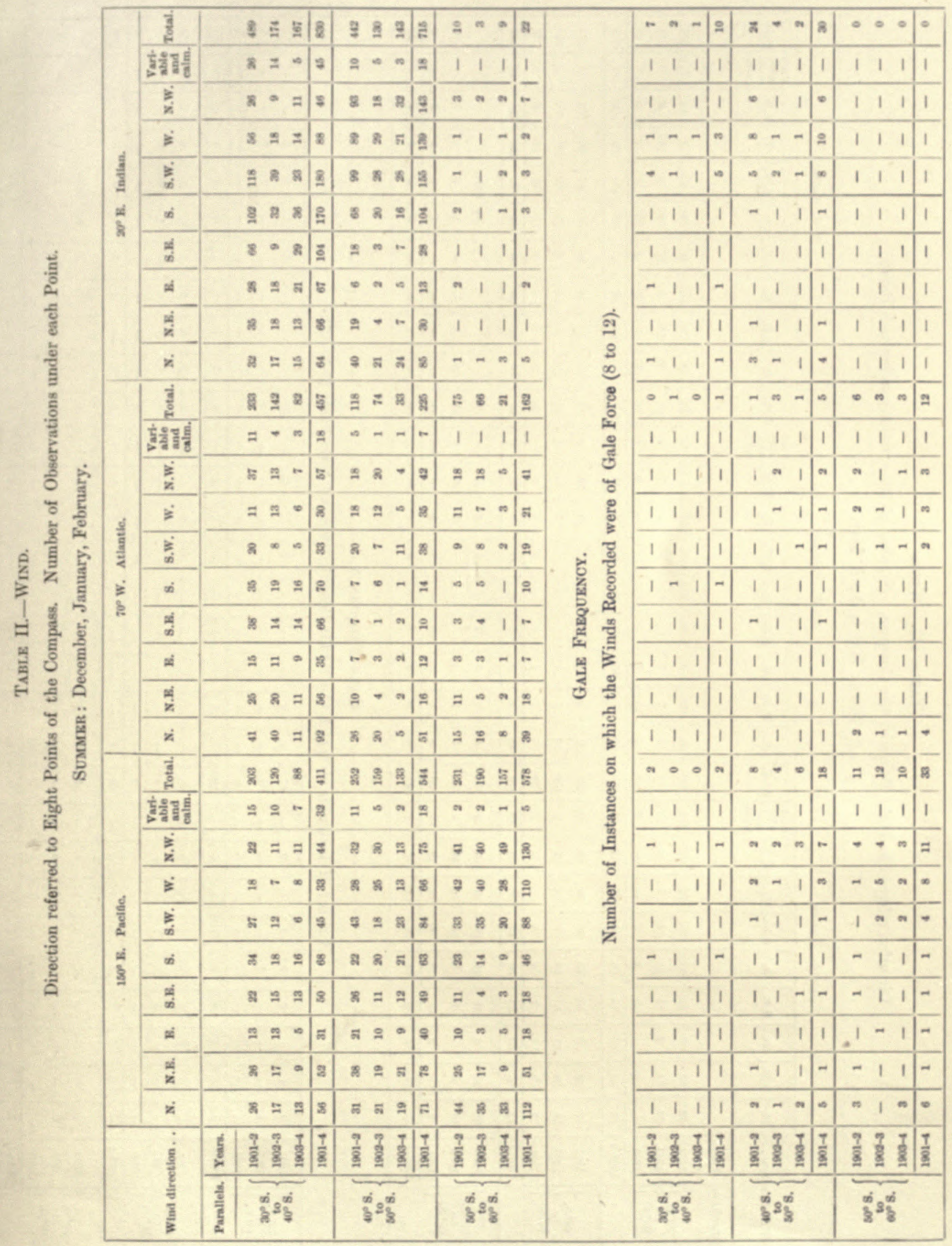




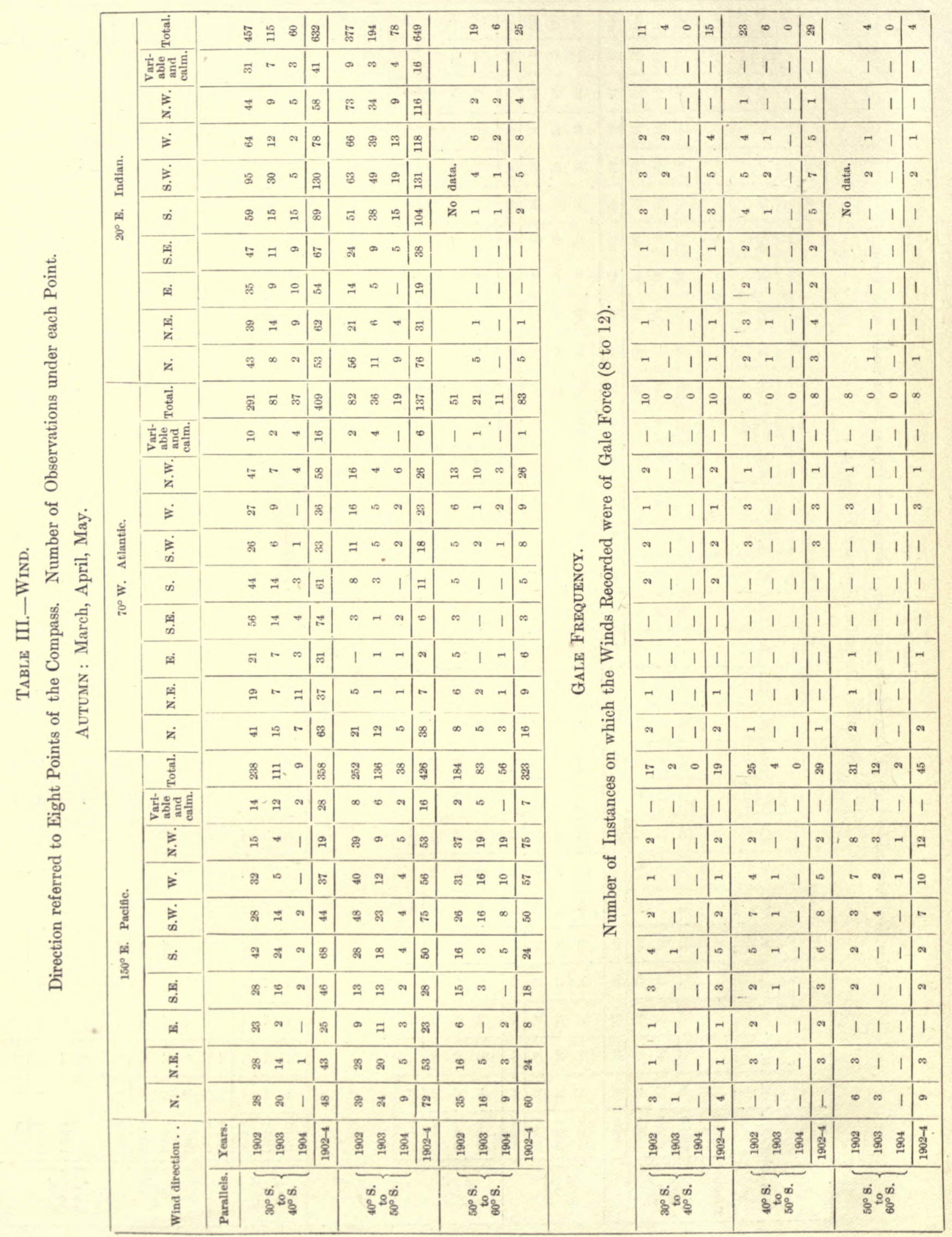




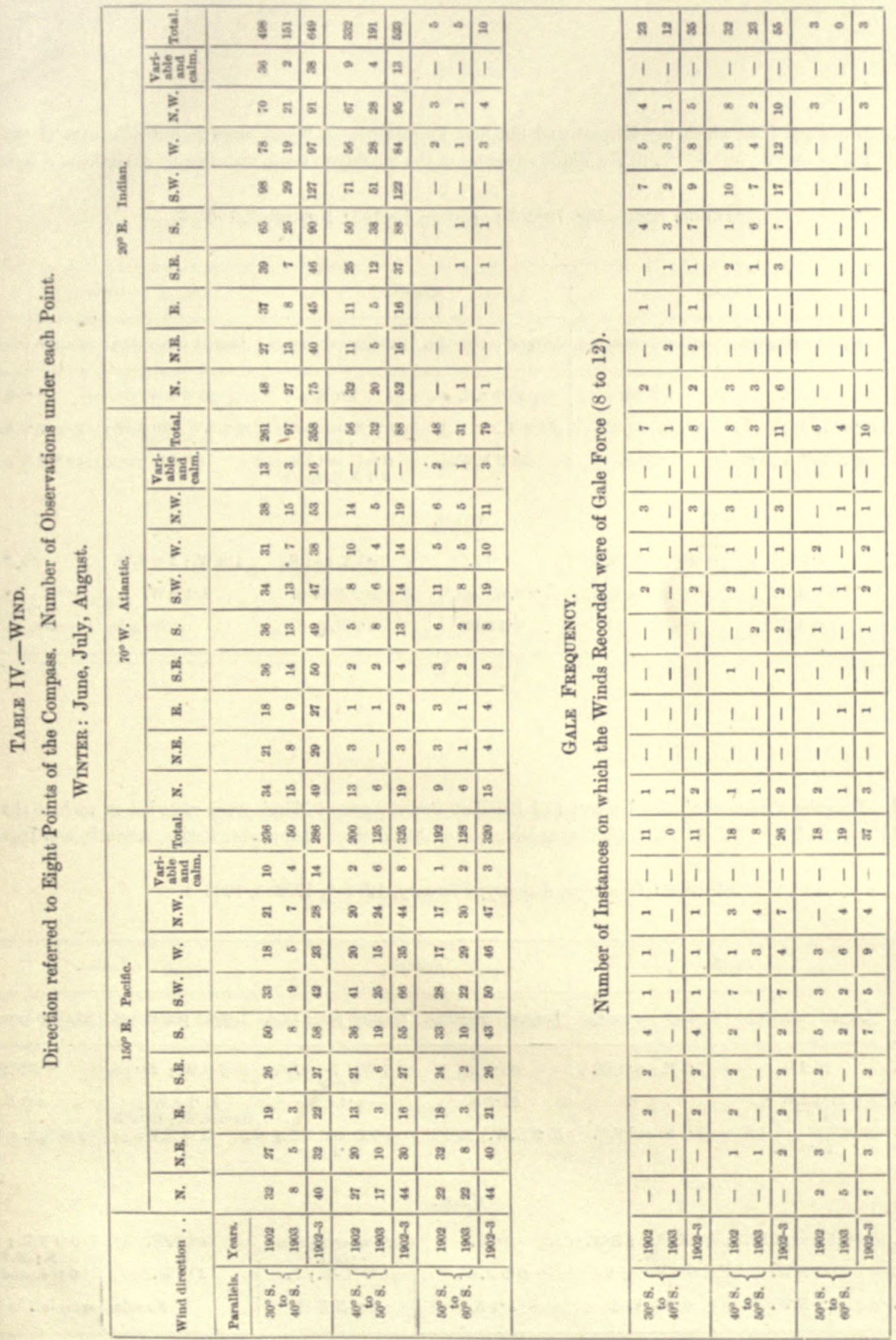


TABLE V.-Directions from which the Largest and Smallest Percentages of Winds were recorded in each of the Zones, $30^{\circ}-40^{\circ}$ S., $40^{\circ}-50^{\circ}$ S., $50^{\circ}-60^{\circ}$ S., in the Three Divisions of the Southern Ocean, viz., Pacific, Atlantic, and Indian.

SPRING : September, 1902-3; October, 1901-3; November, 1901-3.

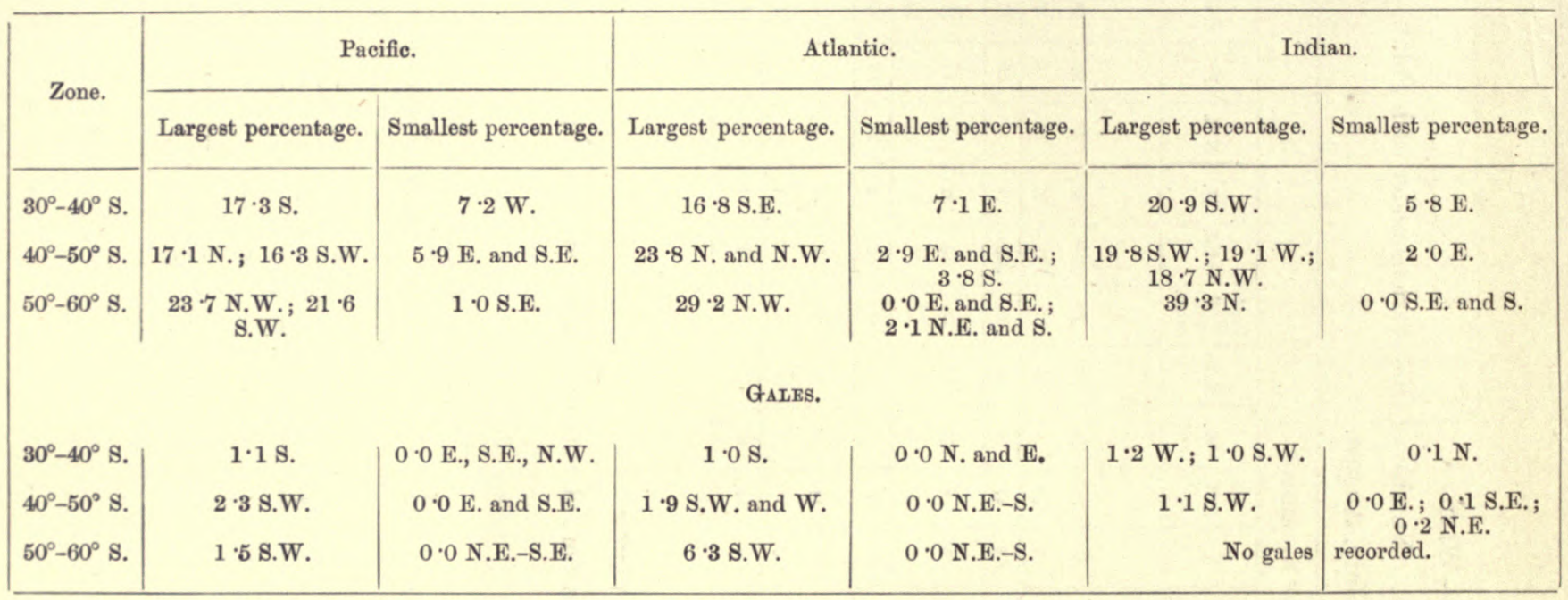

TABLE VI.-Directions from which the Largest and Smallest Percentages of Winds were recorded in each of the Zones, $30^{\circ}-40^{\circ}$ S., $40^{\circ}-50^{\circ}$ S., $50^{\circ}-60^{\circ}$ S., in the Three Divisions of the Southern Ocean, viz., Pacific, Atlantic, and Indian.

SUMmer: December, January, February, 1901-2, 1902-3, 1903-4.

\begin{tabular}{|c|c|c|c|c|c|c|}
\hline \multirow{2}{*}{ Zone. } & \multicolumn{2}{|c|}{ Pacific. } & \multicolumn{2}{|c|}{ Atlantic. } & \multicolumn{2}{|c|}{ Indian. } \\
\hline & Largest percentage. & Smallest percentage. & Largest percentage. & Smallest percentage. & Largest percentage. & Smallest percentage. \\
\hline $\begin{array}{l}30^{\circ}-40^{\circ} \mathrm{s} . \\
40^{\circ}-50^{\circ} \mathrm{s} . \\
50^{\circ}-60^{\circ} \mathrm{s} .\end{array}$ & $\begin{array}{c}16.5 \mathrm{~S} . \\
15 \cdot 4 \text { S.W.; } \\
14 \cdot 3 \mathrm{~N} . \mathrm{E} . \\
22 \cdot 5 \text { N.W.; } 19 \cdot 4 \mathrm{~N} . ; \\
19 \cdot 0 \mathrm{~W} .\end{array}$ & $\begin{array}{c}7.5 \text { E. ; } 8 \cdot 0 \mathrm{~W} . \\
7 \cdot 4 \mathrm{E} . \\
3 \cdot 1 \mathrm{E} \text { and S.E. }\end{array}$ & $\begin{array}{c}20 \cdot 1 \mathrm{~N} \\
22 \cdot 7 \mathrm{~N} \\
25 \cdot 3 \mathrm{~N} . \mathrm{W} \cdot ; 24 \cdot 1 \mathrm{~N}\end{array}$ & $\begin{array}{c}6.6 \mathrm{~W} . ; 7 \cdot 2 \text { S.W.; } \\
7 \cdot 7 \text { E. } \\
4 \cdot 4 \text { S.E. } \\
4.3 \text { E. and S.E.; } \\
6 \cdot 1 \text { S. }\end{array}$ & $\begin{array}{c}21 \cdot 7 \text { S.W.; } 20 \cdot 5 \text { S. } \\
21 \cdot 7 \text { S.W. } \\
20 \cdot 0 \text { N.W.; } 19 \cdot 4 \text { W. } \\
31 \cdot 8 \text { N.W. }\end{array}$ & $\begin{array}{c}5.5 \mathrm{~N} . \mathrm{W} \\
1.8 \mathrm{E} \text {. } \\
0.0 \text { N.E. and S.E. }\end{array}$ \\
\hline & & & GaLes. & & & \\
\hline $\begin{array}{l}30^{\circ}-40^{\circ} \mathrm{s} . \\
40^{\circ}-50^{\circ} \mathrm{s} . \\
50^{\circ}-60^{\circ} \mathrm{s} .\end{array}$ & $\begin{array}{c}0.2 \mathrm{~S} . \text { and N.W. } \\
1.3 \mathrm{~N} . \mathrm{W} \text {. } \\
1.9 \mathrm{~N} . \mathrm{W}\end{array}$ & $\begin{array}{c}0.0 \text { N.-S.E.; S.W.; } \\
\text { W. } \\
0.0 \text { E. and S. } \\
0.2 \text { N.E.-S. }\end{array}$ & $\begin{array}{c}0.2 \mathrm{~S} \\
0.9 \mathrm{~N} . \mathrm{W} \\
2.5 \mathrm{~N}\end{array}$ & $\begin{array}{c}0.0 \text { on every other } \\
\text { point. } \\
0.0 \text { N.-E.; } 8 . \\
0.0 \text { N.E.-S. }\end{array}$ & $\begin{array}{l}0.6 \mathrm{~s} . \mathrm{W} \\
1.4 \mathrm{~W} . \\
\text { No gales }\end{array}$ & $\begin{array}{l}0.0 \text { N.E.; S.E. ; } \\
\text { S.; N.W. } \\
0.0 \text { E. and S.E. } \\
\text { recorded. }\end{array}$ \\
\hline
\end{tabular}


TABLE VII.-Directions from which the Largest and Smallest Percentages of Winds were recorded in each of the Zones, $30^{\circ}-40^{\circ} \mathrm{S}$., $40^{\circ}-50^{\circ} \mathrm{S}$., $50^{\circ}-60^{\circ} \mathrm{S}$., in the Three Divisions of the Southern Ocean, viz., Pacific, Atlantic, and Indian.

AUtuan: : March, 1902, 1903, 1904 ; April, 1902, 1903; May, 1902, 1903.

\begin{tabular}{|c|c|c|c|c|c|c|}
\hline \multirow{2}{*}{ Zone. } & \multicolumn{2}{|c|}{ Pacifie. } & \multicolumn{2}{|c|}{ Atlantie. } & \multicolumn{2}{|c|}{ Indian. } \\
\hline & Largest percentage. & Smallest percentage. & Largest percentage. & Smallest peroentage. & Largest percentage. & Smallest percentage. \\
\hline $30^{\circ}-40^{\circ} \mathrm{s}$ & $19.0 \mathrm{~s}$ & $5 \cdot 3$ N.W.; $7.0 \mathrm{E}$ & $18 \cdot 1$ s.E. & $7 \cdot 6$ E.; 8.1 8.W. & $20 \cdot 6 \mathrm{~s} . \mathrm{W}$ & $8.4 \mathrm{~N}, ; 8.5 \mathrm{E}$. \\
\hline $40^{\circ}-50^{\circ} \mathrm{B}$ & $16 \div 9$ N.; 1644 S.W. & $5.4 \mathrm{E} ; 6.6$ S.E. & $27 \cdot 7 \mathrm{~N}$ & $1.5 \mathrm{E}$ & $20-2$ S.W. $18-2$ W. & $2 \cdot 6 \mathrm{E}$ \\
\hline $50^{\circ}-60^{\circ} 8$ & $23-2$ N.W. & $2 \cdot 5 \mathrm{E}$ & $31 \cdot 3$ N.W.; $19 \cdot 3 \mathrm{~N}$. & 3.6 8.E. & $320 \mathrm{~W}$. & 0.0 E. and S.E. \\
\hline 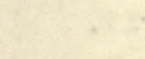 & & & Gazks. & & & \\
\hline $30^{\circ}-40^{\circ} 8$ & 148 & 0-3 N.E. ; E. ; W. & 0.5 N.; S.; 8.W.; & $0.0 \mathrm{E}$. and S.E. & 0.8 s.W. & $0.0 \mathrm{E}$. and $\mathrm{N} . \mathrm{W}$. \\
\hline $40^{\circ}-50^{\circ} 8$ & 19 s.W. & $0.0 \mathrm{~N}$ & $2 \cdot 2$ s.W. and W. & $0-0$ N.E.-S. & $1 \cdot 1 \mathrm{s.W}$. & 0.2 N.W. \\
\hline $50^{\circ}-60^{\circ} 8$ & 37 N.W. & $0.0 \mathrm{E}$. & $3 \cdot 6 \mathrm{~W}$. & 0.0 S.E.-8.W. & 8.0 s.W. & 0.0 N.E.-8.; N.W. \\
\hline
\end{tabular}

TABLE VIII.-Directions from which the Largest and Smallest Percentages of Winds were recorded in each of the Zones, $30^{\circ}-40^{\circ} \mathrm{S}$., $40^{\circ}-50^{\circ} \mathrm{S}$., $50^{\circ}-60^{\circ} \mathrm{S}$., in the Three Divisions of the Southern Ocean, viz., Pacific, Atlantic, and Indian.

Winter: June, July, August, 1902, 1903.

\begin{tabular}{|c|c|c|c|c|c|c|}
\hline \multirow{2}{*}{ Zone. } & \multicolumn{2}{|c|}{ Paeifie. } & \multicolumn{2}{|c|}{ Atlantic. } & \multicolumn{2}{|c|}{ Indian. } \\
\hline & Largest percentage. & Smallest percentage. & Largest percentage. & Smallest percentage. & Largest percentage. & Smallest percentage. \\
\hline $30^{\circ}-40^{\circ} \mathrm{s}$ & $20 \cdot 38$ & $77 \mathrm{E} ; 8.0 \mathrm{~W}$. & $14-8$ N.W.; $14 \cdot 0$ 8.E. & $7 \cdot 5$ E.; $8 \cdot 1$ N.E. & $19.6 \mathrm{s.W}$. & $6-2$ N.R. \\
\hline $40^{\circ}-50^{\circ} \mathrm{8}$ & $20 \cdot 3$ S.W. & $4 \cdot 9 \mathrm{E}$. & $21 \cdot 6 \mathrm{~N}$. and $\mathrm{N} . \mathrm{W}$. & $2 \cdot 3 \mathrm{E}$ & $23 \cdot 3$ 8.W. & 3.1 N.E, and $\mathbf{E}$. \\
\hline $50^{\circ}-60^{\circ} \mathrm{s}$ & $15-68 . W \cdot ; 4-7$ N.W. & $6.6 \mathrm{E}$. & $21 \cdot 5$ 8.W. & $\begin{array}{l}5 \cdot 1 \text { N.E. and E.; } \\
6 \cdot 3 \text { S.E. }\end{array}$ & 40.0 N.W. & 00 N.E.; E. ; S.W. \\
\hline & & & GaLes. & & & \\
\hline $30^{\circ}-40^{\circ} \mathrm{8}$ & 1.48 & $0.0 \mathrm{~N}$. and N.E. & 0.8 N.W. & 0.0 N.E.-8. & 14 8.W. & $0-2 \mathrm{E}$. and S.E. \\
\hline $40^{\circ}-50^{\circ} \mathrm{s}$ & $2 \cdot 2 \mathrm{~B} . \mathrm{W}$. and $\mathrm{N} . \mathrm{W}$. & $0.0 \mathrm{~N}$. & 3.4 N.W. & 0.0 N.E. and $\mathbf{E}$. & $3 \cdot 3$ s.W. & 0.0 X.E. and $E$. \\
\hline $50^{\circ}-60^{\circ} \mathrm{s}$ & $2 \cdot 8 \mathrm{~W}$. & $0.0 \mathrm{E}$. & $3 \cdot 8 \mathrm{X}$ & 00 N.E. and S.E. & 300 N.W. & $00 \mathrm{~N}, \mathrm{~W}$. \\
\hline
\end{tabular}


TABLE IX.-Directions from which the Largest and Smallest Percentages of Winds were recorded in each of the Zones, $30^{\circ}-40^{\circ}$ S., $40^{\circ}-50^{\circ}$ S., $50^{\circ}-60^{\circ}$ S., in the Three Divisions of the Southern Ocean, viz., Pacific, Atlantic, and Indian.

All Seasons : October, 1901, to March, 1904.

\begin{tabular}{|c|c|c|c|c|c|c|}
\hline \multirow{2}{*}{ Zone. } & \multicolumn{2}{|c|}{ Pacific. } & \multicolumn{2}{|c|}{ Atlantic. } & \multicolumn{2}{|c|}{ Indian. } \\
\hline & Largest percentage. & Snallest percentage. & Largest percentage. & Smallest percentage. & Largest percentage. & Smallest percentage. \\
\hline $\begin{array}{l}30^{\circ}-40^{\circ} \mathrm{s} . \\
40^{\circ}-50^{\circ} \mathrm{s} . \\
50^{\circ}-60^{\circ} \mathrm{s} .\end{array}$ & $\begin{array}{c}18 \cdot 2 \text { s. } \\
17 \cdot 1 \text { s.W. } \\
21 \cdot 1 \text { N.W. }\end{array}$ & $\begin{array}{l}7 \cdot 8 \mathrm{E} . ; 8 \cdot 5 \mathrm{~W} . \\
9 \cdot 1 \mathrm{~N} . \mathrm{W} \\
6 \cdot 1 \mathrm{E.} ; 7 \cdot 5 \text { S.E. } \\
4.8 \text { S.E.; } 4 \cdot 0 \mathrm{E} .\end{array}$ & $\begin{array}{c}15 \cdot 9 \text { S.E. } \\
24 \cdot 0 \mathrm{~N} . \\
24 \cdot 7 \text { N.W.; } 22 \cdot 0 \mathrm{~N} .\end{array}$ & $\begin{array}{c}7.5 \text { E. } \\
3 \cdot 4 \text { E. ; } 4.1 \text { S.E. } \\
4 \cdot 0 \text { S.E. } ; 4 \cdot 3 \text { E. }\end{array}$ & $\begin{array}{c}20 \cdot 7 \text { S.W. } \\
21 \cdot 0 \text { S.W.; } 18 \cdot 1 \mathrm{~W} \text {; } \\
18 \cdot 0 \mathrm{~N} . \mathrm{W} . \\
25 \cdot 9 \text { N.; } 23 \cdot 5 \mathrm{~W} .\end{array}$ & $\begin{array}{c}7 \cdot 3 \text { E.; } 7 \cdot 7 \text { N.E. } \\
2 \cdot 4 \text { E. } \\
1 \cdot 2 \text { S.E. }\end{array}$ \\
\hline & & & GALES. & & & \\
\hline $\begin{array}{l}30^{\circ}-40^{\circ} \mathrm{S} . \\
40^{\circ}-50^{\circ} \mathrm{S} . \\
50^{\circ}-60^{\circ} \mathrm{S} .\end{array}$ & $\begin{array}{c}1.0 \mathrm{~s} . \\
1.5 \mathrm{~s} . \mathrm{W} . \\
2.0 \mathrm{~W} . \text { and N.W. }\end{array}$ & $\begin{array}{l}0.2 \mathrm{E} \\
0.2 \mathrm{E} . \\
0.1 \mathrm{E} .\end{array}$ & $\begin{array}{c}0.5 \text { S.W. and N.W. } \\
1.4 \text { S.W.; } 1.3 \mathrm{~W} \text {. } \\
\text { and N.W. } \\
2.7 \mathrm{~N} \text {. and W. }\end{array}$ & $\begin{array}{c}0.0 \mathrm{E} \text {. } \\
0.0 \text { N.E. and E. } \\
0.0 \text { S.E. }\end{array}$ & $\begin{array}{c}0.9 \text { S.W. and W. } \\
1.5 \text { S.W. } \\
3.5 \text { N.W. }\end{array}$ & $\begin{array}{c}0.1 \text { E. and S.E. } \\
0.1 \mathrm{E} \text {. } \\
0.0 \text { N.E.-S.; W. }\end{array}$ \\
\hline
\end{tabular}

TABLE X.-Directions from which the Largest and Smallest Percentages of Winds were recorded in the Southern Ocean in the Respective Seasons during the Years 1901 to 1904; also in All Seasons during that Period.

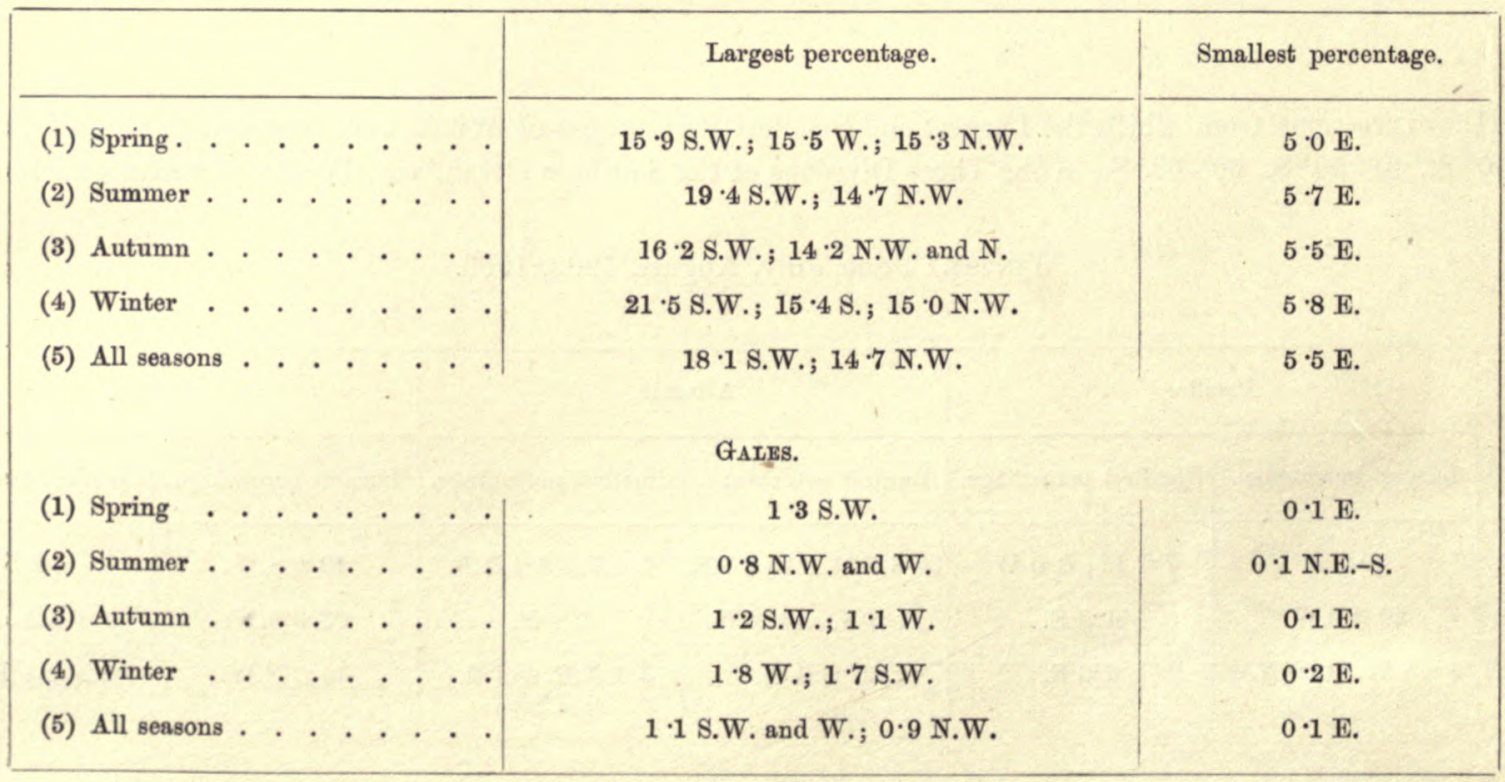




\section{KEY MAP.}

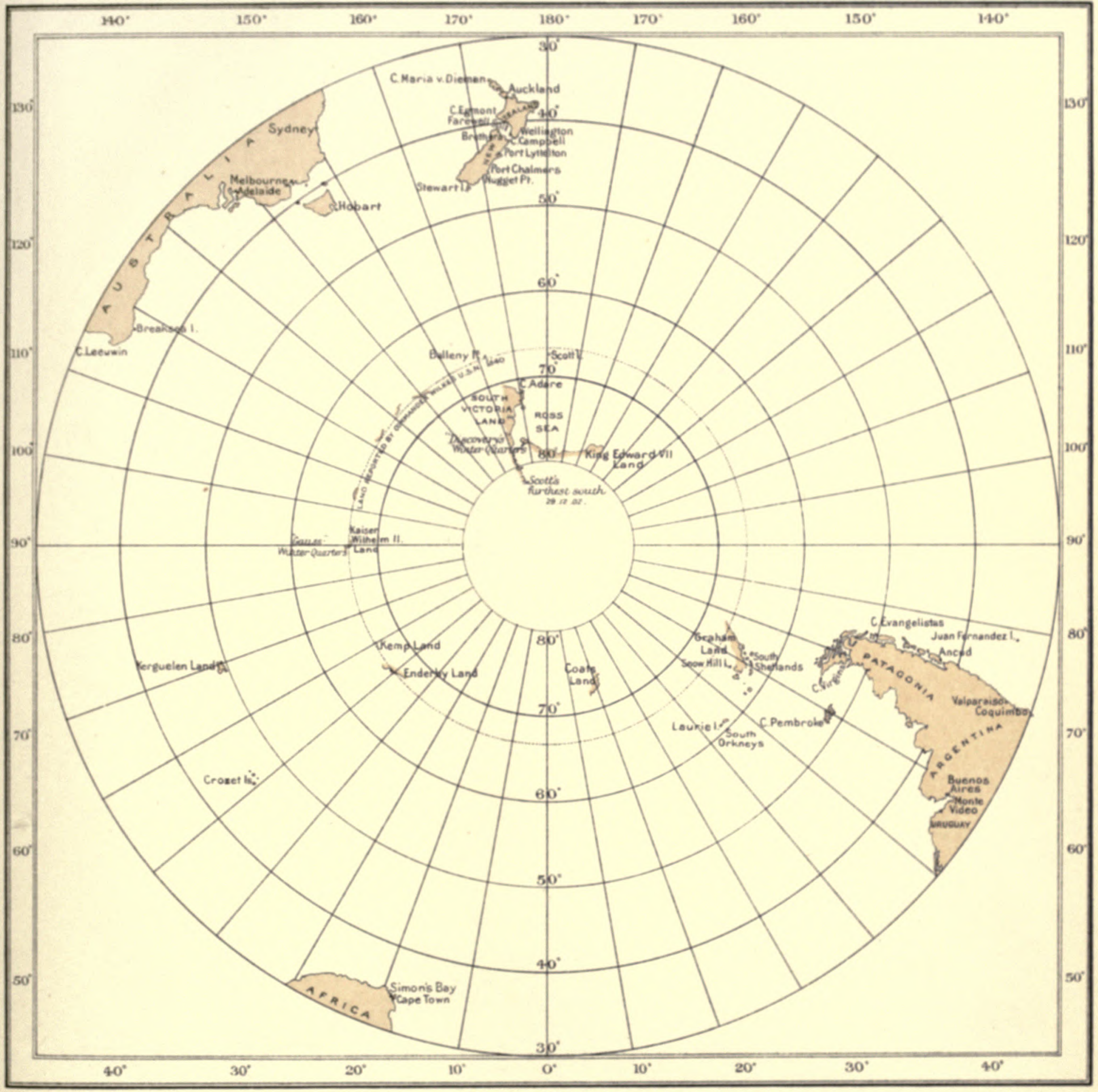

\section{EXPLANATION.}

The Daily and Mean. Monthly charts in this volume are based on daily observations recorded at places indicated on the above chart, in addition to those received from. Ships of the Royal Navy and Mercantile Marine.

The red and blue lines on the charts of Mean Monthly, and Normal Air Temperature are Isotherms or lines of Equal Air Temperature. The lines in red relate to thermometer readings of $35^{\circ}$ Fahr. or above: those in blue to readings of $30^{\circ} \mathrm{Fahr}$. and below.

The red and blue lines on the Daily, Mean Monthly, and Normal charts of Pressure are Isobars or lines of Eval Barometric Pressure. The lines in red relate to barometer readings of 29.7 ins. or above, those in blue to readings of 29.6 ins. and below. The words "High" and "Low" on the Daily charts are introduced where pressure is highest or lowest in anticyclones and depressions respectively. Figures in black refer to Air Temperature; the arrows to Wind. The latter $f l y$ with the wind, the force of which, given in numbers of the Beaufort Scale, is shown as follows: $\circ \mathrm{Calm}, \rightarrow 1 \mathrm{cos}, \longrightarrow 4$ to $6,7 \& 8, \longrightarrow 9 \& 10 \longrightarrow \pi \& 12$. 


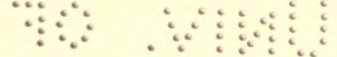

연 

INTERNATIONAL ANTARCTIC COOPERATION.

SYNCMRONOUS CHARTS OF SEA-LEVEL PRESSURE FOR NOON GMT.

WITH WINDS ANO AIR TEMPERATURES.
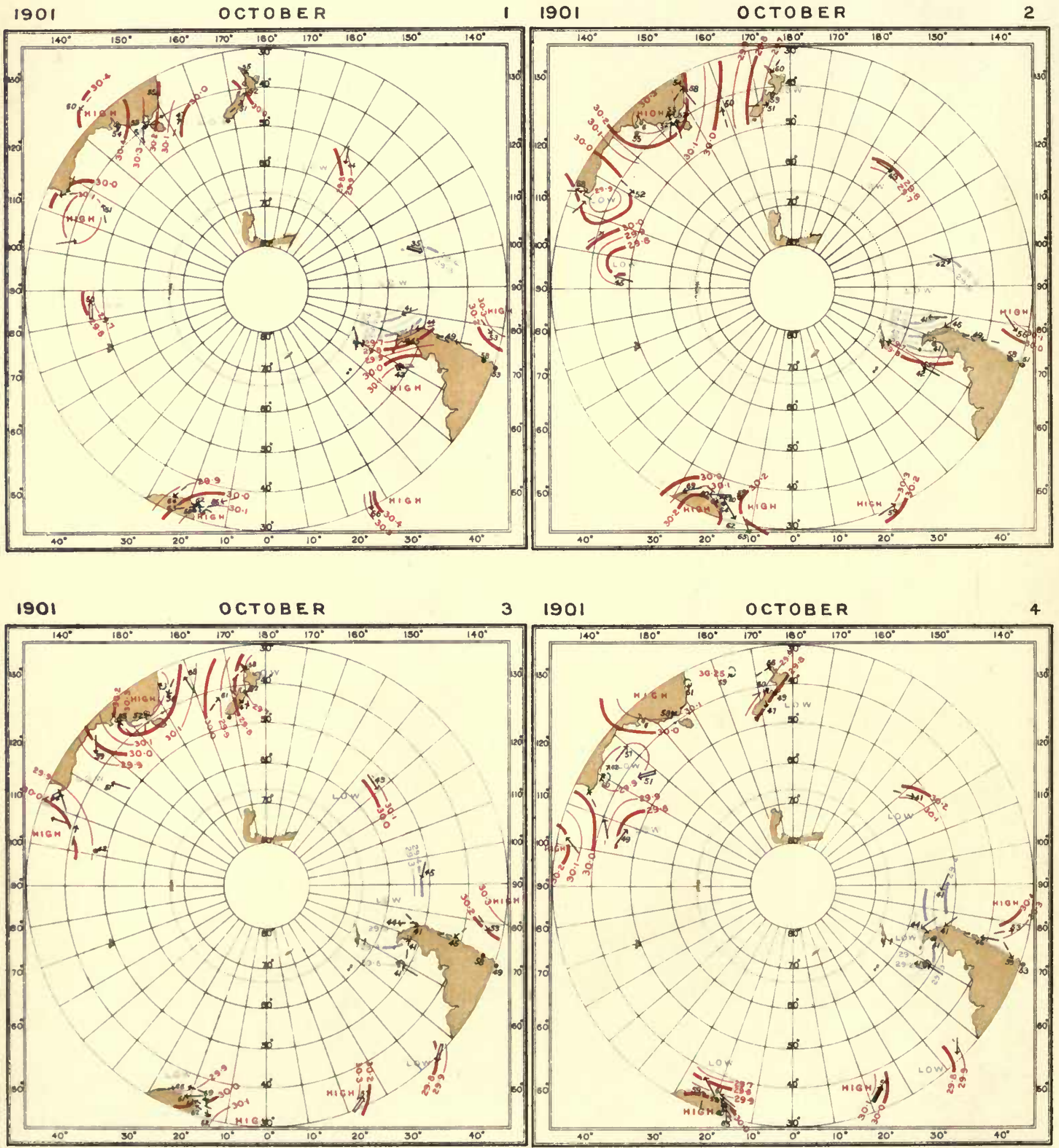
INTERNATIONAL ANTARCTIC CO-OPERATION.

SYNCHRONOUS CHARTS OF SEA-LEVEL PRESSURE FOR NOON G.M.T

WITH WINDS AND AIR TEMPERATURES
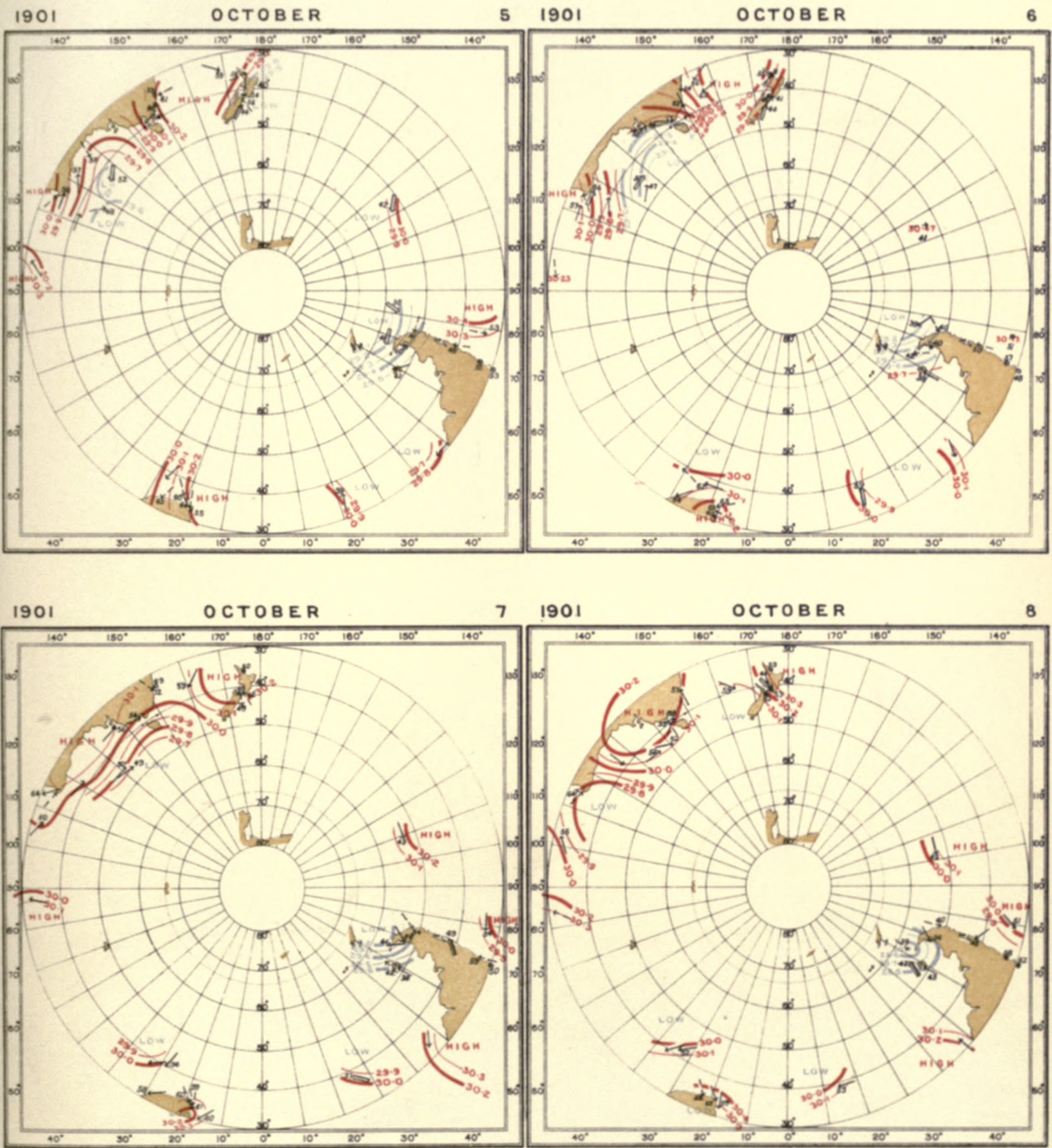


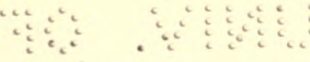

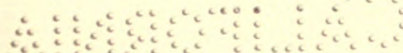


a

$\cdots$ 
INTERNATIONAL ANTARCTIC CO-OPERATION.

SYNCHRONOUS CHARTS OF SEALEVEL PRESSURE FOR NOON GMT

WITH WINDS AND AIR TEMPERATURES
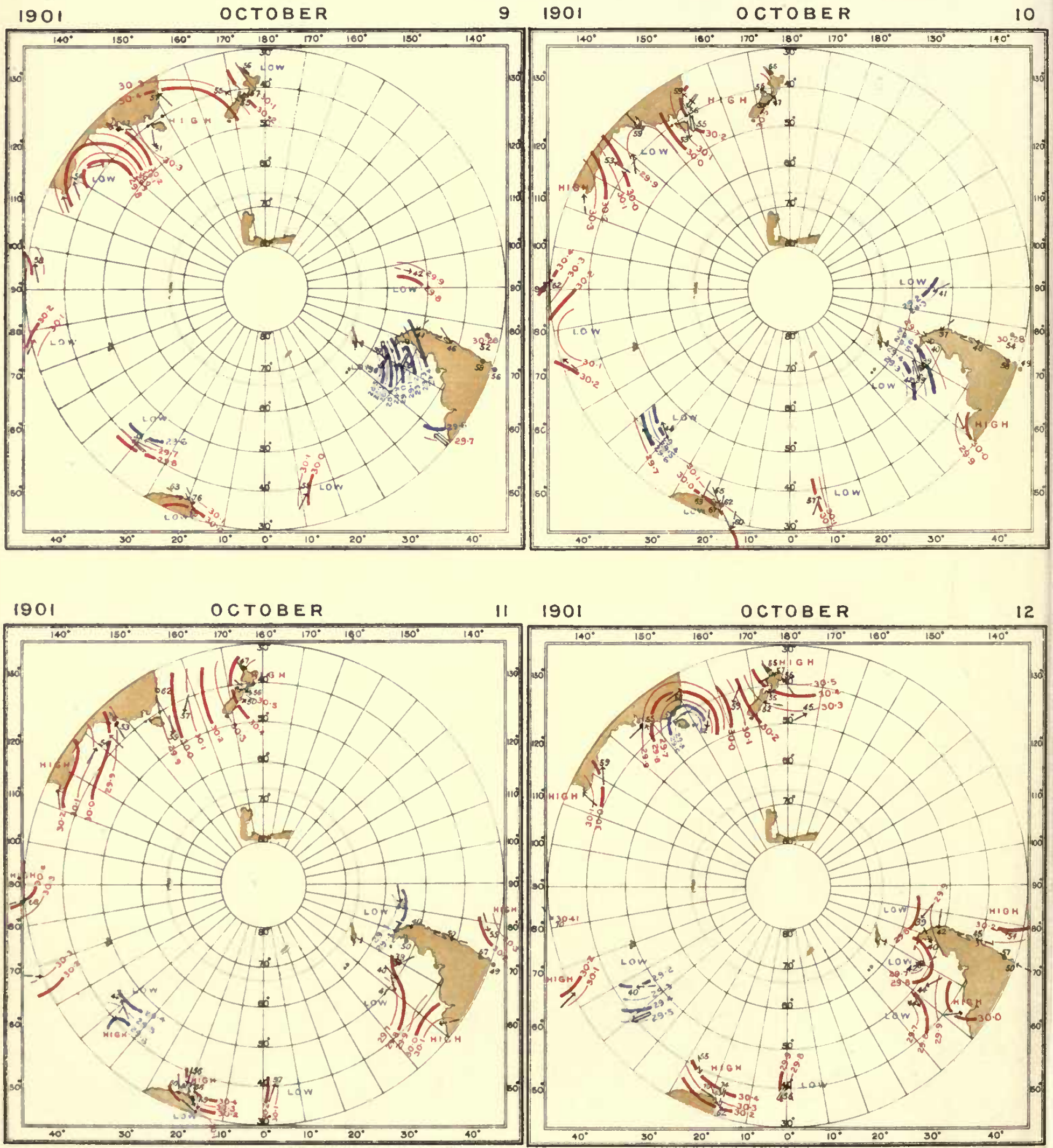
INTERNATIONAL ANTARCTIC CO-OPERATION.

SYNCHRONOUS CHARTS OF SEA-LEVEL PRESSURE FOR NOON G.MTT

WITH WINOS AND AIR TEMPERATURES
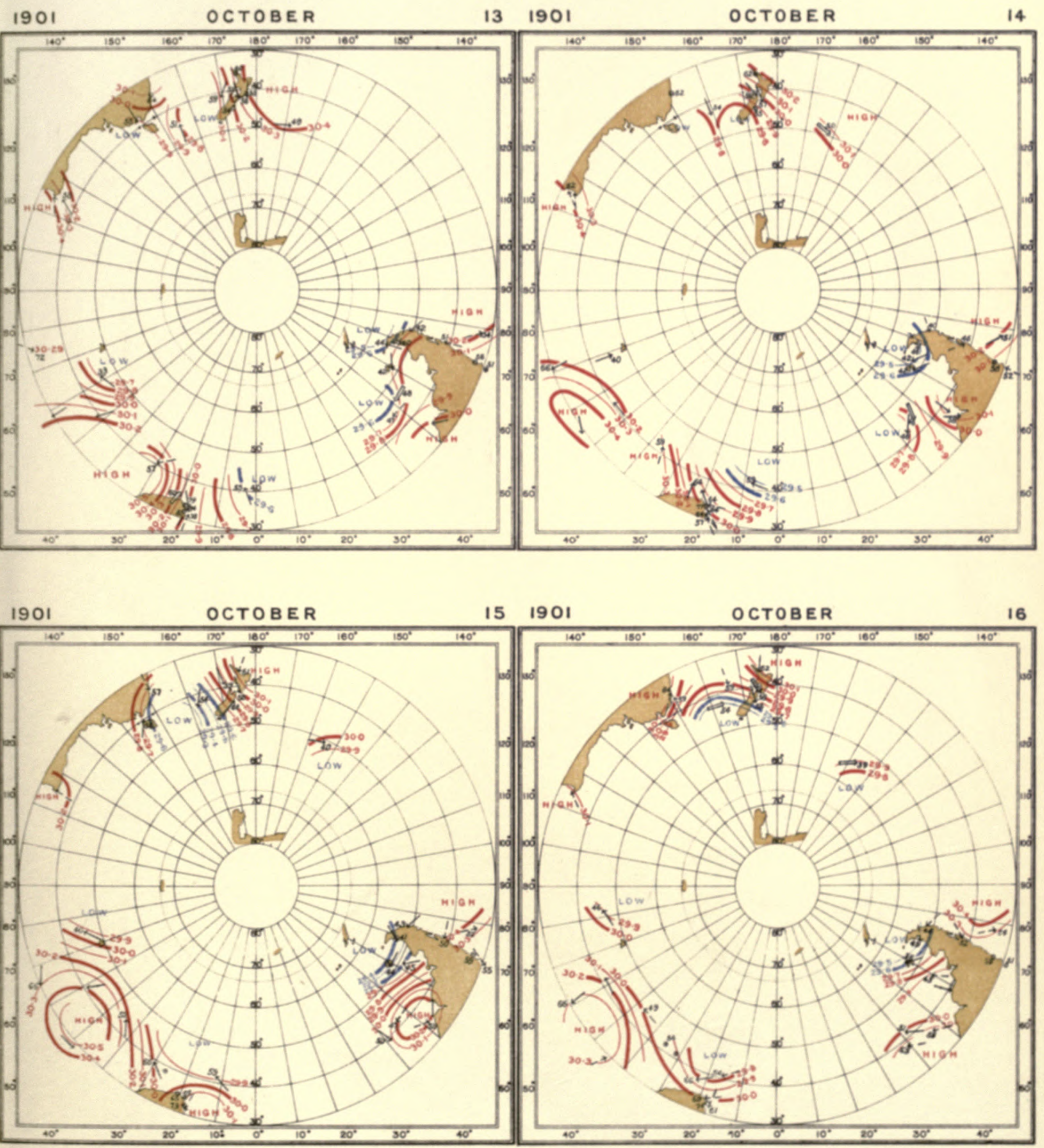


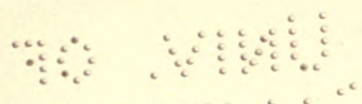


$+1$

4

… 
INTERNATIONAL ANTARCTIC COOPERATION.

SYNGHRONOUS CHARTS OF SEA-LEVEL PRESSURE FOR NOON G.M.T

WITH WINDS AND AIR TEMPERATURES

1901

OCTOBER

17

1901

OCTOBER

18
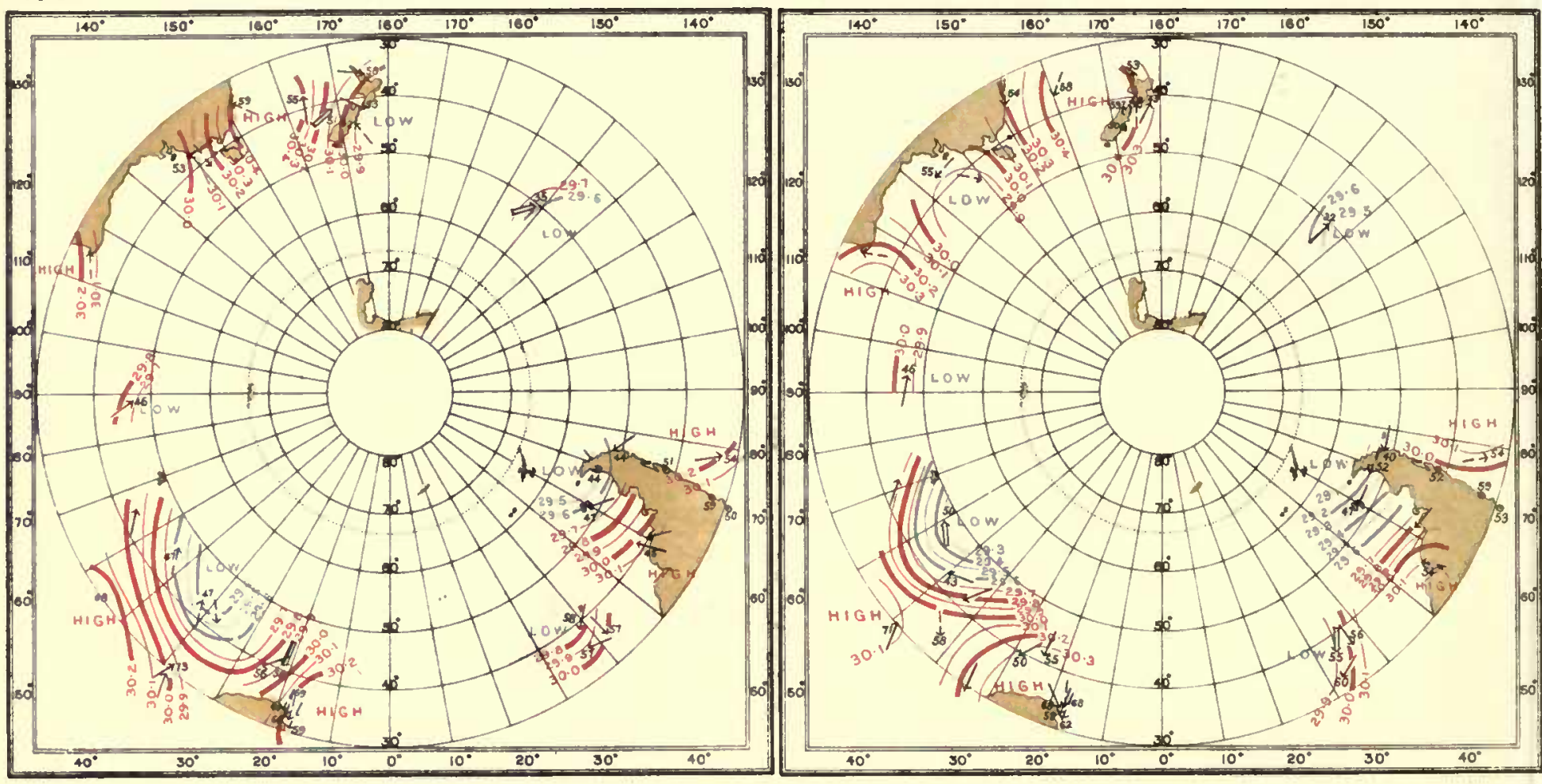

1901

OCTOBER

$19 \quad 1901$

OCTOBER

20
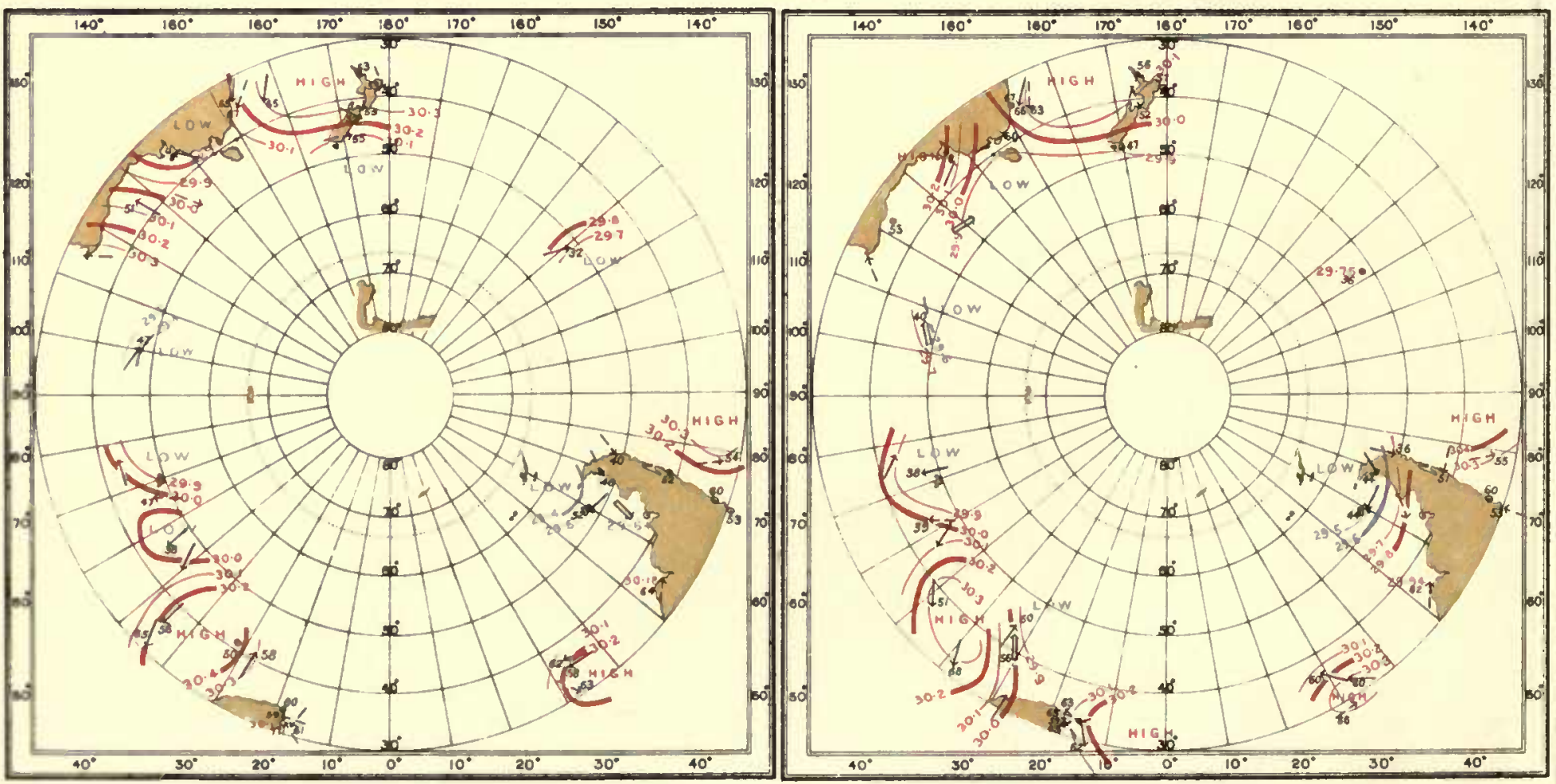
INTERNATIONAL ANTARCTIC CO-OPERATION.

SYNCHRONOUS CHARTS OF SEA-LEVEL PRESSURE FOR NOON G.M.T WITH WINDS AND AIR TEMPERATURES
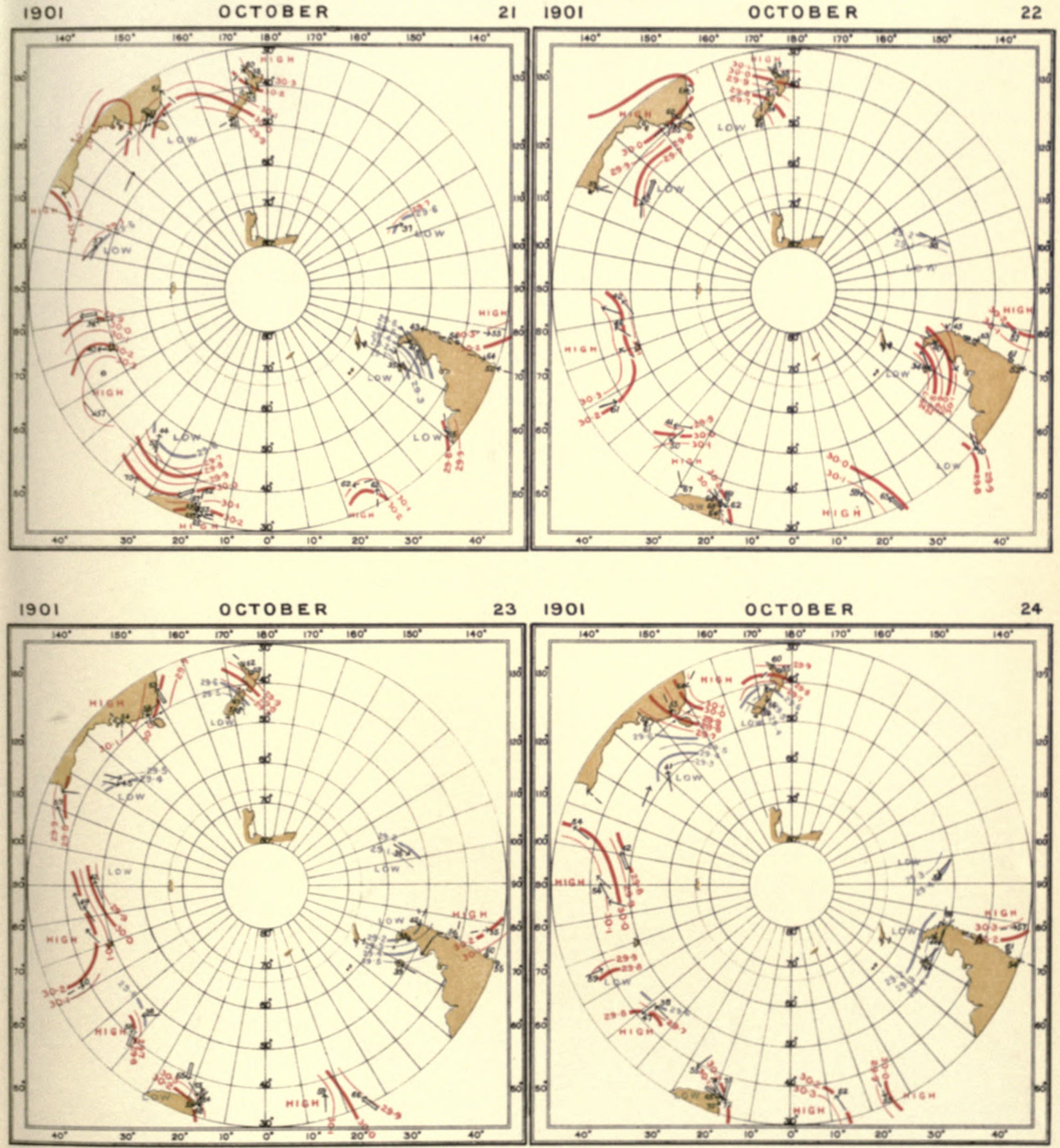


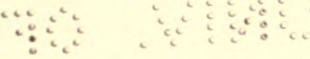

$\therefore=$ 
$\therefore$

6. A 
INTERNATIONAL ANTARCTIC COOPERATION.

SYNCHRONOUS CHARTS OF SEA-LEVEL PRESSURE FOR NOON G.M.T.

WITH WINDS AND AIR TEMPERATURES.

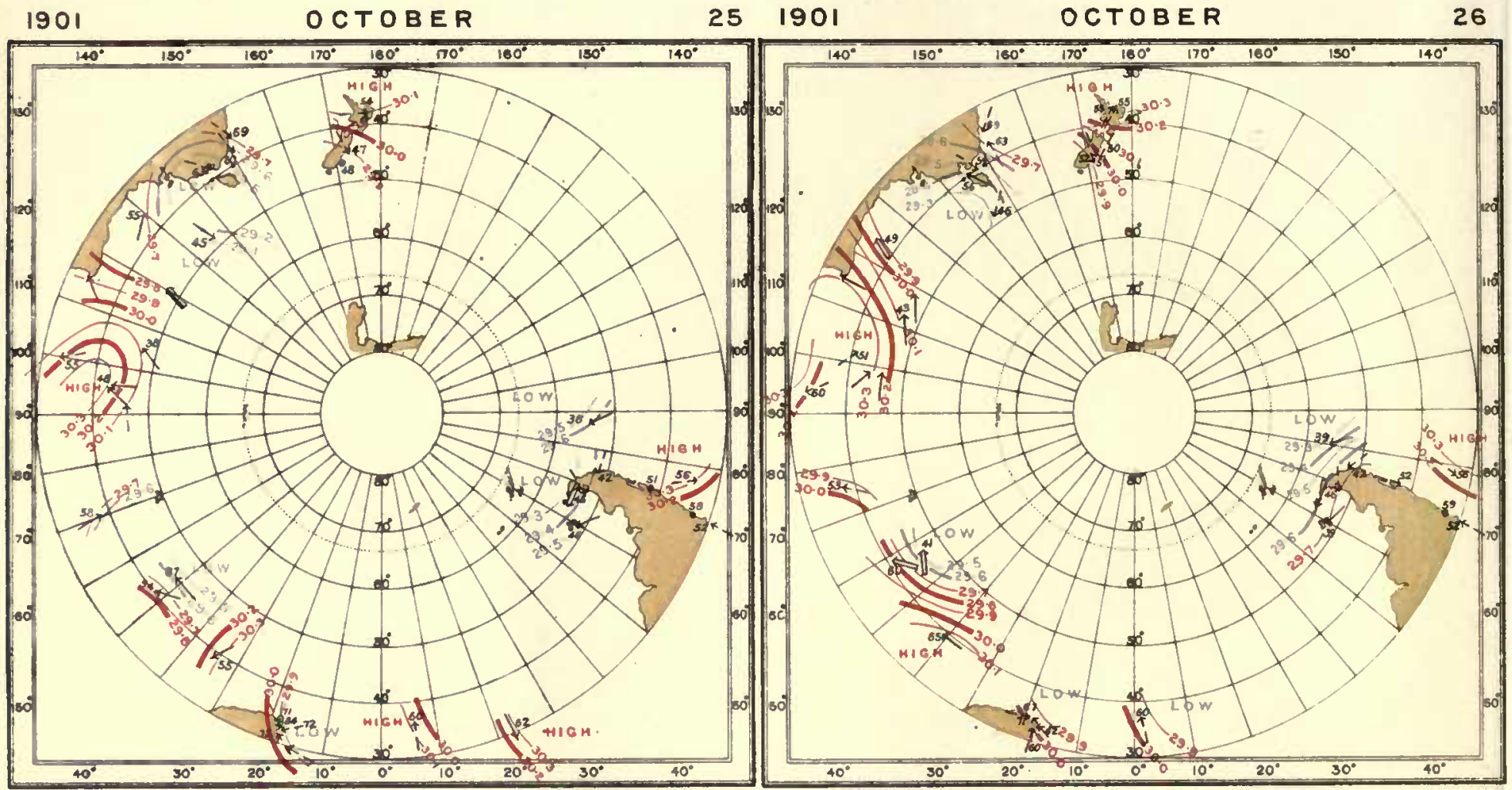

1901

OCTOBER

$27 \cdot 1901$

OCTOBER

28
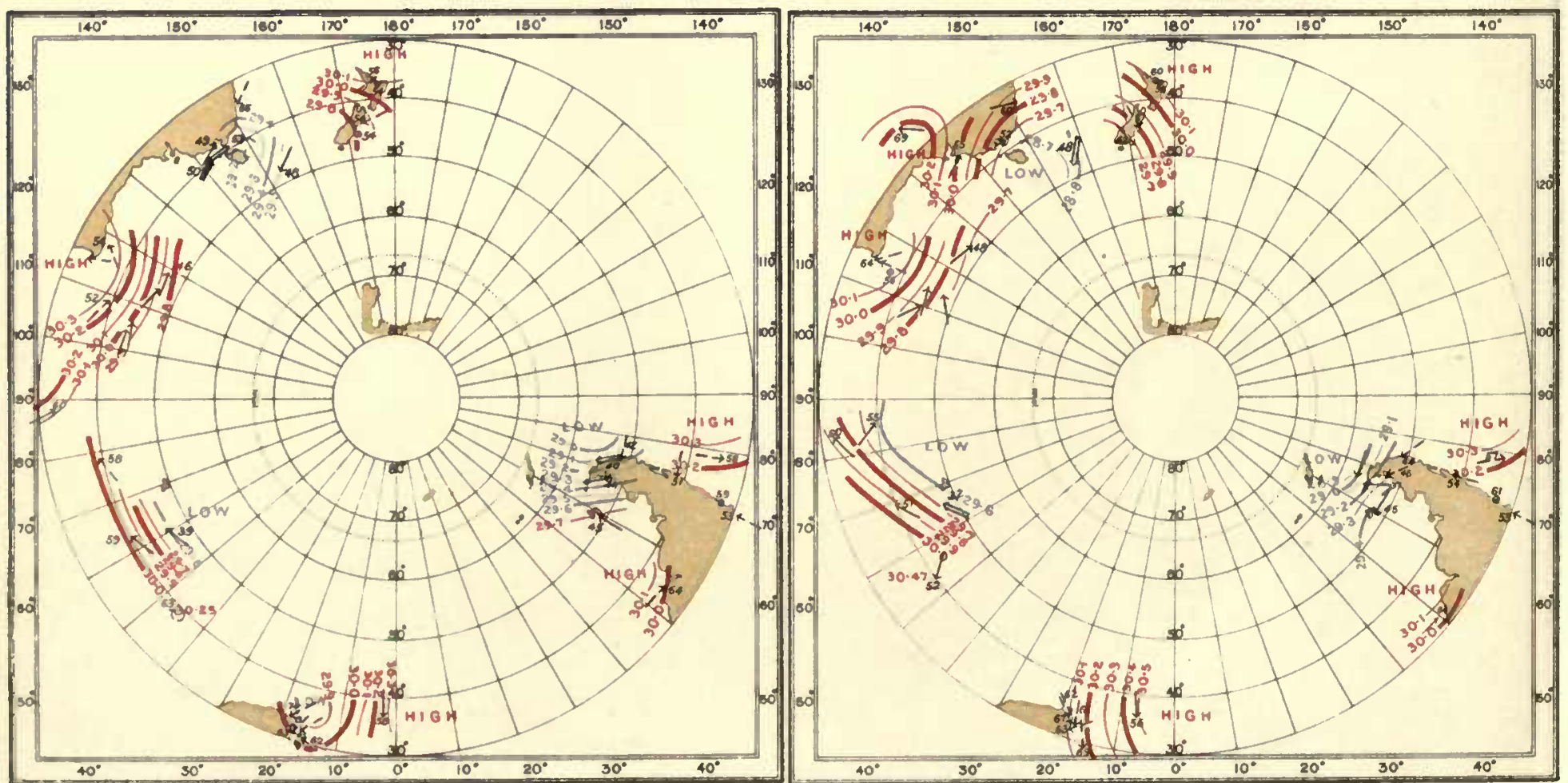
INTERNATIONAL ANTARCTIC CO-OPERATION.

SYNCHRONOUS CHARTS OF SEA-LEVEL PRESSURE FOR NOON G.M.T.

WITH WINDS AND AIR TEMPERATURES
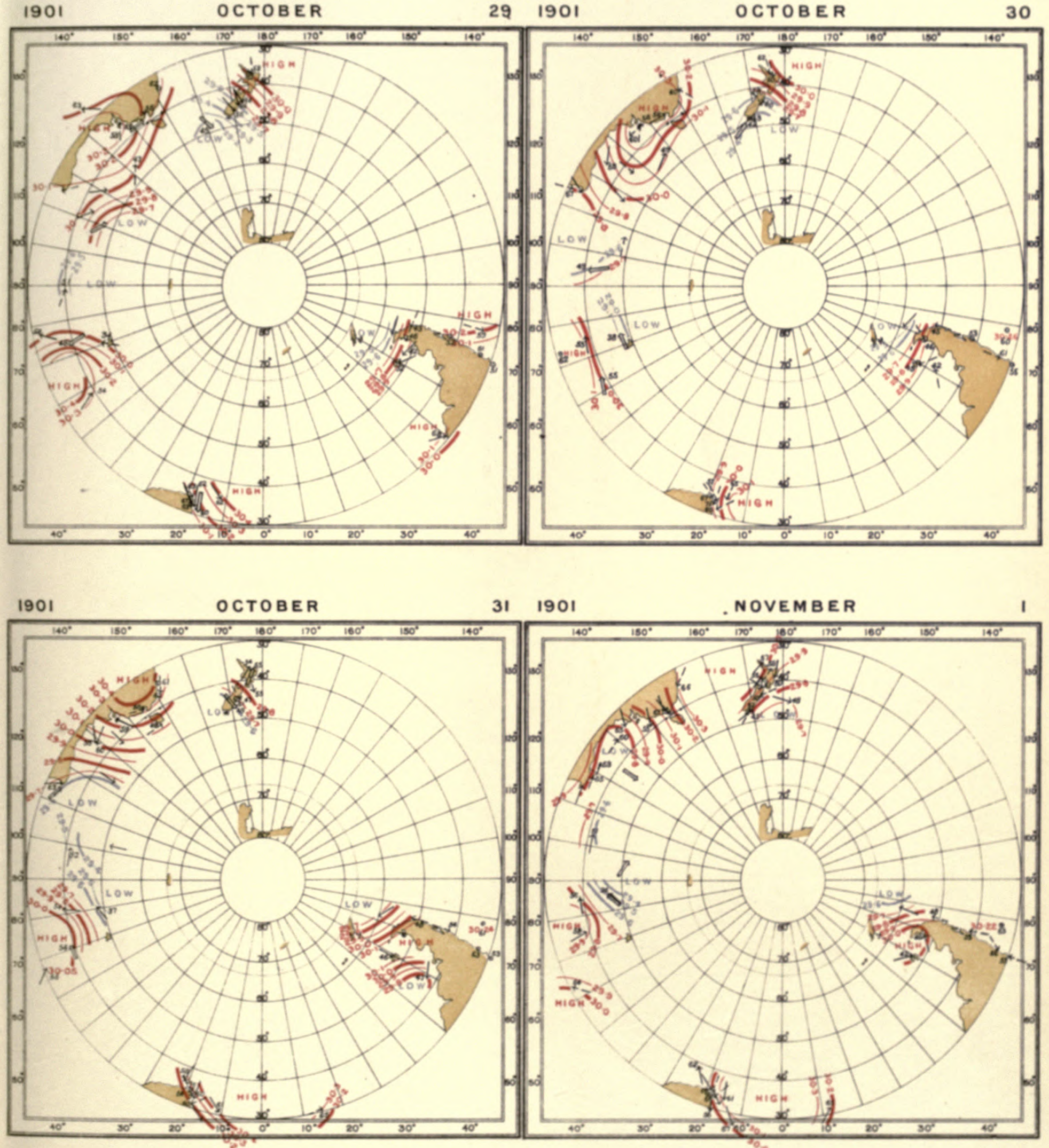
唯。 
INTERNATIONAL ANTARCTIC COOPERATION. WITH WINDS AND AIR TEMPERATURES

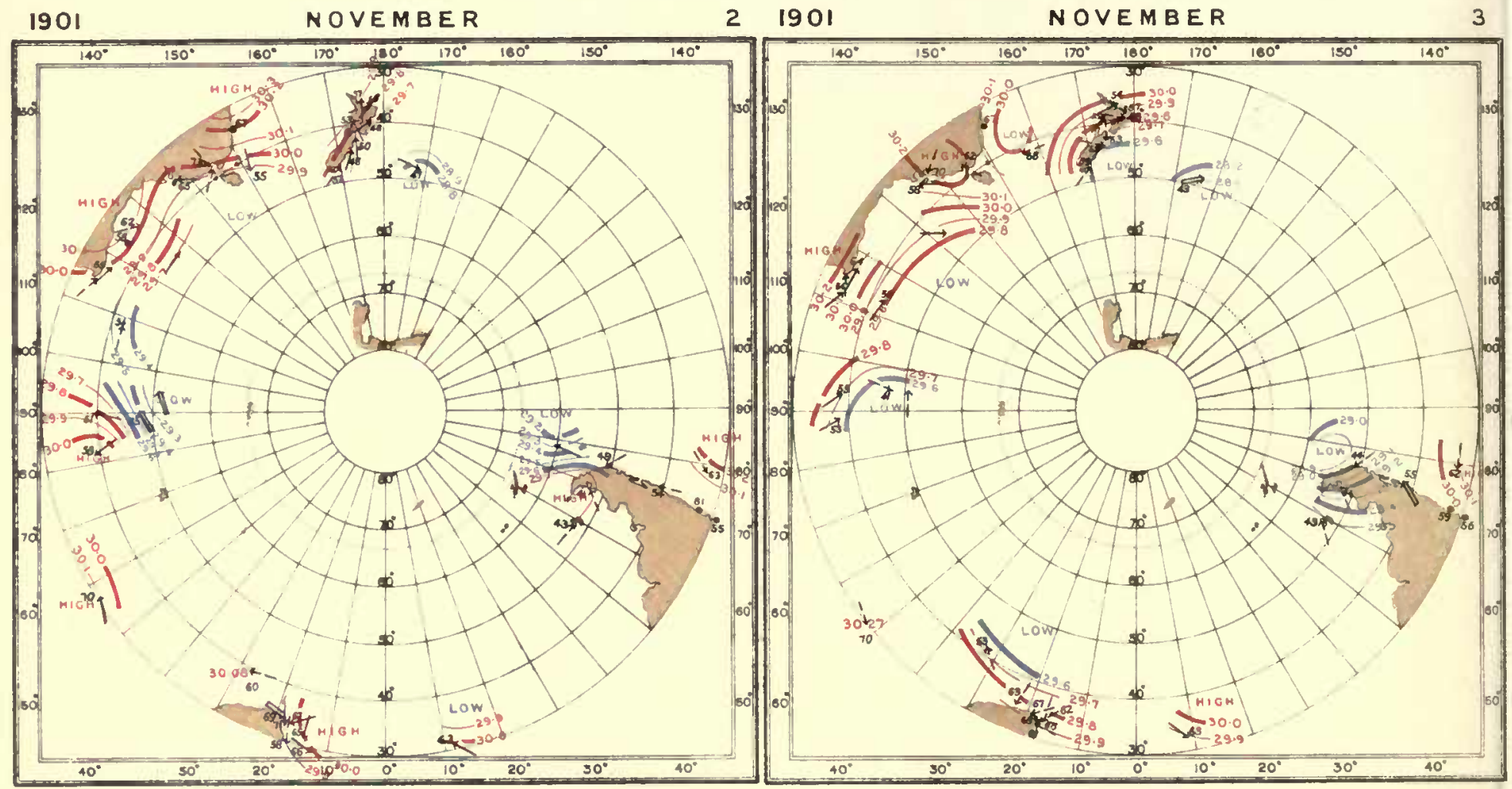

1901

NOVEMBER

$4 \quad 1901$

NOVEMBER

5
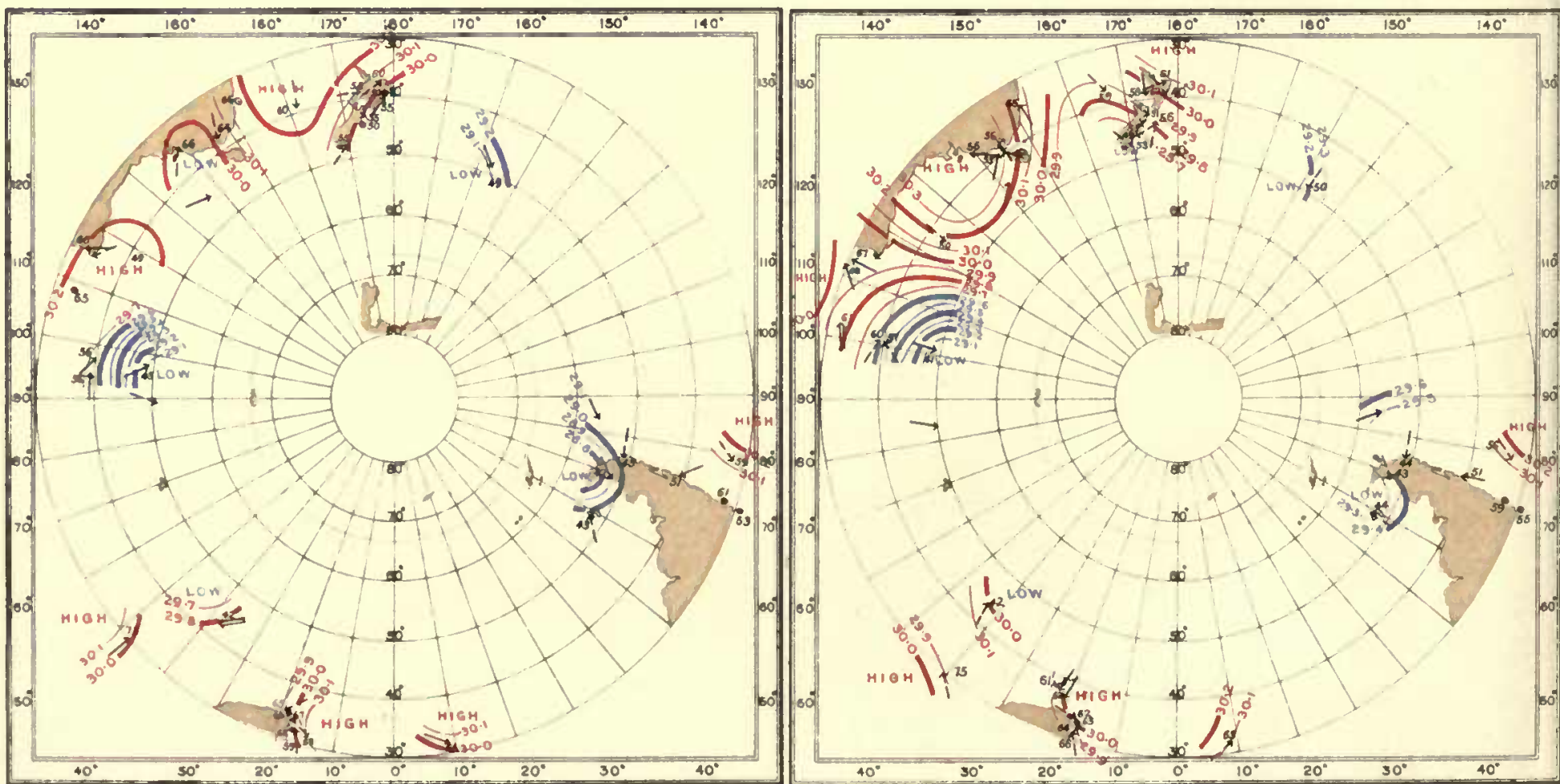
INTERNATIONAL ANTARCTIC CO-OPERATION.

SYNCHRONOUS CHARTS OF SEA-LEVEL PRESSURE FOR NOON G.M.T.

WITH WINDS AND AIR TEMPERATURES
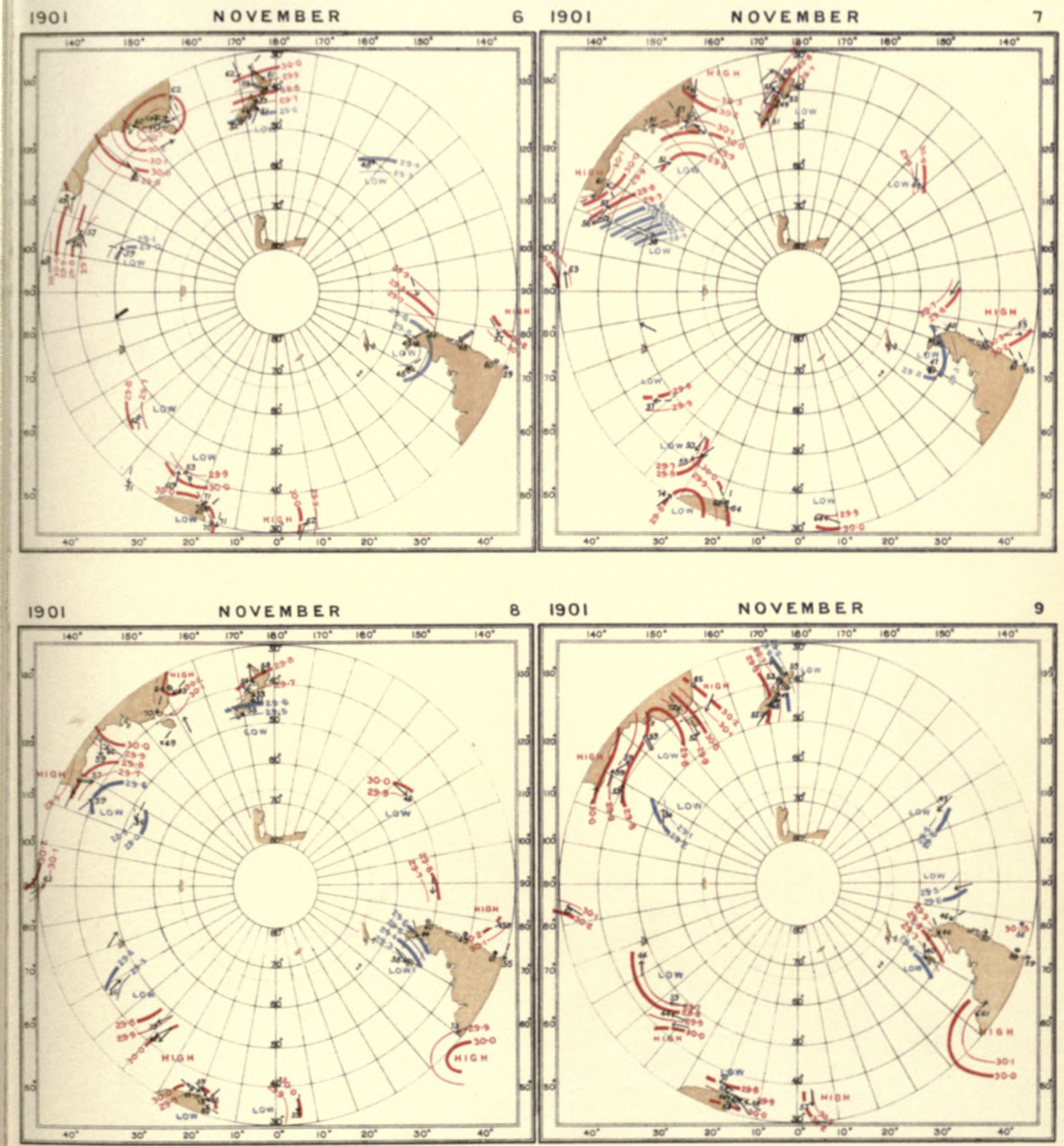


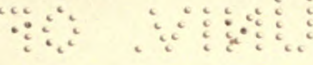

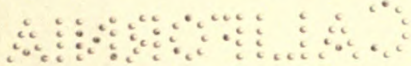


:

\% 
INTERNATIONAL ANTARCTIC CO-OPERATION

SYNCHRONOUS CHARTS OF SEALEVEL PRESSURE FOR NOON GM.T

WITH WINDS AND AIR TEMPERATURES.

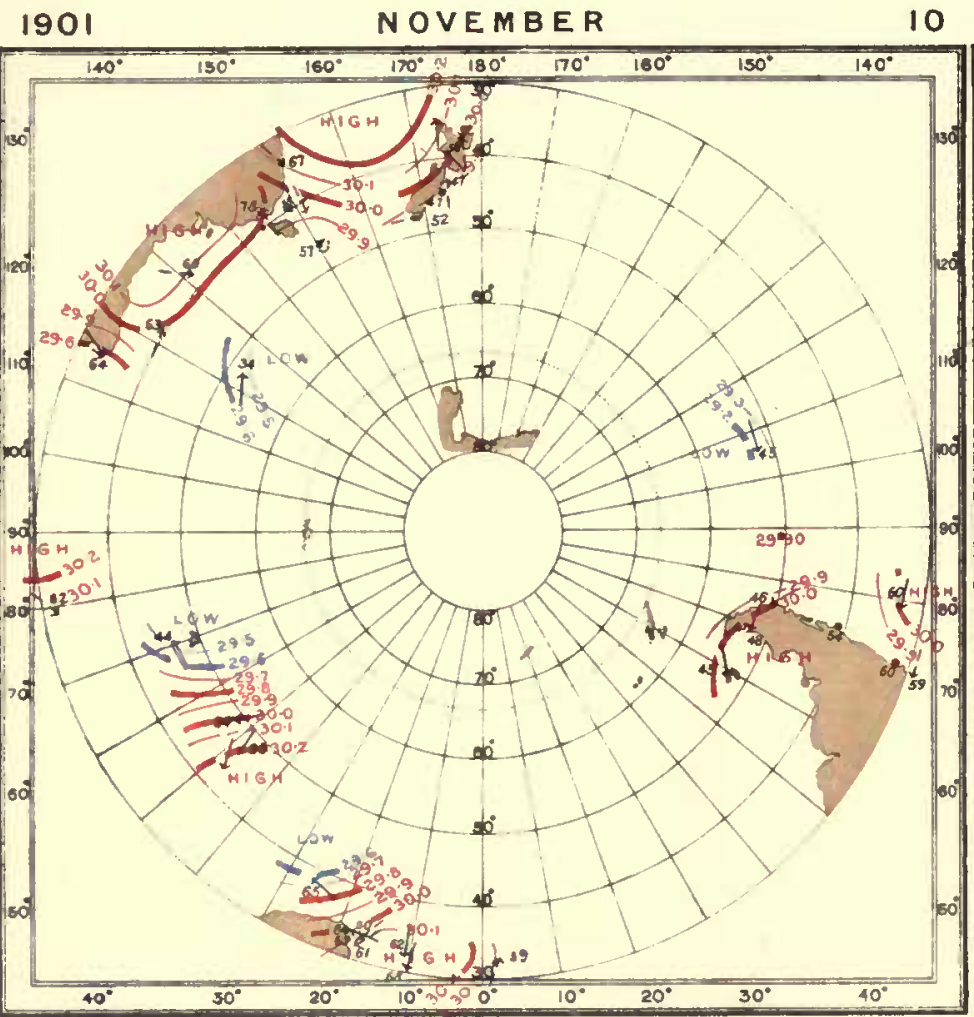

1901

NOVEMBER

II
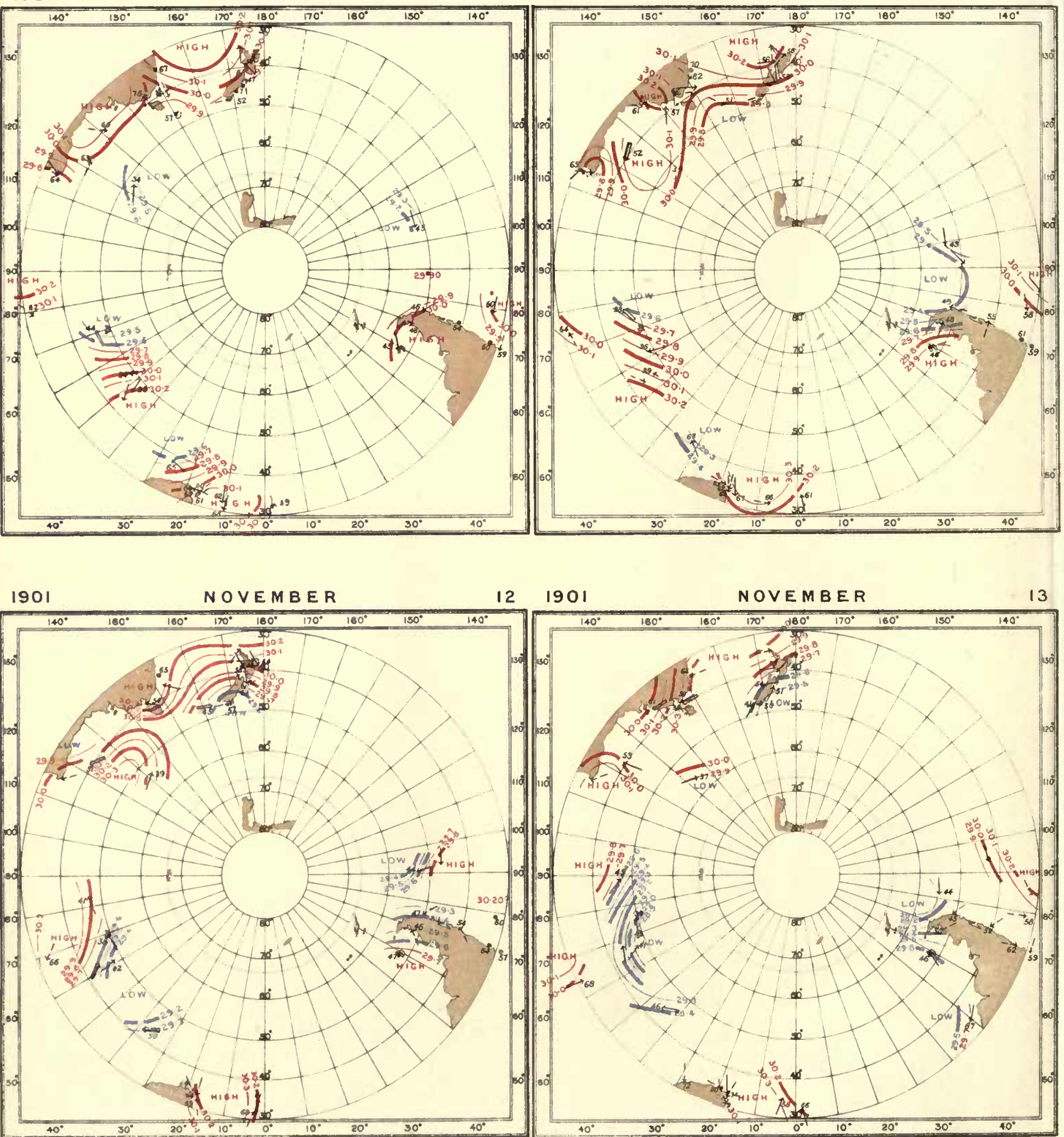
INTERNATIONAL ANTARCTIC CO-OPERATION.

SYNCHRONOUS CHARTS OF SEALEVEL PRESSURE FOR NOON GMT

WITH WINDS AND AIR TEMPERATURES
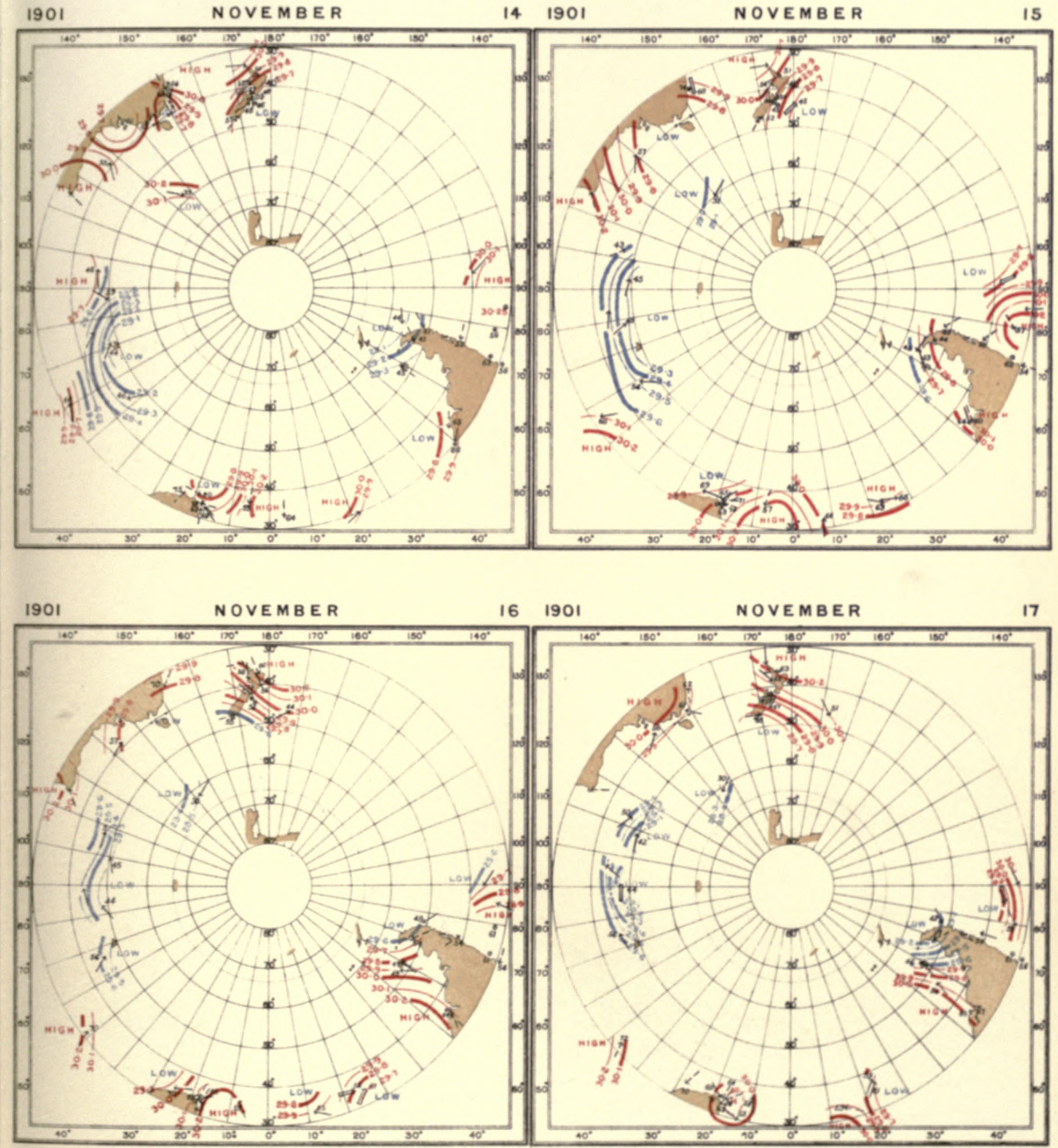
\begin{tabular}{c}
3 \\
\hdashline \\
$a$
\end{tabular} 

INTERNATIONAL ANTARCTIC CO-OPERATION.

SYNGHRONOUS CHARTS OF SEA-LEVEL PRESSURE FOR NOON G.M.T

WITH WINDS AND AIR TEMPERATURES
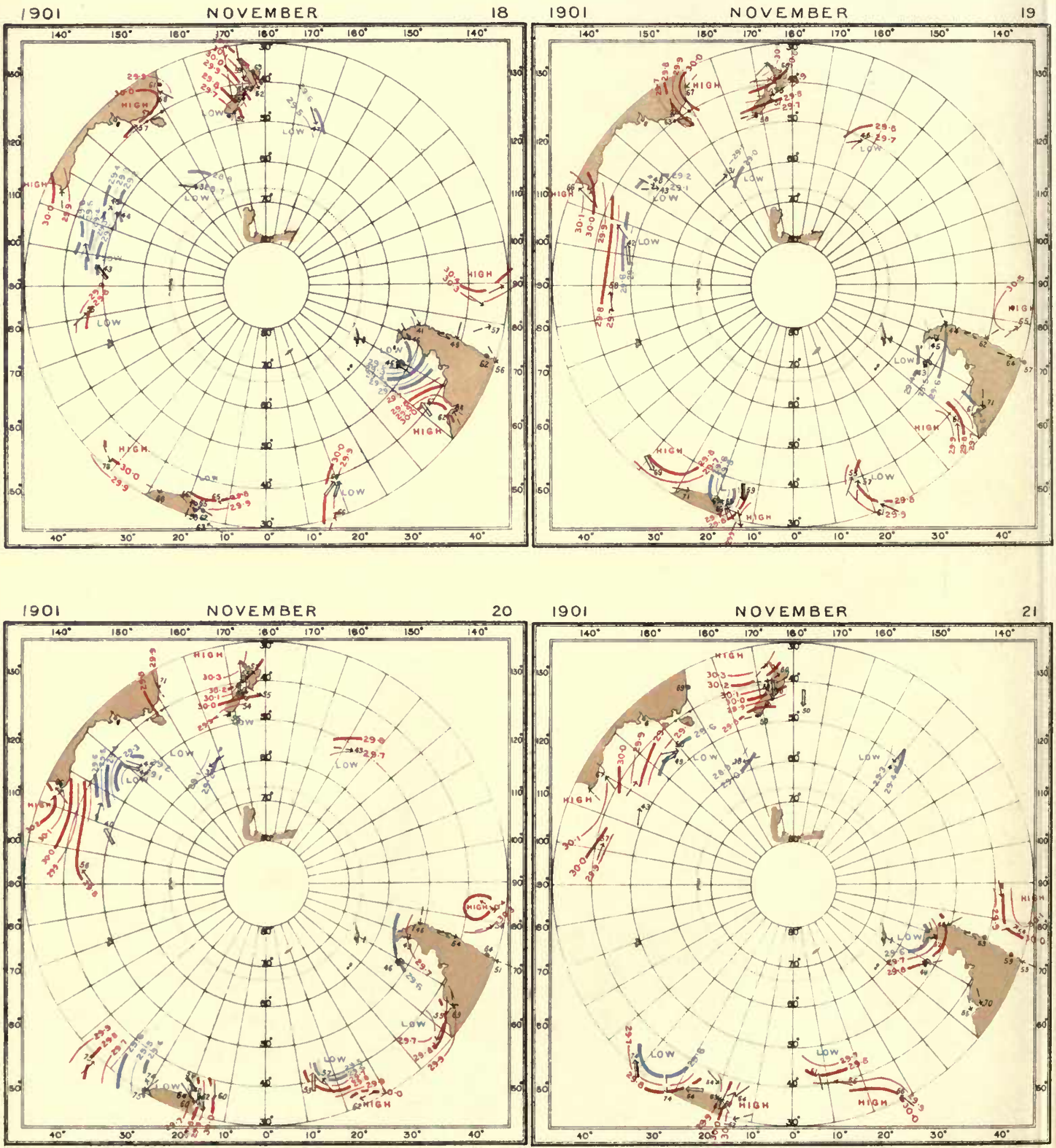
4.

and 
INTERNATIONAL ANTARCTIC CO-OPERATION.

SYNCHRONOUS CHARTS OF SEA-LEVEL PRESSURE FOR NOON GMT

WITH WINDS AND AIR TEMPERATURES
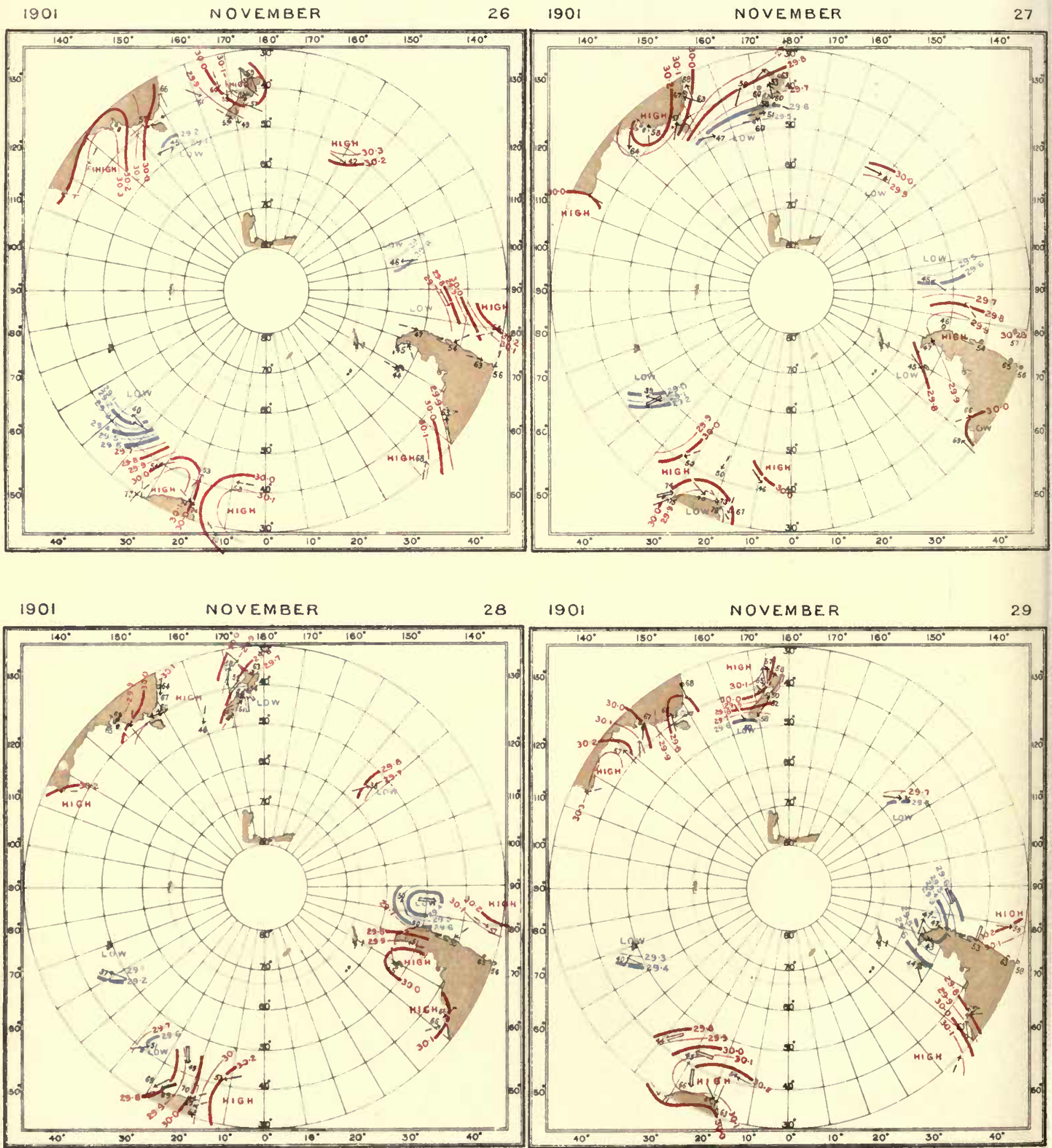
INTERNATIONAL ANTARCTIC CO-OPERATION.

SYNCHRONOUS CHARTS OF SEA-LEVEL PRESSURE FOR NOON GMT

WITH WINDS AND AIR TEMPERATURES

1901

NOVEMBER

$30 \quad 1901$

DECEMBER

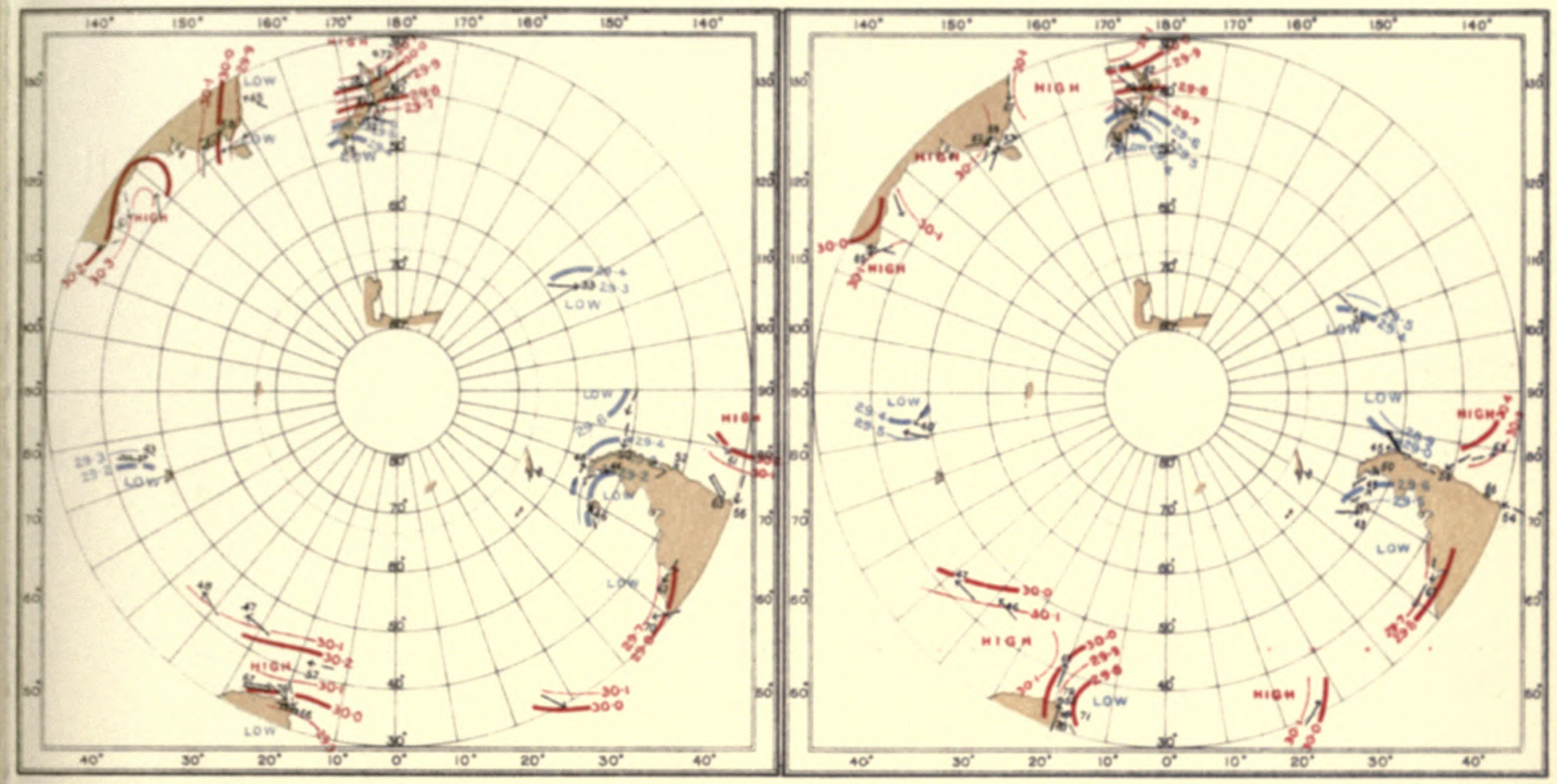

190

DECEMBER

21901

DECEMBER

3

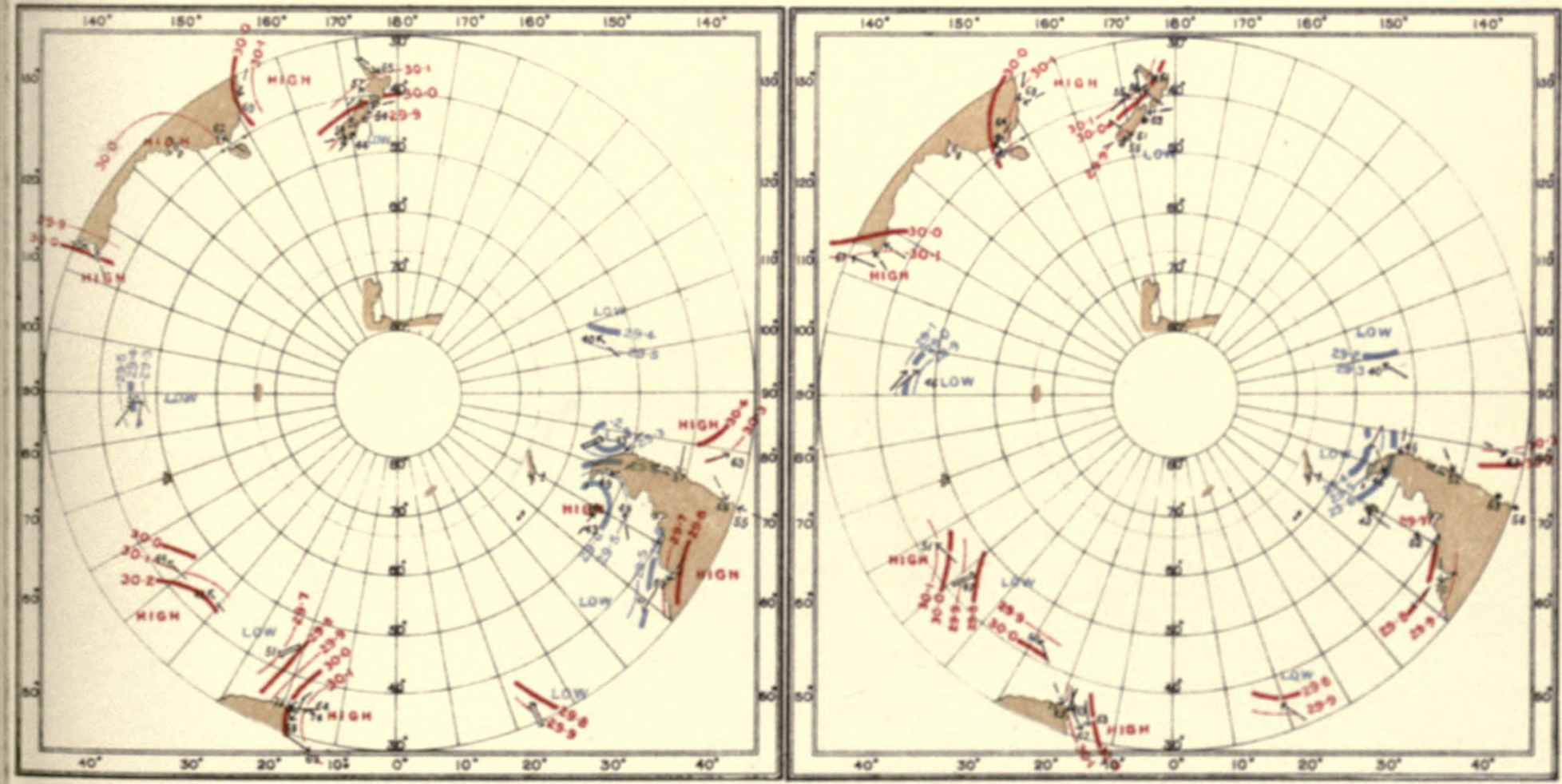


(4)

a 
14:

3. 
INTERNATIONAL ANTARCTIC COOPERATION.

SYNCHRONOUS CHARTS OF SEA-LEVEL PRESSURE FOR NOON G.M.T WITH WINDS AND AIR TEMPERATURES.
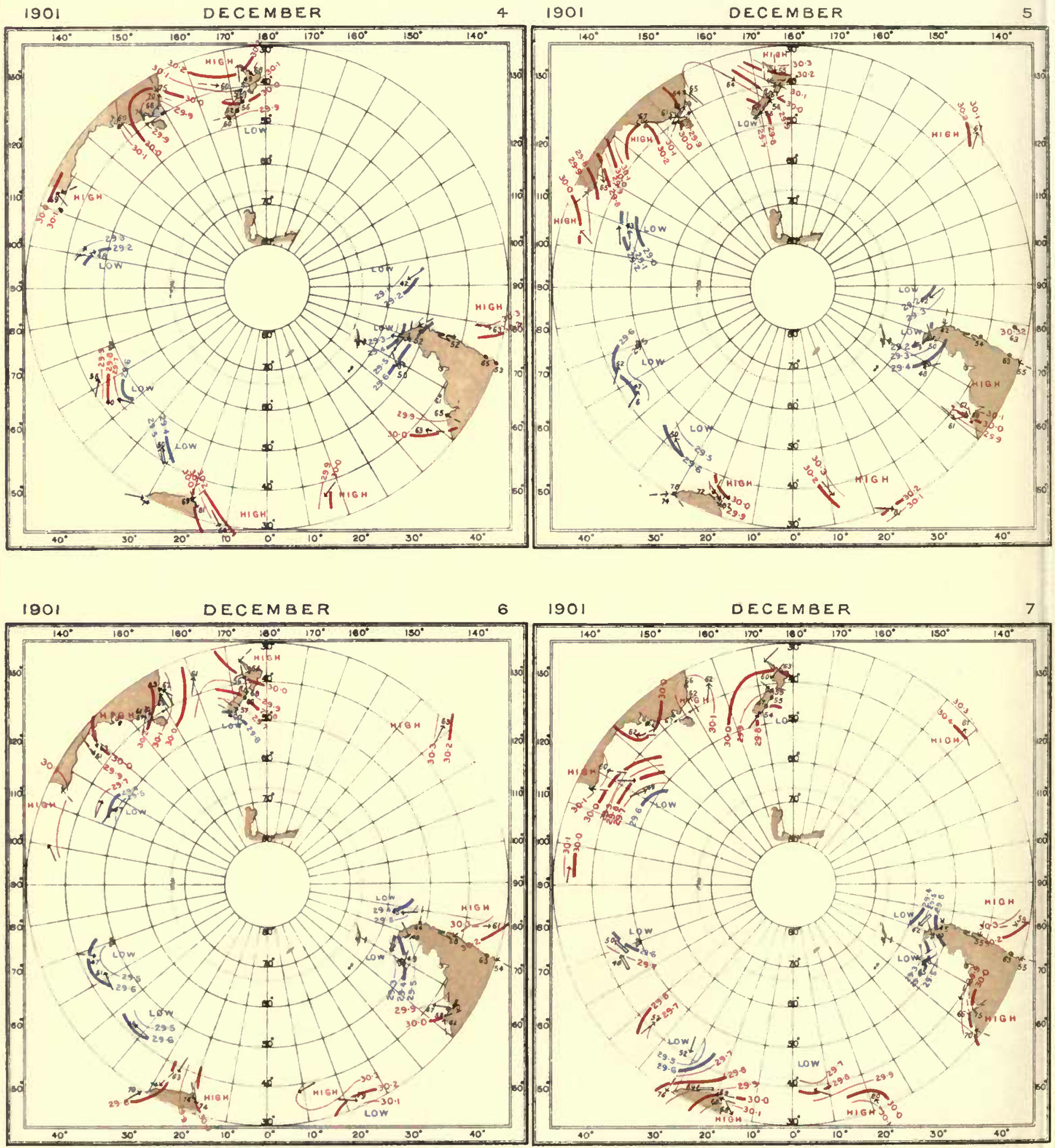
INTERNATIONAL ANTARCTIC COOOPERTION.

SYNCHRONOUS CHARTS OF SEA-LEVEL PRESSURE FOR NOON G.M.T

WITH WINOS AND AIR TEMPERATURES

1901

DECEMBER

$8 \quad 1901$

DECEMBER

9
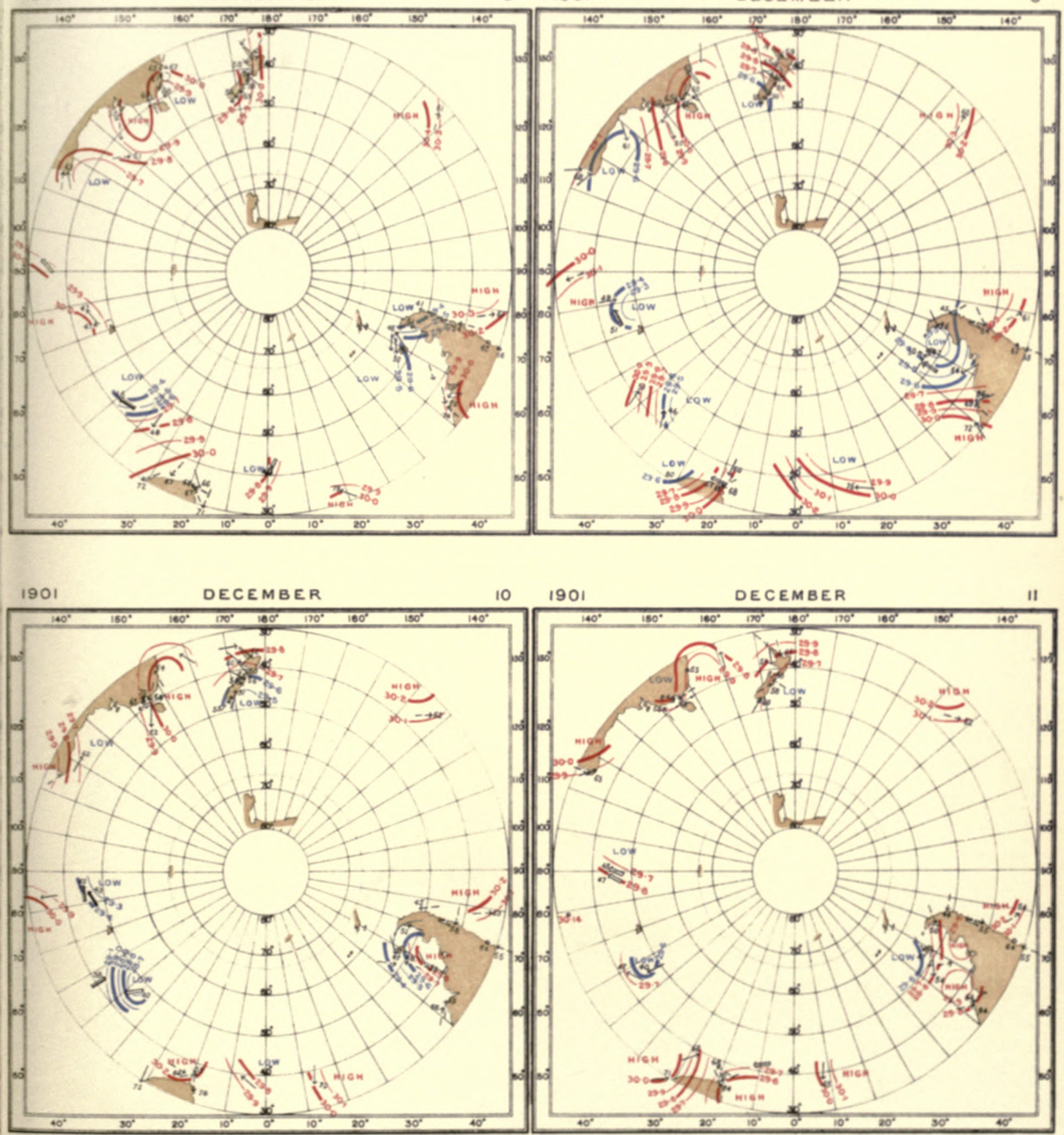
and

a 
INTERNATIONAL ANTARCTIC CO-OPERATION.

SYNCHRONOUS CHARTS OF SEA-LEVEL PRESSURE FOR NOON G.M T.

WITH WINDS AND AIR TEMPERATURES
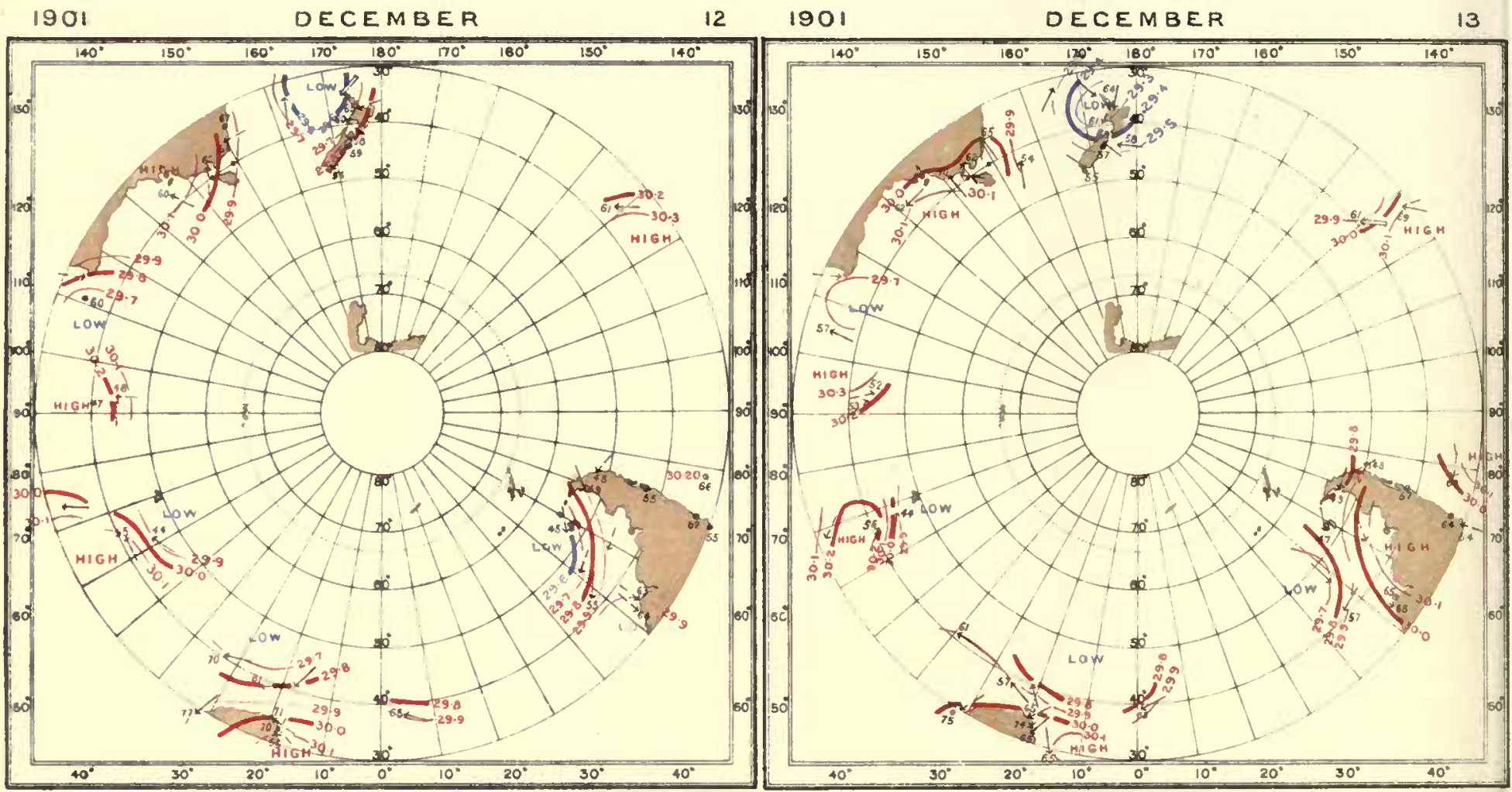

1901

DECEMBER

1901

DECEMBER
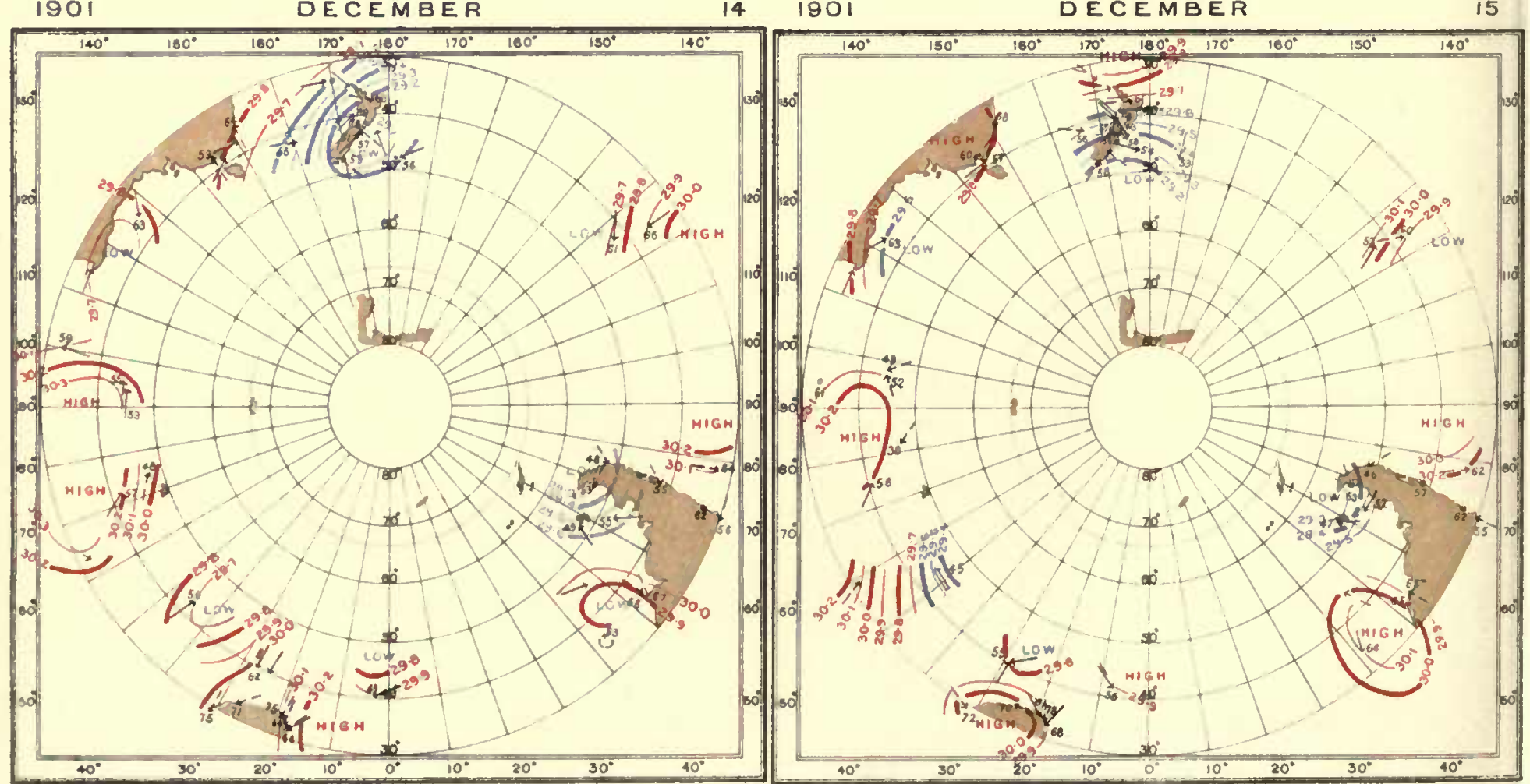
$\because \because \quad \because \because \frac{1}{\ddots}$

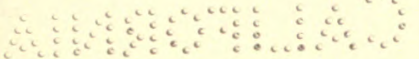


19

A. \& 
INTERNATIONAL ANTARCTIC COOPERATION.

SYNCHRONOUS CHARTS OF SEA-LEVEL PRESSURE FOR NOON G.M.T

WITH WINDS AND AIR TEMPERATURES.
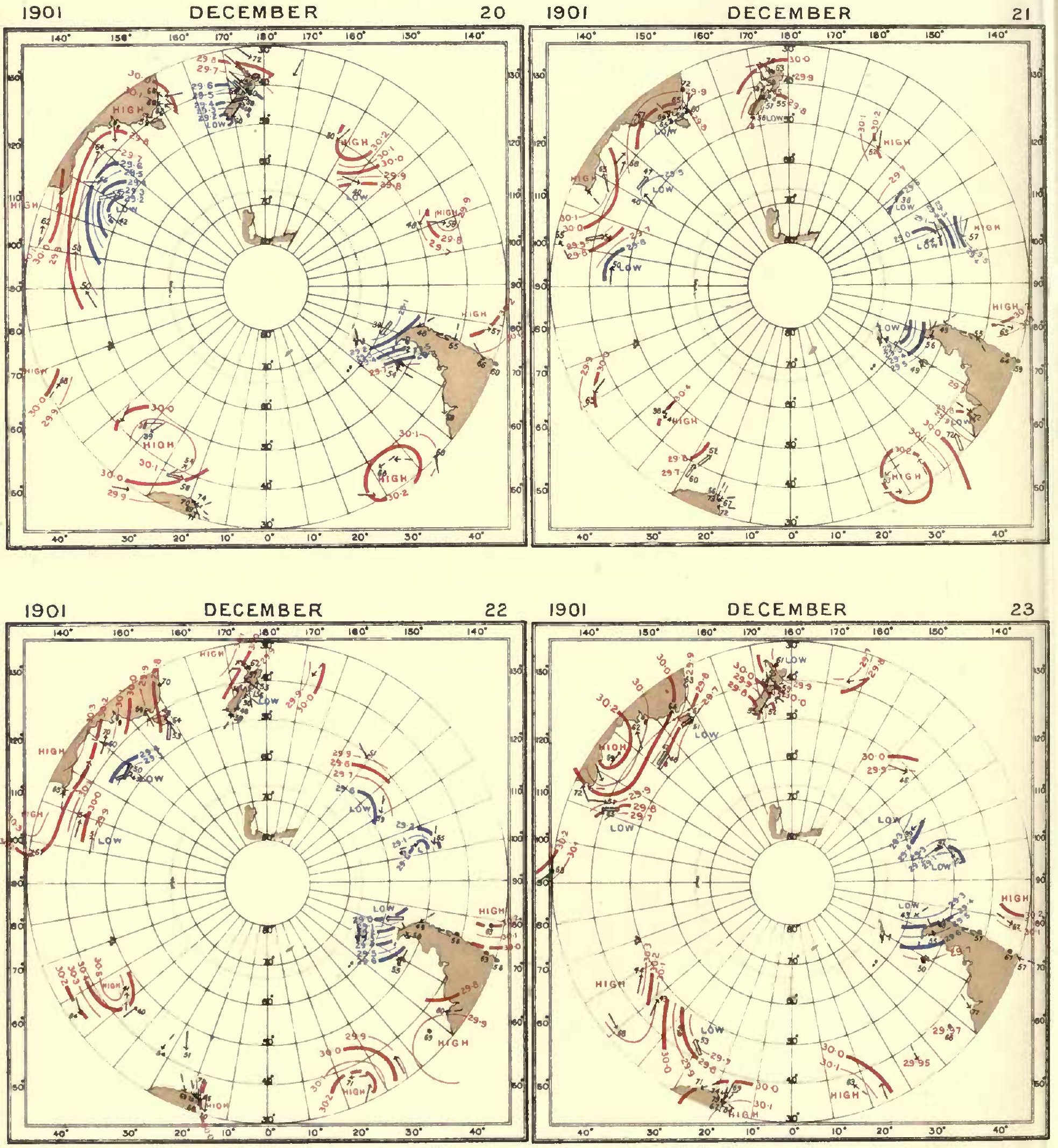


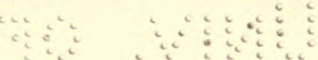

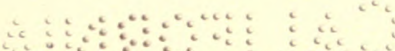


1)

a d 
INTERNATIONAL ANTARCTIC CO-OPERATION

SYNCHRONOUS CHARTS OF SEALLEVEL PRESSURE FOR NOONGMT

WITH WINDS AND AIR TEMPERATURES
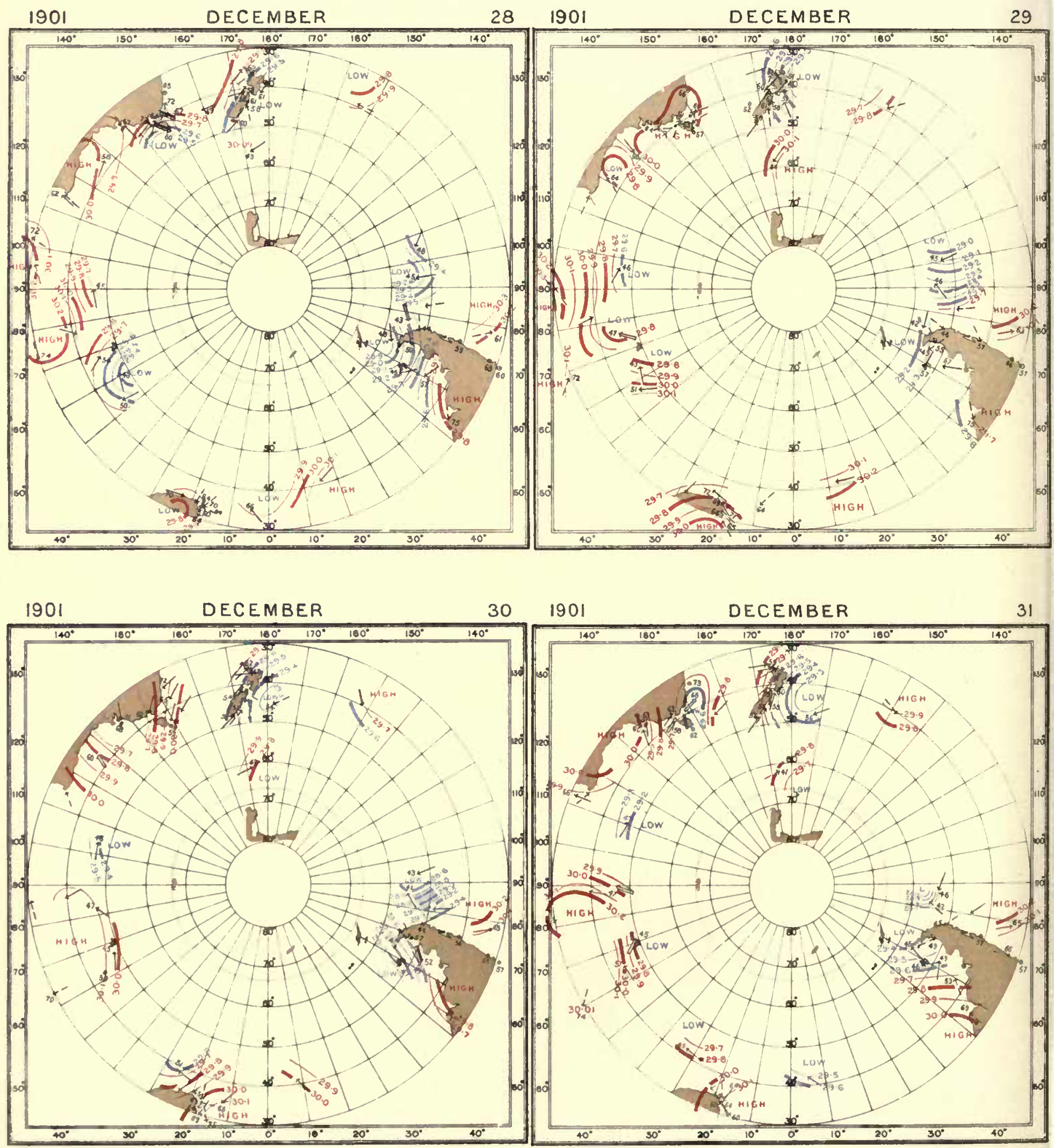
INTERNATIONAL ANTARCTIC CO-OPERATION.

SYNCHRONOUS CHARTS OF SEA-LEVEL PRESSURE FOR NOON G.M.T

WITH WINOS AND AIR TEMPERATURES
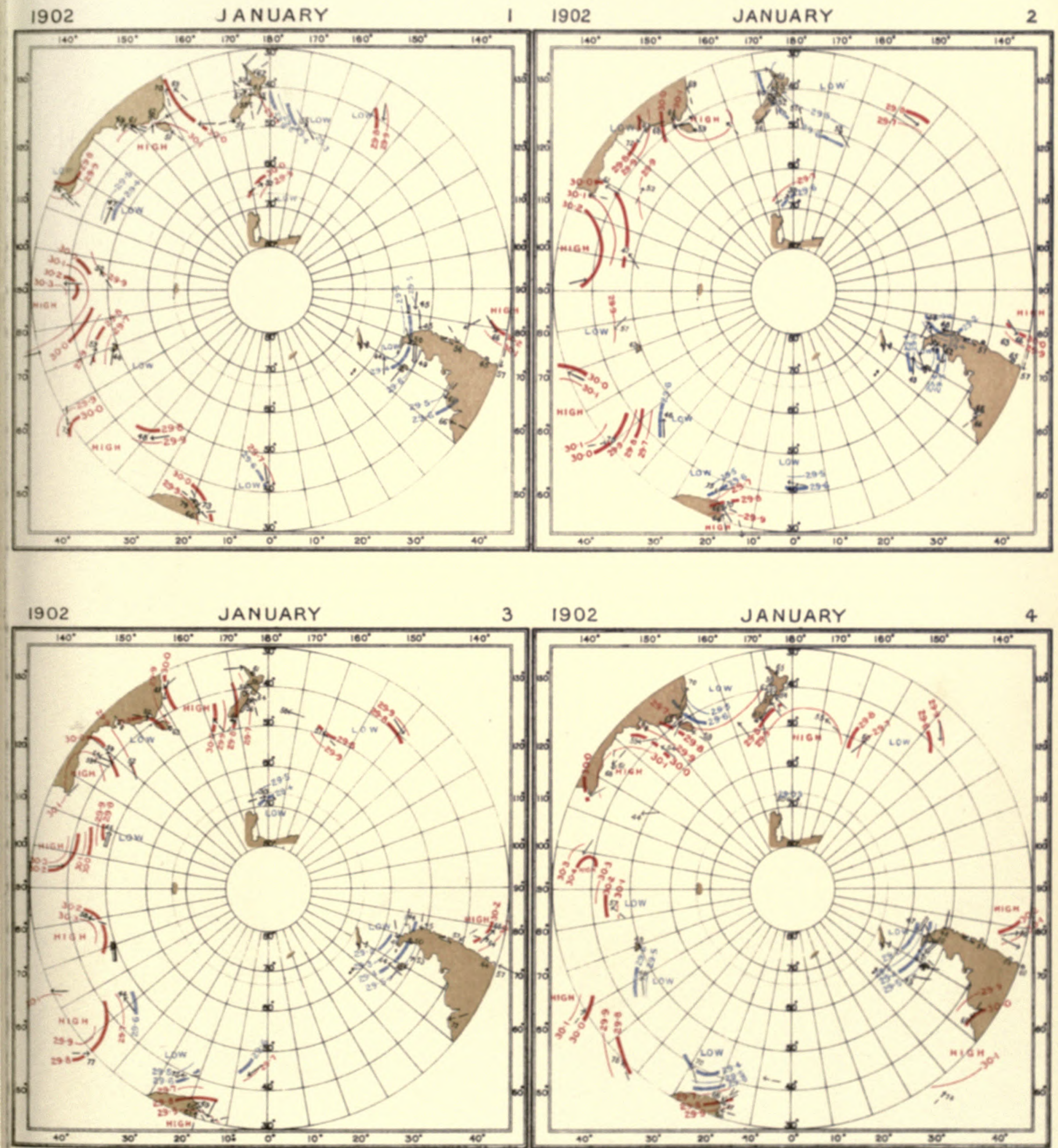


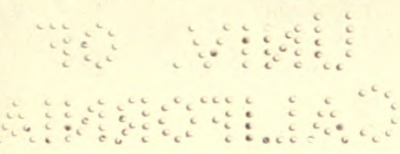


11

C

a 
INTERNATIONAL ANTARCTIC CO-OPERATION.

SYNCHAONOUS CHARTS OF SEA-LEVEL PRESSURE FOR NOON G.M.T WITH WINDS AND AIR TEMPERATURES
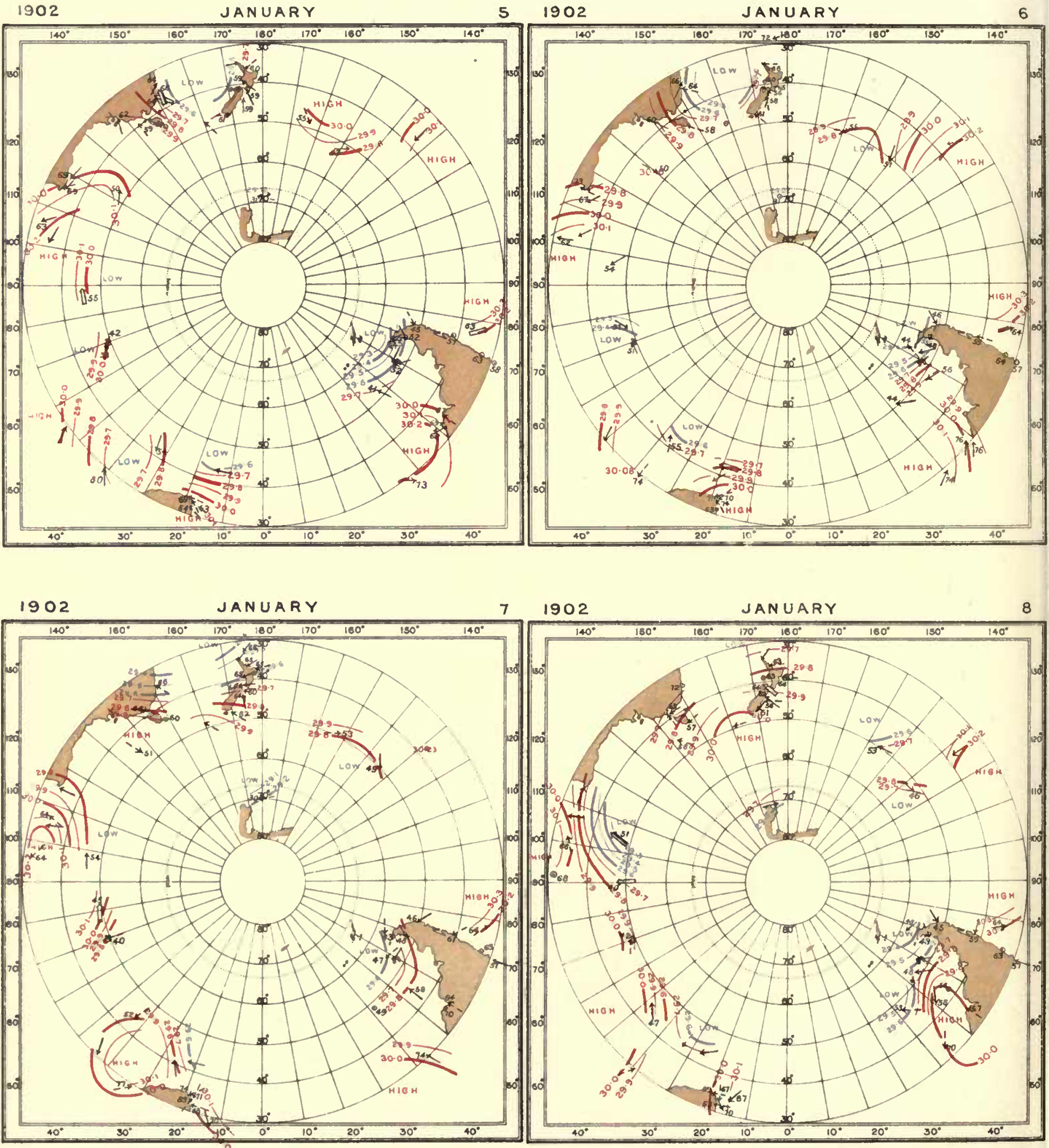
a

ㅁ.....

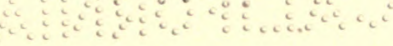


!)

$\%$ क औ 
INTERNATIONAL ANTARCTIC CO-OPERATION.

SYNCHRONOUS CHARTS OF SEA-LEVEL PRESSURE FOR NOON G.M.T

WITH WINDS AND AIR TEMPERATURES.
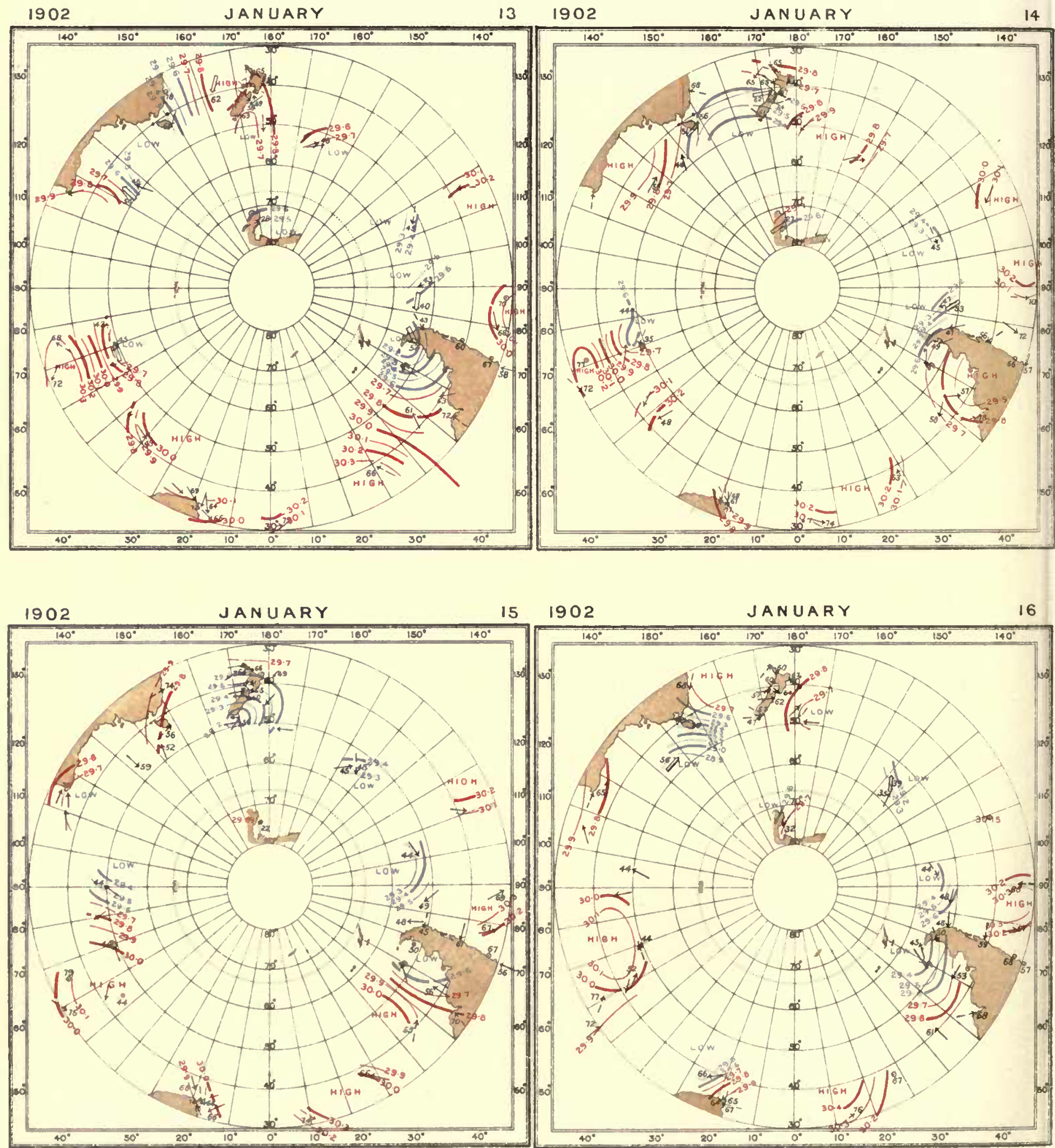


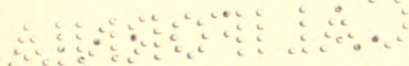


a

A A 
INTERNATIONAL ANTARCTIC COOPERATION.

SYNCHRONOUS CHARTS OF SEALEVEL PRESSURE FOR NOON GM T

WITH WINDS AND AIR TEMPERATURES

1902

JANUARY

$21 \quad 1902$

JANUARY

22
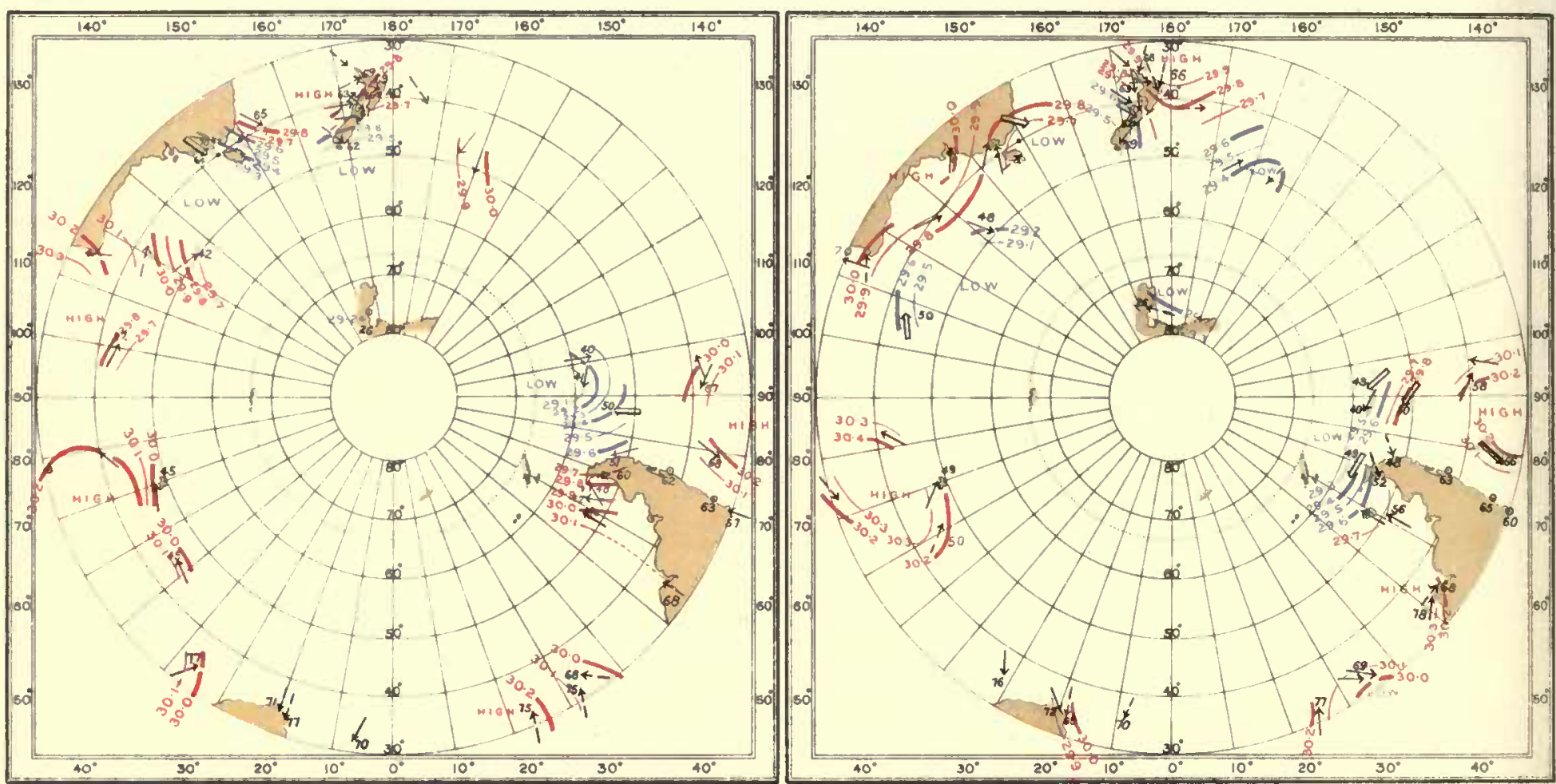

1902

JANUARY

23

1902

JANUARY

24
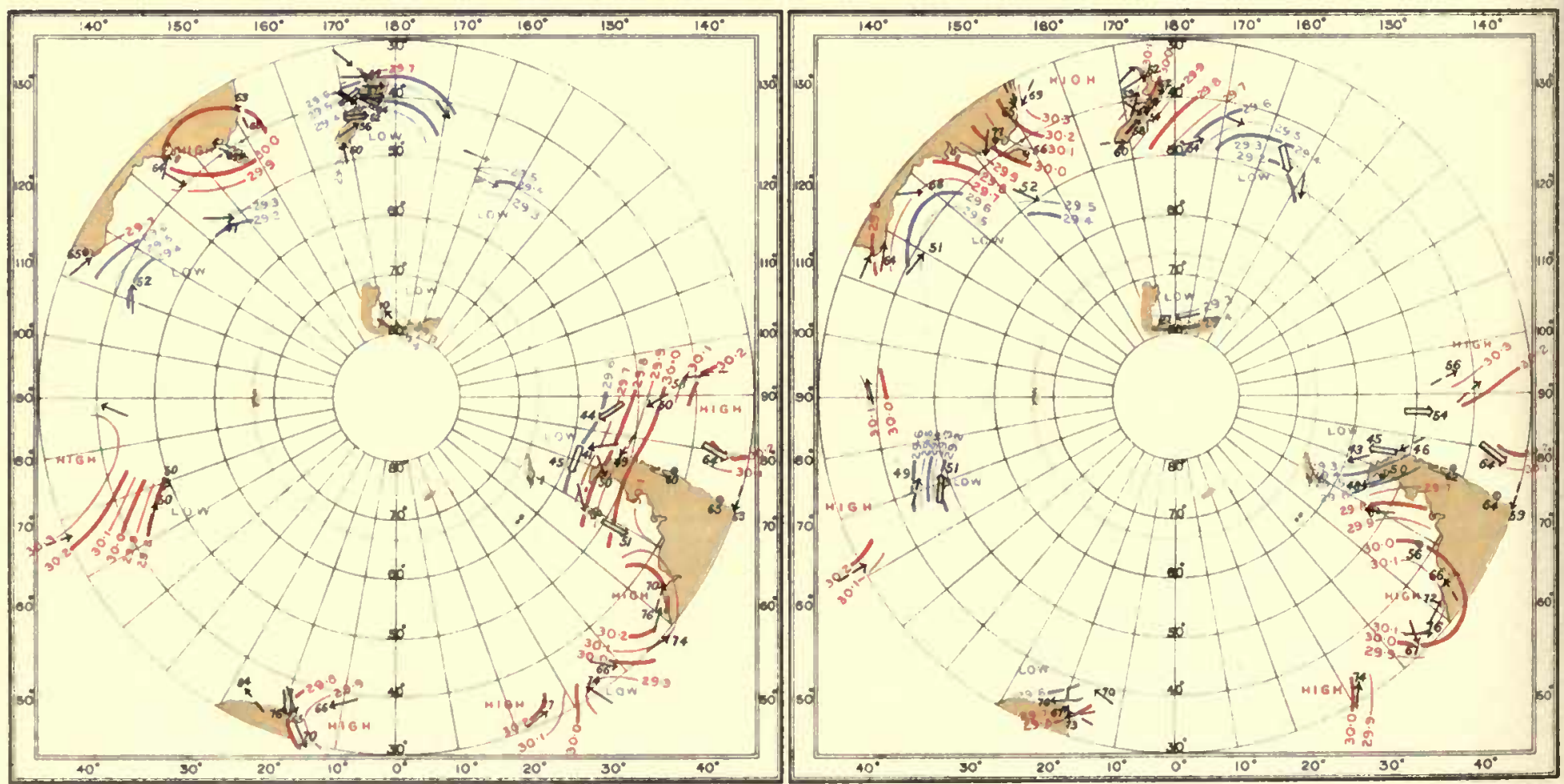
INTERNATIONAL ANTARCTIC CO-OPERATION

SYNCHRONOUS CHARTS OF SEA-LEVEL PRESSURE FOR NOON GM.T

WITH WINDS AND AIR TEMPERATURES

1902

JAN UARY

$25 \quad 1902$

JAN UARY

26

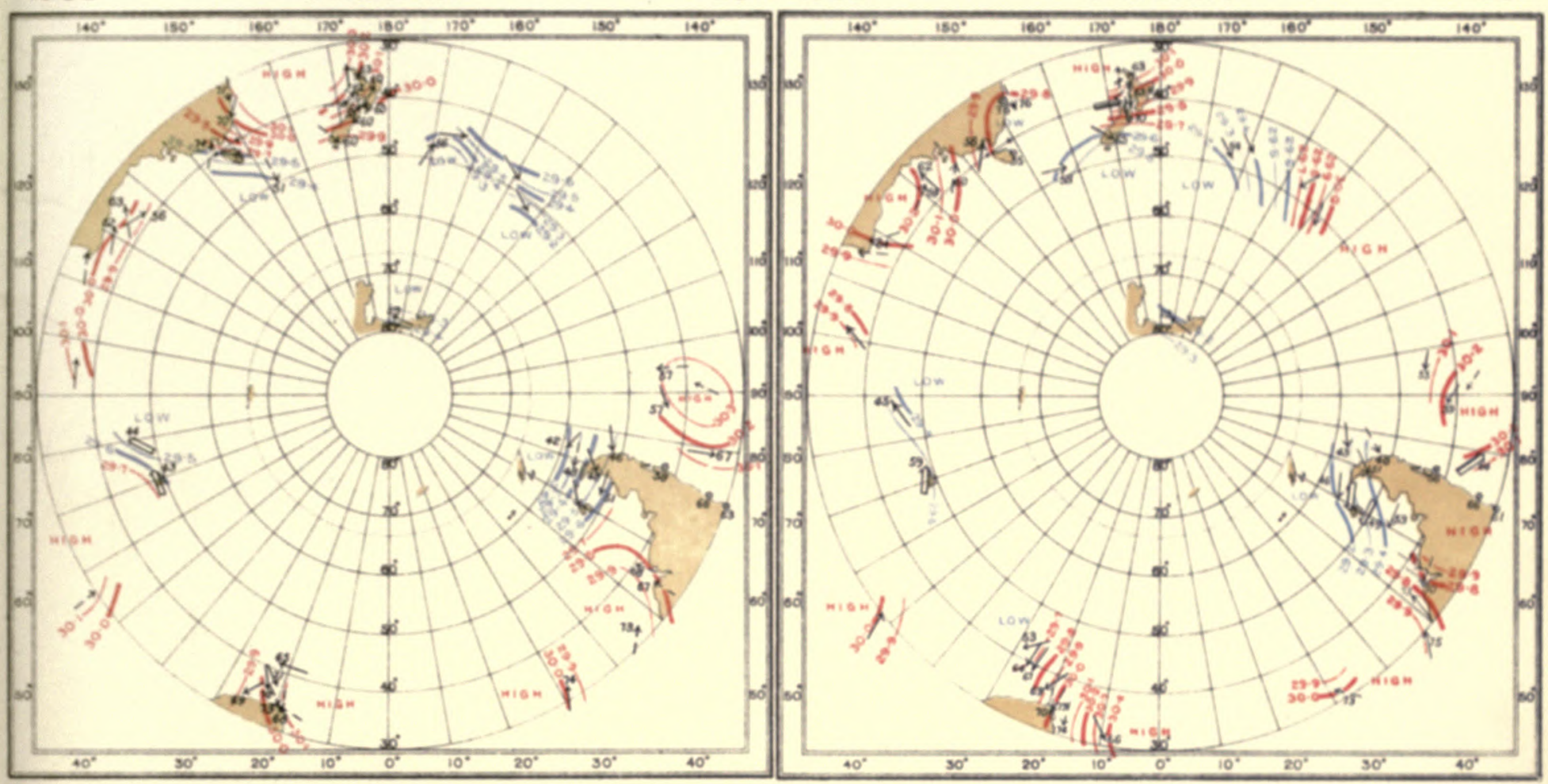

1902

JAN UARY

$27 \quad 1902$

JANUARY

28

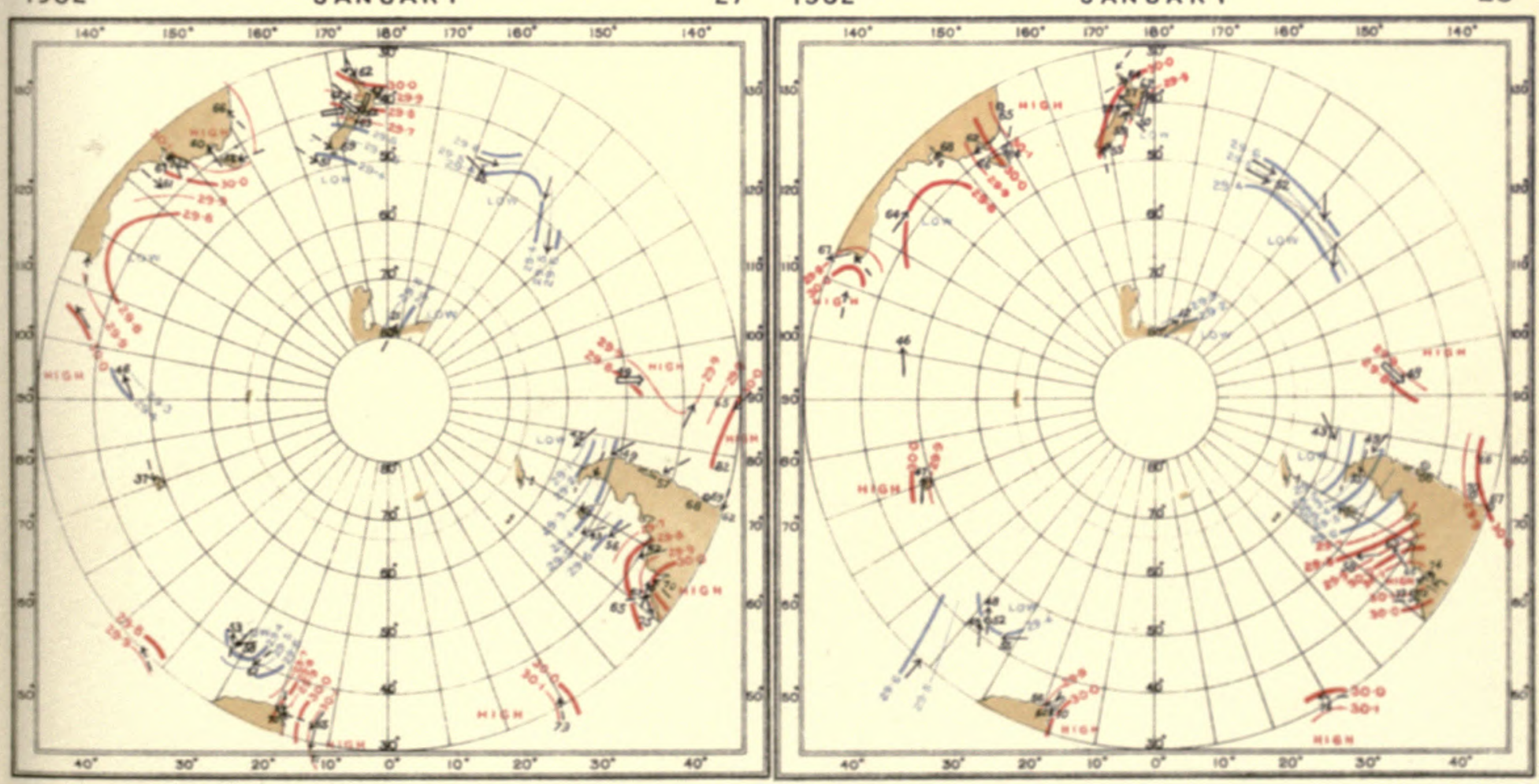




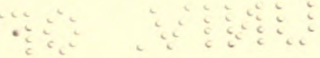

4. 
INTERNATIONAL ANTARCTIC CO-OPERATION.

SYNCHRONOUS CHARTS OF SEA-LEVEL PRESSURE FOR NOON G.M T

WITH WINDS AND AIR TEMPERATURES.

1902

JAN UARY

$29 \quad 1902$

JANUARY

30
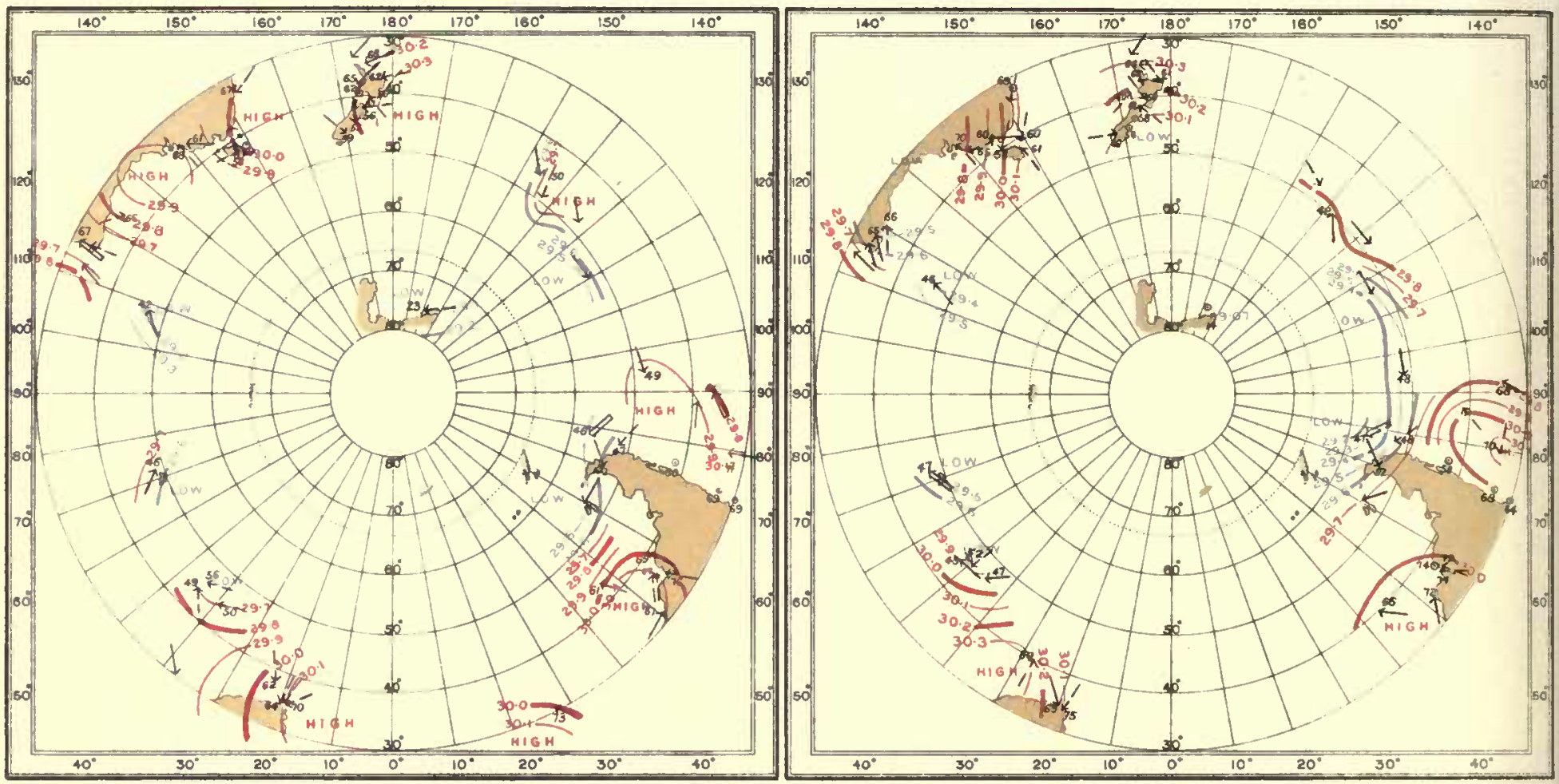

1902

JANUARY

$31 \quad 1902$

FEBRUARY

1
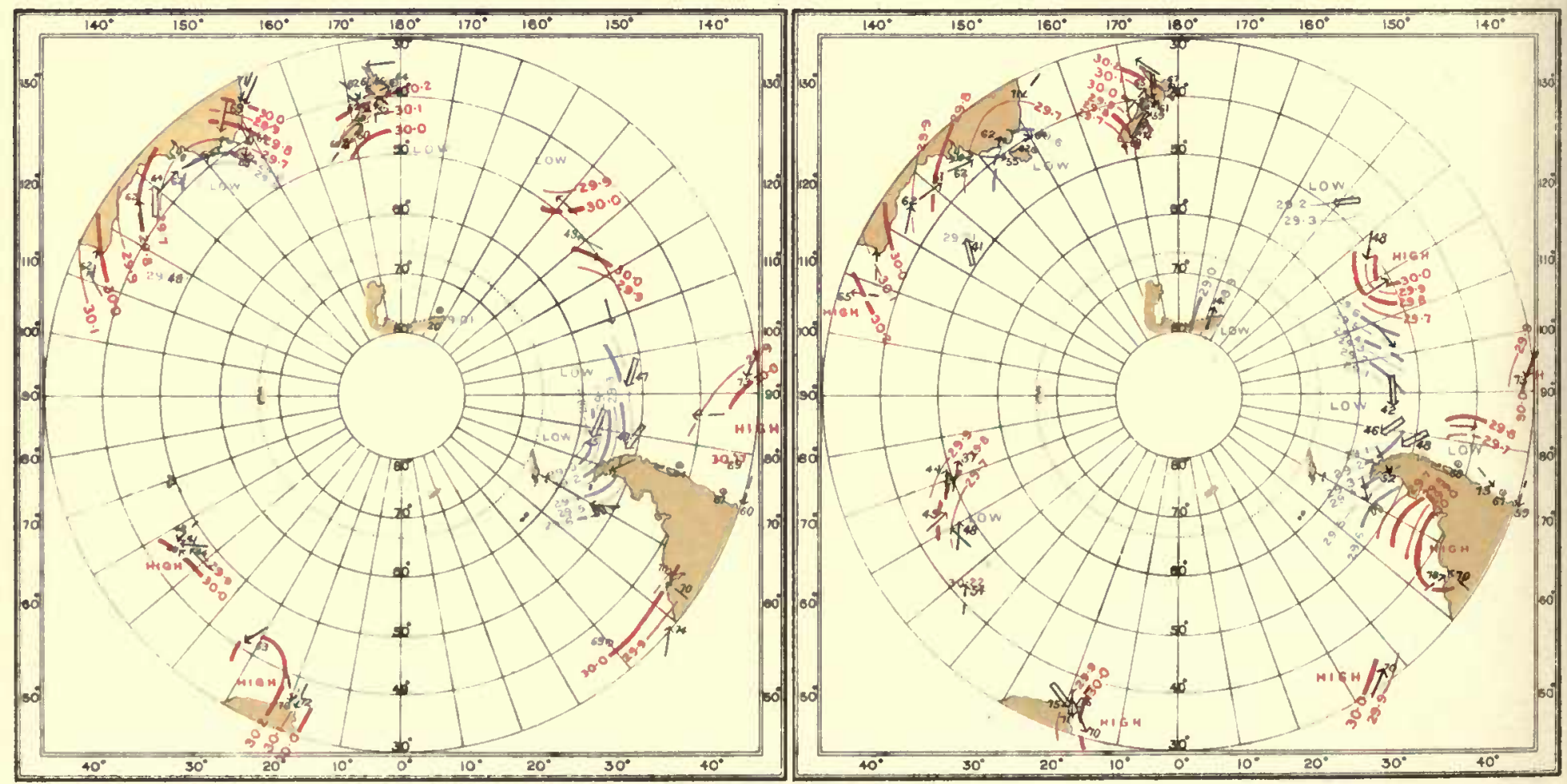
INTERNATIONAL ANTARCTIC COOPERATION.

SYNCHRONOUS CHARTS OF SEA-LEVEL PRESSURE FOR NOON G.M.T

WITH WINDS ANO AIR TEMPERATURES
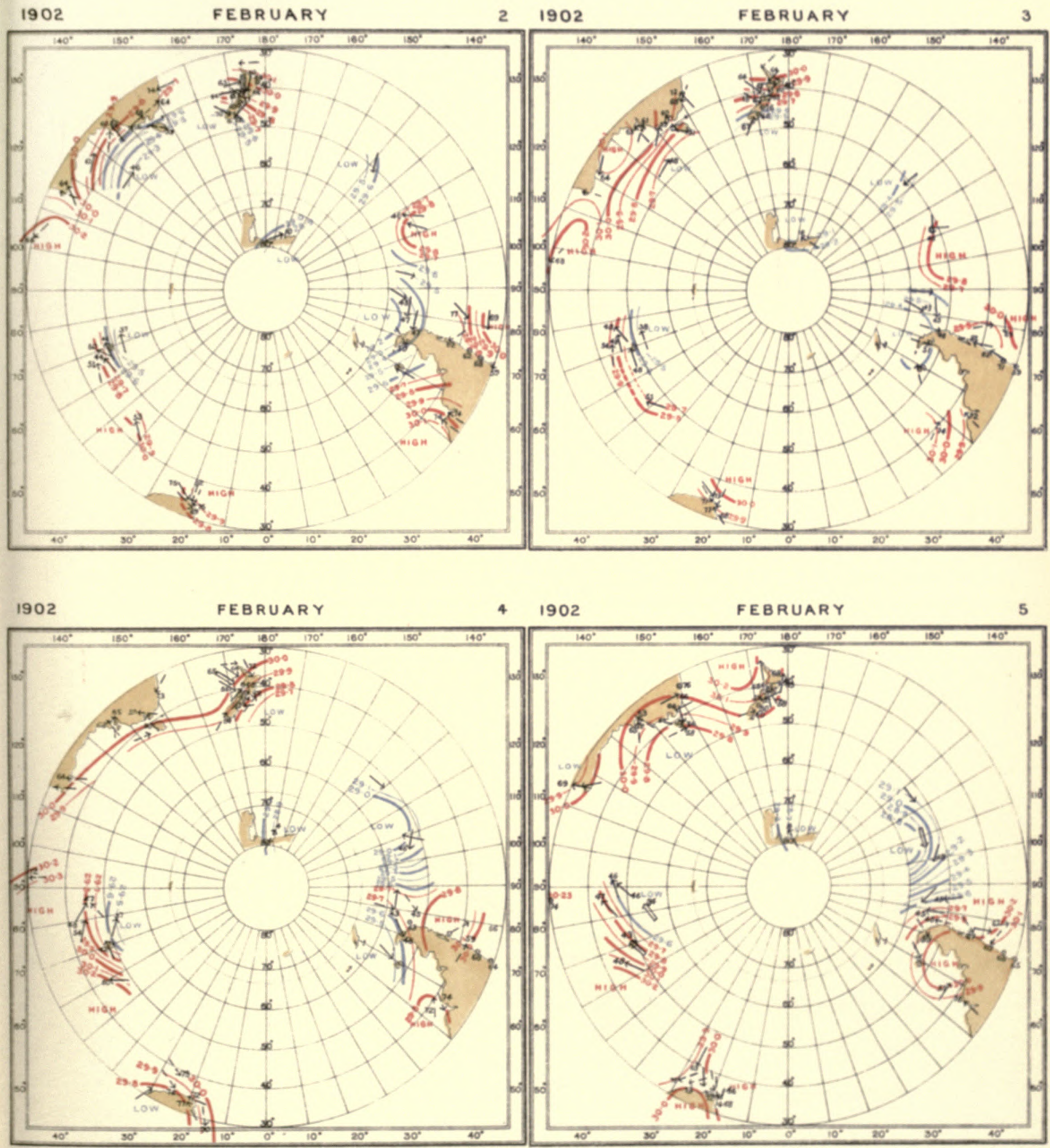


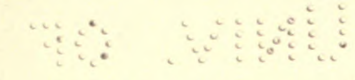

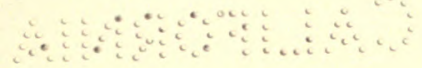


INTERNATIONAL ANTARCTIC COOPERATION.

SYNCHRONOUS CHARTS OF SEALEVEL PRESSURE FOR NOONGM T

WITH WINOS AND AIR TEMPERATURES

1902 FEBRUARY

$6 \quad 1902$

FEBRUARY

7

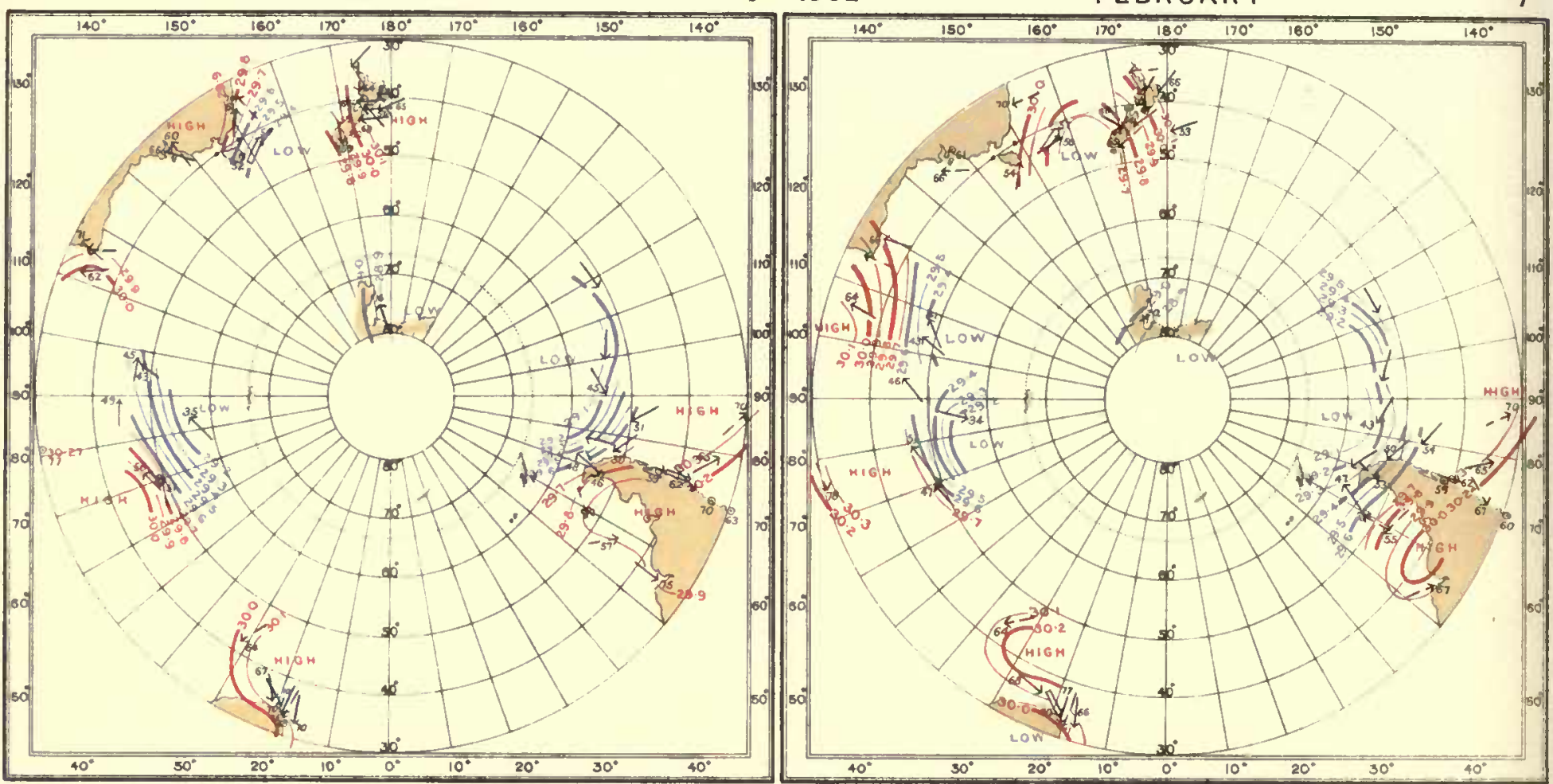

1902

FEBRUARY

$8 \quad 1902$

FEBRUARY
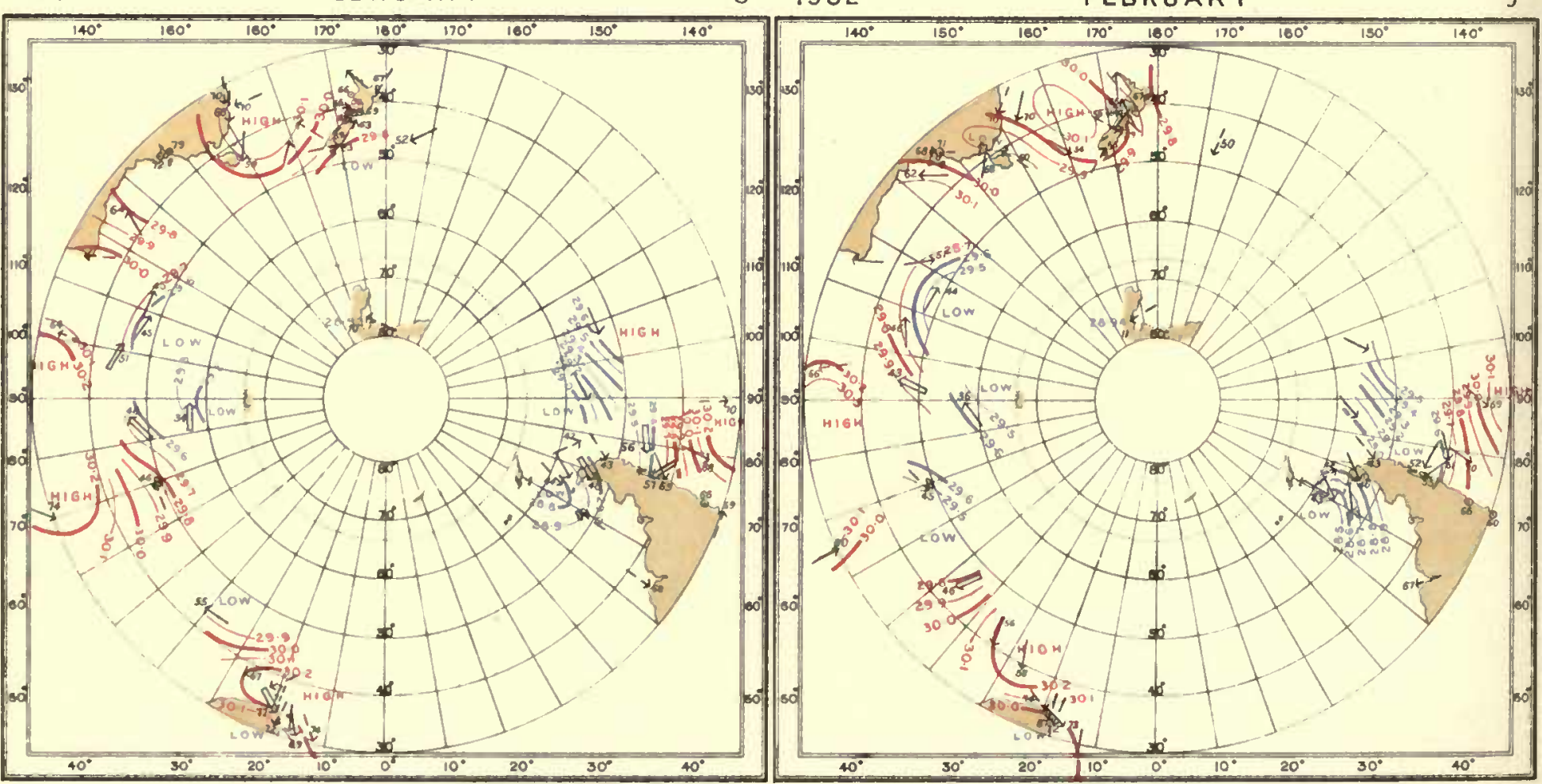
INTERNATIONAL ANTARCTIC CO-OPERATION

SYNCHRONOUS CHARTS OF SEALEVEL PRESSURE FOR NOON G.M.T

WITH WINDS AND AIR TEMPERATURES
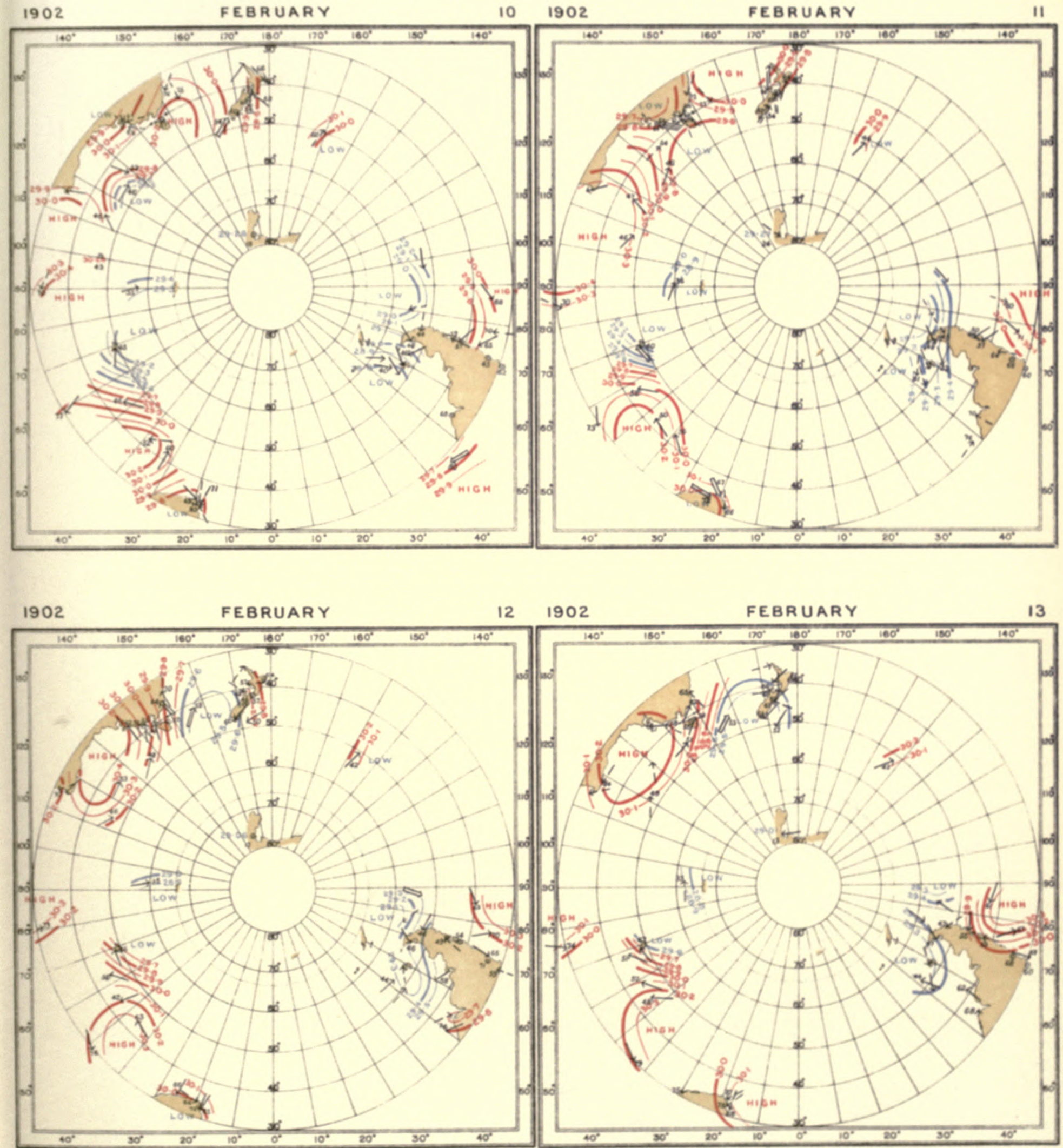
$\because 2 \quad \because \because 3$

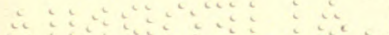

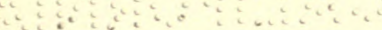




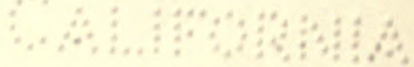


INTERNATIONAL ANTARCTIC CO-OPERATION.

SYNCHRONOUS CHARTS OF SEA-LEVEL PRESSURE FOR NOON G.M T WITH WINDS AND AIR TEMPERATURES
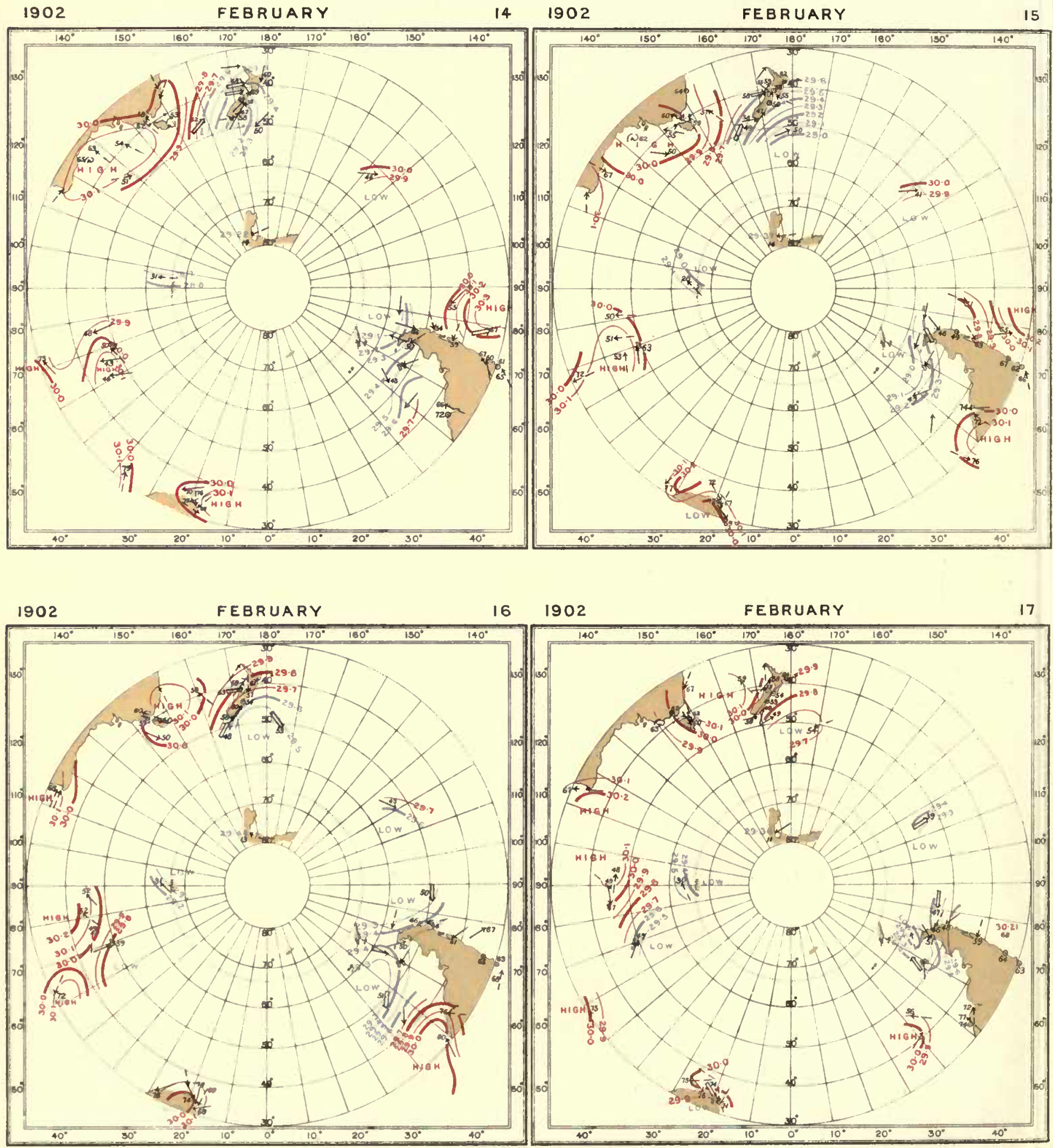
INTERNATIONAL ANTARCTIC CO-OPERATION.

SYNCHRONOUS CHARTS OF SEALEVEL PRESSURE FOR NOON G.M.T WITH WINDS AND AIR TEMPERATURES
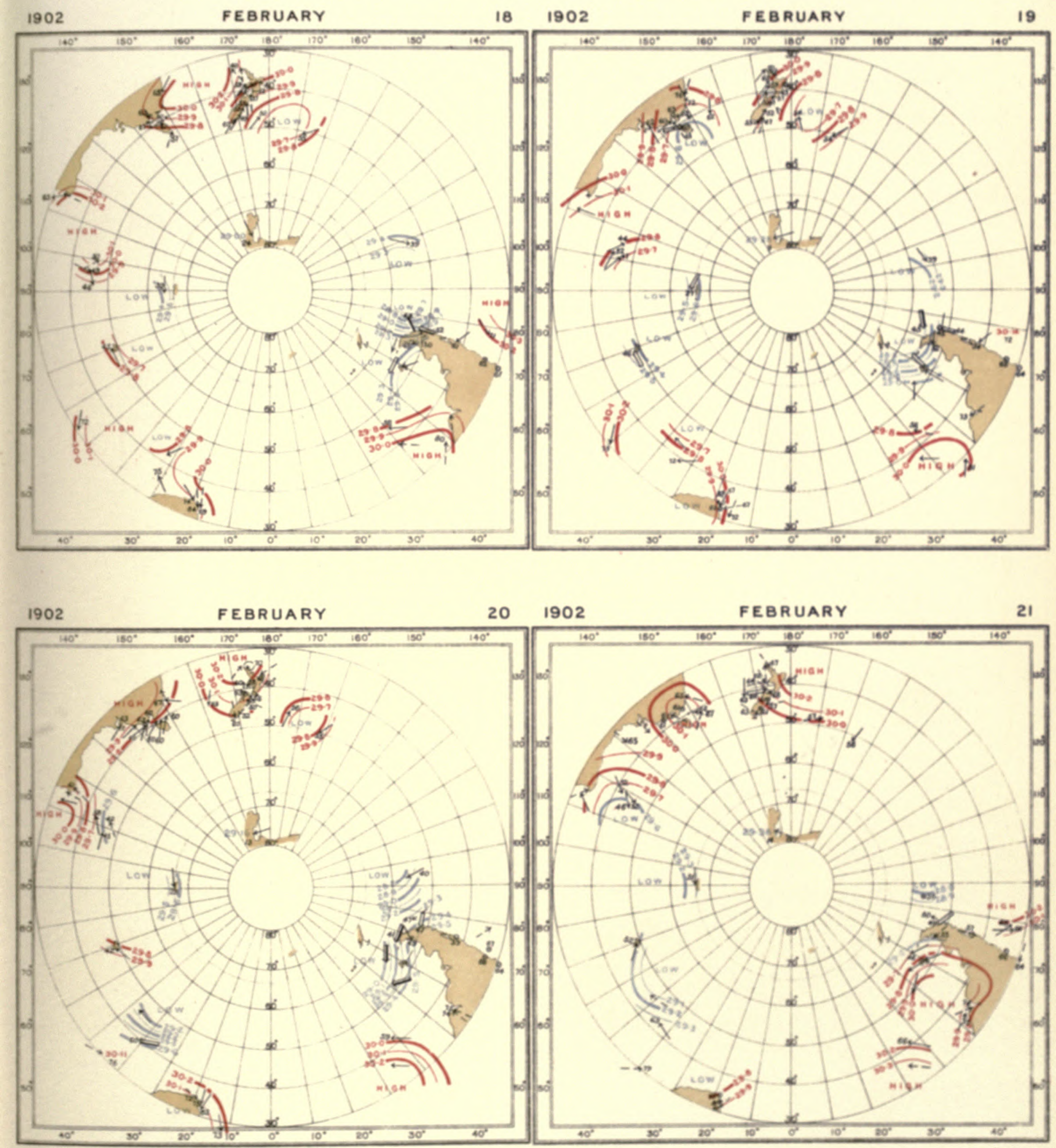


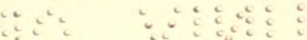

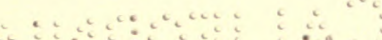

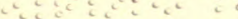




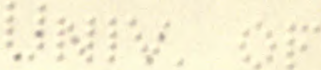

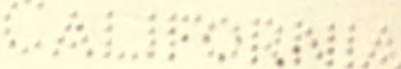


INTERNATIONAL ANTARCTIC CO-OPERATION.

SYNCHRONOUS CHARTS OF SEALLVEL PRESSURE FOR NOON G.M.T.

WITH WINDS AND AIR TEMPERATURES

1902

FEBR UARY

$22 \quad 1902$

FEBRUARY

23
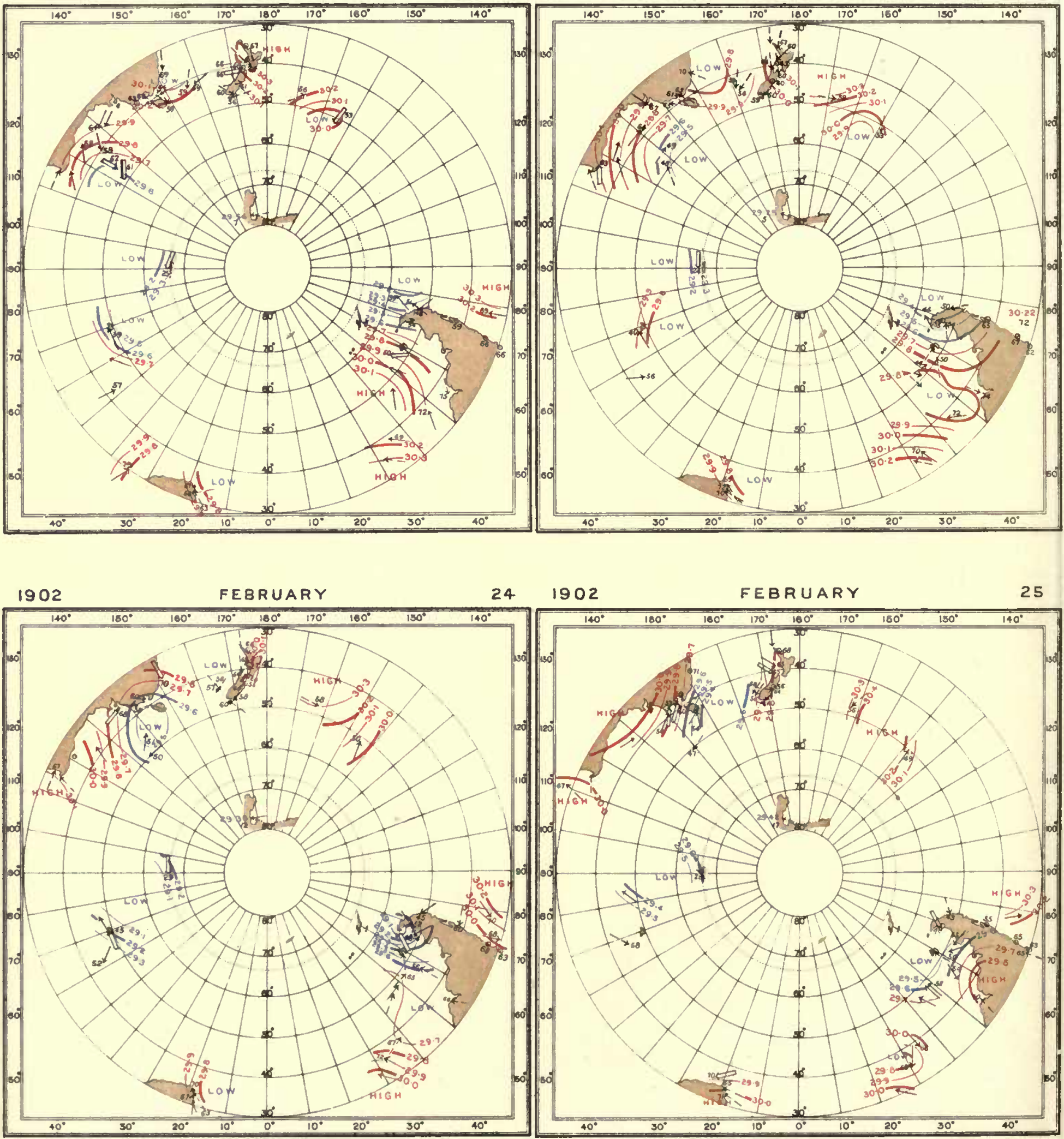
INTERNATIONAL ANTARCTIC COOPERATION

SYNCHRONOUS CHARTS OF SEA-LEVEL PRESSURE FOR NOON GMT

WITH WINDS AND AIR TEMPERATURES

1902

FEBRUARY

$26 \quad 1902$

FEBRUARY

27

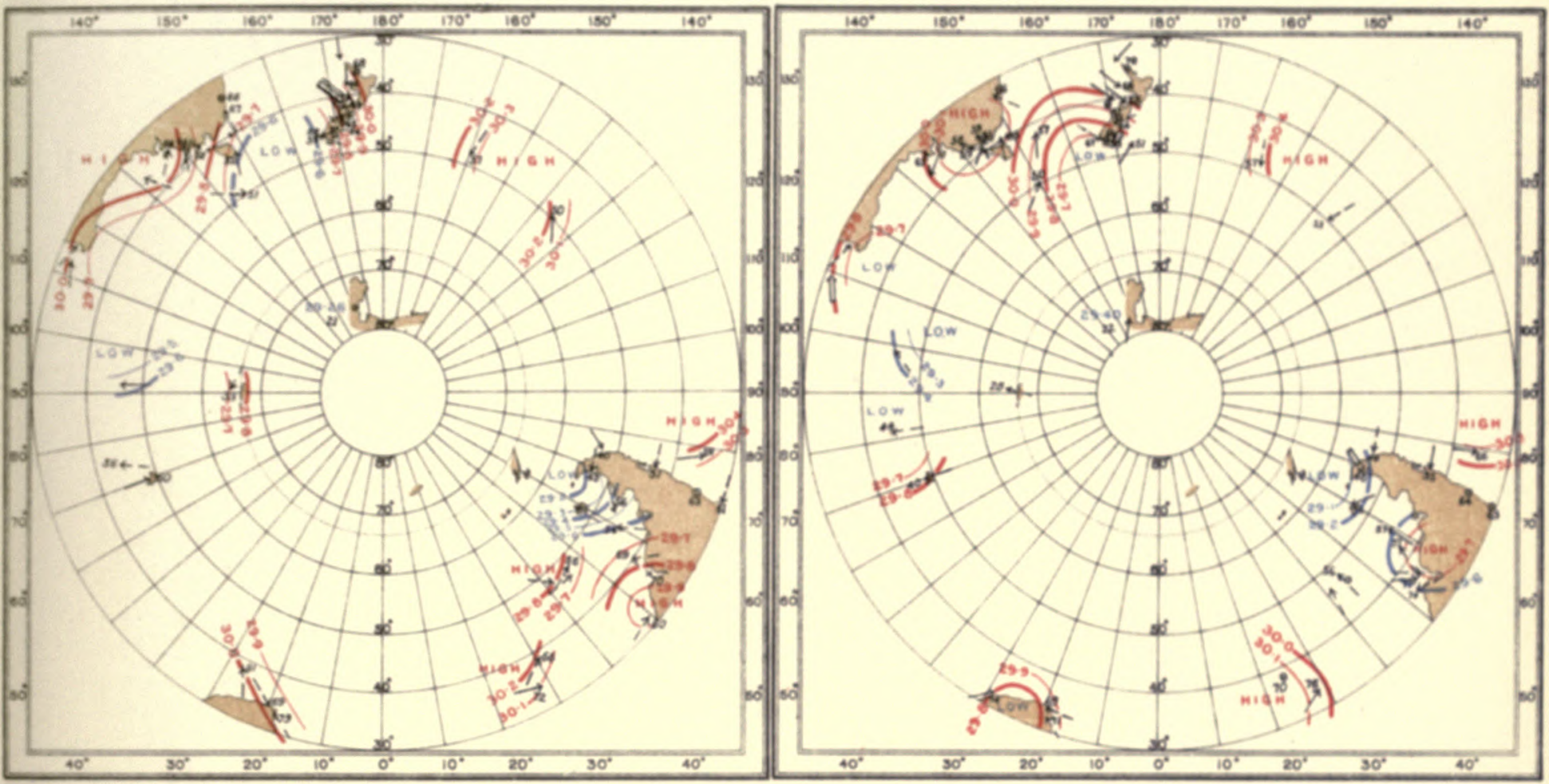

1902

FEBRUARY

$28 \quad 1902$

M ARCH

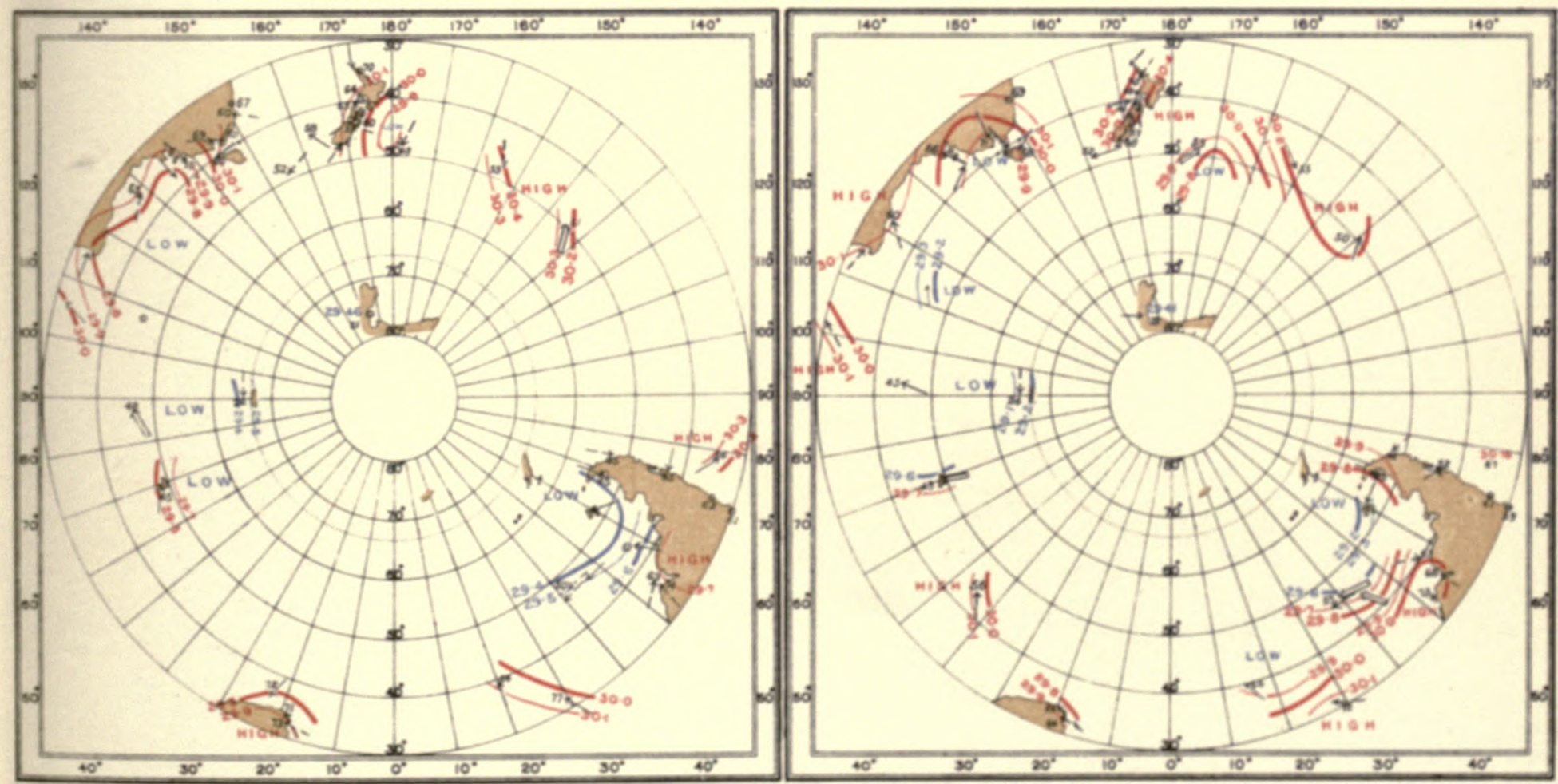


« 
a

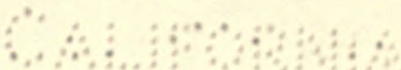


INTERNATIONAL ANTARCTIC CO-OPERATION.

SYNCHRONOUS CHARTS OF SEA-LEVEL PRESSURE FOR NOON G.M.T

WITH WINDS AND AIR TEMPERATURES
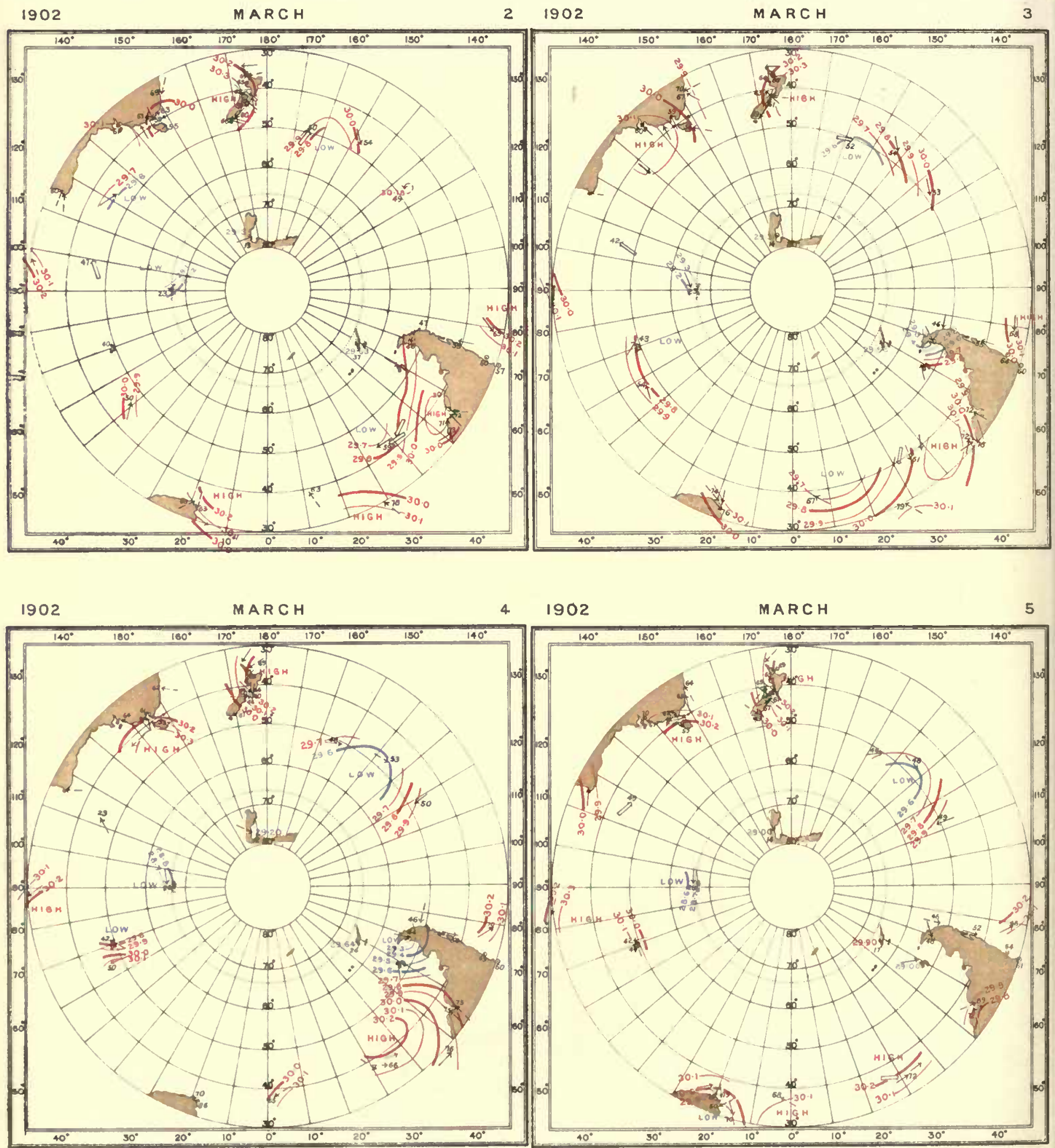
INTERNATIONAL ANTARCTIC COOPERATION

SYNCHRONOUS CHARTS OF SEA-LEVEL PRESSURE FOR NOON GMT

WITH WINDS AND AIR TEMPERATURES

1902

M A R C H

$6 \quad 1902$

MARCH

7
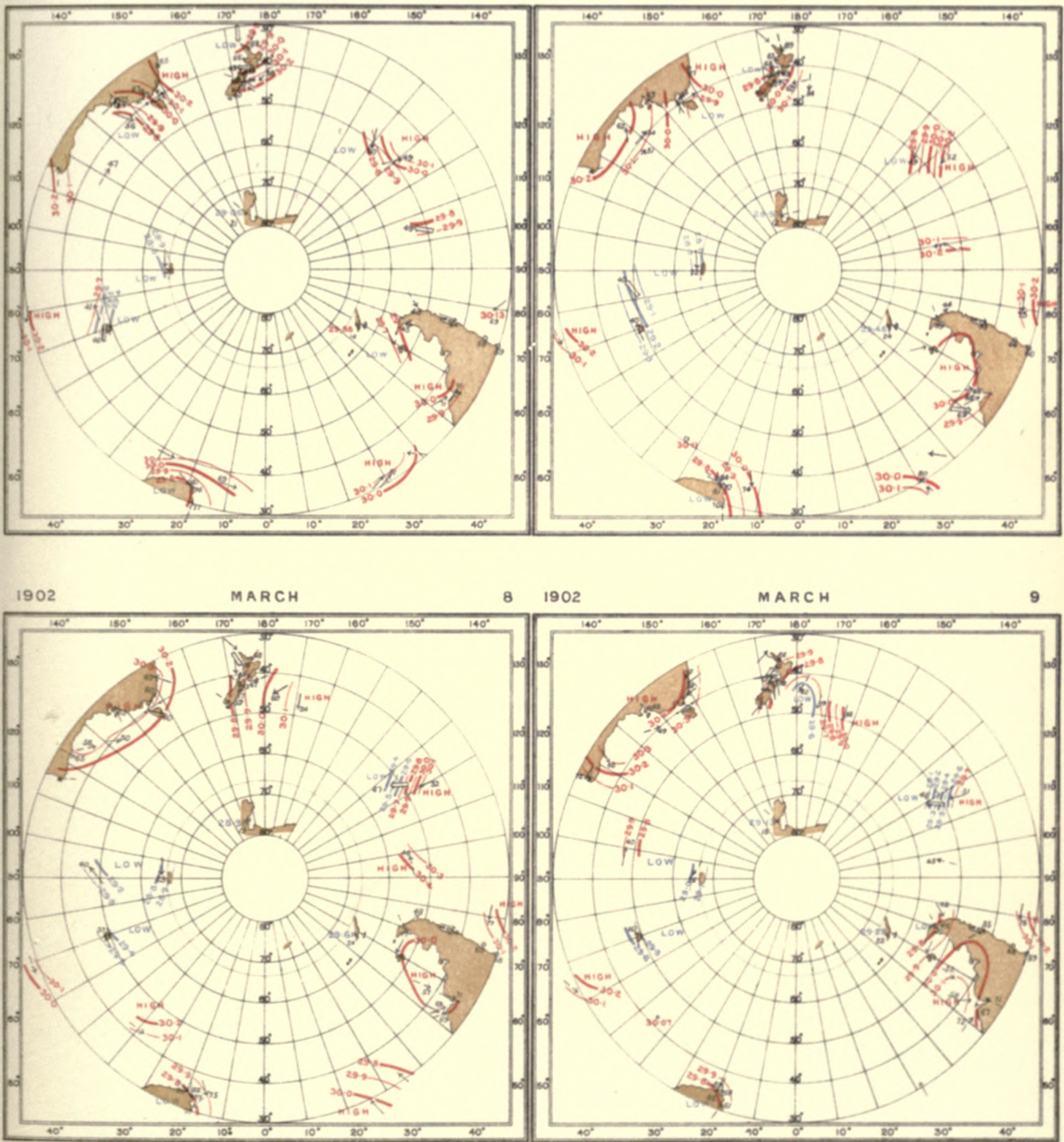
y

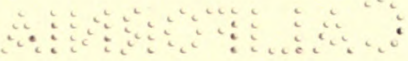


1)

a : 
INTERNATIONAL ANTARCTIC COOPERATION.

SYNCHRONOUS CHARTS OF SEA-LEVEL PRESSURE FOR NOON G.M.T

WITH WINOS AND AIR TEMPERATURES

$1902 \quad M A R C H$

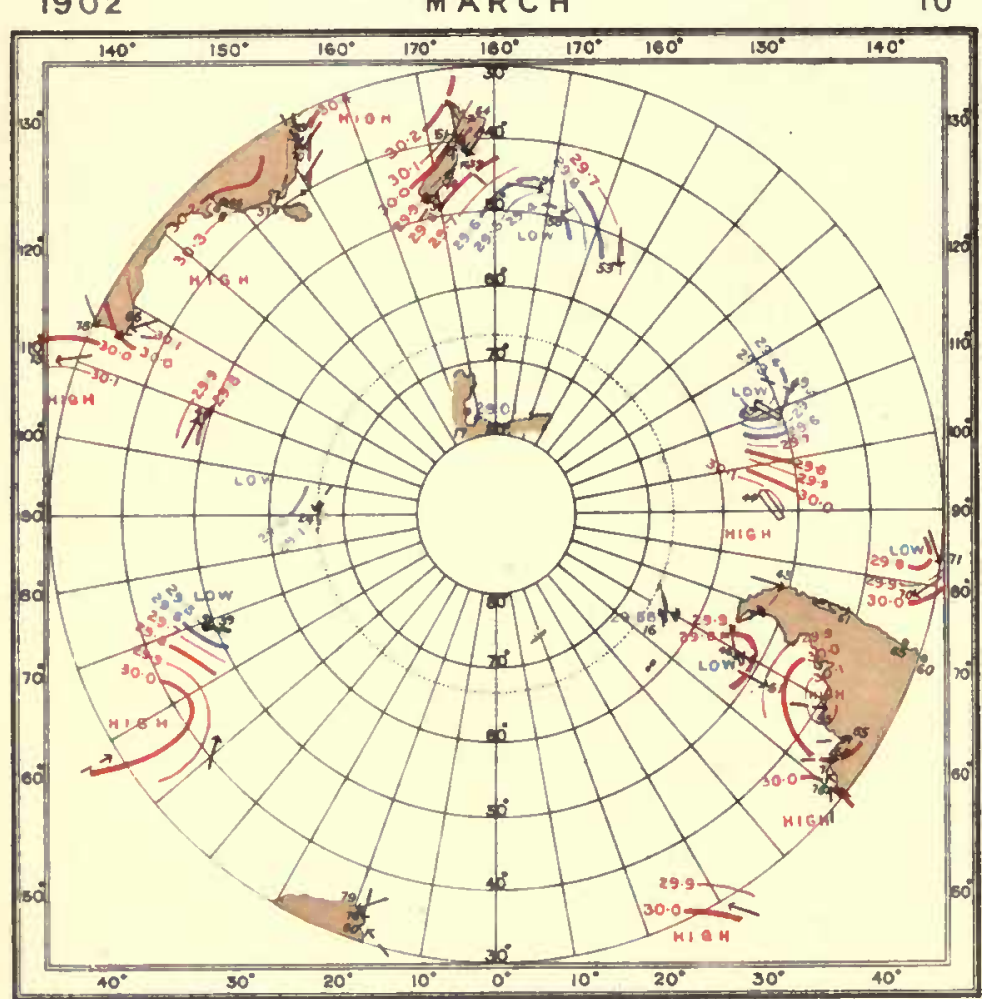

1902

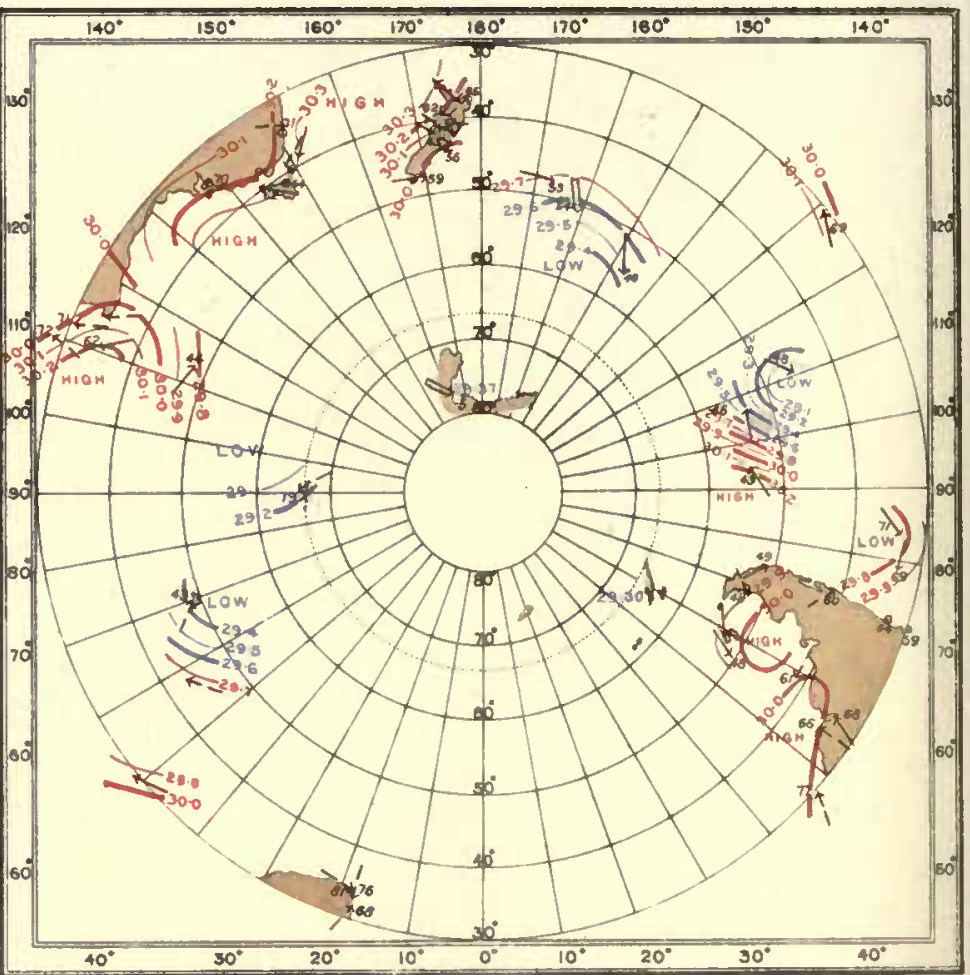

1802

MARCH

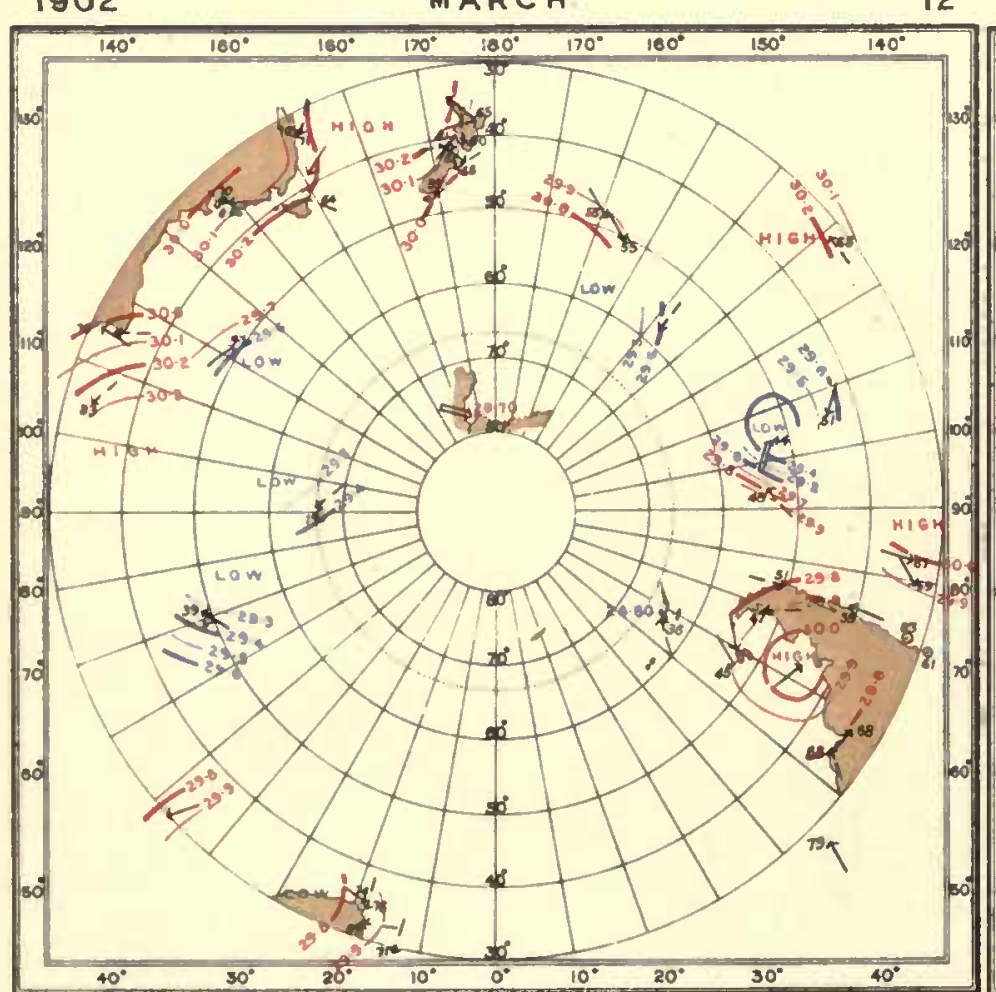

MARCH

13

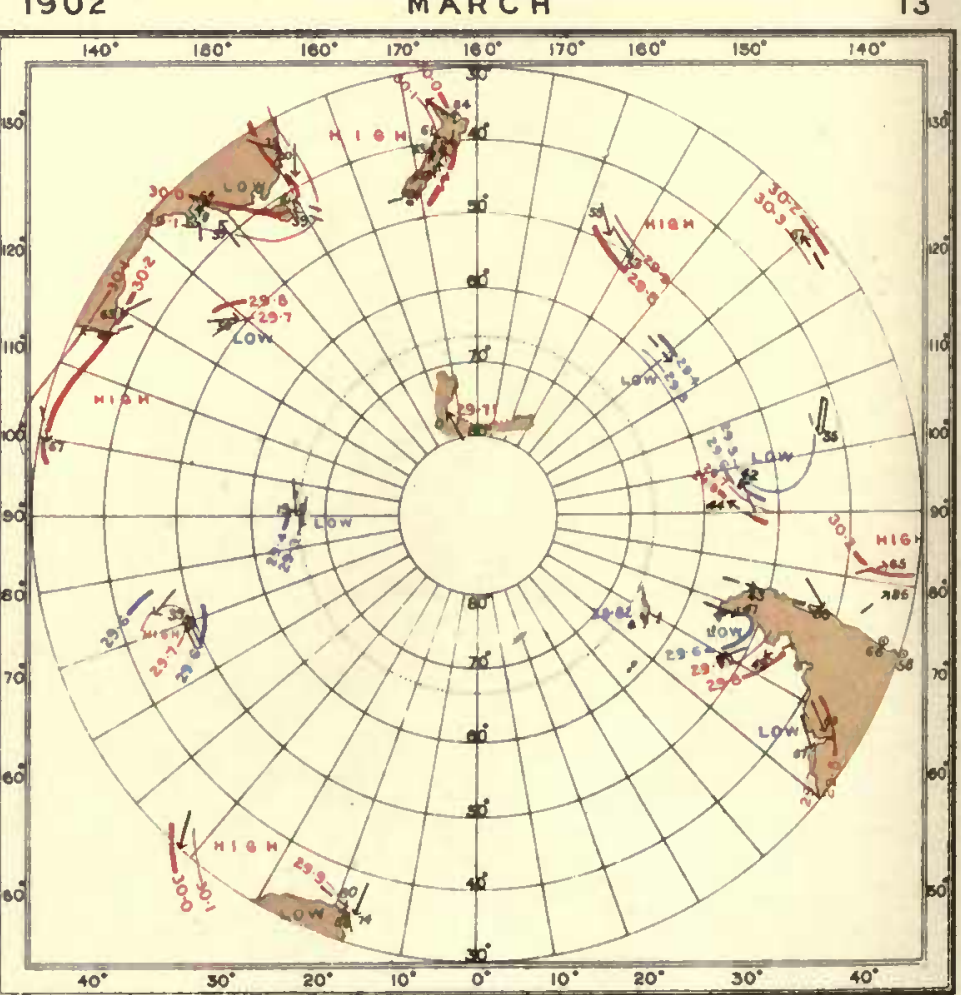


INTERNATIONAL ANTARCTIC CO-OPERATION.

SYNCHRONOUS CHARTS OF SEA-LEVEL PRESSURE FOR NOON G.M.T.

WITH WINDS AND AIR TEMPERATURES.
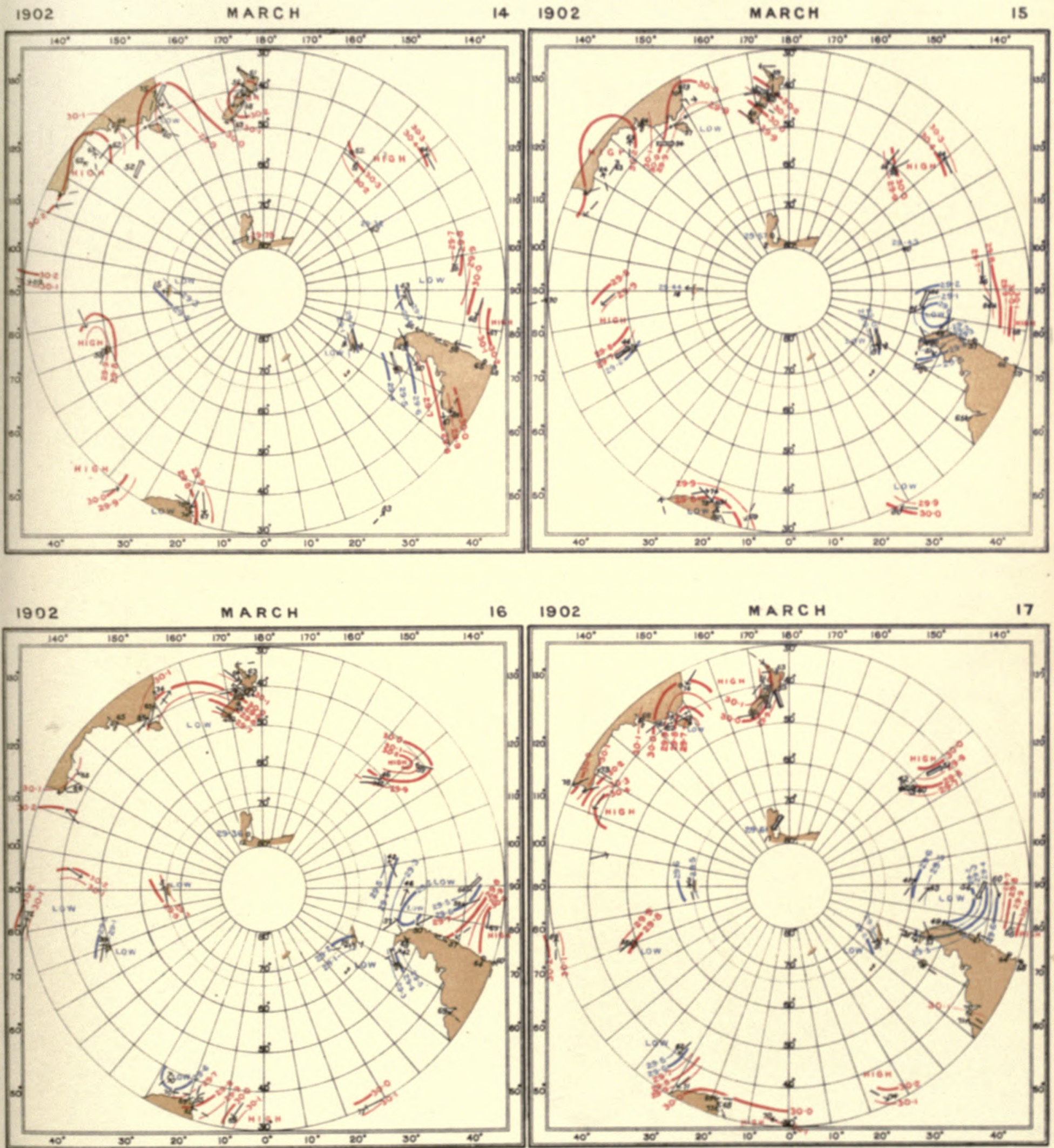


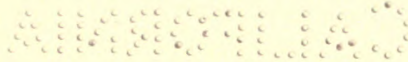


\%

औ: 
INTERNATIONAL ANTARCTIC COOOPERATION.

SYNCHRONOUS CHARTS OF SEA-LEVEL PRESSURE FOR NOON G.M.T

WITH WINDS ANO AIR TEMPERATURES.

1902

MARCH

$18 \quad 1902$

MARCH

19
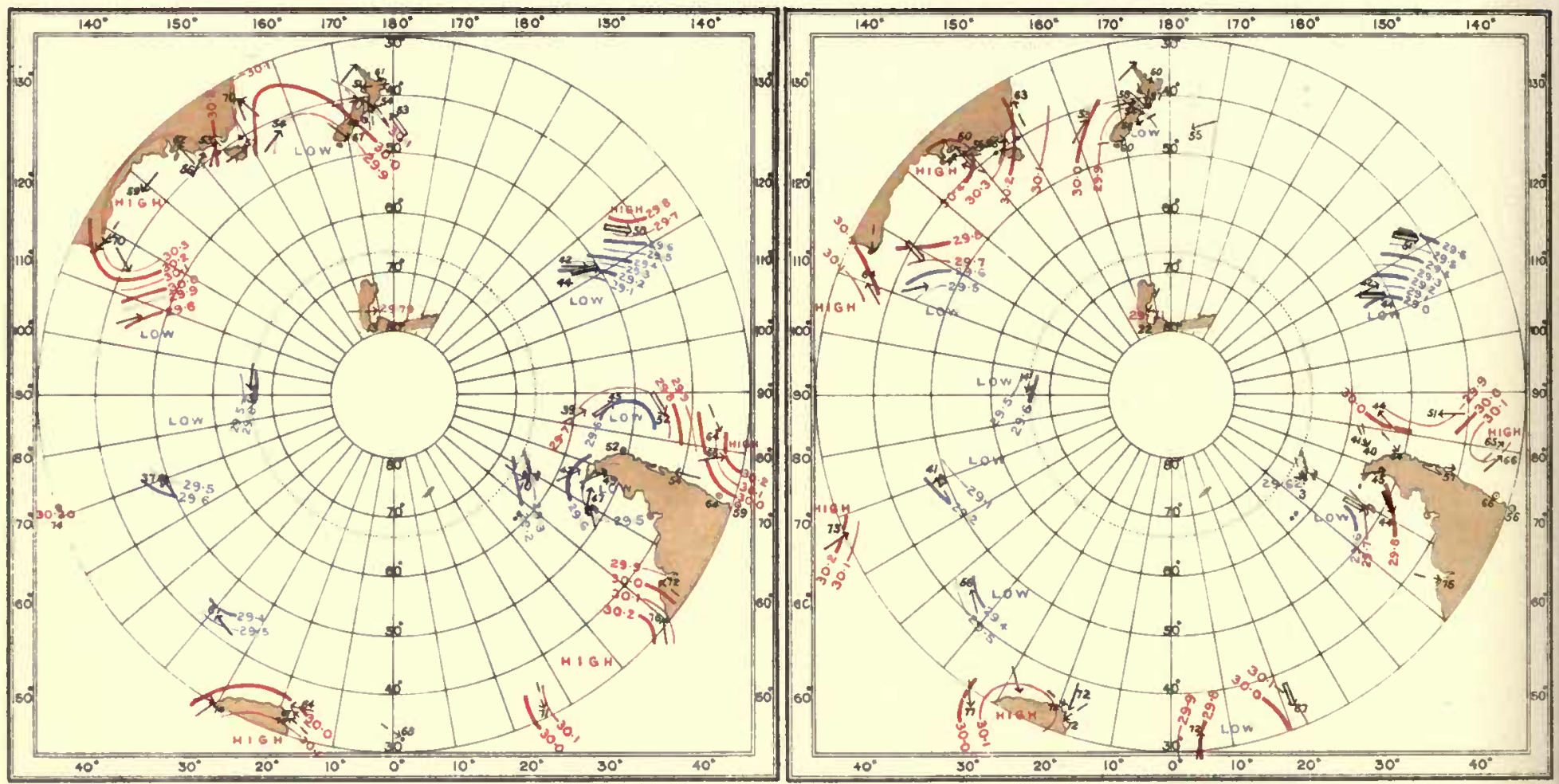

1902

MARCH

20

1902

M A R C H

21
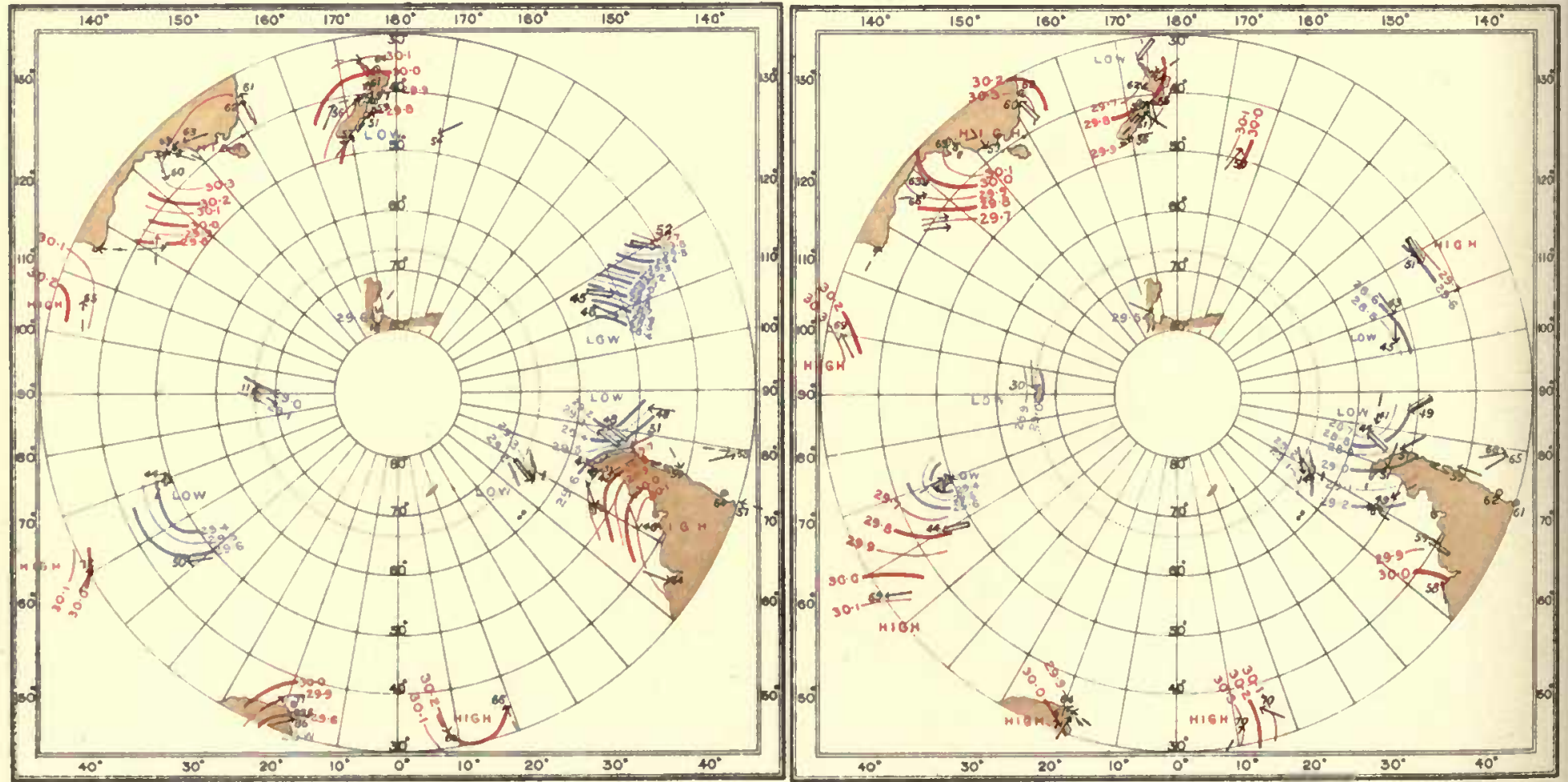
INTERNATIONAL ANTARCTIC COOPERATION

SYNCHRONOUS CHARTS OF SEA-LEVEL PRESSURE FOR NOON G.M.T

WITH WINDS AND AIR TEMPERATURES.
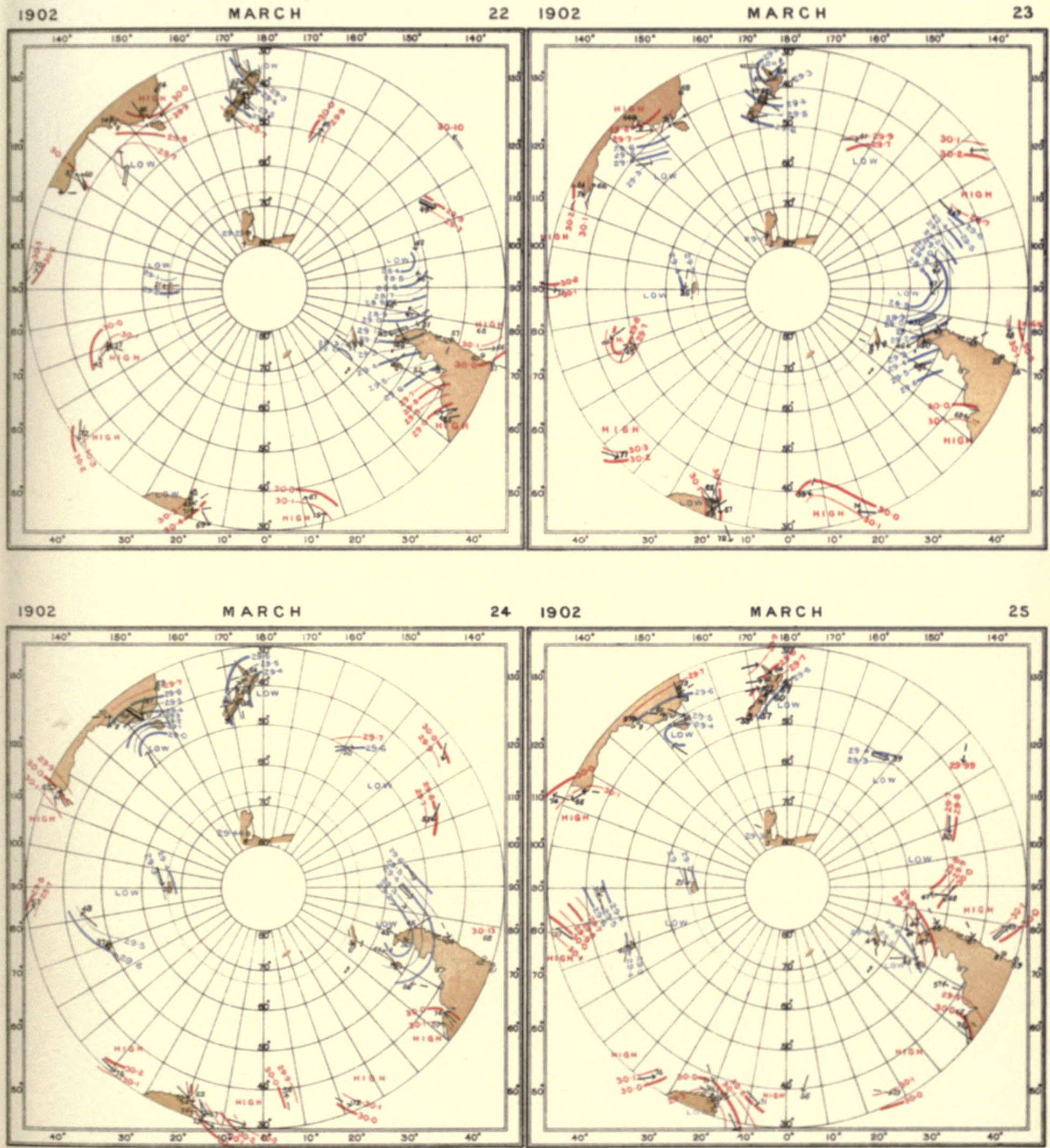
군

策 
$\vdots 30 \%$

30 
INTERNATIONAL ANTARCTIC COOPERATION.

SYNCHRONOUS CHARTS OF SEALEVEL PRESSURE FOR NOON G.M.T.

WITH WINDS AND AIR TEMPERATURES
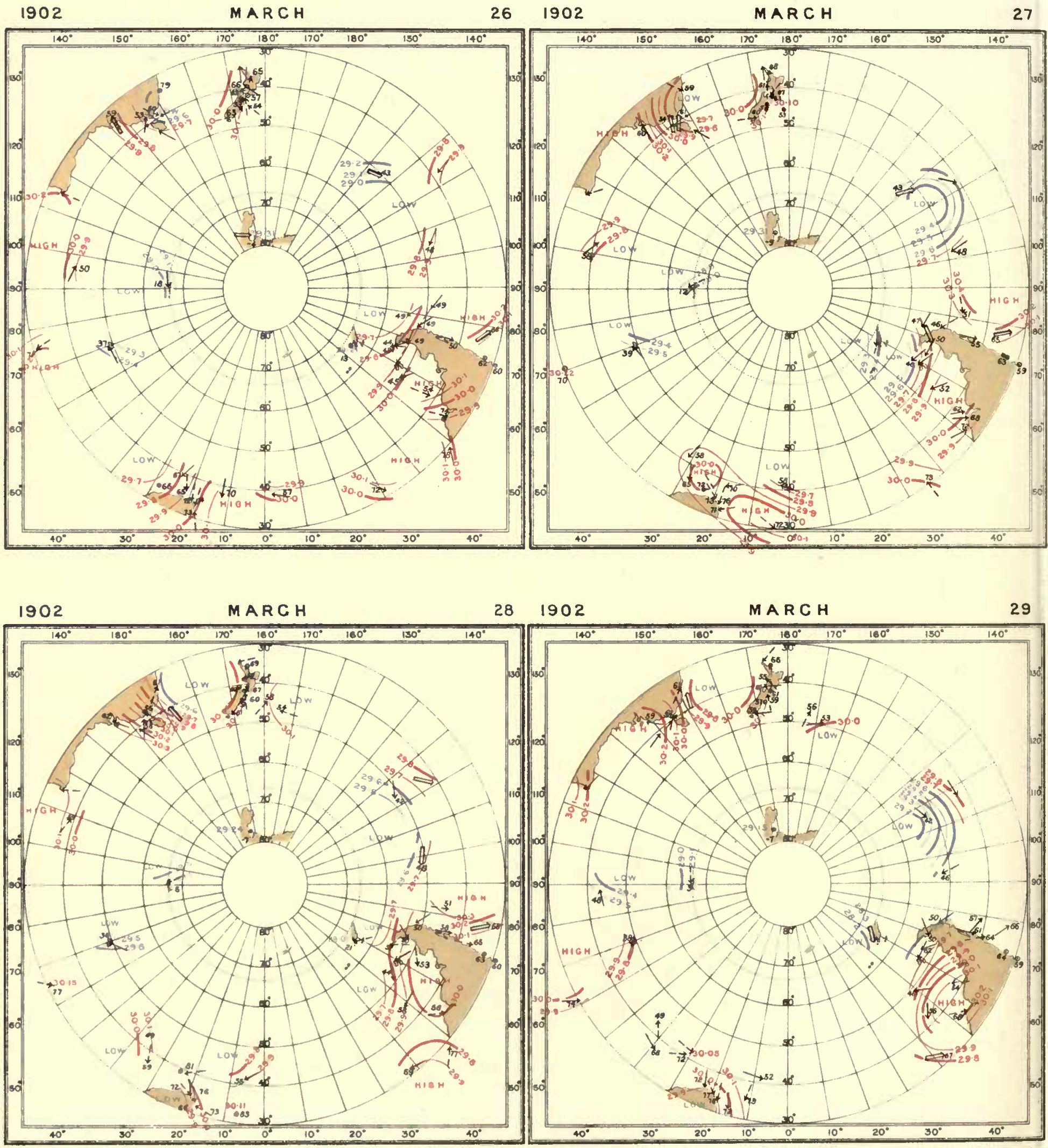
INTERNATIONAL ANTARCTIC COOPERATION

SYNCHRONOUS CHARTS OF SEALEVEL PRESSURE FOR NOON GMT

WITH WINDS AND AIR TEMPERATURES
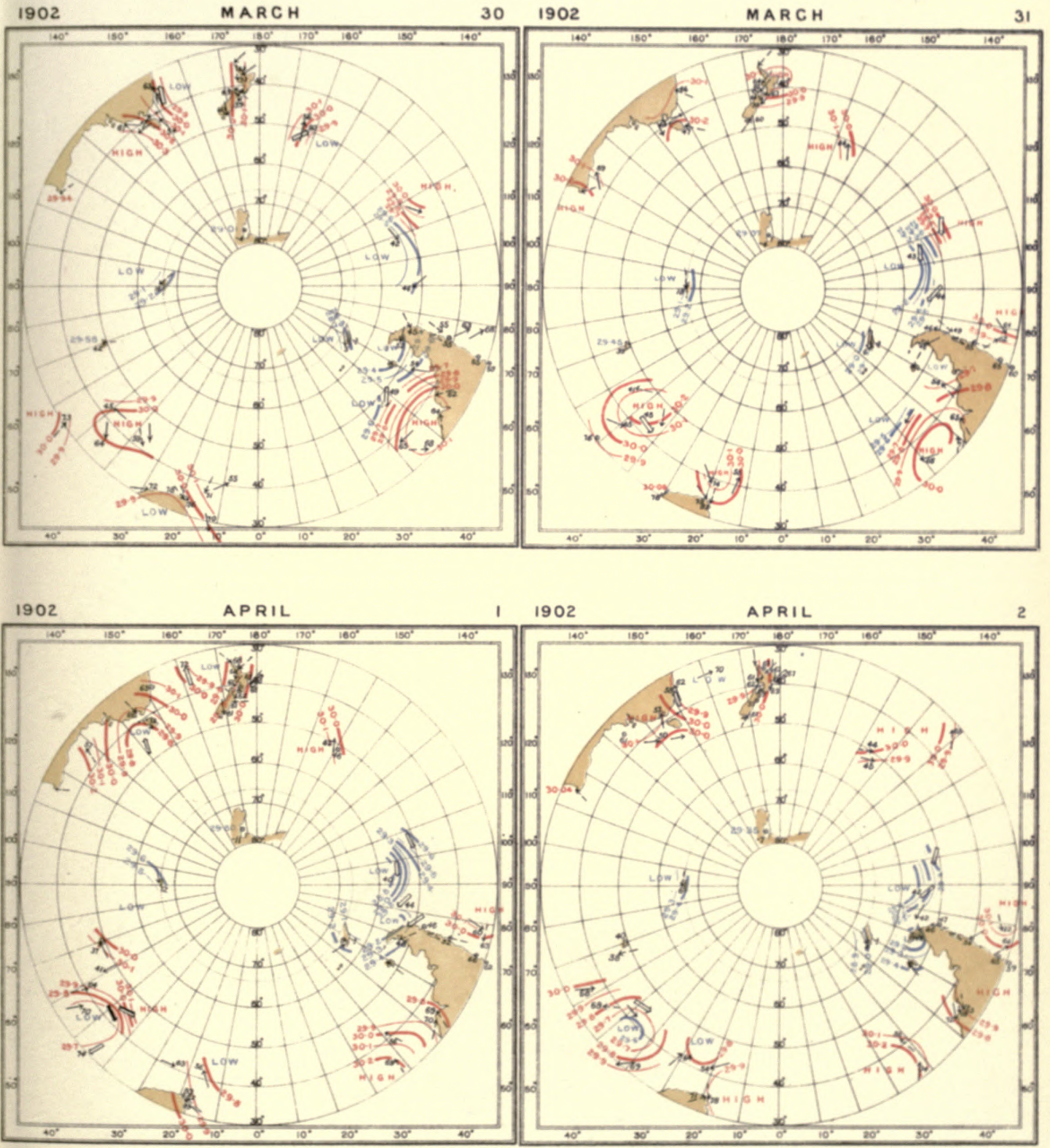


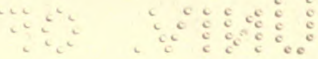

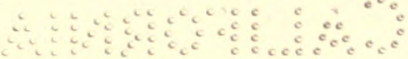


$\therefore \ldots$

$+\ldots+$ 
INTERNATIONAL ANTARCTIC CO-OPERATION

SYNCHRONOUS CHARTS OF SEA-LEVEL PRESSURE FOR NOON GMT

WITH WINDS AND AIR TEMPERATURES

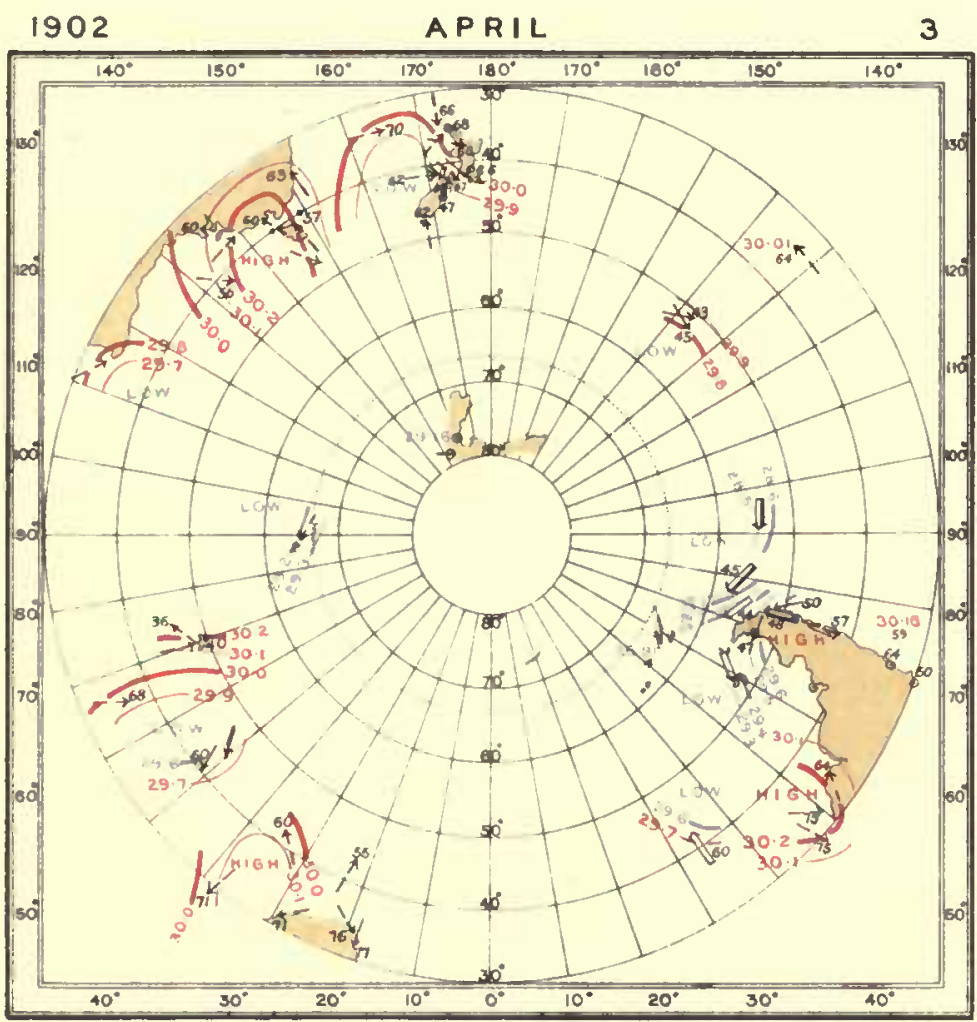

1902

APRIL

4
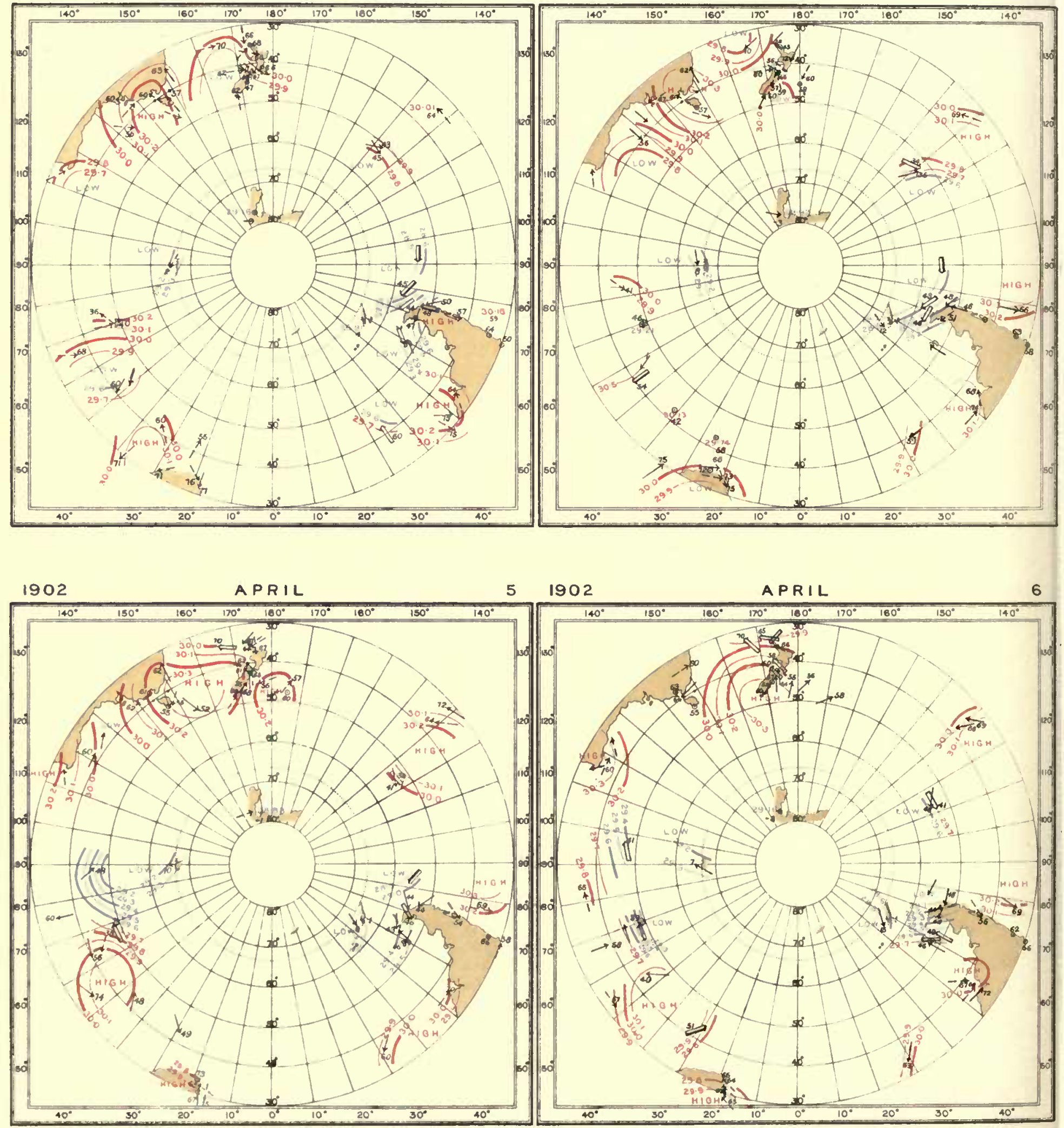
INTERNATIONAL ANTARCTIC COOPERATION

SYNCHRONOUS CHARTS OF SEALEVEL PRESSURE FOR NOON G.MT

WITH WINDS AND AIR TEMPERATURES
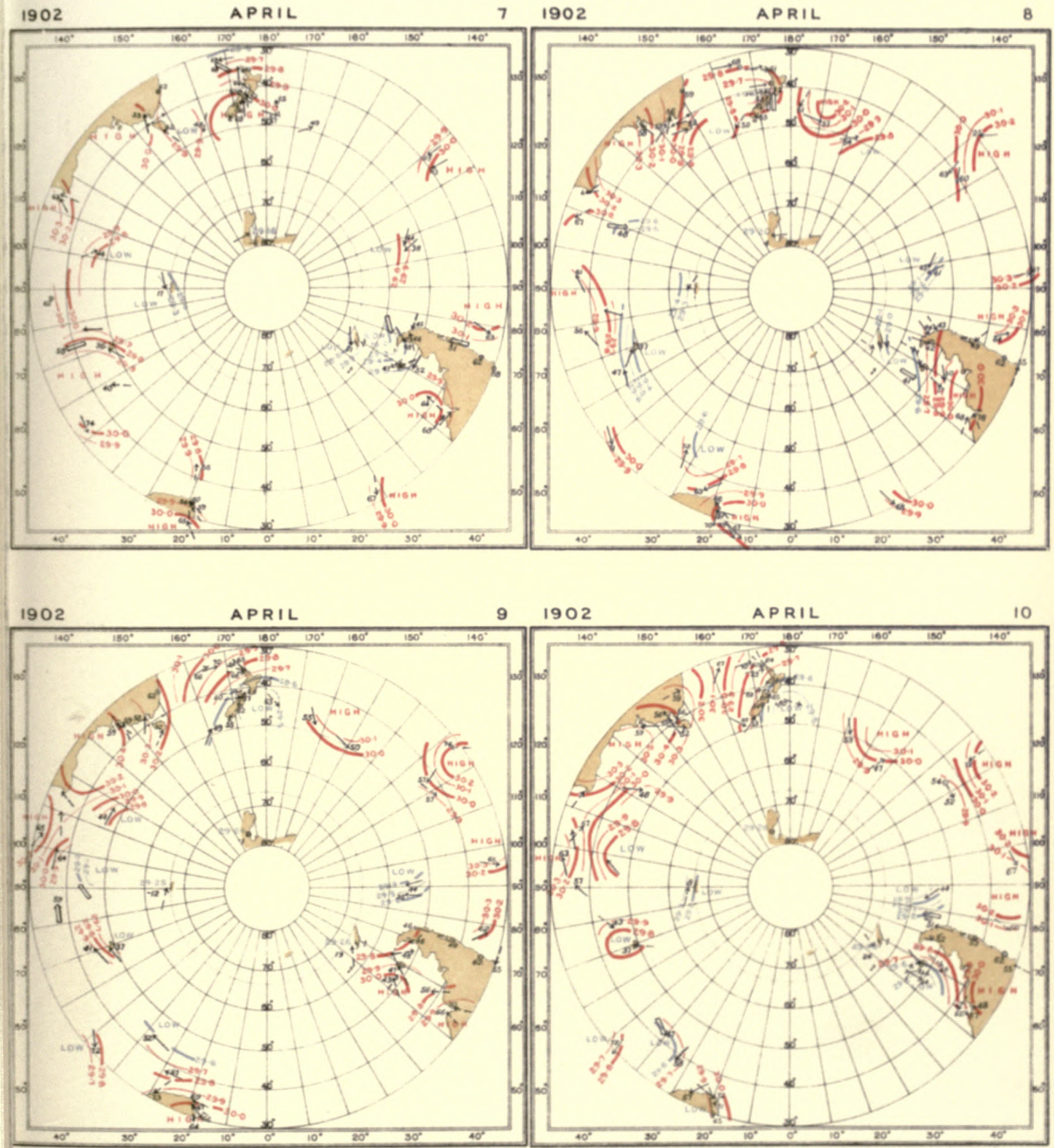

INTERNATIONAL ANTARCTIC COOPERATION.

SYNCHRDNOUS CHARTS OF SEA-LEVEL PRESSURE FOR NOON G.M.T.

WITH WINDS AND AIR TEMPERATURES.
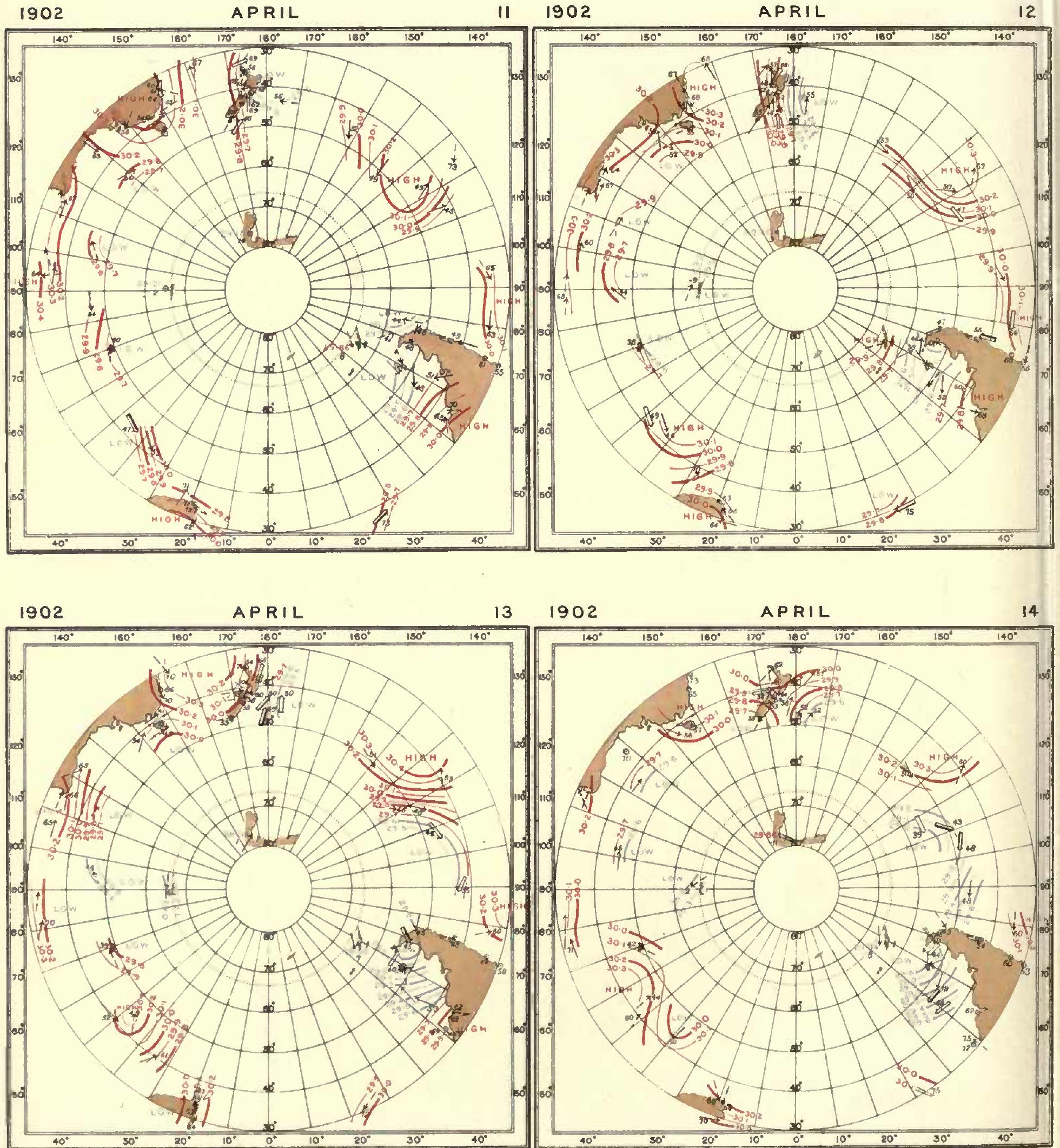
40

$\therefore 50$ 
30

a 
INTERNATIONAL ANTARCTIC CO-OPERATION.

SYNCHRONOUS CHARTS OF SEA-LEVEL PRESSURE FOR NOON G.M.T.

WITH WINDS AND AIR TEMPERATURES.
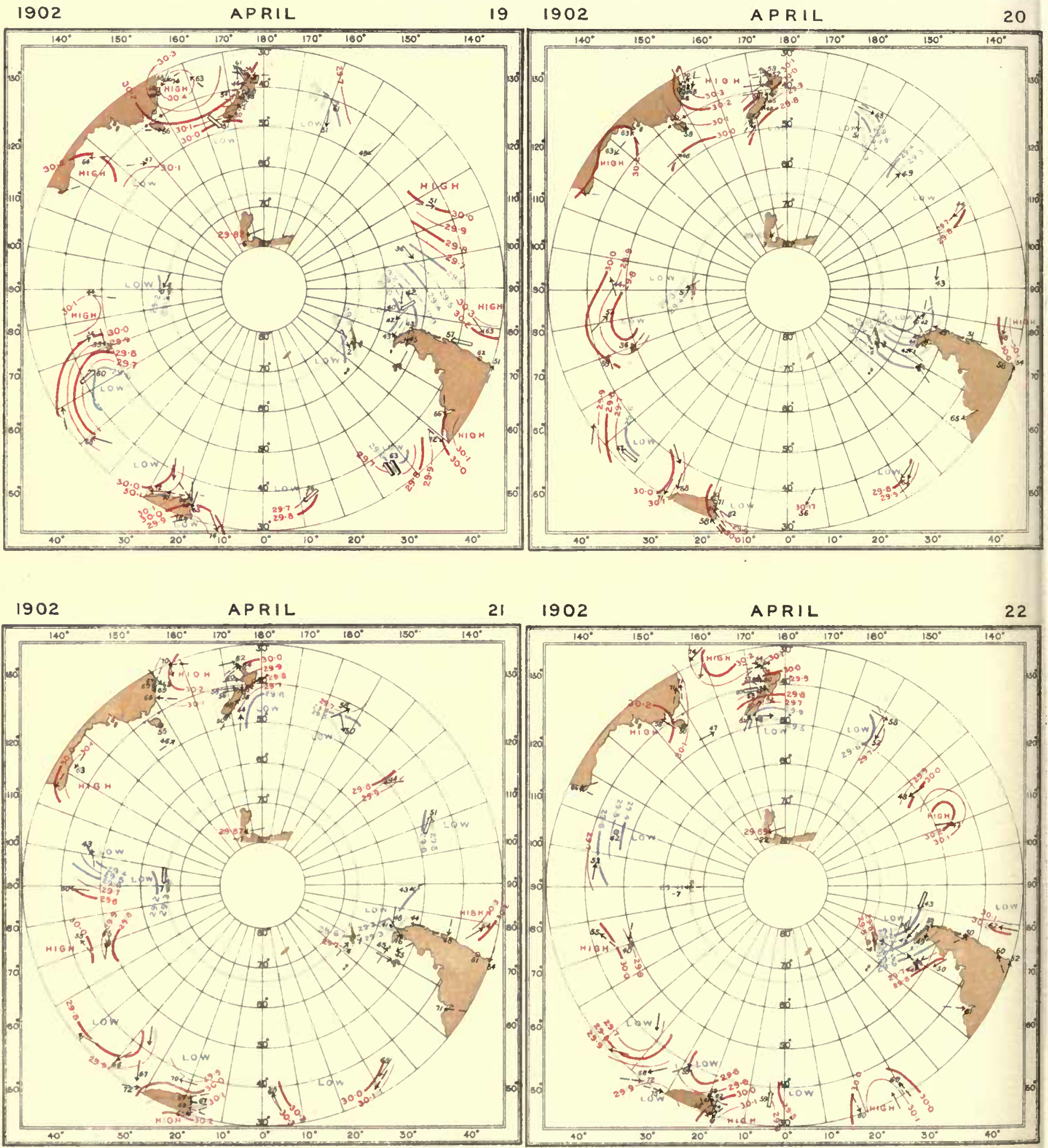


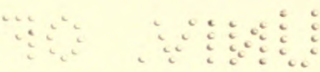

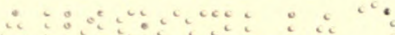

슬 
a

and 
INTERNATIONAL ANTARCTIC COOOERATION.

SYNCHRONOUS CHARTS OF SEA-LEVEL PRESSURE FOR NOON G.M.T

WITH WINOS AND AIR TEMPERATURES

1902

APRIL

$27 \quad 1902$

APRIL
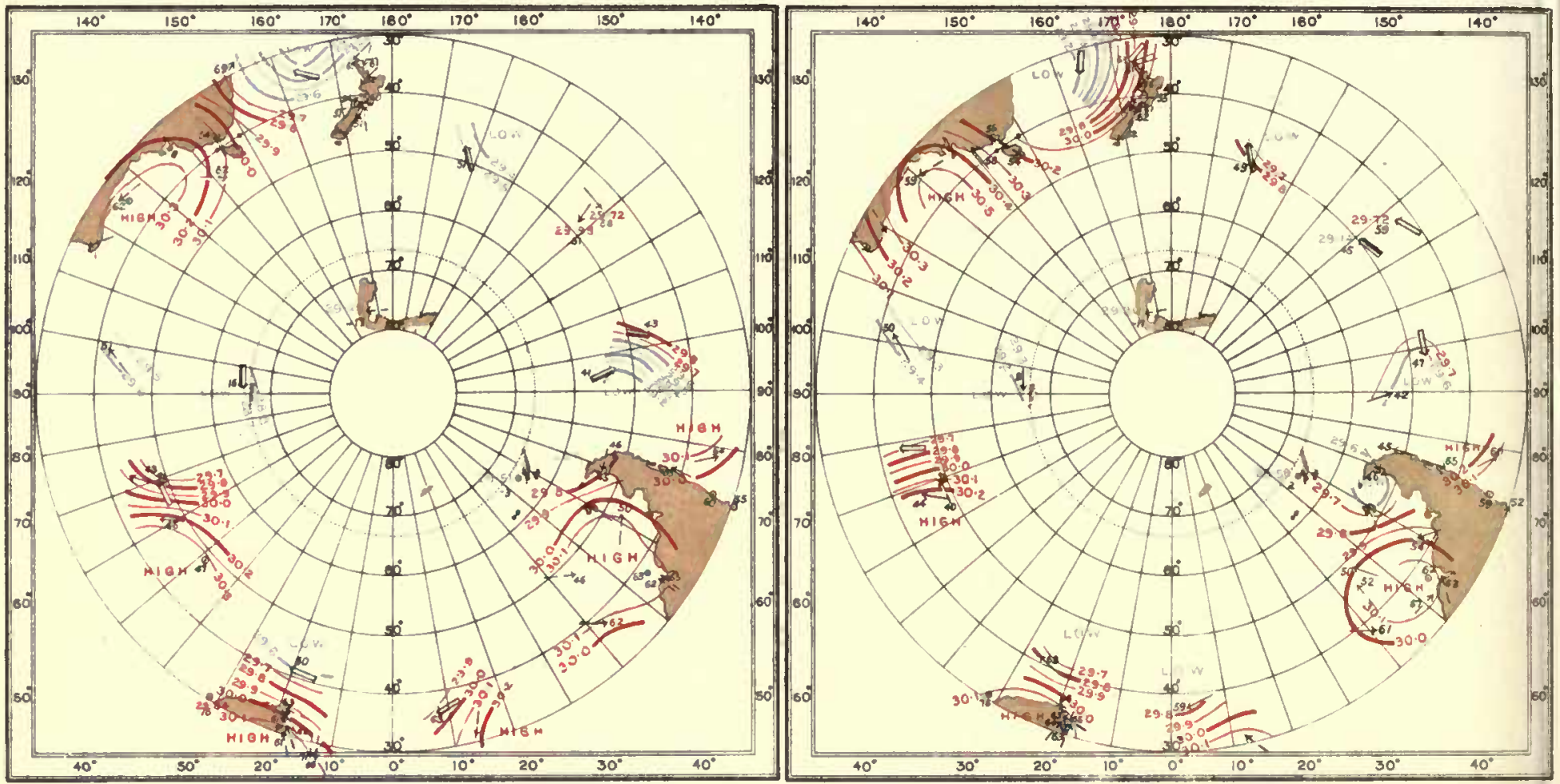

1902

A PRIL

$29 \quad 1902$

APRIL
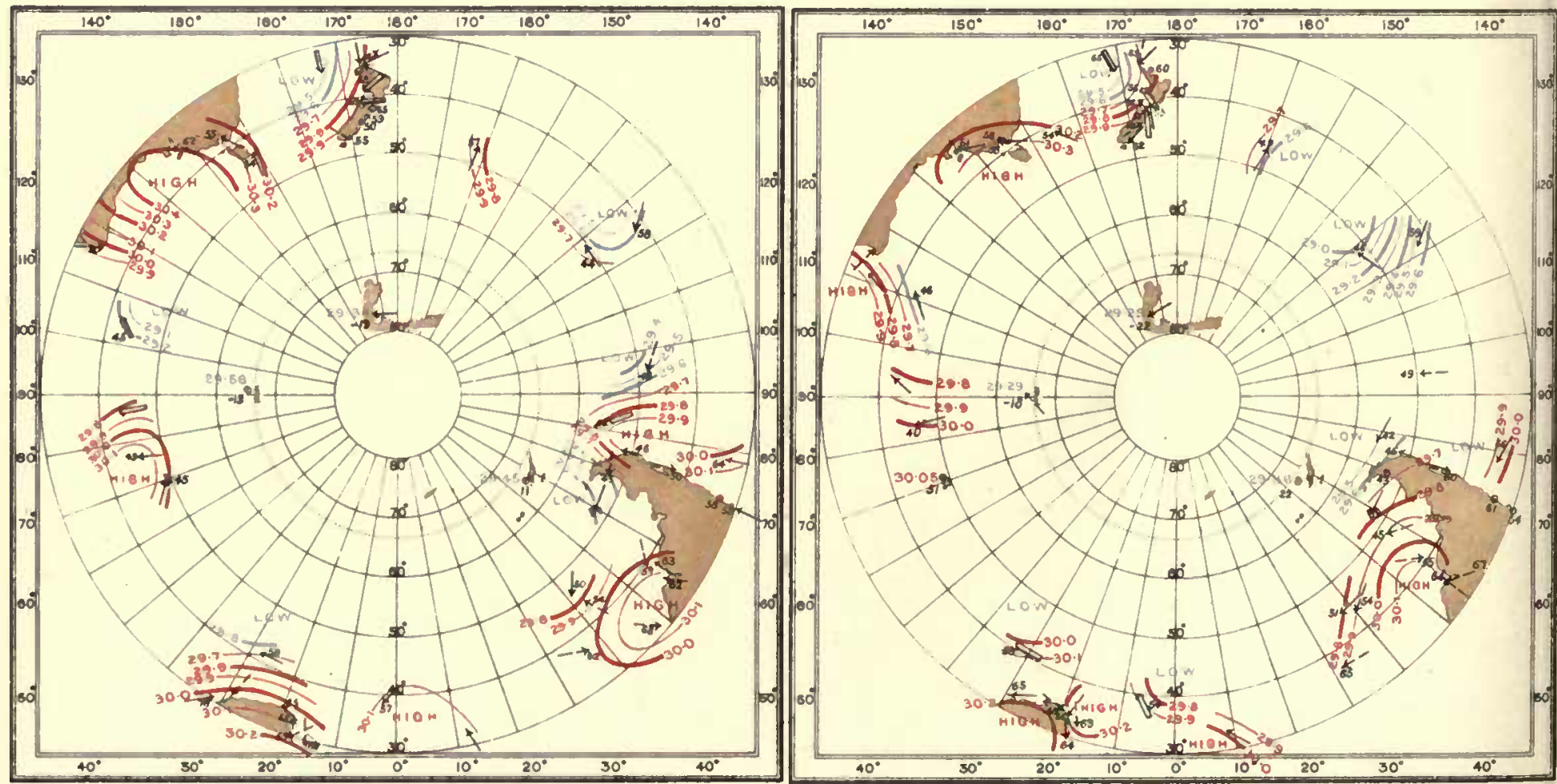
INTERNATIONAL ANTARCTIC CO-OPERATION.

SYNCHRONOUS CHARTS OF SEALEVEL PRESSURE FOR NOONGMT

WITH WINDS AND AIR TEMPERATURES

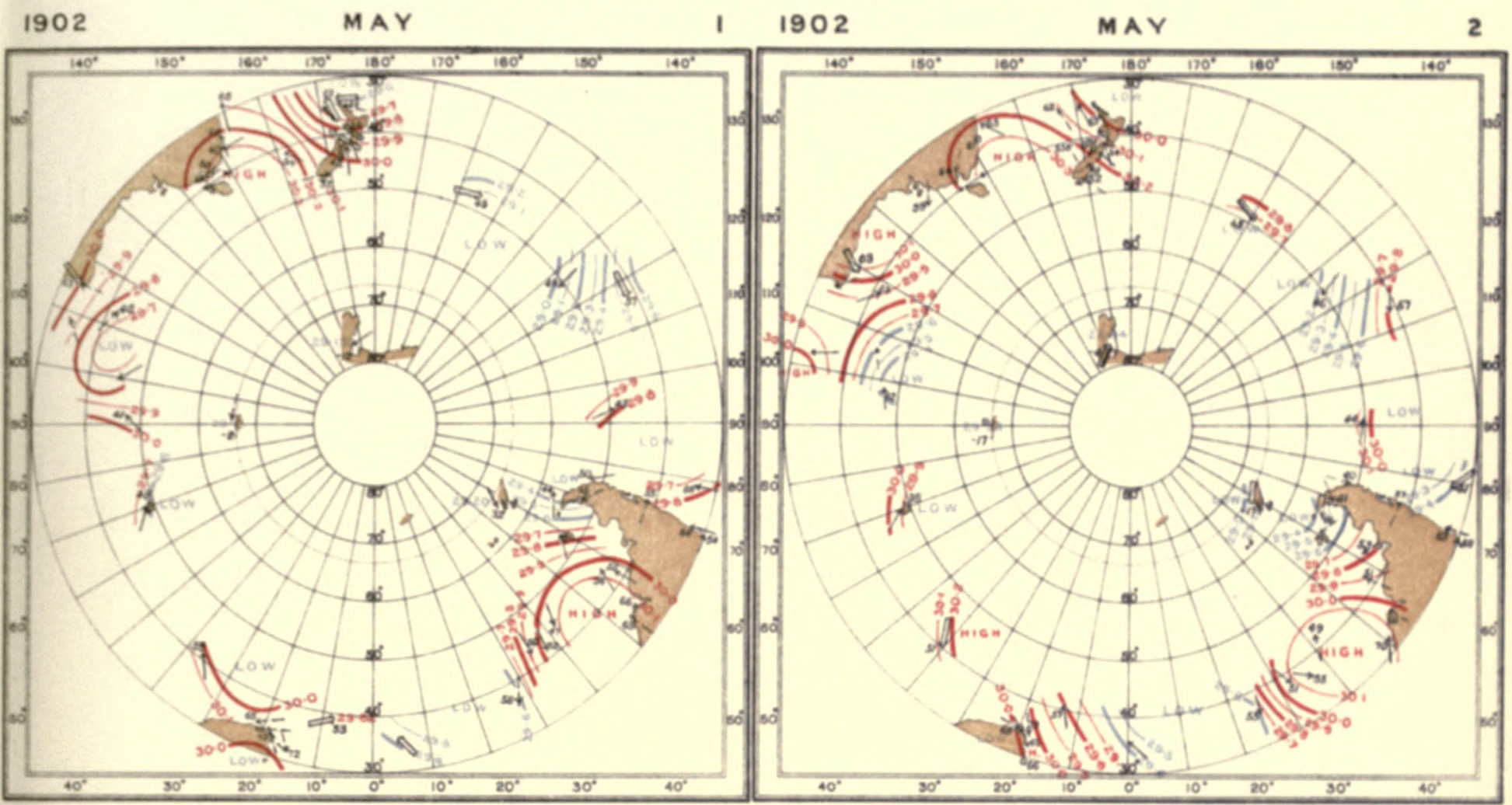

1902

M A Y

$3 \quad 1902$

$M A Y$
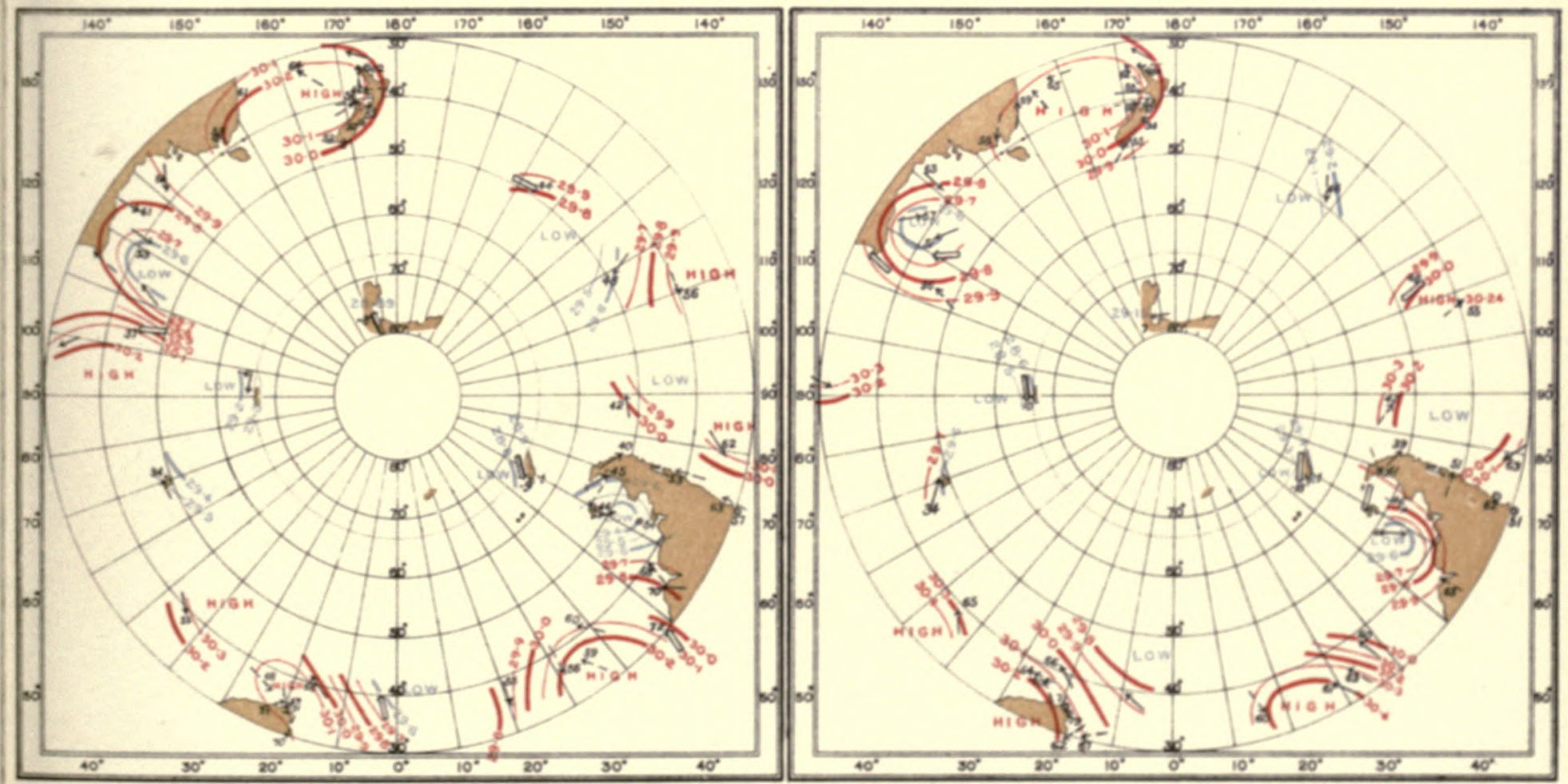
40 
INTERNATIONAL ANTARCTIC CO-OPERATION.

SYNCHRONOUS CHARTS OF SEA-LEVEL PRESSURE FOR NOON G.M.T

WITH WINDS AND AIR TEMPERATURES.
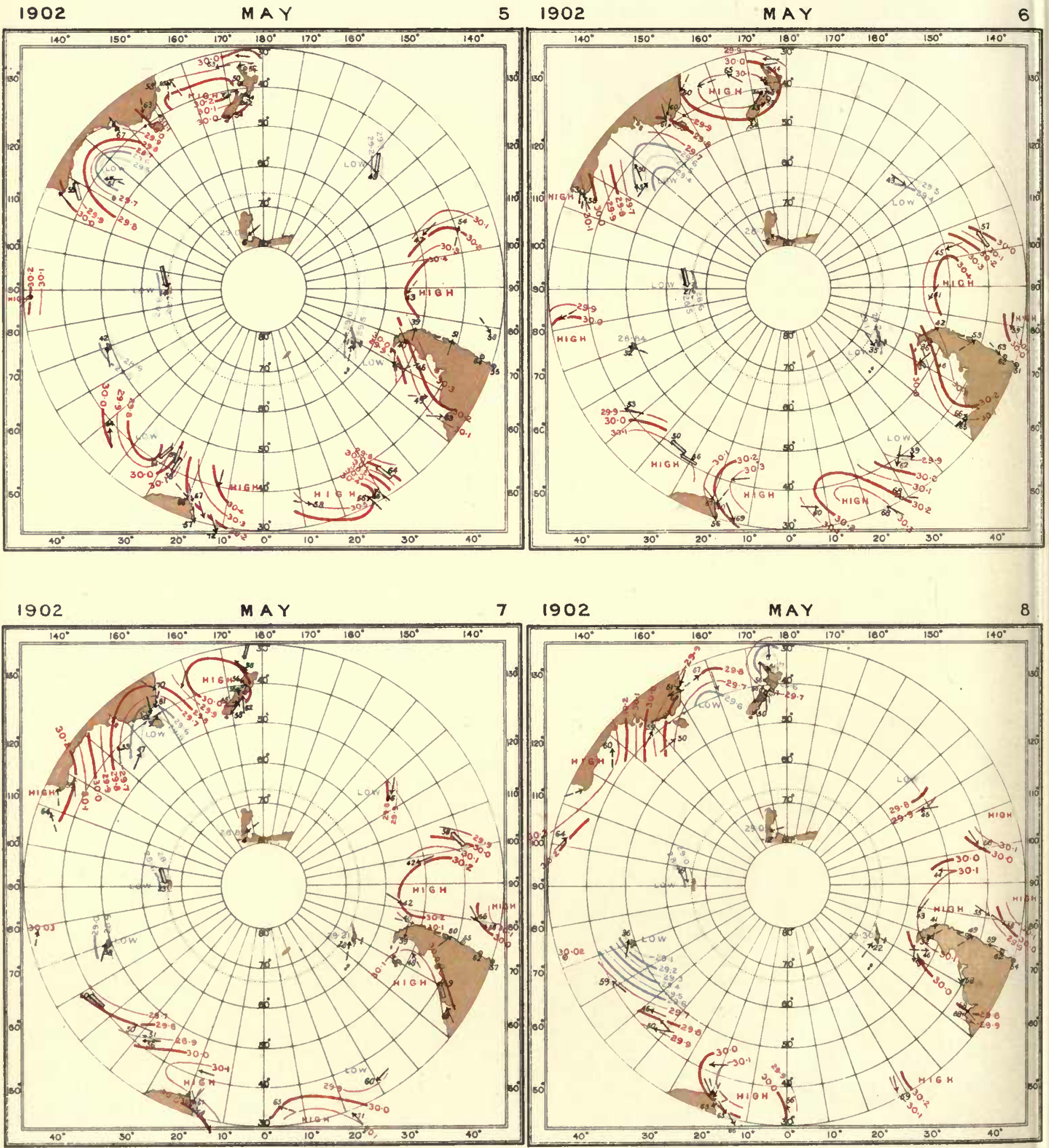
INTERNATIONAL ANTARCTIC COOPERATION

SYNCHRONOUS CHARTS OF SEA-LEVEL PRESSURE FOR NOON G.M.T

WITH WINDS AND AIR TEMPERATURES
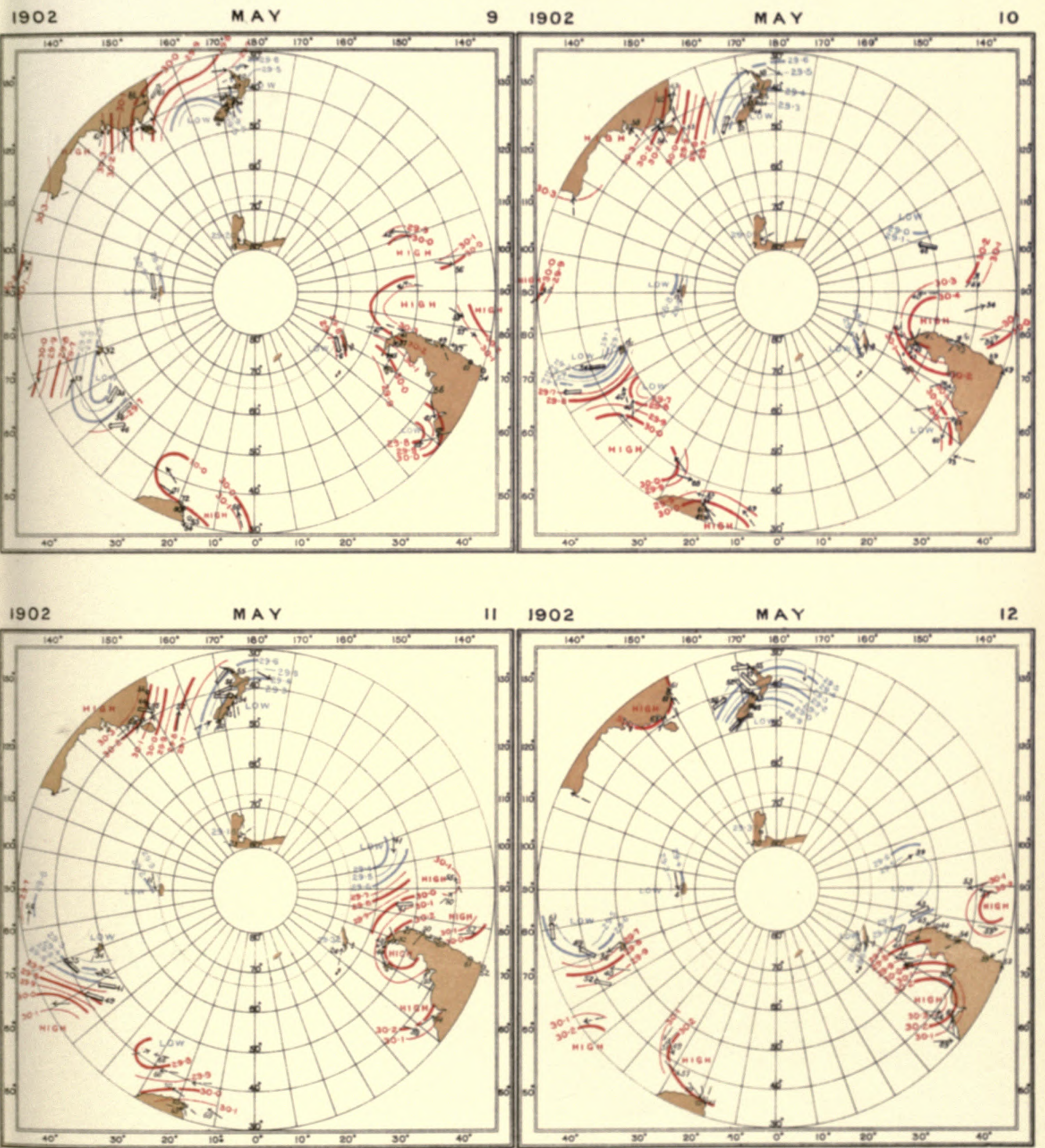
$\therefore=\therefore \because \because \because \vdots \vdots \therefore \cdots$ 
$\therefore: \because \quad 4$

a 
INTERNATIONAL ANTARCTIC COOPERATION.

SYNCHRONOUS CHARTS OF SEALLEVEL PRESSURE FOR NOON G.M.T

WITH WINDS AND AIR TEMPERATURES

1902

MAY

$13 \quad 1902$

M A Y

14
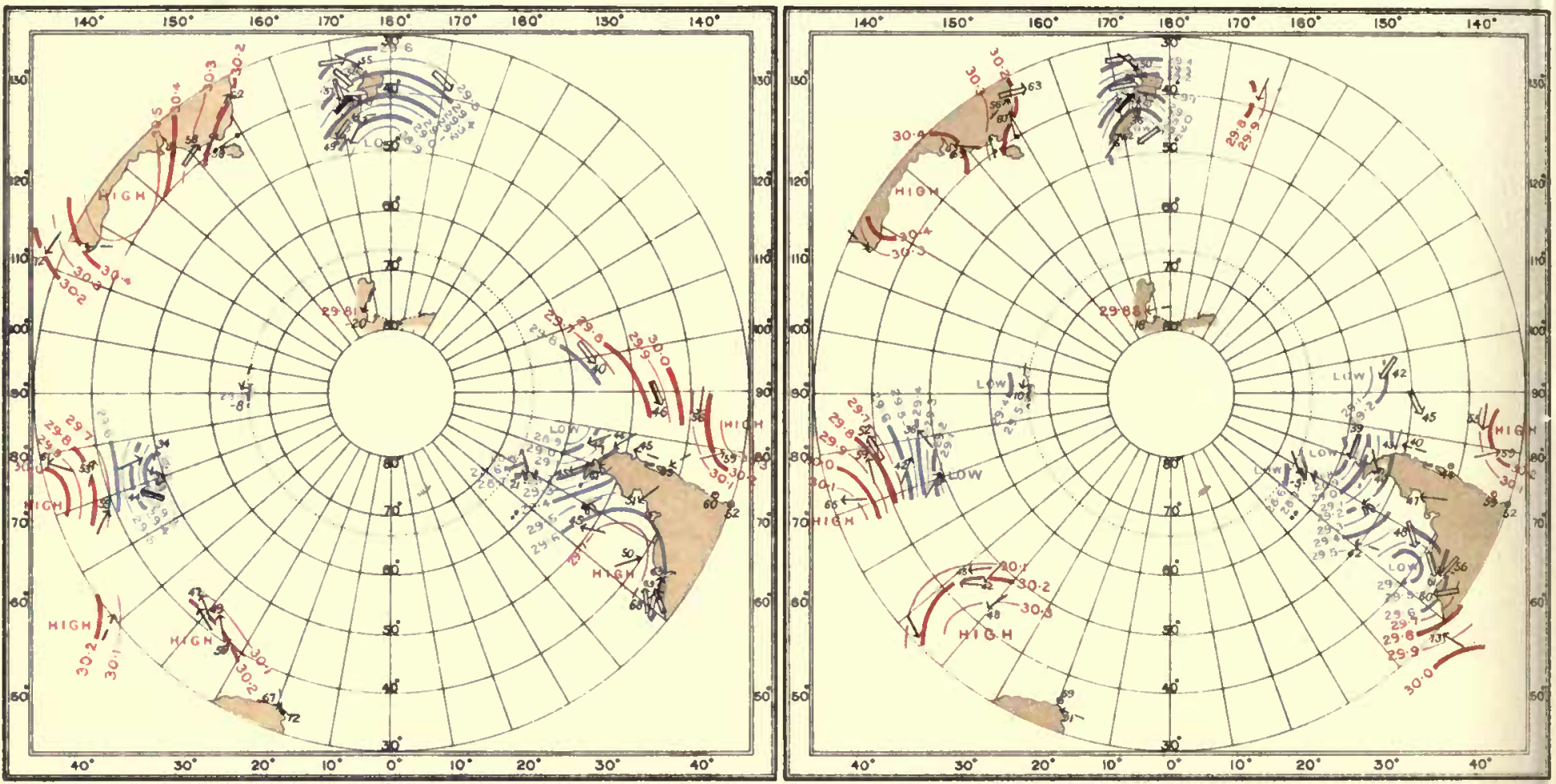

1902

M A Y

$15 \quad 1902$

MAY
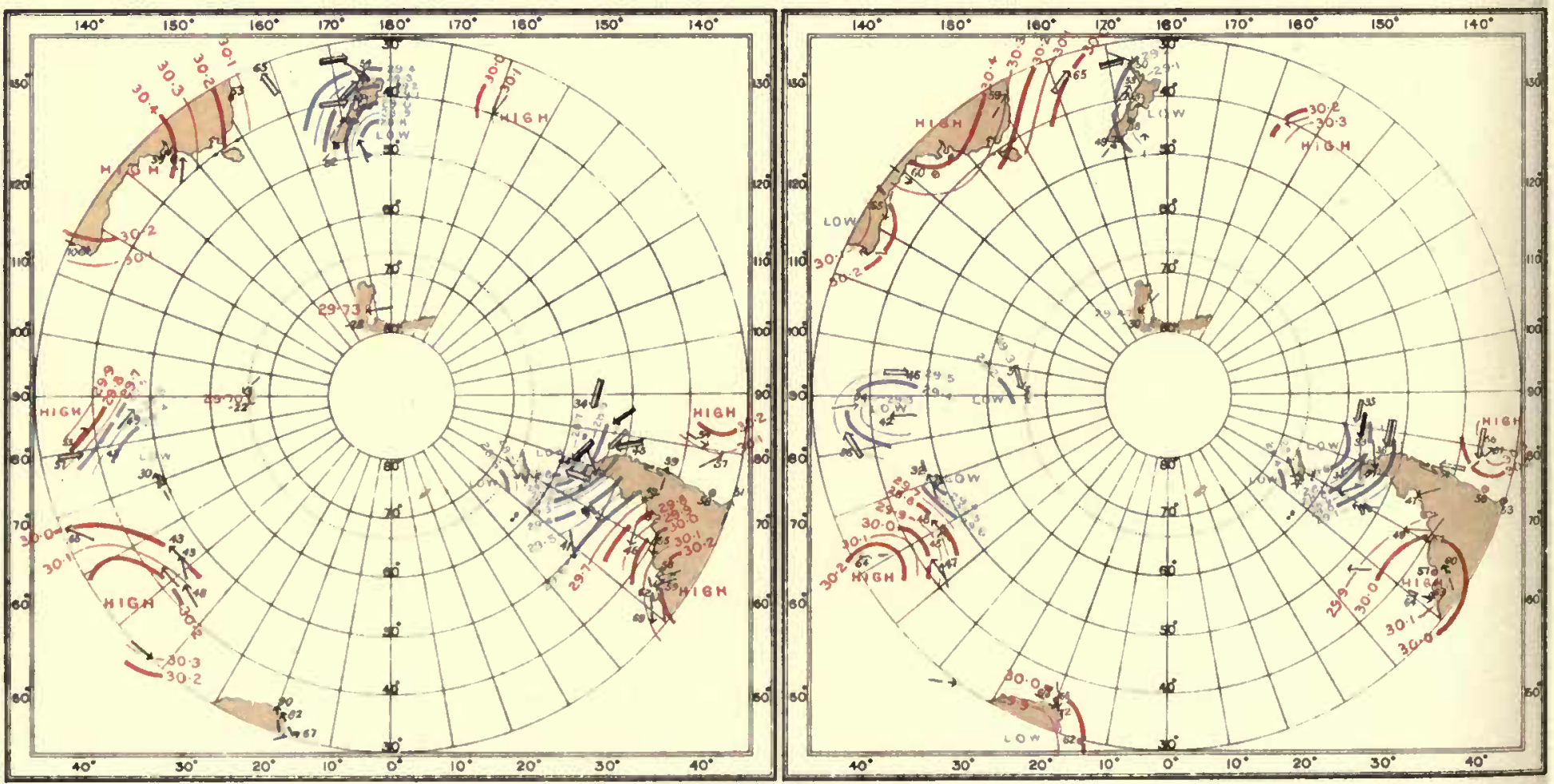
INTERNATIONAL ANTARCTIC COOPERATION,

SYNCHRONOUS CHARTS OF SEA-LEVEL PRESSURE FOR NOON G.M.T

WITH WINDS AND AIR TEMPERATURES

1902

$M A Y$

$17 \quad 1902$

MAY

18

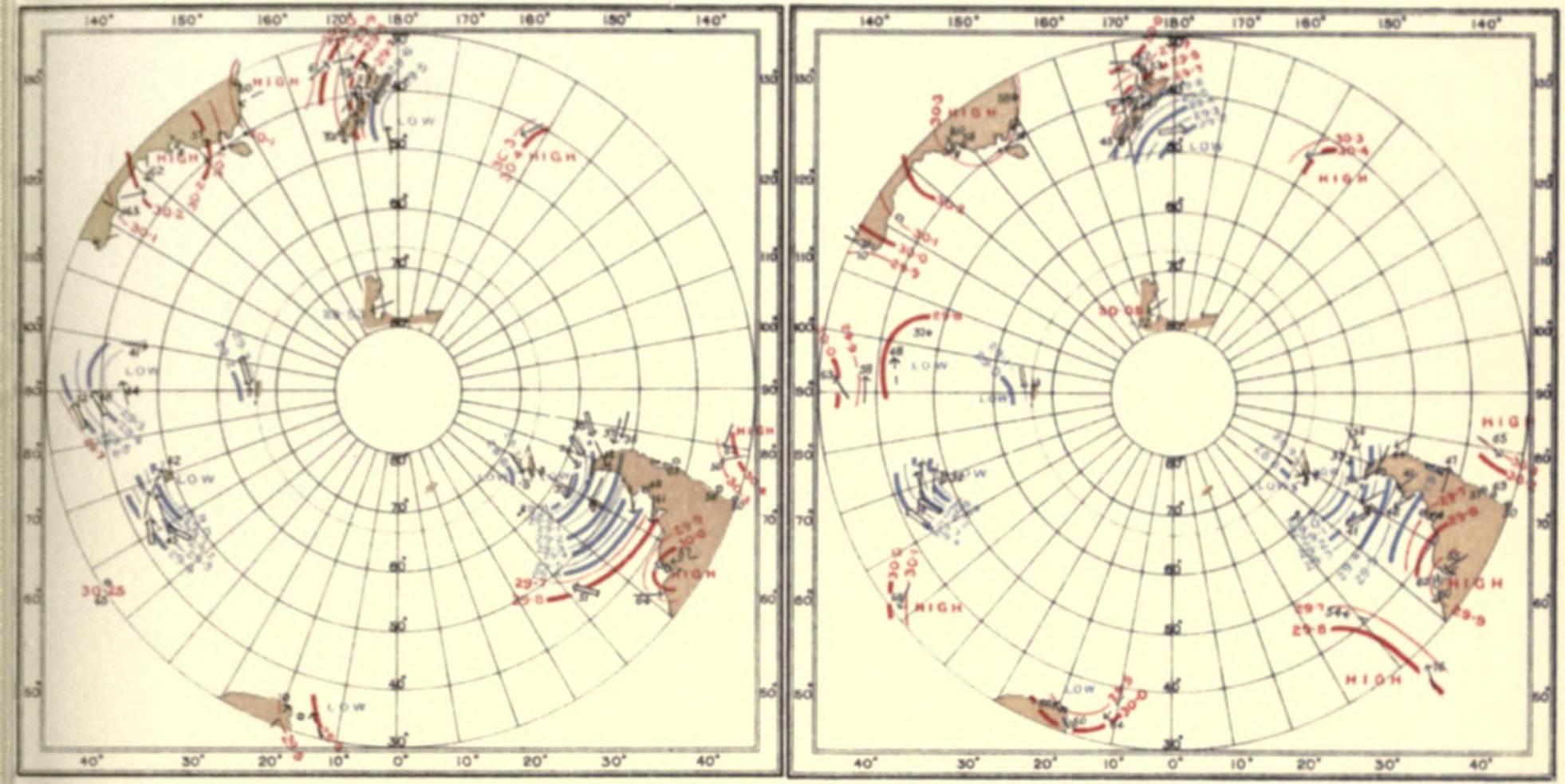

M A Y

$19 \quad 1902$

M A Y

20

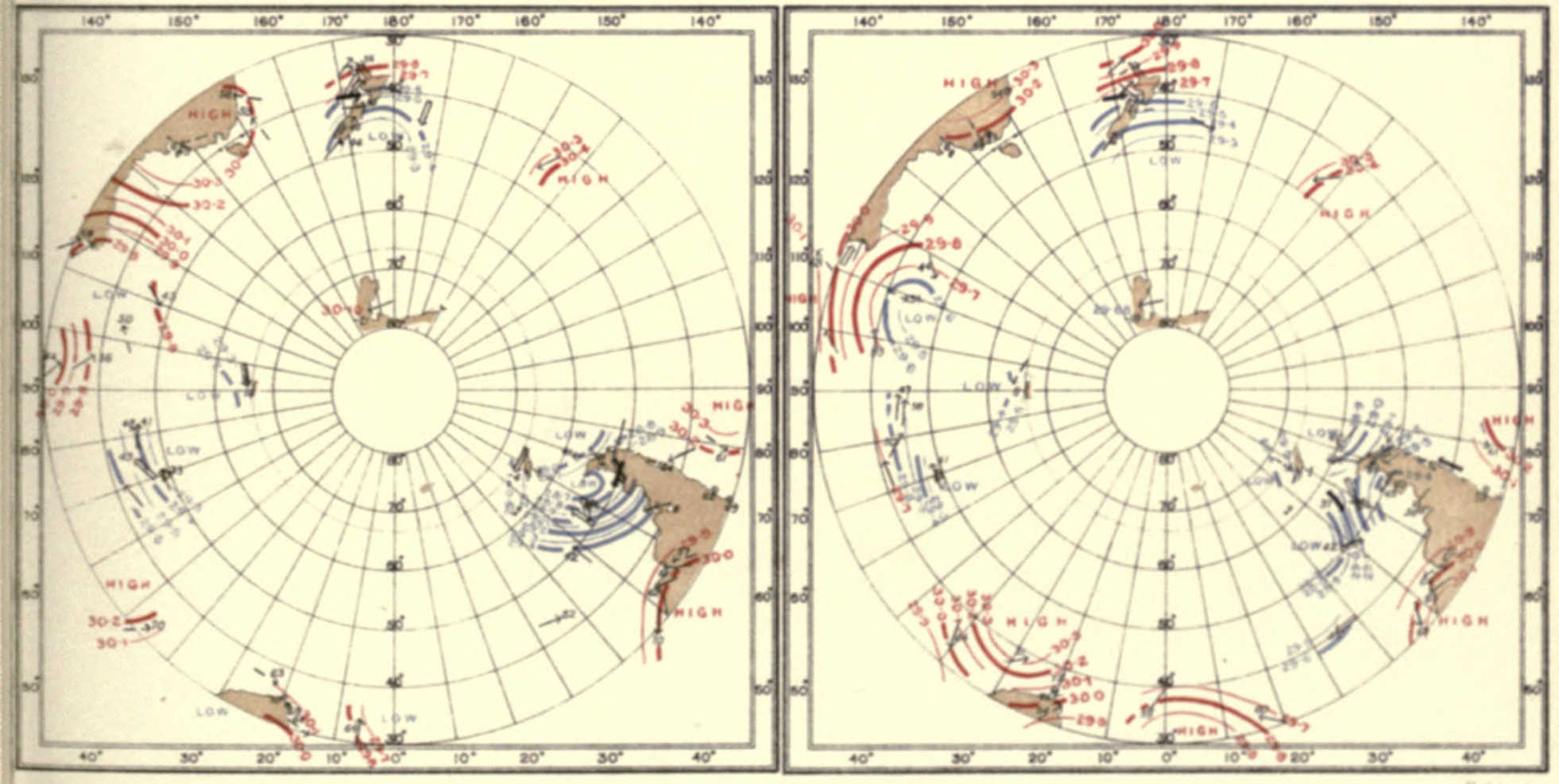




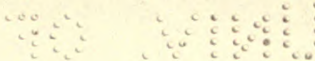

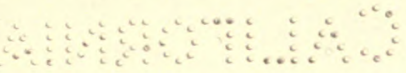


1

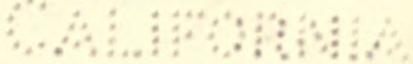


INTERNATIONAL ANTARCTIC COOPERATION.

SYNCHRONOUS CHARTS OF SEALLEVEL PRESSURE FOR NOON GMT.

WITH WINOS AND AIR TEMPERATURES
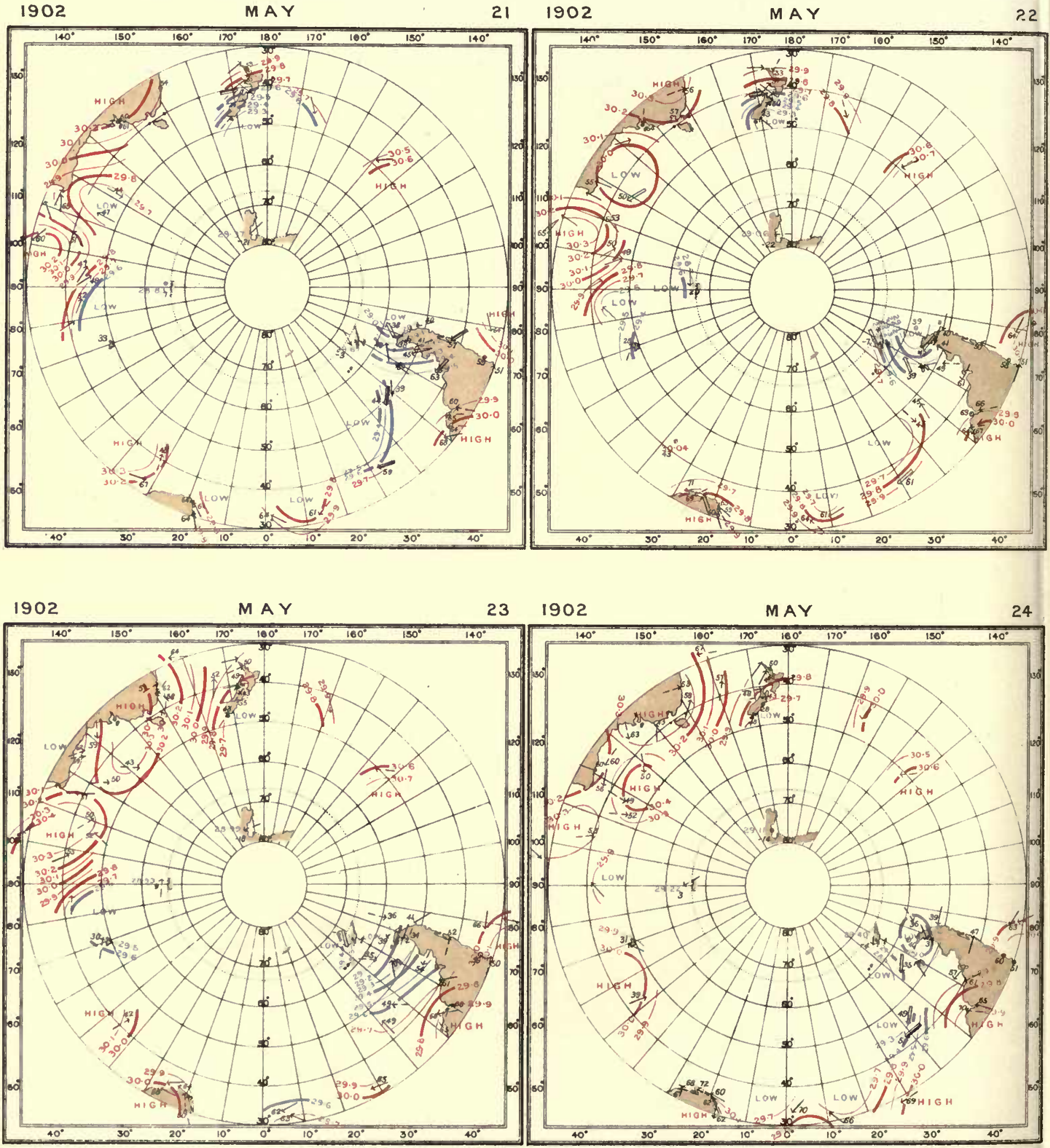
INTERNATIONAL ANTARCTIC COOPERATION

SYNCHRONOUS CHARTS OF SEA-LEVEL PRESSURE FOR NOON G.M.T

WITH WINDS AND AIR TEMPERATURES
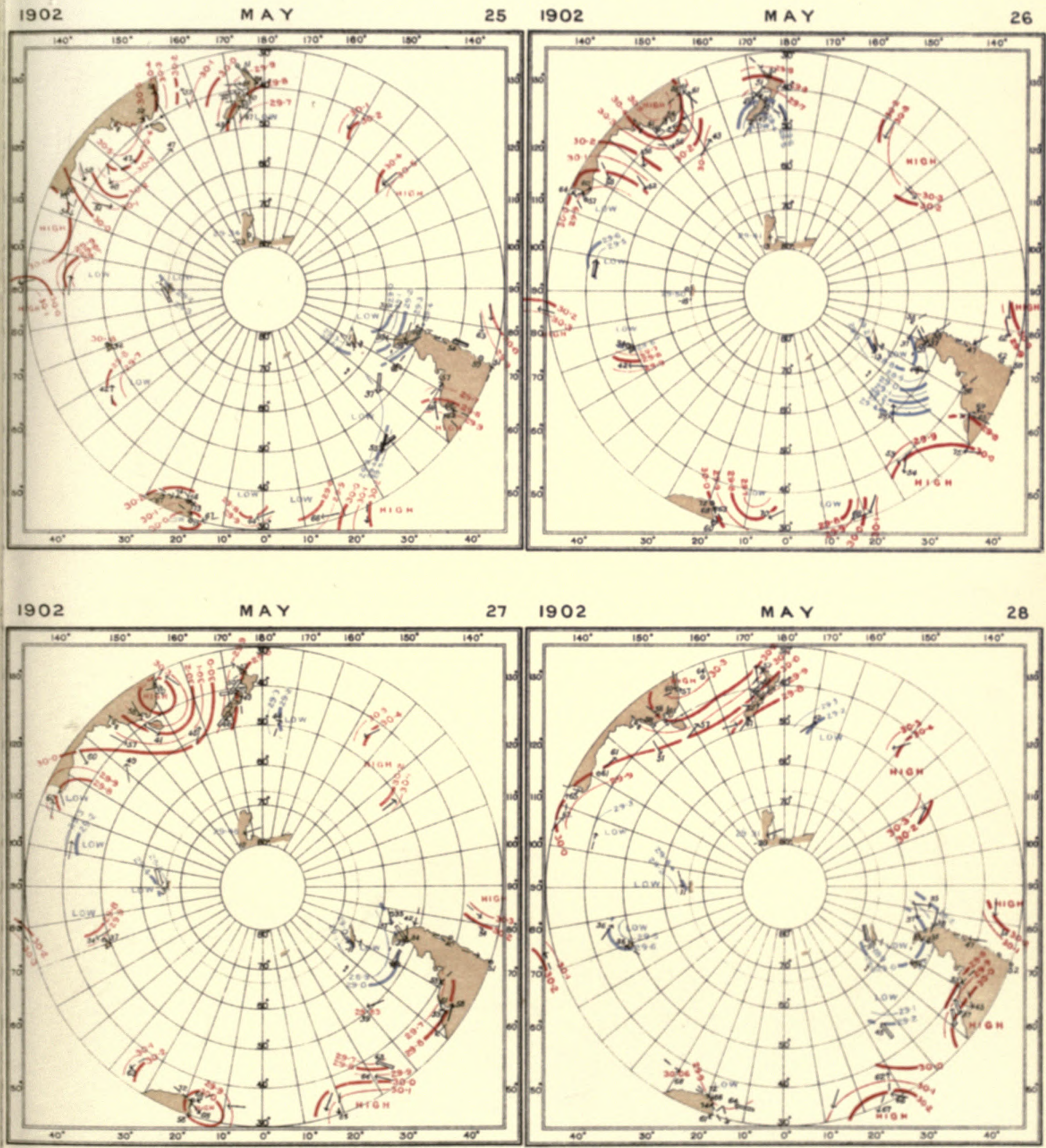


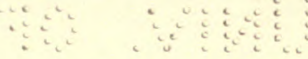

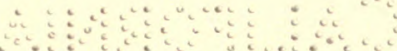



INTERNATIONAL ANTARCTIC COOPERATION.

SYNCHRONOUS CHARTS OF SEA-LEVEL PRESSURE FOR NOON GM.T.

WITH WINDS AND AIR TEMPERATURES
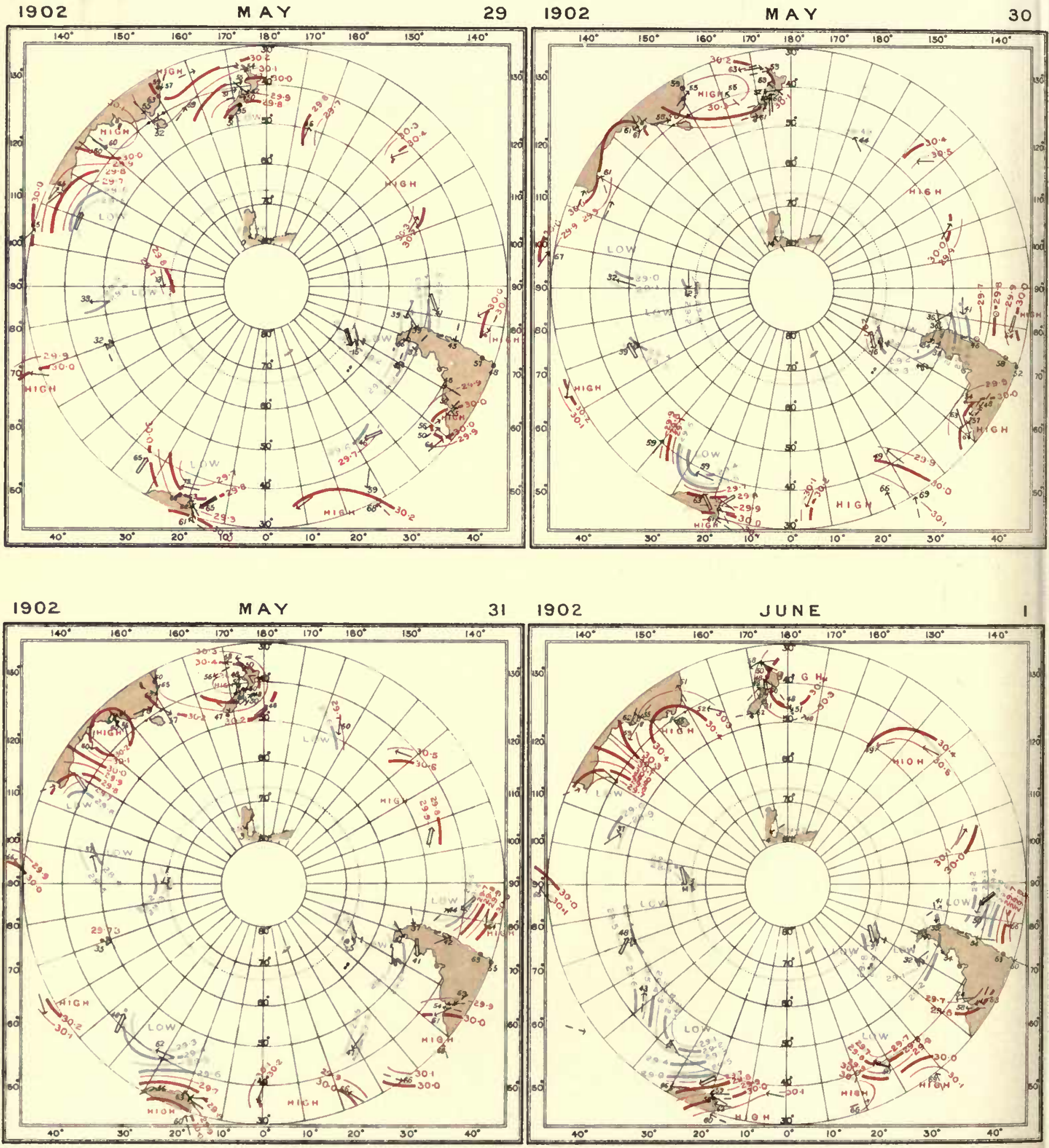
$\because$\begin{tabular}{l}
0 \\
\hdashline \\
\hdashline
\end{tabular}

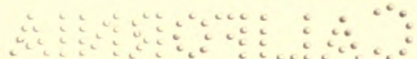


(1)

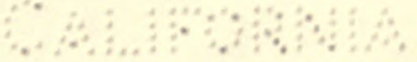


INTERNATIONAL ANTARCTIC CO-OPERATION.

SYNCHRONOUS CHARTS OF SEA-LEVEL PRESSURE FOR NOON G.MT.

WITH WINOS AND AIR TEMPERATURES

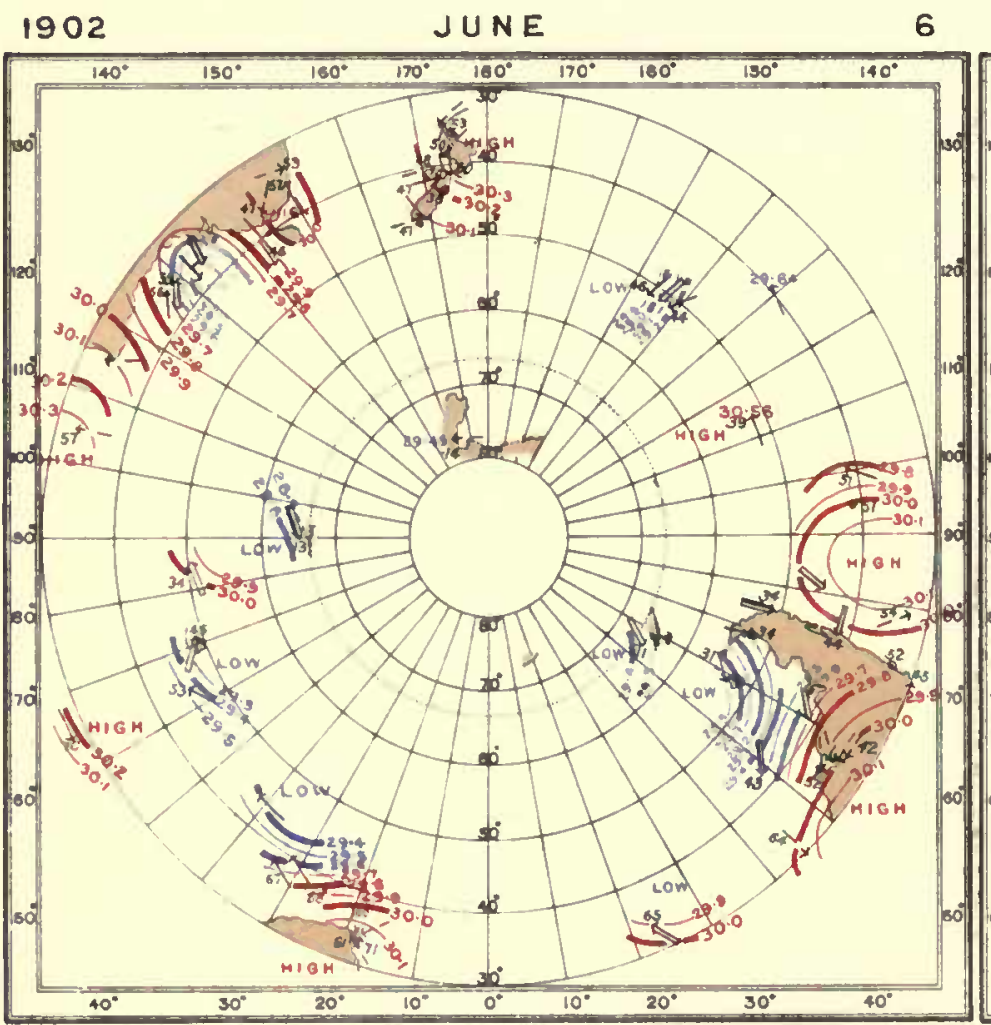

1902

JUNE

7

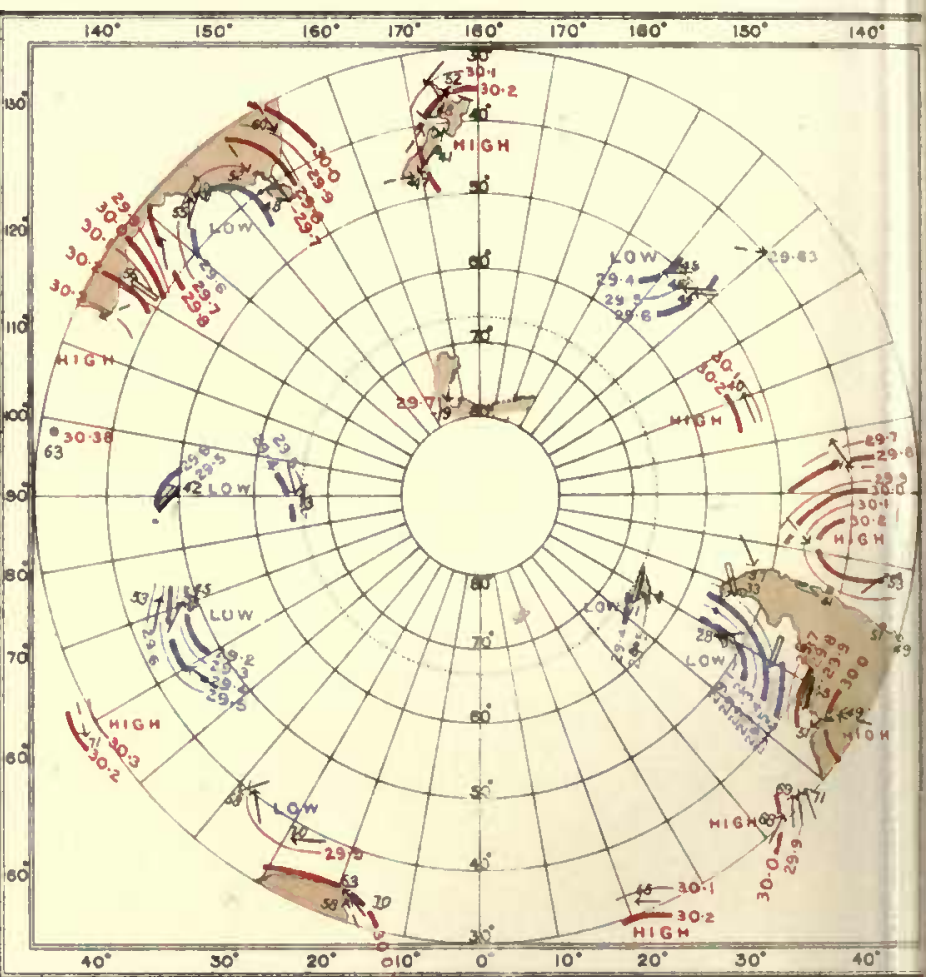

1902

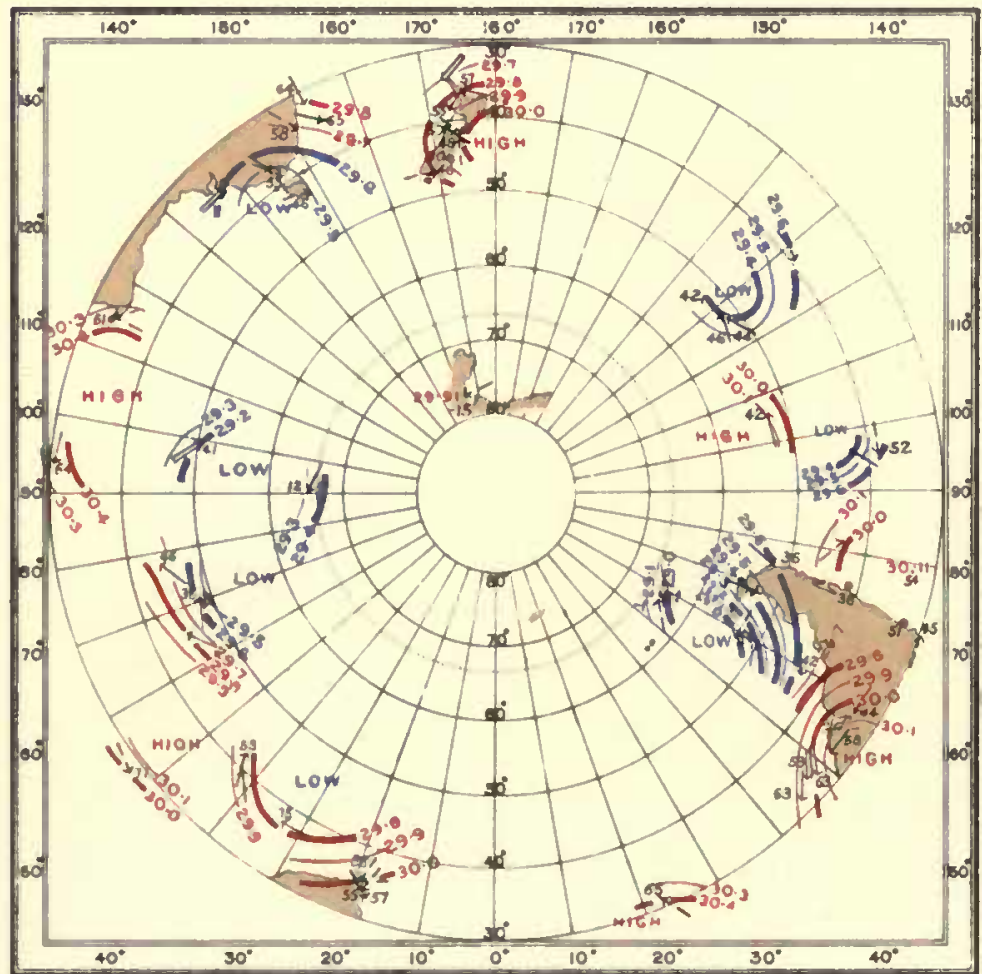

$8 \quad 1902$

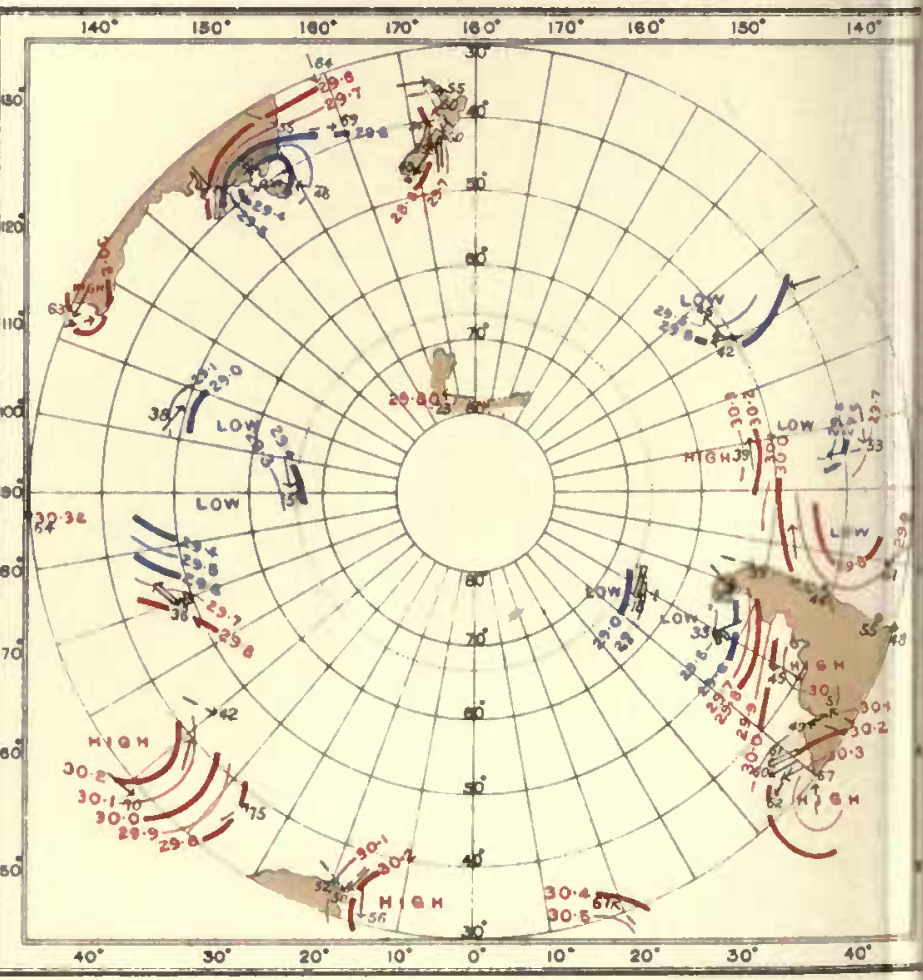


INTERNATIONAL ANTARCTIC COOPERATION,

SYNCHRONOUS CHARTS OF SEA-LEVEL PRESSURE FOR NOON GMT

WITH WINDS AND AIR TEMPERATURES.

1902

$\begin{array}{lll}J U N E & 10 \quad 1902\end{array}$

JUNE

II
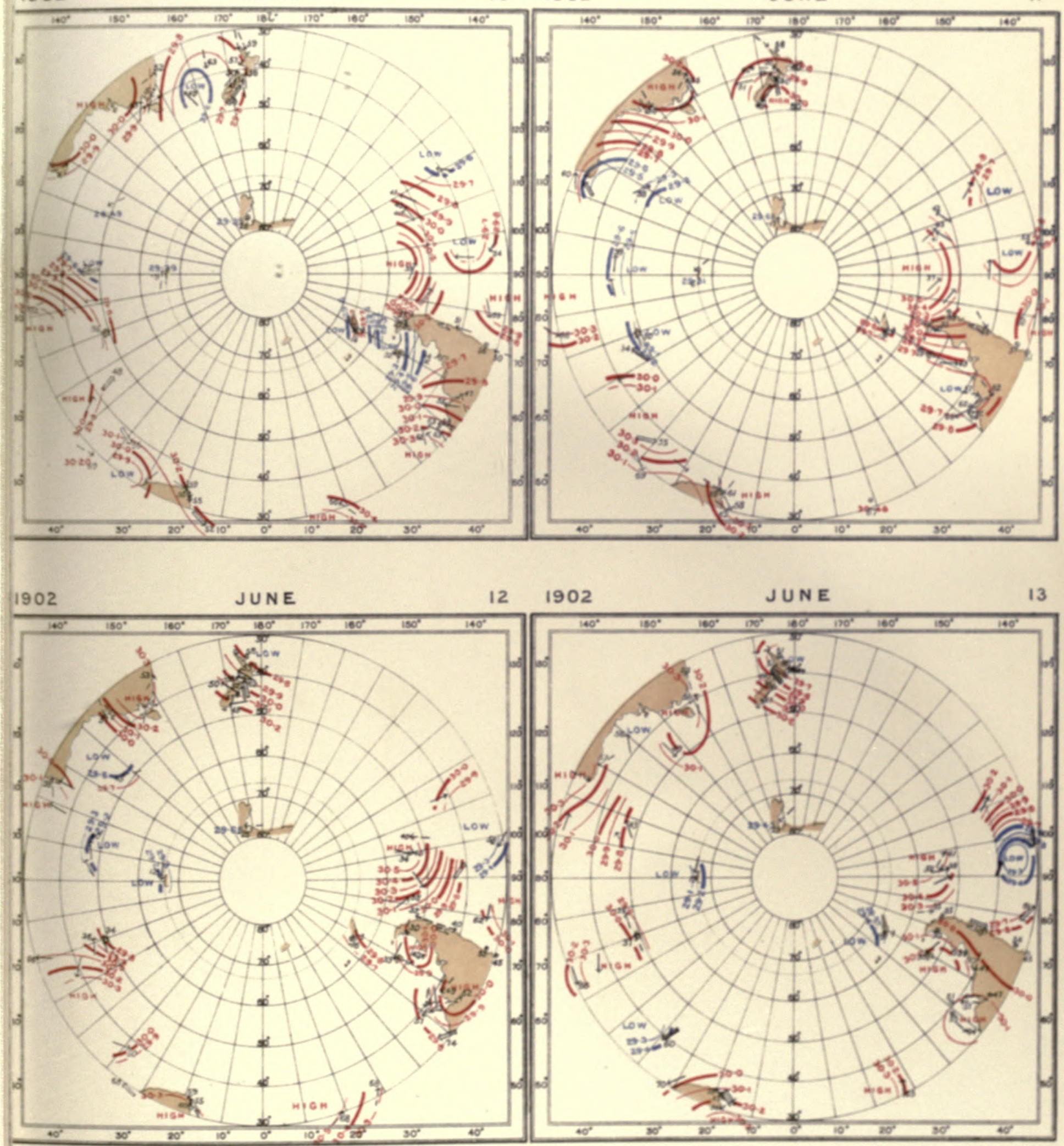


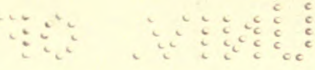

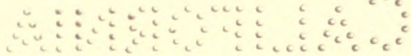



INTERNATIONAL ANTARCTIC COOPERATION.

SYNCHRONOUS CHARTS OF SEA-LEVEL PRESSURE FOR NOON G.M.T.

WITH WINDS AND AIR TEMPERATURES.

1902

JUNE

$14 \quad 1902$

$J \cup N E$

15
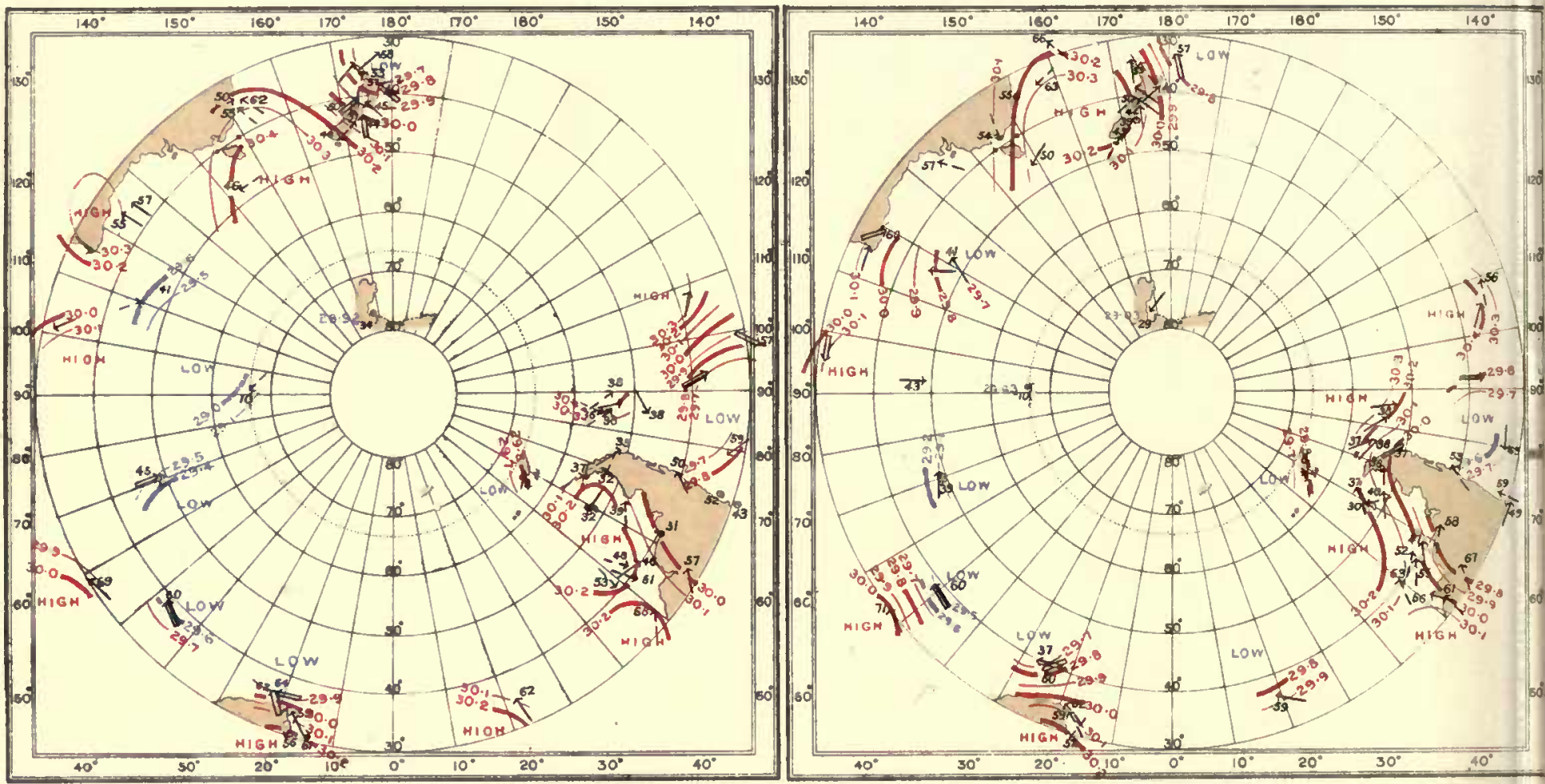

1902

JUNE

$16 \quad 1902$

JUNE

17
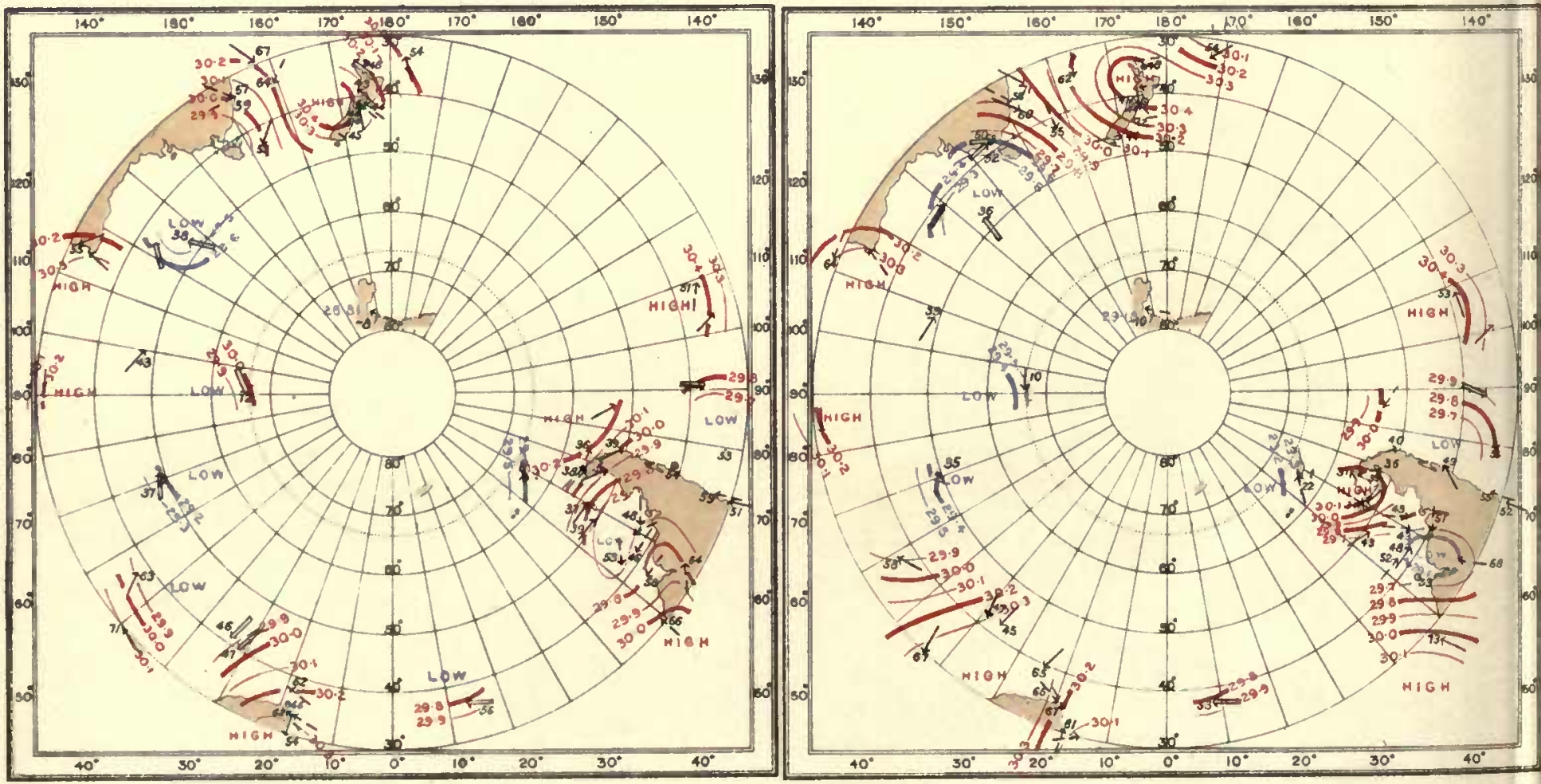
INTERNATIONAL ANTARCTIC COOPERATION

SYNCHRONOUS CHARTS OF SEALLVEL PRESSURE FOR NOON G.M.T WITH WINDS AND AIR TEMPERATURES.
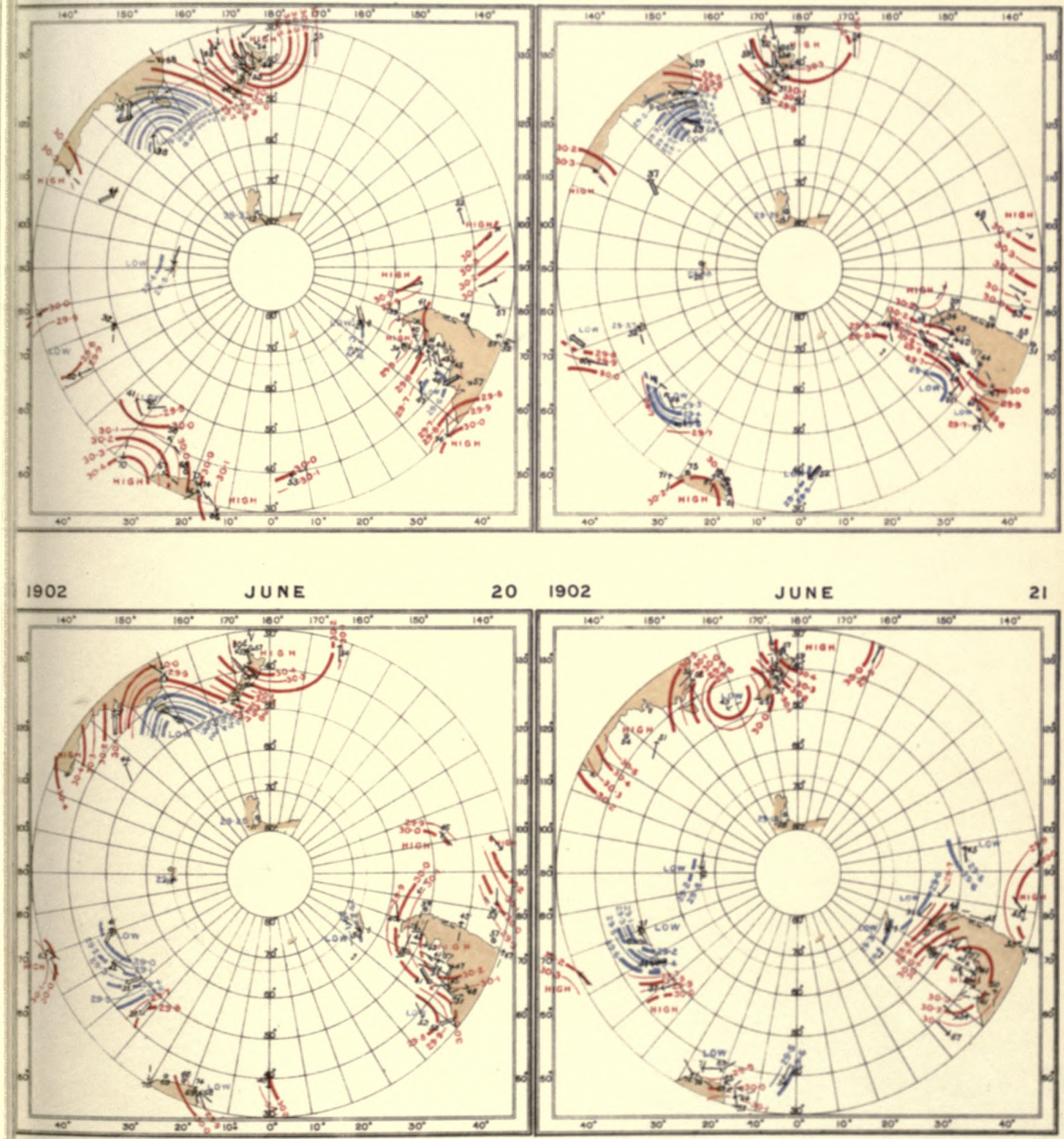


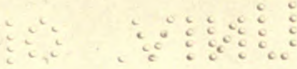

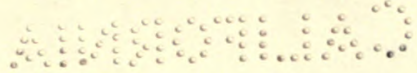


1)

a 
INTERNATIONAL ANTARCTIC COOOPERATION.

SYNCHRONOUS CHARTS OF SEA-LEVEL PRESSURE FOR NOON G.M.T

WITH WINDS AND AIR TEMPERATURES.

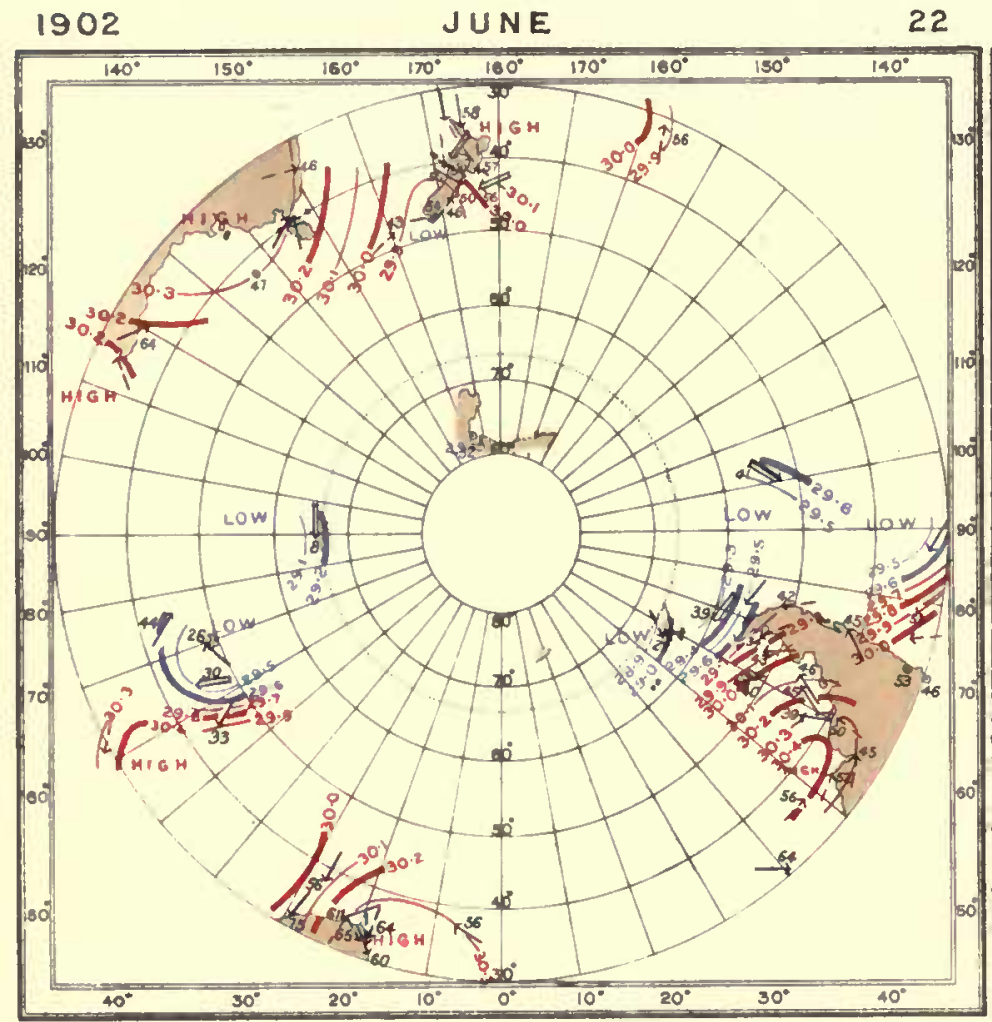

1902

JUNE

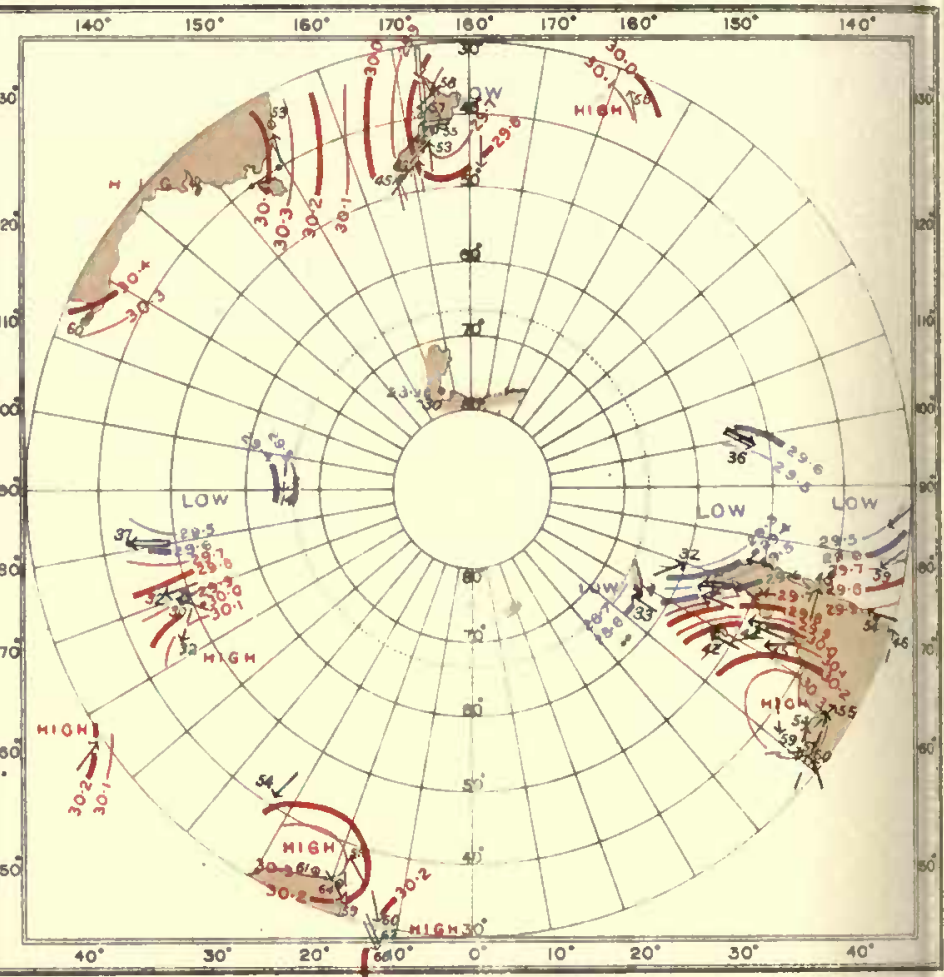

1902

JUNE

$24 \quad 1902$

JUNE

25
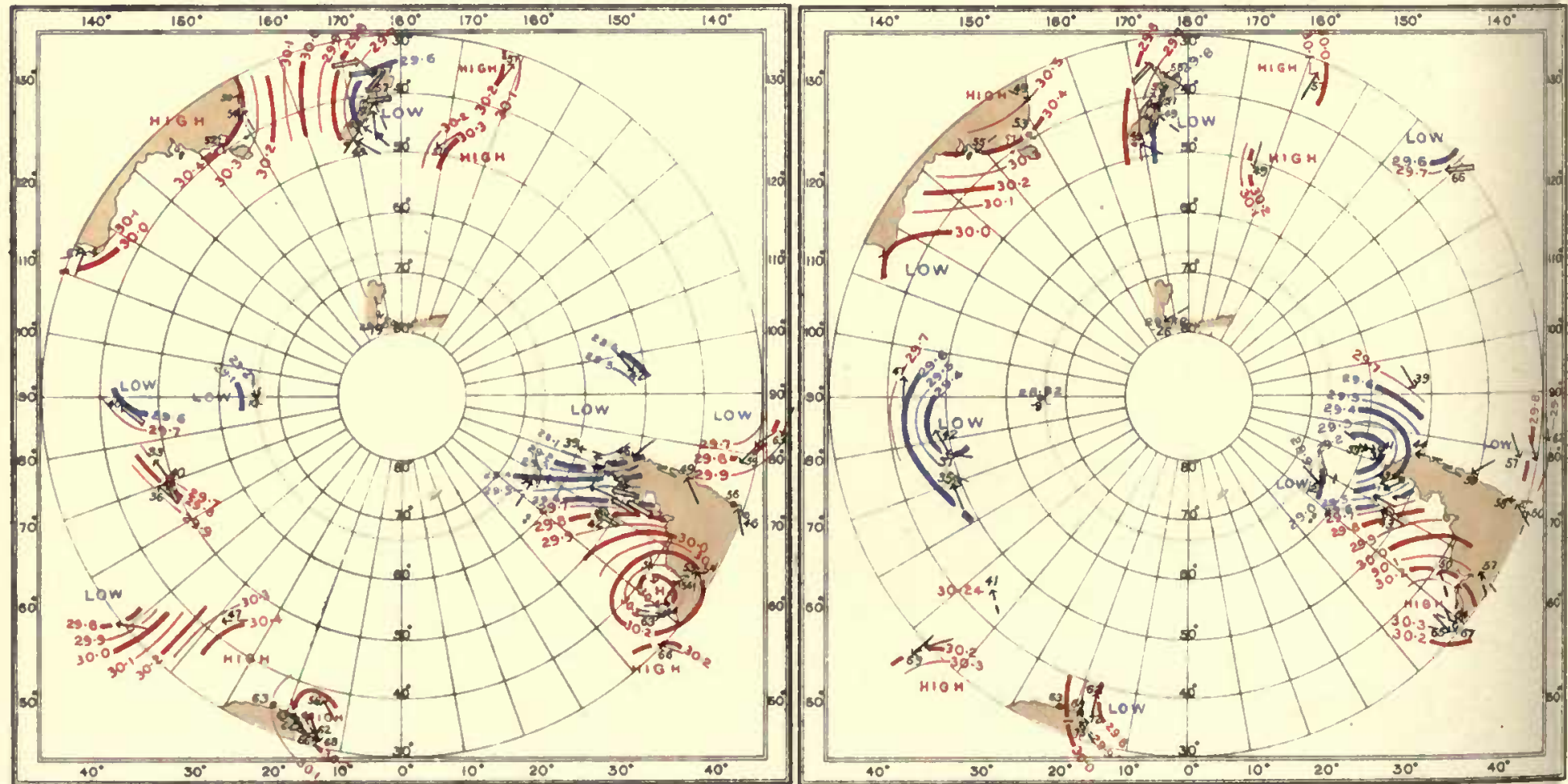
INTERNATIONAL ANTARCTIC CO-OPERATION

SYNCHRONOUS CHARTS OF SEA-LEVEL PRESSURE FOR NOON GMT

WITH WINDS AND AIR TEMPERATURES

JUNE

$26 \quad 1902$

JUNE
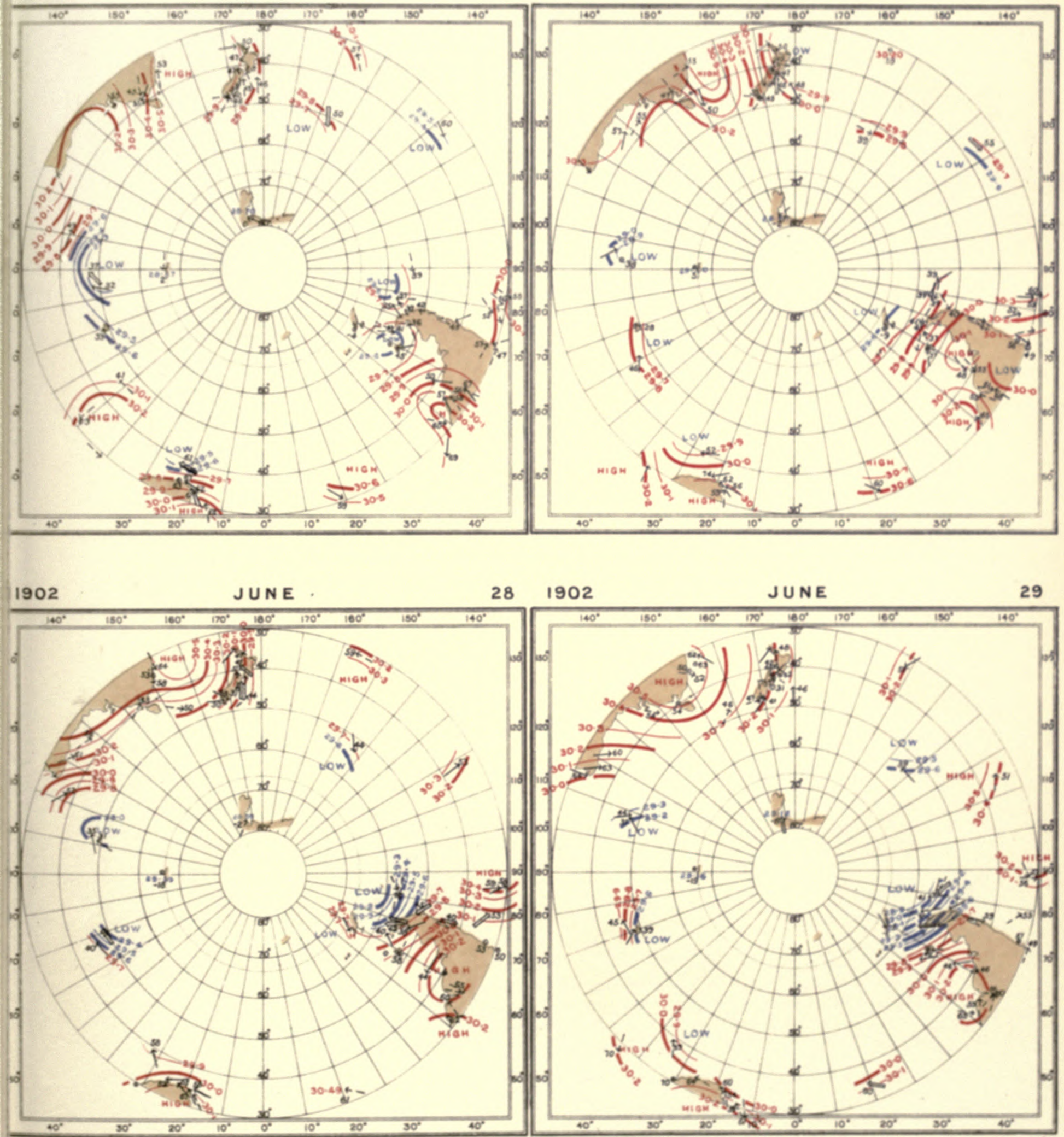


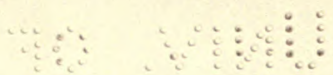

$\therefore-a_{0}$ 
\%

औ 
INTERNATIONAL ANTARCTIC CO-OPERATION.

SYNGHRONOUS CHARTS OF SEALEVEL PRESSURE FOR NOON G.M.T.

WITH WINDS AND AIR TEMPERATURES
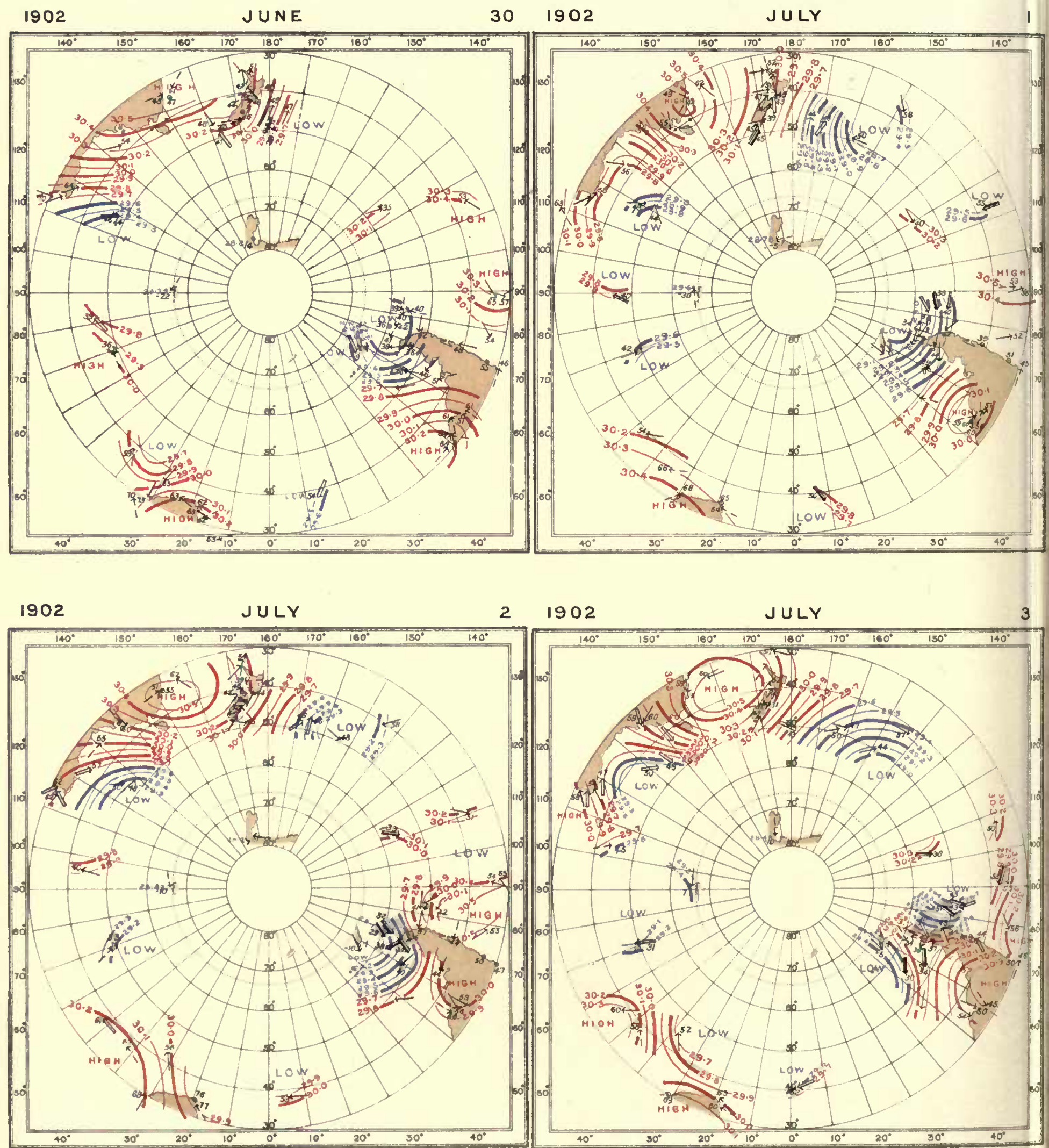
INTERNATIONAL ANTARCTIC CO-OPERATION

SYNCHRONOUS CHARTS OF SEA-LEVEL PRESSURE FOR NOON G.M.T

WITH WINDS AND AIR TEMPERATURES

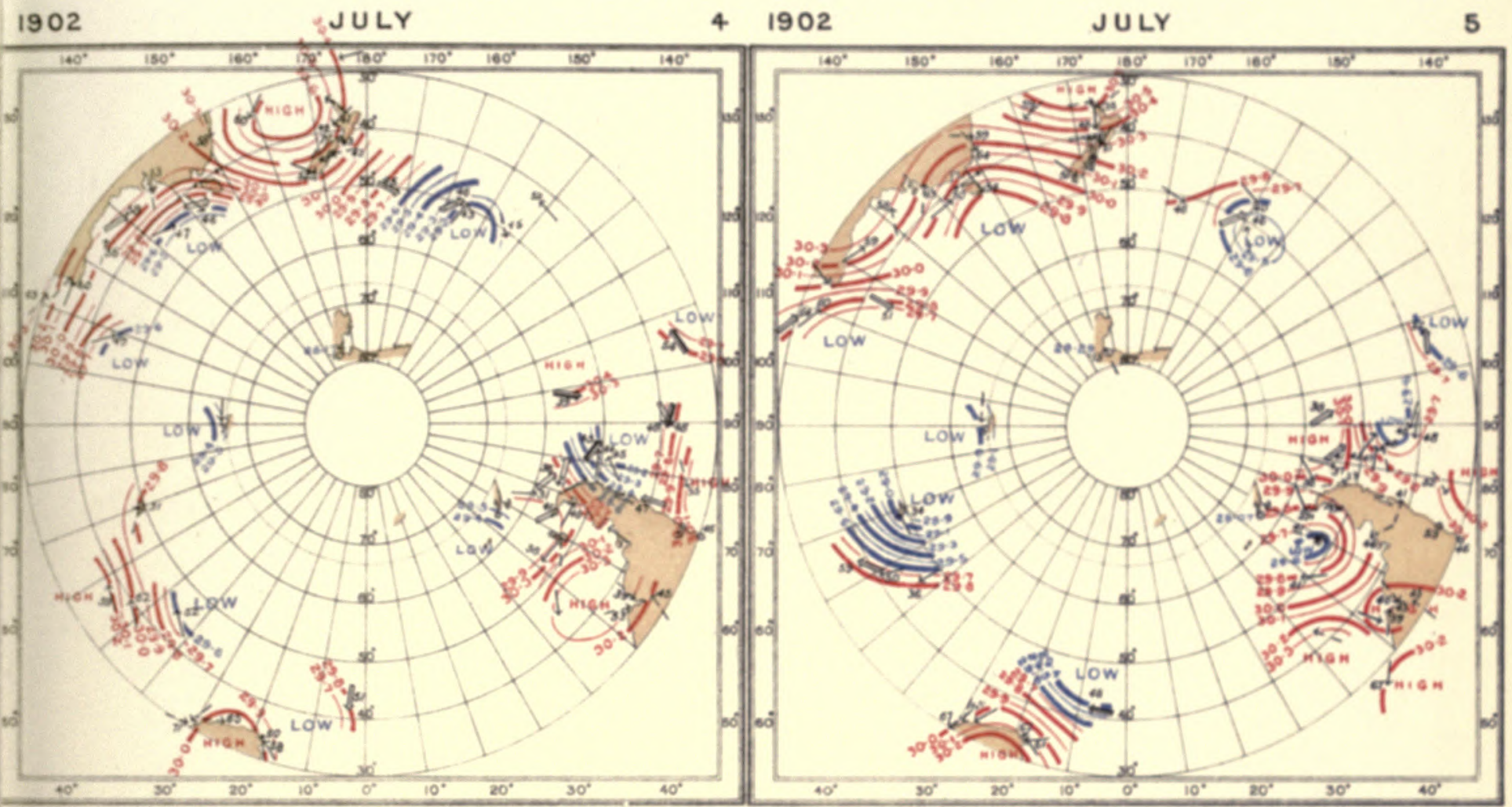

$6 \quad 1902$

JULY

7

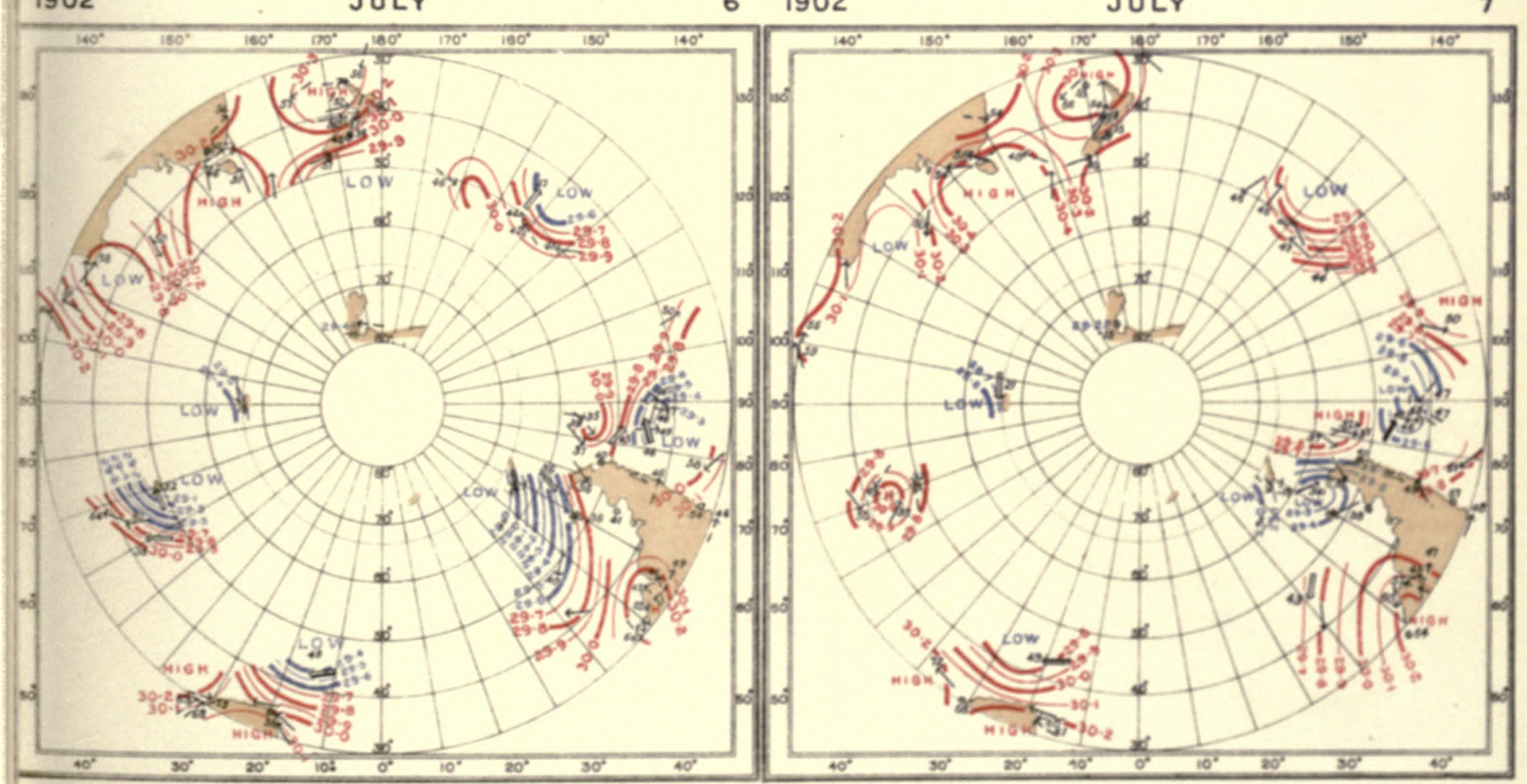


$\therefore=x_{0}$ 


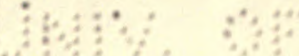

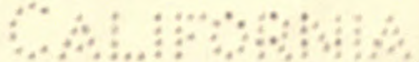




\section{INTERNATIONAL ANTARCTIC COOPERATION}

SYNCHRONOUS CHARTS OF SEA-LEVEL PRESSURE FOR NOON G.MT WITH WINDS AND AIR TEMPERATURES.
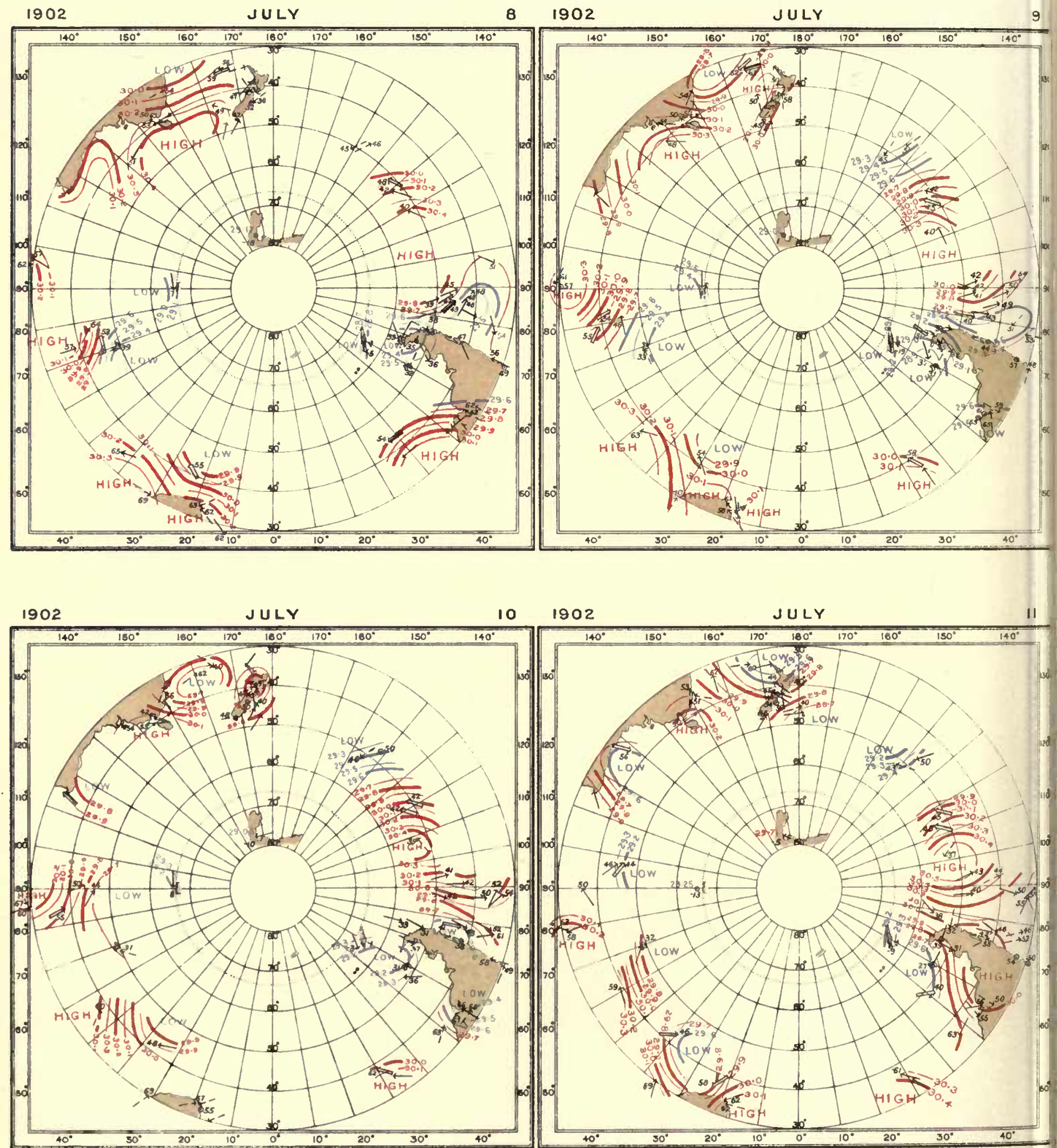
$\vdots:$\begin{tabular}{l:l}
$\vdots$ \\
\hdashline
\end{tabular}

INTERNATIONAL ANTARCTIC COOPERATION,

SYNCHRONOUS CHARTS OF SEA-LEVEL PRESSURE FOR NOON G.M.T

WITH WINDS AND AIR TEMPERATURES
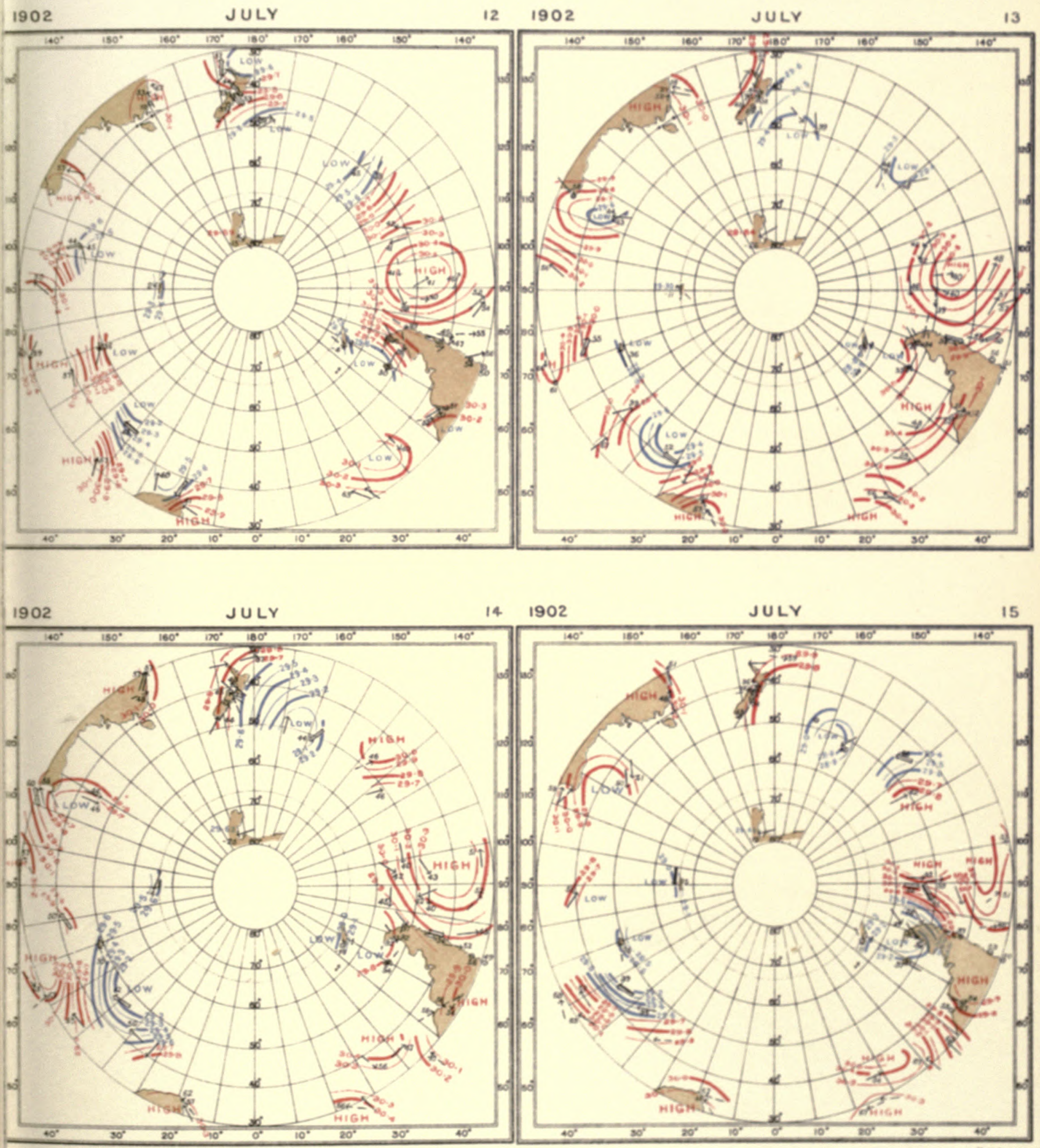


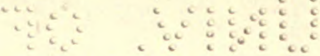

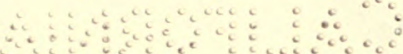


!)

औ 
INTERNATIONAL ANTARCTIC CO-OPERATION.

SYNCHRONOUS CHARTS OF SEA-LEVEL PRESSURE FOR NOON G.M.T

WITH WINDS AND AIR TEMPERATURES

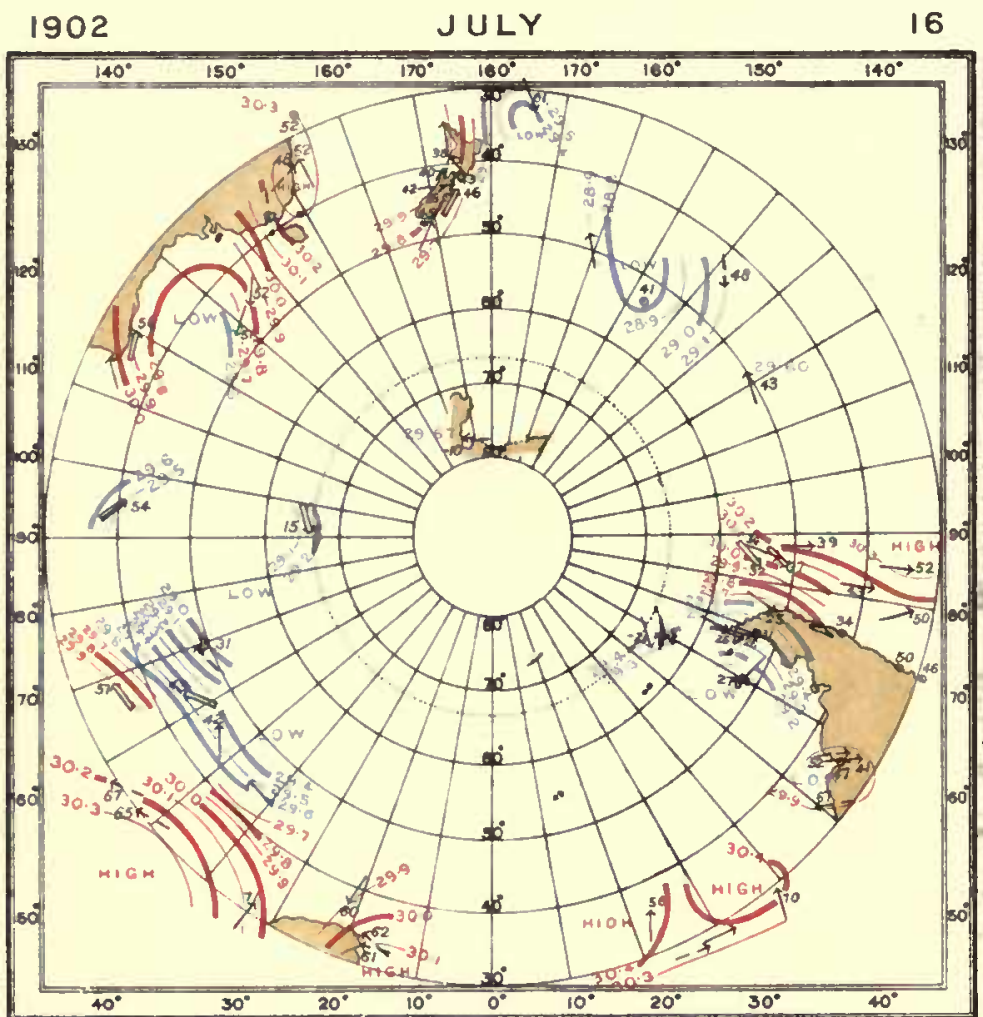

1902 JULY

17
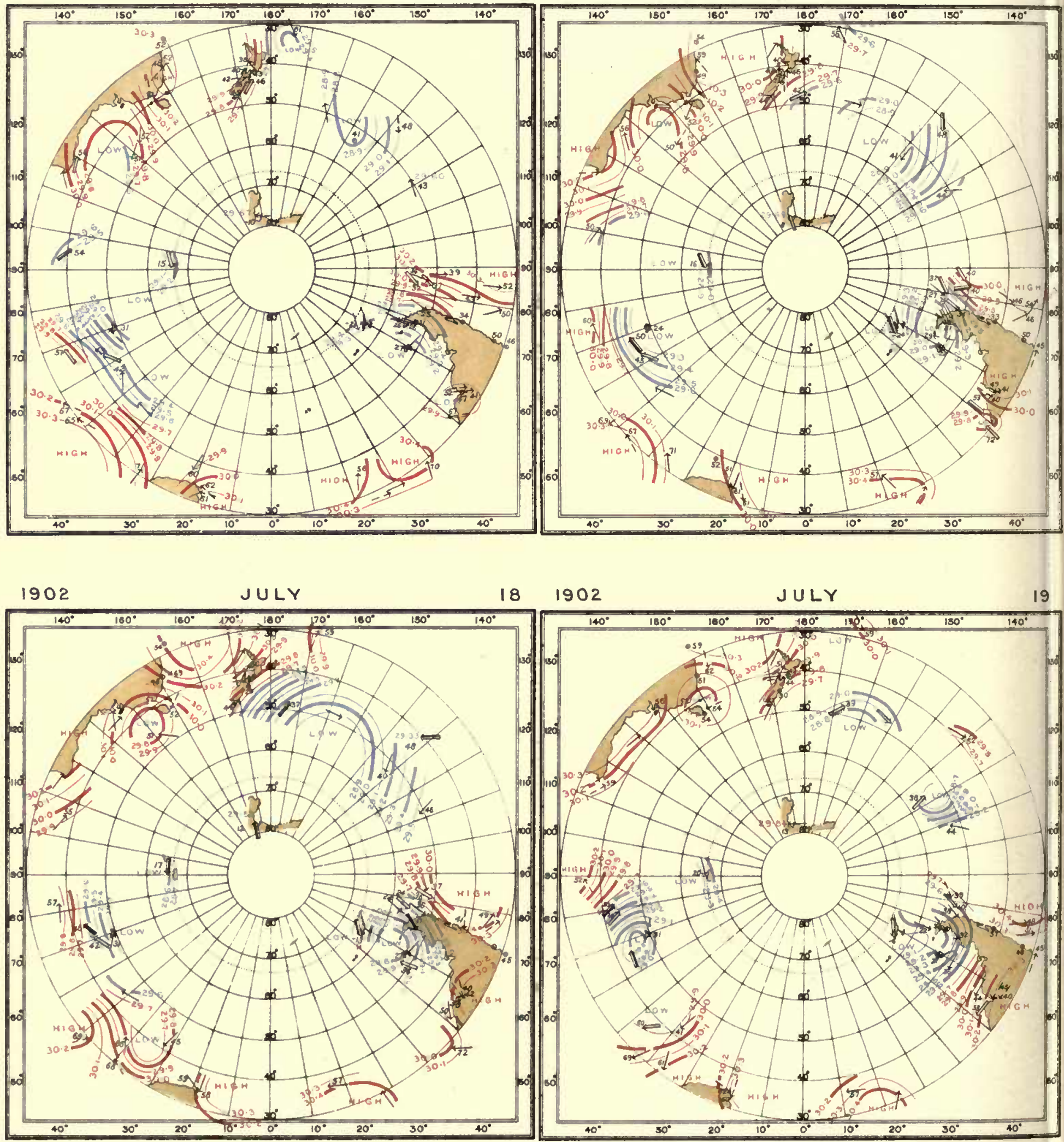
INTERNATIONAL ANTARCTIC COOPERATION

SYNCHRONOUS CHARTS OF SEALEVEL PRESSURE FOR NOON GMT

WITH WINDS AND AIR TEMPERATURES
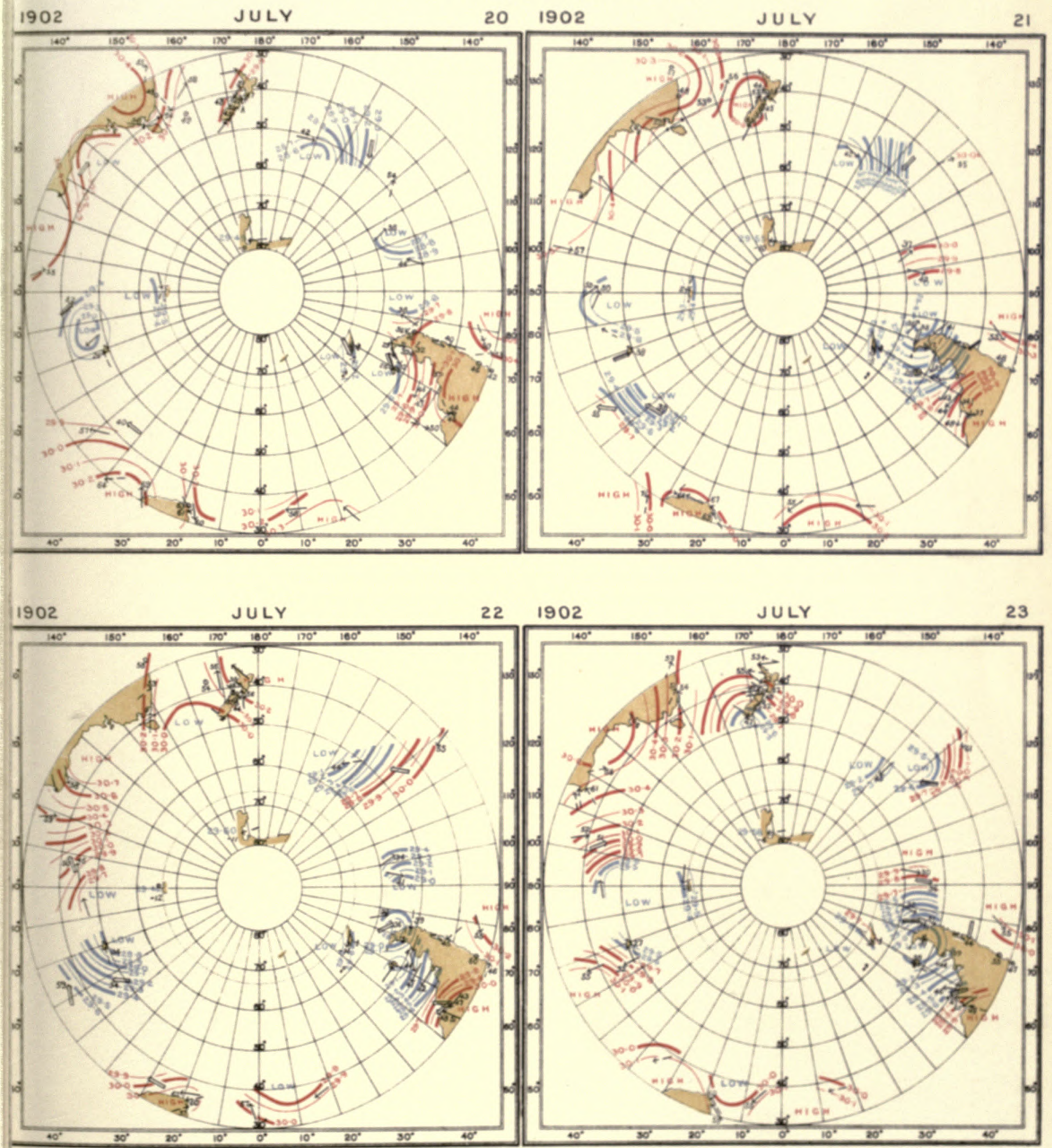
$\therefore y$ 
$1 \%$

a 
INTERNATIONAL ANTARCTIC CO-OPERATION.

SYNCHRONOUS CHARTS OF SEA-LEVEL PRESSURE FOR NOON G.M.T

WITH WINDS ANO AIR TEMPERATURES
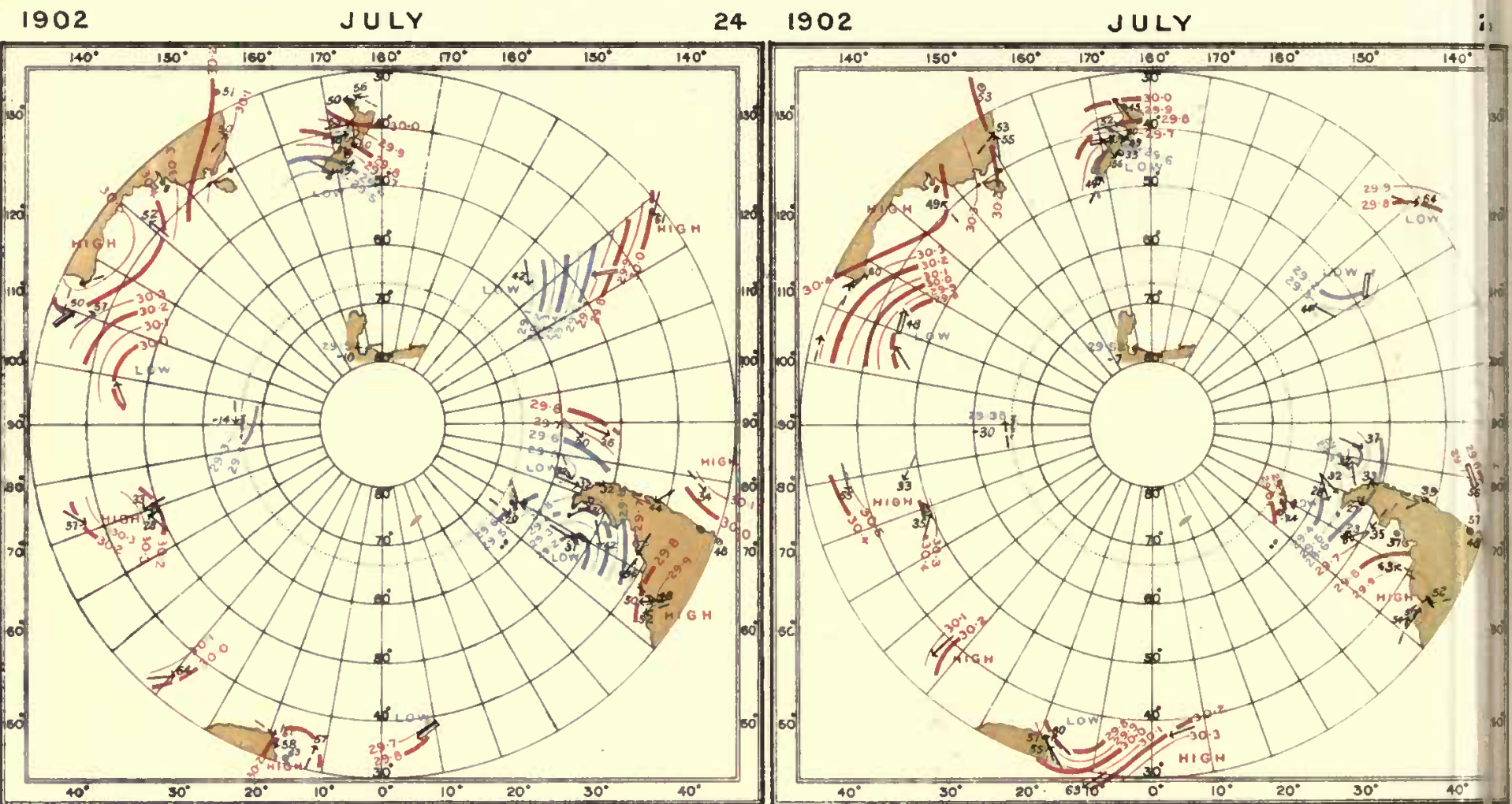

JULY

$26 \quad 1902$

JULY
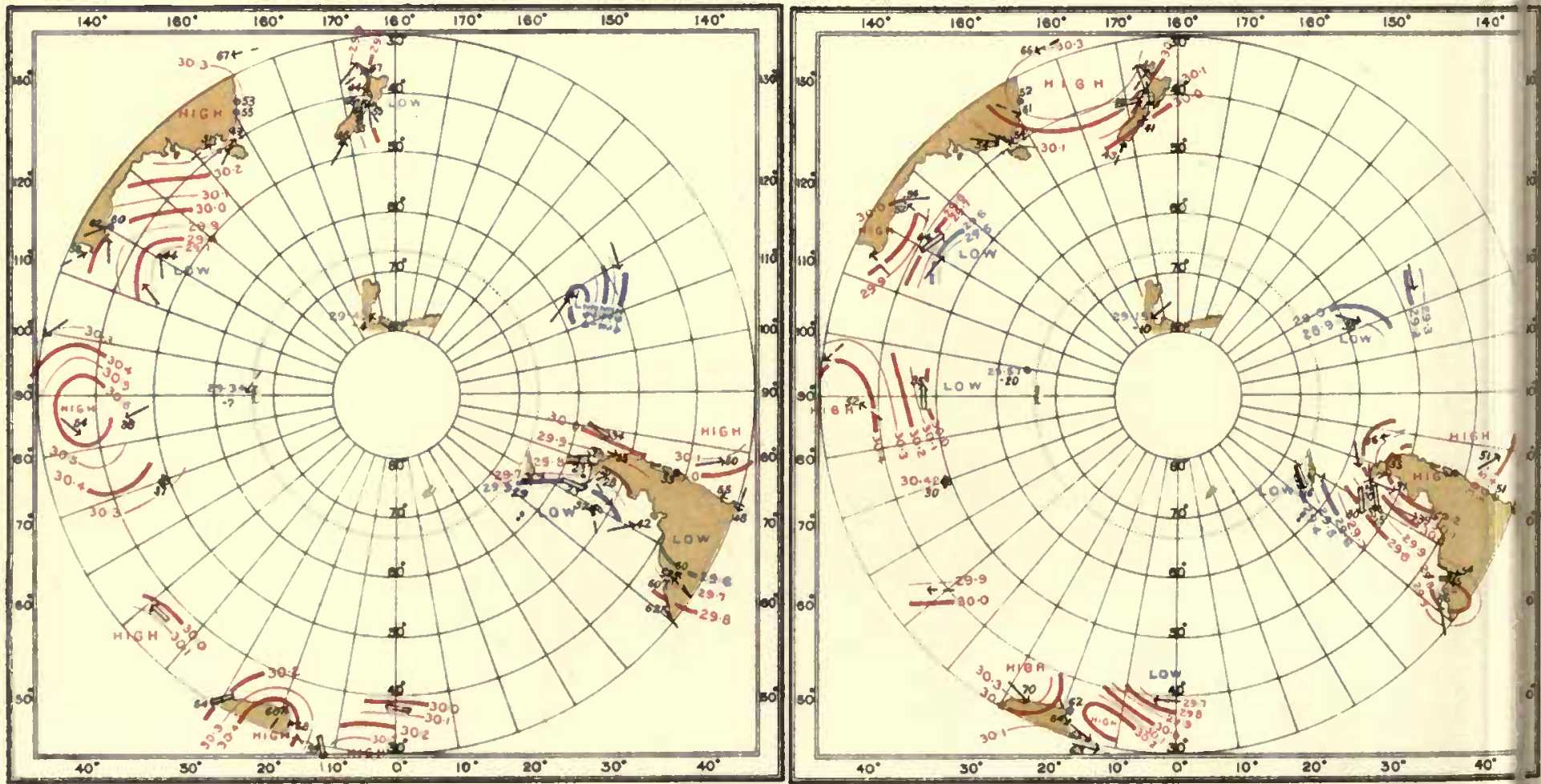
INTERNATIONAL ANTARCTIC CO-OPERATION

SYNCHRONOUS CHARTS OF SEALEVEL PRESSURE FOR NOON GMT

WITH WINDS AND AIR TEMPERATURES.

1902

JULY

$28 \quad 1902$

JULY

29

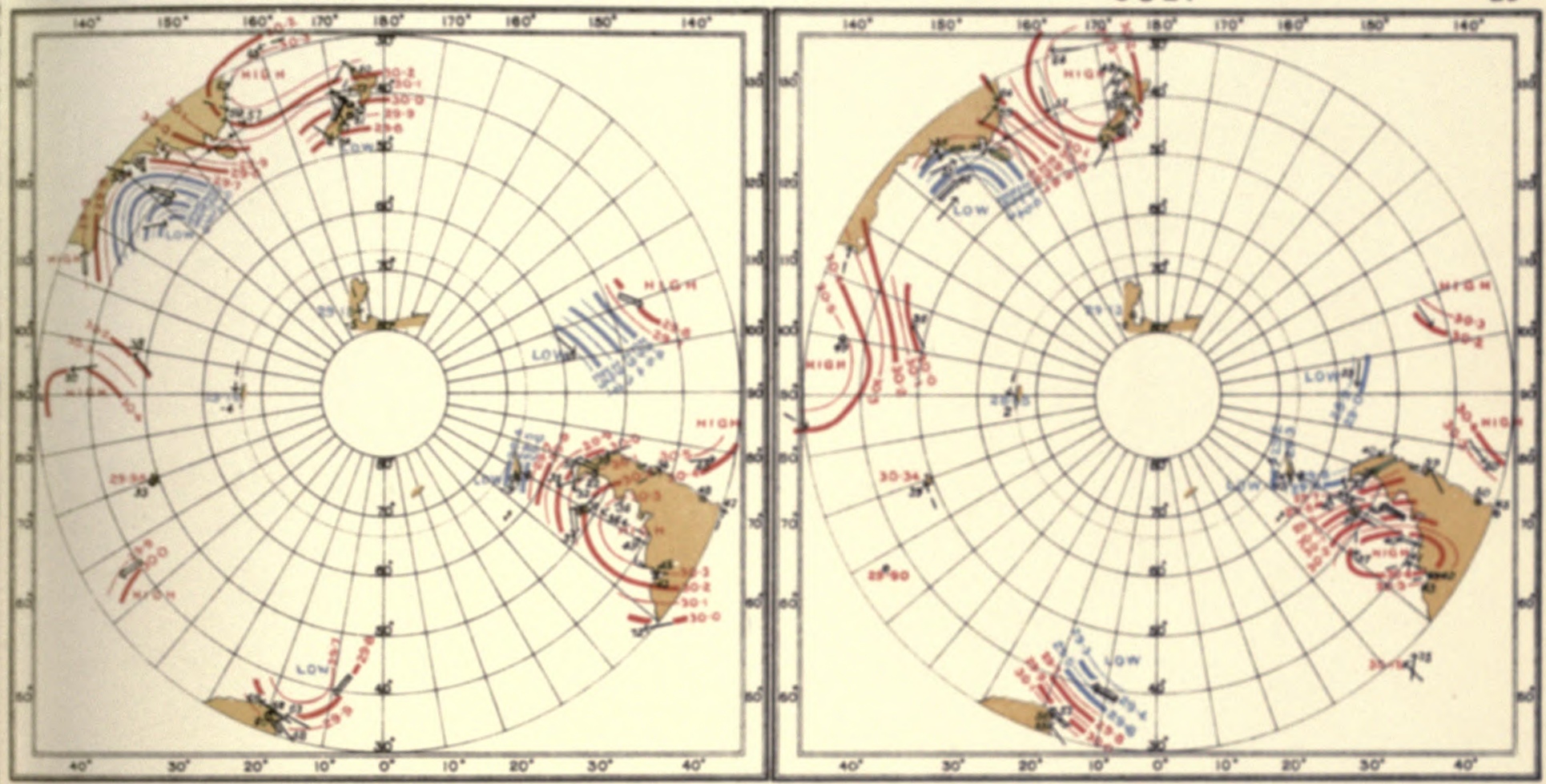

1902

JULY

$30 \quad 1902 \quad$ JULY

31

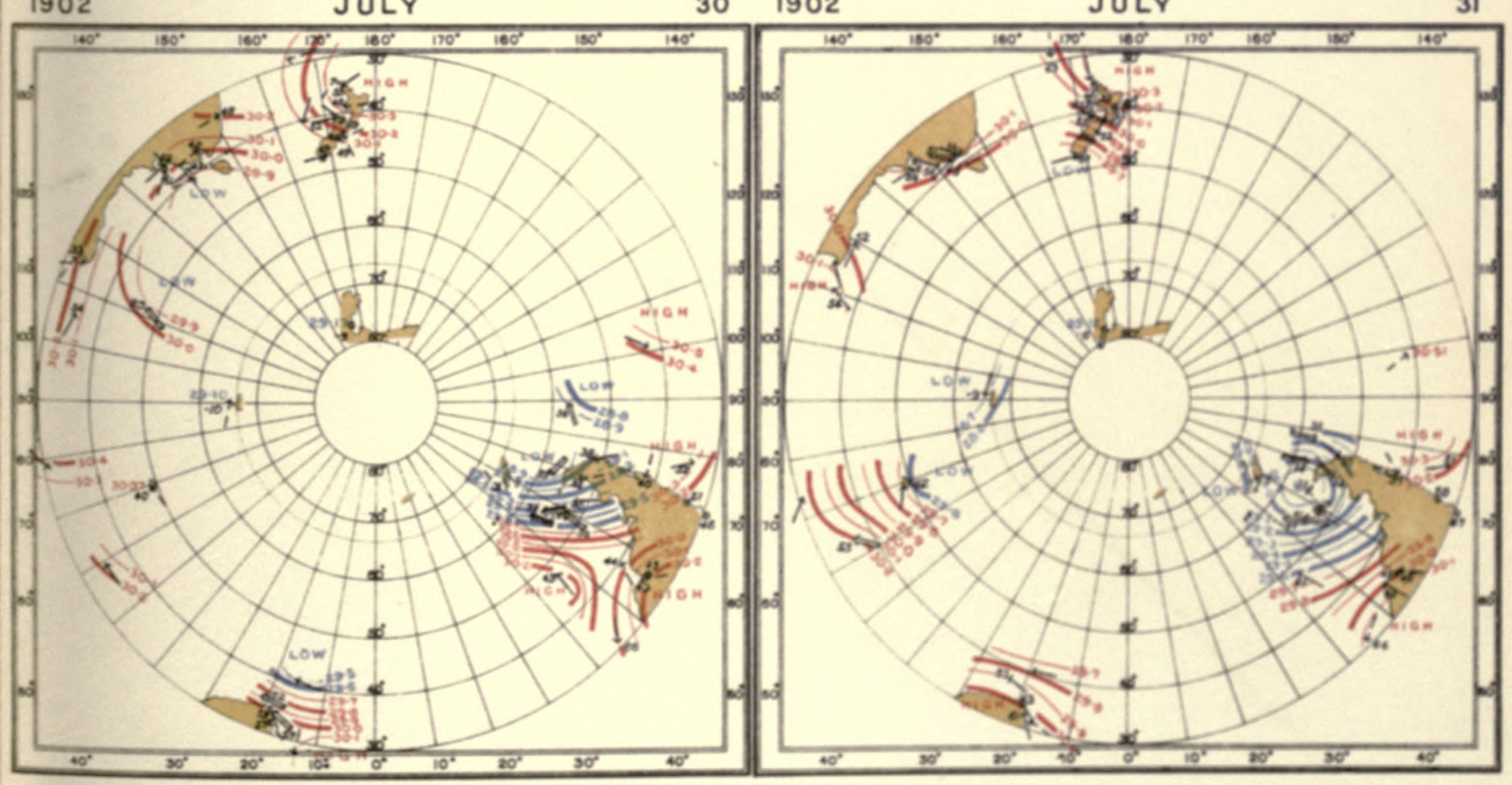


$\because \div \quad \because \vdots 3 \vdots$

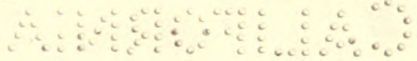


1)

a 
INTERNATIONAL ANTARGTIC CO-OPERATION.

SYNCHRONOUS CHARTS OF SEA-LEVEL PRESSURE FOR NOON G.M.T WITH WINDS AND AIR TEMPERATURES

1902

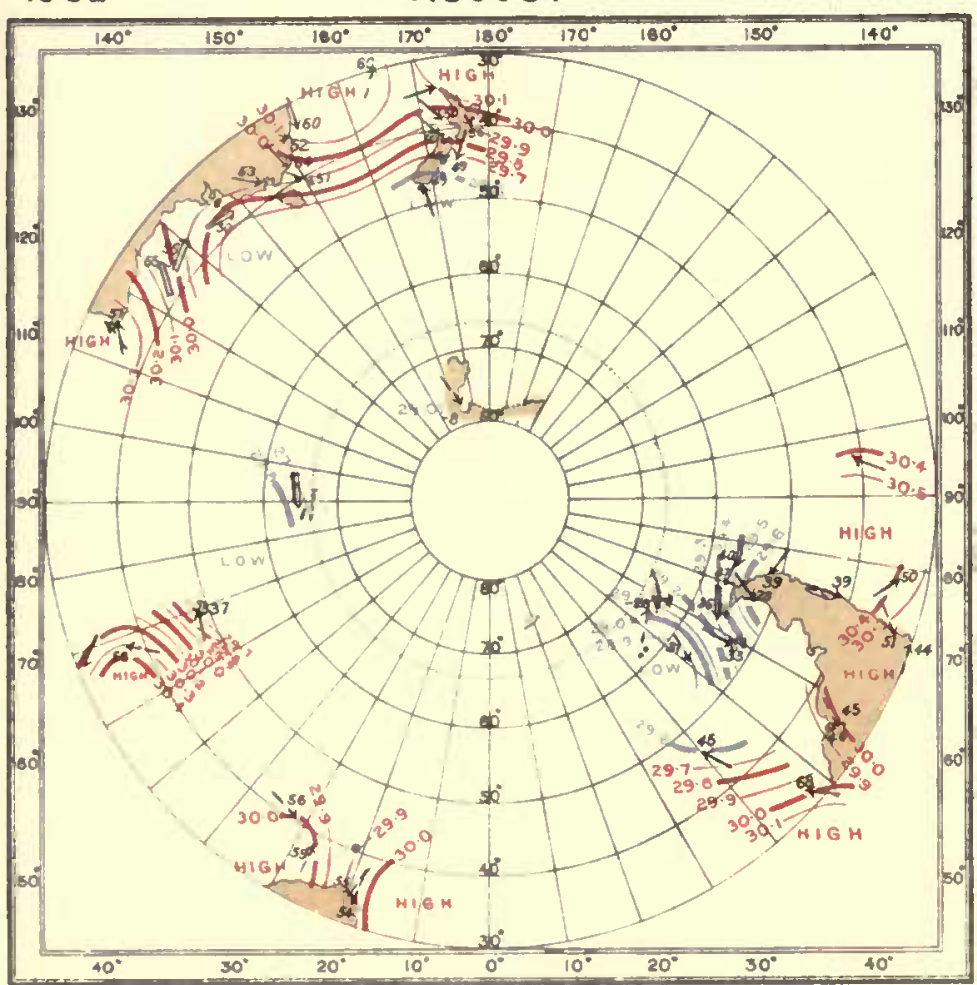

A U G UST

2

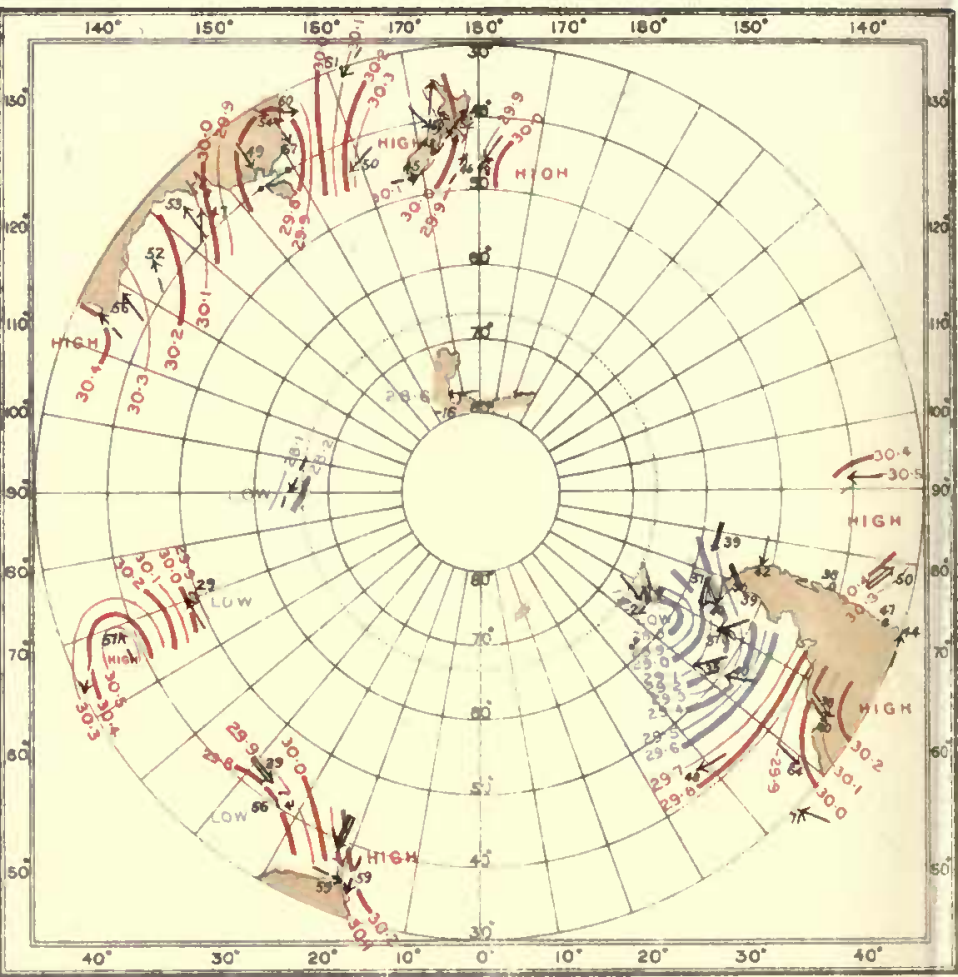

1902

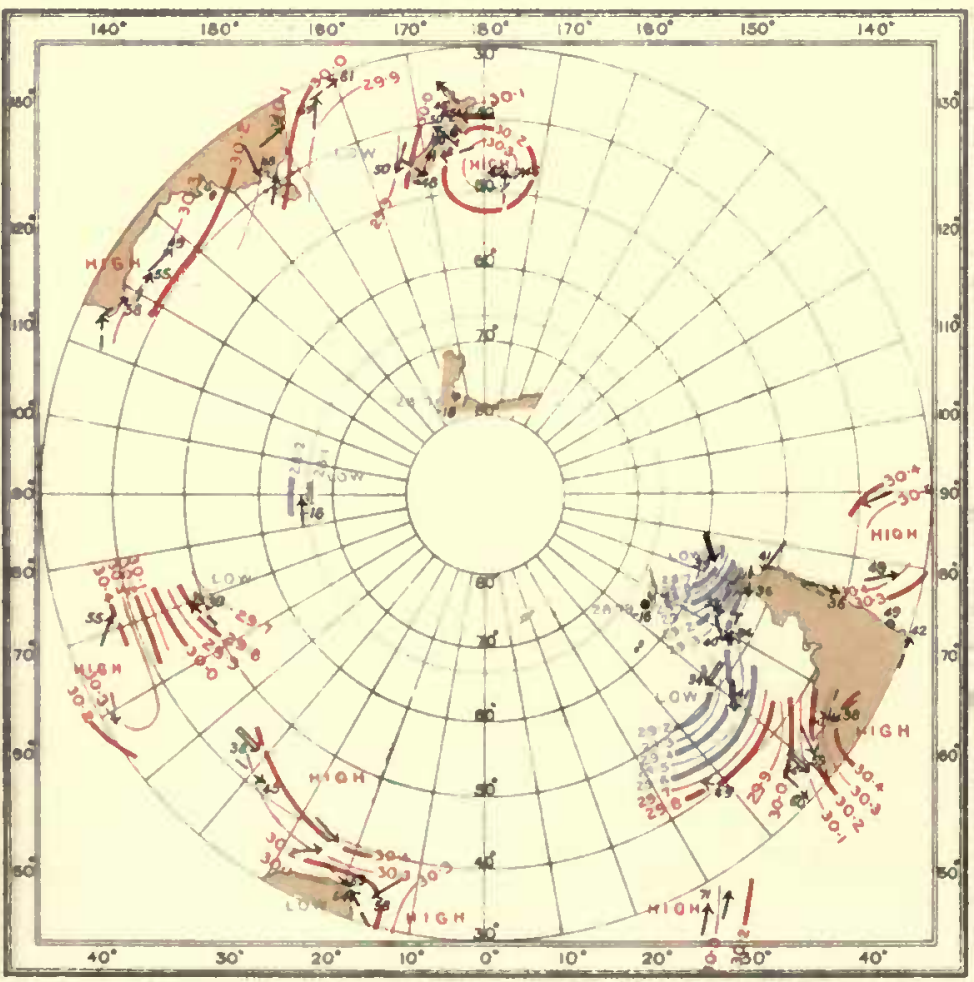

AUGUST

4

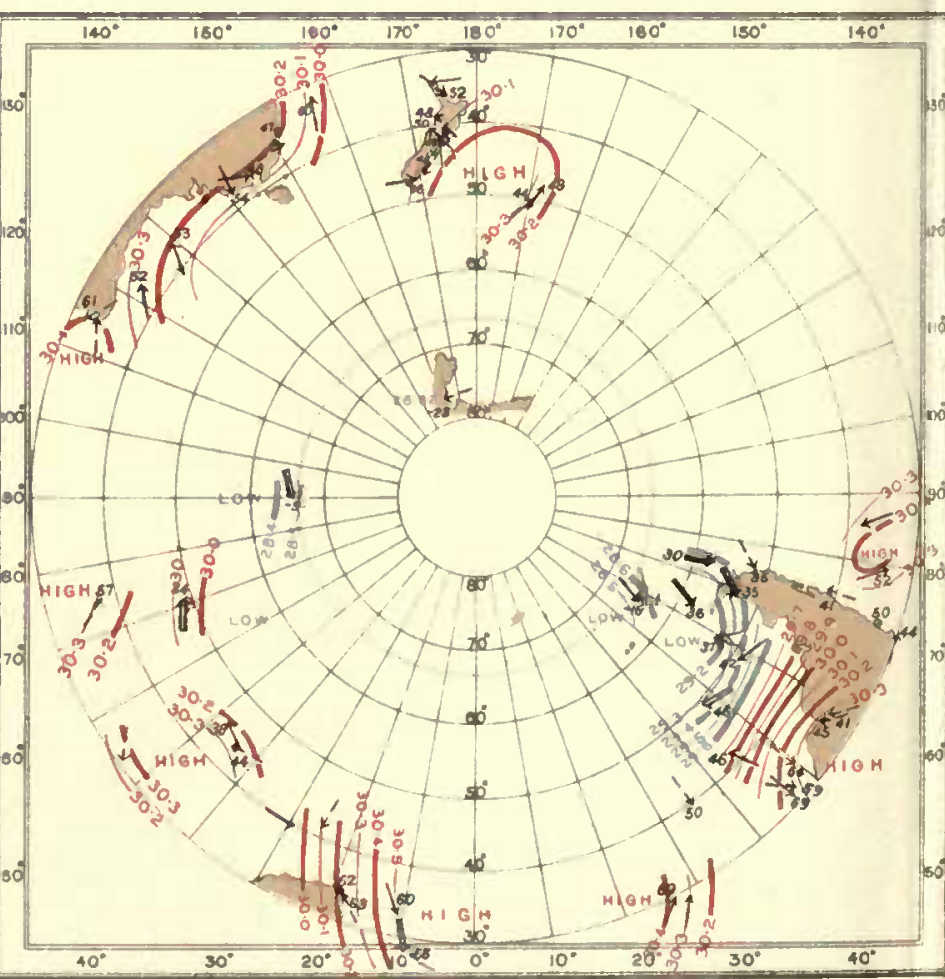


INTERNATIONAL ANTARCTIC CO-OPERATION.

SYNCHRONOUS CHARTS OF SEALLEVEL PRESSURE FOR NOON GMT

WITH WINDS AND AIR TEMPERATURES

1902

A U G U T

$5 \quad 1902$

AUGUST

6
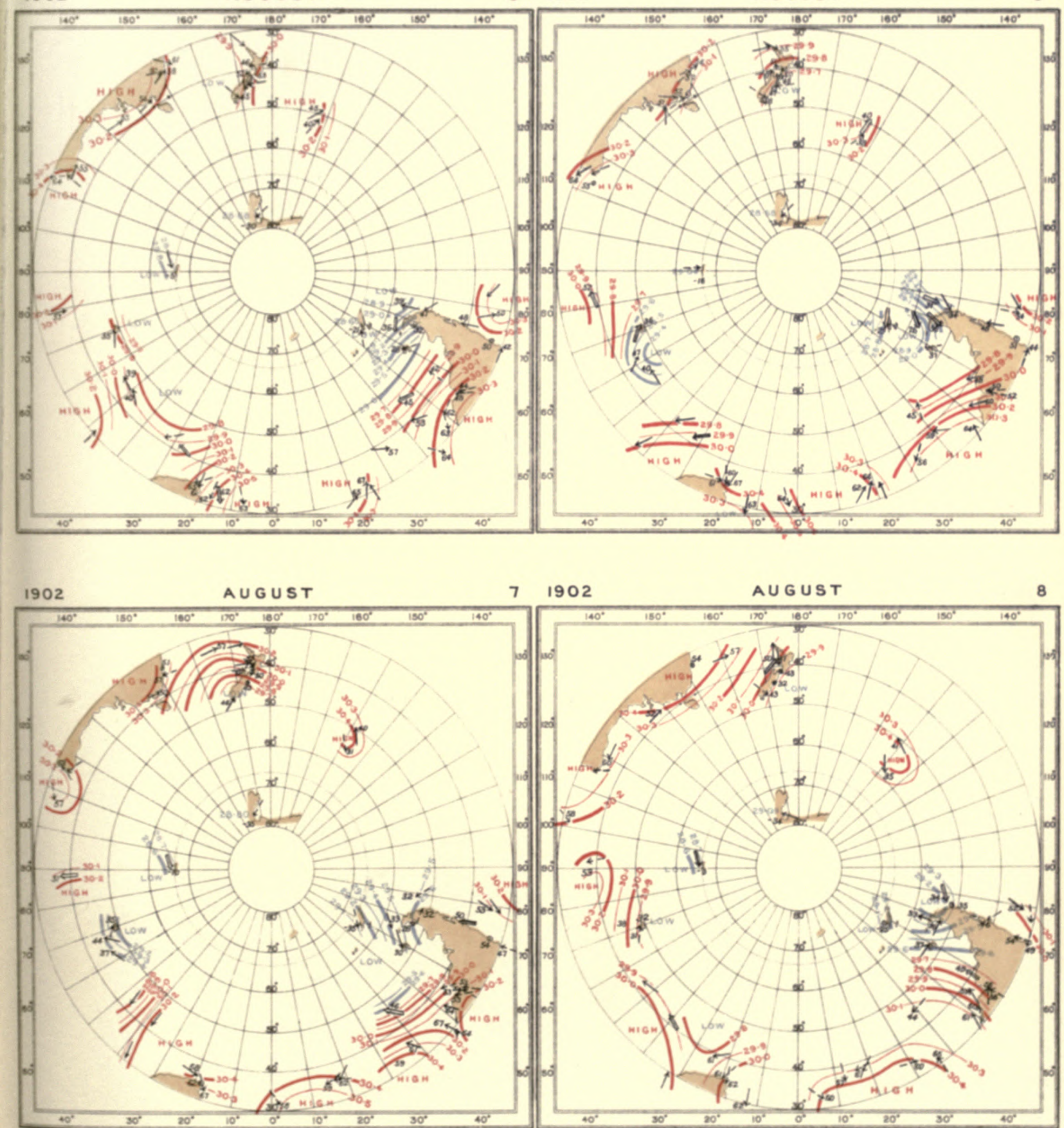

$\because 4 \quad y=$

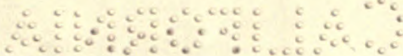




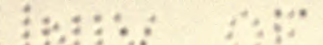

6 
INTERNATIONAL ANTARCTIC CO-OPERATION.

SYNCHRONOUS CHARTS OF SEALEVEL PRESSURE FOR NOON G.M.T

WITH WINDS AND AIR TEMPERATURES.
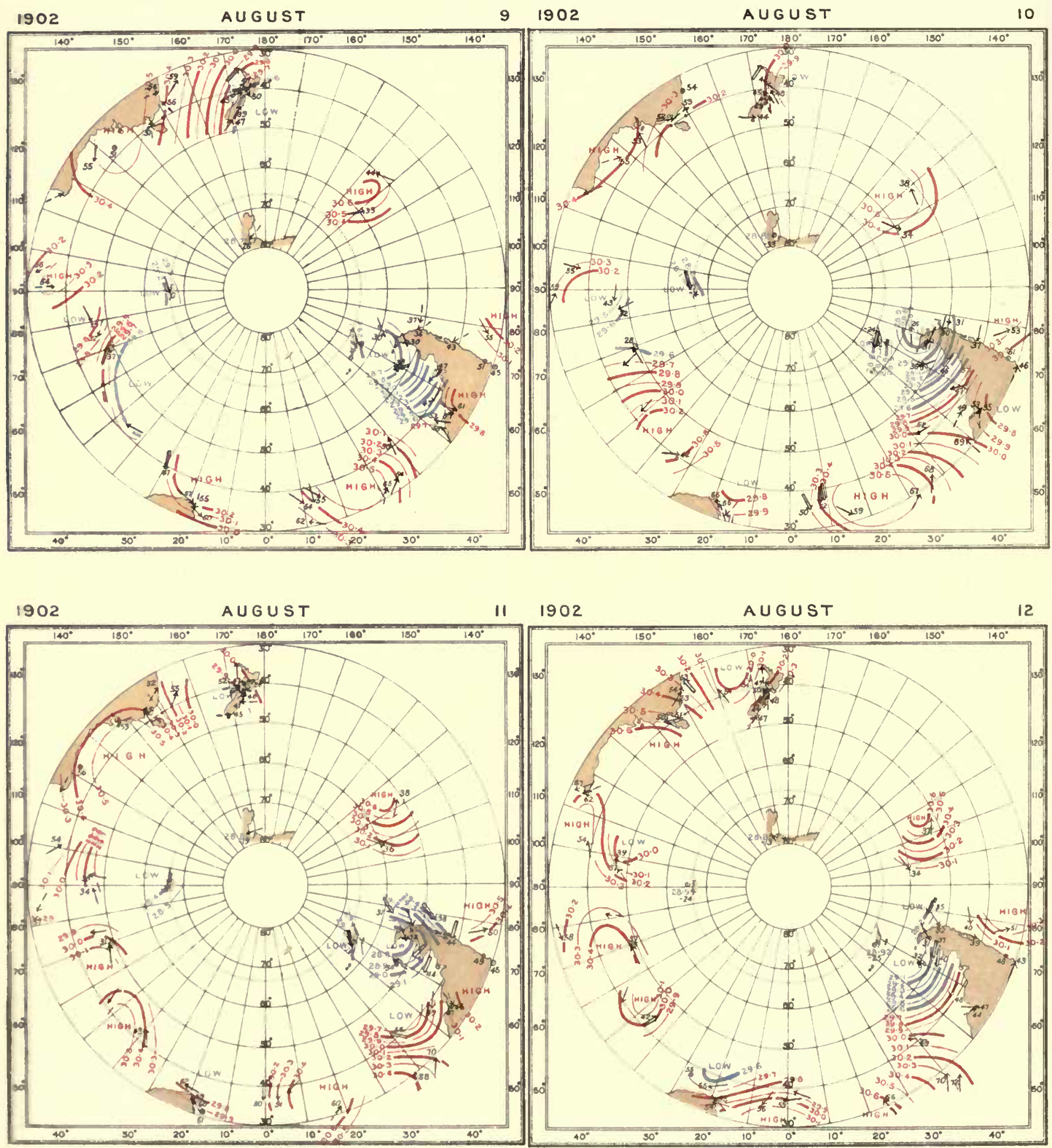

1902 AUGUST

12

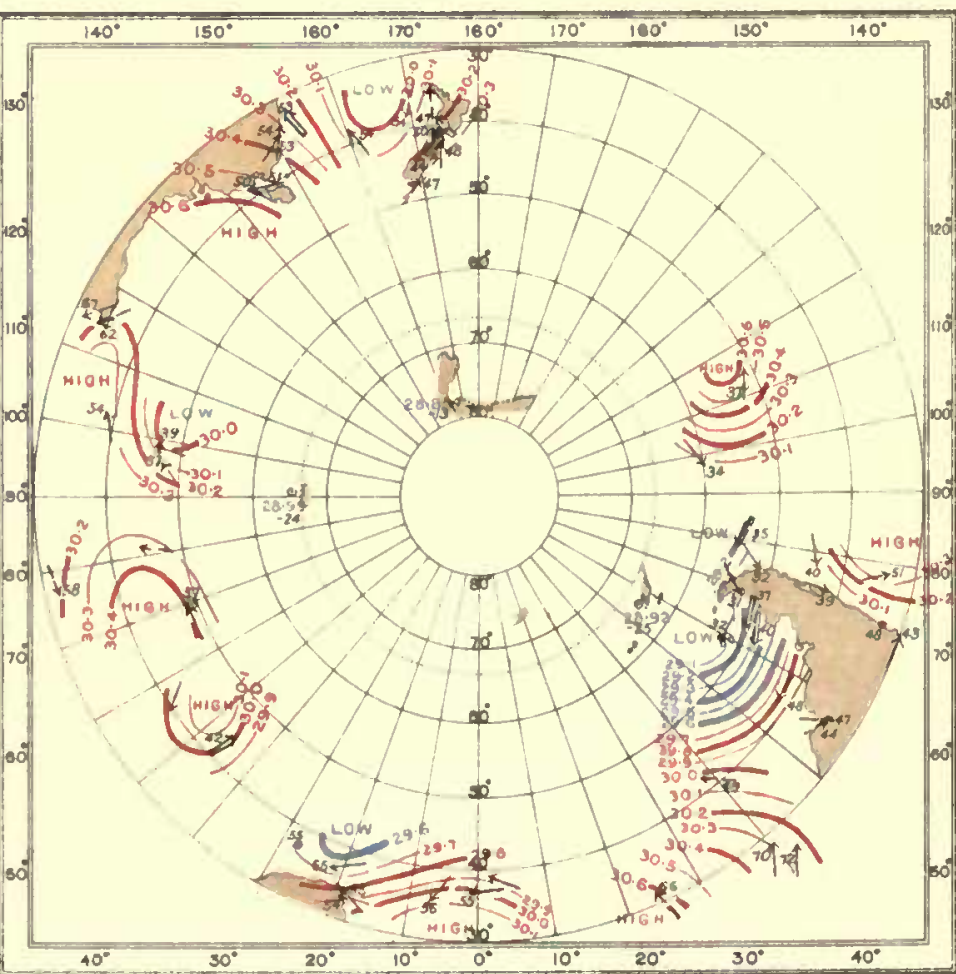


INTERNATIONAL ANTARCTIC CO-OPERATION.

SYNCHRONOUS CHARTS OF SEALEYVEL PRESSURE FOR NOON GM.T

WITH WINDS AND AIR TEMPERATURES.

1902

A U G UST

$13 \quad 1902$

A U G U ST

14
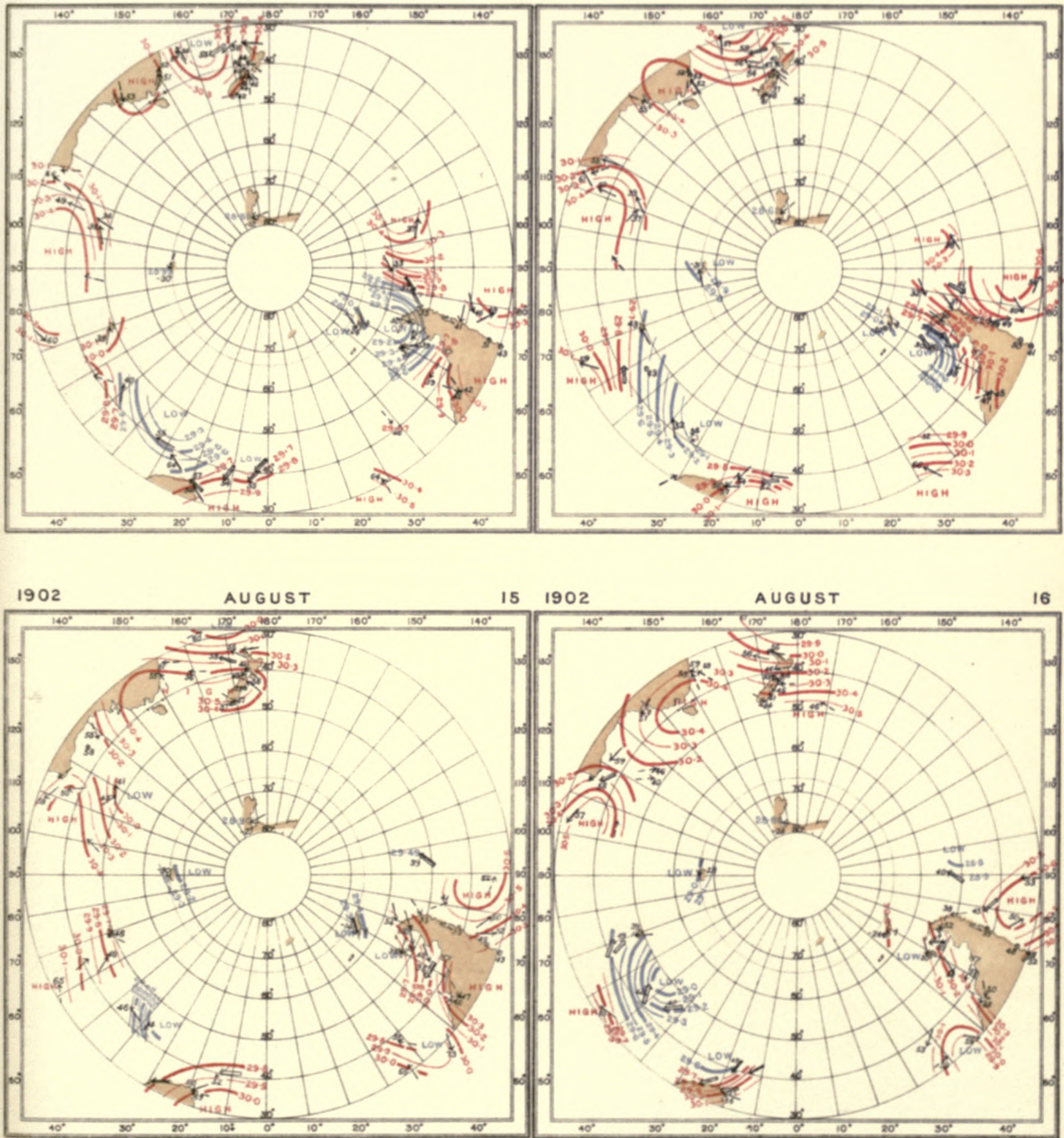
a 
a 
INTERNATIONAL ANTARCTIC CO-OPERATION.

SYNCHRONOUS CHARTS OF SEALLVEL PRESSURE FOR NOON G.M.T

WITH WINDS AND AIR TEMPERATURES
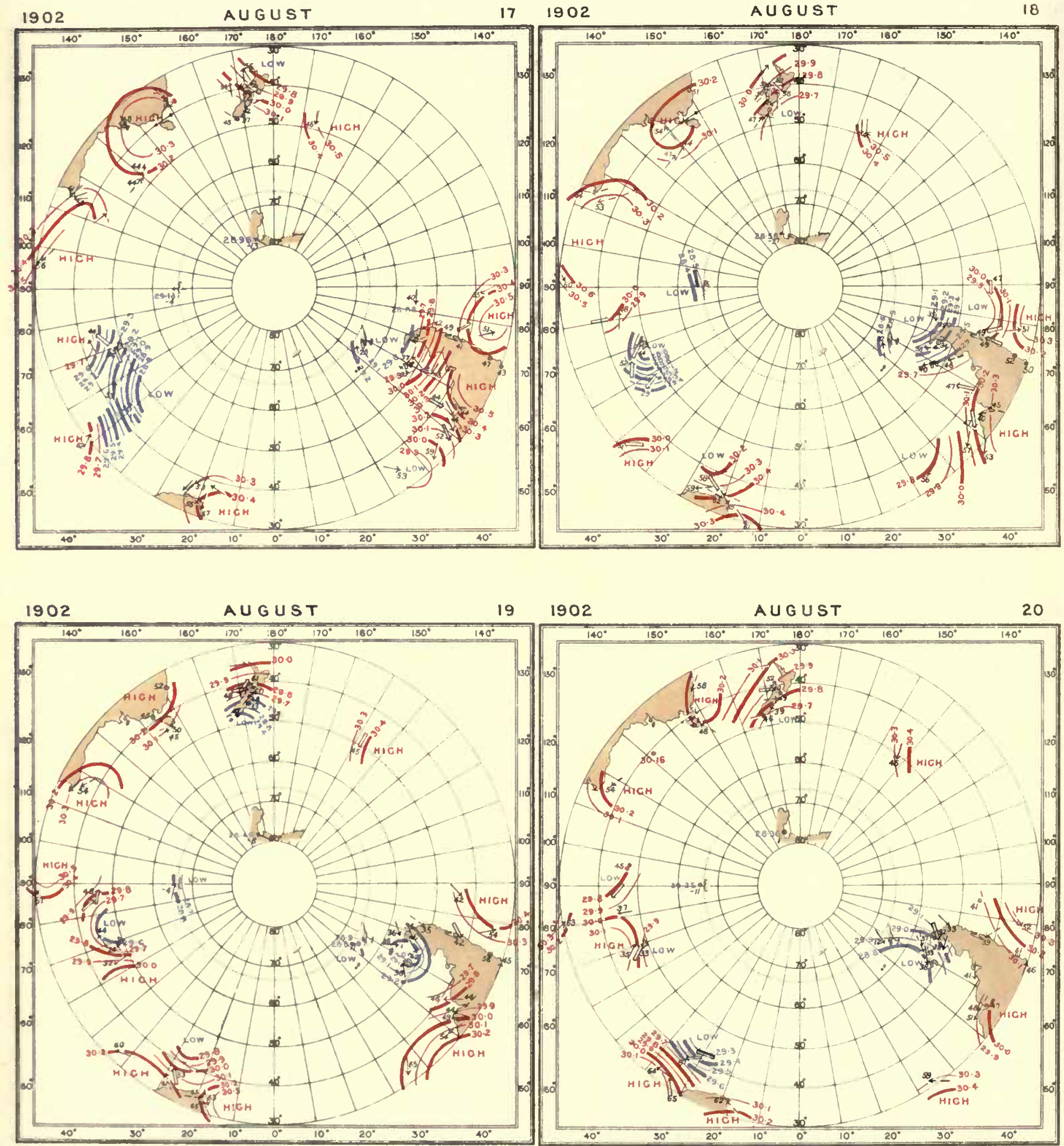
INTERNATIONAL ANTARCTIC CO-OPERATION.

SYNCHRONOUS CHARTS OF SEA-EEVEL PRESSURE FOR NOON GMT

WITH WINDS AND AIR TEMPERATURES

1902

$A \cup G U S T$

$21 \quad 1902$

AUGUST

22

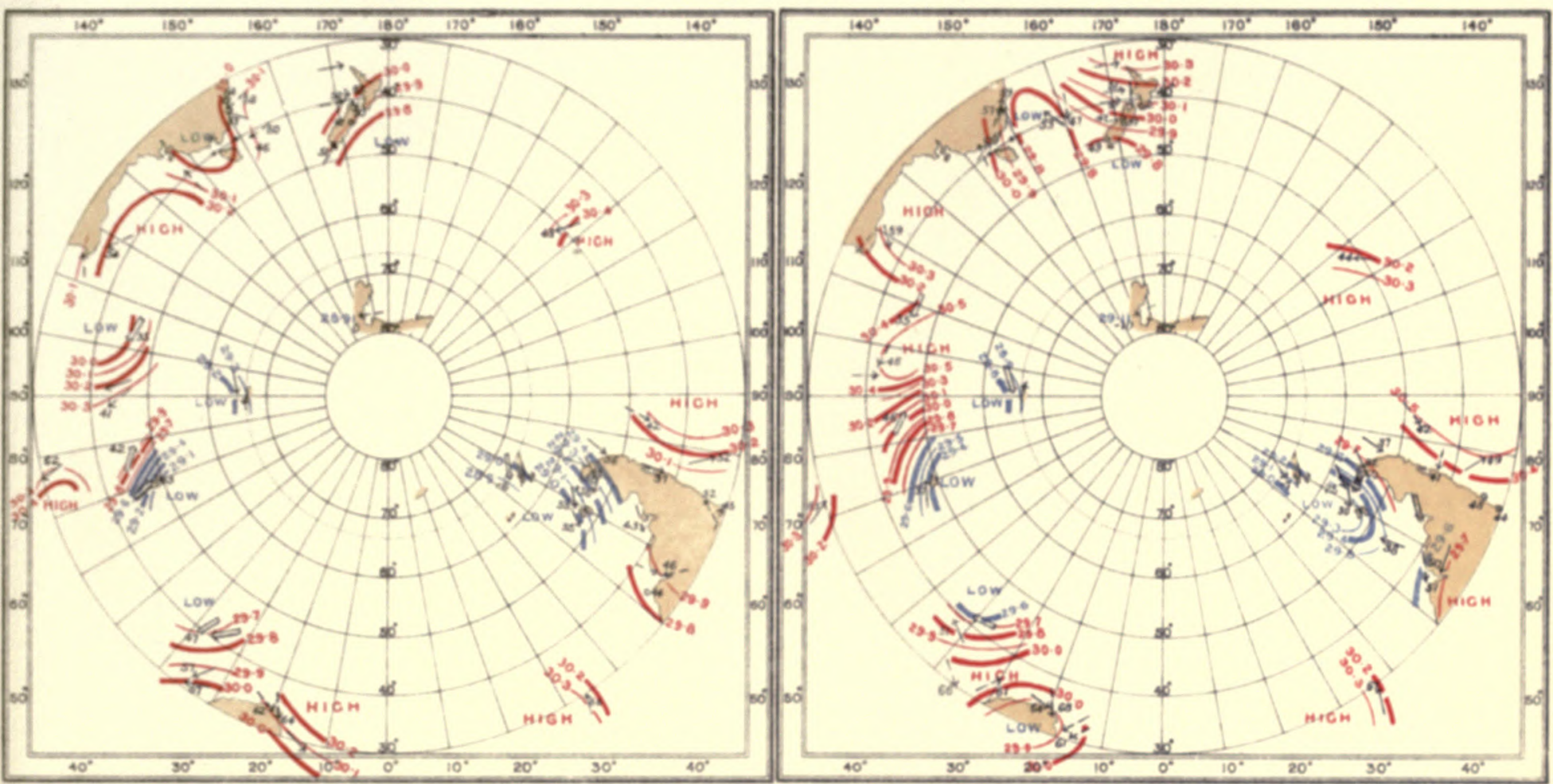

1902

A U G U ST

$23 \quad 1902$

AUGUST

24

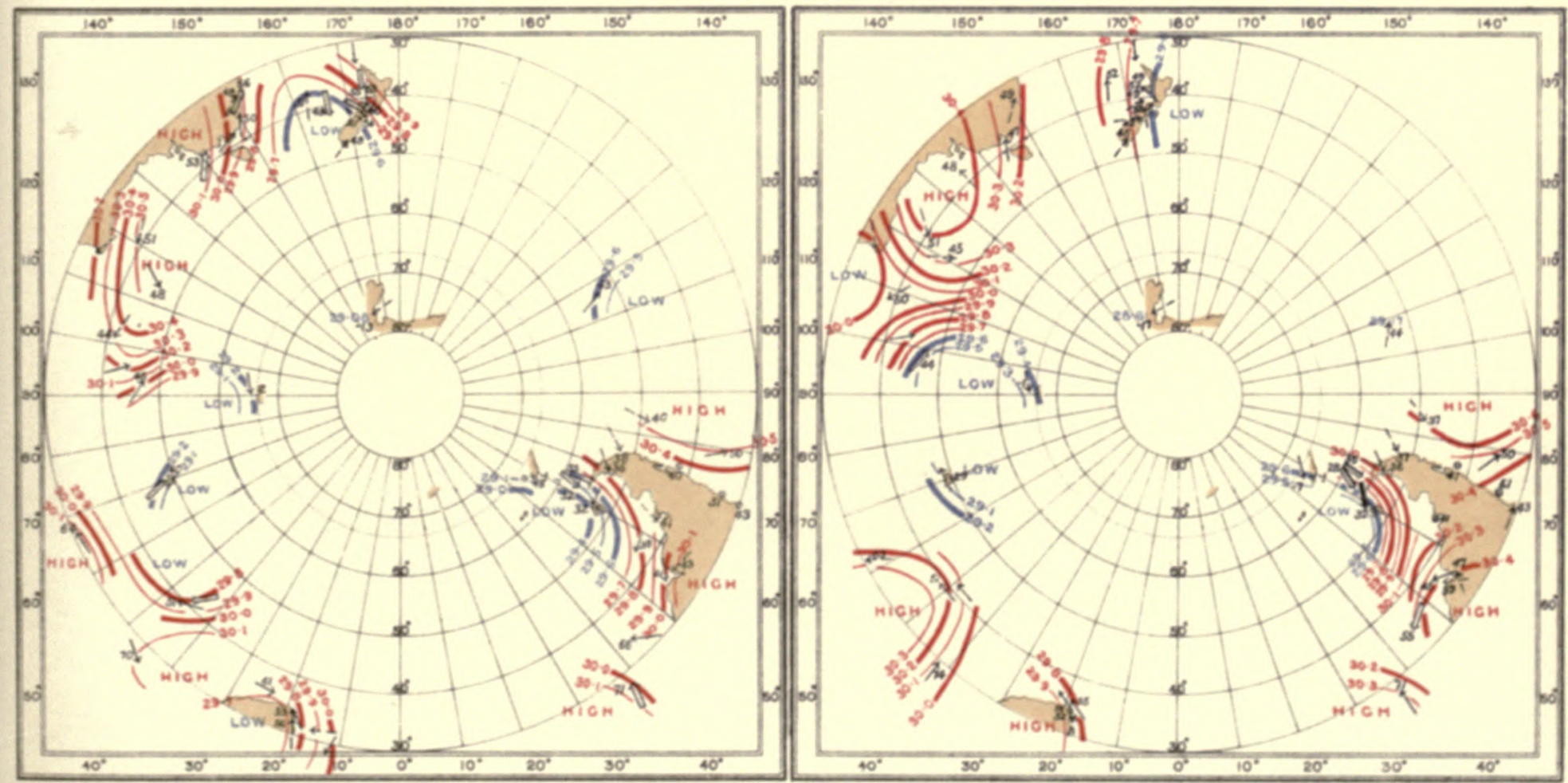




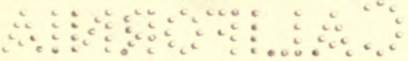


*

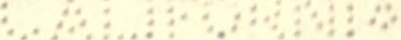


INTERNATIONAL ANTARCTIC CO-OPERATION.

SYNCHRONOUS CHARTS OF SEA-LEVEL PRESSURE FOR NOON G.M.T

WITH WINOS AND AIR TEMPERATURES

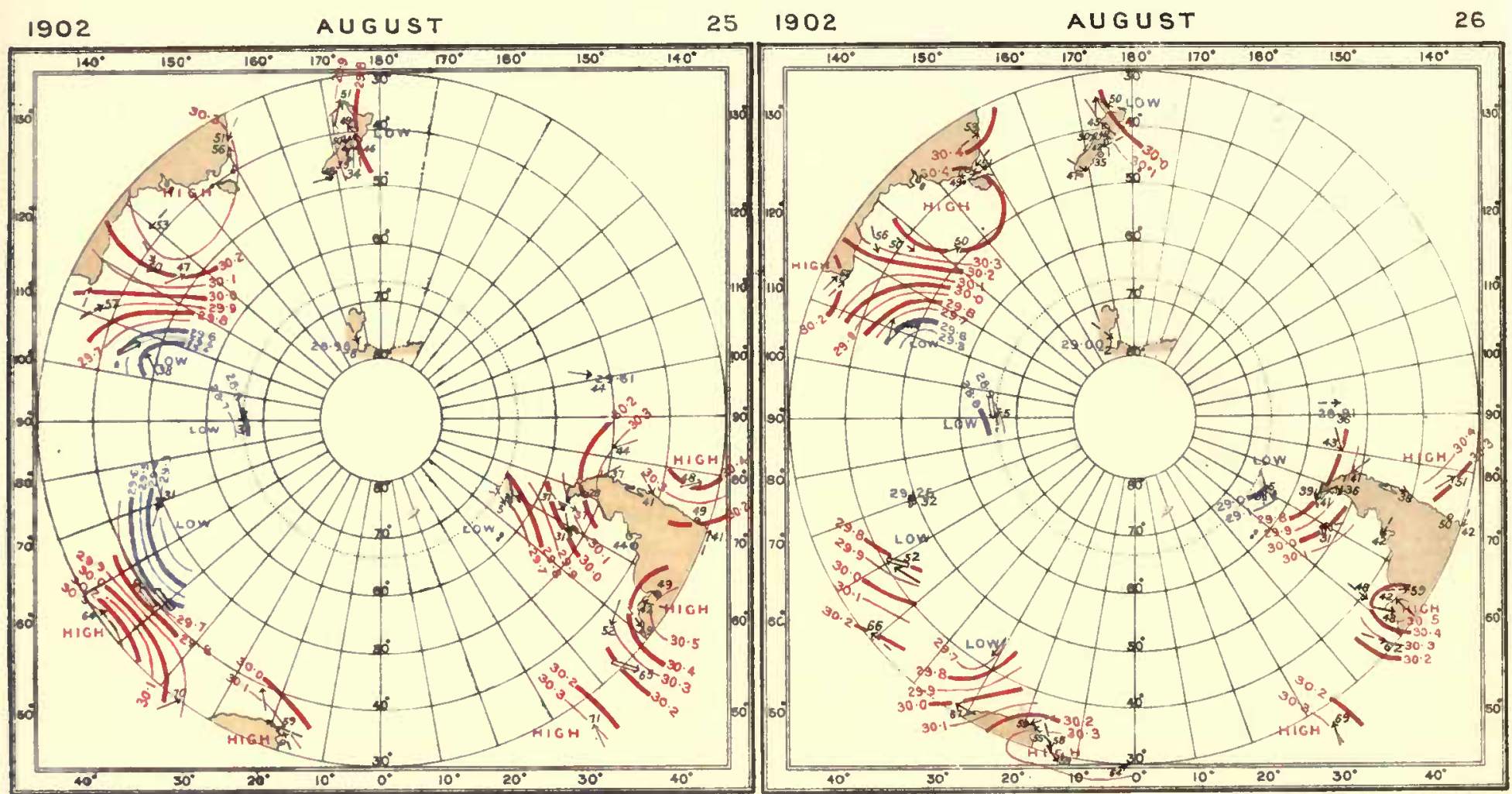

1902

$A \cup G \cup S T$

27

1902

$A \cup G \cup S T$

28
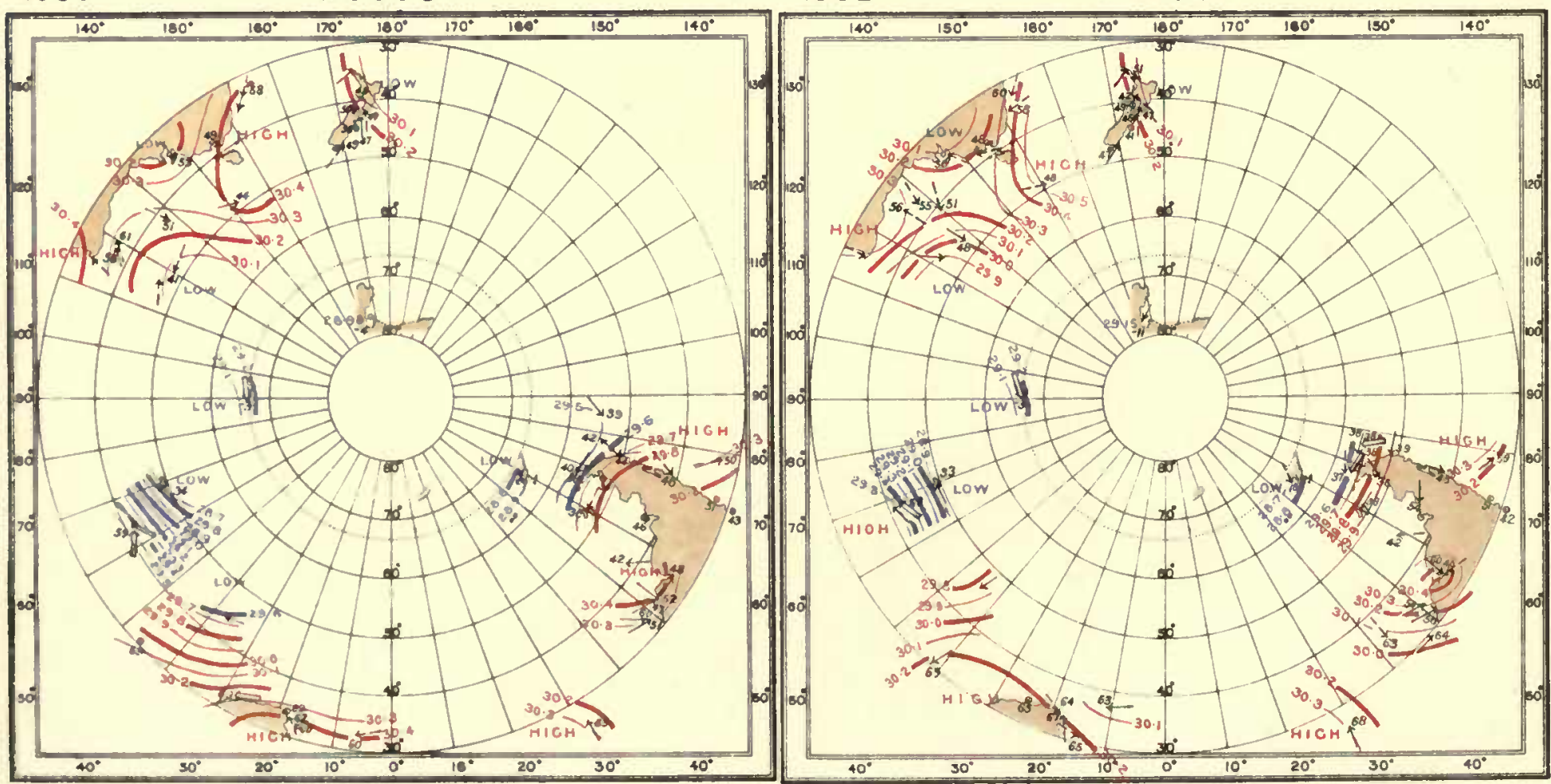
INTERNATIONAL ANTARCTIC CO-OPERATION.

SYNCHRONOUS CHARTS OF SEALEVEL PRESSURE FOR NOON G.M.T.

WITH WINDS AND AIR TEMPERATURES

1902

$A \cup G \cup S T$

$29 \quad 1902$

AUGUST

30

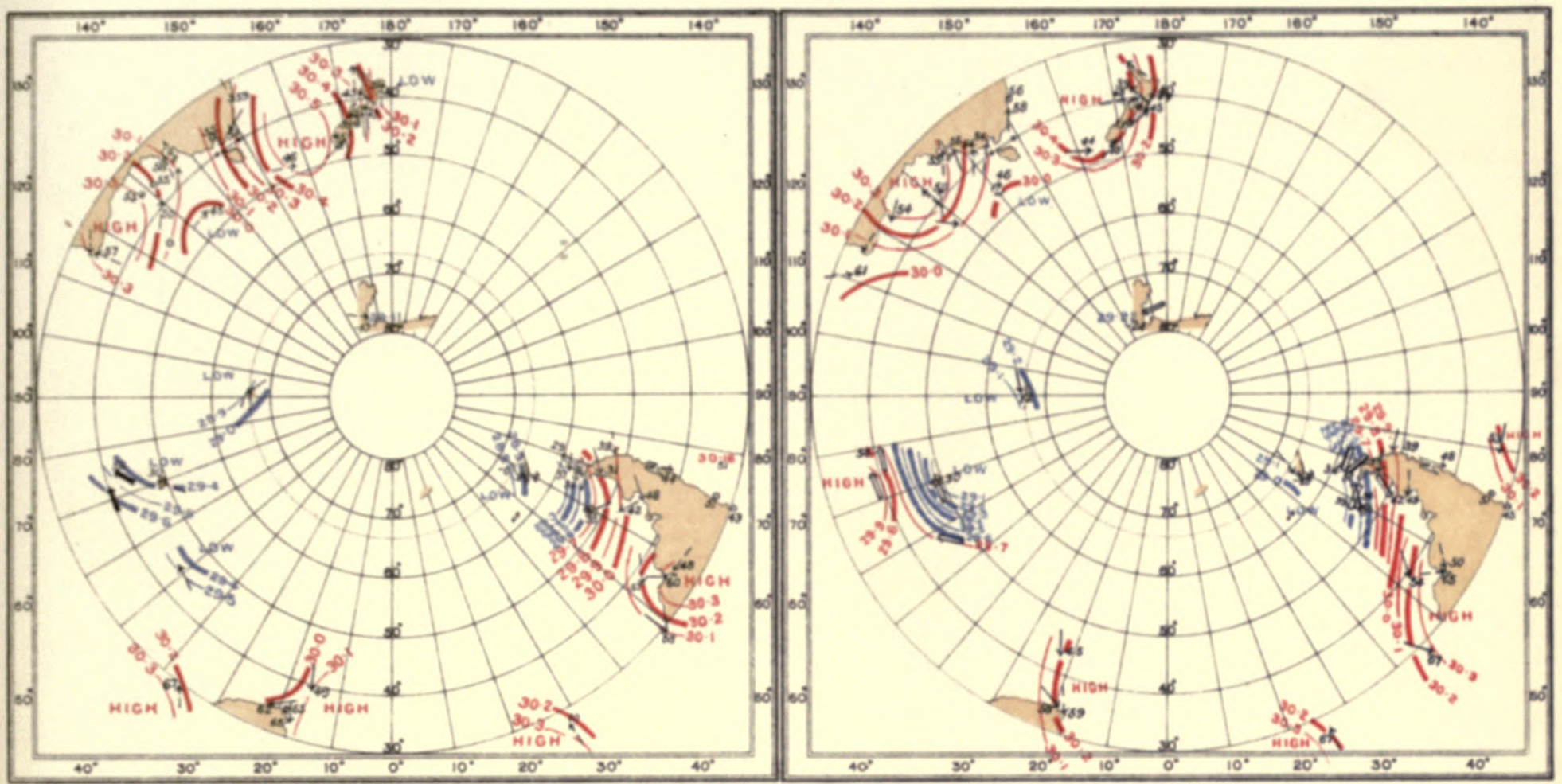

1902

AUGUST

$31 \quad 1902$

SEPTEMBER

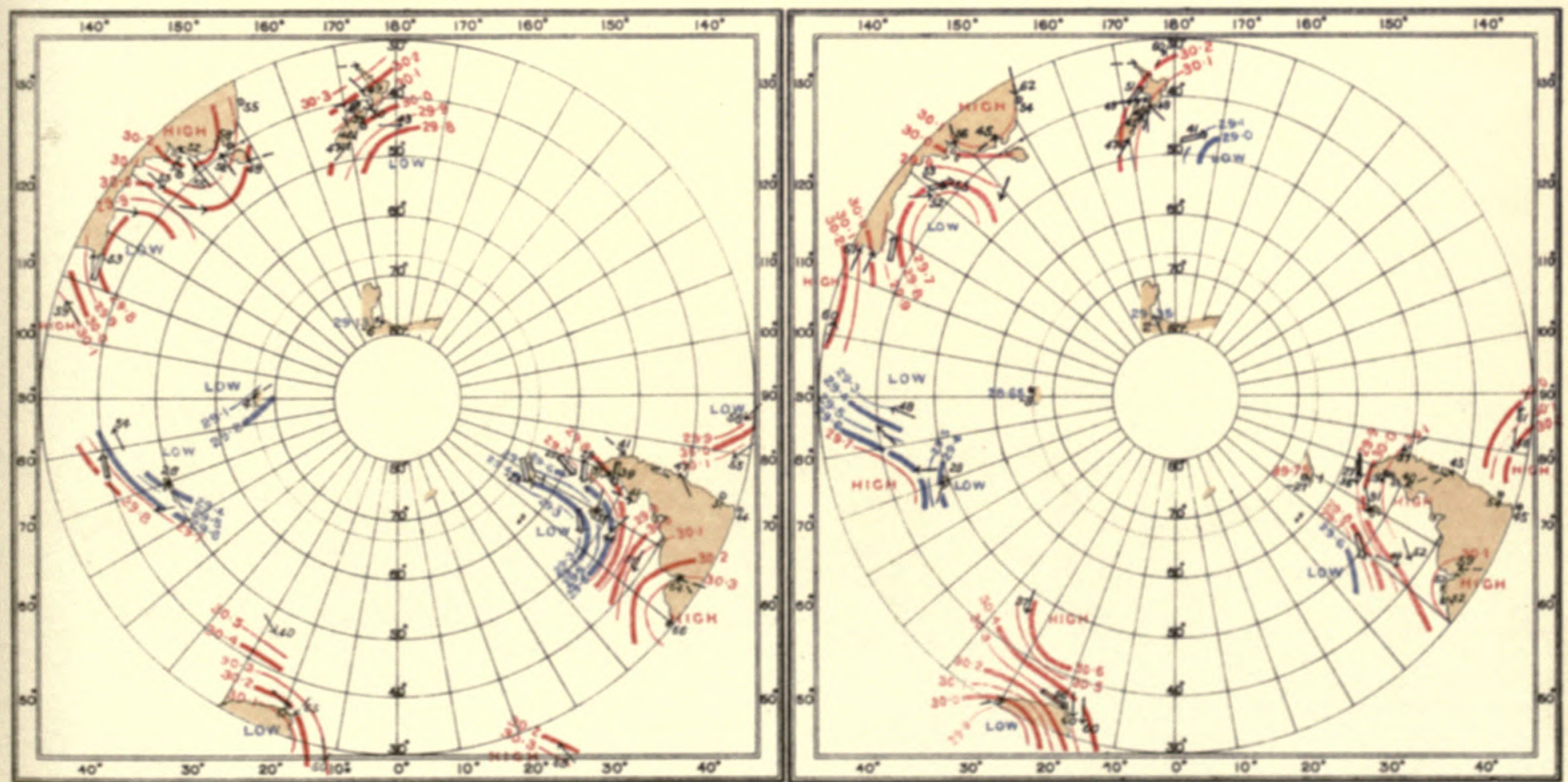


$\because \vdots \vdots \quad \because \vdots \vdots \vdots \vdots$

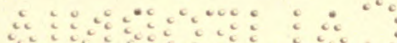

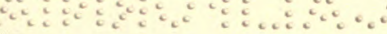




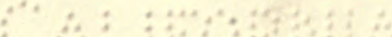

…… 
INTERNATIONAL ANTARCTIC COOOPEATION.

SYNCHRONOUS CHARTS OF SEALLVEL PRESSURE FOR NOON G.M.T

WITH WINDS AND AIR TEMPERATURES

1902

SEPTEMBER

21902

SEPTEMBER

3
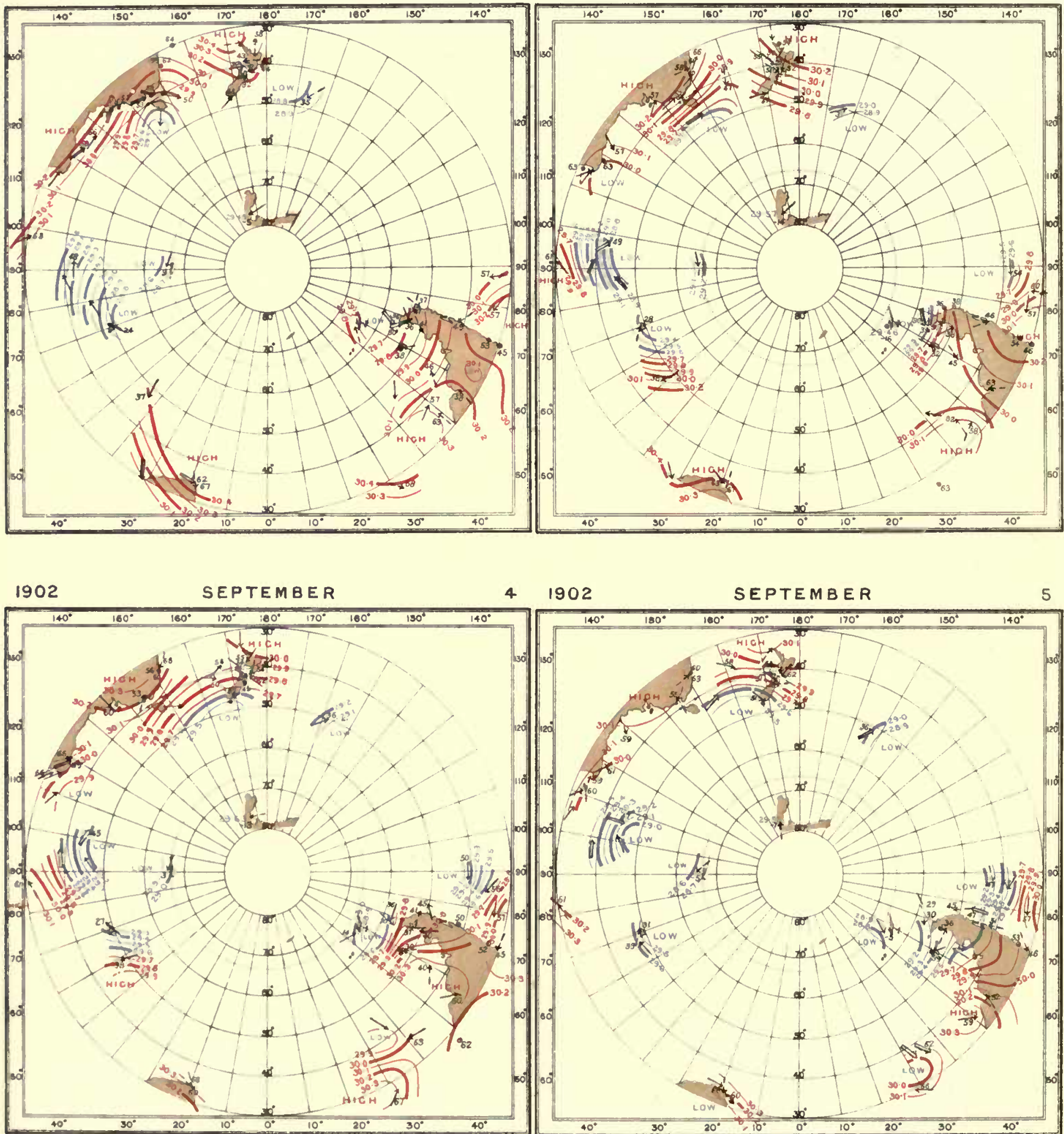

$4 \quad 1902$

SEPTEMBER

5

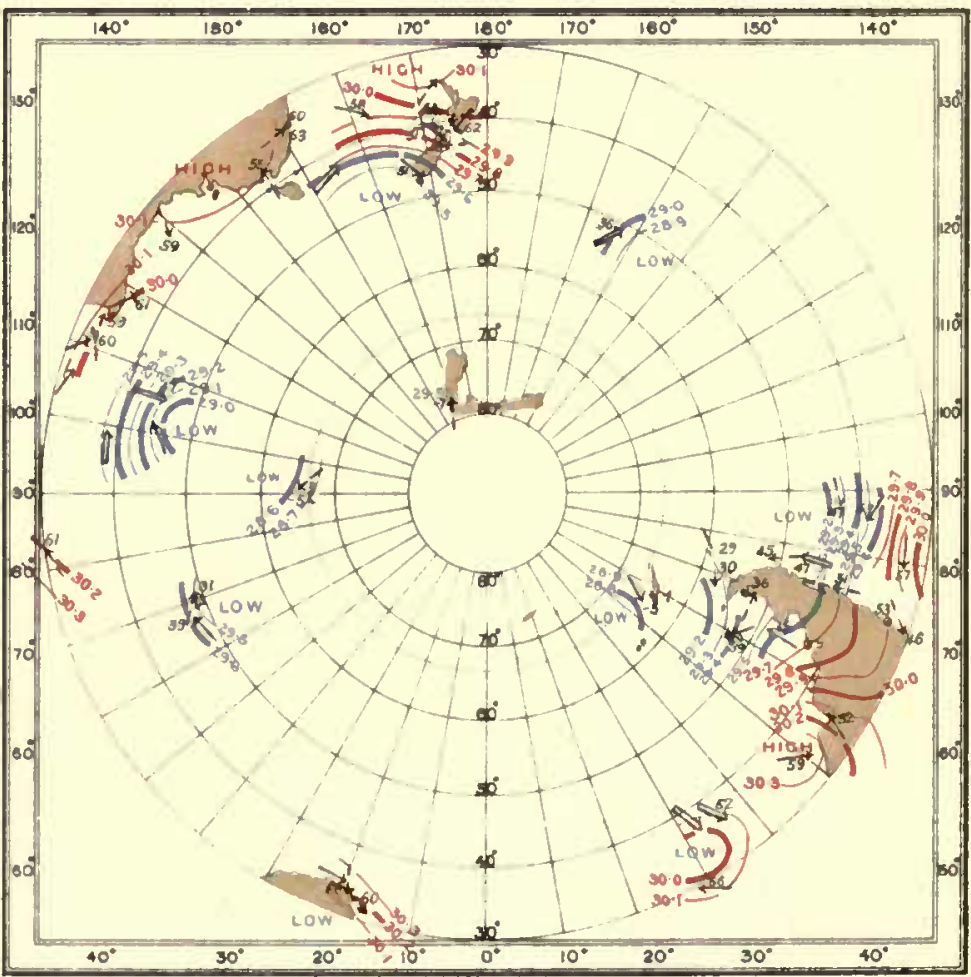


INTERNATIONAL ANTARCTIC COOPERATION.

SYNCHRONOUS CHARTS OF SEA-LEVEL PRESSURE FOR NOON G.M.T.

WITH WINDS AND AIR TEMPERATURES.
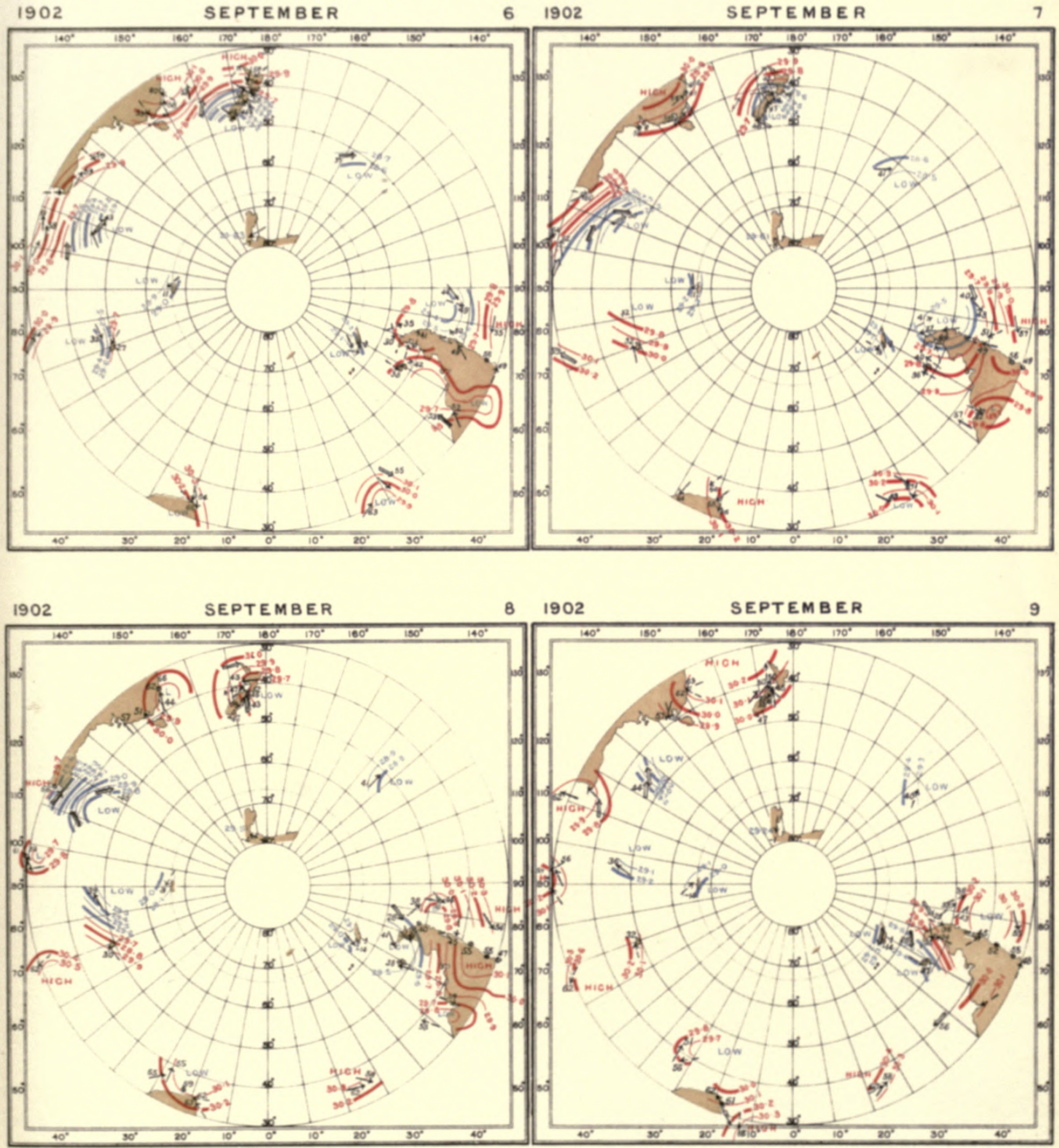
$\because$

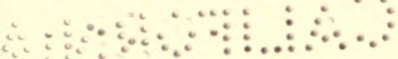



INTERNATIONAL ANTARCTIC CO-OPERATION.

SYNCHRONOUS CHARTS OF SEALLVEL PRESSURE FOR NOONGMT

WITH WINDS AND AIR TEMPERATURES

1902

SEPTEM BER

$10 \quad 1902$

SEPTEMBER

11

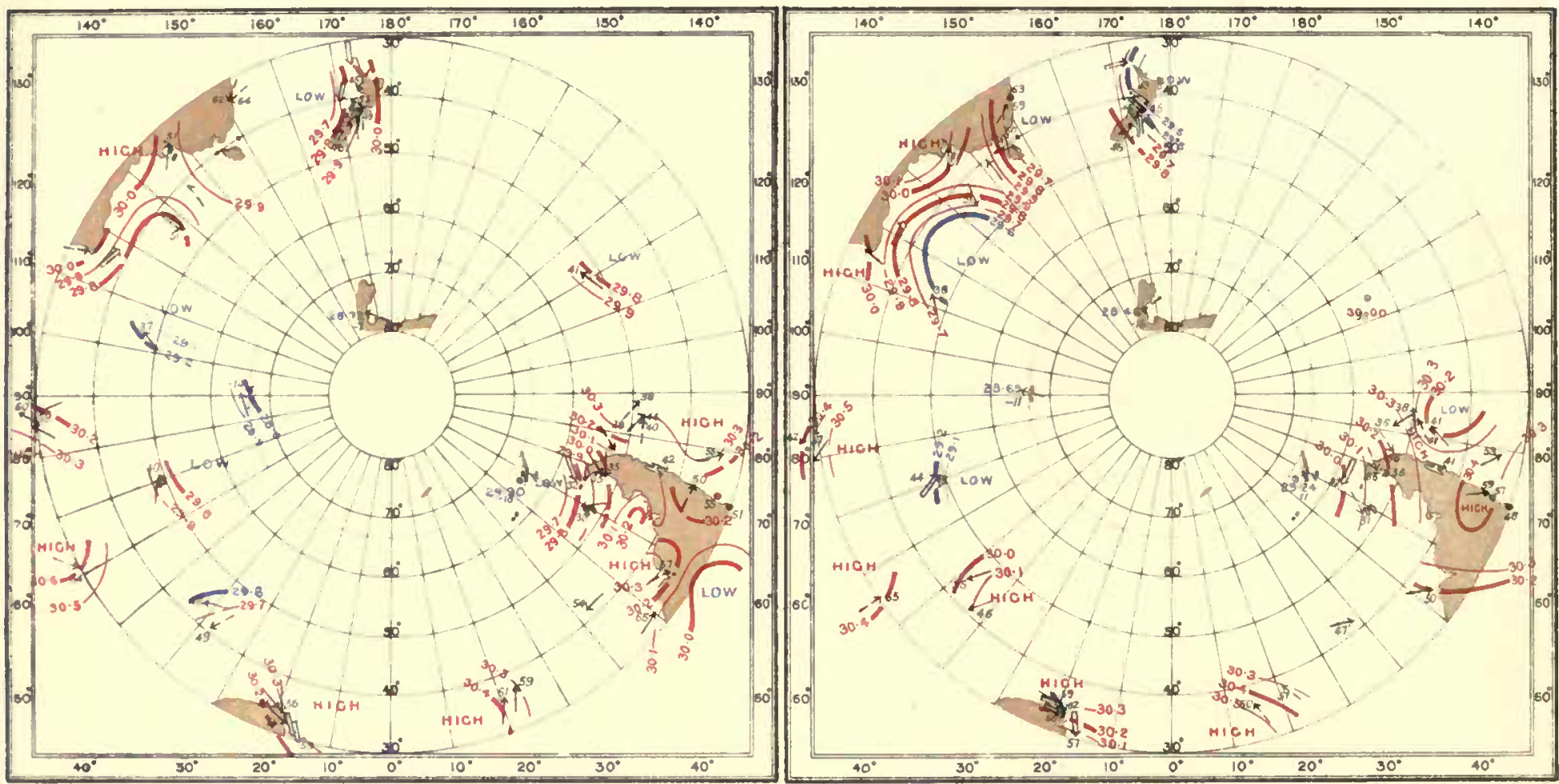

1902 SEPTEMBER

$12 \quad 1902$

SEPTEMBER

13
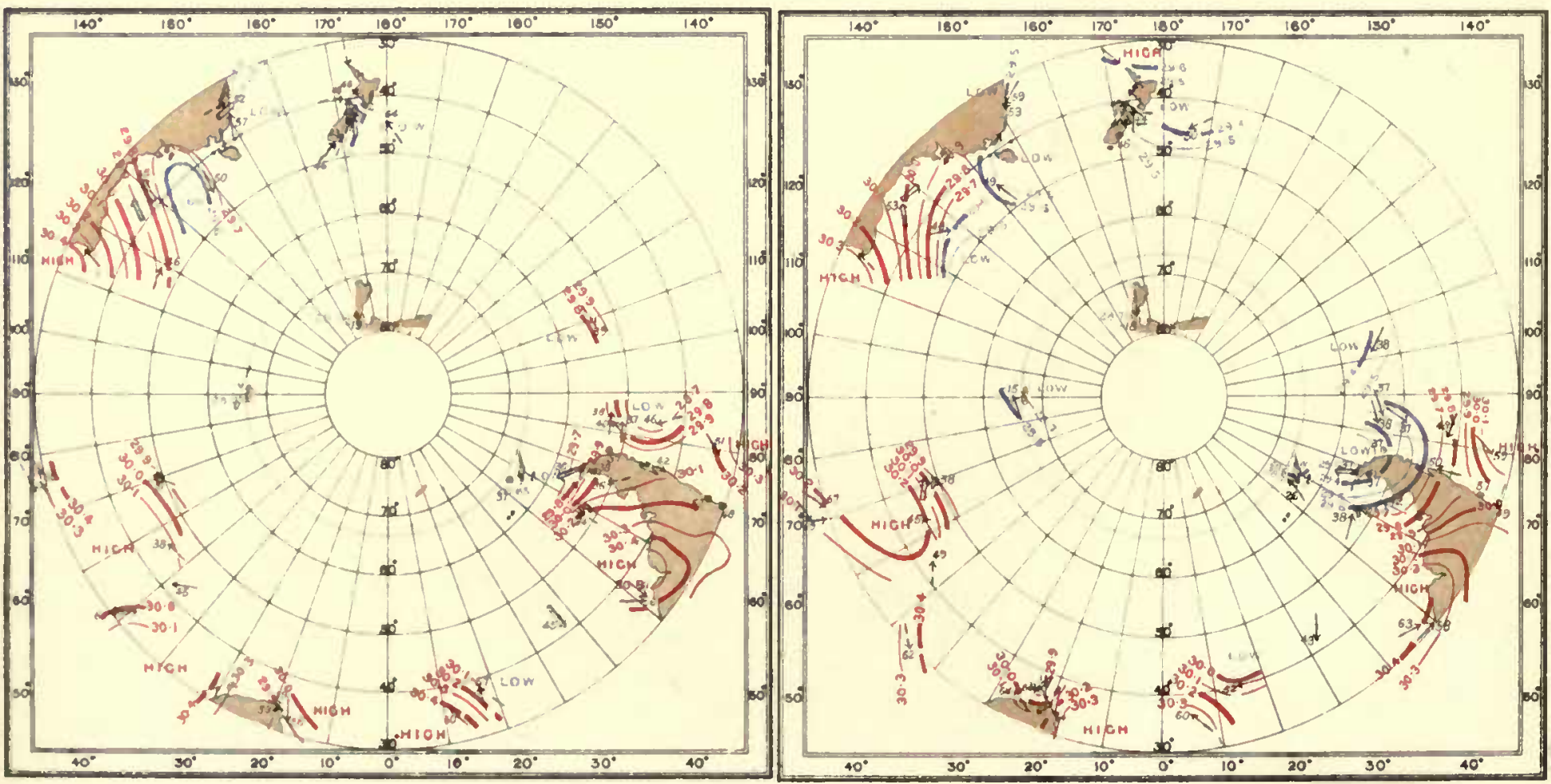
INTERNATIONAL ANTARCTIC CO-OPERATION.

SYNCHRONOUS CHARTS OF SEALLEEL PRESSURE FOR NOONGMT

WITH WINDS AND AIR TEMPERATURES
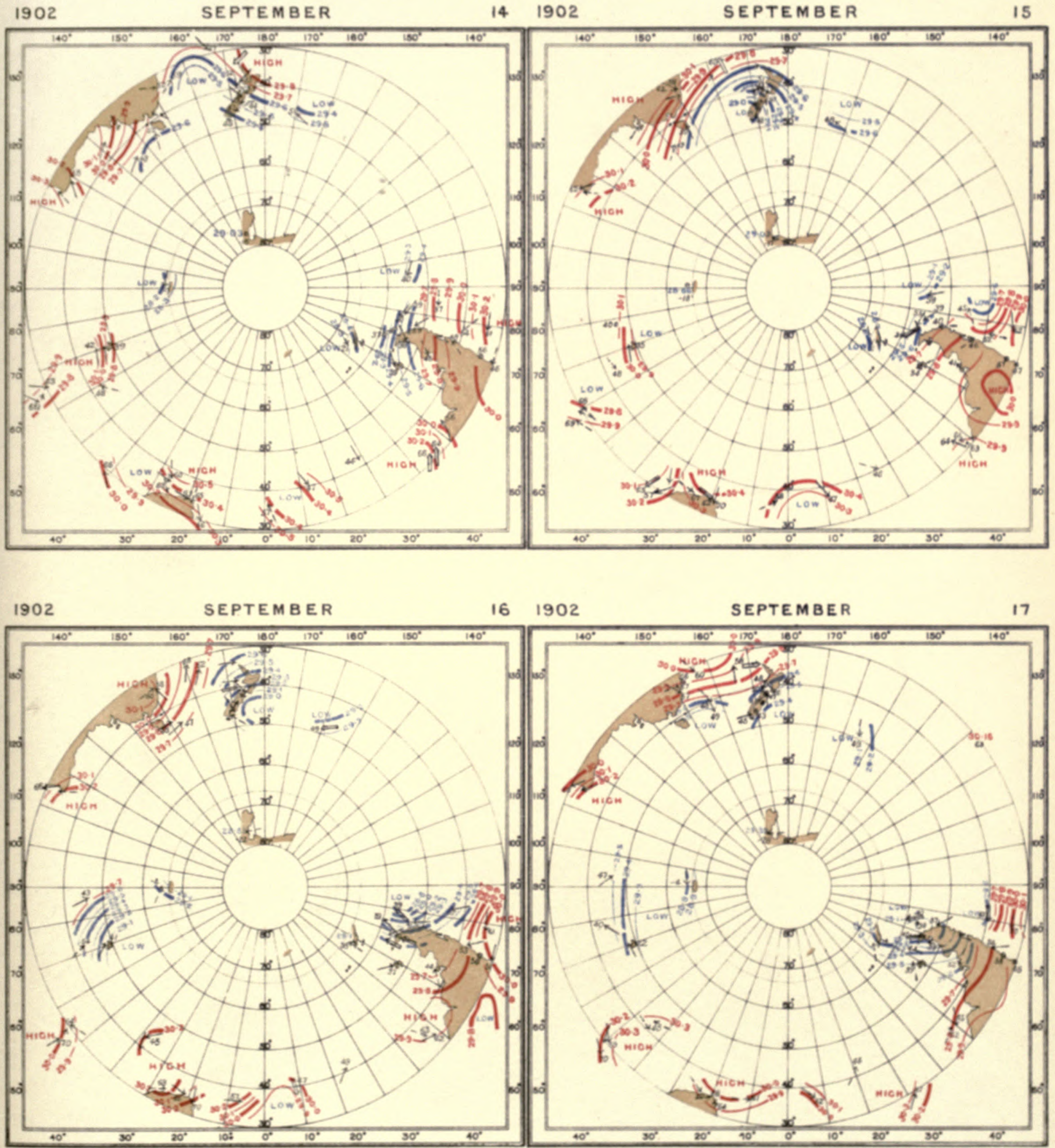
$\because$\begin{tabular}{l}
2 \\
\hdashline
\end{tabular}

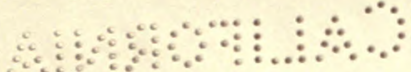




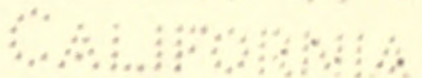

: 
INTERNATIONAL ANTARCTIC CO-OPERATION.

SYNCHIONOUS CHARTS OF SEALEVEL PRESSURE FOR NOON G.M T

WITH WINDS AND AIR TEMPERATURES
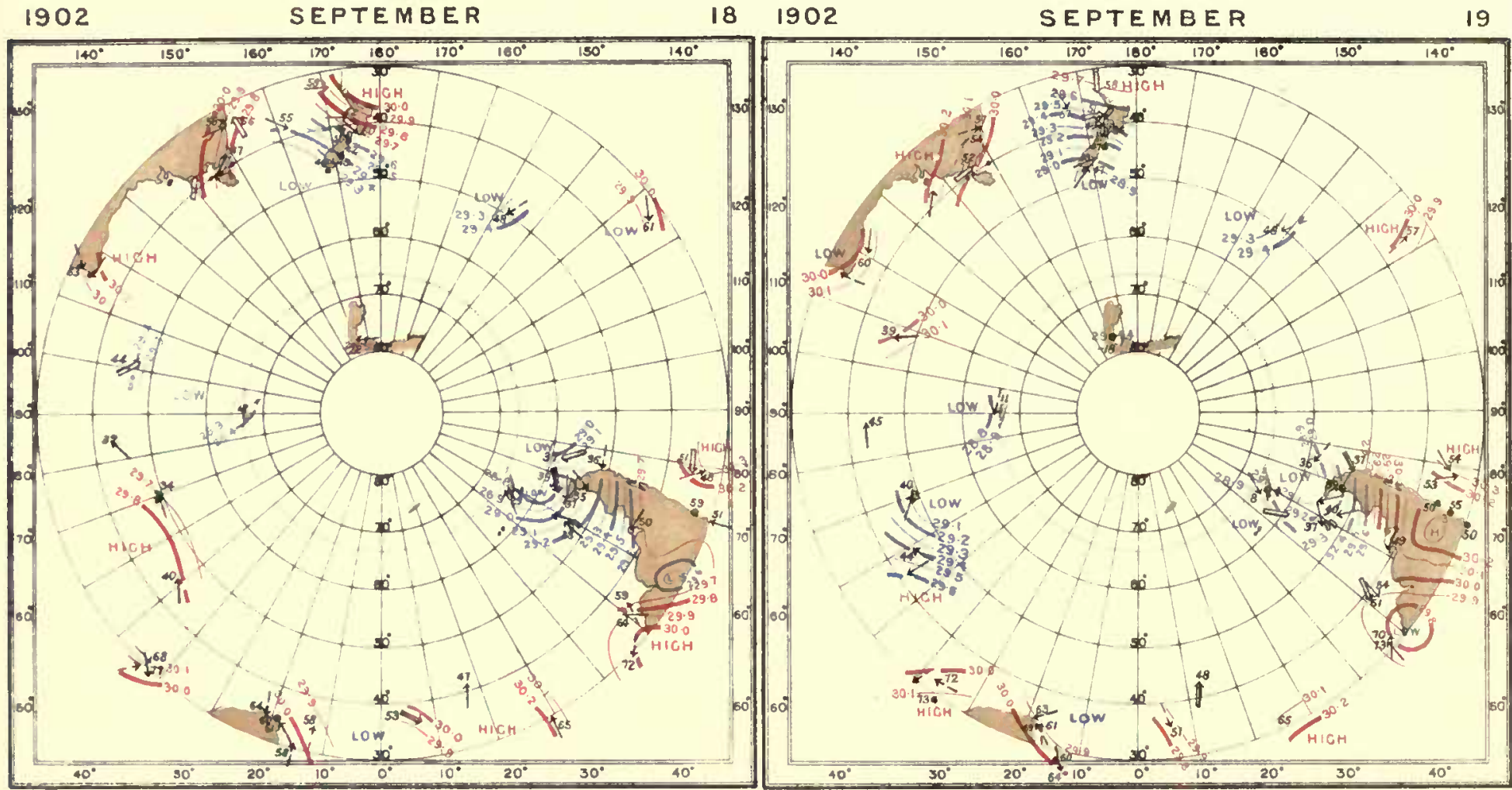

1902

SEPTEMBER

20

1902

SEPTEMBER

21
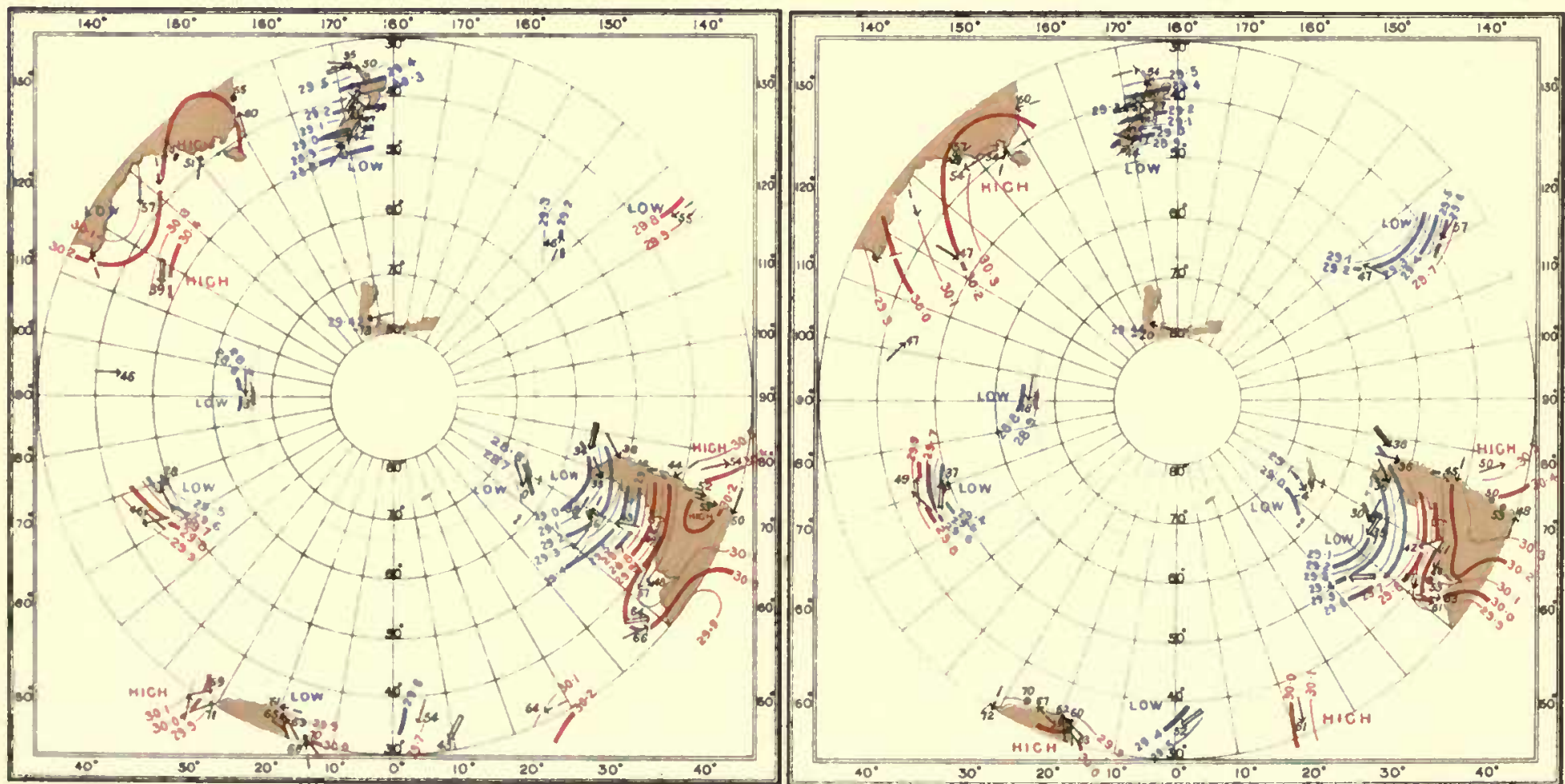
INTERNATIONAL ANTARCTIC COOPERATION.

SYNCHRONOUS CHARTS OF SEALLEVEL PRESSURE FOR NOON G.M.T

WITH WINOS AND AIR TEMPERATURES

1902

SEPTEMBER

$22 \quad 1902$

SEPTEMBER

23

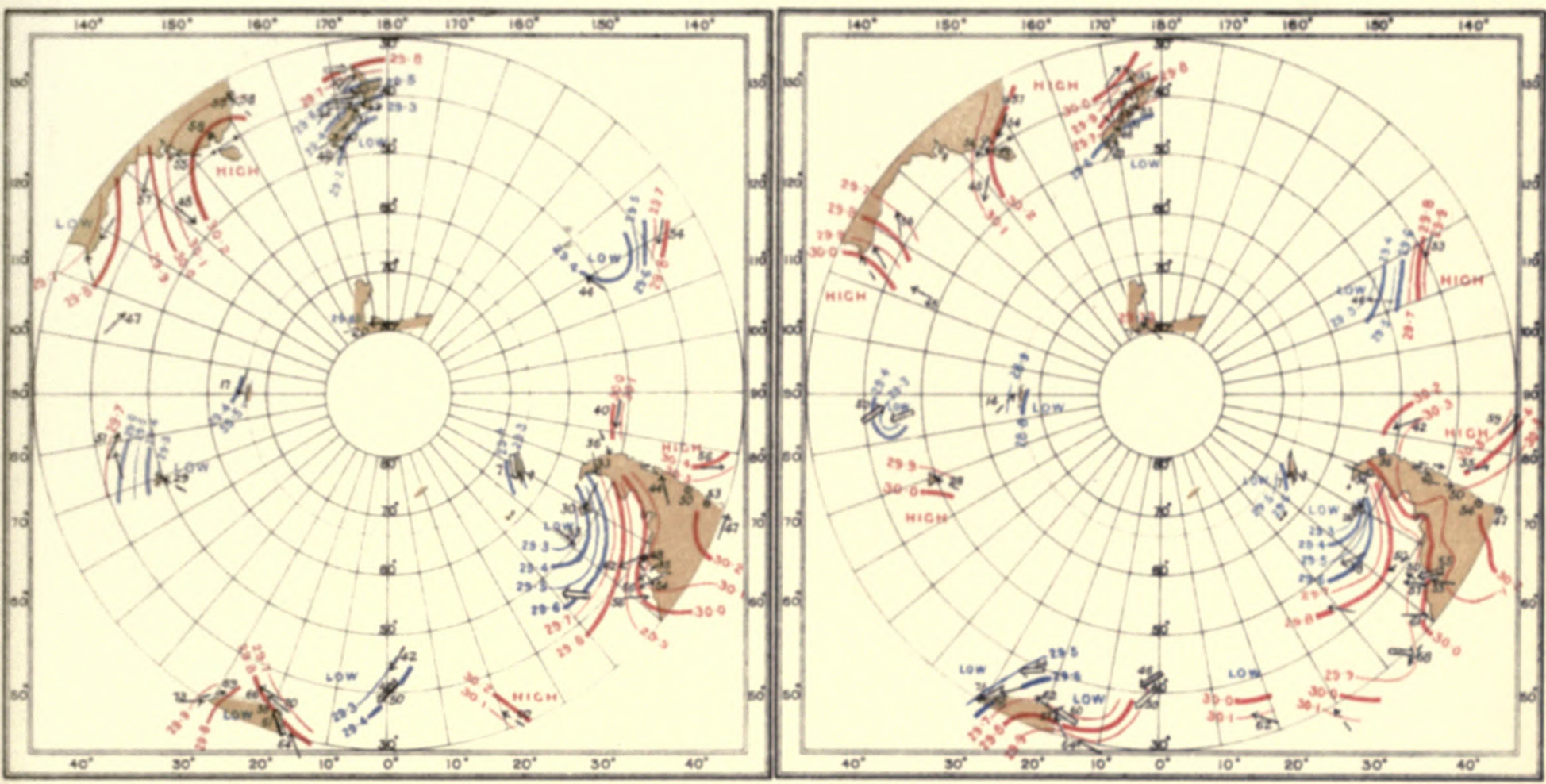

1902 SEPTEMBER

$\begin{array}{llll}24 & 1902 & \text { SEPTEMBER }\end{array}$

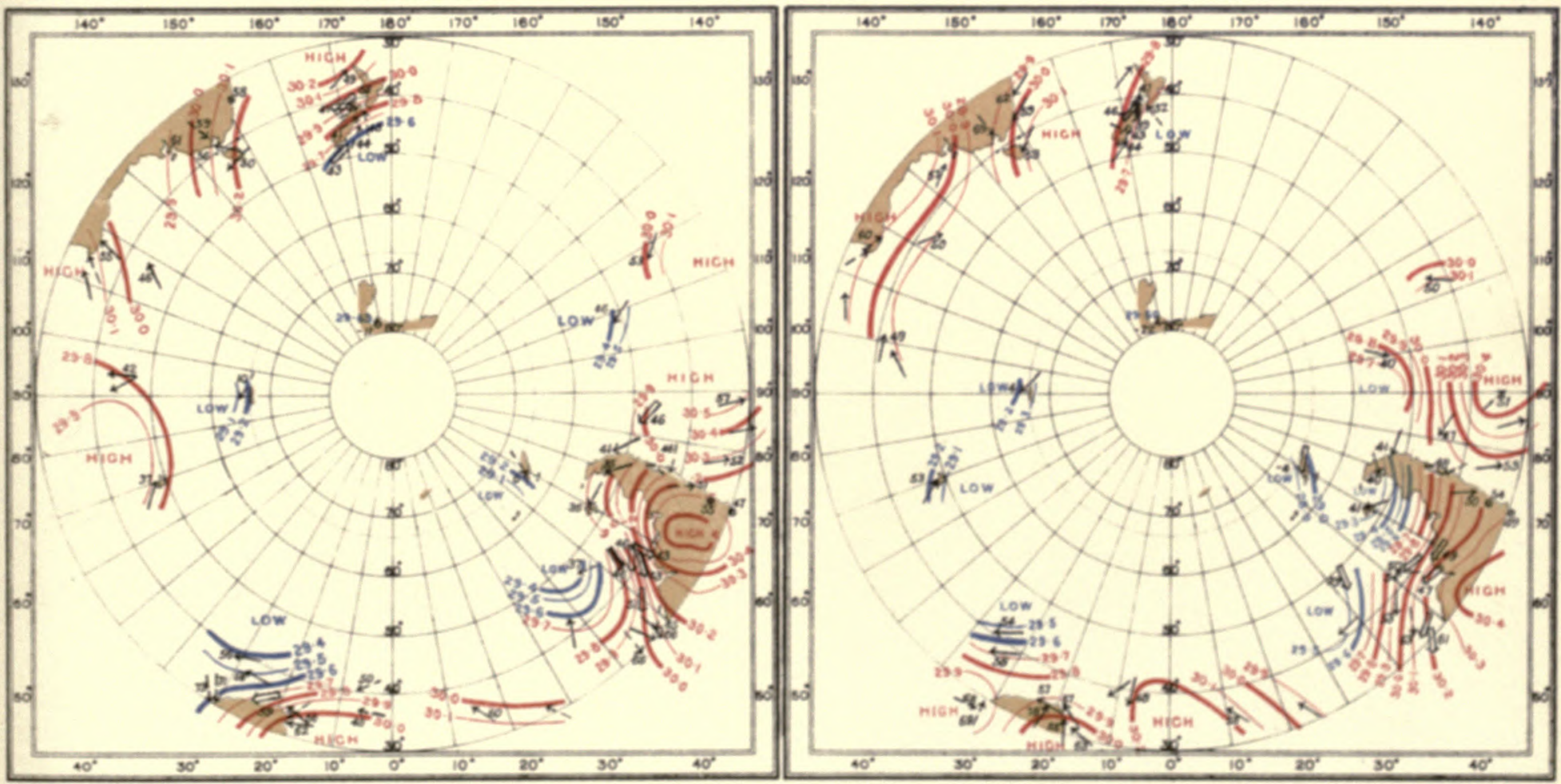




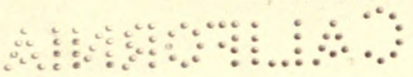




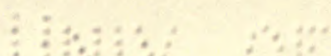

a o 
INTERNATIONAL ANTARCTIC CO-OPERATION.

SYNCHRONOUS CHARTS OF SEA-LEVEL PRESSURE FOR NOON GMT

WITH WINDS AND AIR TEMPERATURES
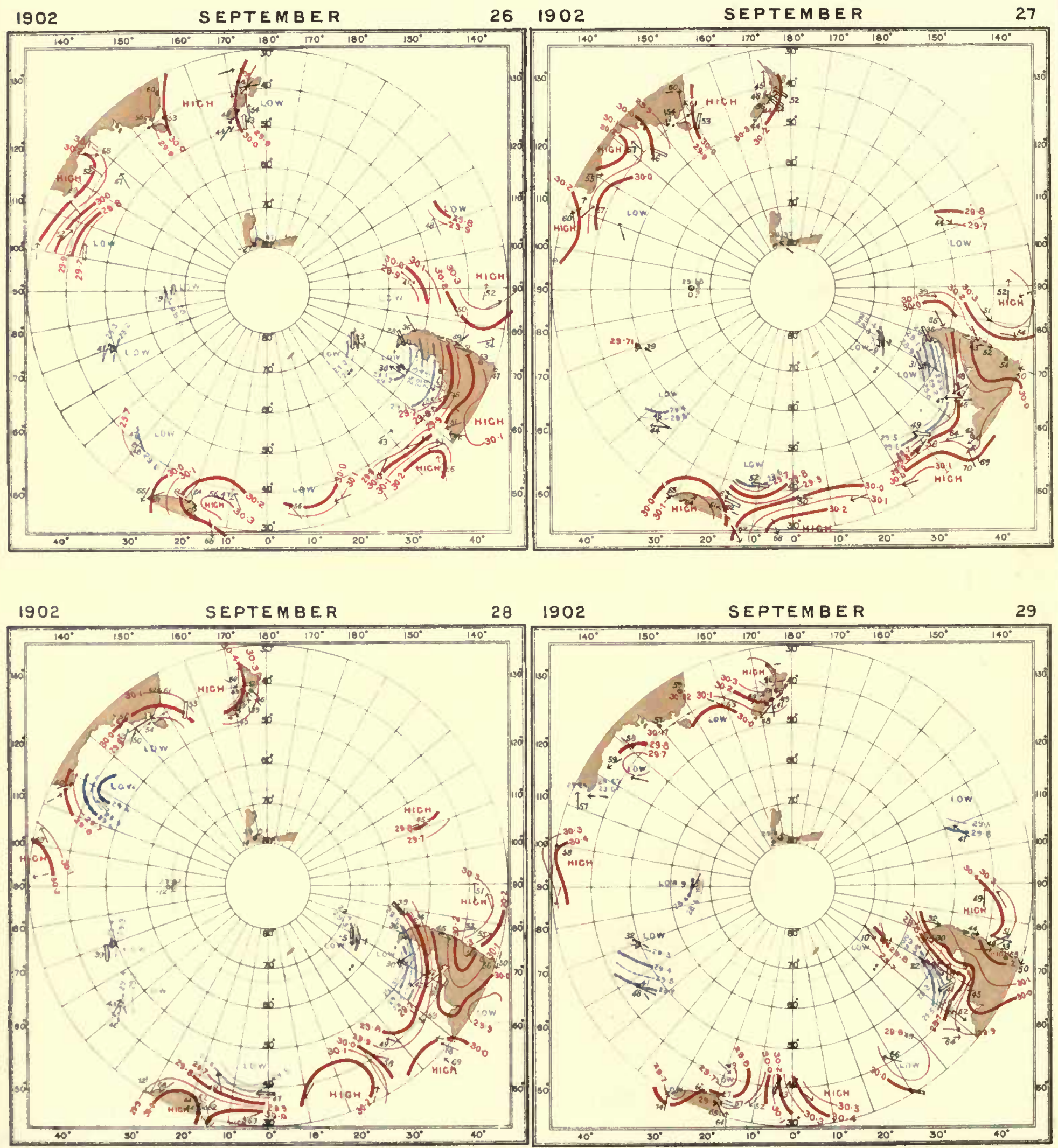
INTERNATIONAL ANTARCTIC CO-OPERATION

SYNCHRONOUS CHARTS OF SEALEVEL PRESSURE FOR NOON GMT

WITH WINDS AND AIR TEMPERATURES
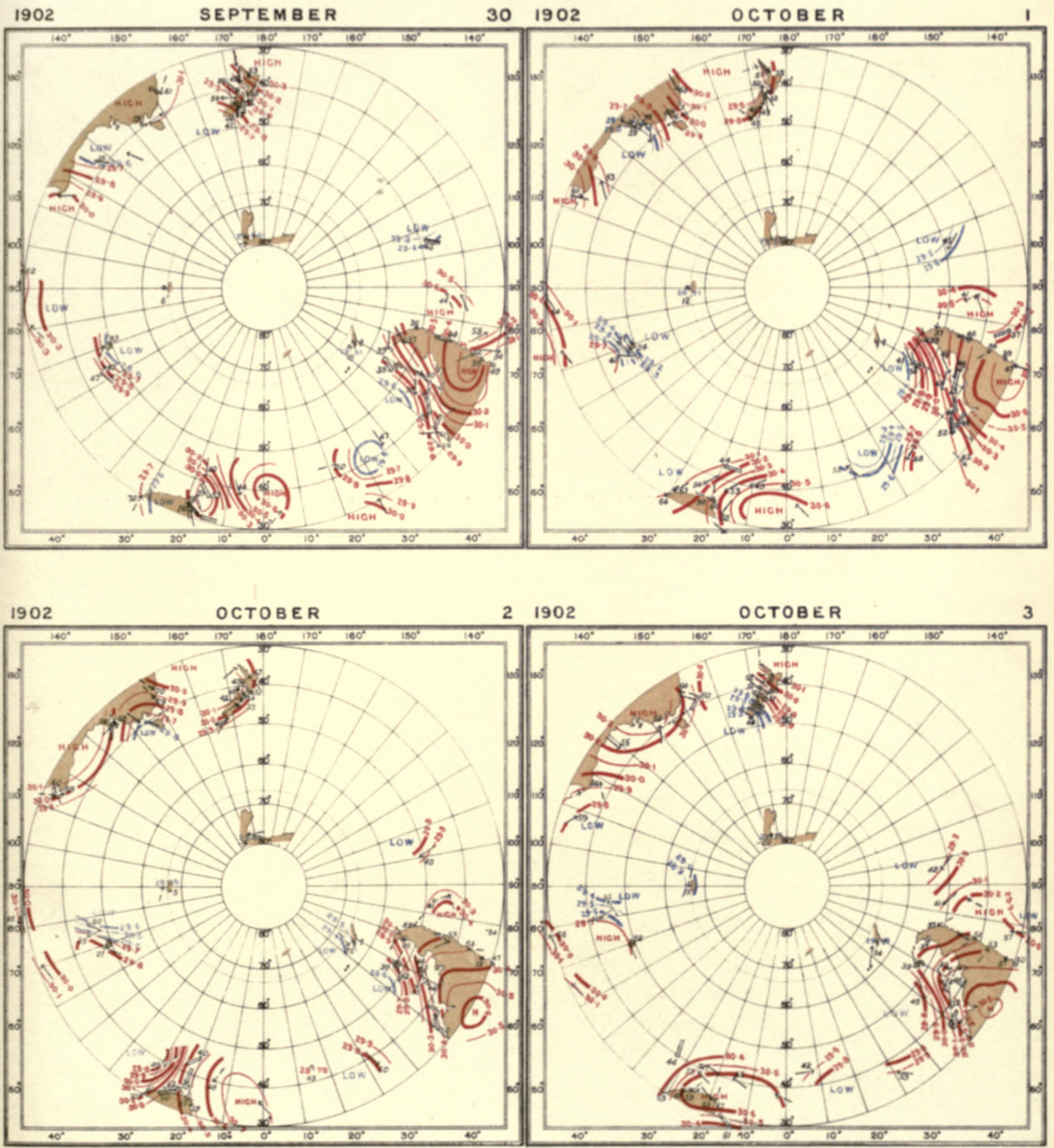


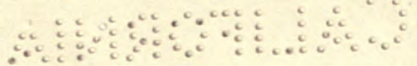


:

a $\quad \div \quad:$ 
INTERNATIONAL ANTARCTIC CO-OPERATION

SYNCHRONOUS CHARTS OF SEA-LEVEL PRESSURE FOR NOON G.MT

WITH WINDS AND AIR TEMPERATURES
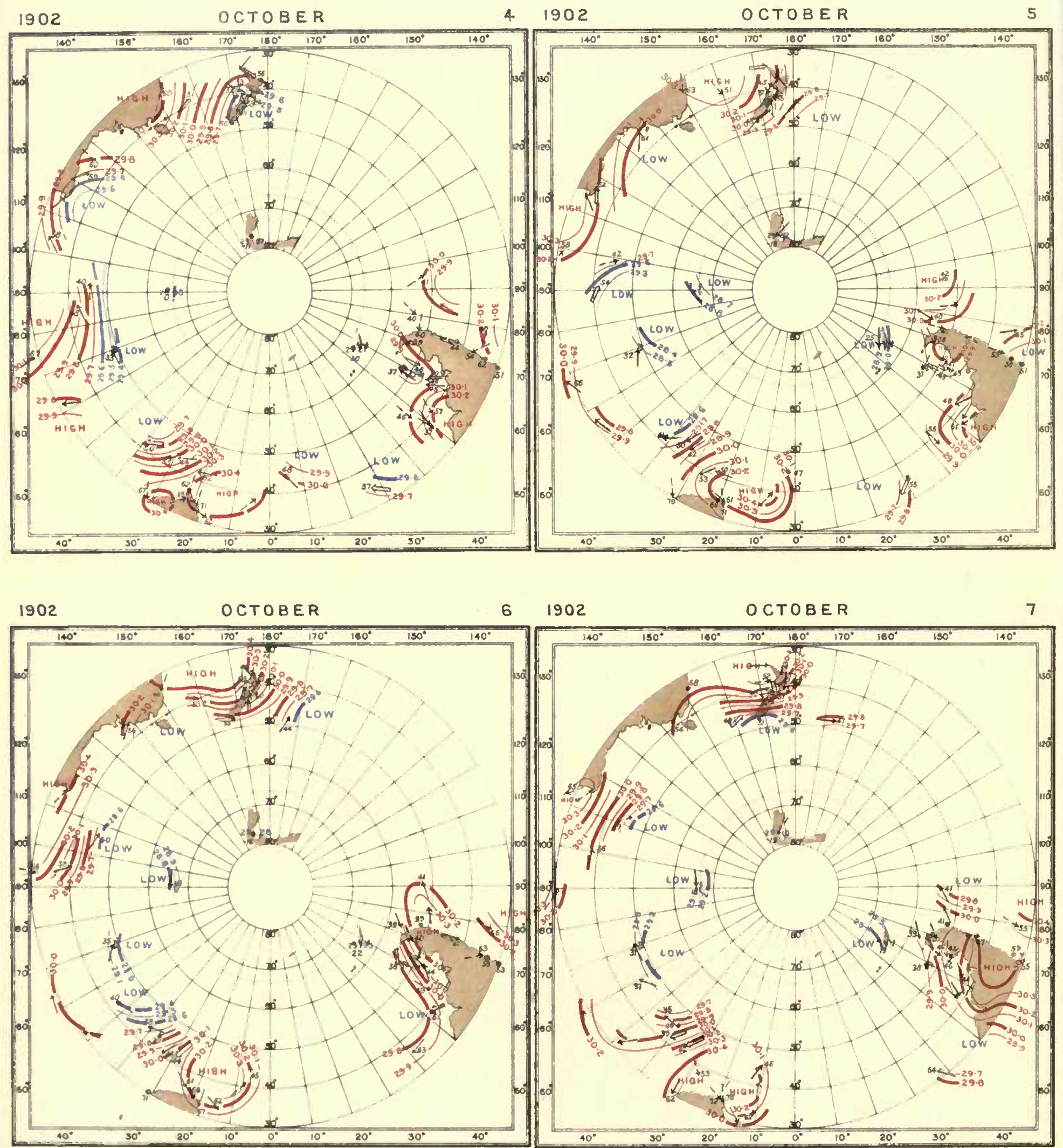
INTERNATIONAL ANTARCTIC CO-OPERATION

SYNCHRONOUS CHARTS OF SEALEVEL PRESSURE FOR NOON G.M.T

WITH WINDS AND AIR TEMPERATURES
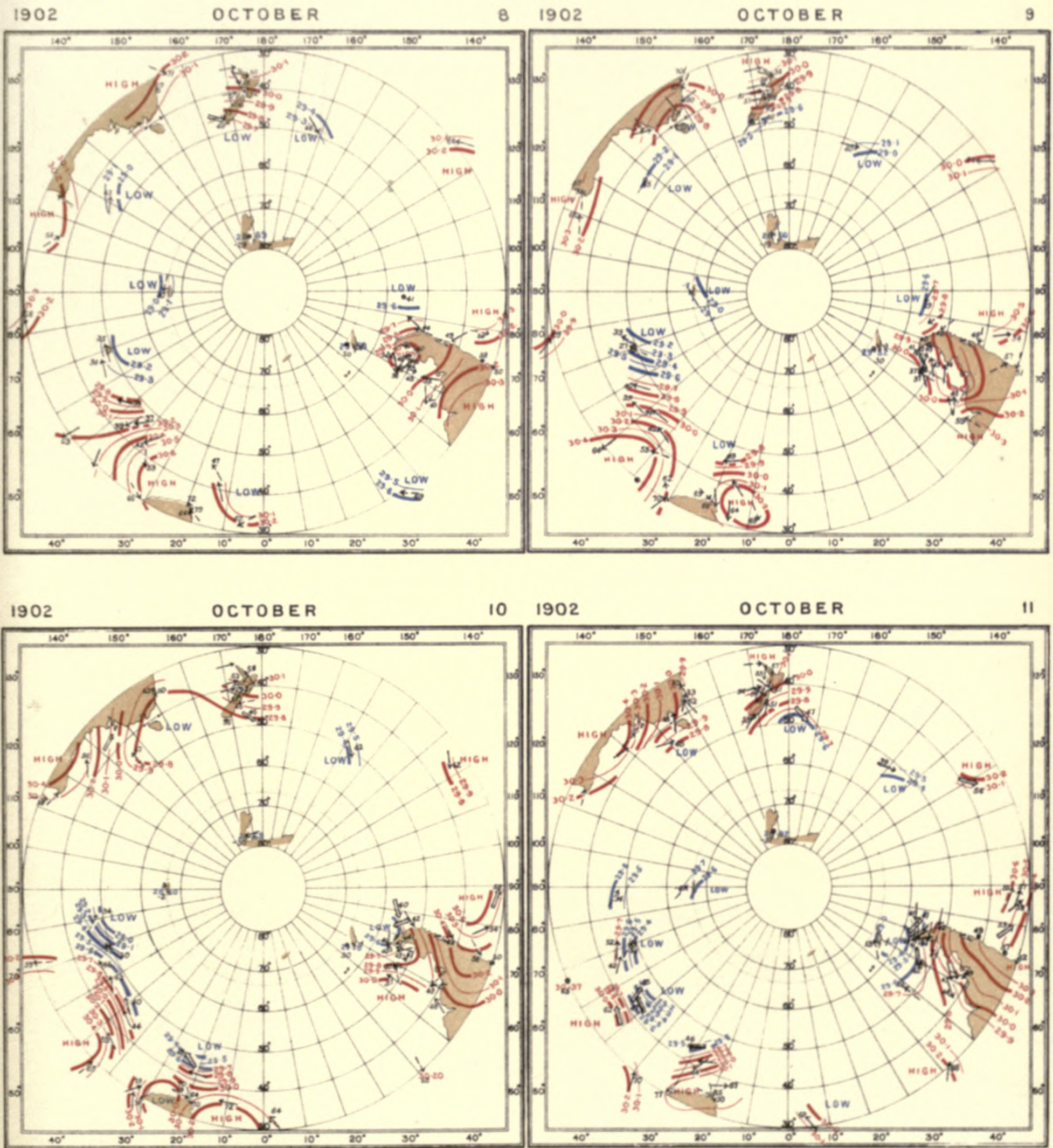
$\because y$

$\therefore \vdots$\begin{tabular}{c}
0 \\
\hdashline
\end{tabular} 
$\vdots \begin{gathered}\vdots \\ \vdots\end{gathered}$

0
$\cdots$$\cdots$

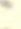


INTERNATIONAL ANTARCTIC COOPERATION

SYNCHRONOUS CHARTS OF SEA-LEVEL PRESSURE FOR NOON GM T

WITH WINDS AND AIR TEMPERATURES
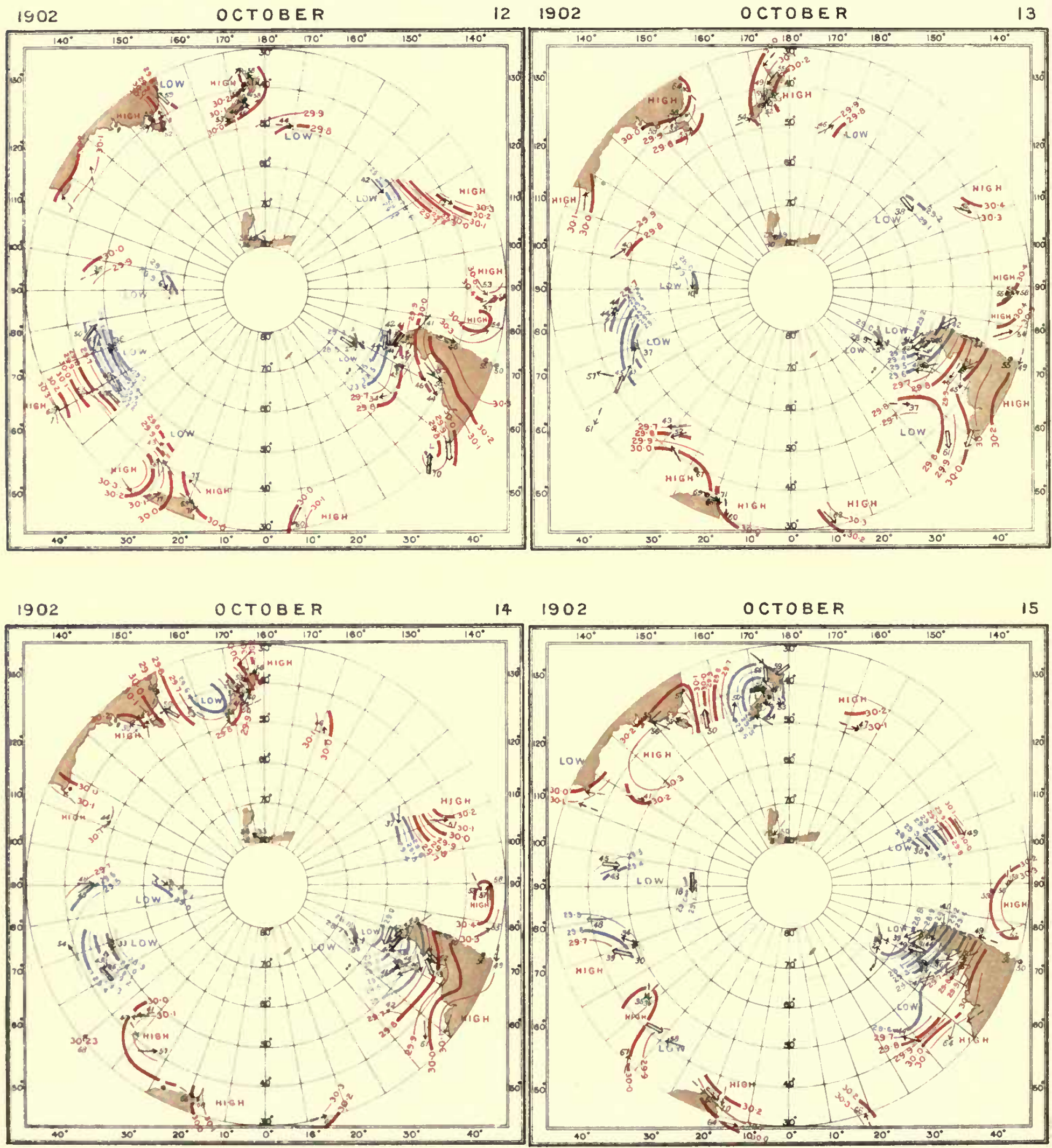
INTERNATIONAL ANTARCTIC COOPERATION

SYNCHRONOUS CHARTS OF SEA-'EVEL PRESSURE FOR NOON GMT

WITH WINDS AND AIR TEMPERATURES
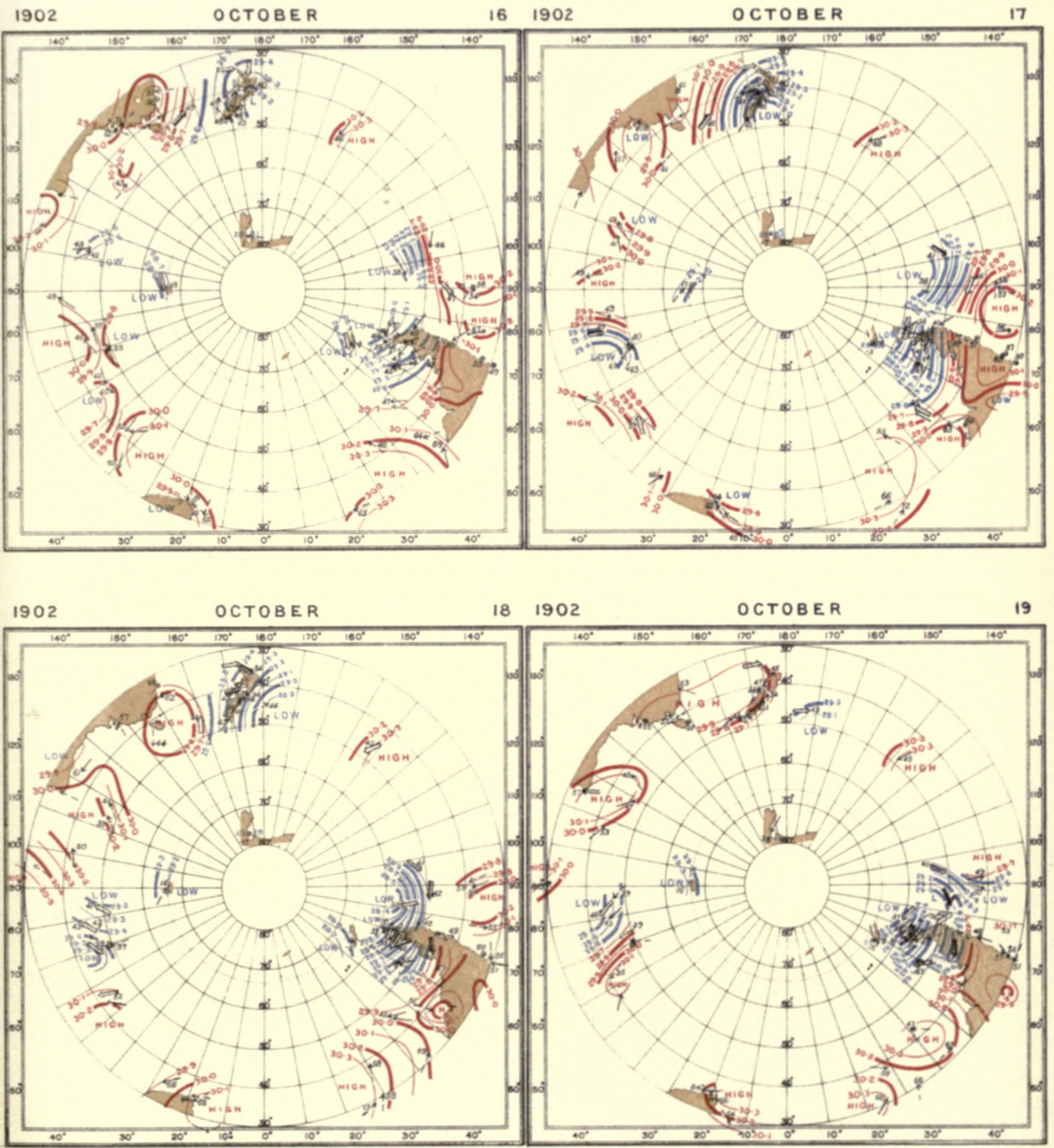
$\because \vdots \vdots \quad \because \vdots \vdots \vdots \vdots \vdots \vdots \vdots \vdots \vdots 0$

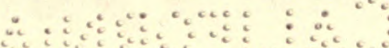



INTERNATIONAL ANTARCTIC COOPERATION.

SYNCHRONOUS CHARTS OF SEALEVEL PRESSURE FOR NOON G.M.T.

WITH WINDS ANO AIR TEMPERATURES.
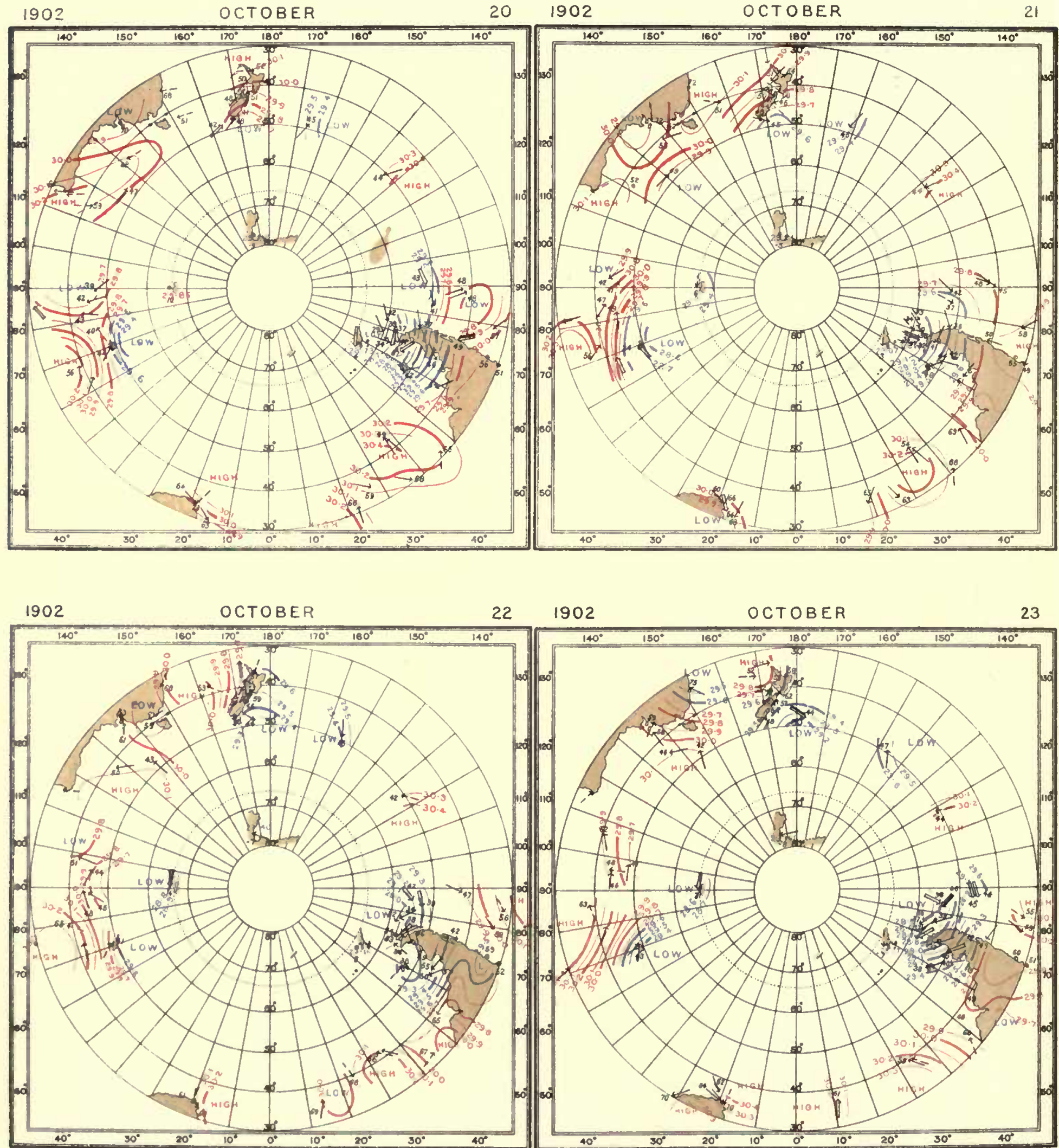
INTERNATIONAL ANTARCTIC CO-OPERATION.

SYNCHRONOUS CHARTS OF SEAII.EVEL PRESSURE FOR NOON G.M.T.

WITH WINDS AND AIR TEMPERATURES.

1902

OCTOBER

$24 \quad 1902$

OCTOBER

25
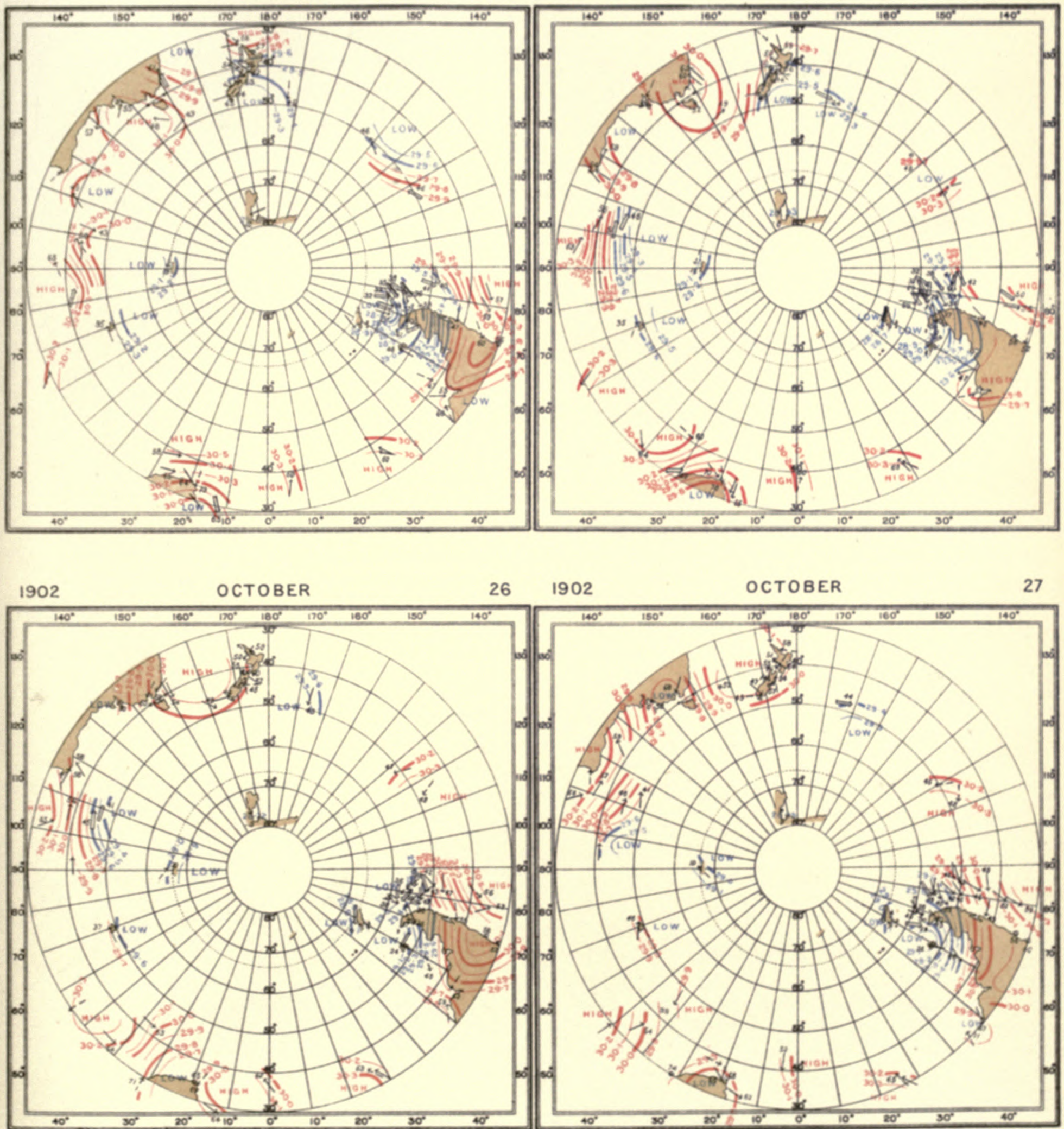
40

ל 


$$
\leftrightarrow \quad
$$


INTERNATIONAL ANTARCTIC CO-OPERATION.

SYNCHRONOUS CHARTS OF SEA-LEVEL PRESSURE FOR NOON G.M.T

WITH WINDS AND AIR TEMPERATURES.
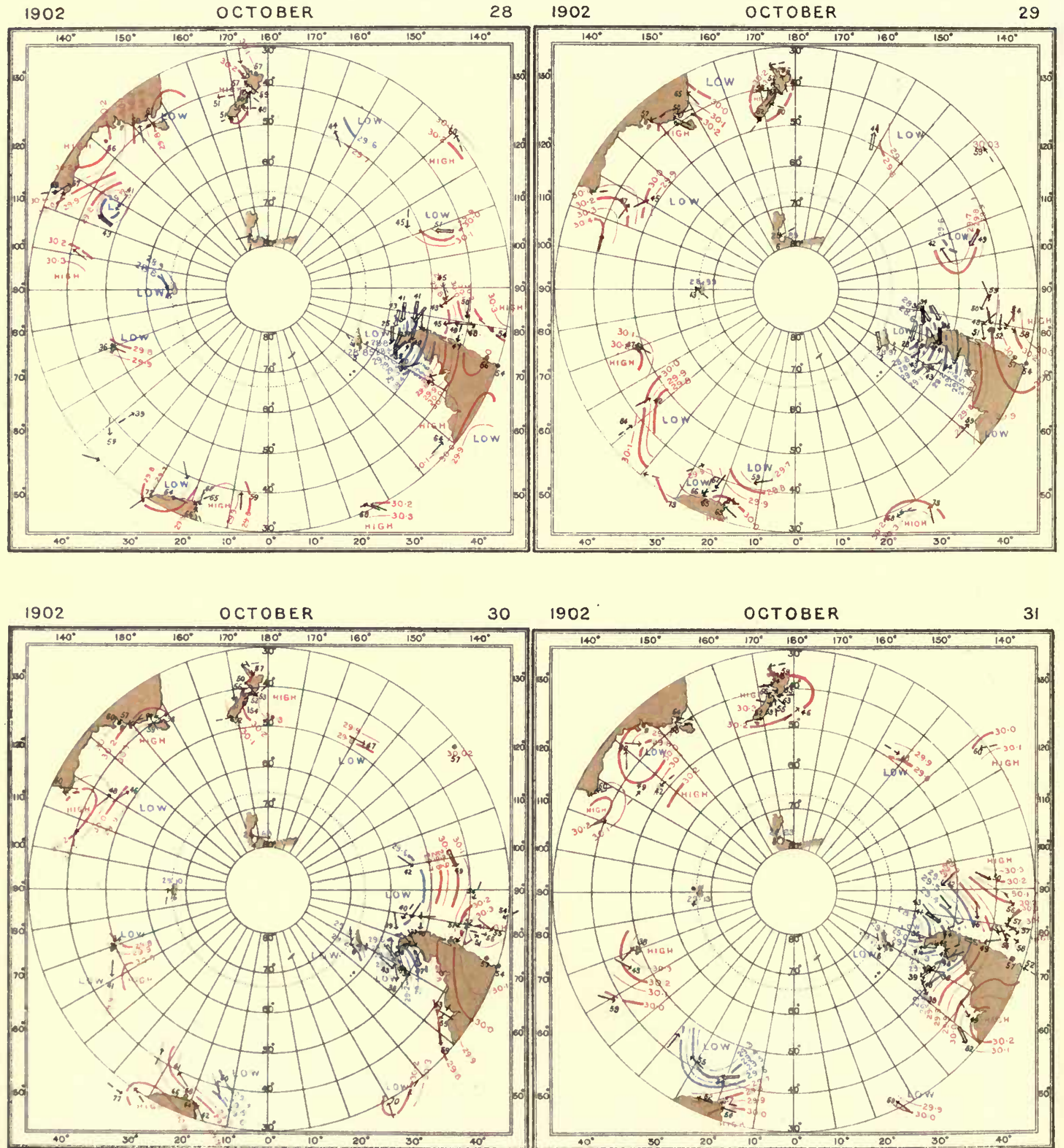
INTERNATIONAL ANTARCTIC COOPERATION. $\quad \cdots \quad \ldots$

SYNCHRONOUS CHARTS OF SEA-LEVEL PRESSURE FOR NOON G.M.T

WITH WINDS AND AIR TEMPERATURES
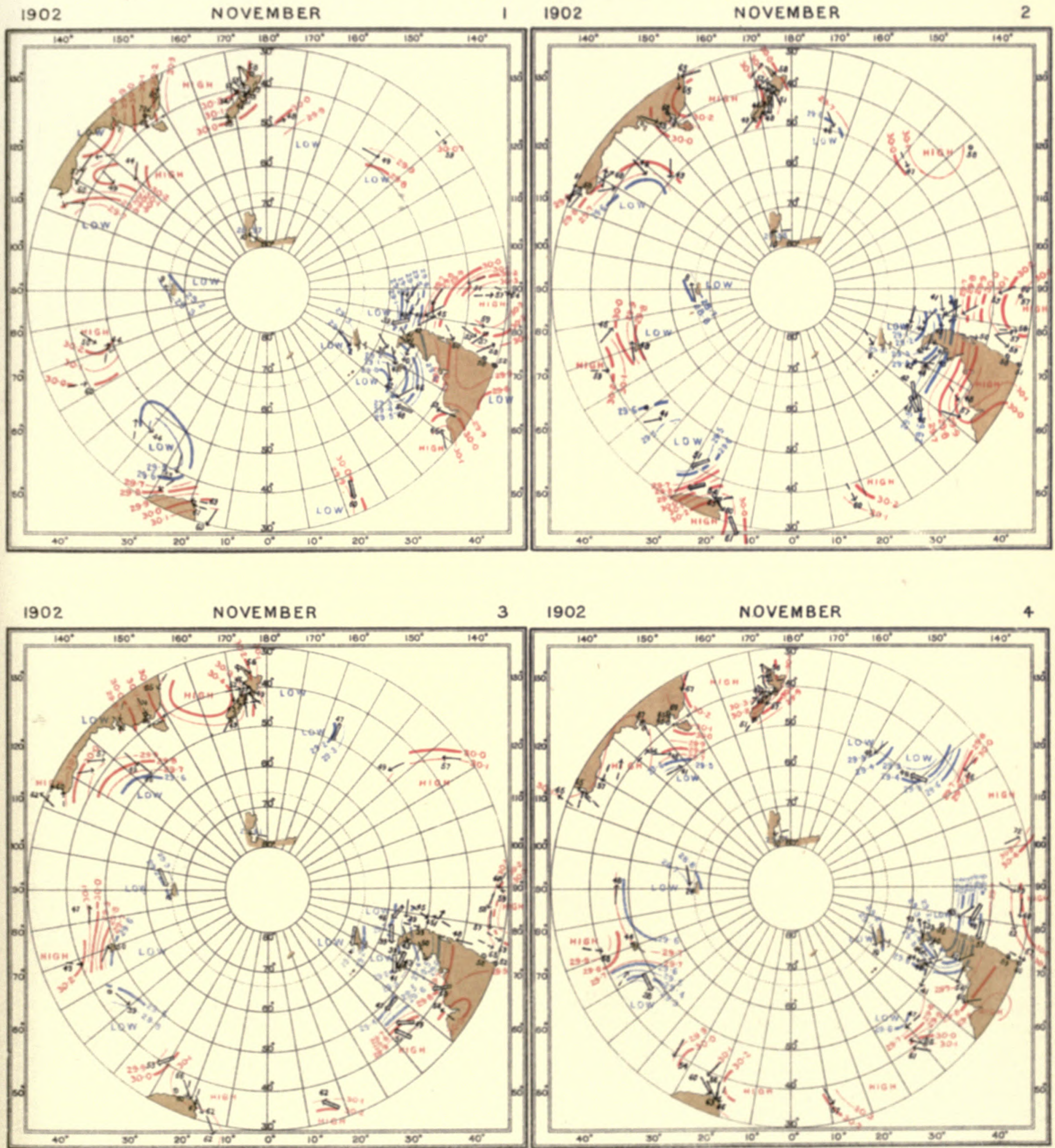

Hiuth, Londen. 
和

a 
$\vdots \vdots \vdots:: \cdots$

and 
INTERNATIONAL ANTARCTIC CO-OPERATION.

SYNCHRONOUS CHARTS OF SEA-LEVEL PRESSURE FOR NOON G.M.T.

WITH WINDS AND AIR TEMPERATURES.

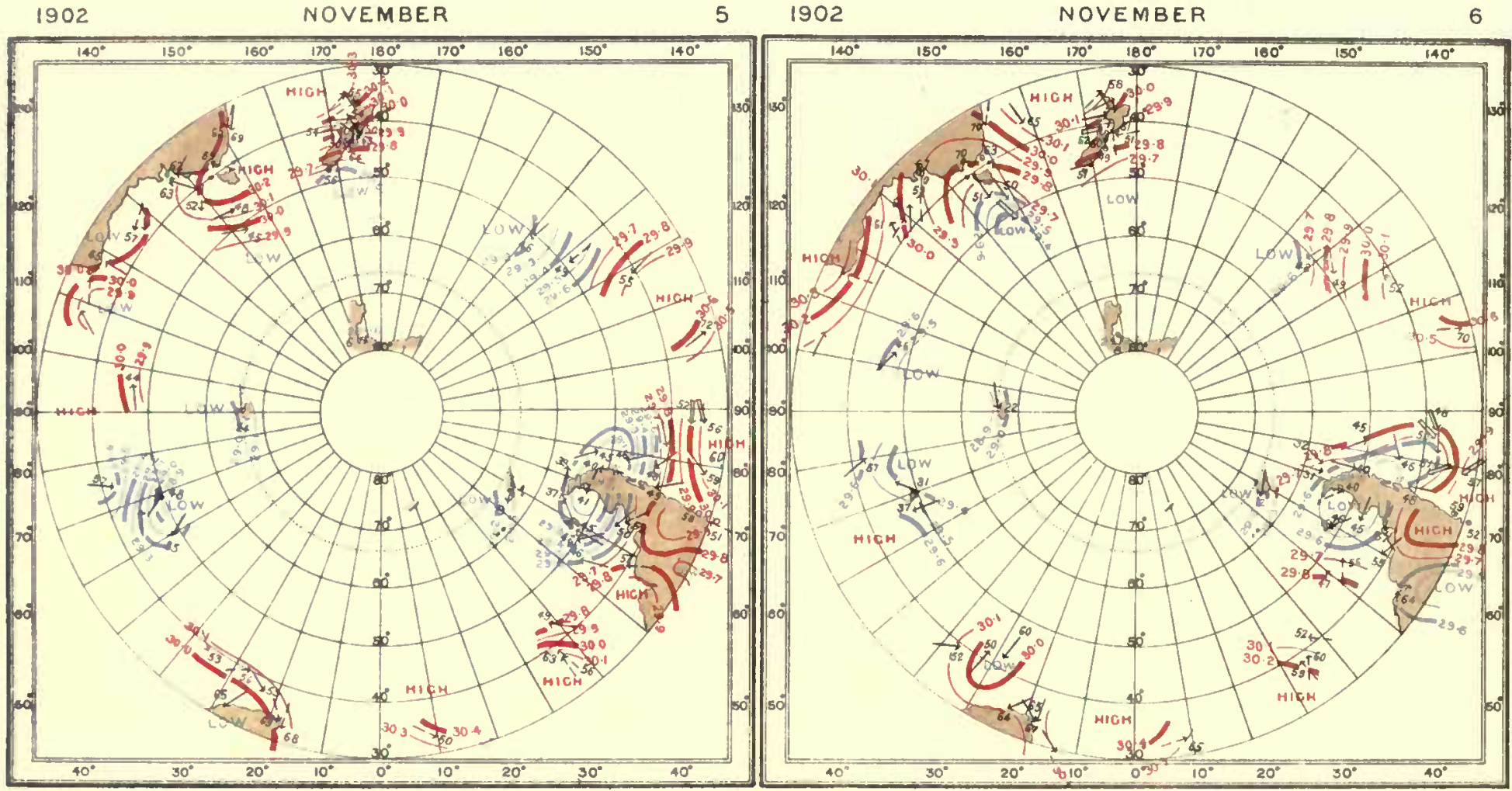

1902 NOVEMBER

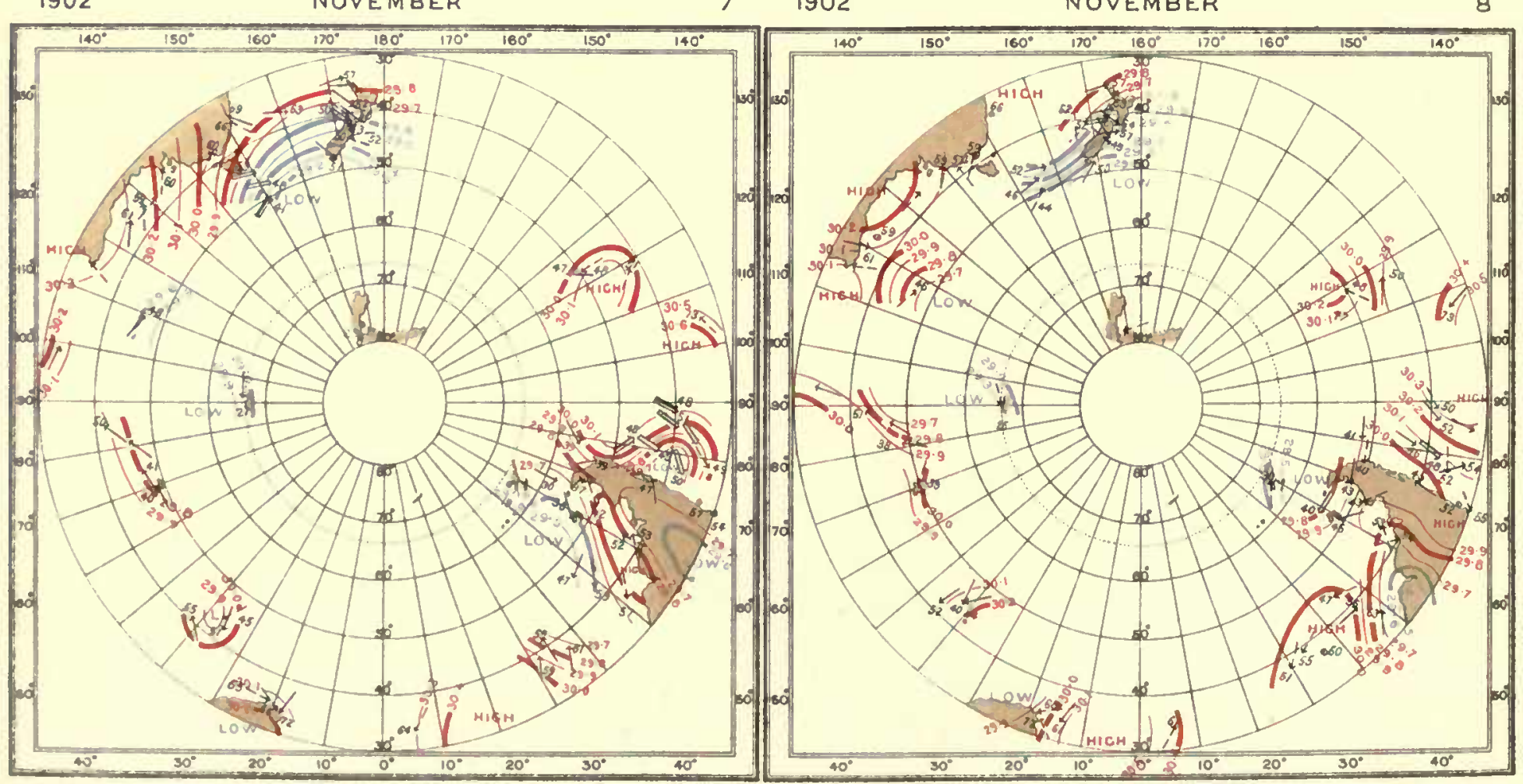


INTERNATIONAL ANTARCTIC COOPERATION $\because \because \ldots \ldots: \because \because \vdots \vdots$

SYNCHRONOUS CHARTS OF SEA-LEVEL PRESSURE FOR NOON G.M.T.

WITH WINDS AND AIR TEMPERATURES

1902 NOVEMBER

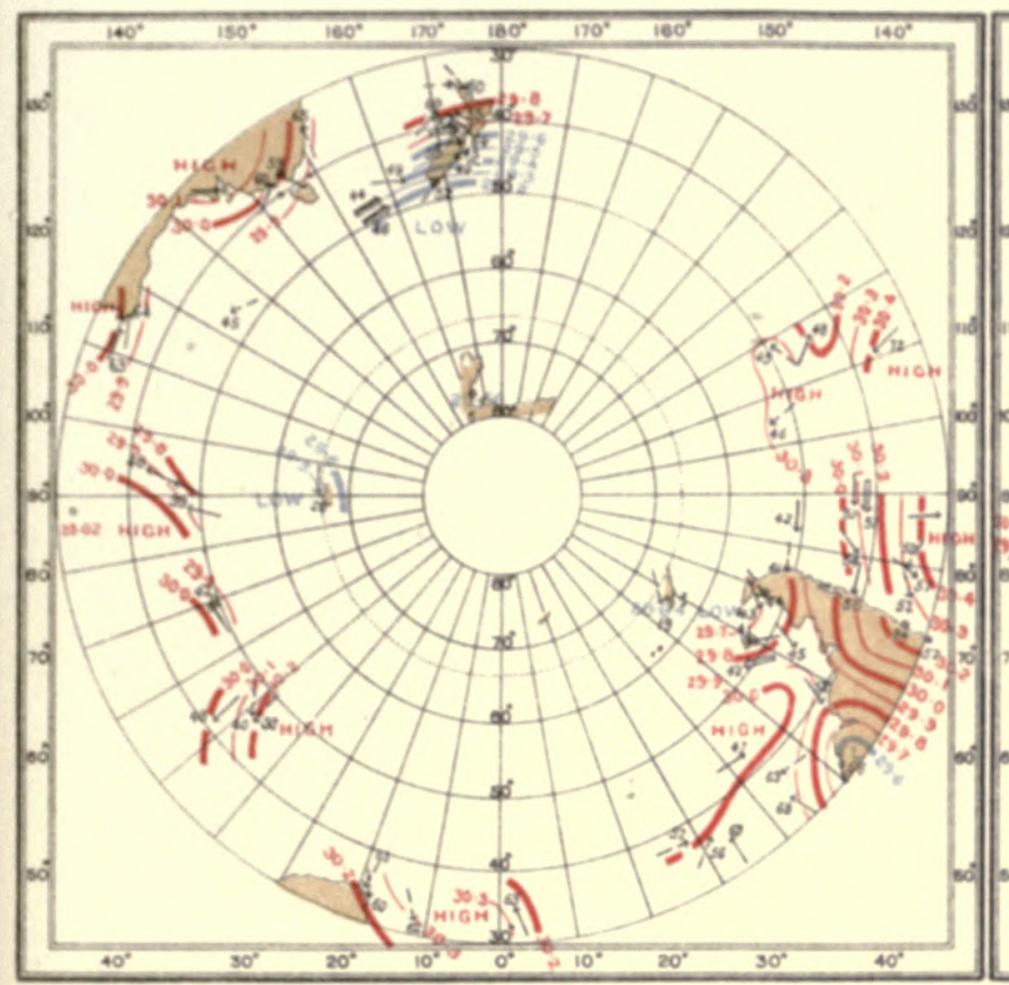

1902 NOVEMBER

10
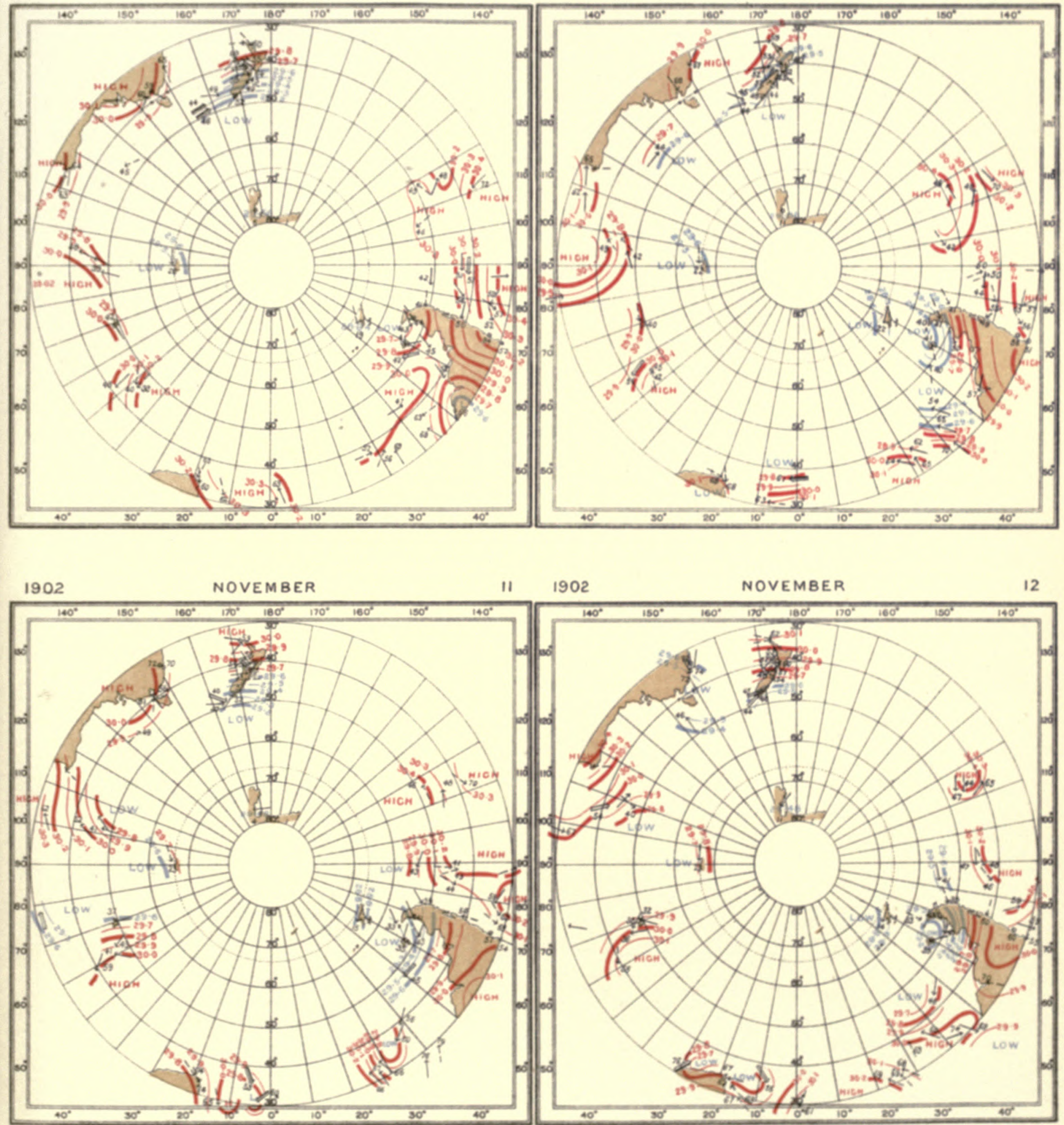

Huth London. 
$\because \because \vdots \quad \because \vdots \vdots \vdots \vdots \vdots \vdots \vdots \vdots \vdots 0$

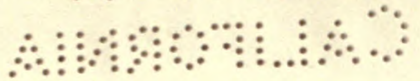


$: \vdots_{i}, \ldots$

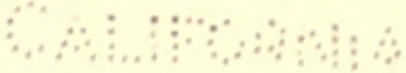


INTERNATIONAL ANTARCTIC CO-OPERATION.

SYNCHRONOUS CHARTS OF SEA-LEVEL PRESSURE FOR NOON G.M.T

WITH WINDS ANO AIR TEMPERATURES.
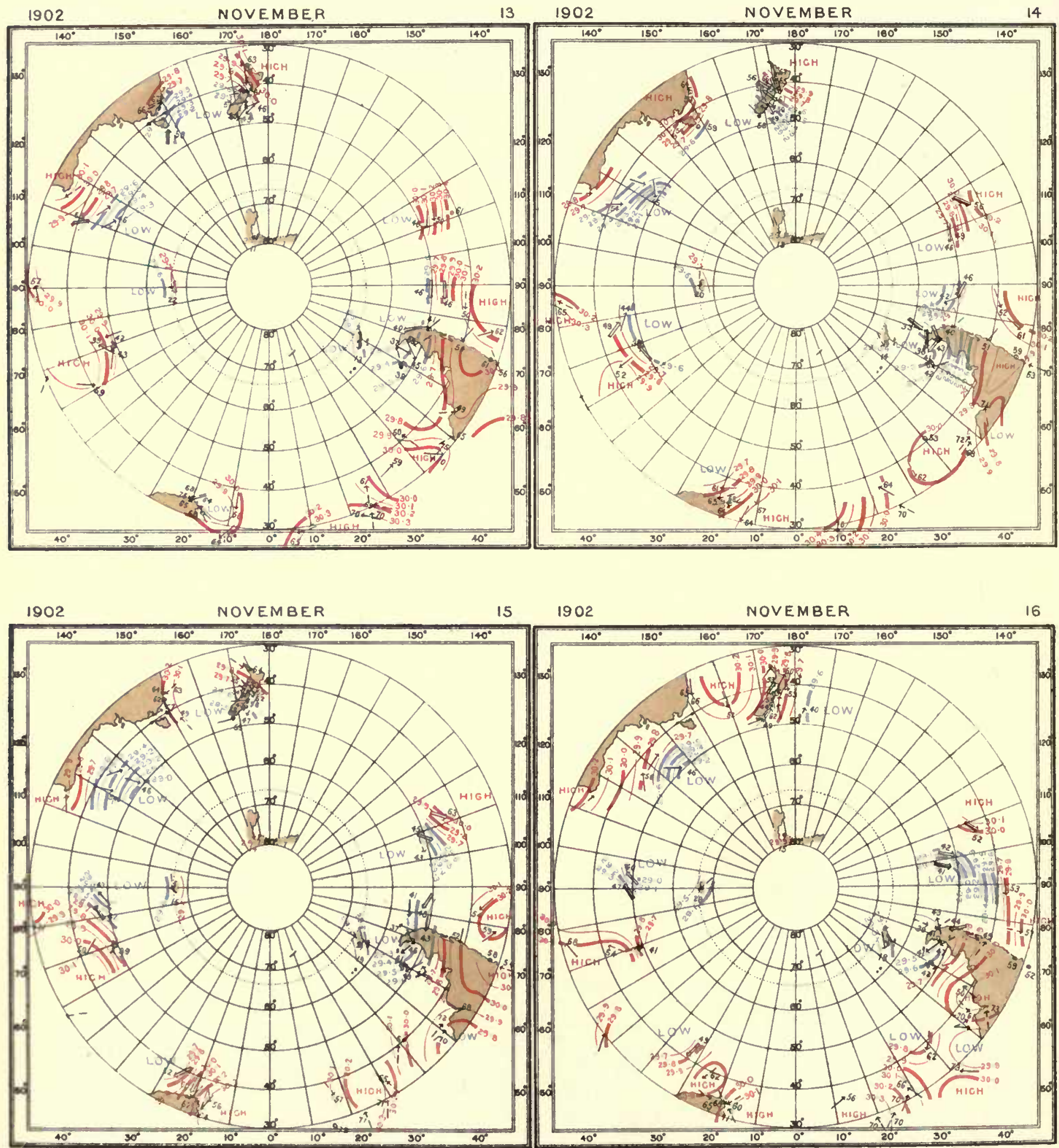
INTERNATIONAL ANTARCTIC CO-OPERATION.

SYNCHRONOUS CHARTS OF SEALEVEL PRESSURE FOR NOON G.M.T.

WITH WINDS AND AIR TEMPERATURES
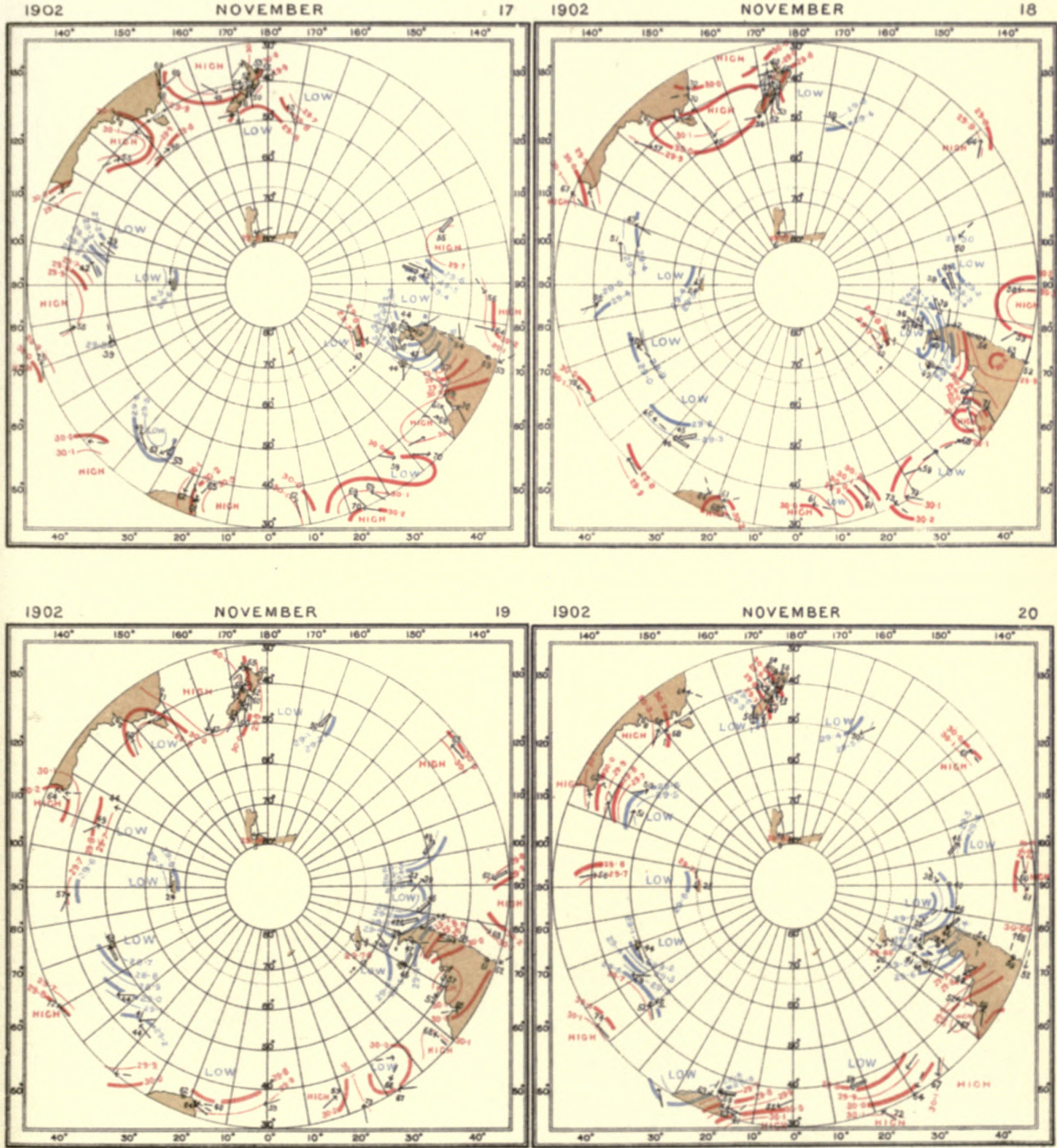


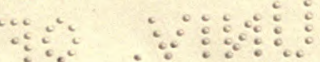

a 


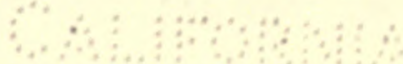


INTERNATIONAL ANTARCTIC COOPERATION.

SYNGHRONOUS CHARTS OF SEALEVEL PRESSURE FOR NOON G,M.T.

WITH WINDS AND AIR TEMPERATURES.
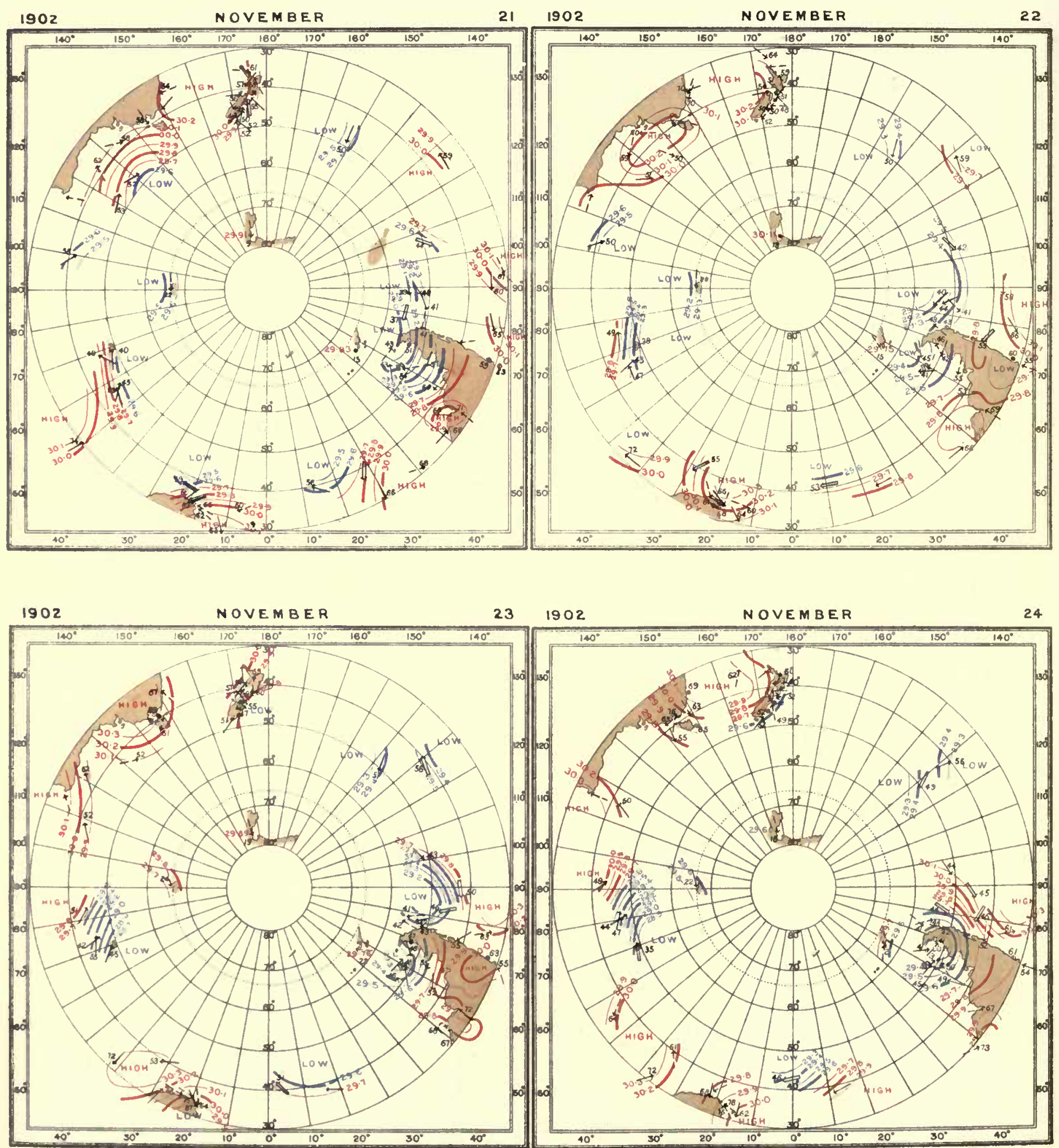
INTERNATIONAL ANTARCTIC CO-OPERATION.

SYNCHRONOUS CHARTS OF SEALEVEL PRESSURE FOR NOON G.M.T.

WITH WINDS AND AIR TEMPERATURES
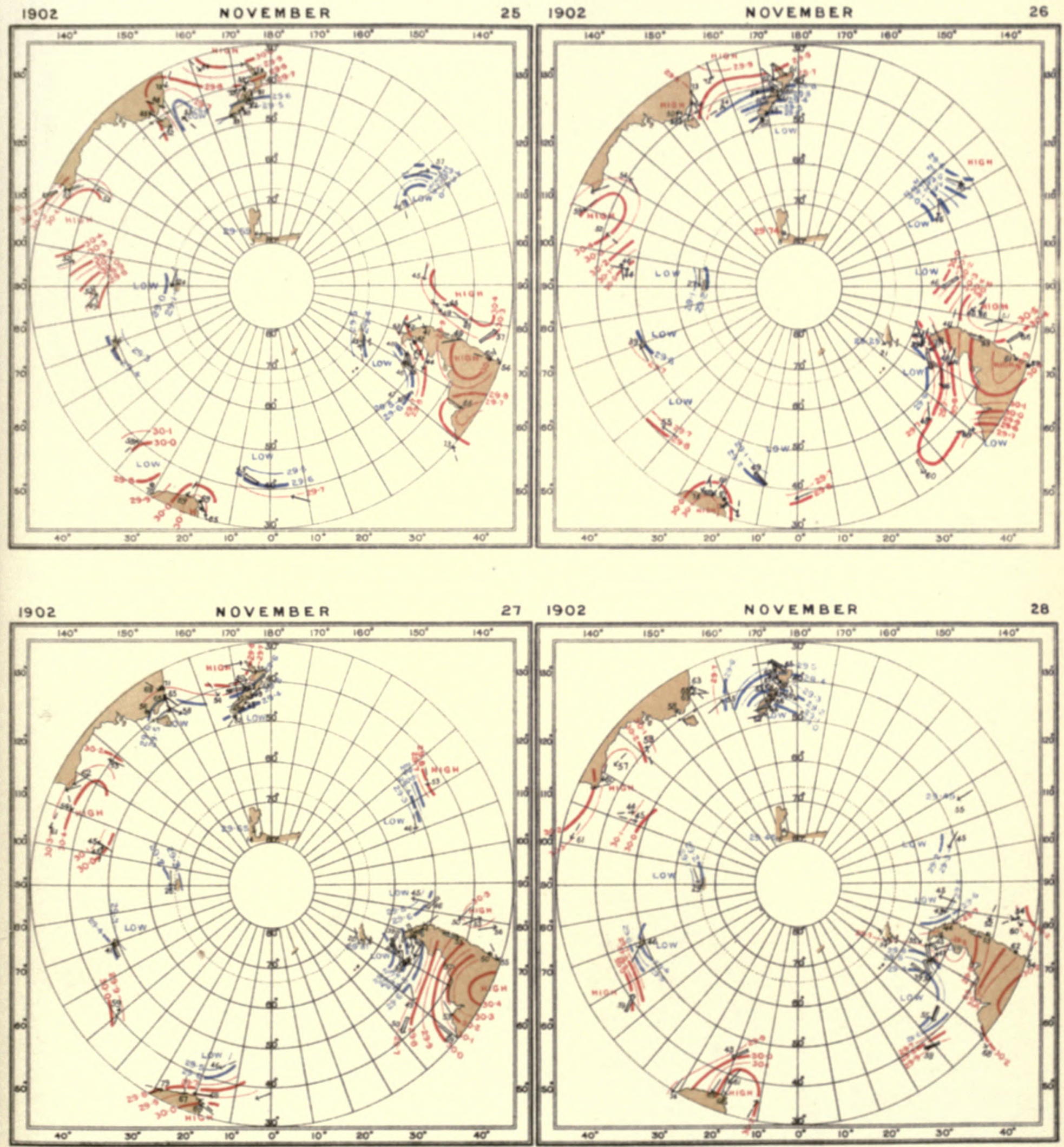
$\because \because \quad \because \vdots \vdots \vdots \vdots \vdots \vdots \vdots \vdots \vdots \vdots 0$

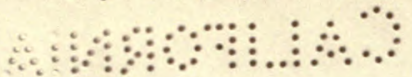




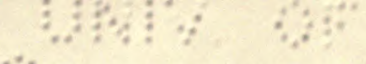

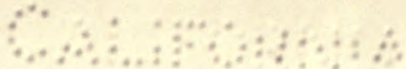


INTERNATIONAL ANTARCTIC CO-OPERATION.

SYNGHRONOUS CHARTS OF SEA-LEVEL PRESSURE FOR NOON G.M.T.

WITH WINDS AND AIR TEMPERATURES.
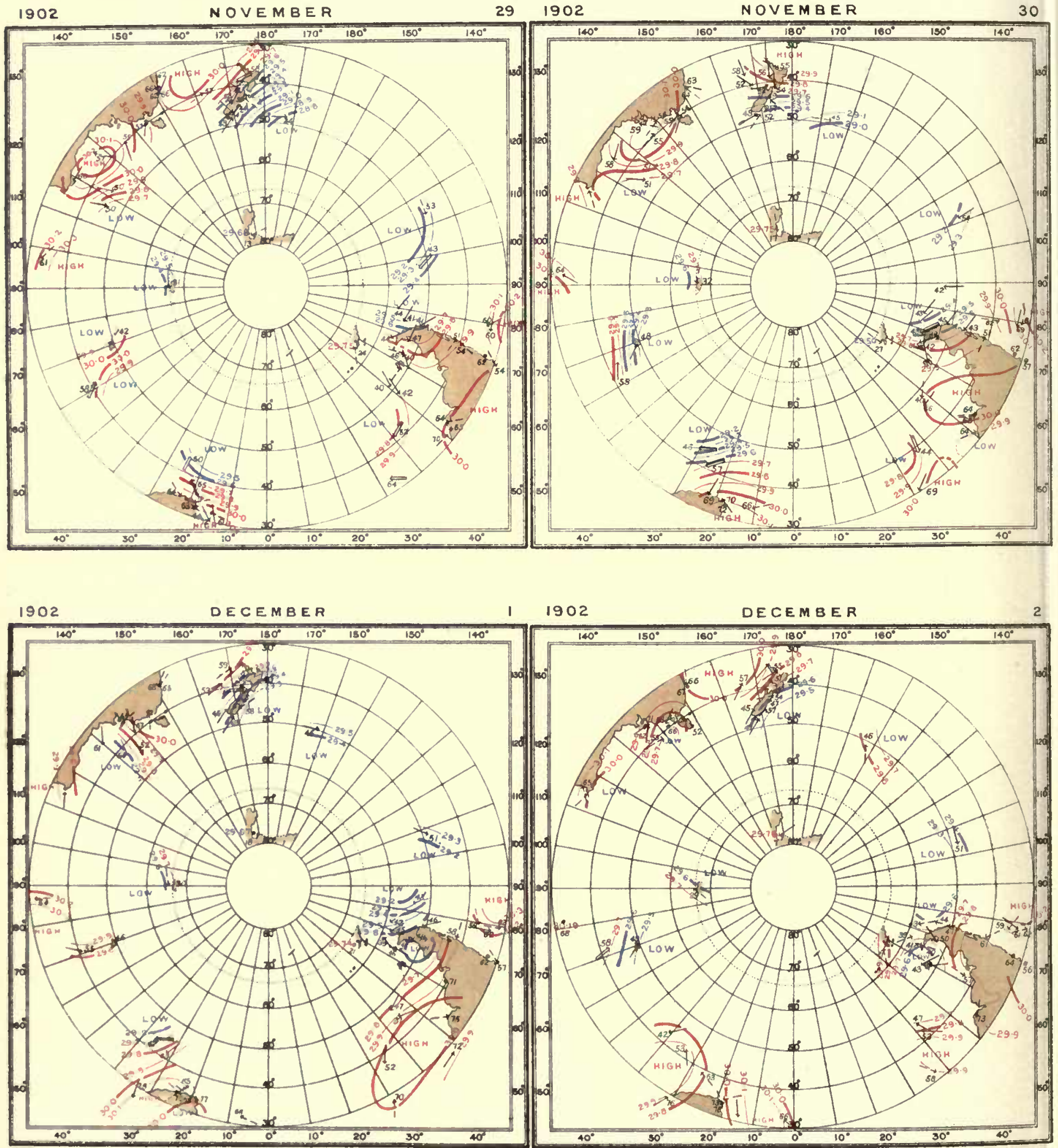
INTERNATIONAL ANTARCTIC CO-OPERATION.

SYNCHRONOUS CHARTS OF SEA-LEVEL PRESSURE FOR NOON G.M.T.

WITH WINDS AND AIR TEMPERATURES.
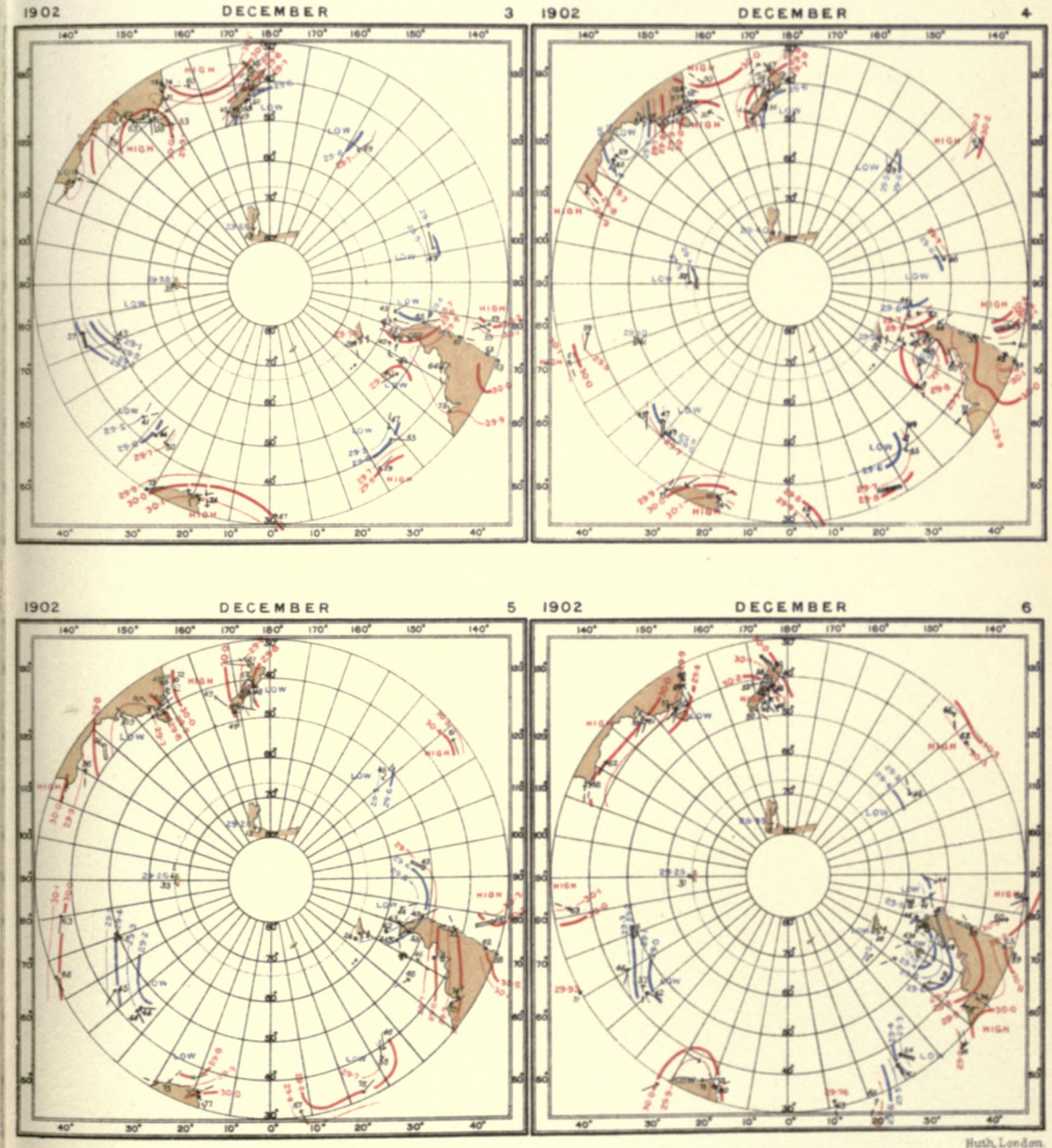
40

a 
1\%

\% : 
INTERNATIONAL ANTARCTIC CO-OPERATION.

SYNCHRONOUS CHARTS OF SEA-LEVEL PRESSURE FOR NOON G.M.T.

WITH WINDS AND AIR TEMPERATURES.
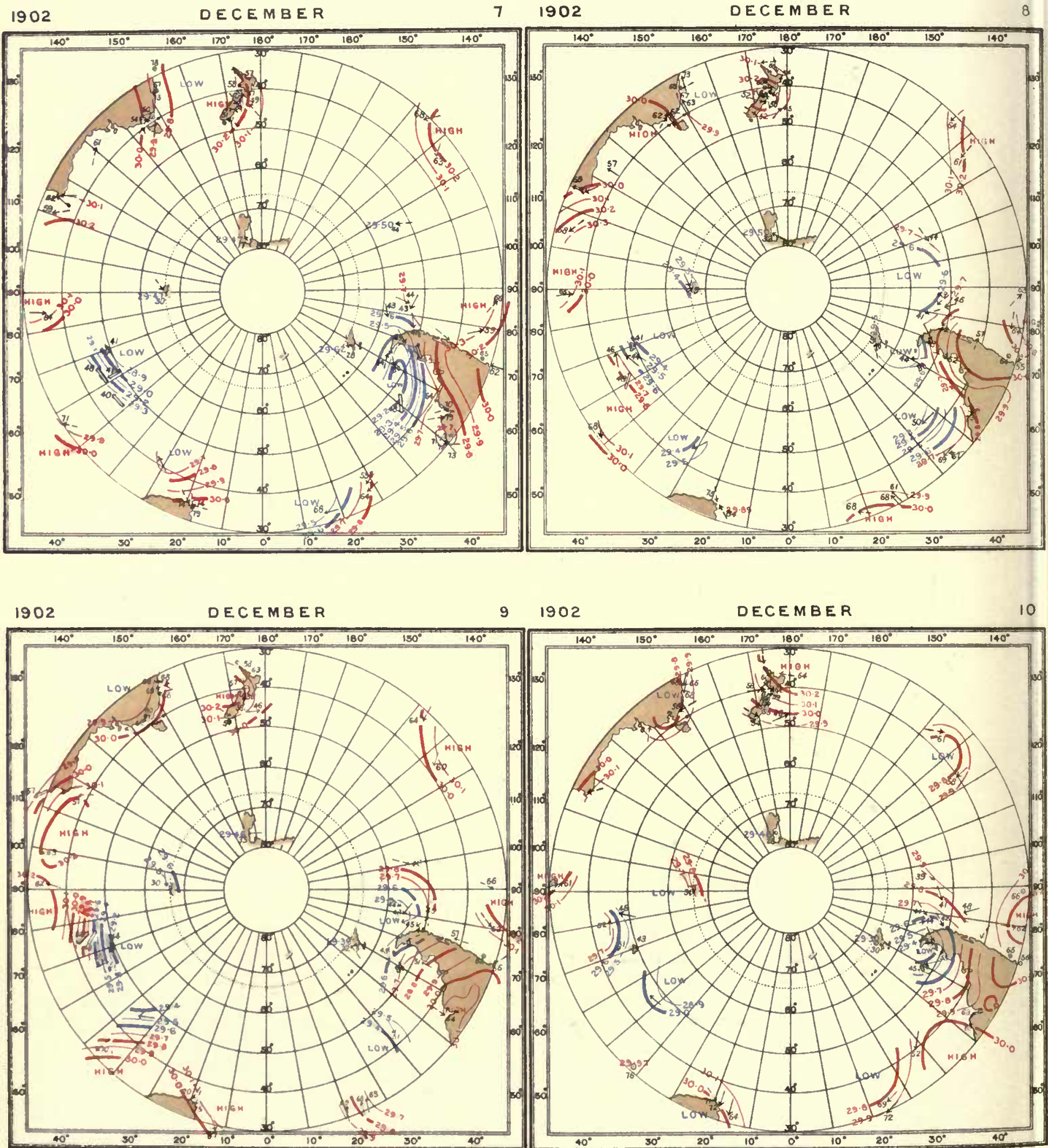
INTERNATIONAL ANTARCTIC CO-OPERATION.

SYNCHRONOUS CHARTS OF SEALEVEL PRESSURE FOR NOON G.M.T.

WITH WINDS AND AIR TEMPERATURES.
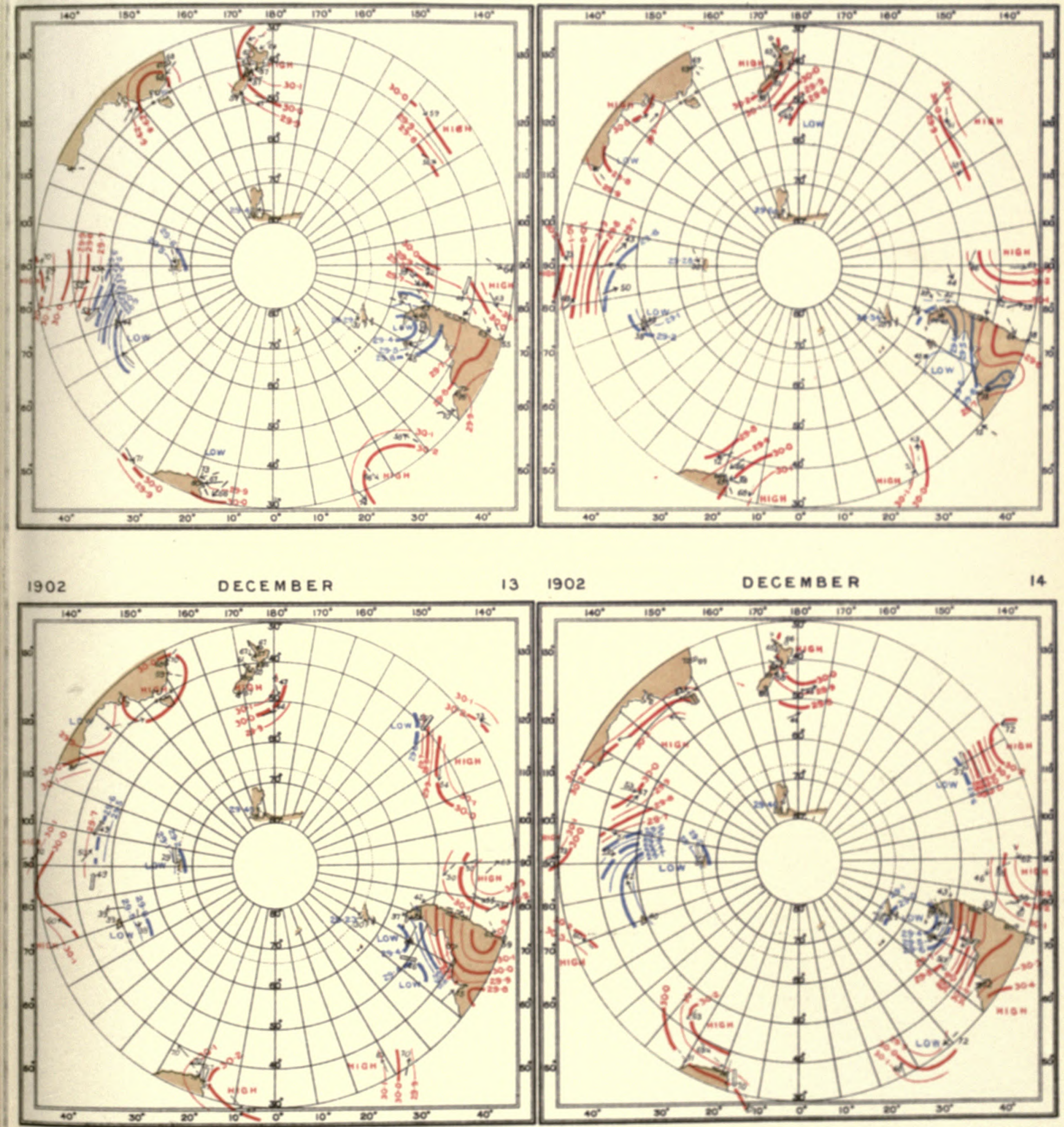
$\because \because \because \div \div$

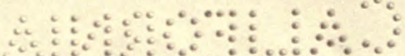




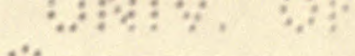

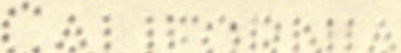


INTERNATIONAL ANTARCTIC COOOPRATION.

SYNCHRONOUS CHARTS OF SEA-LEVEL PRESSURE FOR NOON G.M.T

WITH WINDS AND AIR TEMPERATURES.

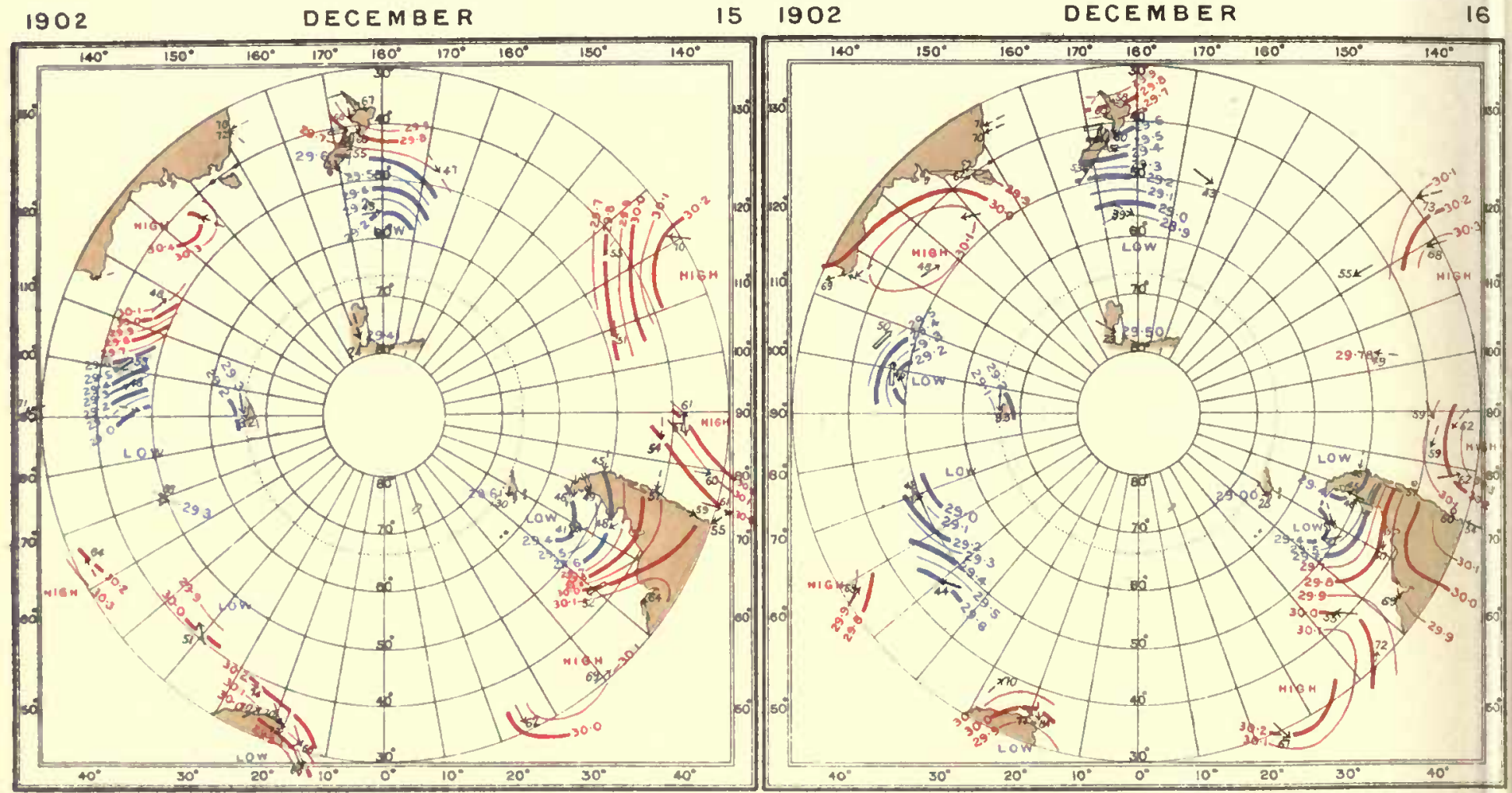

1902

DECEMBER

$17 \quad 1902$

DECEMBER

18

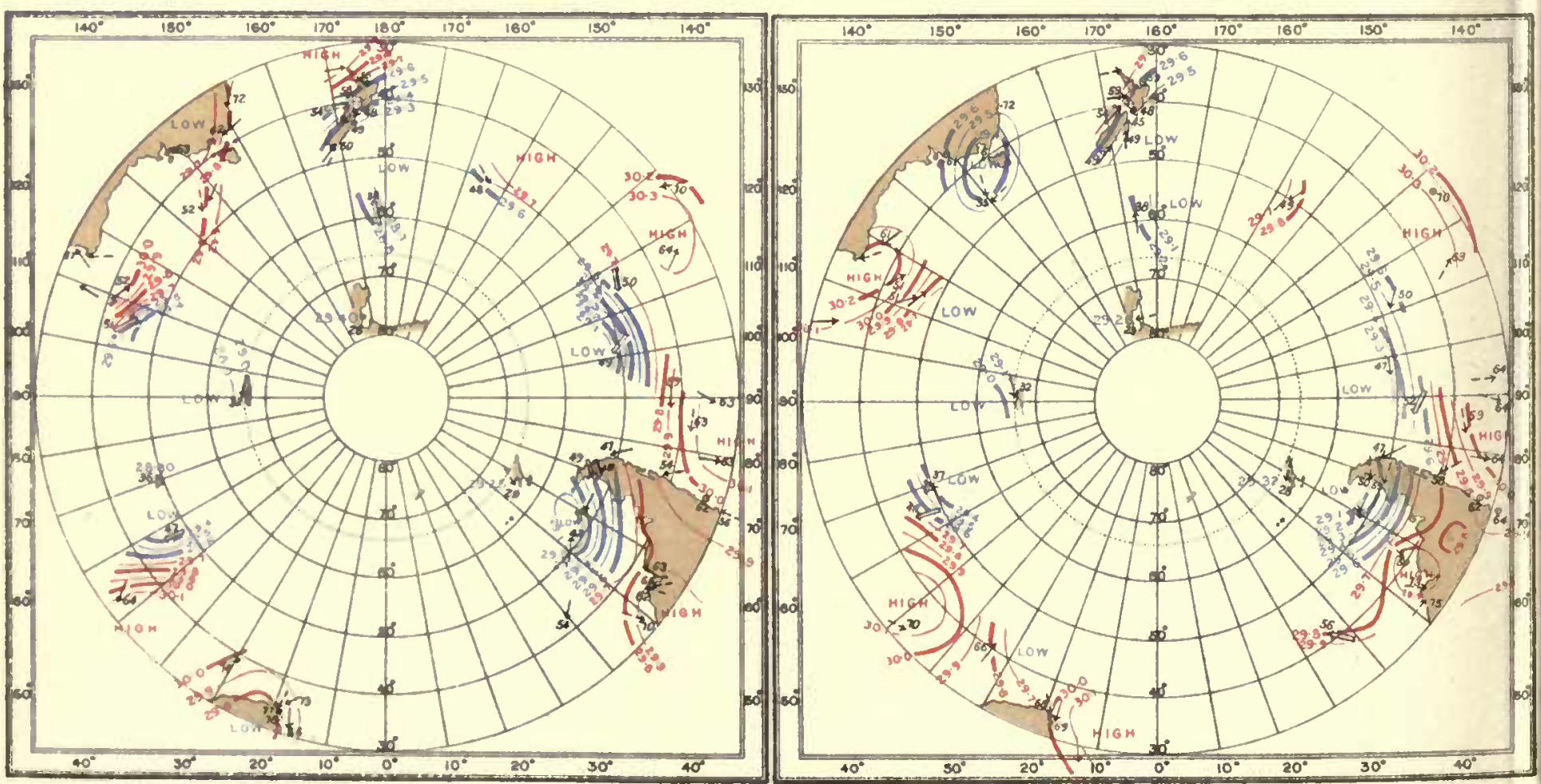


INTERNATIONAL ANTARCTIC CO-OPERATION.

SYNCHRONOUS CHARTS OF SEA-LEVEL PRESSURE FOR NOON G.M.T.

WITH WINDS AND AIR TEMPERATURES.

1902

DECEMBER

$19 \quad 1902$

DECEMBER

20
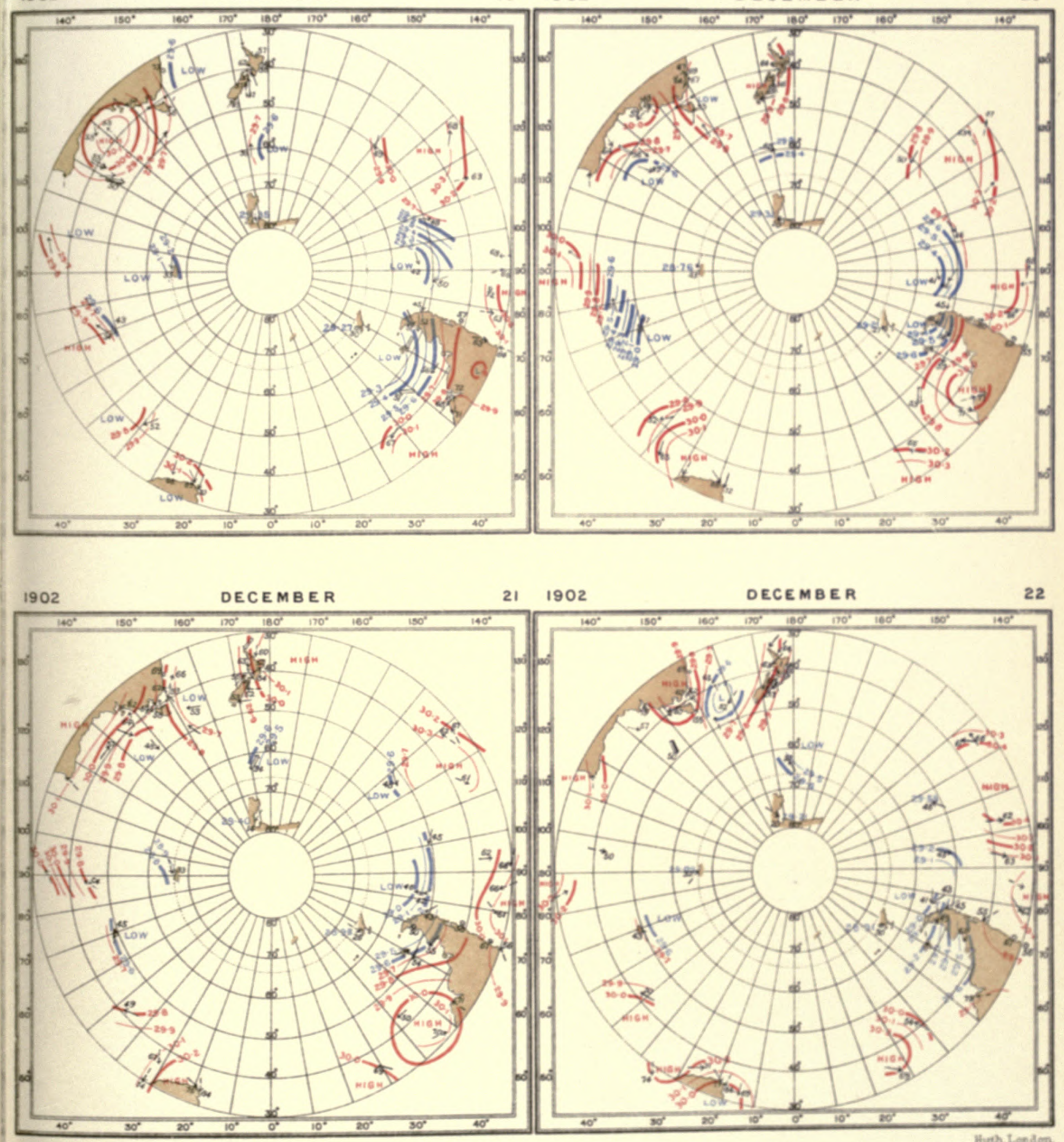
$\because \because \quad \because \because \vdots \vdots \vdots 0$

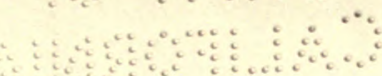




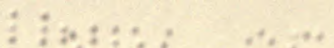

¿n 
INTERNATIONAL ANTARCTIC CO-OPERATION.

SYNCHRONOUS CHARTS OF SEA-LEVEL PRESSURE FOR NOON G.M.T.

WITH WINDS AND AIR TEMPERATURES.

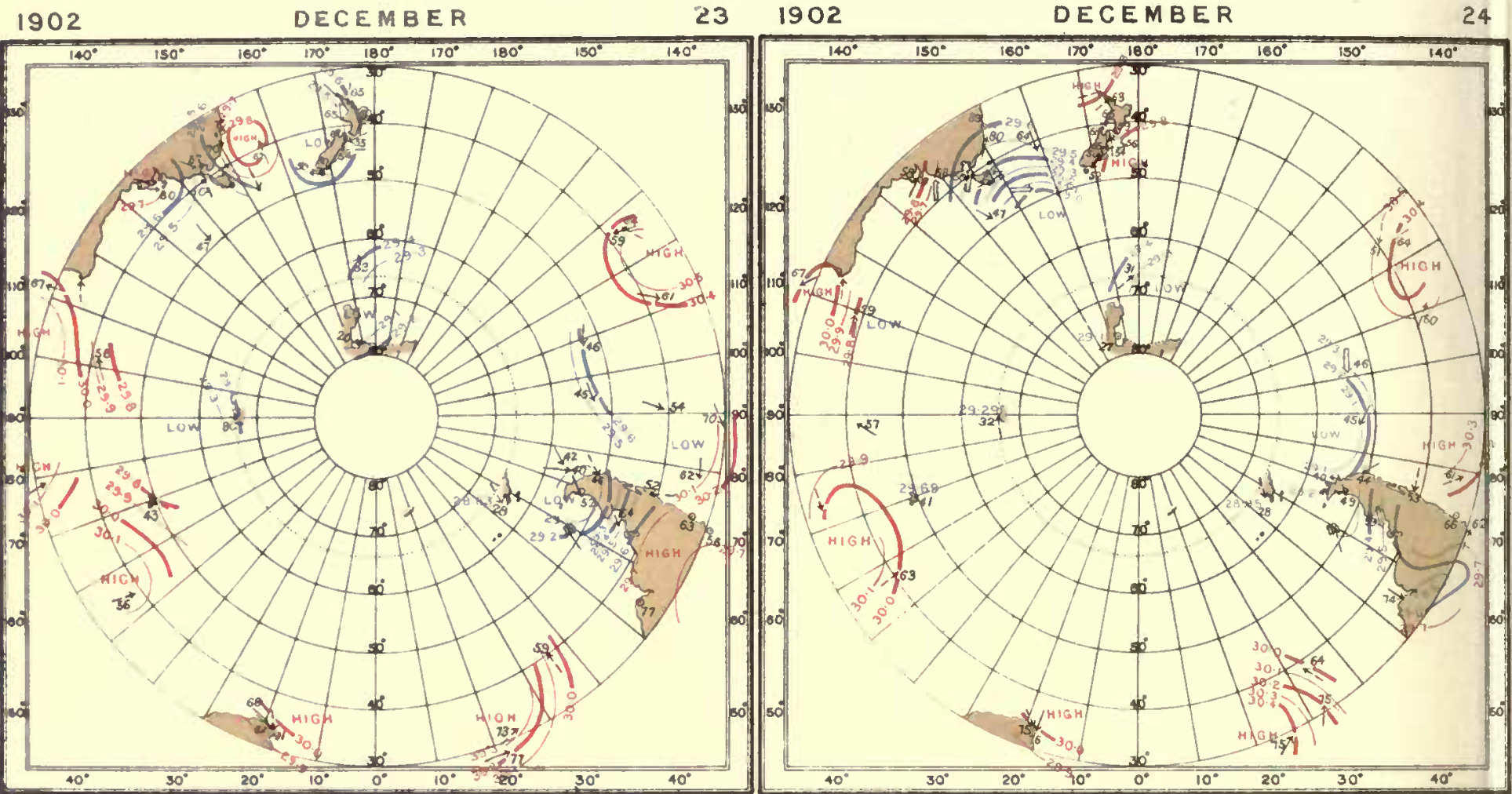

1902

DECEMBER

$25 \quad 1902$

DECEMBER

26

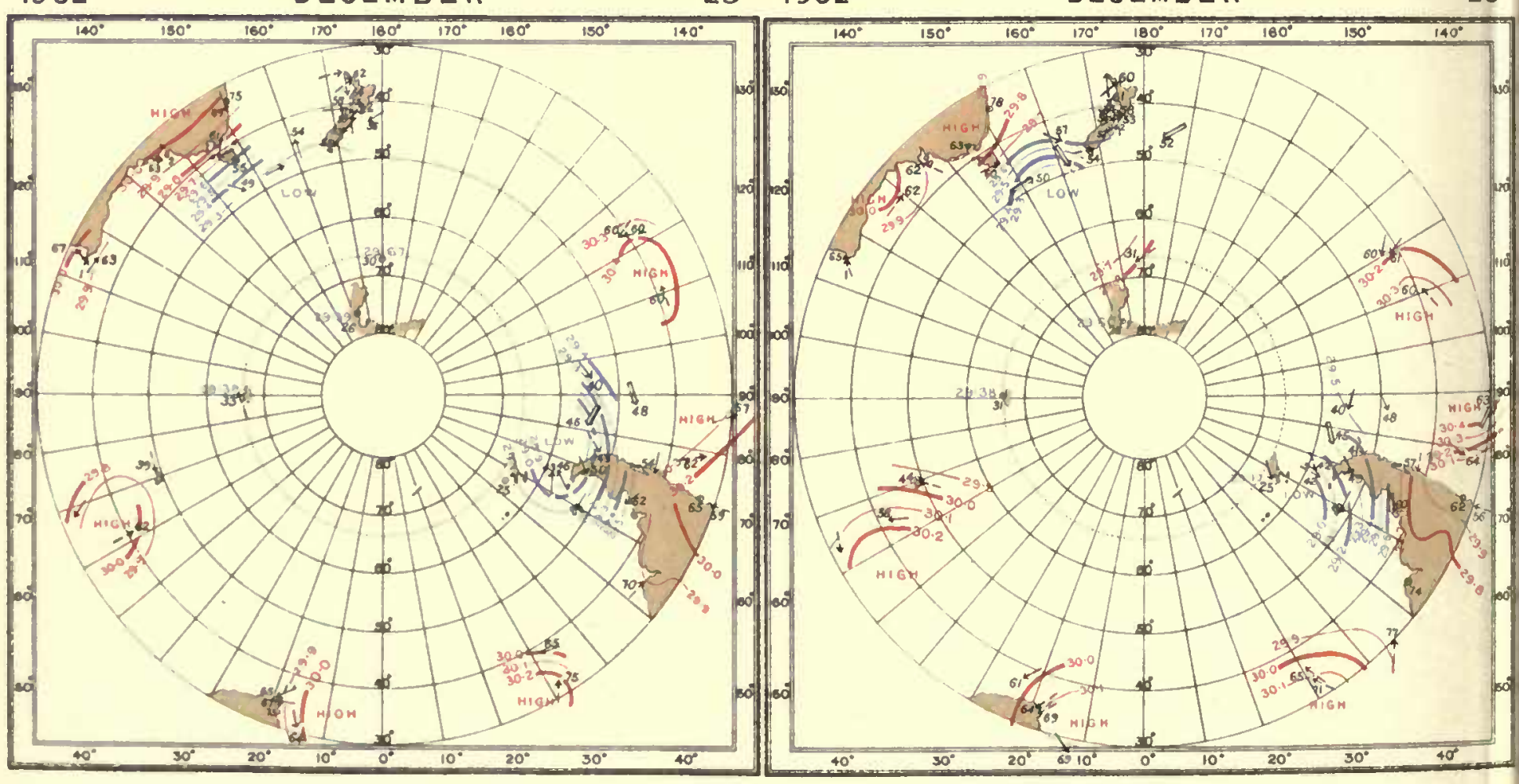


$\because 40$

$\therefore$ a 

INTERNATIONAL ANTARCTIC CO-OPERATION.

SYNCHRONOUS CHARTS OF SEA-LEVEL PRESSURE FOR NOON GM.T

WITH WINDS AND AIR TEMPERATURES
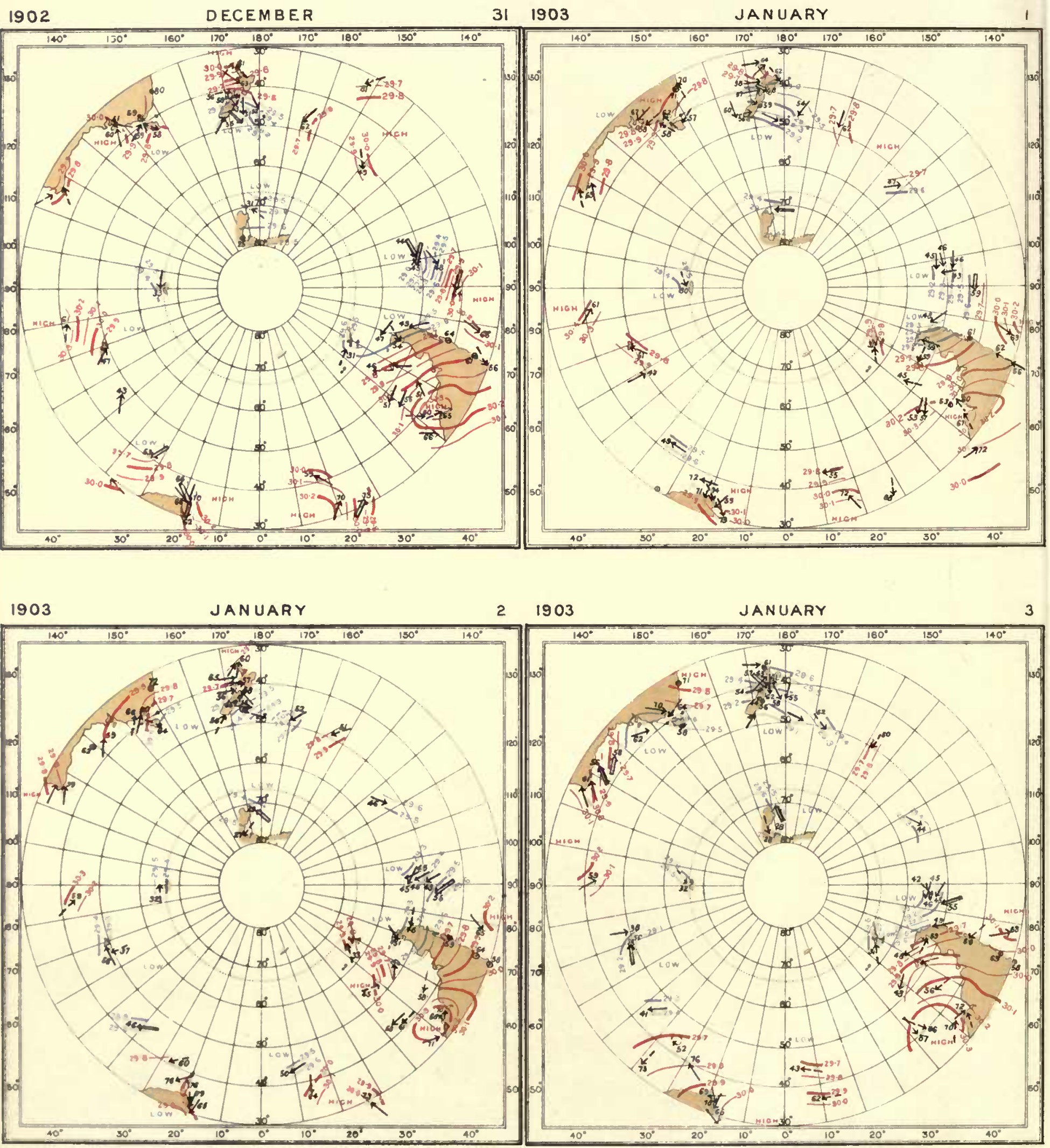
INTERNATIONAL ANTARCTIC CO-OPERATION.

SYNCHRONOUS CHARTS OF SEALLEVEL PRESSURE FOR NOON GM.T

WITH WINDS AND AIR TEMPERATURES.
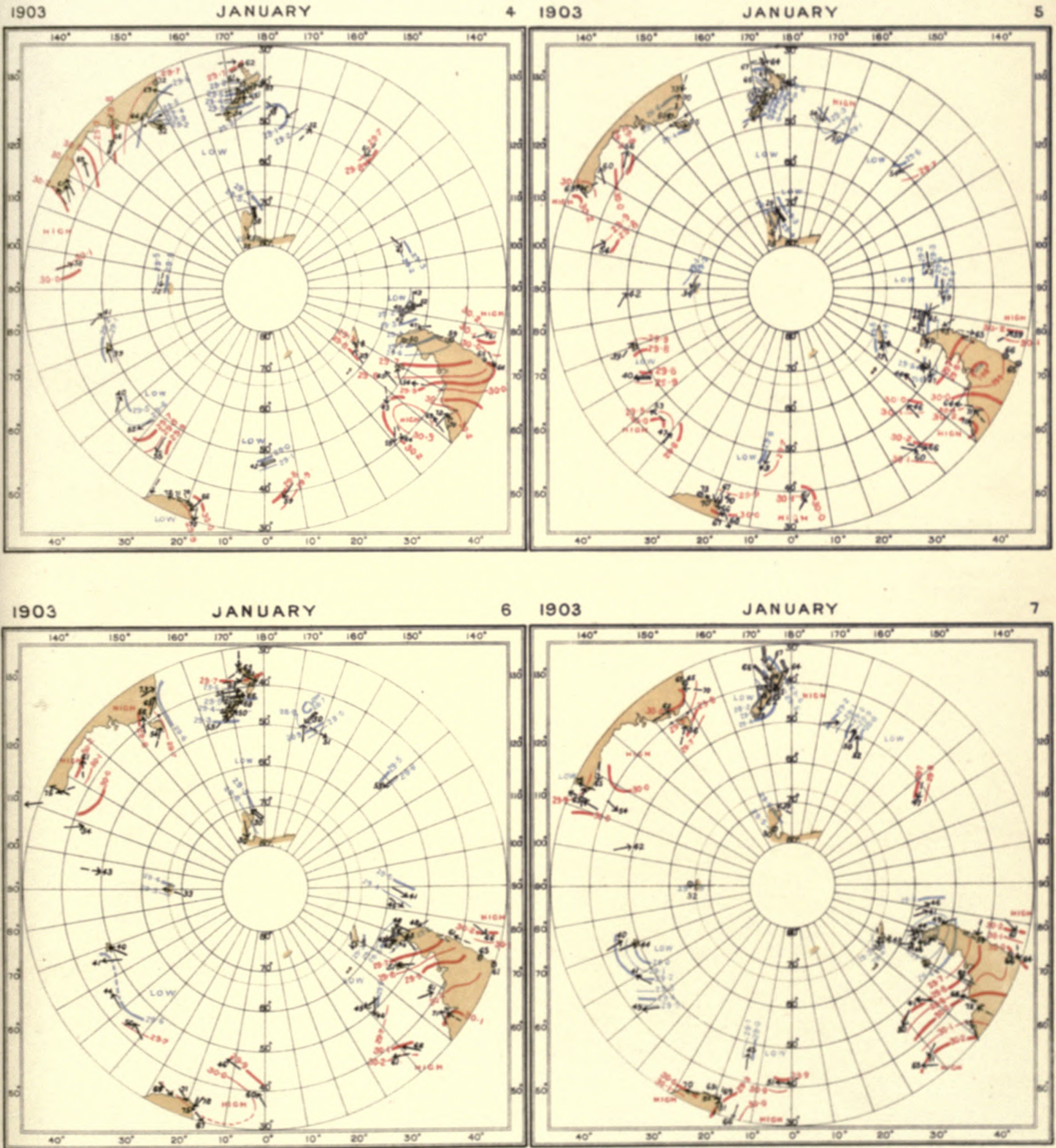
$\because \vdots \quad \because \because 30$

$\therefore$ a 
at?

a d

a. 
INTERNATIONAL ANTARCTIC COOPERATION.

SYNCHRONOUS CHARTS OF SEA-LEVEL PRESSURE FOR NOON GM.T.

WITH WINDS AND AIR TEMPERATURES
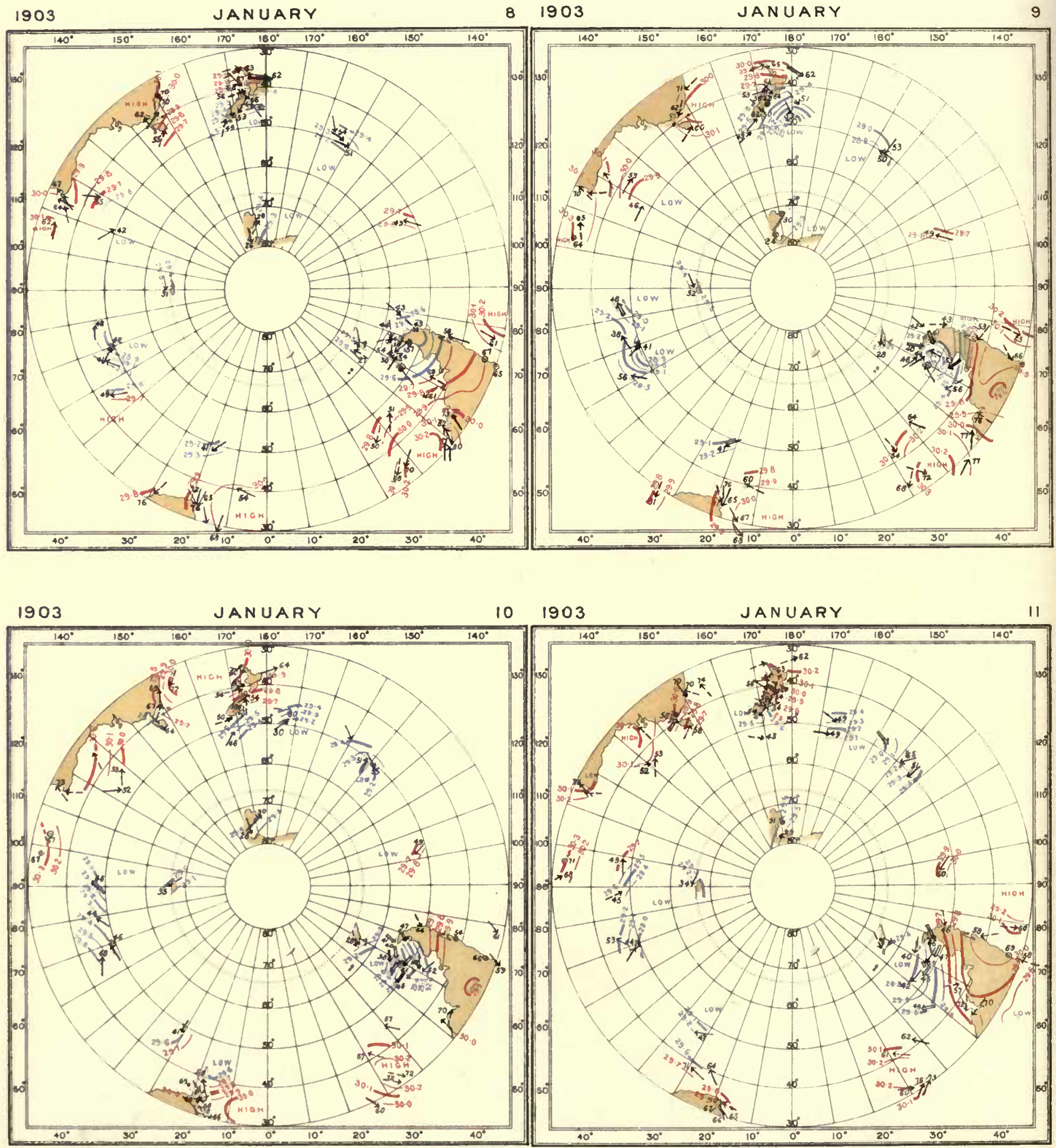
INTERNATIONAL ANTARCTIC CO-OPERATION

SYNCHRONOUS CHARTS OF SEA-LEVEL PRESSURE FOR NOON G.M.T

WITH WINDS AND AIR TEMPERATURES
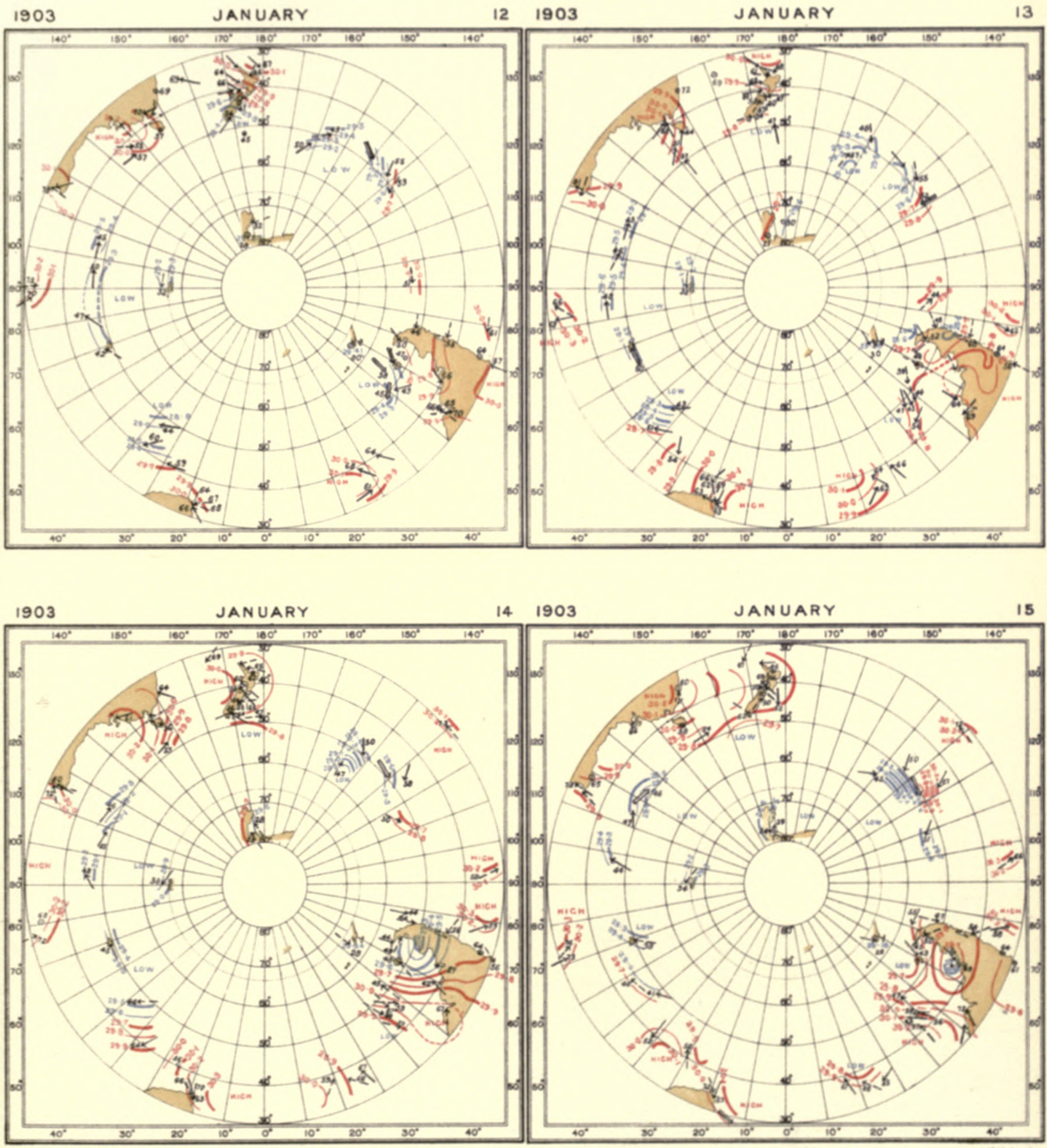
$\because \vdots=\quad \because \vdots \because \vdots \vdots$

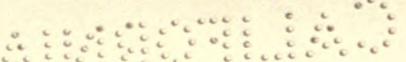




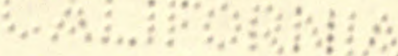


INTERNATIONAL ANTARCTIC COOOPERATION

SYNCHRONOUS CHARTS OF SEALEVEL PRESSURE FOR NOON G.M.T

WITH WINDS AND AIR TEMPERATURES.
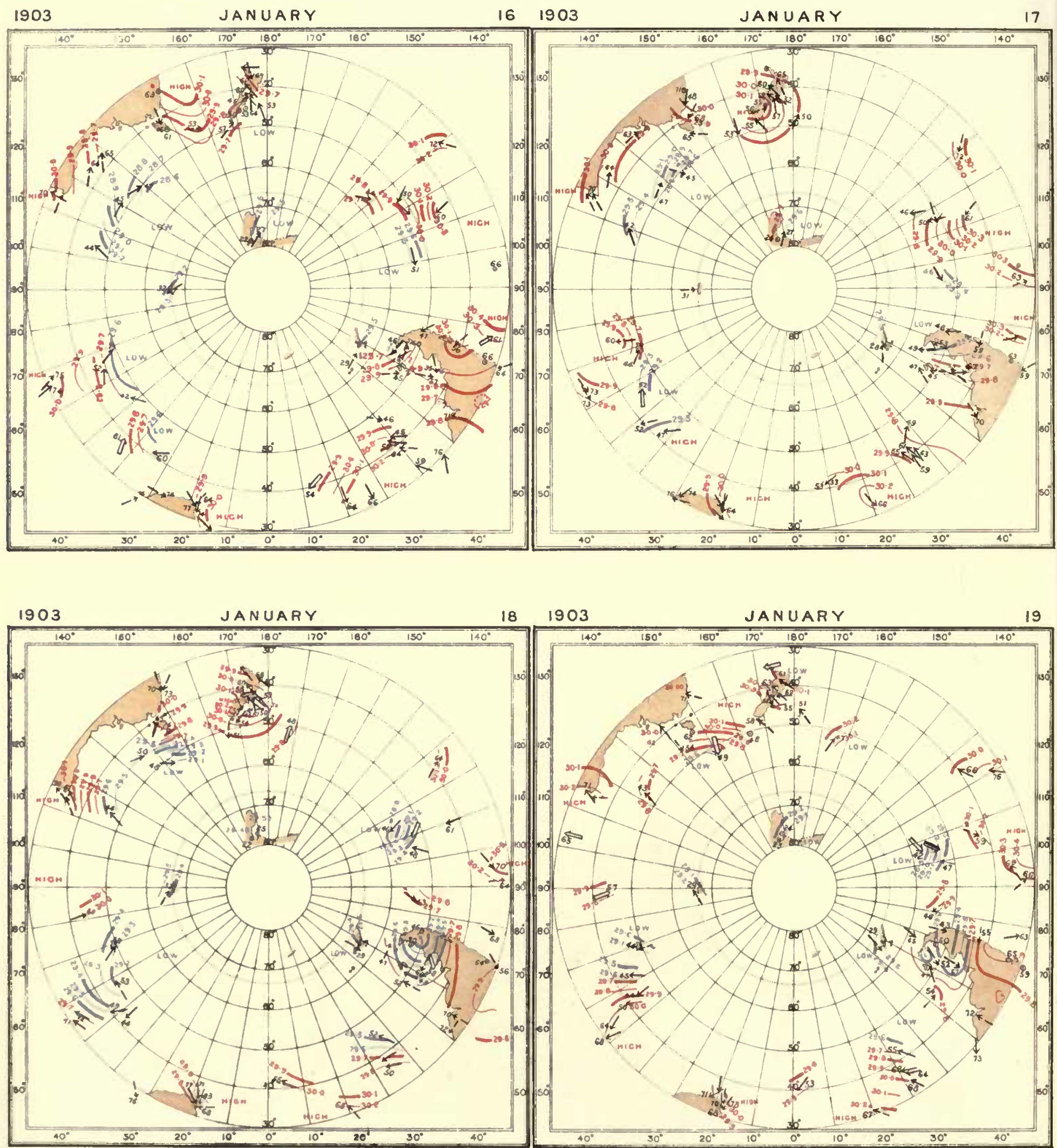
INTERNATIONAL ANTARCTIC CO-OPERATION.

SYNCHRONOUS CHARTS OF SEA-LEVEL PRESSURE FOR NOON G.M.T

WITH WINDS AND AIR TEMPERATURES

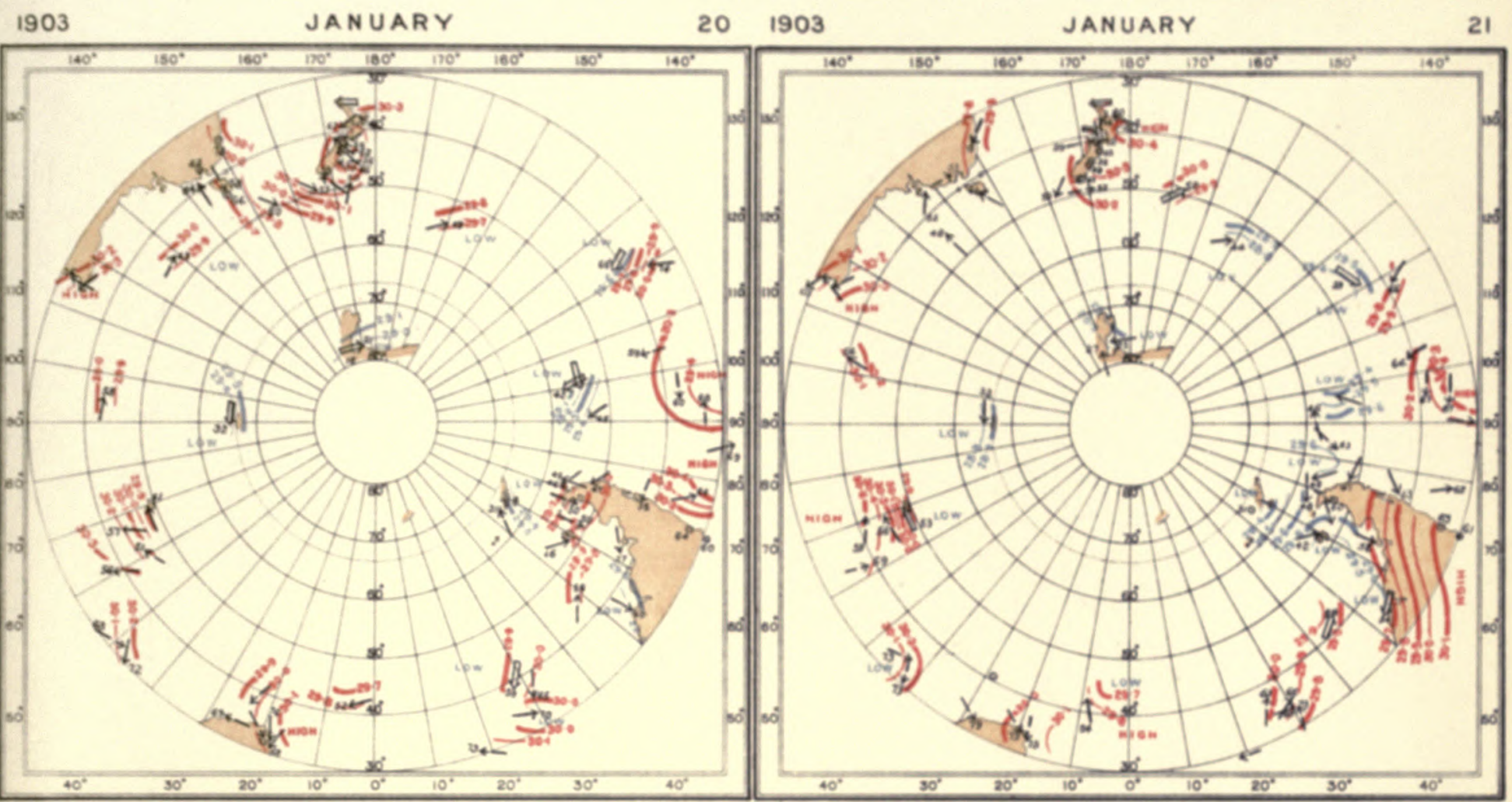

$1903 \quad$ JANUARY 52

1903 JANUARY

23

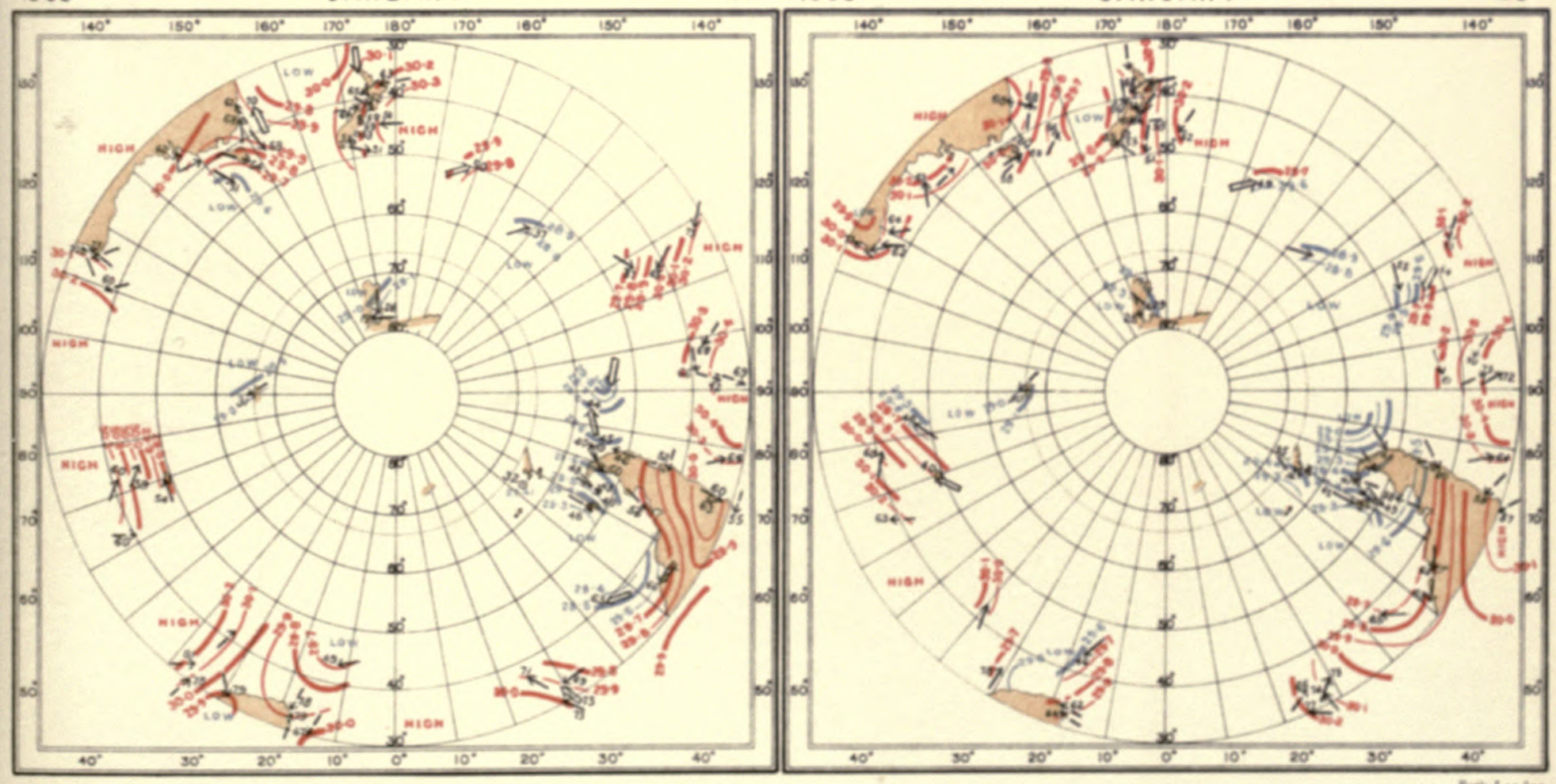


$\because \because=\quad \because \because \vdots \vdots \vdots \vdots \vdots \vdots \vdots 0$

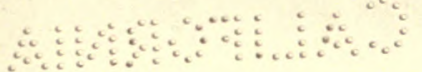

• 


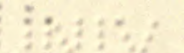

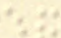

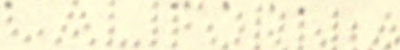


INTERNATIONAL ANTARCTIC COOPERATION.

SYNCHRONOUS CHARTS OF SEA-LEVEL PRESSURE FOR NOON G.M.T.

WITH WINOS AND AIR TEMPERATURES
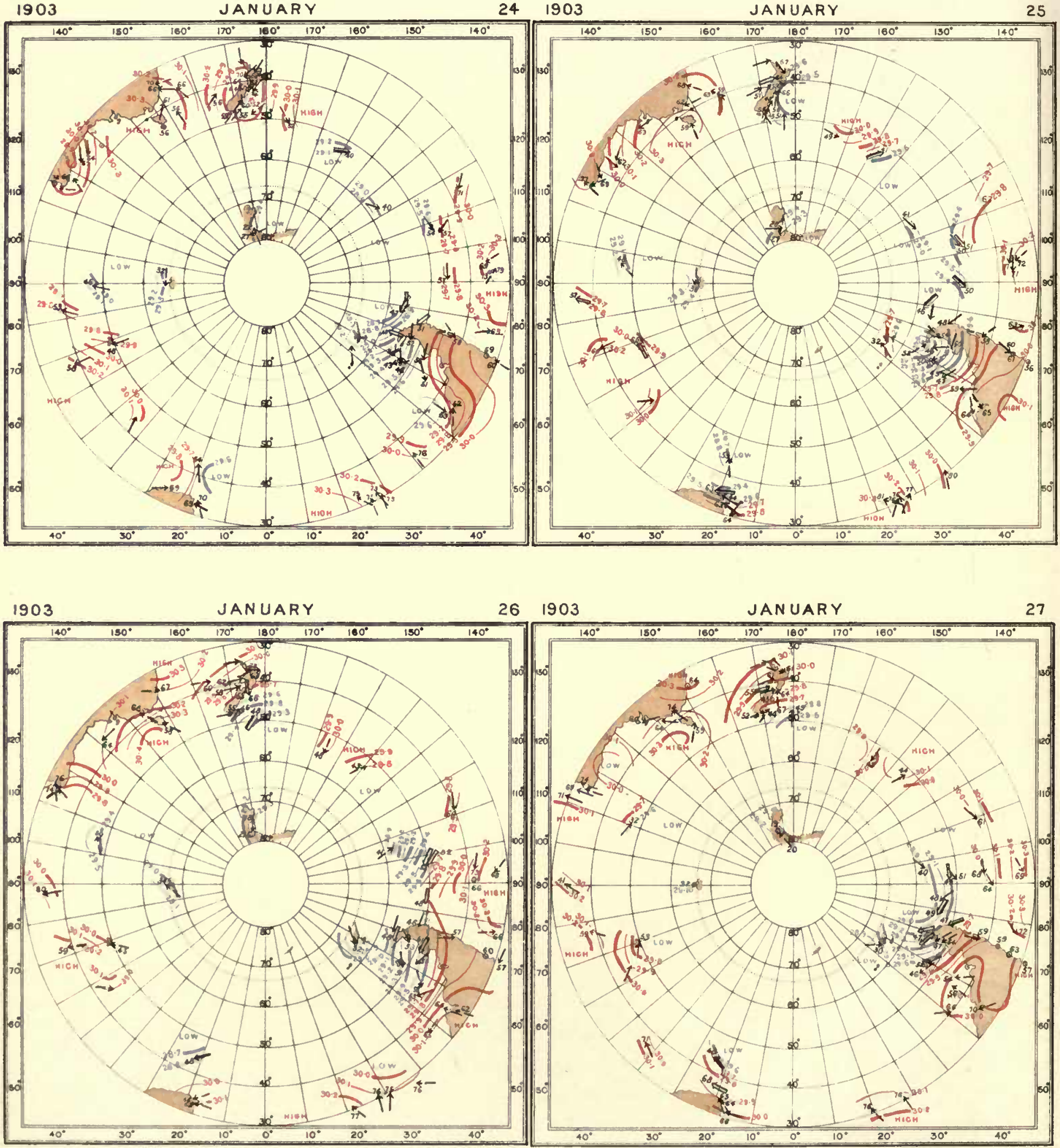
INTERNATIONAL ANTARCTIC COOOPERATION.

SYNCHRONOUS CHARTS OF SEALLVEL PRESSURE FOR NOON G.M.T.

WITH WINDS AND AIR TEMPERATURES

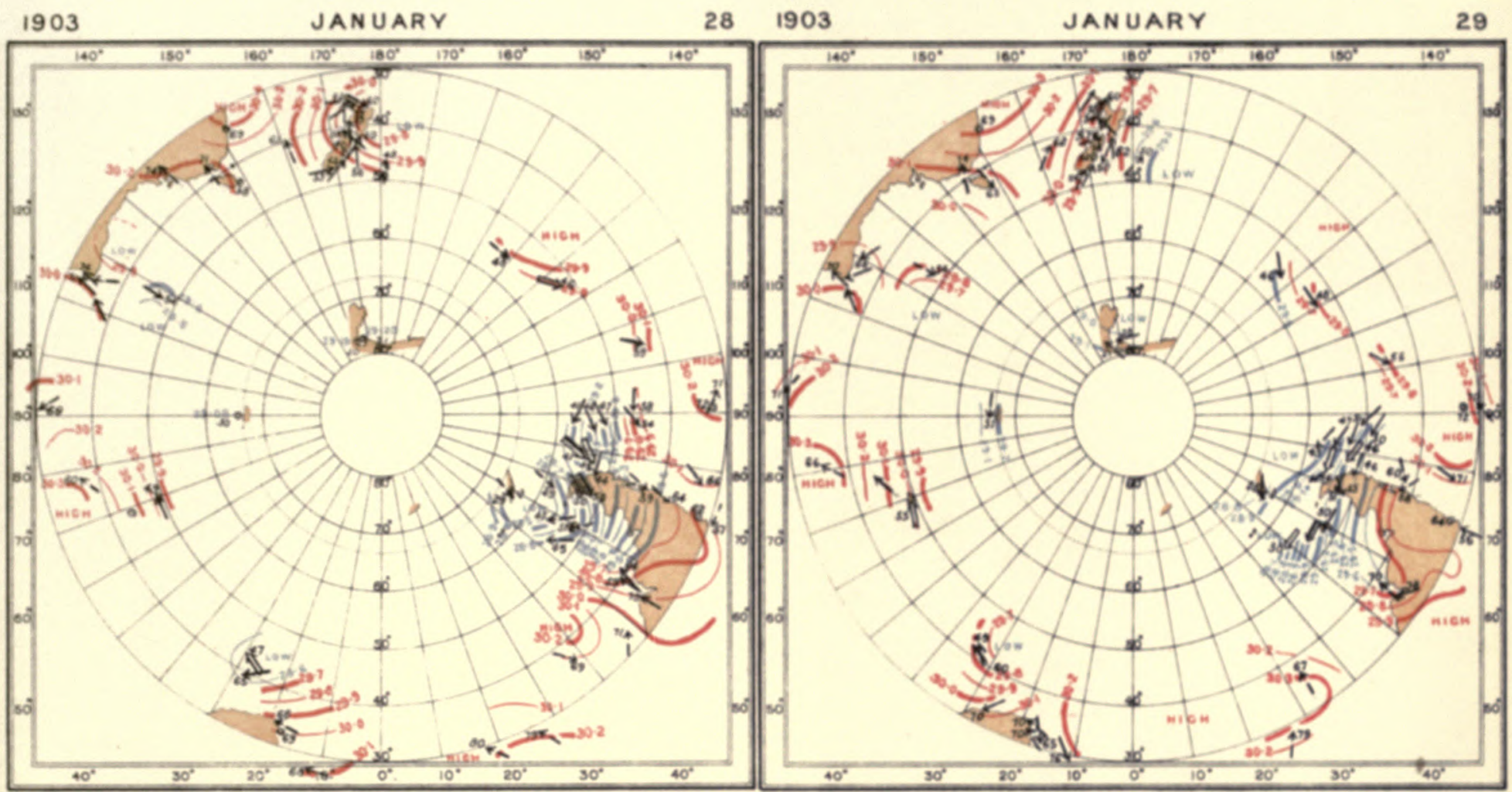

1903

JANUARY

$30 \quad 1903$

JAN UARY

31

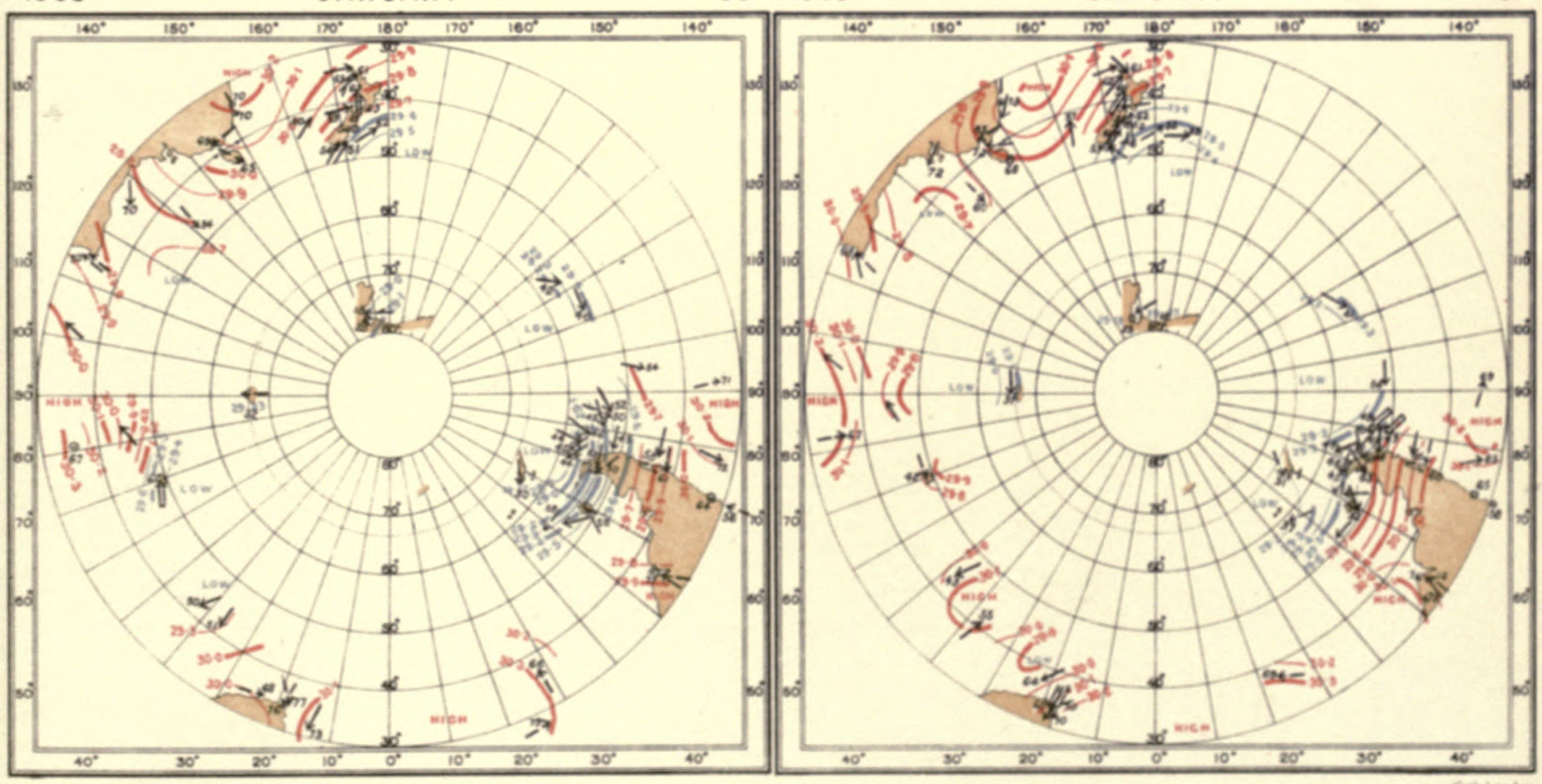


and 
(2) $\%$,

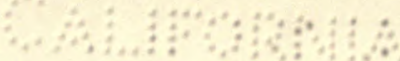


INTERNATIONAL ANTARCTIC COOPERATION.

SYNCHRONOUS CHARTS OF SEA-LEVEL PRESSURE FOR NOON G.M.T

WITH WINDS ANO AIR TEMPERATURES
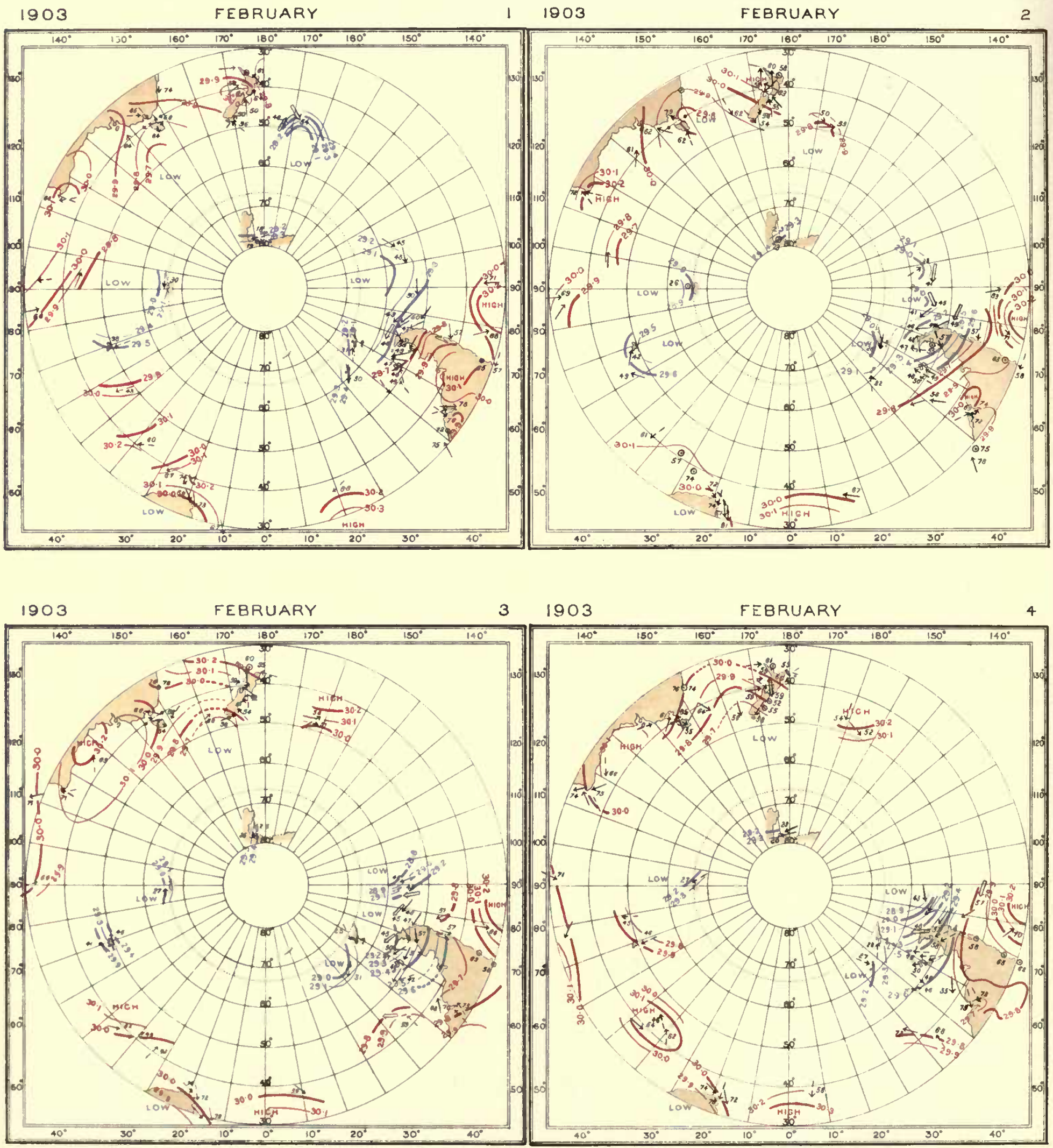
INTERNATIONAL ANTARCTIC CO-OPERATION.

SYNCHRONOUS CHARTS OF SEALEVEL PRESSURE FOR NOON G.M.T. WITH WINDS AND AIR TEMPERATURES
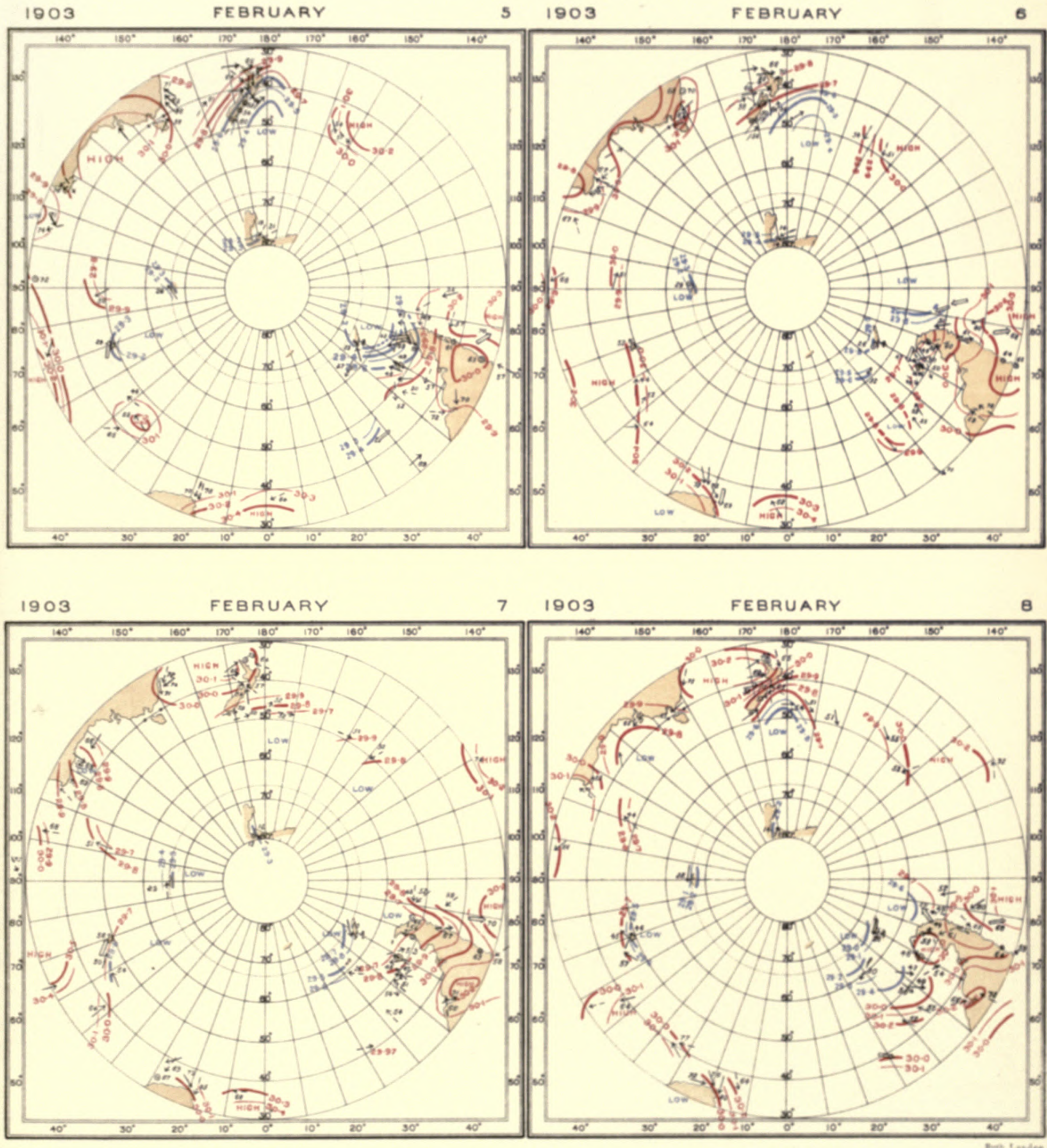
a con

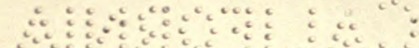


(1)

a 
INTERNATIONAL ANTARCTIC COOPERATION

SYNCHRONOUS CHARTS OF SEA-LEVEL PRESSURE FOR NOON GMT

WITH WINOS AND AIR TEMPERATURES.

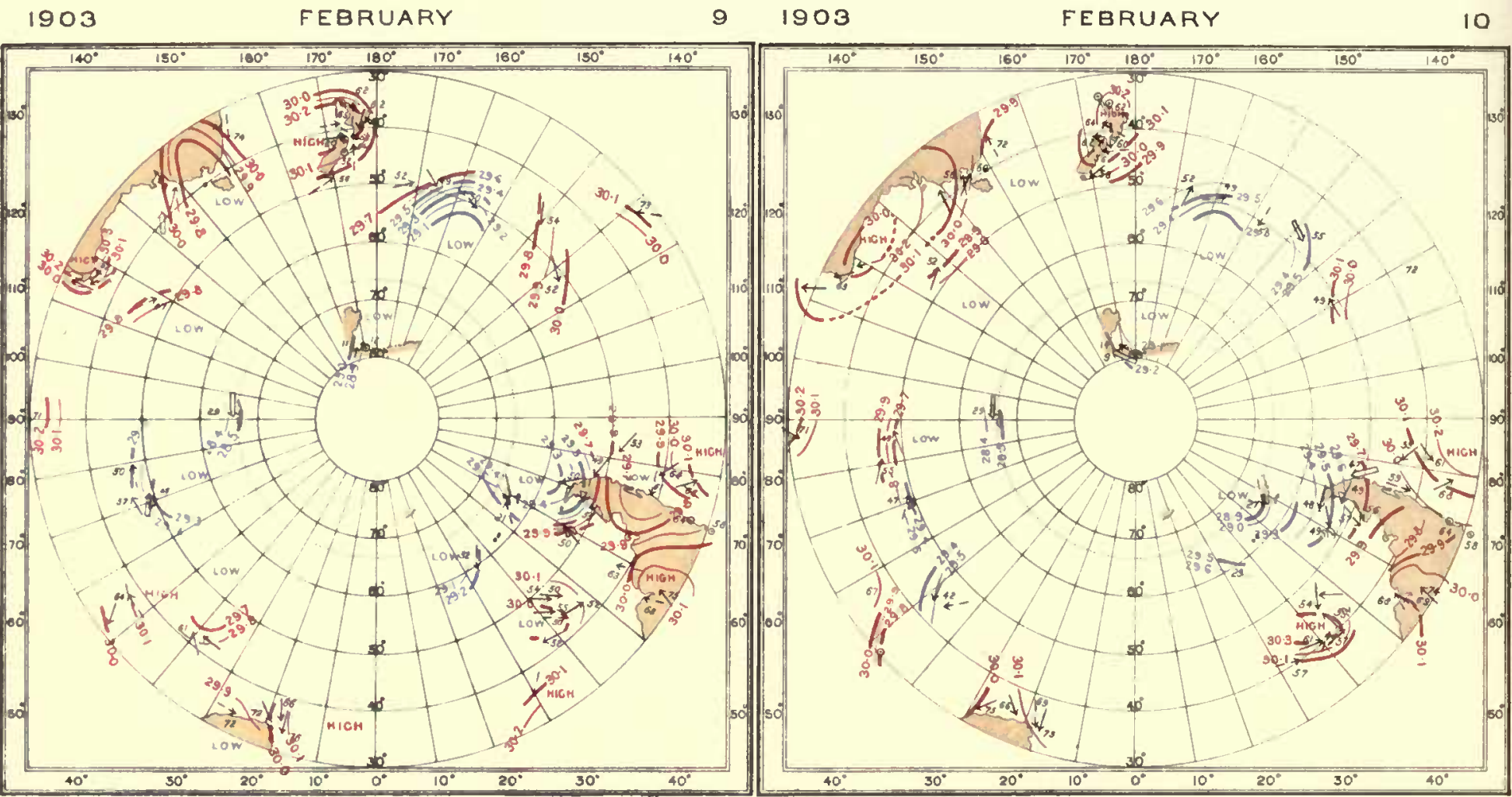

1903

FEBRUARY

$11 \quad 1903$

FEBRUARY

12

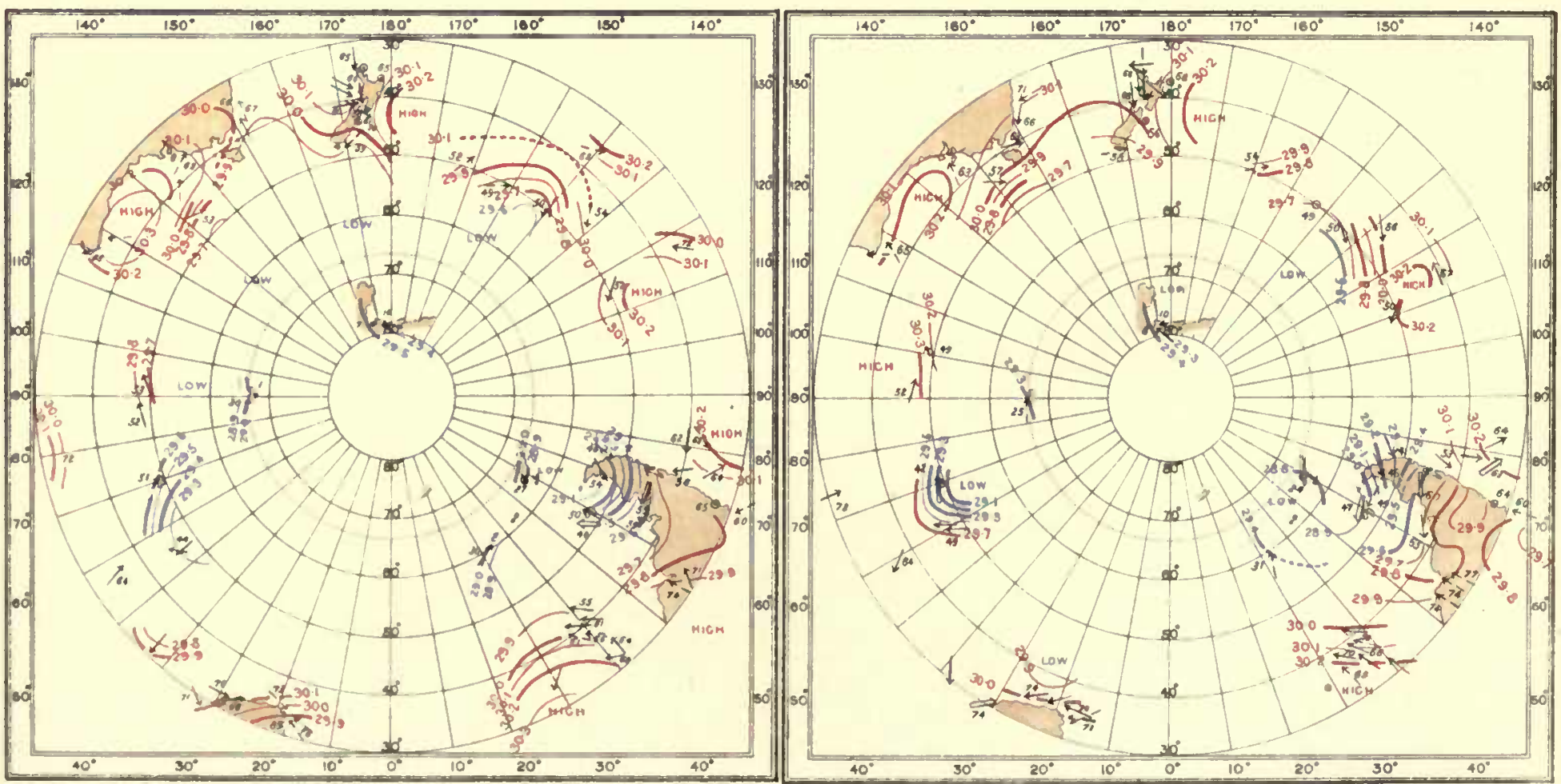


INTERNATIONAL ANTARCTIC CO-OPERATION.

SYNCHRONOUS CHARTS OF SEA-LEVEL PRESSURE FOR NOON G.M.T

WITH WINDS AND AIR TEMPERATURES

FEBRUARY

$13 \quad 1903$

FEBRUARY

14
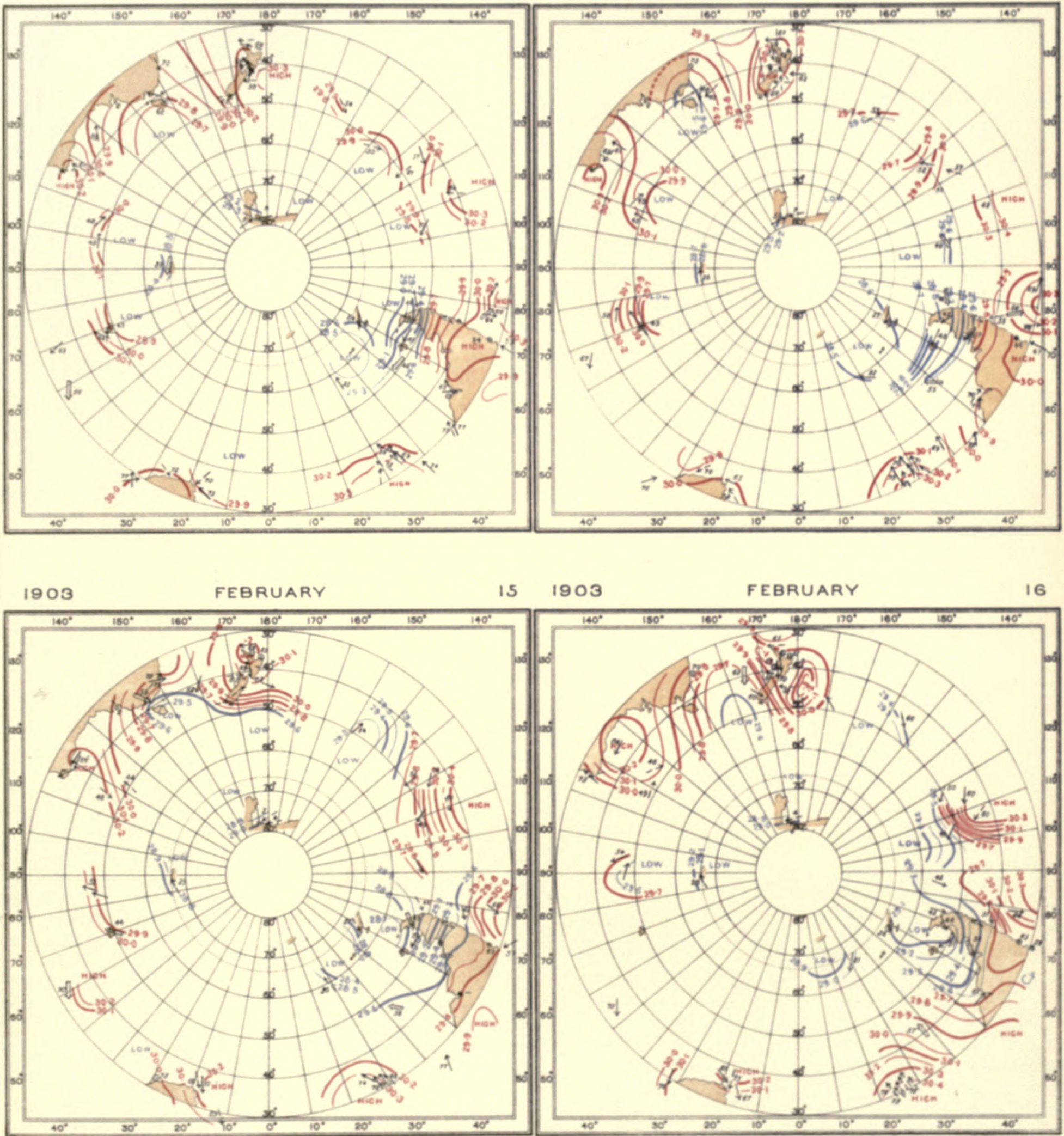
$\because \vdots \vdots \quad \because \because \vdots \vdots \vdots \vdots \vdots$

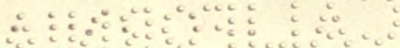


$\%$

C. 
INTERNATIONAL ANTARCTIC CO-OPERATION.

SYNCHRONOUS CHARTS OF SEA-LEVEL PRESSURE FOR NOON GMT

WITH WINDS AND AIR TEMPERATURES

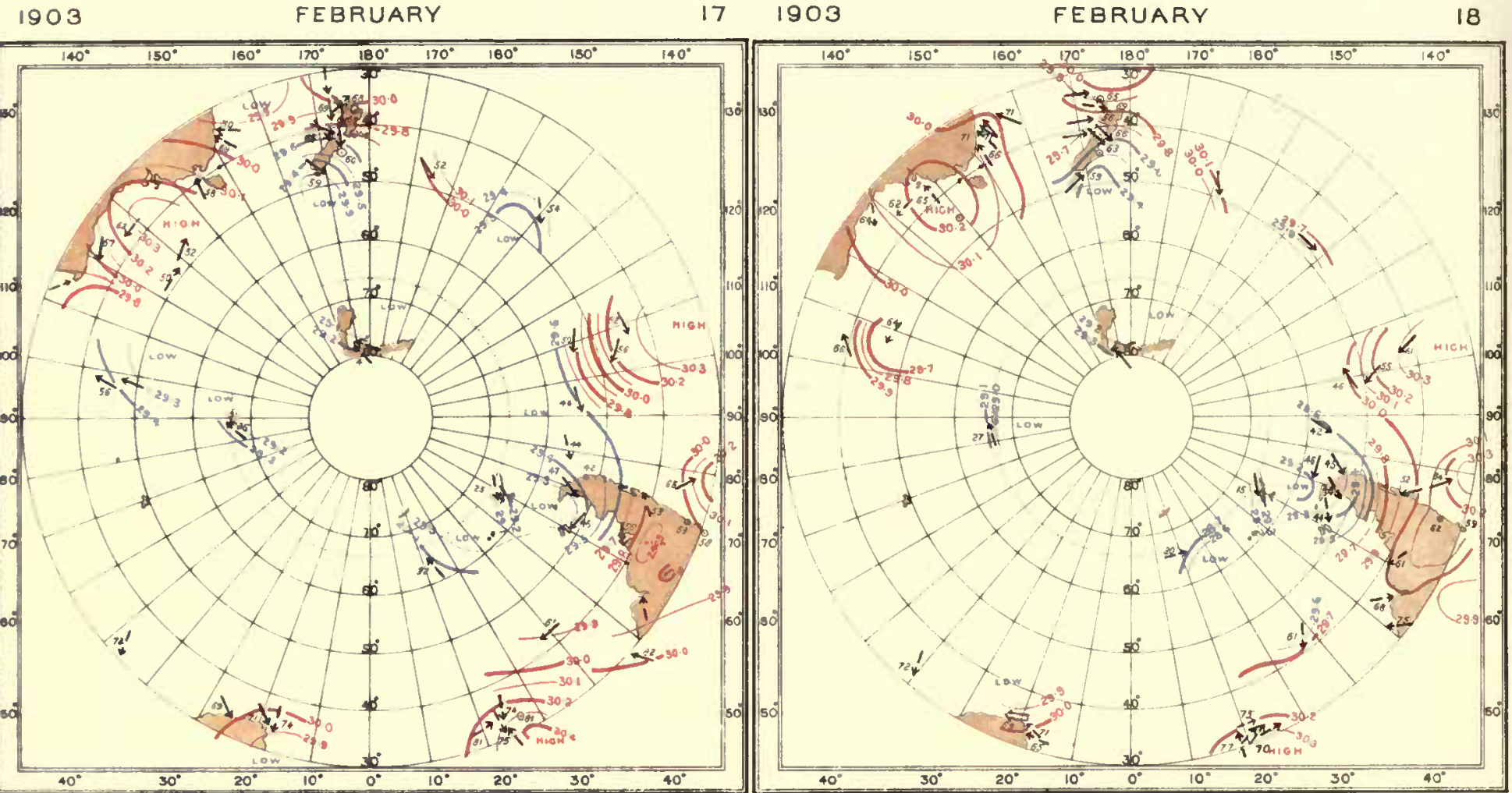

1903

FEBRUARY

$19 \quad 1903$

FEBRUARY

20

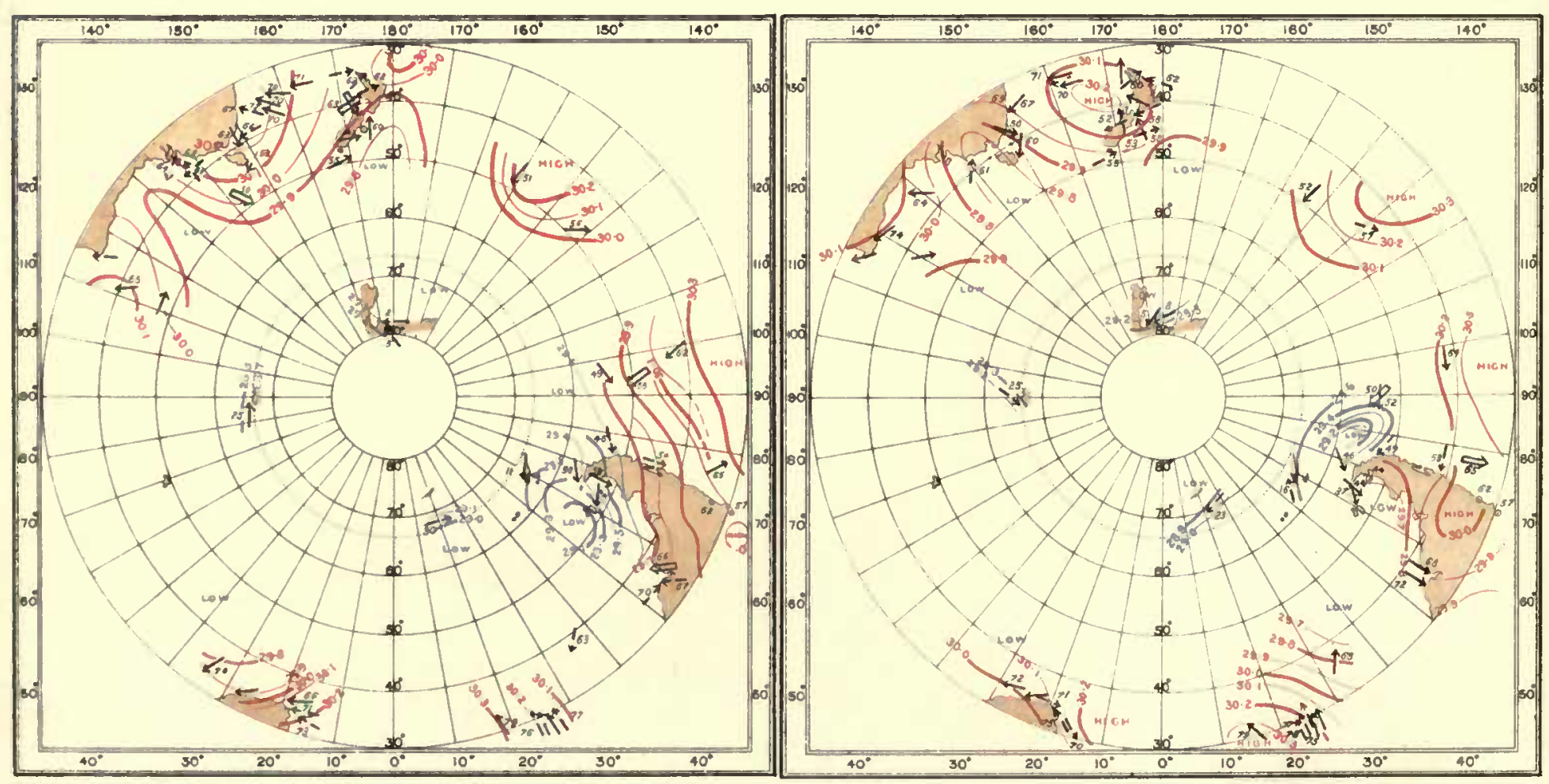


INTERNATIONAL ANTARCTIC CO-OPERATION.

SYNCHRONOUS CHARTS OF SEA-LEVEL PRESSURE FOR NOON G.M.T

WITH WINDS AND AIR TEMPERATURES
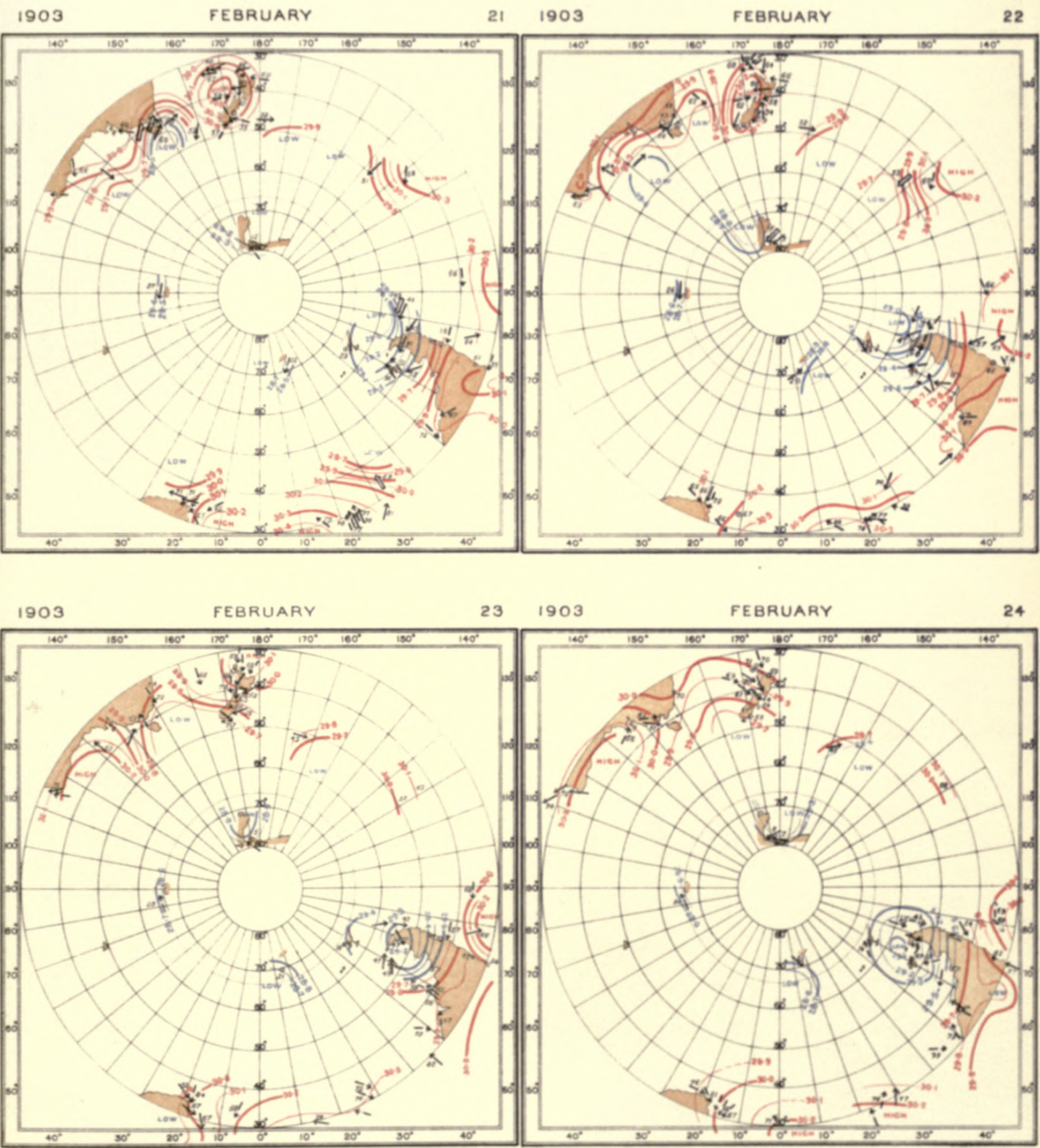
$\because \because \quad \because 8 \because$

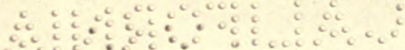


$\therefore \because 4: \% \quad \%$

a b o a 
INTERNATIONAL ANTARCTIC CO-OPERATION.

SYNCHRONOUS CHARTS OF SEALLEVEL PRESSURE FOR NOON G.M.T

WITH WINDS AND AIR TEMPERATURES
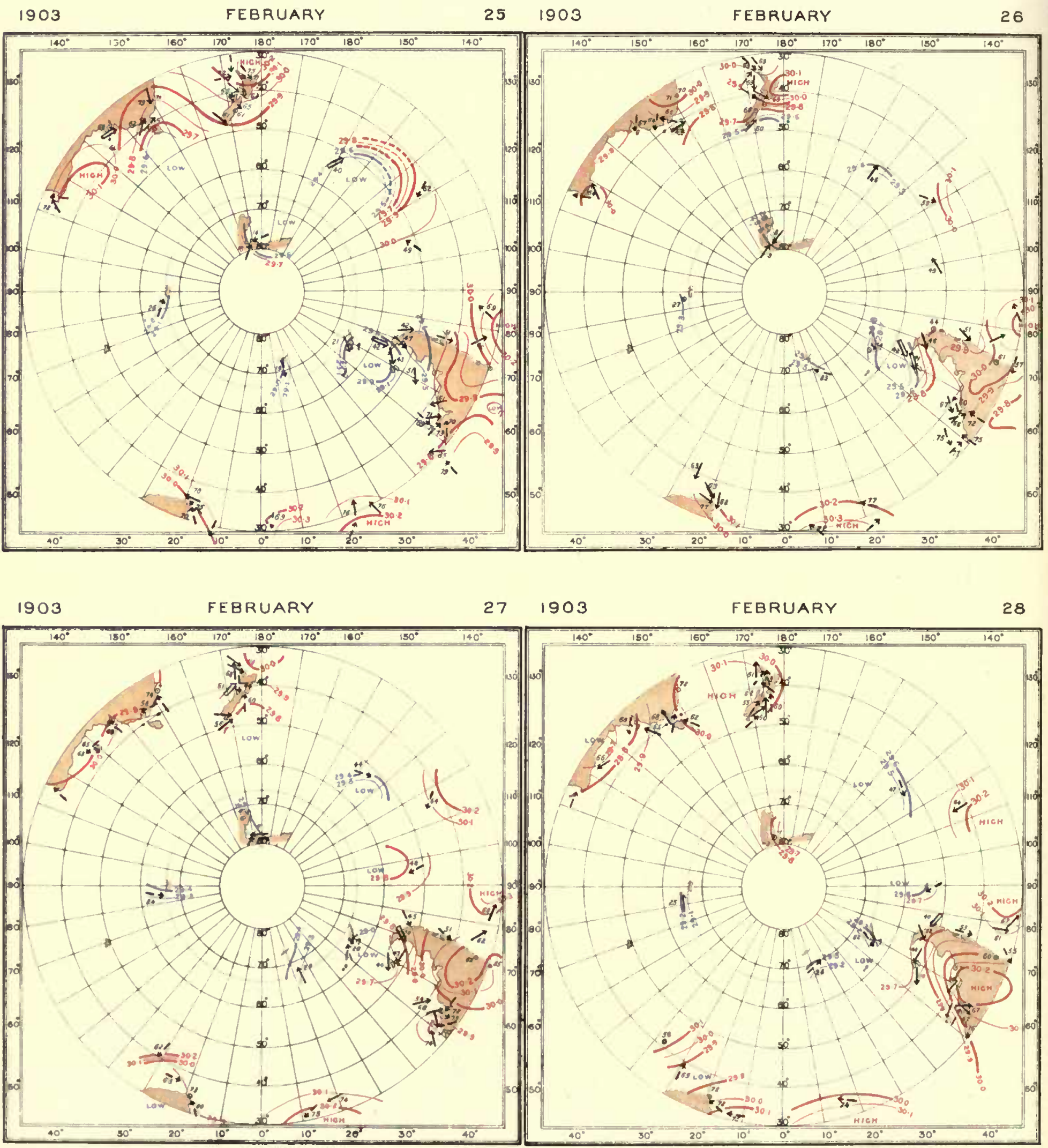
INTERNATIONAL ANTARCTIC CO-OPERATION.

SYNCHRONOUS CHARTS OF SEA-LEVEL PRESSURE FOR NOON G.M.T

WITH WINDS AND AIR TEMPERATURES

1903 MARCH $1903 \quad$ MARCH

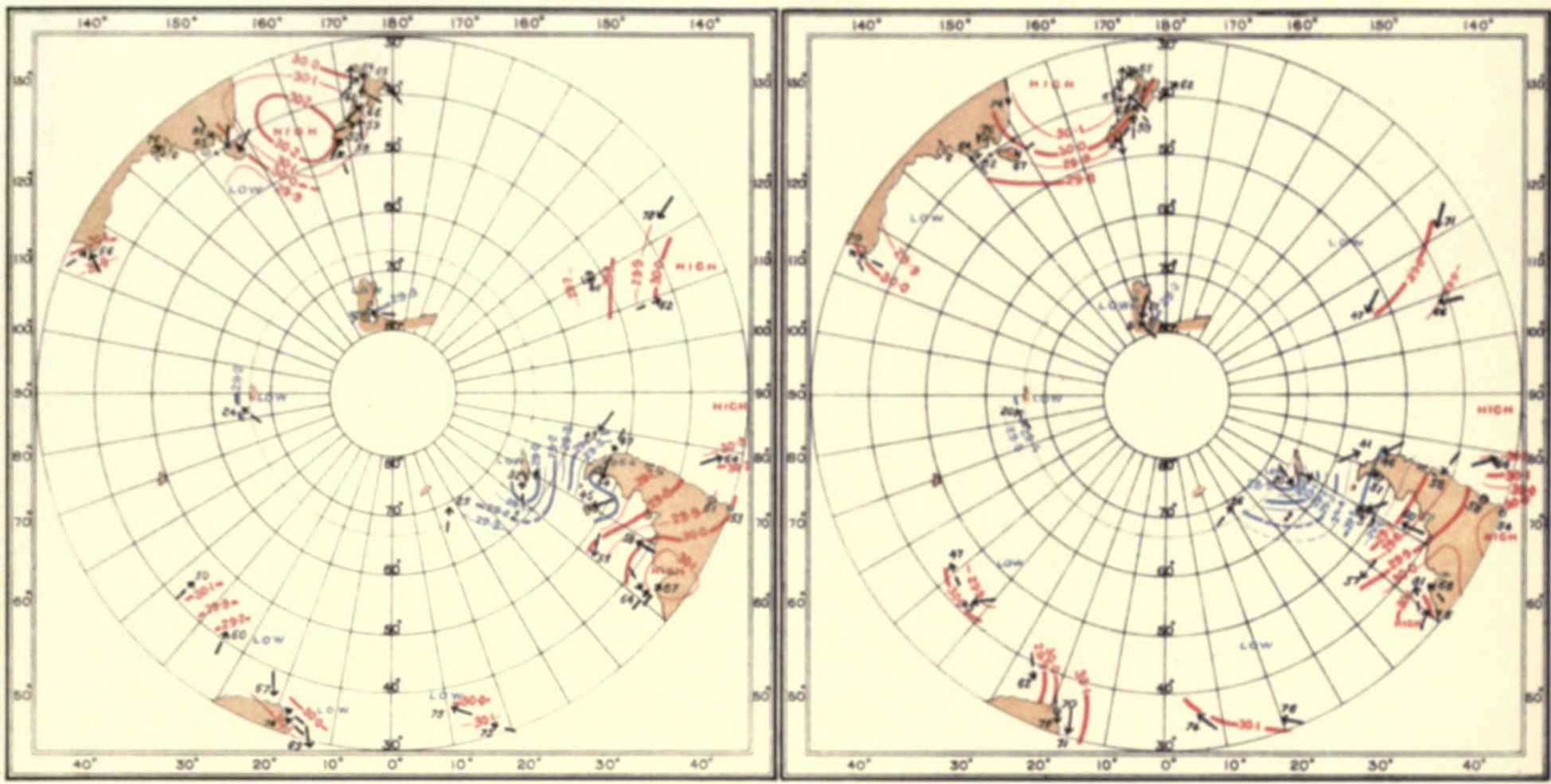

$\begin{array}{lllll}1903 & \text { MARCH } & 3 & 1903 & \text { MARCH }\end{array}$

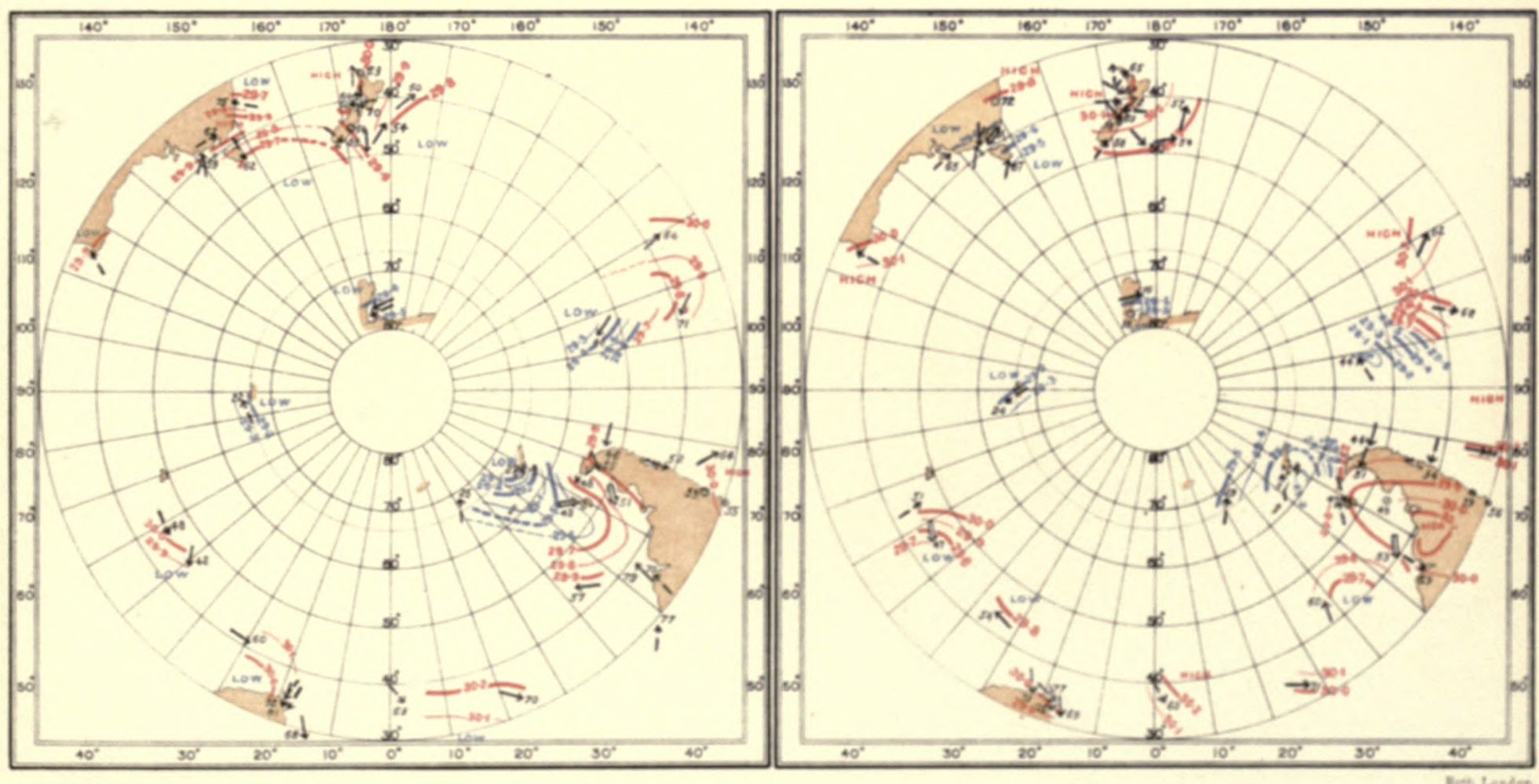




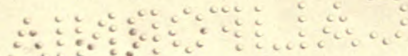


WA 
INTERNATIONAL ANTARCTIC CO-OPERATION.

SYNCHRONOUS CHARTS OF SEA-LEVEL PRESSURE FOR NOON G.M.T.

WITH WINDS AND AIR TEMPEHATURES
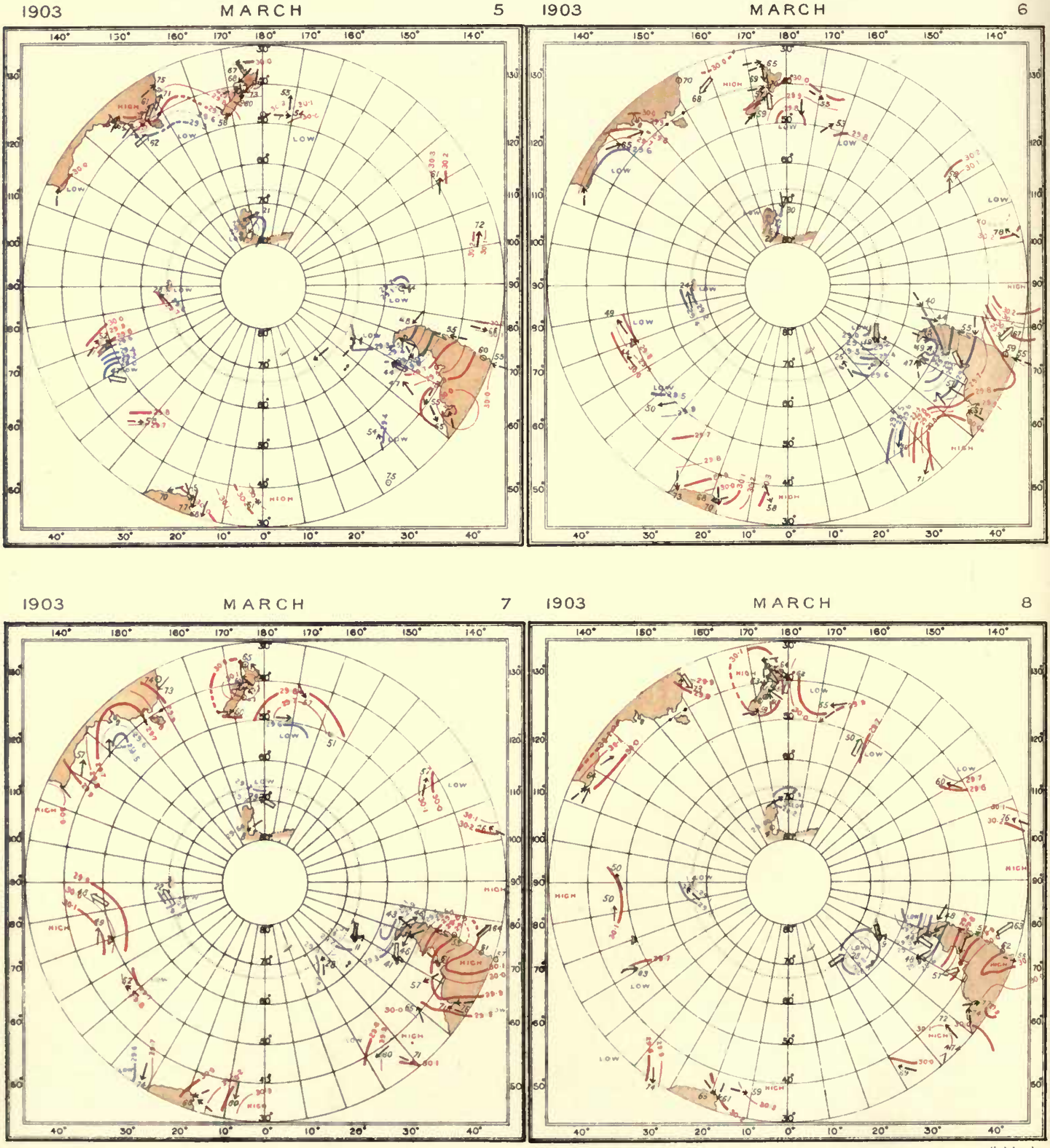
INTERNATIONAL ANTARCTIC COOPERATION.

SYNCHRONOUS CHARTS OF SEALEVEL PRESSURE FOR NOON G.M.T

WITH WINDS AND AIR TEMPERATURES

$1903 \quad$ MARCH $\quad 9 \quad 1903 \quad$ MARCH
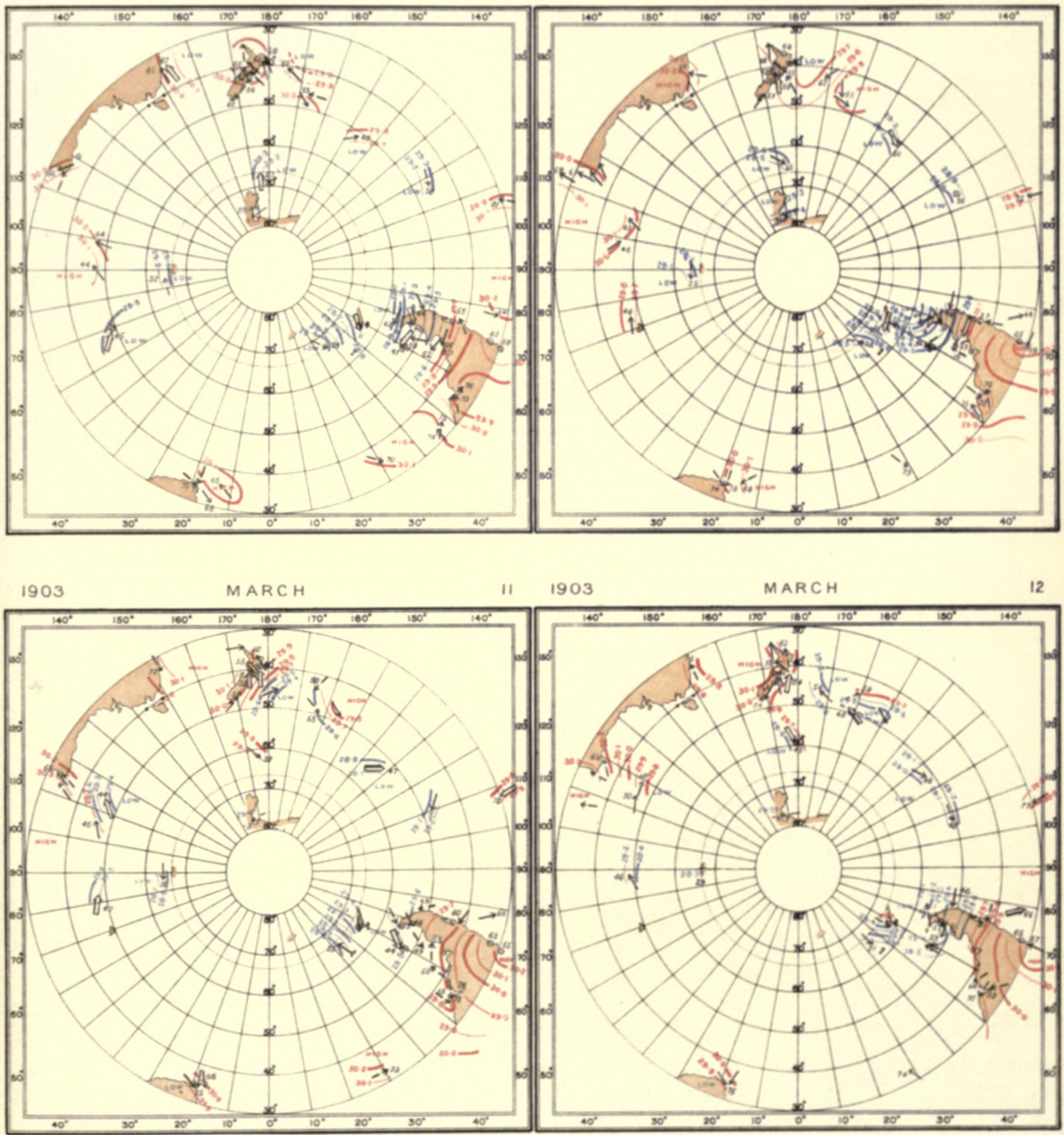


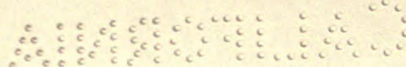


W $\quad$ W 
INTERNATIONAL ANTARCTIC CO-OPERATION.

SYNCHRONOUS CHARTS OF SEALEVEL PRESSURE FOR NOON G.M.T.

WITH WINDS AND AIR TEMPERATURES

1903

MARCH

$13 \quad 1903$

MARCH

14
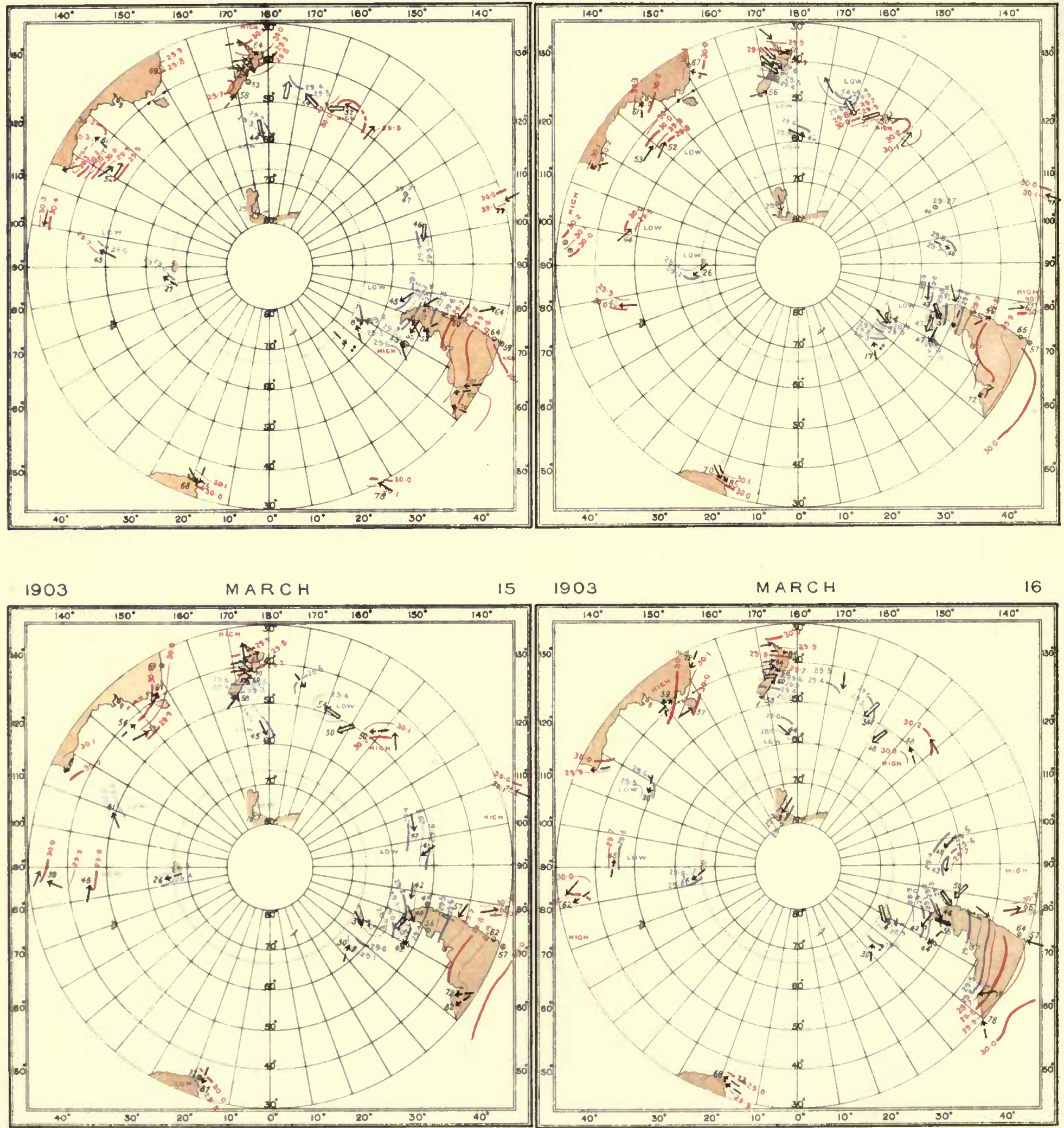
INTERNATIONAL ANTARCTIC COOPERATION.

SYNCHRONOUS CHARTS OF SEA-LEVEL PRESSURE FOR NOON G.M.T

WITH WINDS AND AIR TEMPERATURES

$1903 \quad$ MARCH

$17 \quad 1903$

MARCH

18

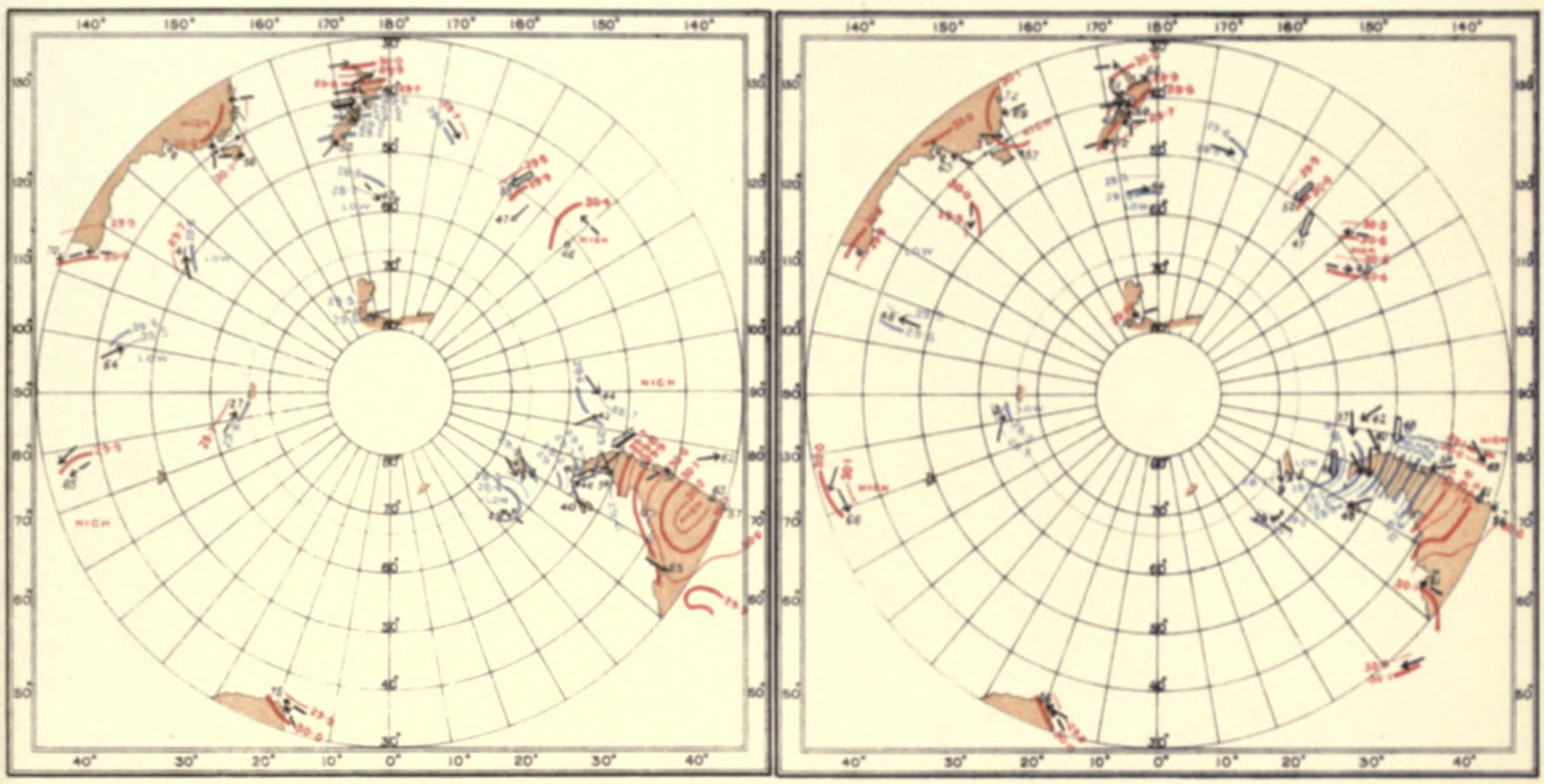

1903 MARCH

$19 \quad 1903$

M ARCH

20

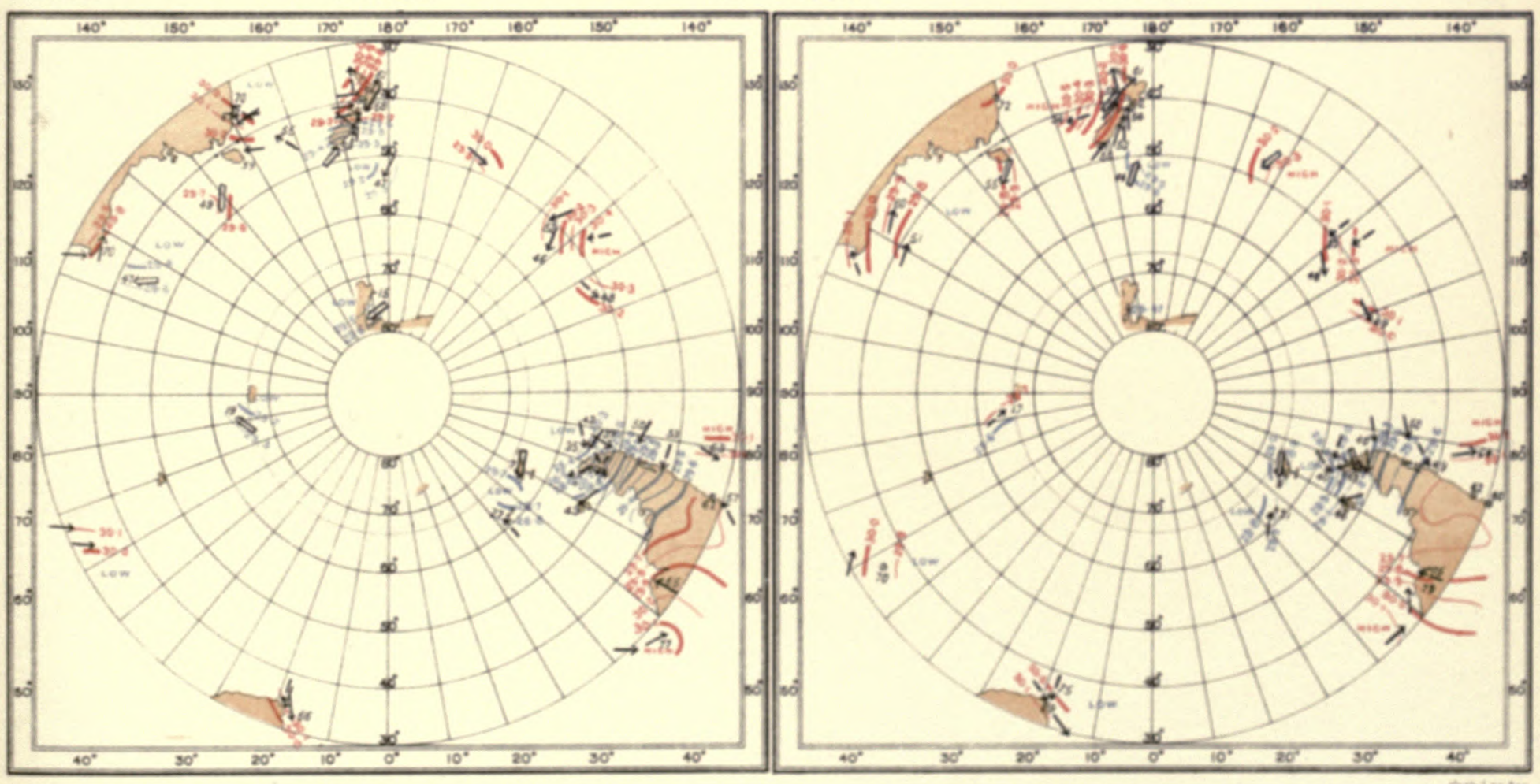




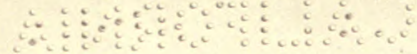




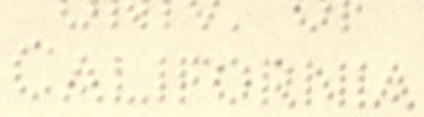


INTERNATIONAL ANTARCTIC COOPERATION

SYNCHRONOUS CHARTS OF SEA-LEVEL PRESSURE FOR NOON G.M.T.

WITH WINDS AND AIR TEMPERATURES
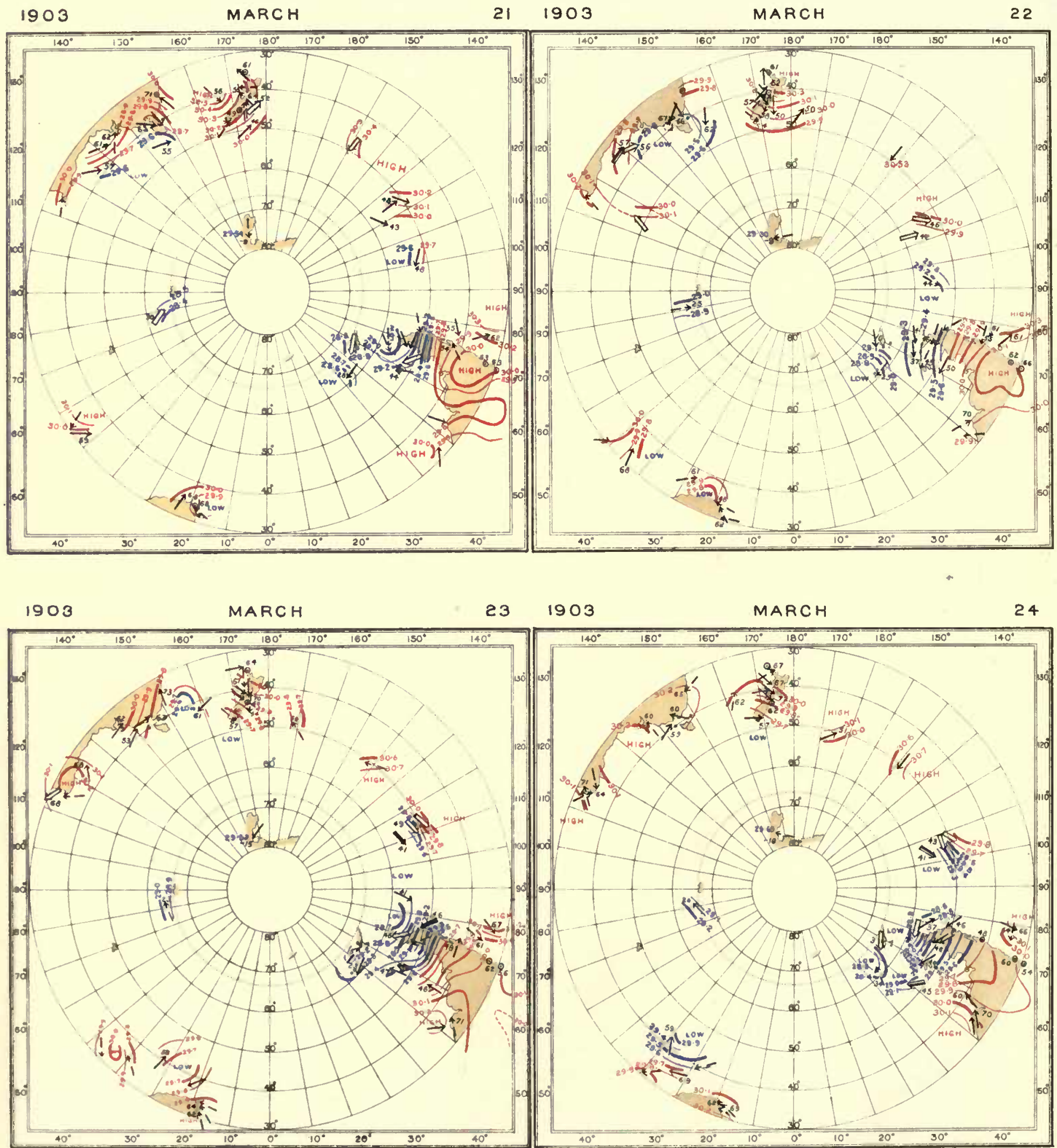
INTERNATIONAL ANTARCTIC CO-OPERATION.

SYNCHRONOUS CHARTS OF SEA-LEVEL PRESSURE FOR NOON GMT

WITH WINDS AND AIR TEMPERATURES
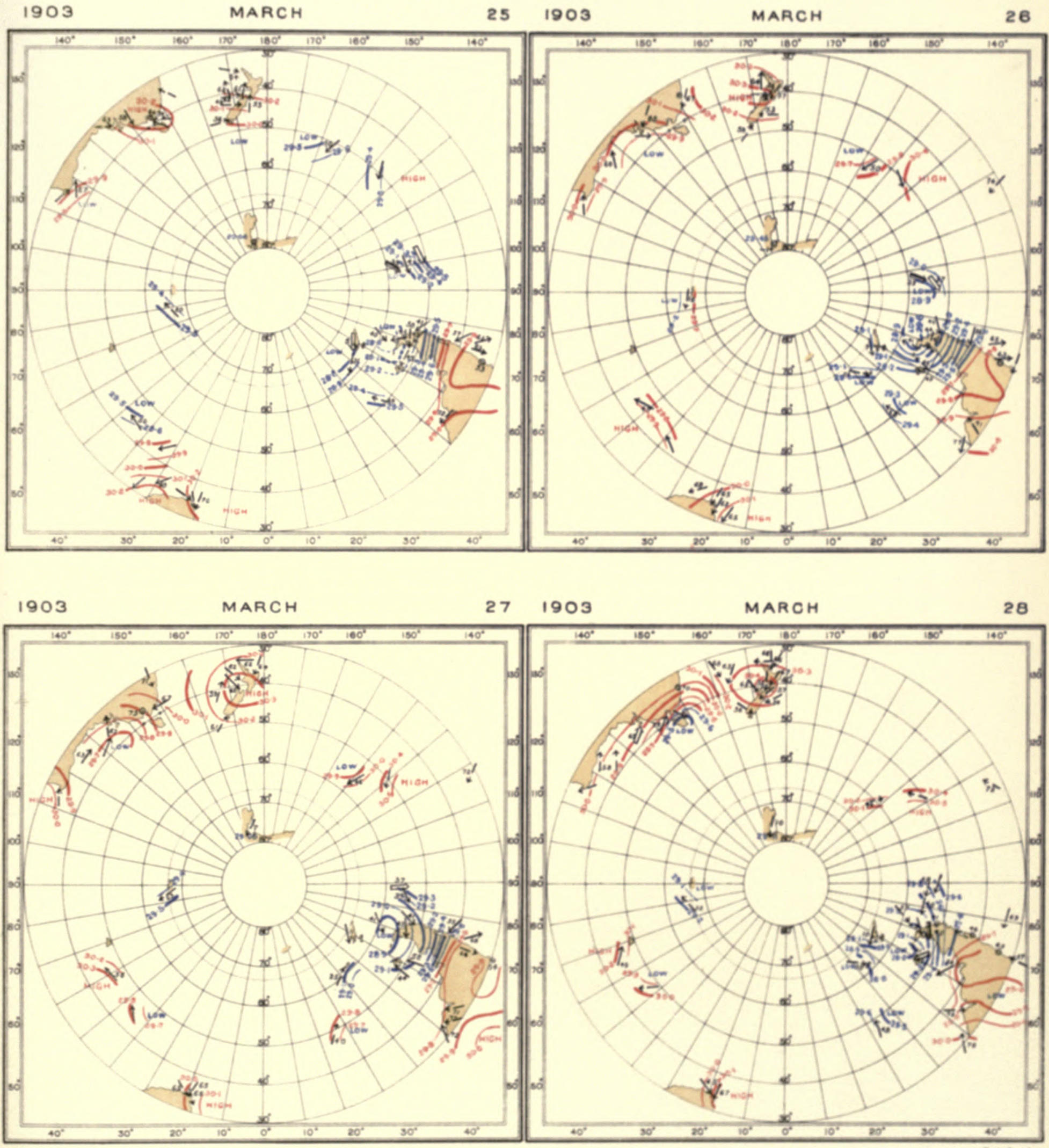


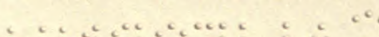

a. 

INTERNATIONAL ANTARCTIC CO-OPERATION.

SYNCHRONOUS CHARTS OF SEALEVEL PRESSURE FOR NOON GM T.

WITH WINDS AND AIR TEMPERATURES

MARCH

$29 \quad 1903$

MARCH
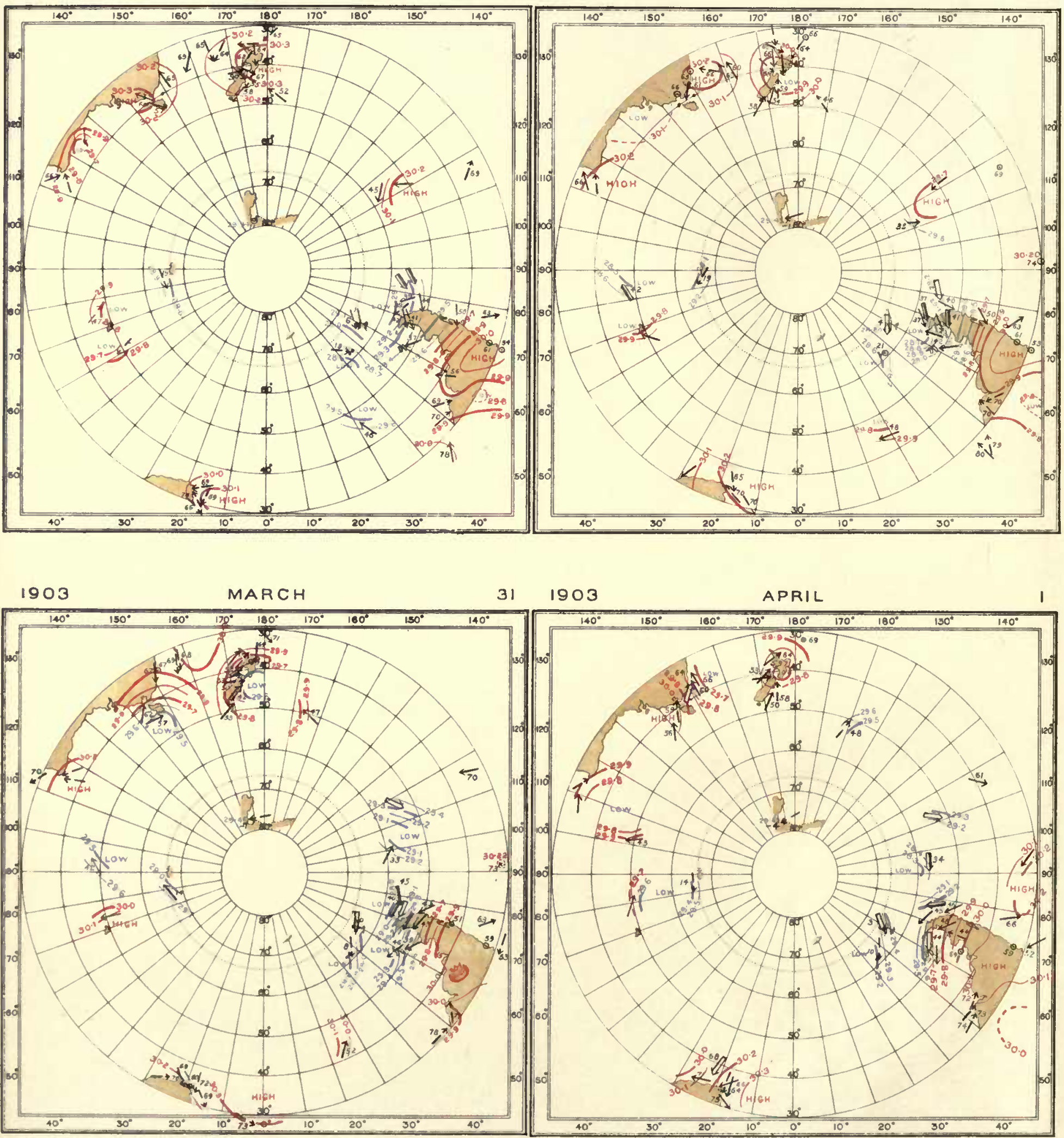
INTERNATIONAL ANTARCTIC CO-OPERATION.

SYNCHAONOUS CHARTS OF SEA-LEVEL PRESSURE FOR NOON G.M.T.

WITH WINDS AND AIR TEMPERATURES

1903

APRIL

21903

APRIL

3

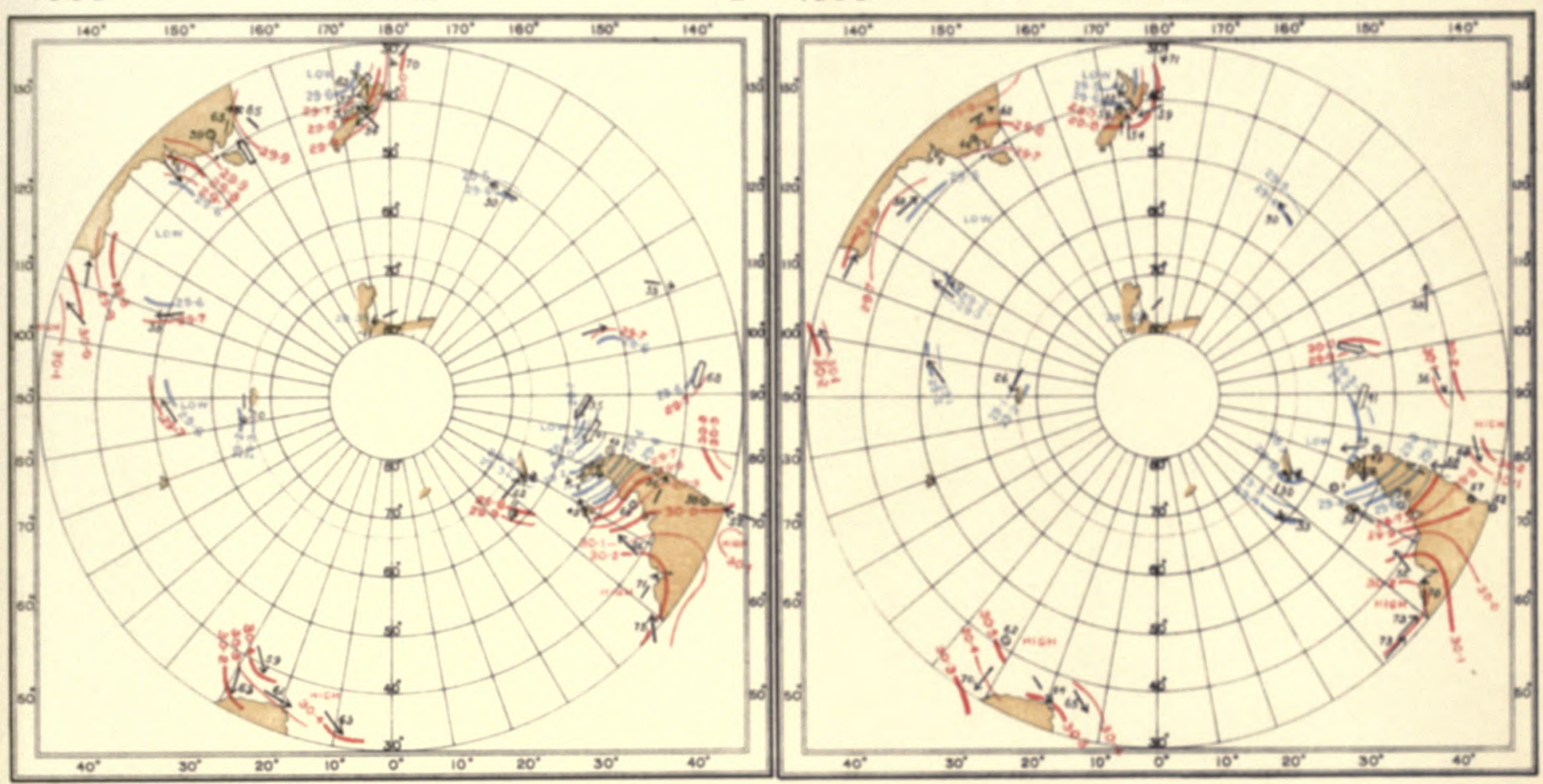

1903

APRIL

$4 \quad 1903$

APRIL

5

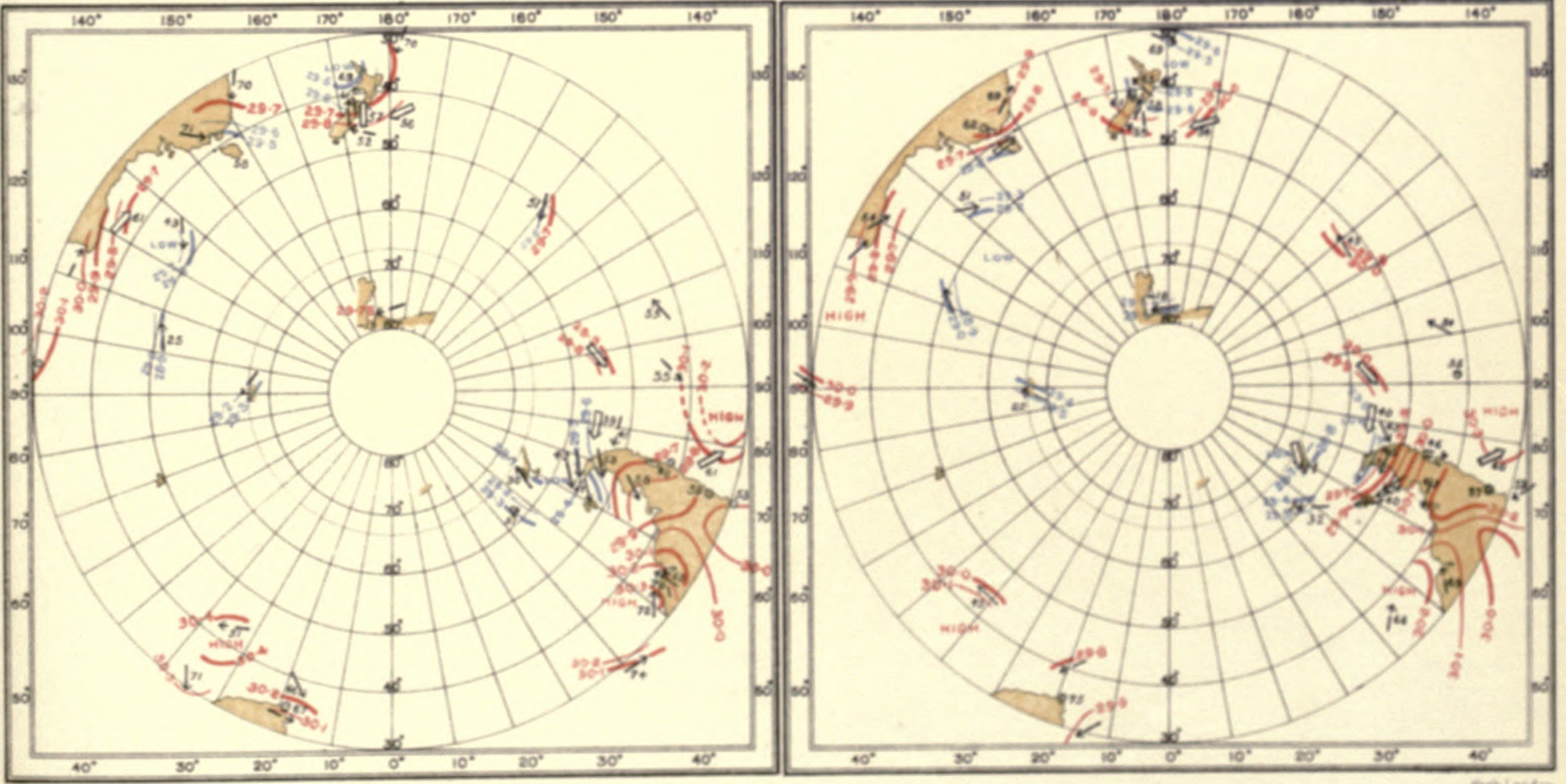




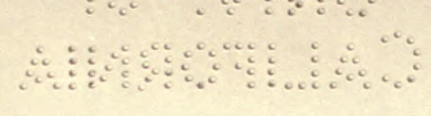


a A 
INTERNATIONAL ANTARCTIC COOPERATION.

SYNGHRONOUS CHARTS OF SEALLVEL PRESSURE FOR NOON G.M.T WITH WINDS AND AIR TEMPERATURES
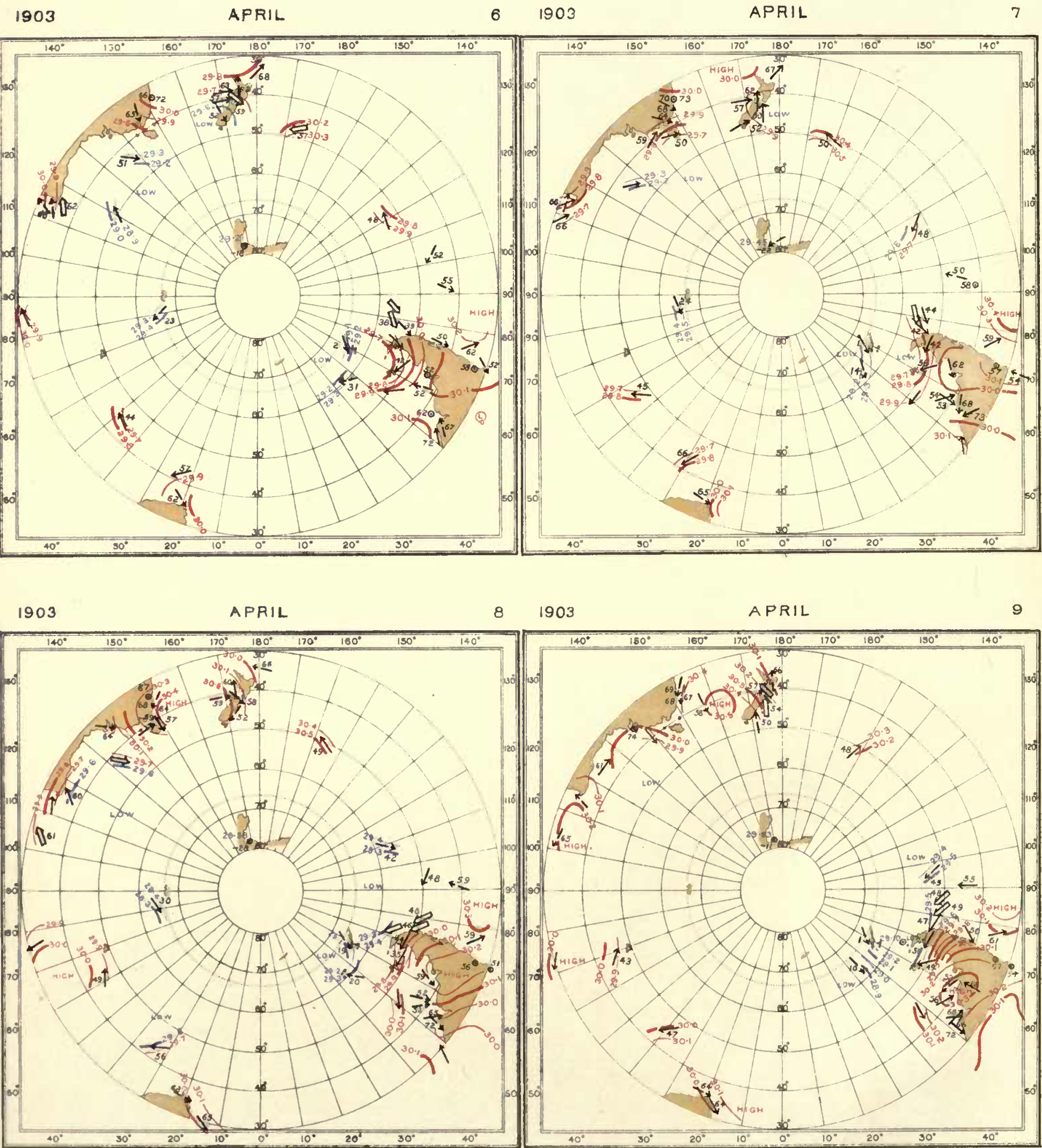
INTERNATIONAL ANTARCTIC CO-OPERATION.

SYNCHRONOUS CHARTS OF SEALEVEL PRESSURE FOR NOON GMT

WITH WINDS AND AIR TEMPERATURES

$\begin{array}{lllll}1903 & \text { APRIL } & 10 & 1903 & \text { APRIL }\end{array}$

11

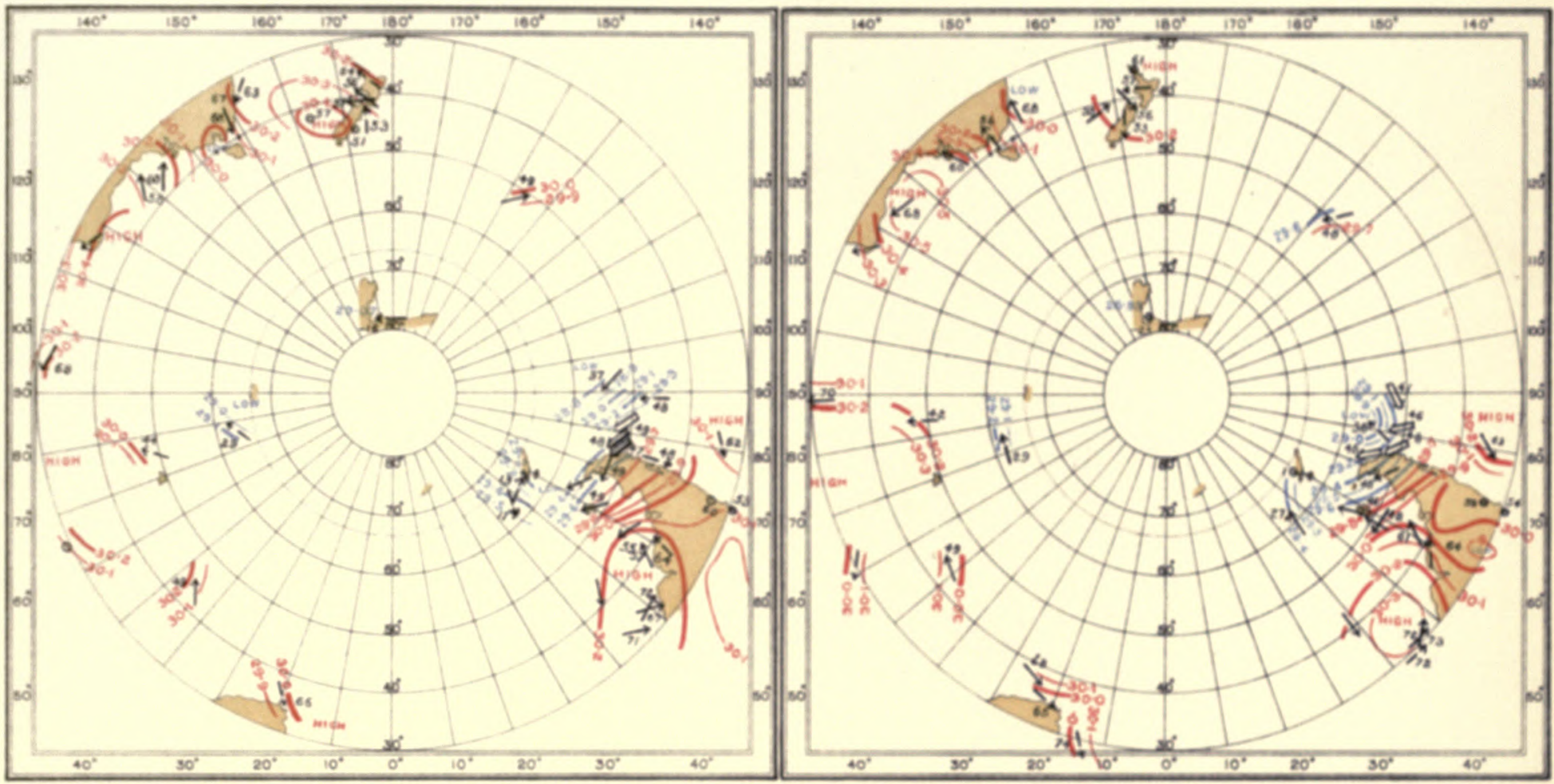

$\begin{array}{llll}1903 & \text { APRIL } & \text { 12 } & 1903\end{array}$

APRIL

13

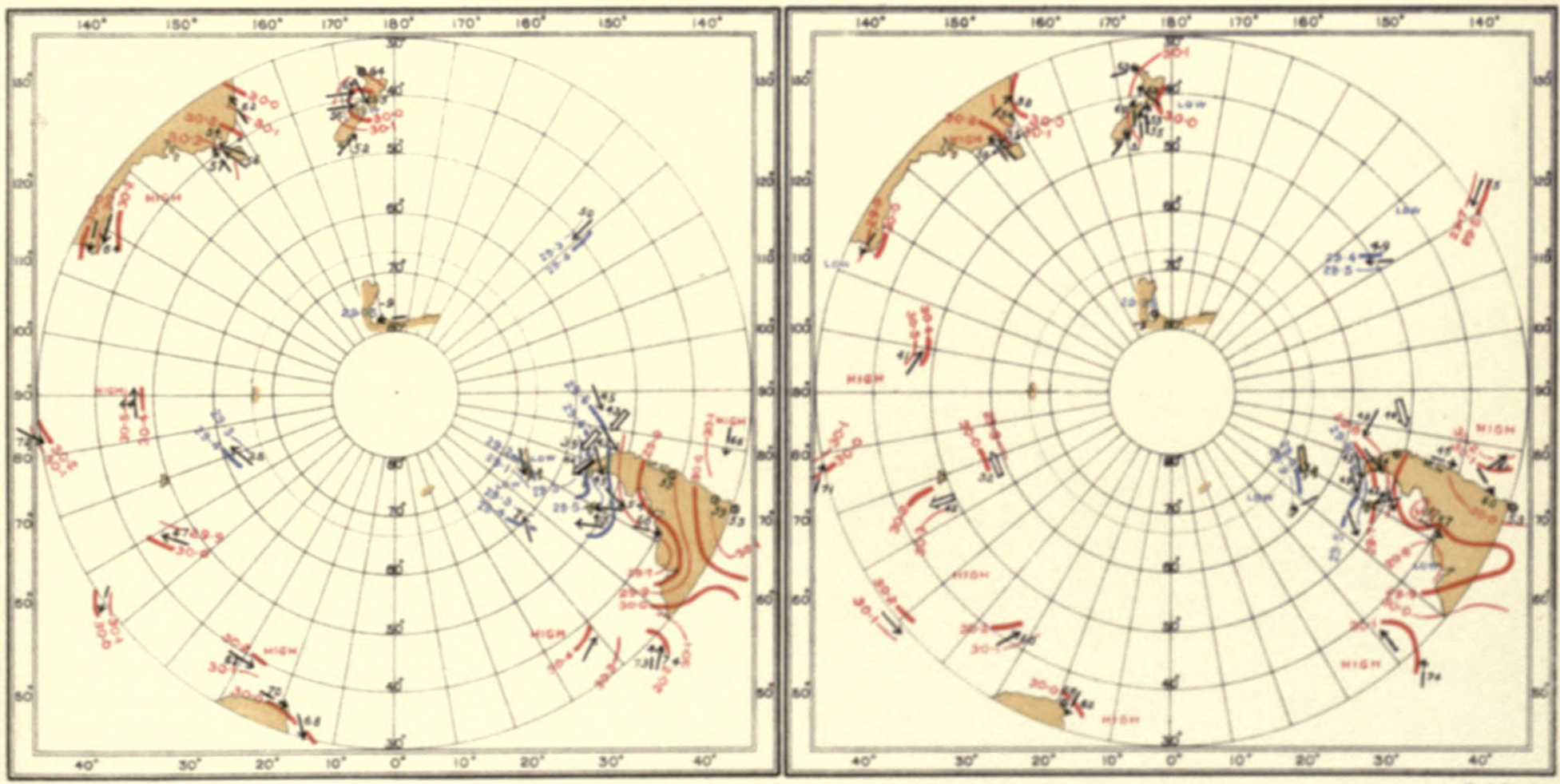




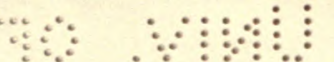

a 


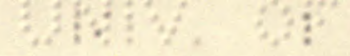

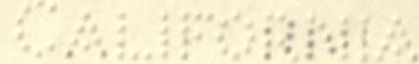


INTERNATIONAL ANTARCTIC COOPERATION.

SYNCHRONOUS CHARTS OF SEALEVEL PRESSURE FOR NOON G.M.T.

WITH WINDS AND AIR TEMPERATURES
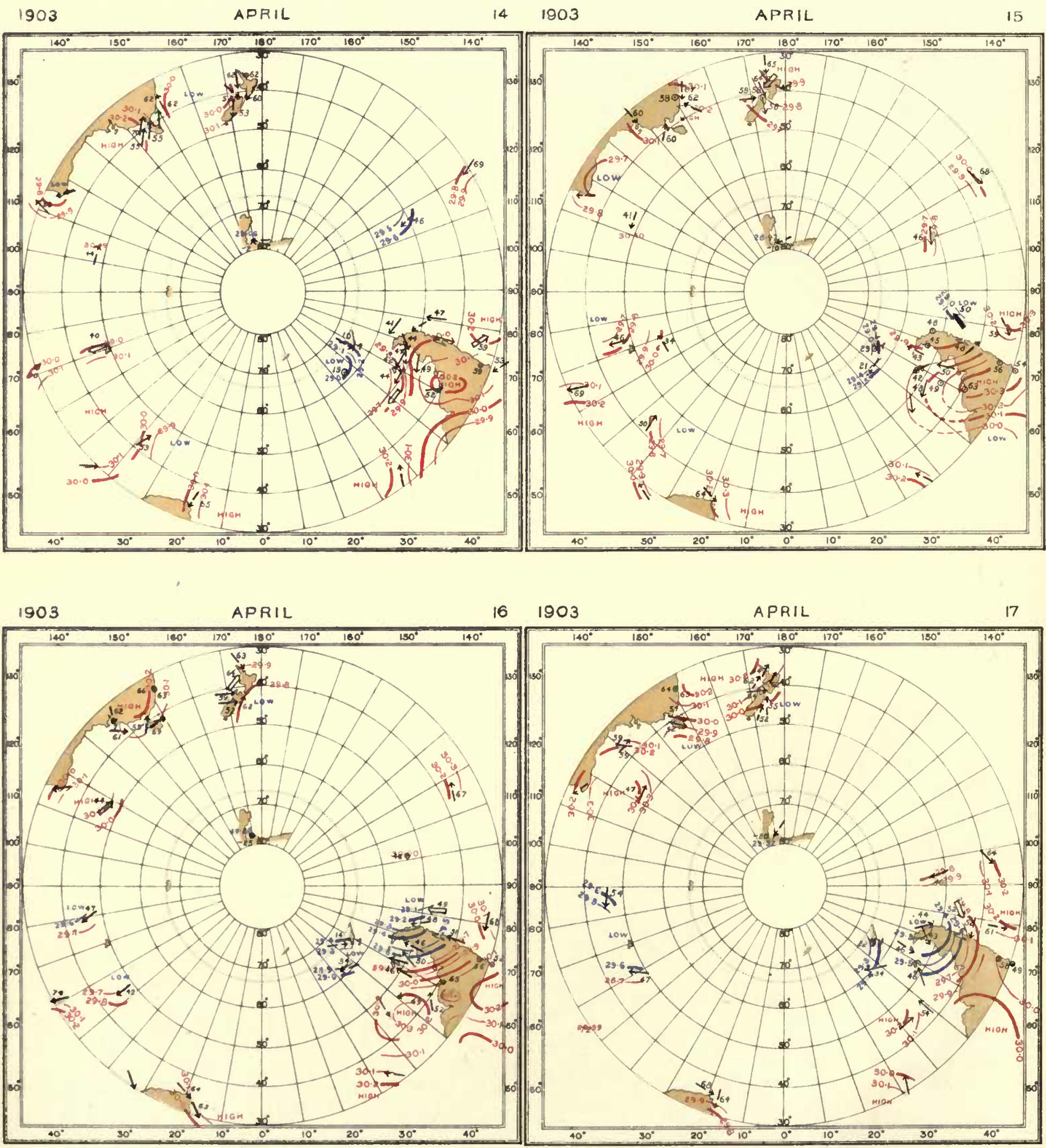
INTERNATIONAL ANTARCTIC COOOPERTION.

SYNCHRONOUS CHARTS OF SEALEVEL PRESSURE FOR NOON G.M.T.

WITH WINDS AND AIR TEMPERATURES

1903

APRIL

$18 \quad 1903$

APRIL

19
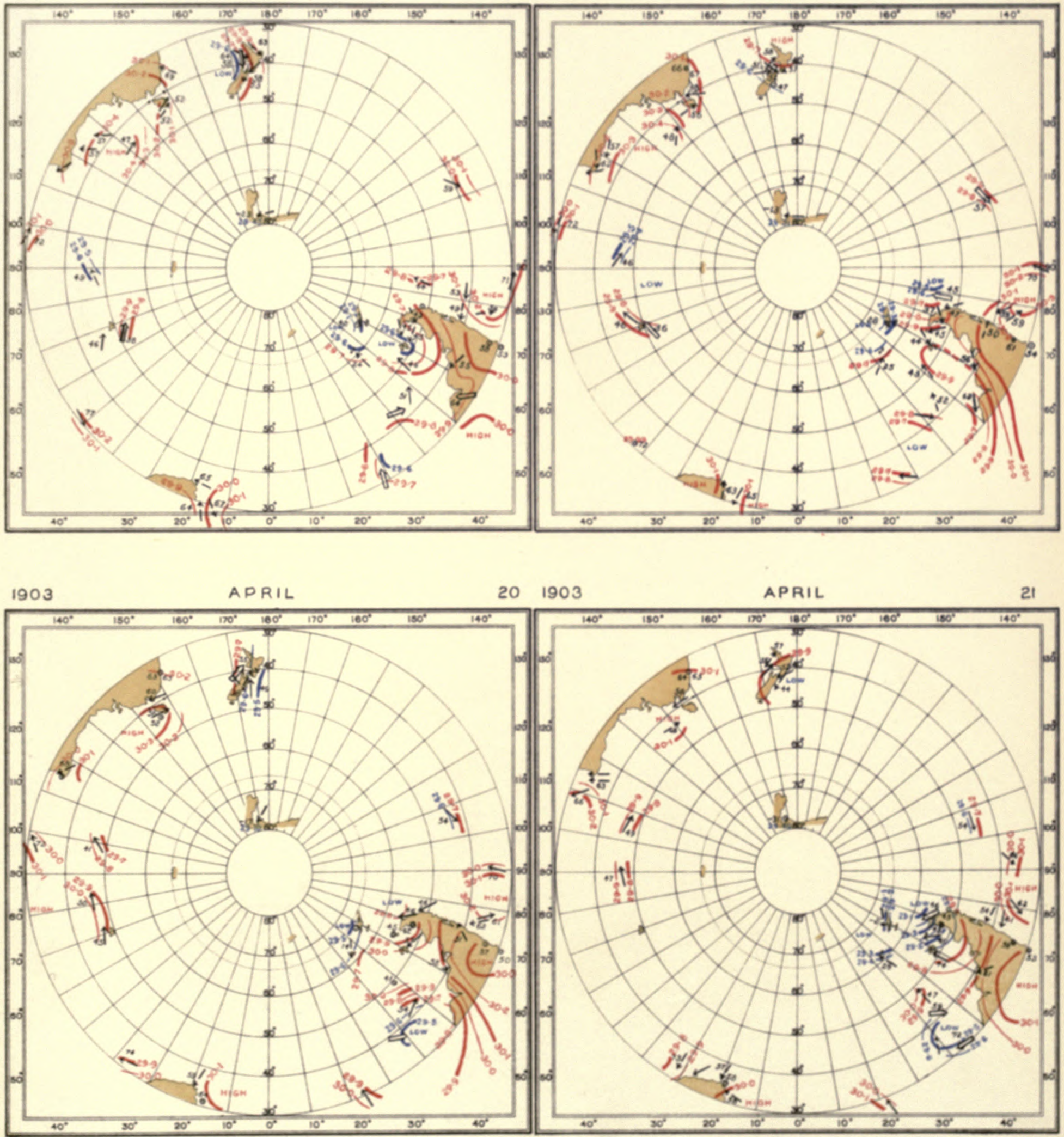
$\because \vdots \quad \because \because \vdots \vdots \vdots 0$

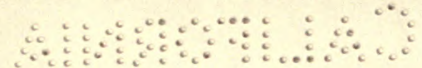




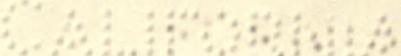


INTERNATIONAL ANTARCTIC CO-OPERATION.

SYNGHRONOUS CHARTS OF SEALEVEL PRESSURE FOR NOON G.M.T

WITH WINDS ANO AIR TEMPERATURES

APRIL

$22 \quad 1903$

APRIL

23
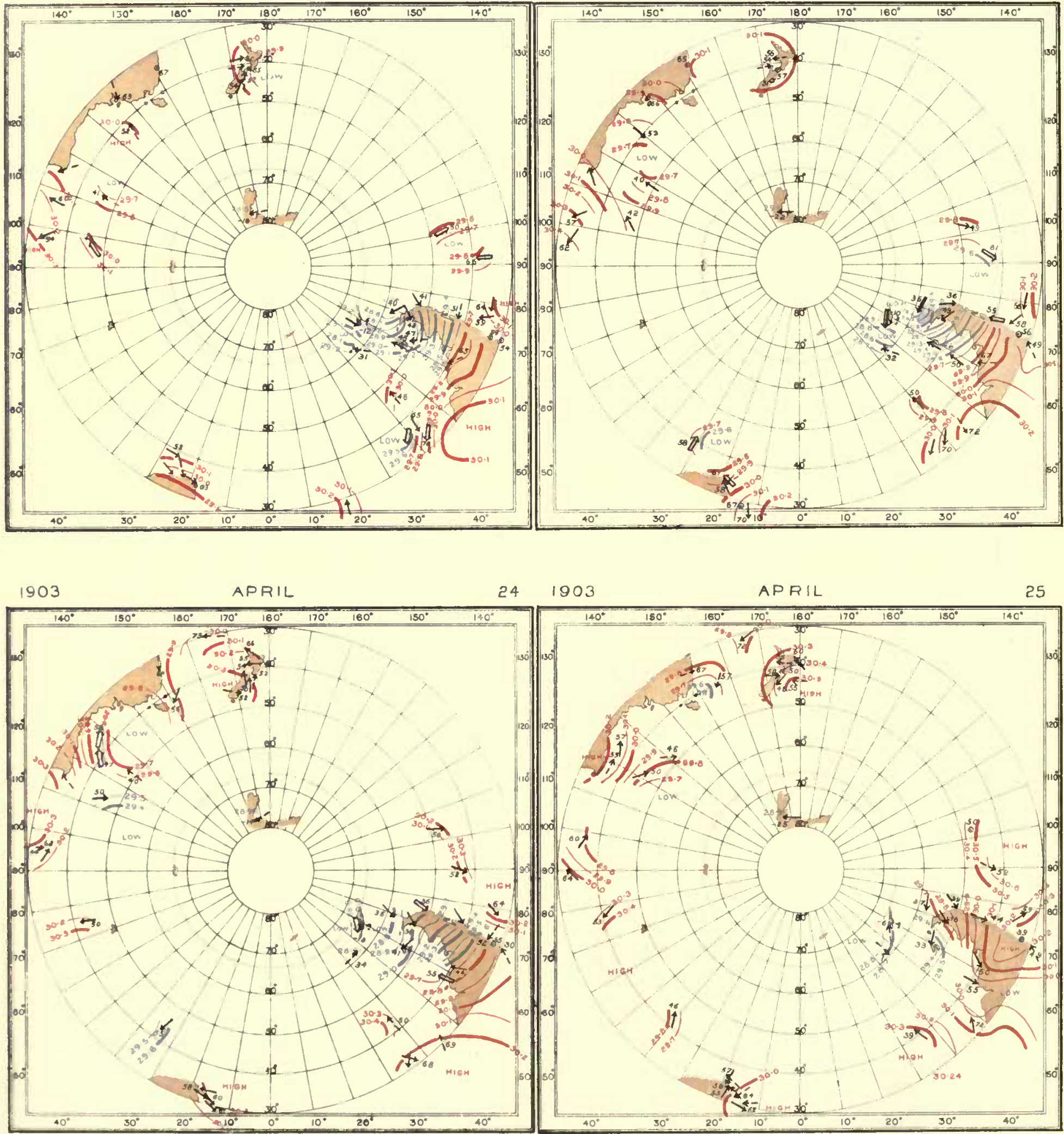
INTERNATIONAL ANTARCTIC CO-OPERATION.

SYNCHRONOUS CHARTS OF SEA-LEVEL PRESSURE FOR NOON GM.T

WITH WINDS AND AIR TEMPERATURES

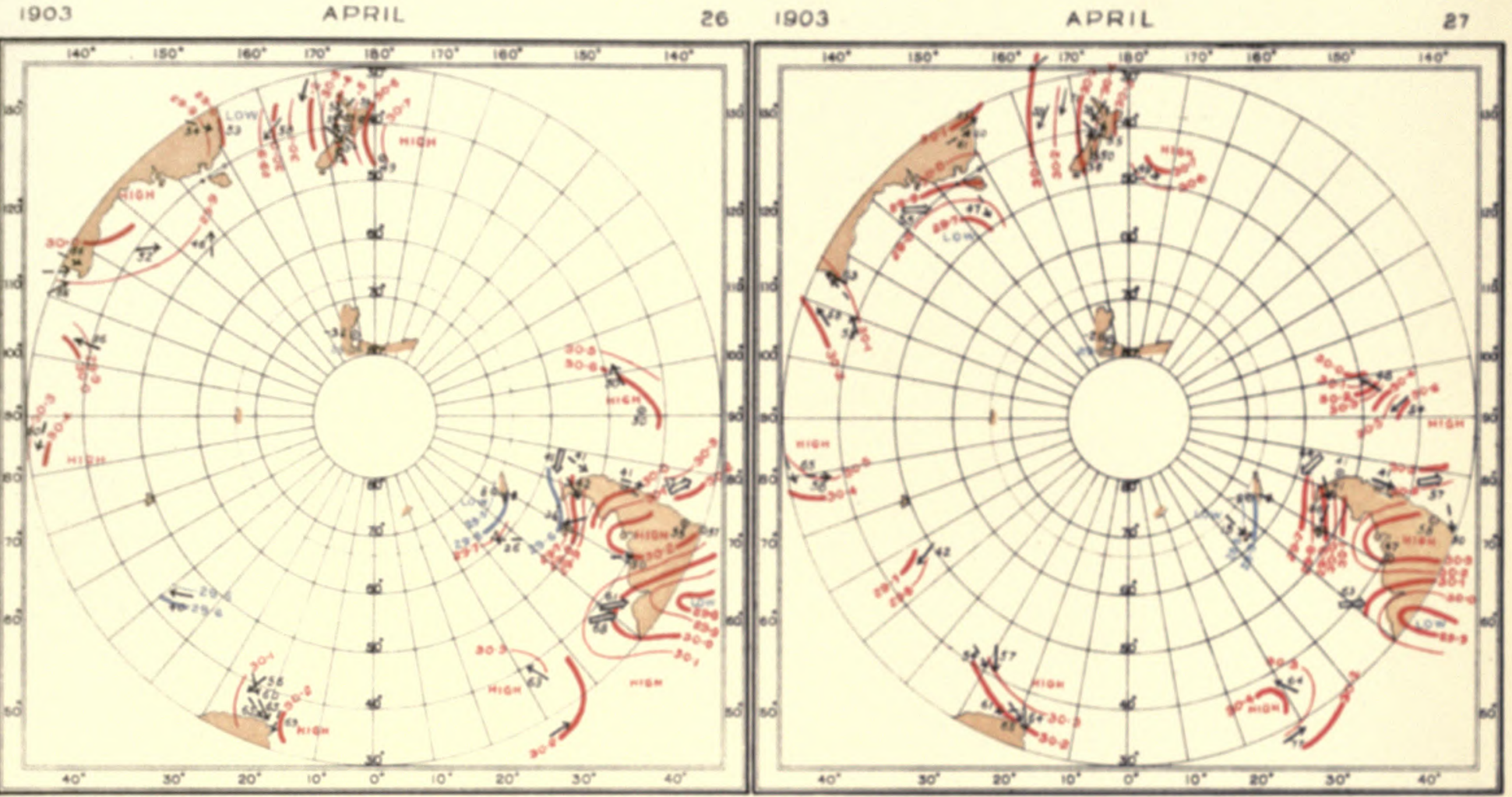

1903

APRIL

$28 \quad 1903$

APRIL

29

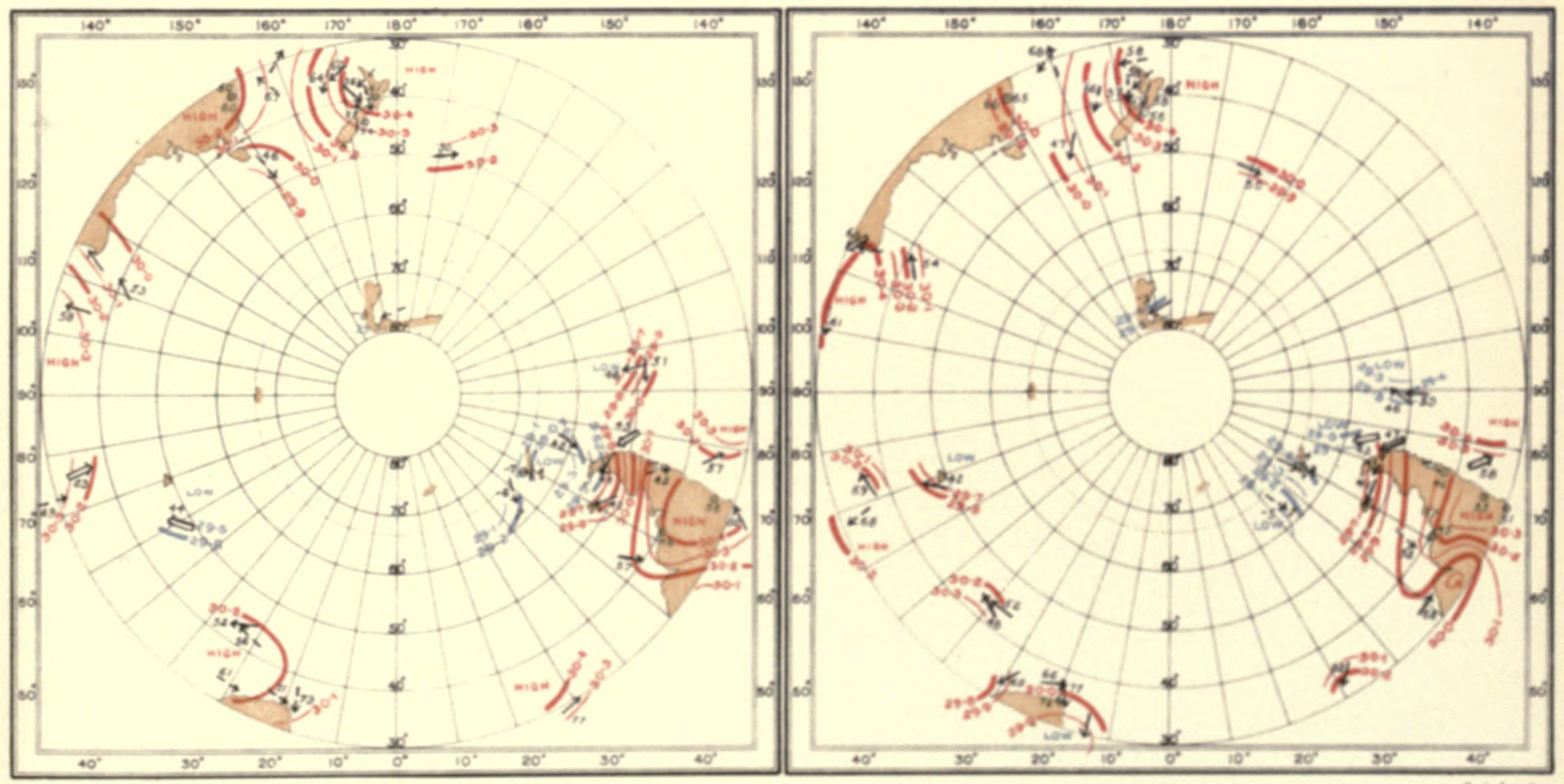



$\because \because \quad \because \because \because \vdots$

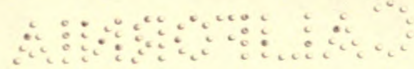


$3,1: \div ; \quad \because \ldots$

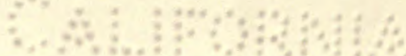


INTERNATIONAL ANTARCTIC CO-OPERATION.

SYNCHRONOUS CHARTS OF SEA-LEVEL PRESSURE FOR NOON GM T. WITH WINDS AND AIR TEMPERATURES
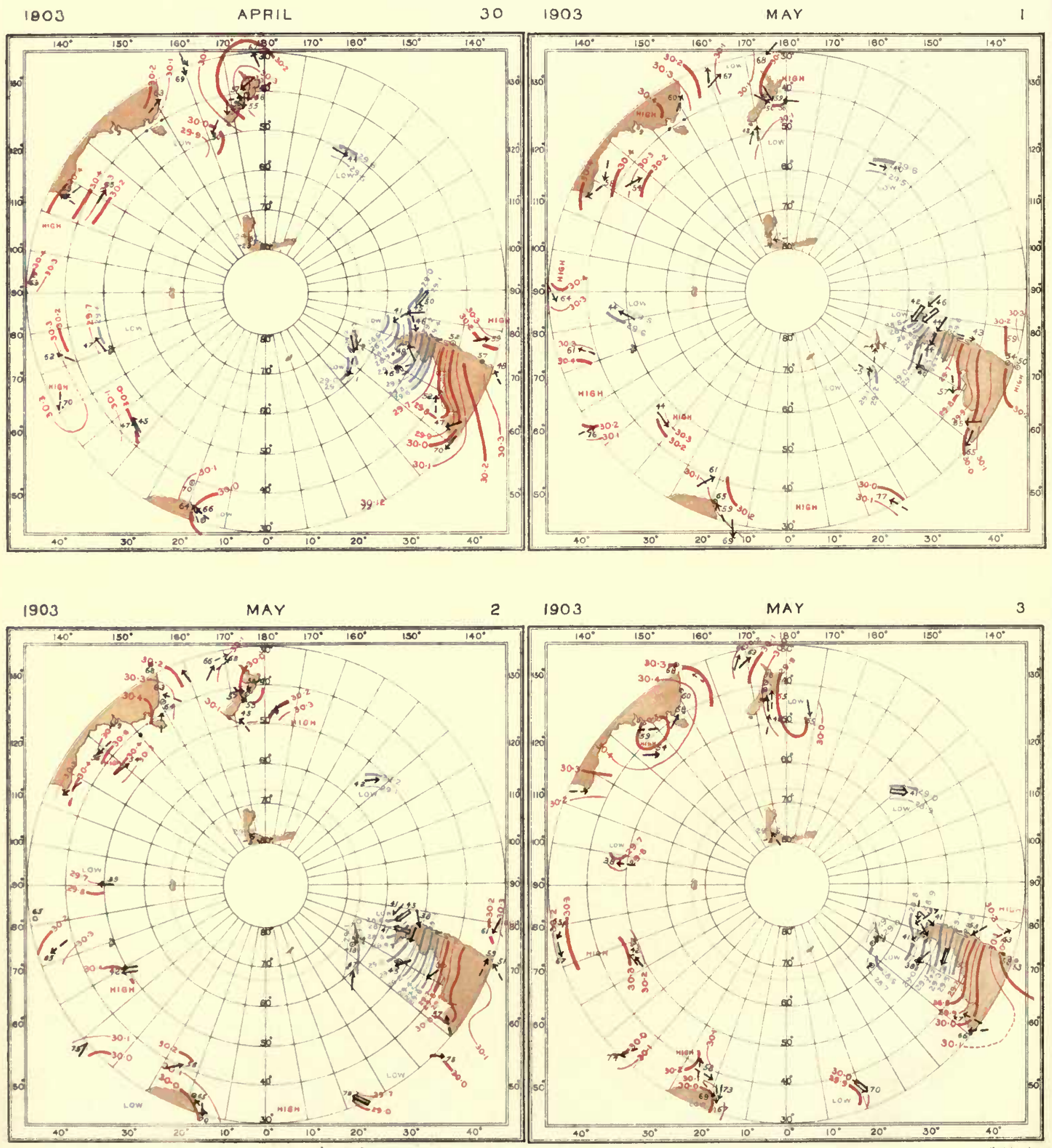
INTERNATIONAL ANTARCTIC CO-OPERATION.

SYNCHRONOUS CHARTS OF SEALEVEL PRESSURE FOR NOON GMT WITH WINOS AND AIR TEMPERATURES

MAY

$4 \quad 1903$

MAY

5
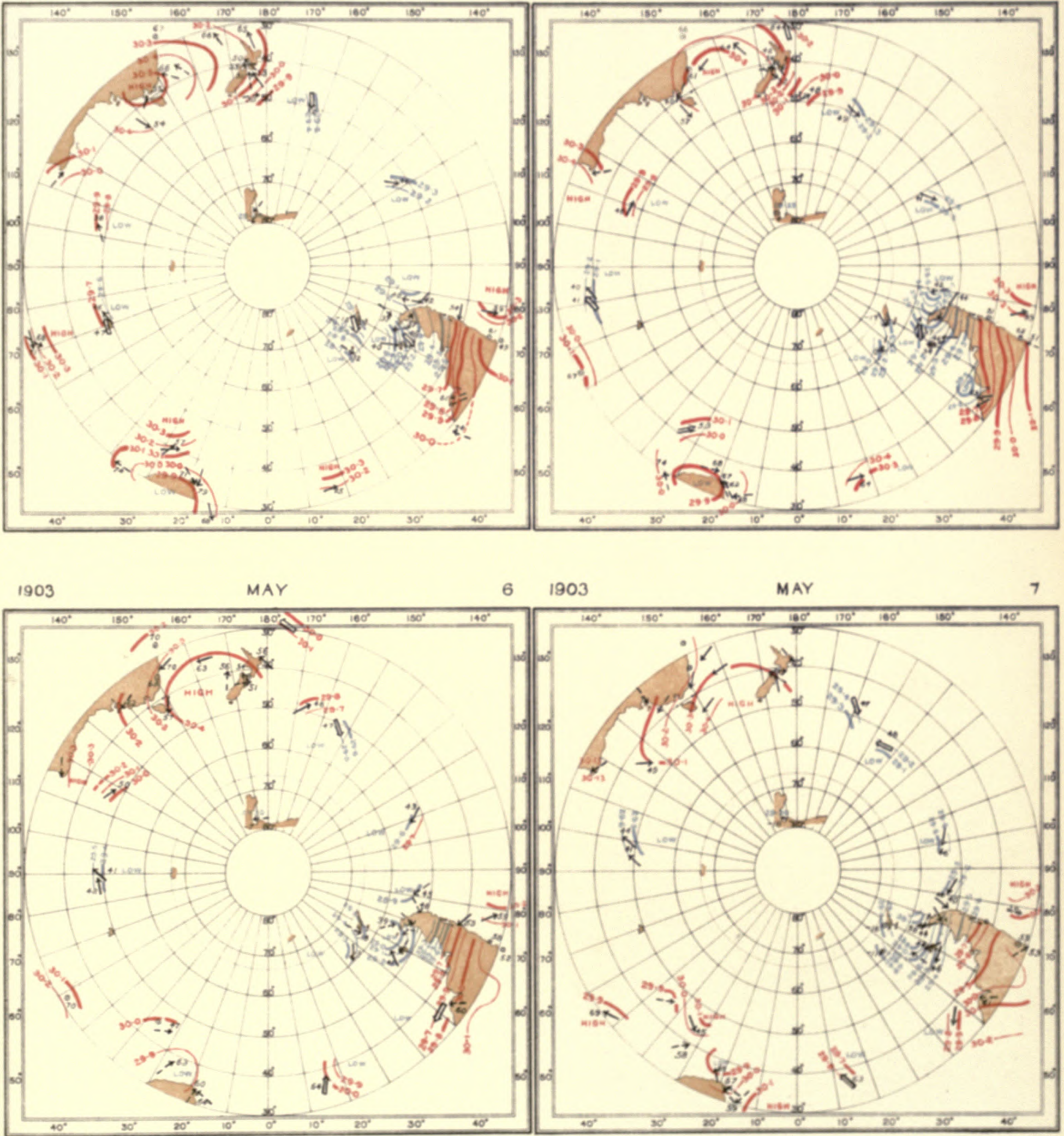


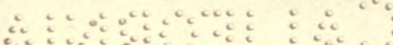

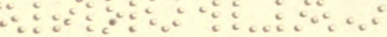



INTERNATIONAL ANTARCTIC CO-OPERATION.

SYNCHRONOUS CHARTS OF SEALEVEL PRESSURE FOR NOON GM.T

WITH WINDS AND AIR TEMPERATURES
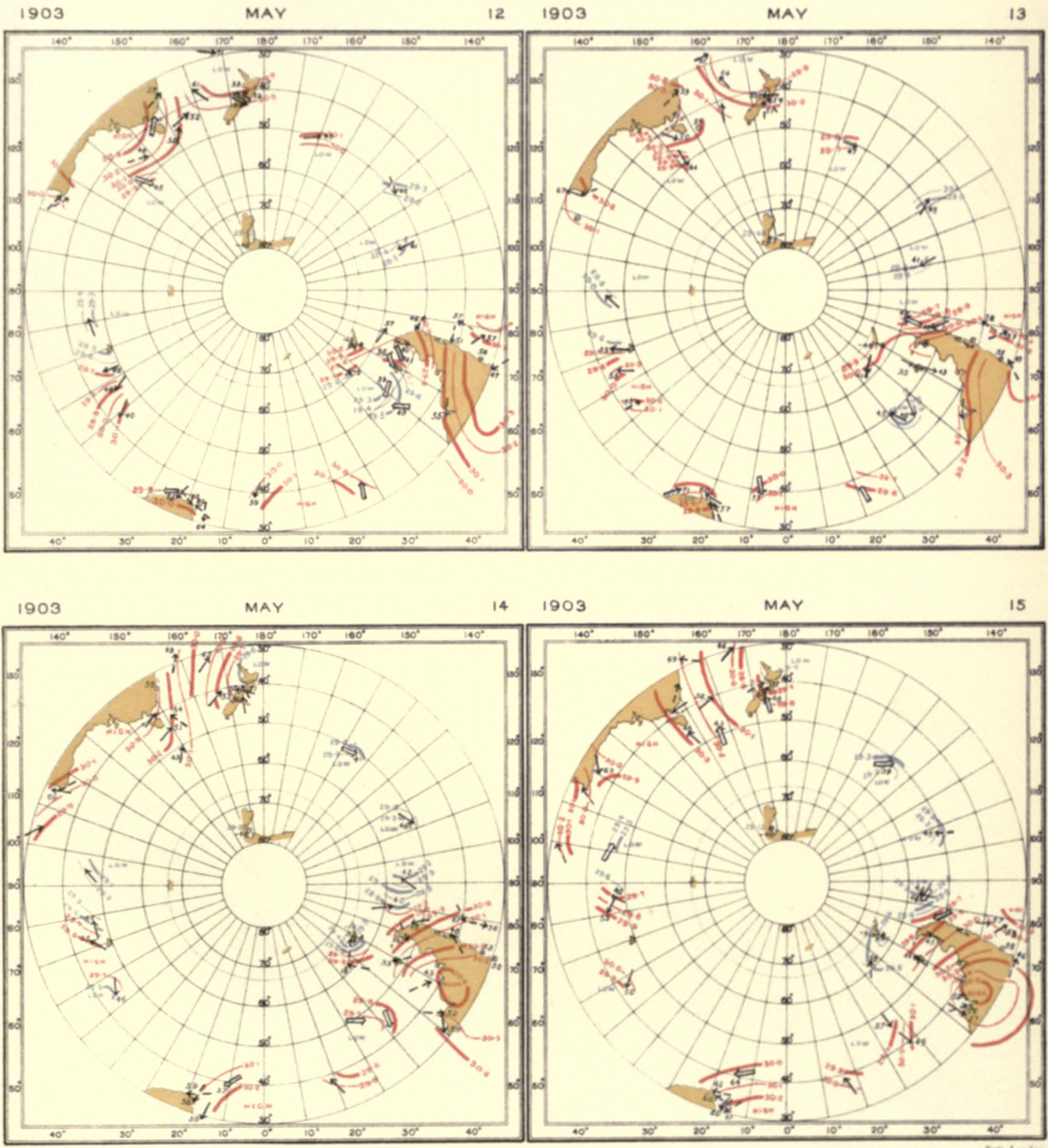
$\therefore 5 \div \div \div \because \div \because \vdots \vdots \therefore$

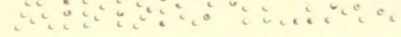




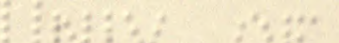

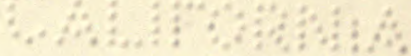


INTERNATIONAL ANTARCTIC COOPERATION

SYNCHRONOUS CHARTS OF SEA-LEVEL PRESSURE FOR NOON GMT

WITH WINDS AND AIR TEMPERATURES
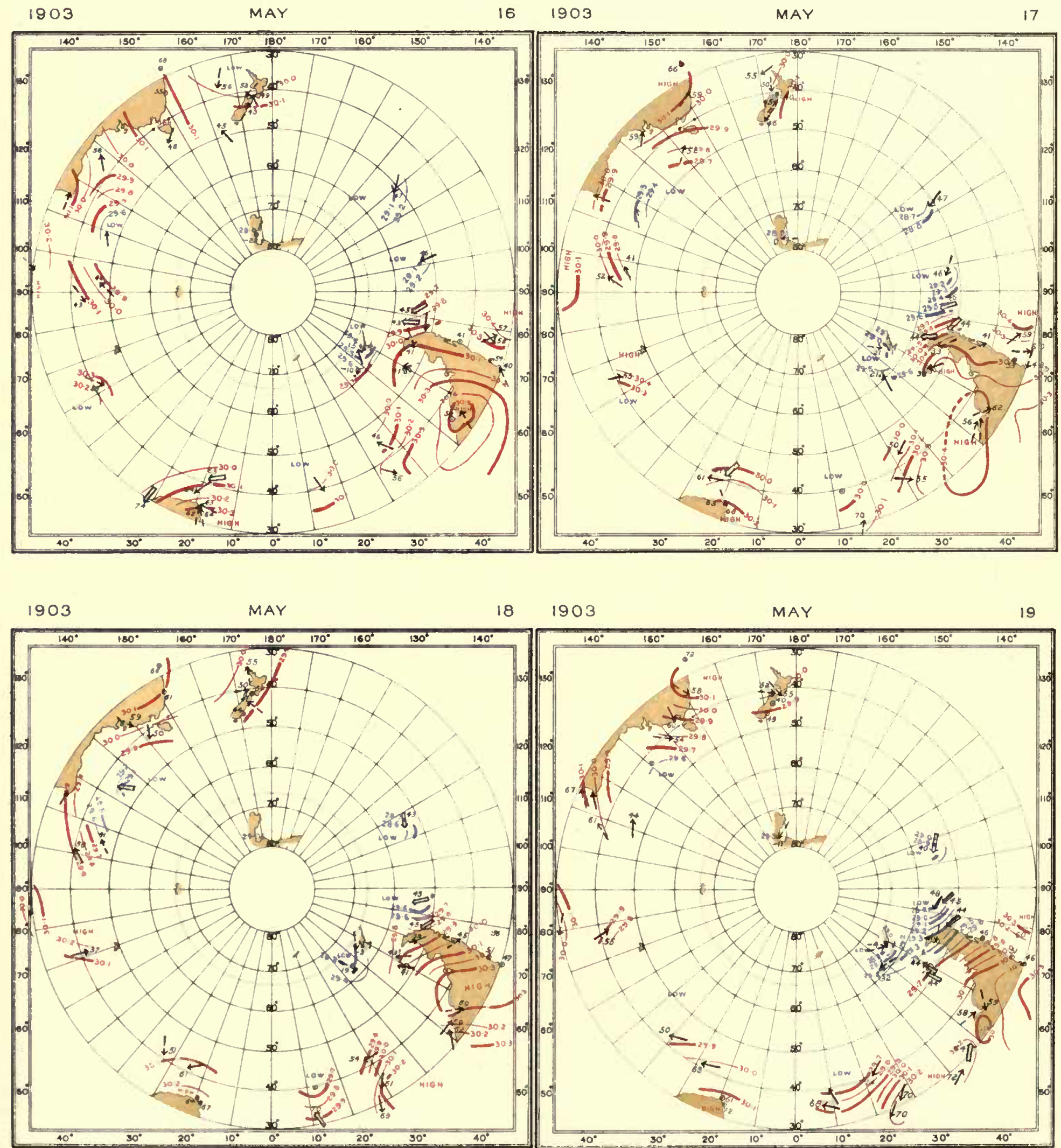
INTERNATIONAL ANTARCTIC CO-OPERATION.

SYNCHRONOUS CHARTS OF SEA-LEVEL PRESSURE FOR NOON GM.T

WITH WINDS AND AIR TEMPERATURES

1903

MAY

$20 \quad 1903$

MAY

21
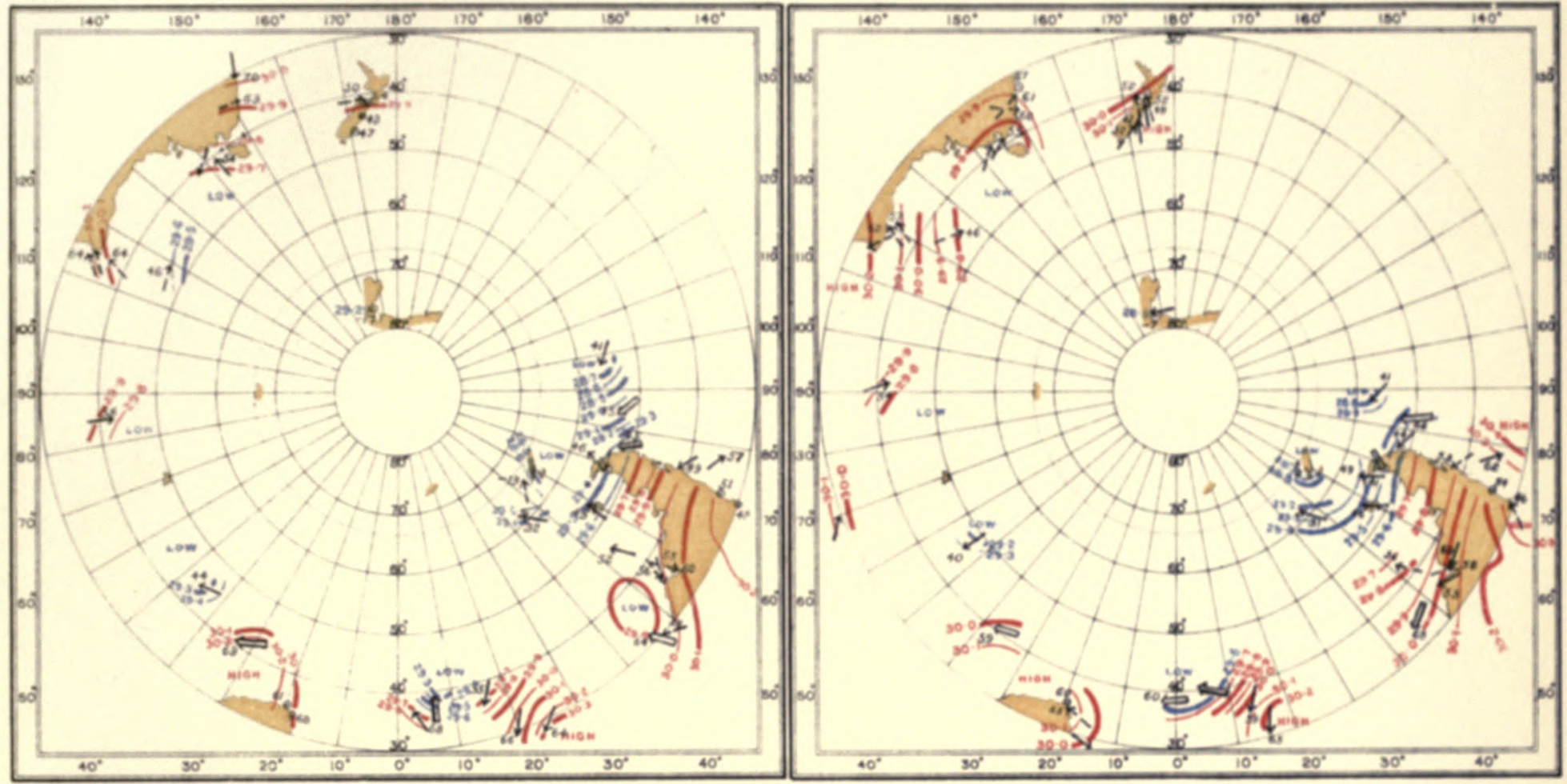

1903

MAY

$22 \quad 1903$

MAY

23

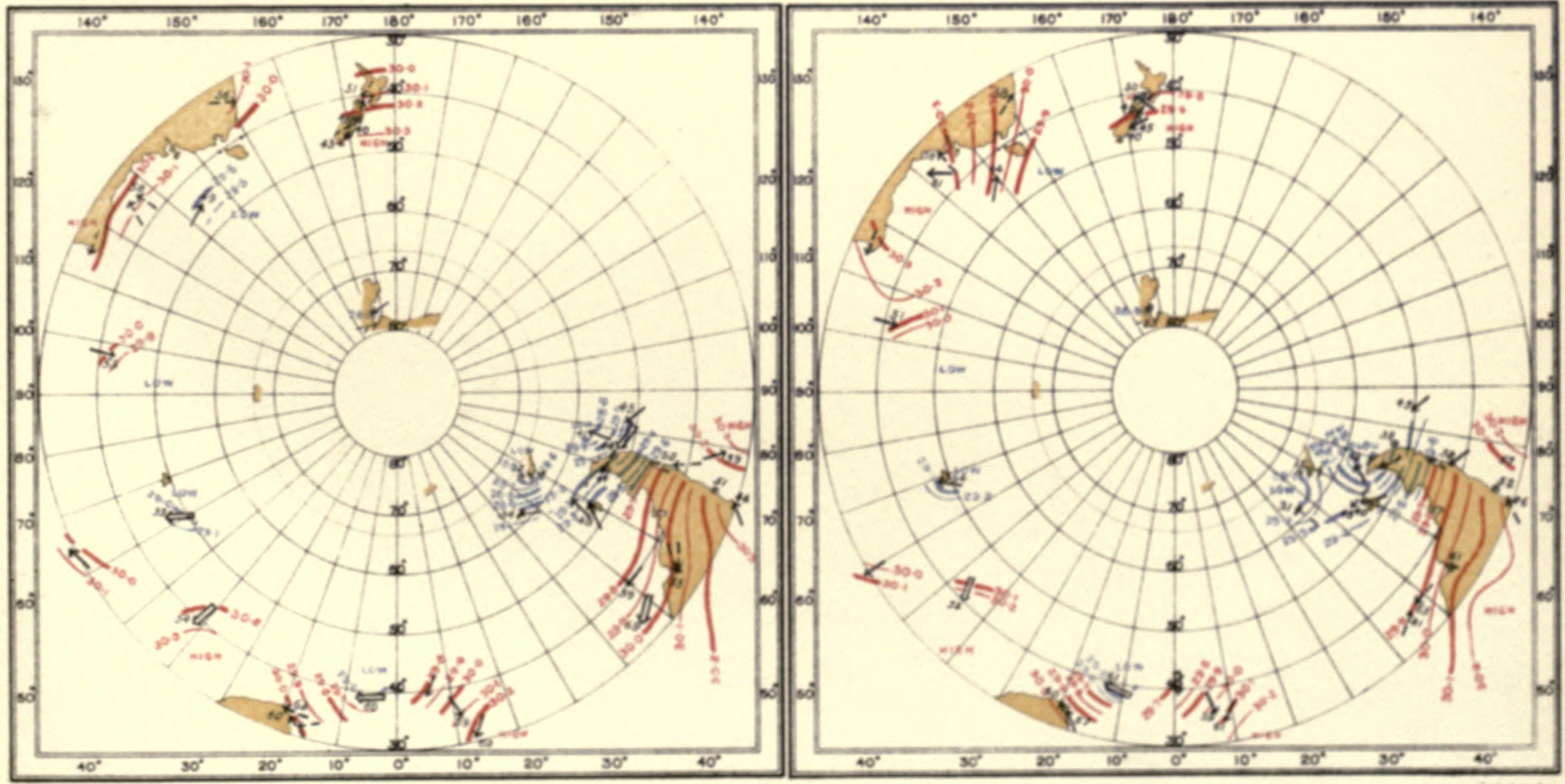




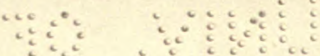

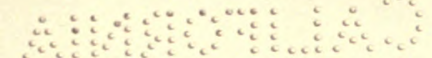

, 
a

a d a 
INTERNATIONAL ANTARCTIC COOPERATION.

SYNCHRONOUS CHARTS OF SEA-LEVEL PRESSURE FOR NOON GM.T.

WITH WINOS ANO AIR TEMPERATURES.
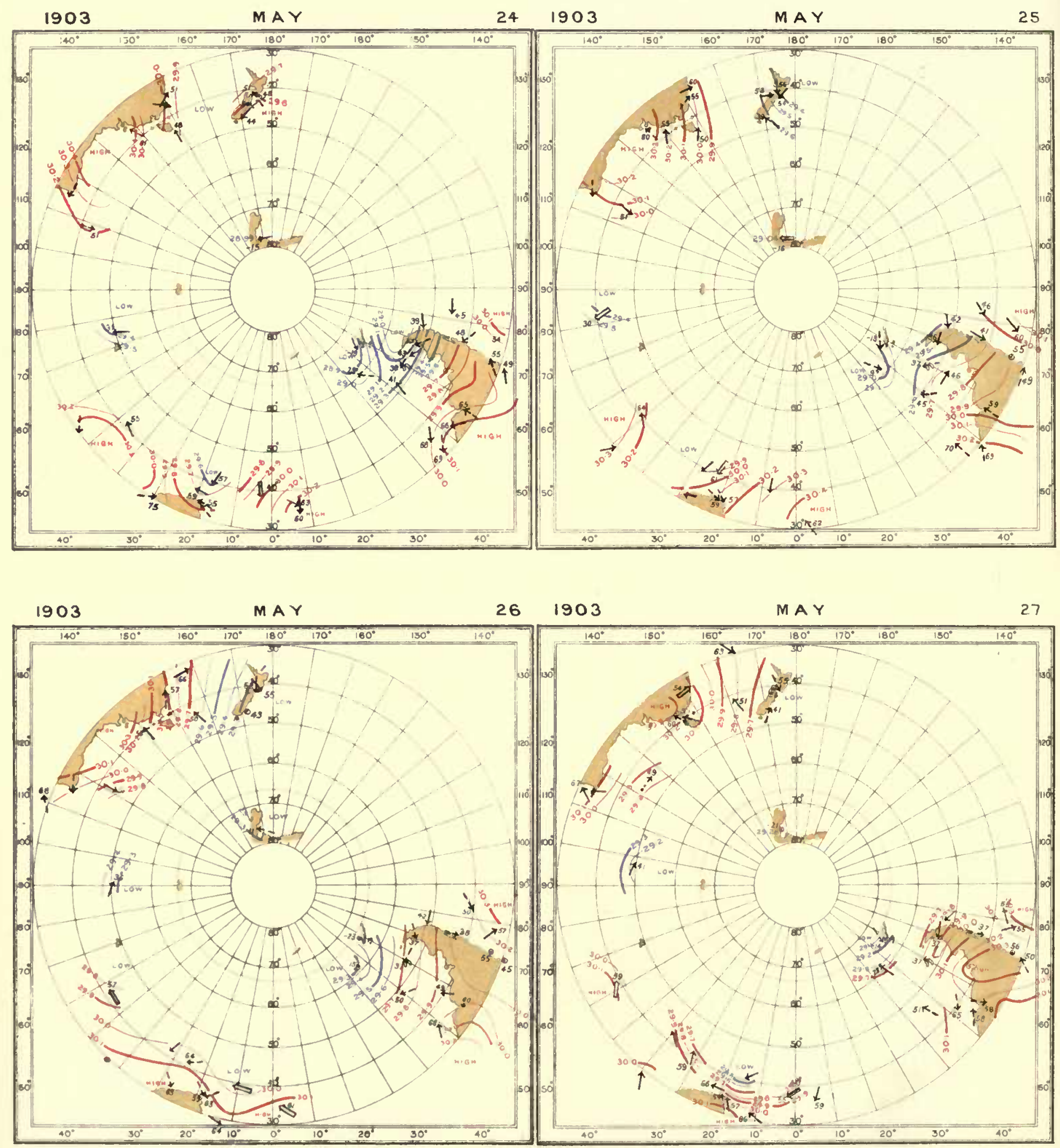
INTERNATIONAL ANTARCTIC CO-OPERATION.

SYNCHRONOUS CHARTS OF SEA-LEVEL PRESSURE FOR NOON GMT

WITH WINDS AND AIR TEMPERATURES
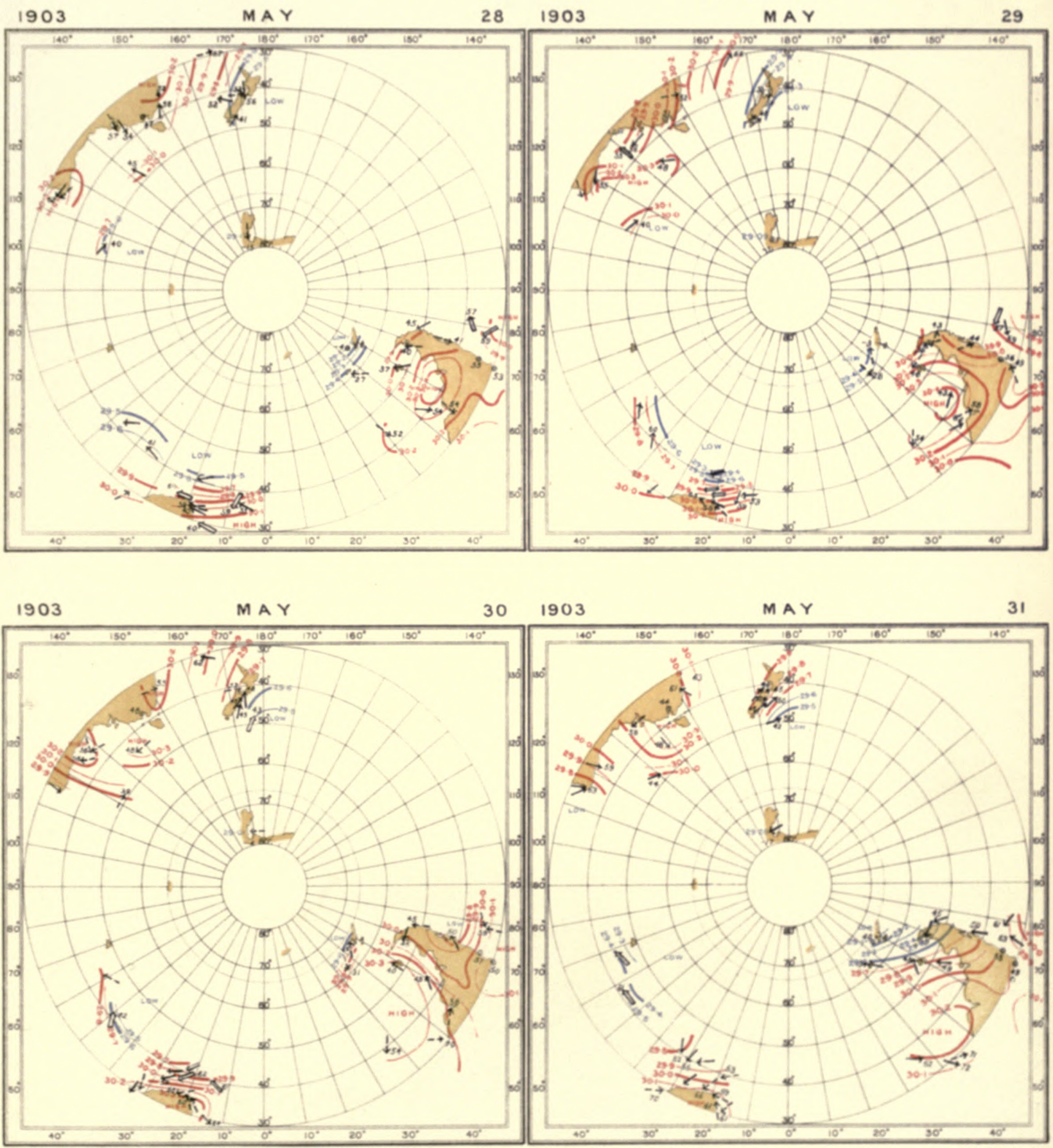
$\because \because \quad \because \because \frac{1}{2}$

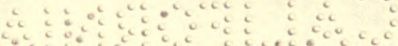


to: : : : :

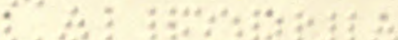

6.t. 
INTERNATIONAL ANTARCTIC COOPERATION.

SYNCHRONOUS CHARTS OF SEALEVEL PRESSURE FOR NOON GM.T

WITH WINDS AND AIR TEMPERATURES

JUNE

1903

JUNE

2
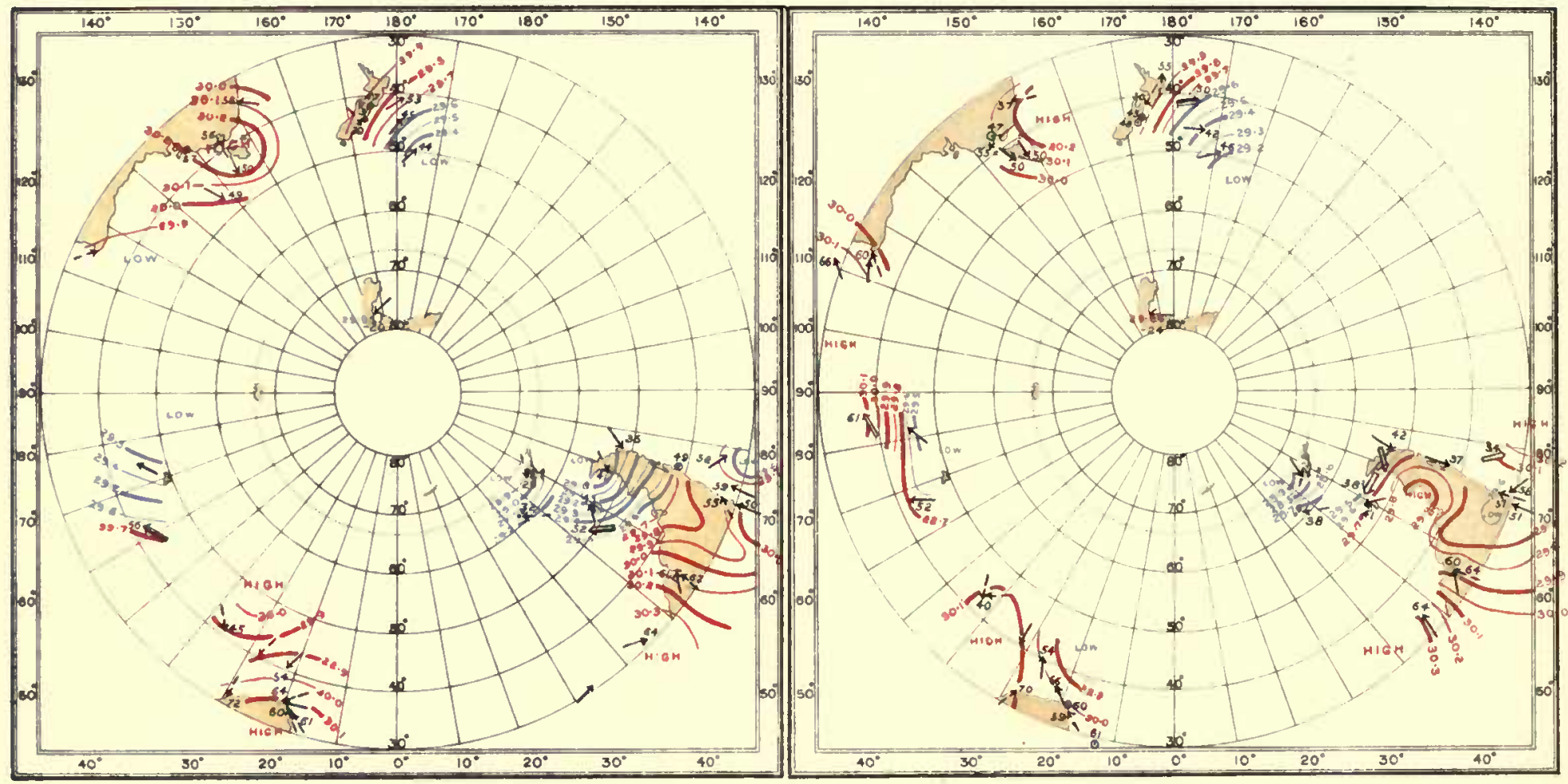

1903

JUNE

31903

JUNE
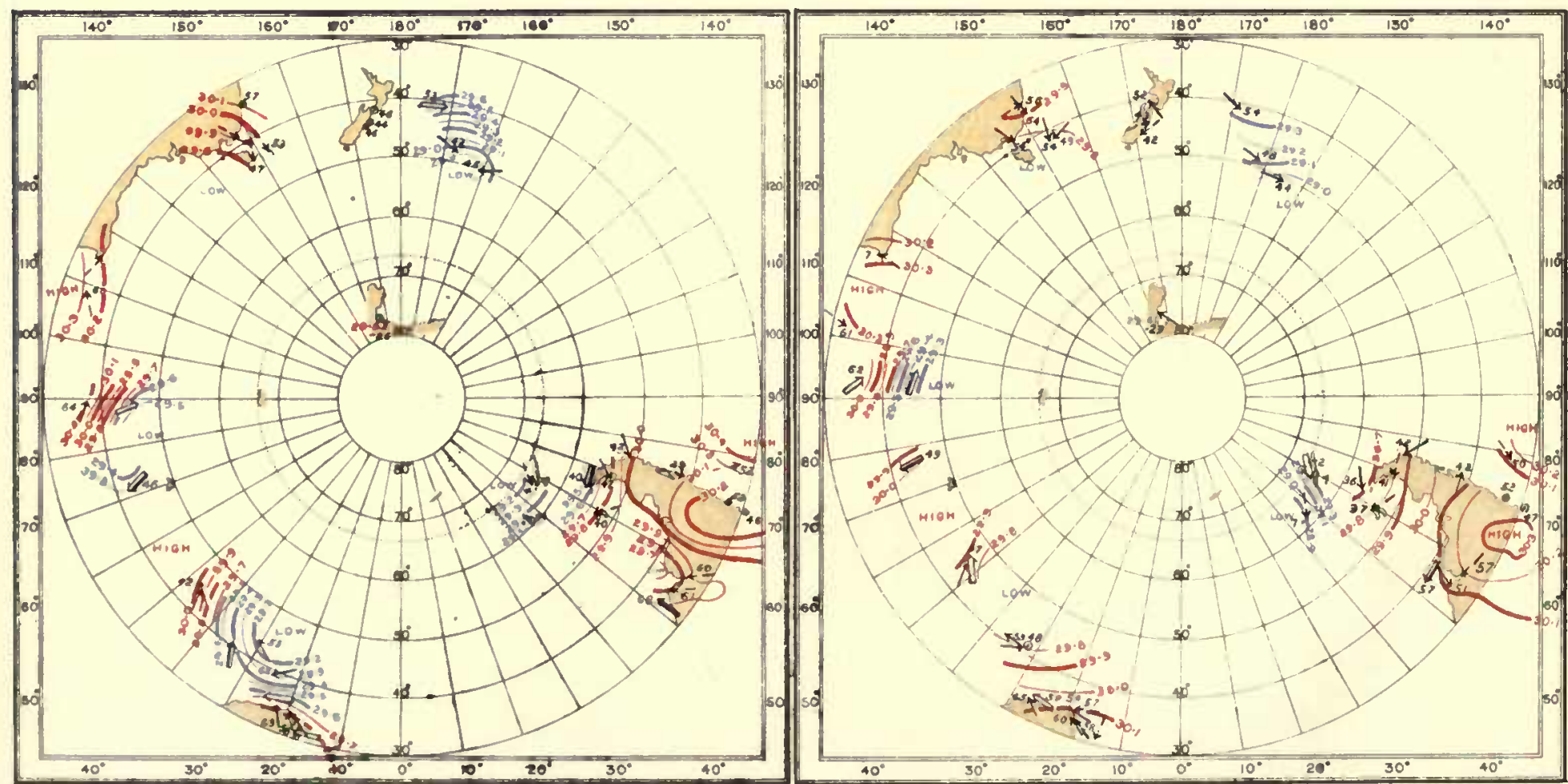
INTERNATIONAL ANTARCTIC CO-OPERATION.

SYNCHRONOUS CHARTS OF SEA-LEVEL PRESSURE FOR NOON GM.T

WITH WINDS AND AIR TEMPERATURES
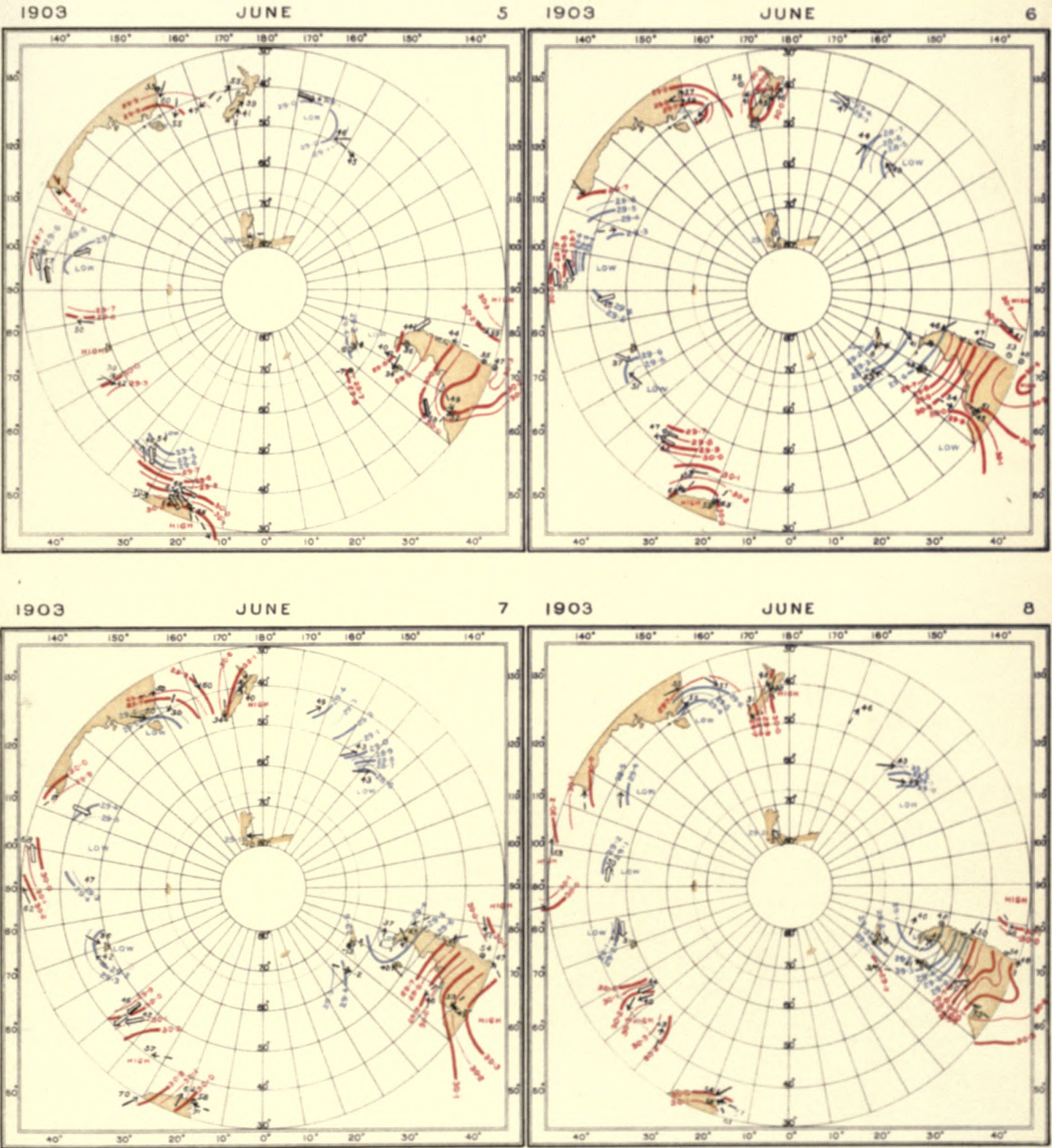


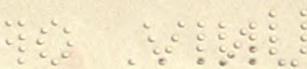

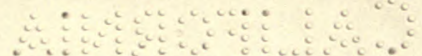


INTERNATIONAL ANTARCTIC COOPERATION.

SYNCHRONOUS CHARTS OF SEALEVEL PRESSURE FOR NOONGMT

WITH WINDS AND AIR TEMPERATURES

1903

JUNE

$9 \quad 1903$

JUNE

10

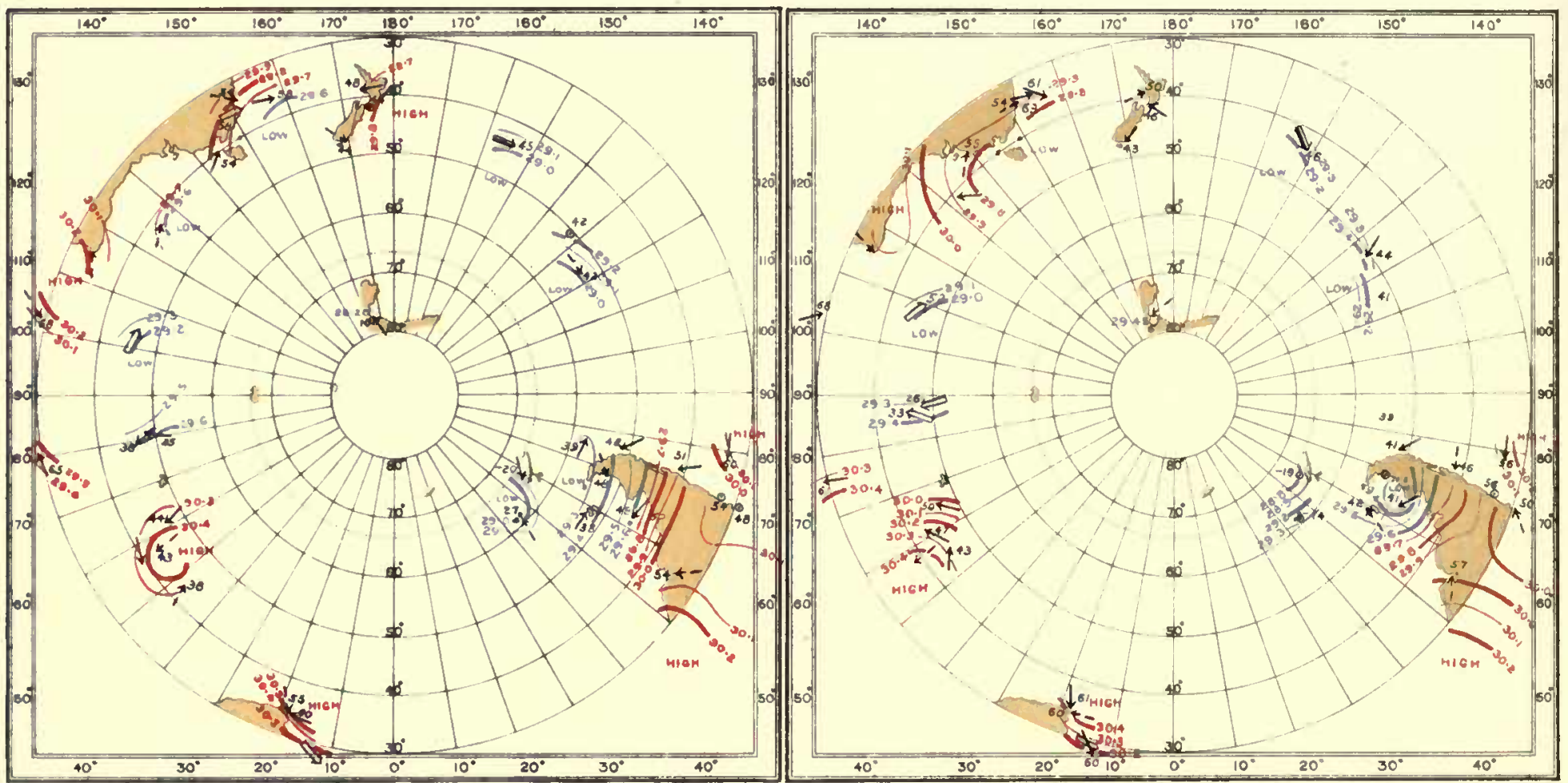

1903

JUNE

$11 \quad 1903$

JUNE

12
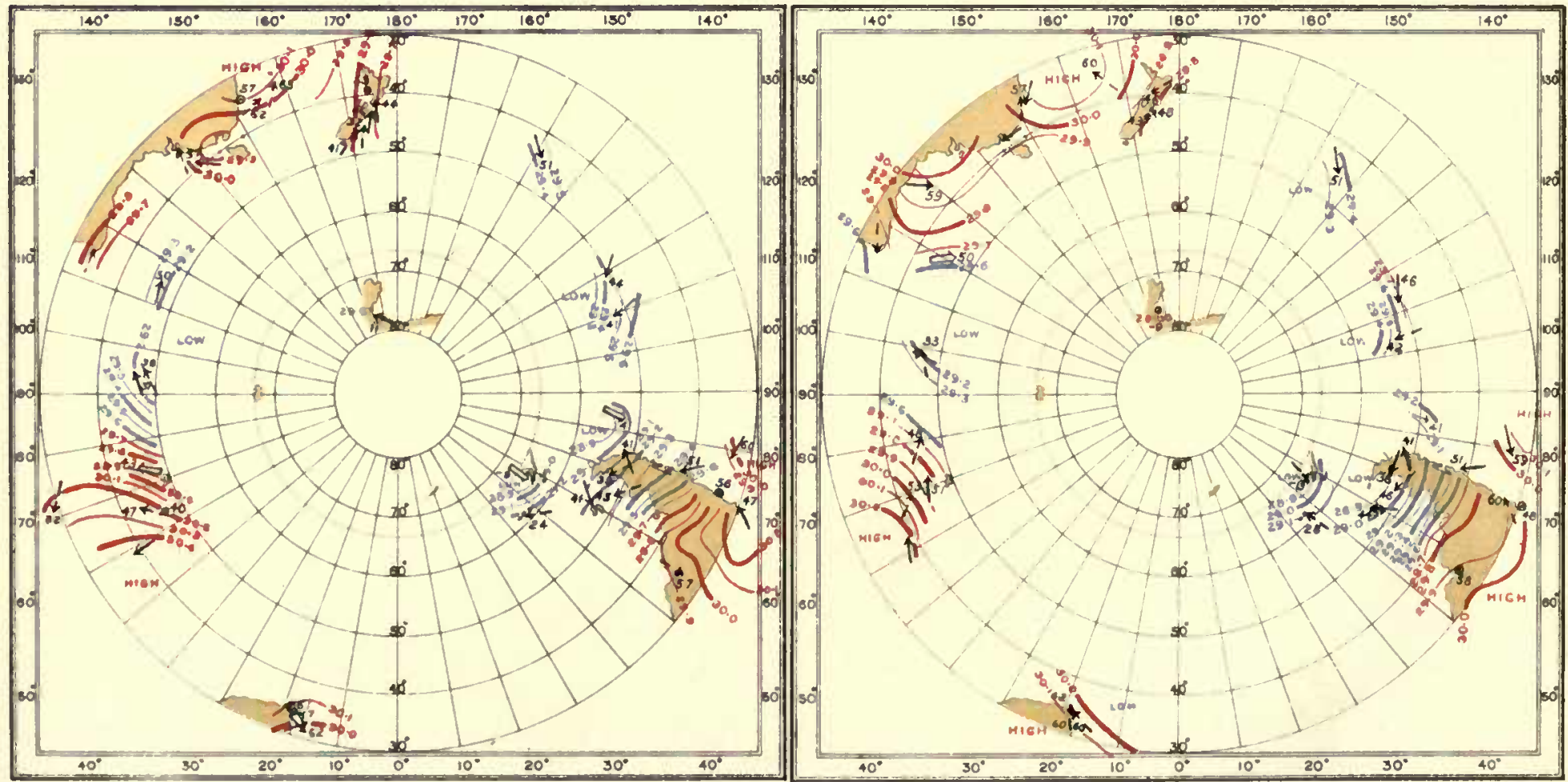
INTERNATIONAL ANTARCTIC CO-OPERATION

SYNCHRONOUS CHARTS OF SEA-LEVEL PRESSURE FOR NOON GMT

WITH WINDS AND AIR TEMPERATURES

1903

JUNE

$13 \quad 1903$

JUNE

14

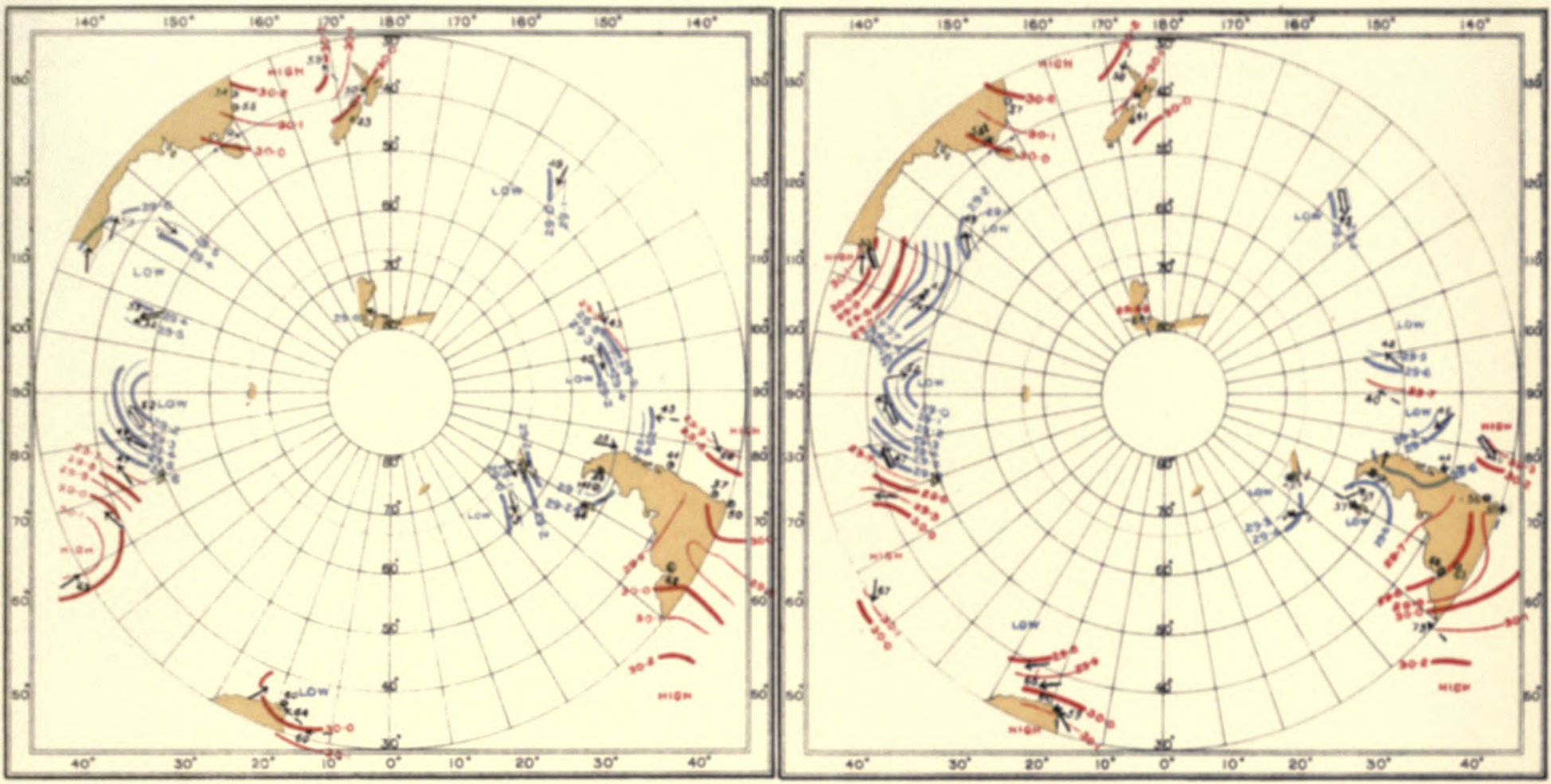

$1903 \quad J \cup N E$

$15 \quad 1903$

JUNE

18

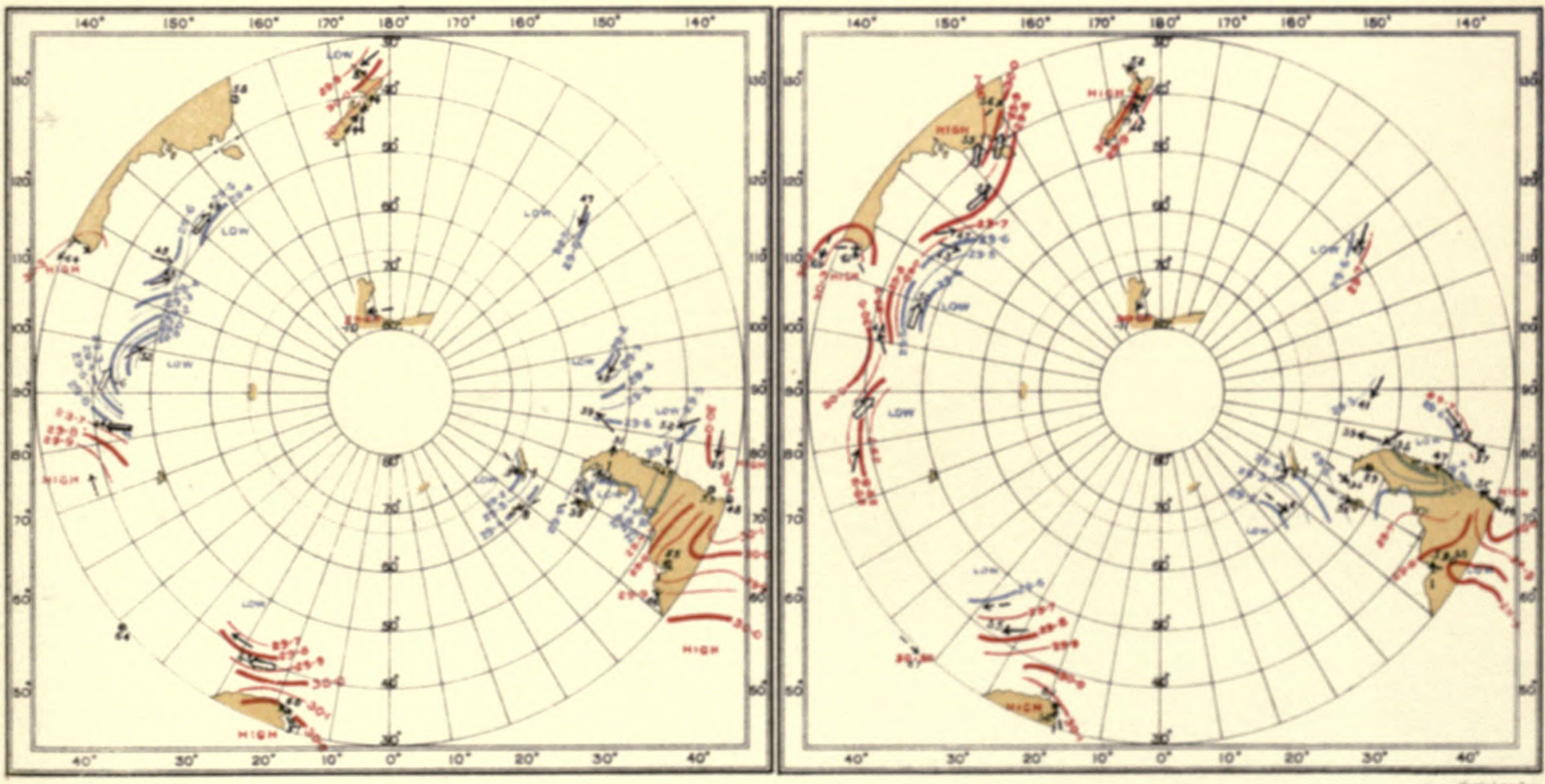


$\because 2 \quad \because 39 \vdots$

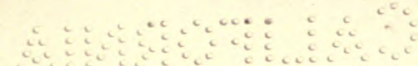


:

\% 
INTERNATIONAL ANTARCTIC COOPERATION.

SYNCHRONOUS CHARTS OF SEA-LEVEL PRESSURE FOR NOON G.M.T.

WITH WINDS AND AIR TEMPERATURES

1903

JUNE

$17 \quad 1903$

$J \cup N E$

18
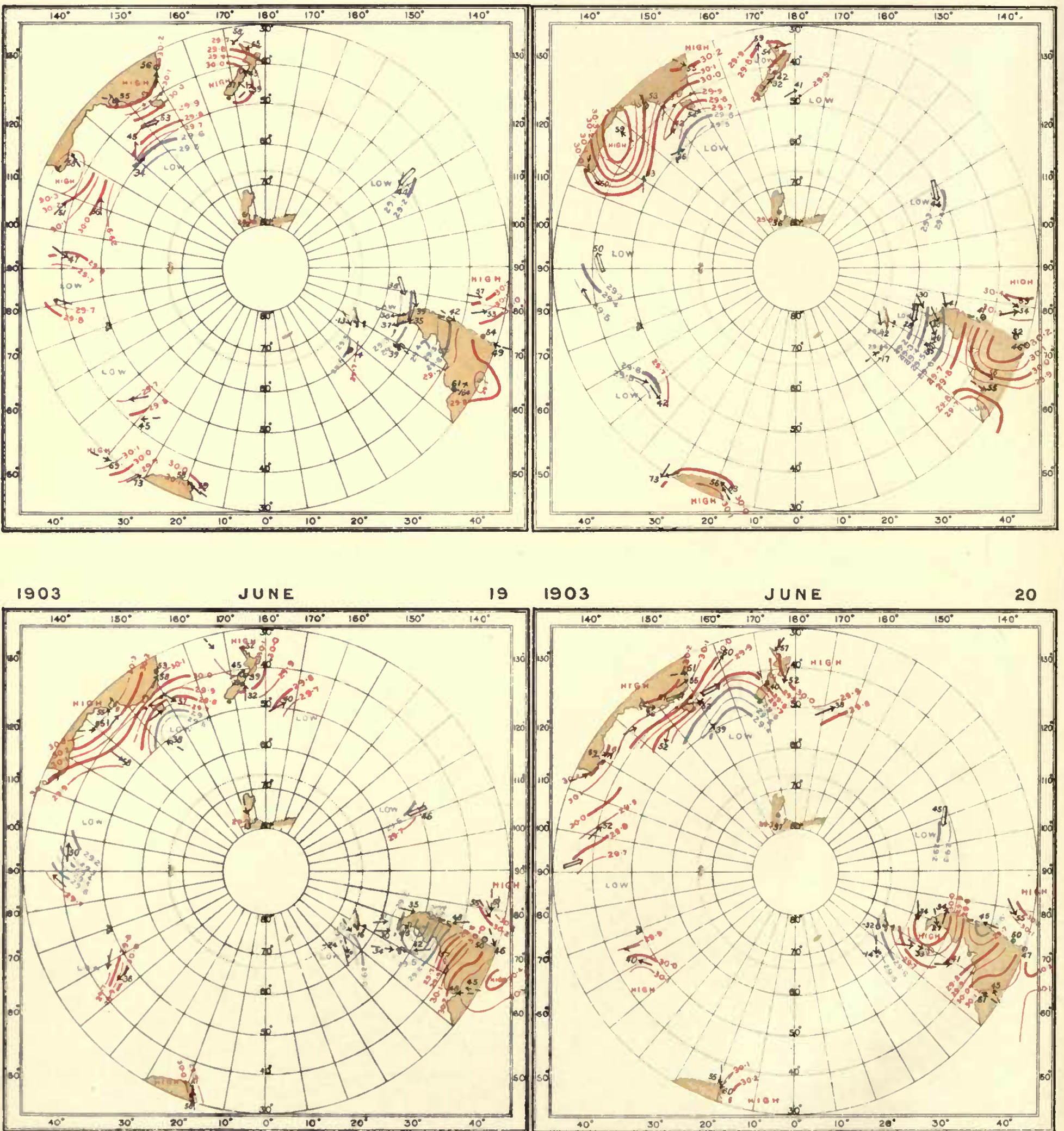

1903

JUNE

20

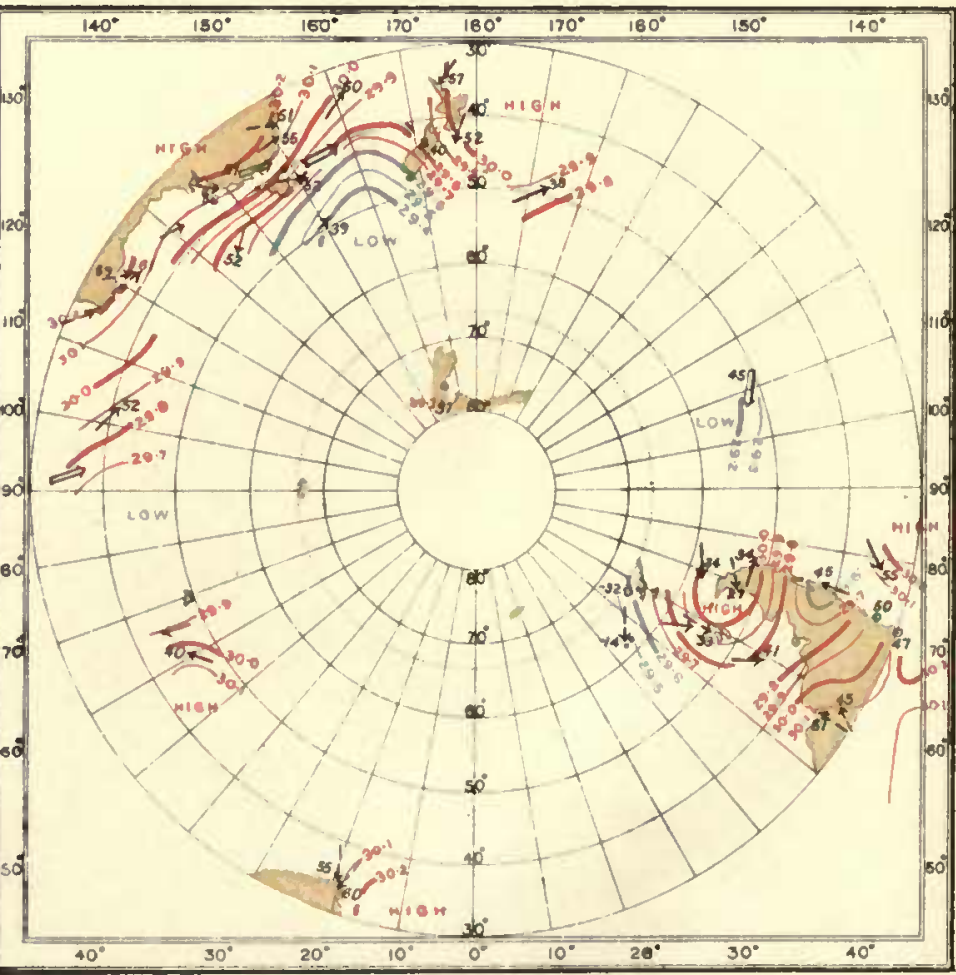


INTERNATIONAL ANTARCTIC CO-OPERATION.

SYNCHRONOUS CHARTS OF SEALEVEL PRESSURE FOR NOON GM.T

WITH WINDS AND AIR TEMPERATURES

1903

JUNE $21 \quad 1903$

JUNE

22

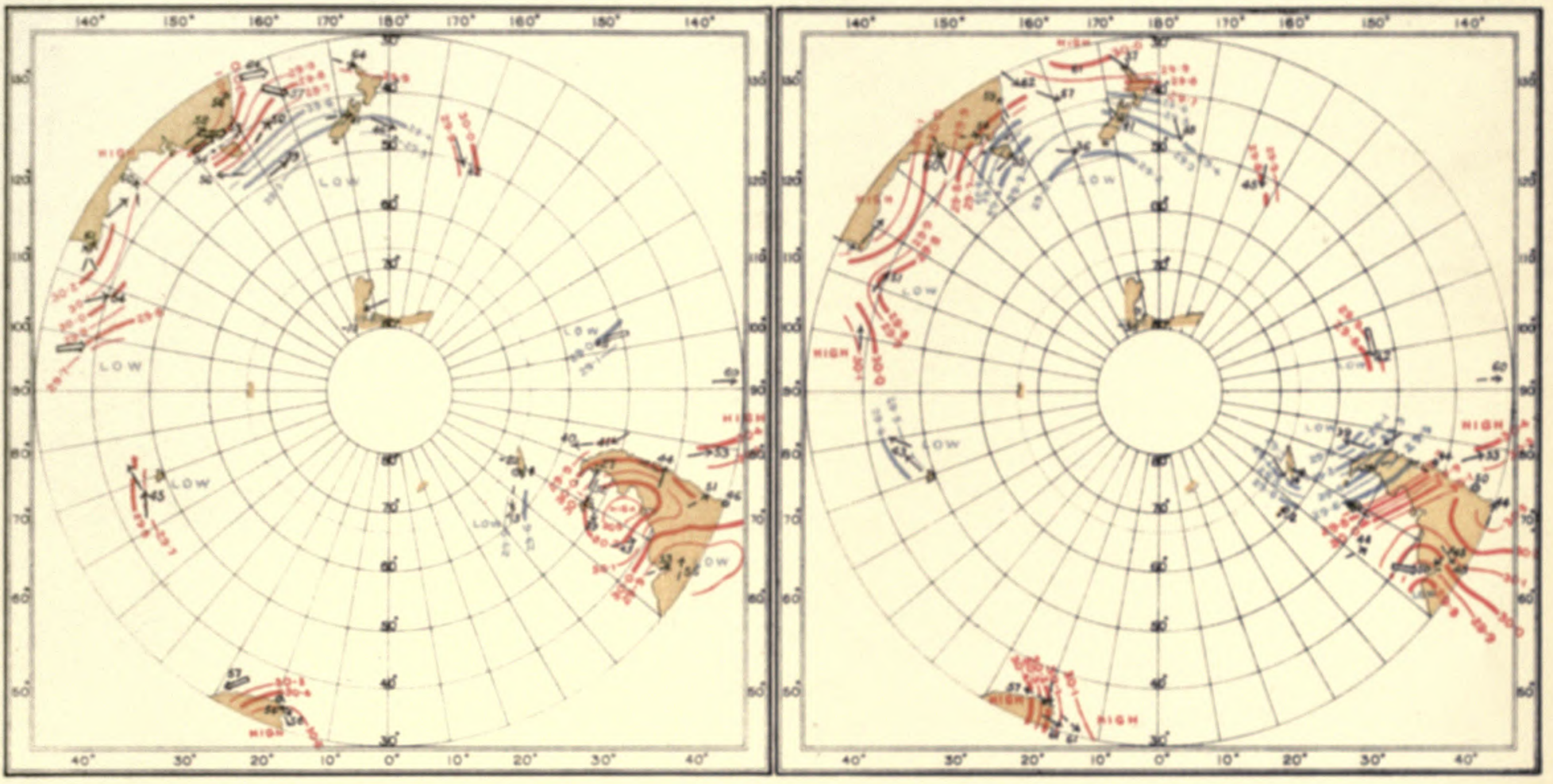

1903

JUNE

$23 \quad 1903$

JUNE

24

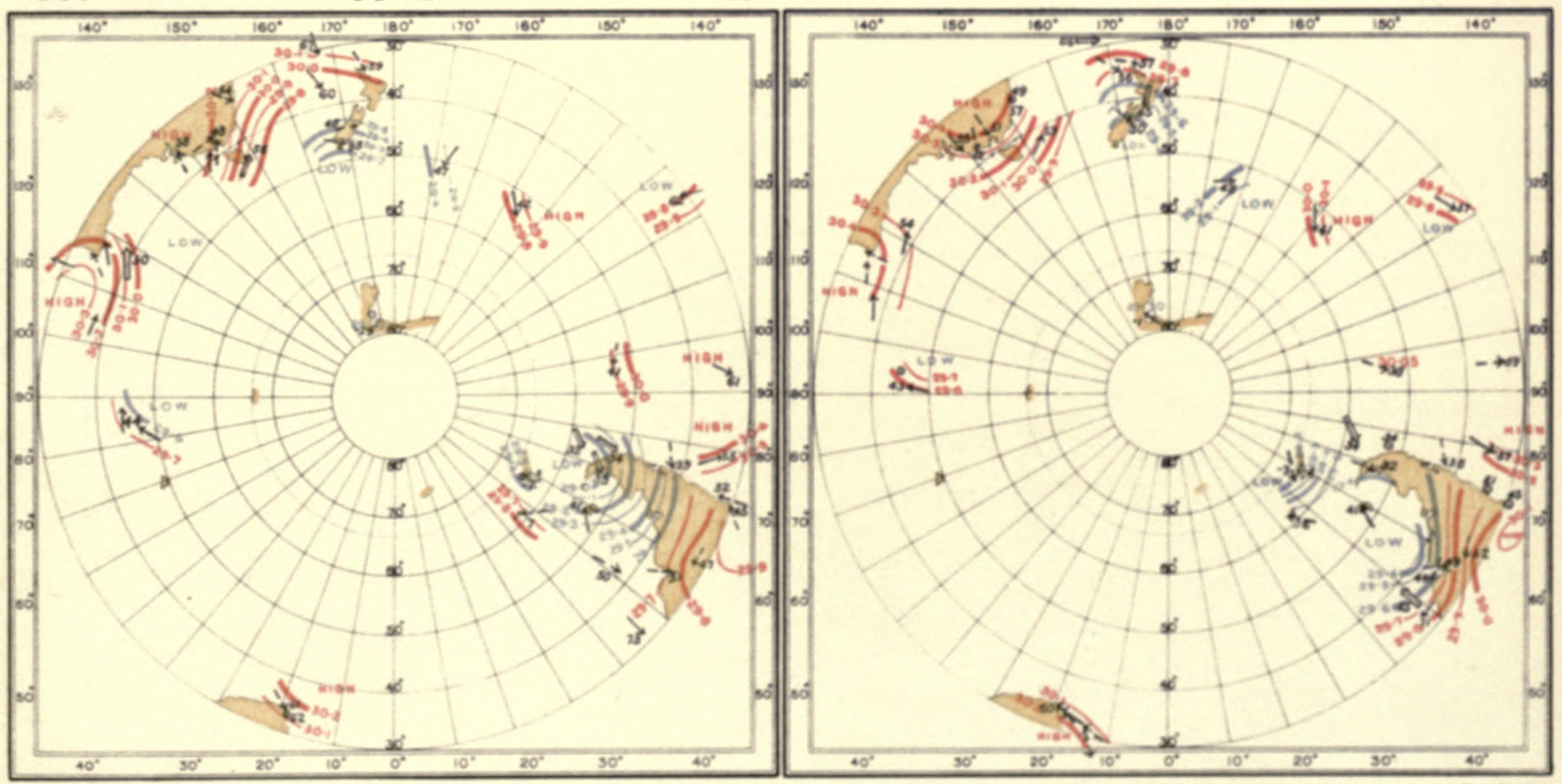


$\because \vdots=\quad \because \because \vdots 3$

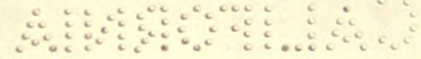


$4: 2,2, ;: \quad n, \ldots$

t 
INTERNATIONAL ANTARCTIC CO-OPERATION.

SYNCHRONOUS CHARTS OF SEA-LEVEL PRESSURE FOR NOONGMT WITH WINDS AND AIR TEMPERATURES
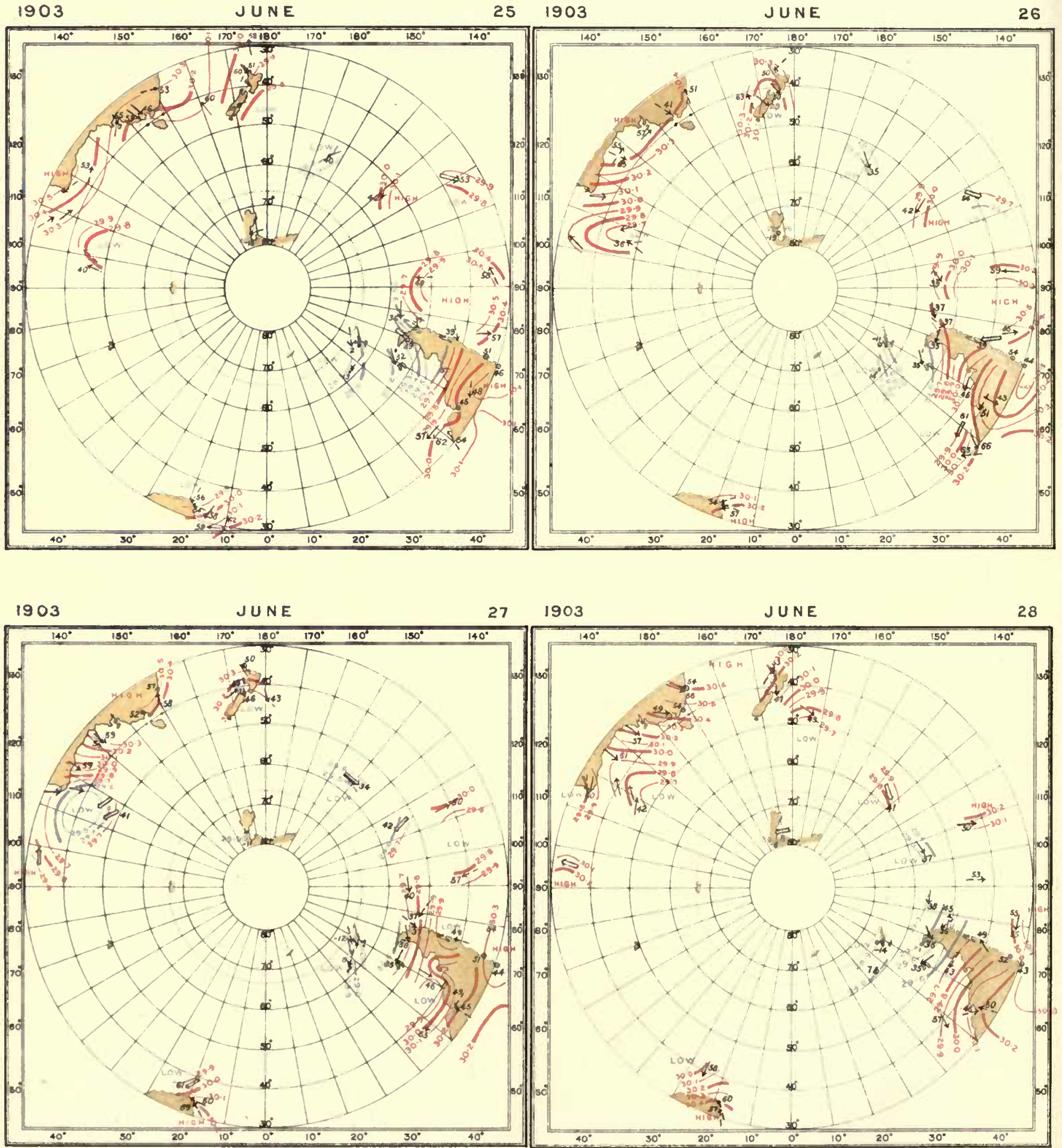
INTERNATIONAL ANTARCTIC CO-OPERATION

SYNCHRONOUS CHARTS OF SEALEVEL PRESSURE FOR NOON GMT

WITH WINDS AND AIR TEMPERATURES
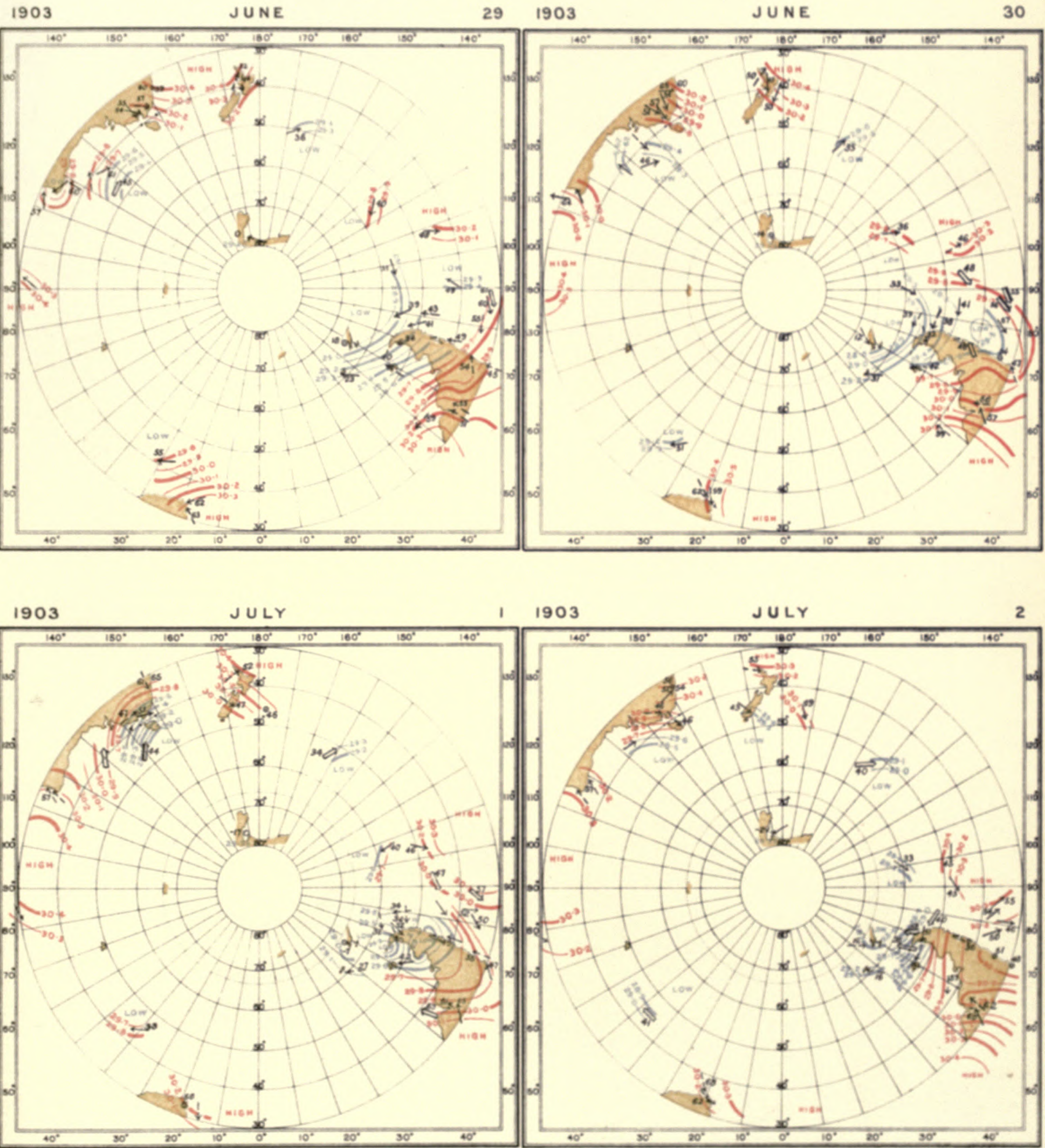
$\because \because \quad \because \because \vdots \vdots$

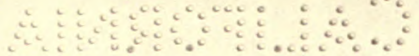


INTERNATIONAL ANTARCTIC COOPERATION.

SYNCHRONOUS CHARTS OF SEA-LEVEL PRESSURE FOR NOON GMT WITH WINDS AND AIR TEMPERATURES
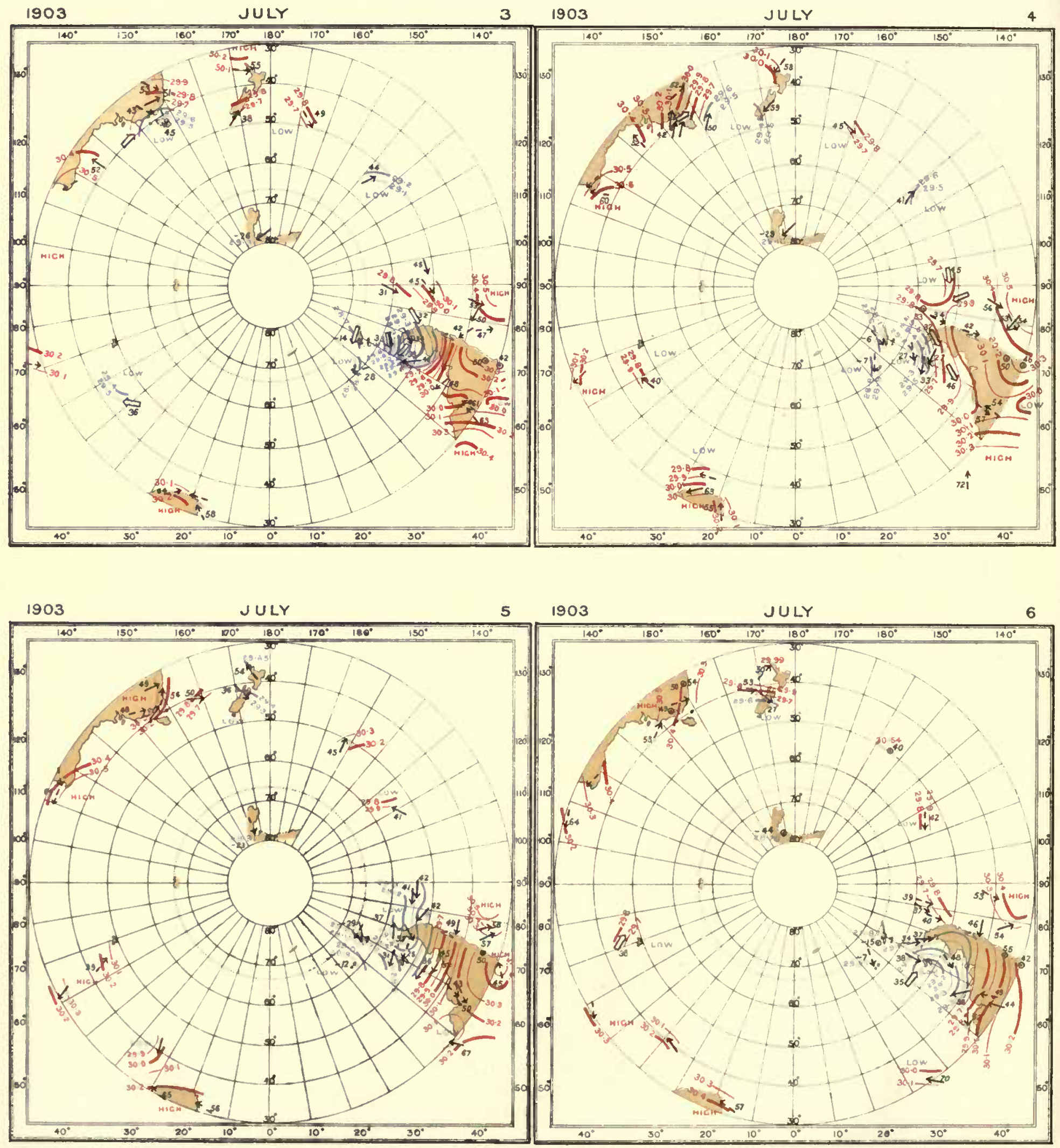
INTERNATIONAL ANTARCTIC CO-OPERATION.

SYNCHRONOUS CHARTS OF SEA-LEVEL PRESSURE FOR NOON GMT

WITH WINDS AND AIR TEMPERATURES

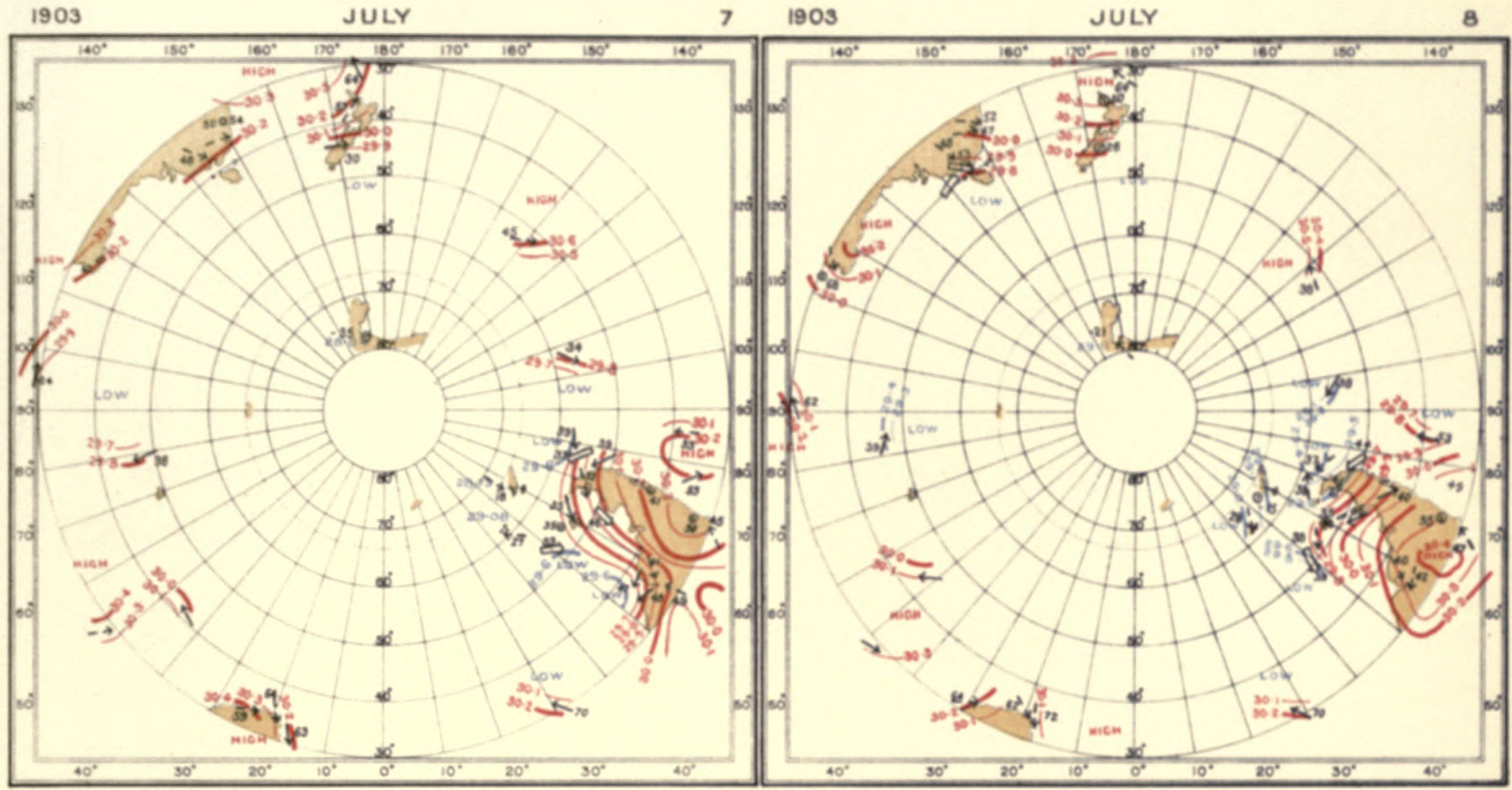

$1903 \quad J \cup L Y$

1903

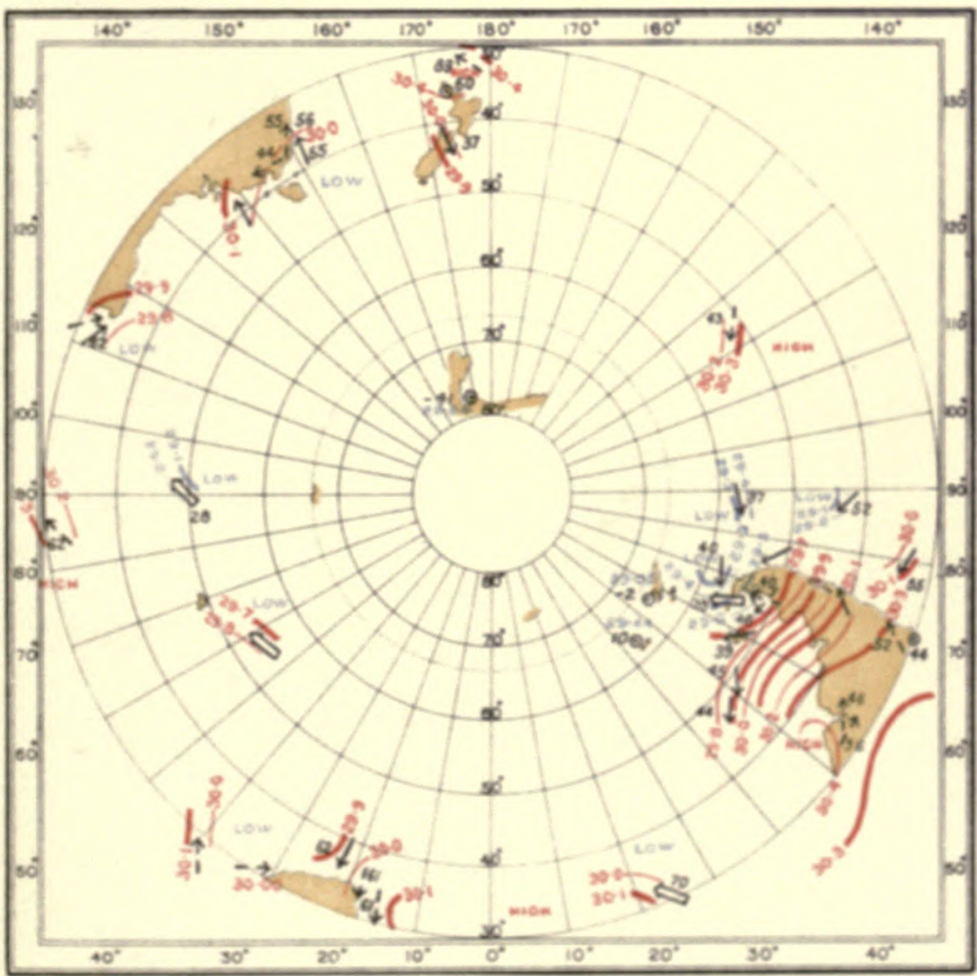

JULY 10

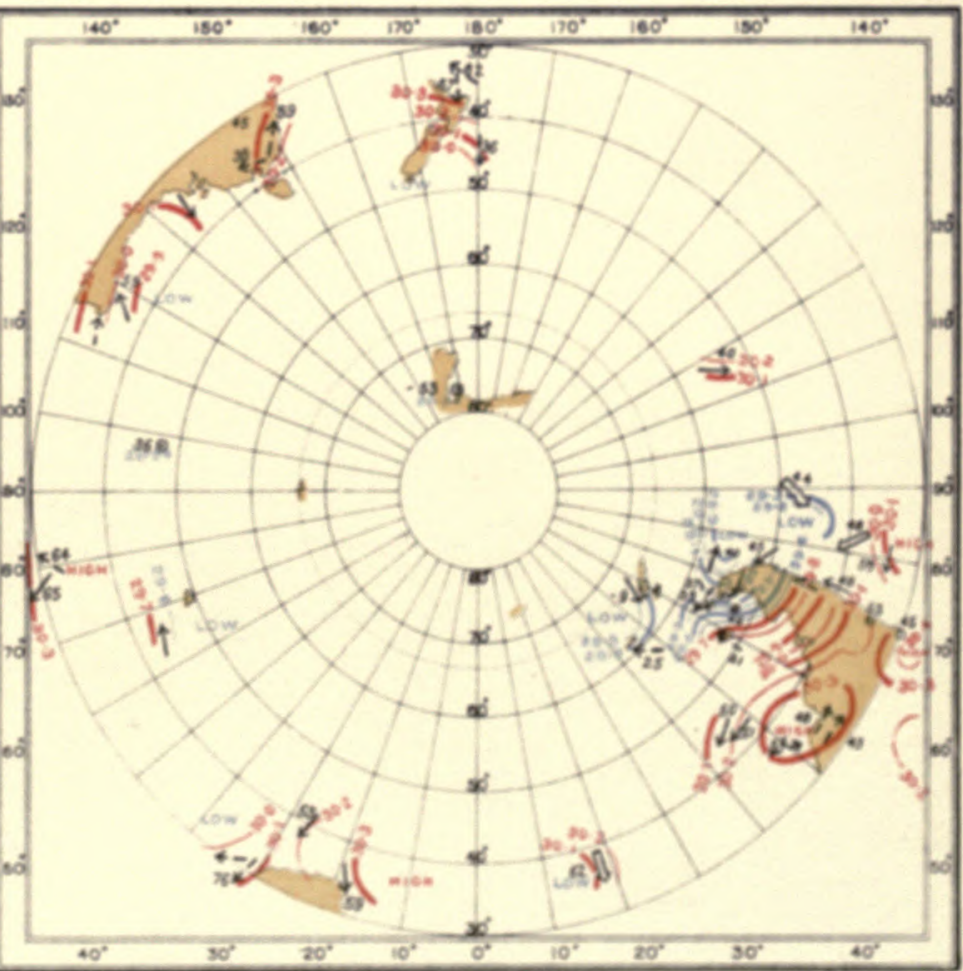


$\because \because \quad \because \because \vdots \vdots \vdots \vdots \vdots \vdots \vdots \vdots 0$

$\therefore \vdots \vdots \because \because \because \cdots \vdots \vdots \therefore \cdots$ 

INTERNATIONAL ANTARCTIC CO-OPERATION.

SYNCHRONOUS CHARTS OF SEA-LEVEL PRESSURE FOR NOON GMT.

WITH WINDS AND AIR TEMPERATURES
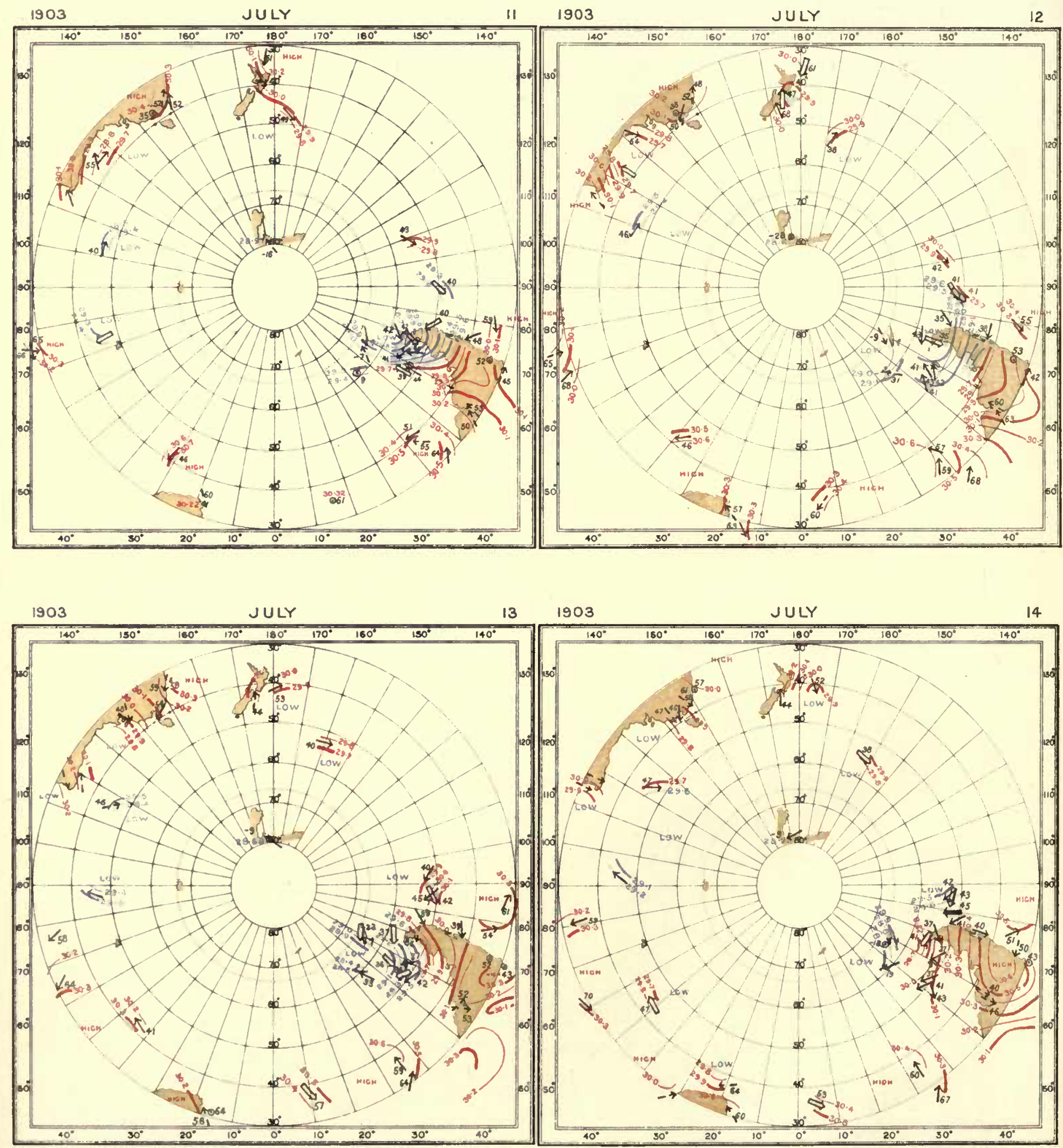
INTERNATIONAL ANTARCTIC CO-OPERATION

SYNCHRONOUS CHARTS OF SEALEVEL PRESSURE FOR NOON GMT

WITH WINDS AND AIR TEMPERATURES
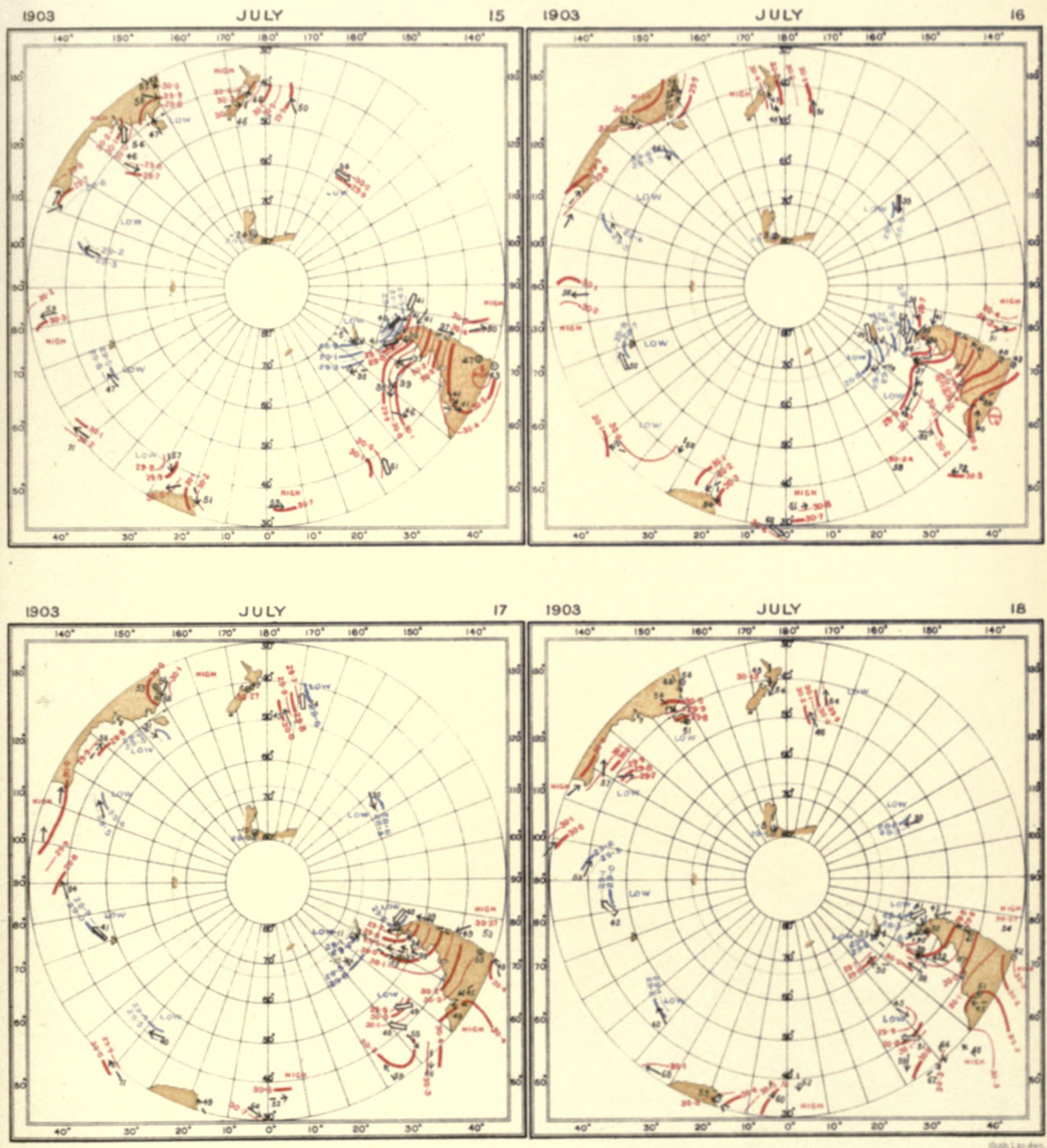


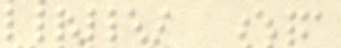

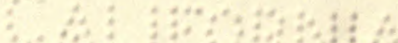


INTERNATIONAL ANTARCTIC COOPERATION

SYNCHRONOUS CHARTS OF SEA-LEVEL PRESSURE FOR NOON GMT.

WITH WINDS AND AIR TEMPERATURES
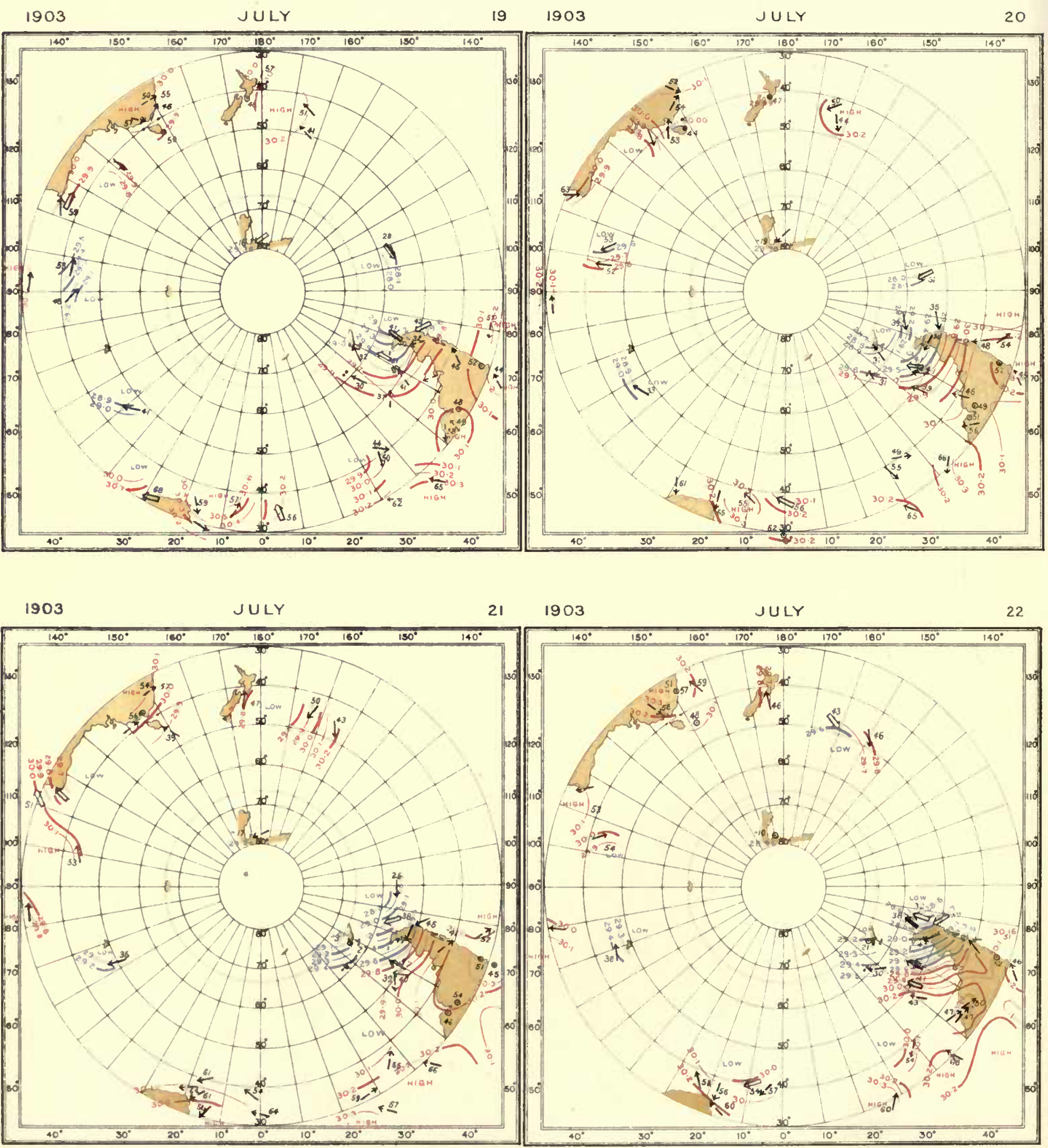
INTERNATIONAL ANTARCTIC CO-OPERATION

SYNCHRONOUS CHARTS OF SEA-LEVEL PRESSURE FOR NOON GM.T

WITH WINDS AND AIR TEMPERATURES

1903

$J U L Y$

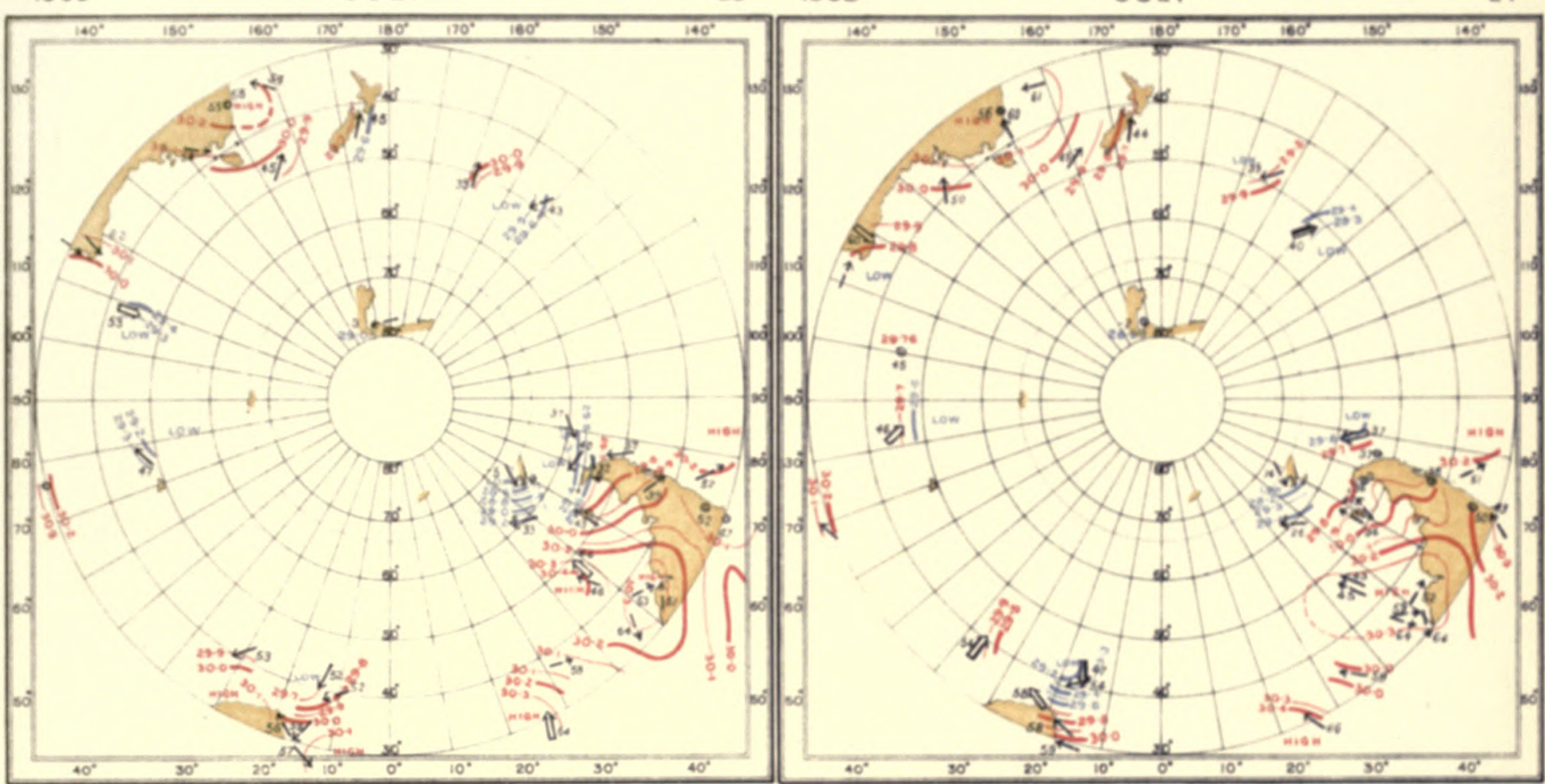

1903

JULY

$25 \quad 1903$

JULY

26

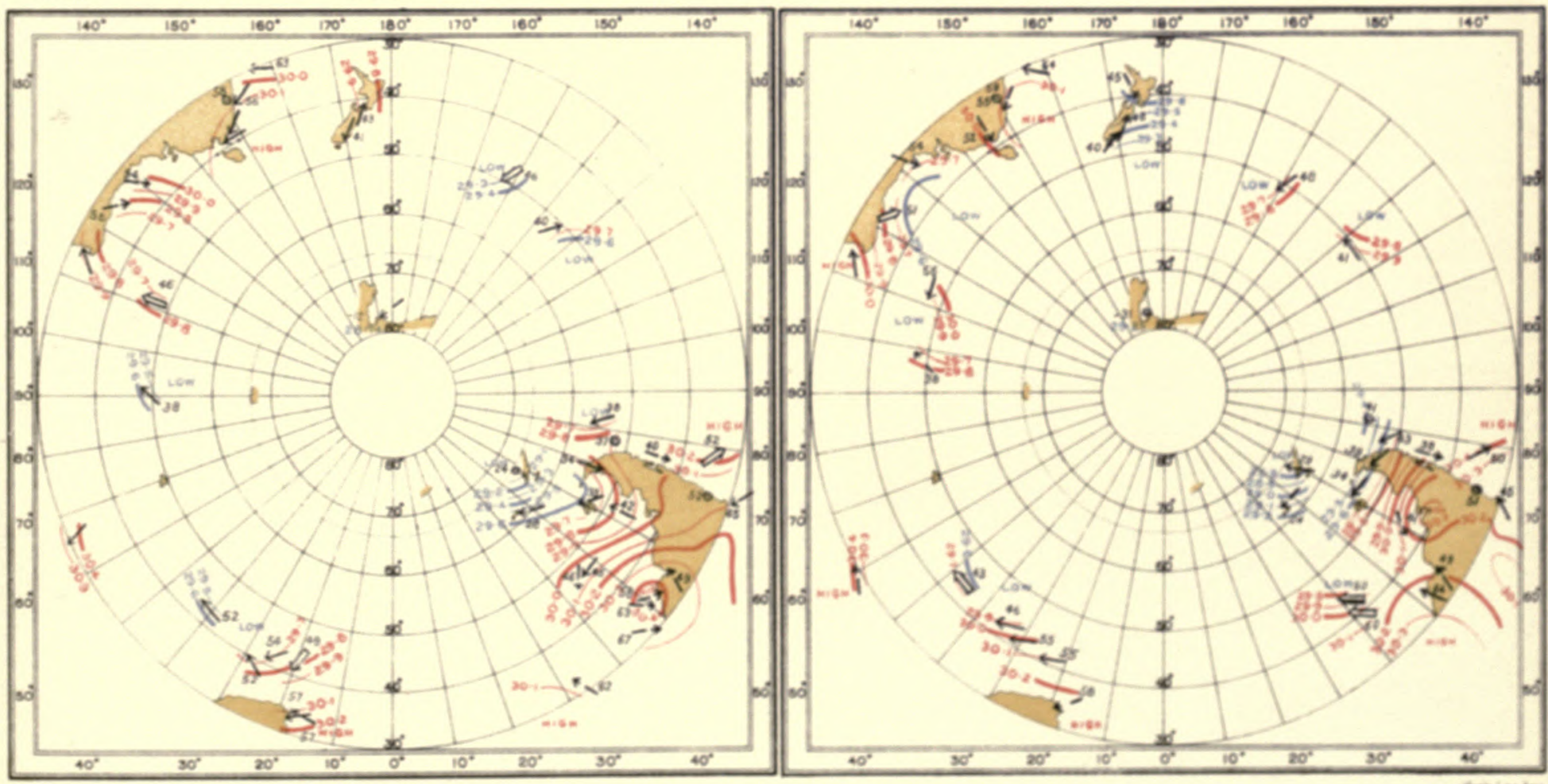




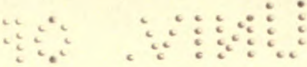

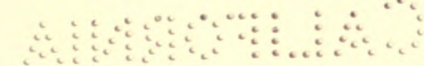


1)

a 
INTERNATIONAL ANTARCTIC CO-OPERATION.

SYNCHRONOUS CHARTS OF SEA-LEVEL PRESSURE FOR NOON G.M.T.

WITH WINDS AND AIR TEMPERATURES

1903 JULY

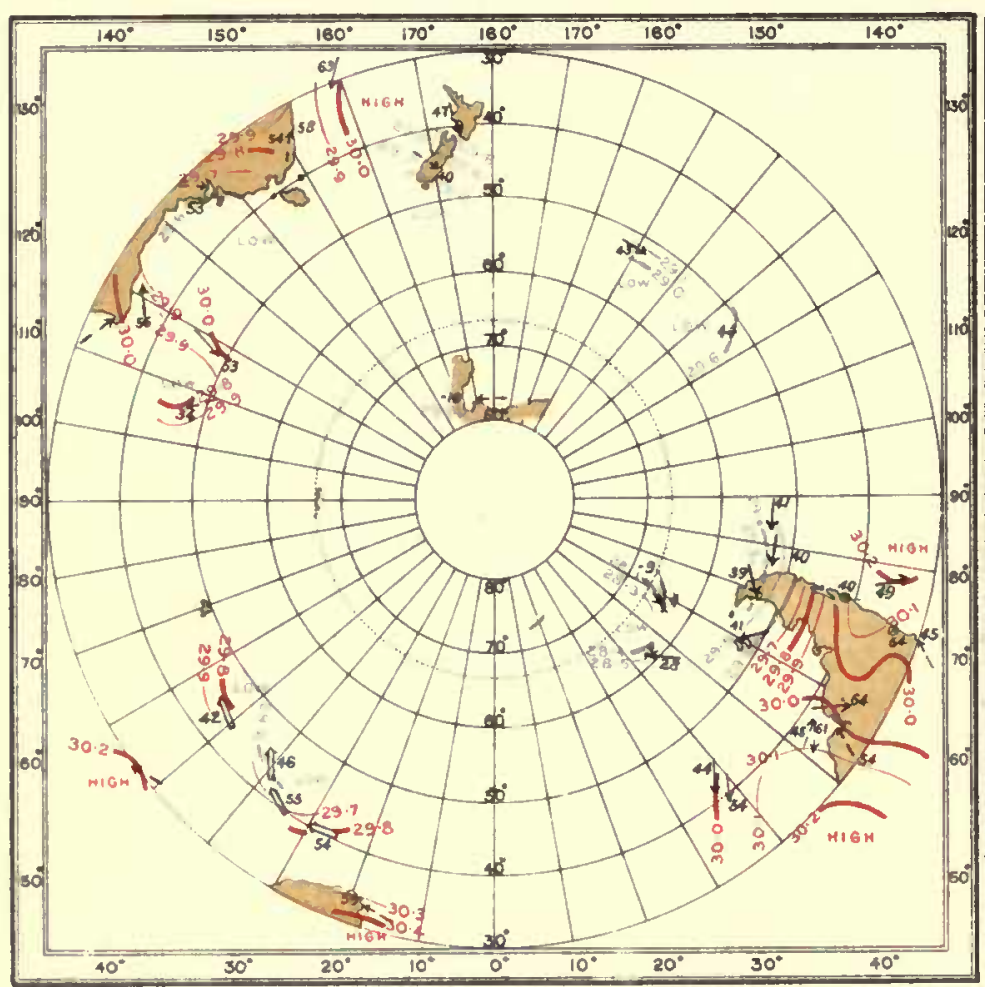

$27 \quad 1903$

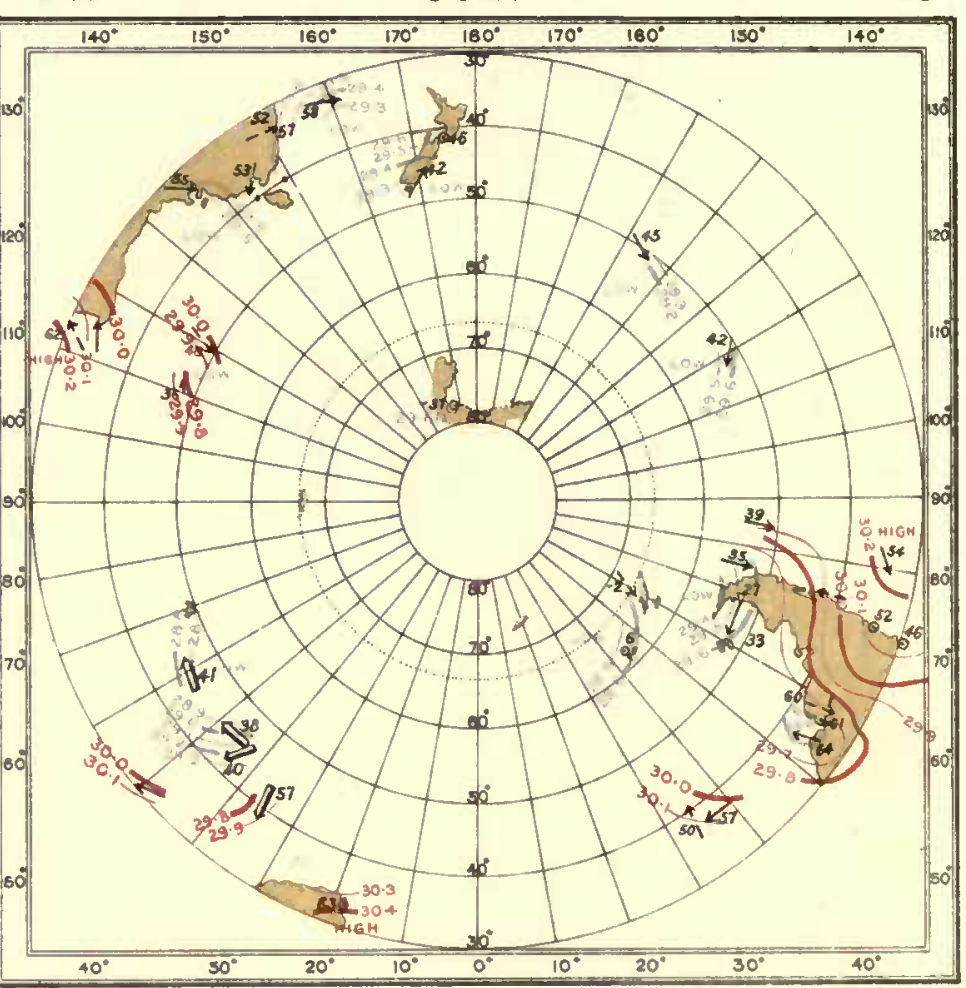

1903

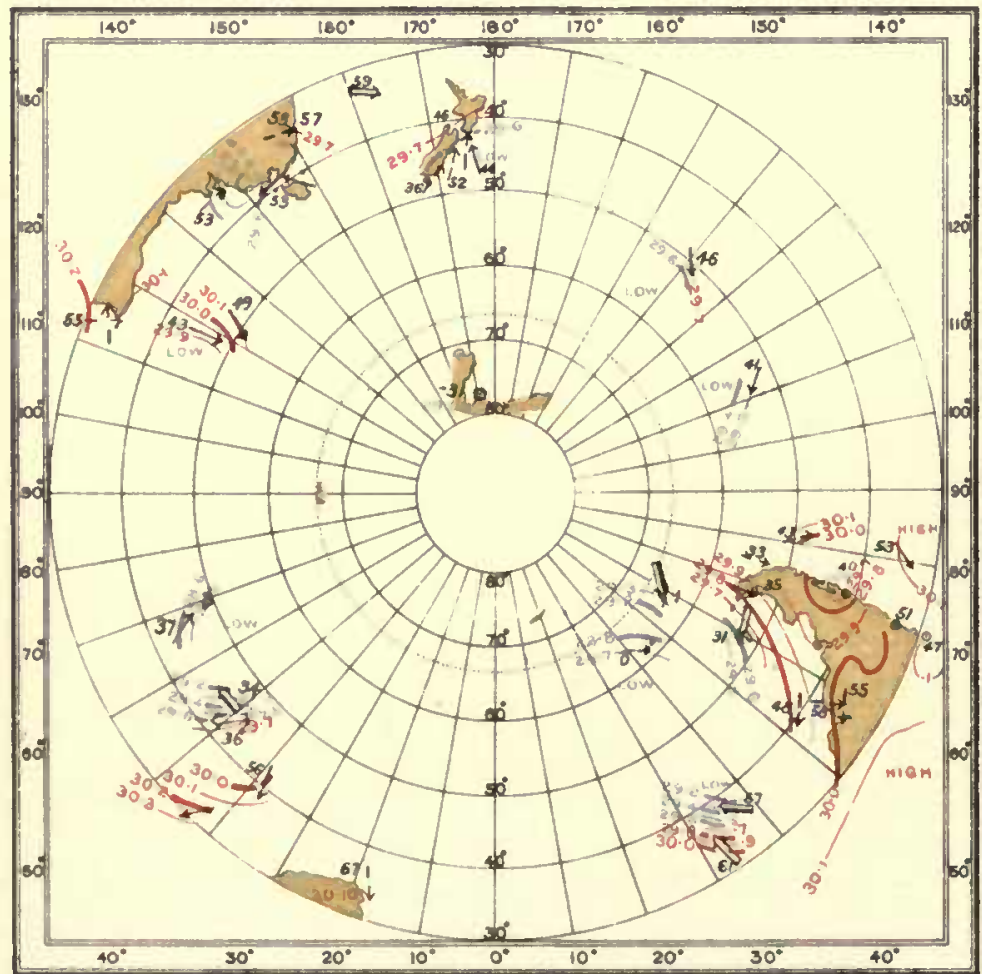

$29 \quad 1903$

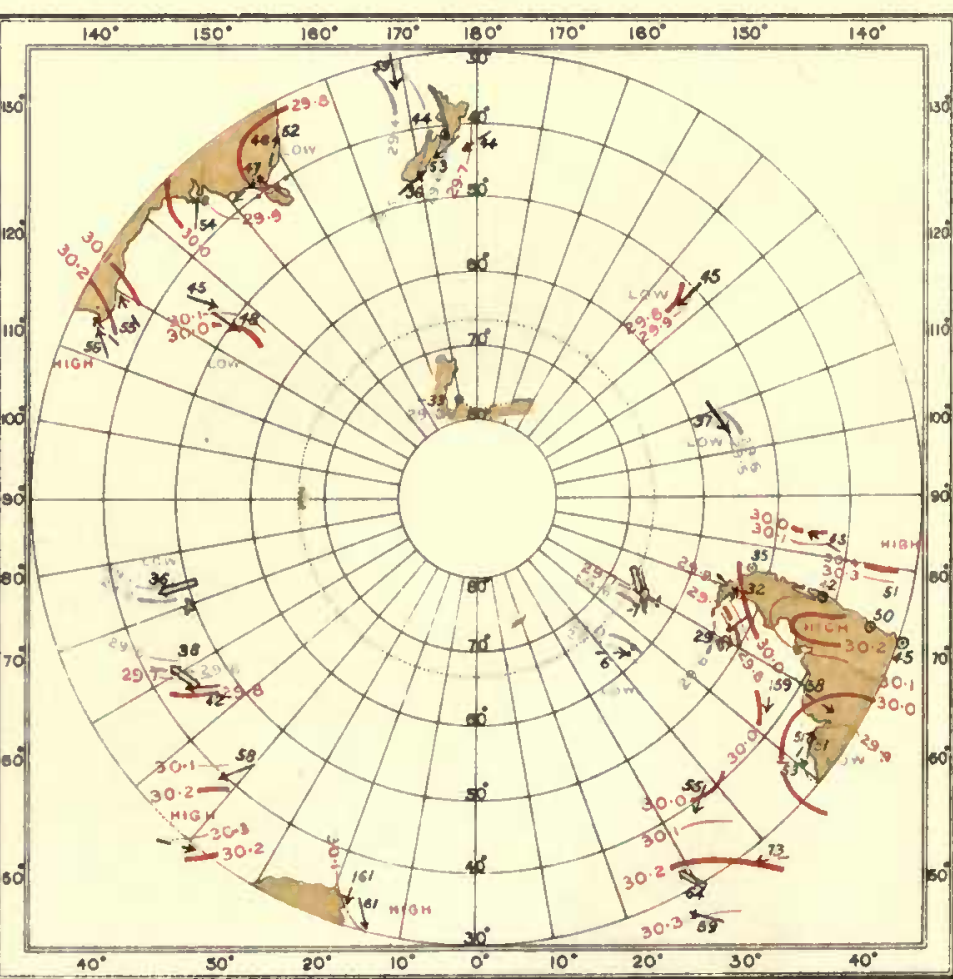


INTERNATIONAL ANTARCTIC CO-OPERATION.

SYNCHRONOUS CHARTS OF SEA-LEVEL PRESSURE FOR NOON GM.T.

WITH WINDS AND AIR TEMPERATURES
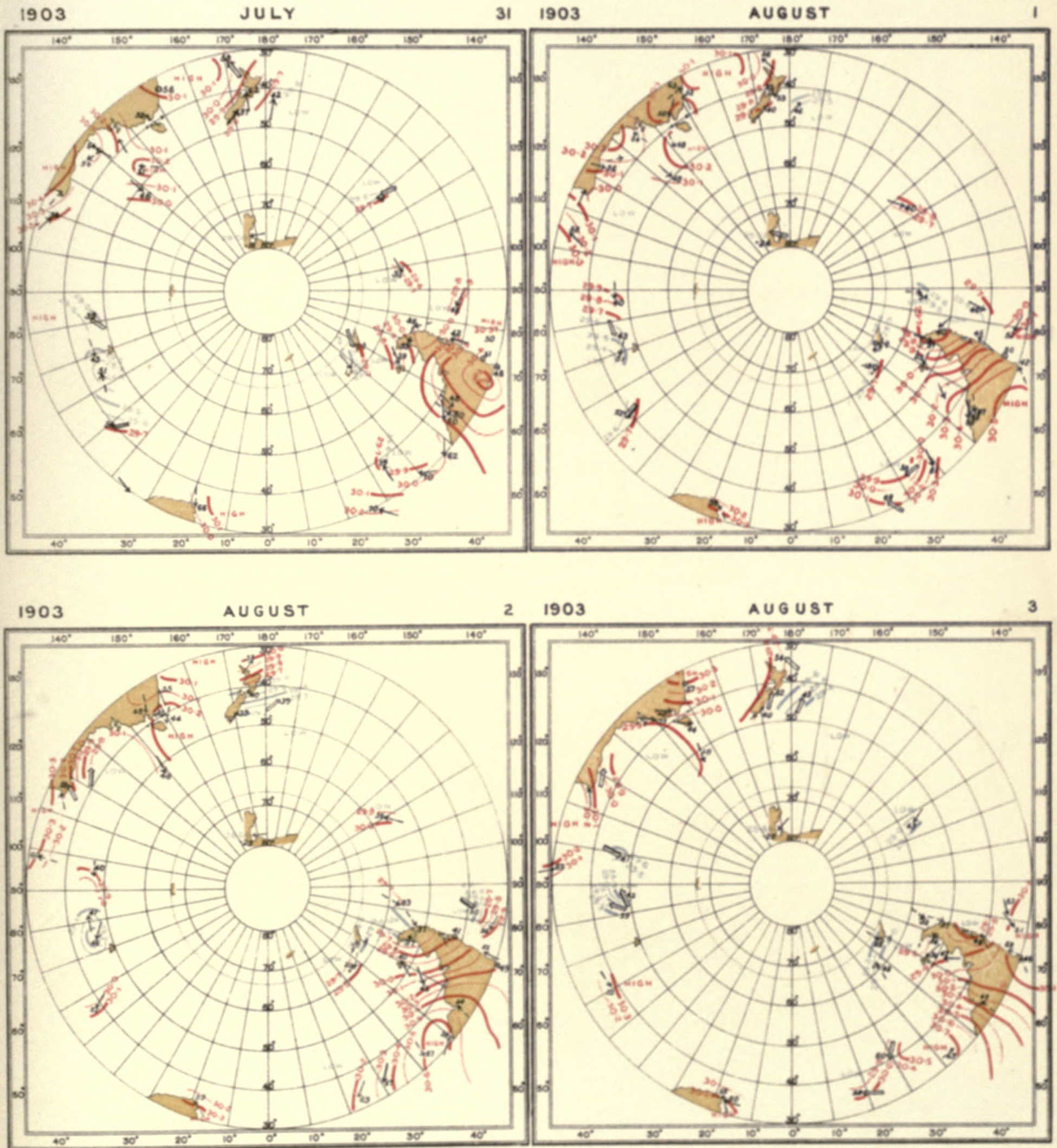


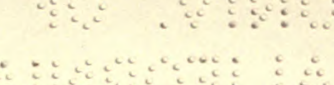

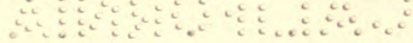




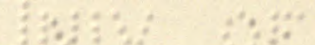

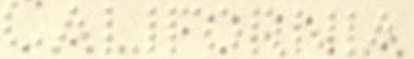


INTERNATIONAL ANTARCTIC COOPERATION.

SYNCHRONOUS CHARTS OF SEA-LEVEL PRESSURE FOR NOON G.M.T.

WITH WINDS AND AIR TEMPERATURES
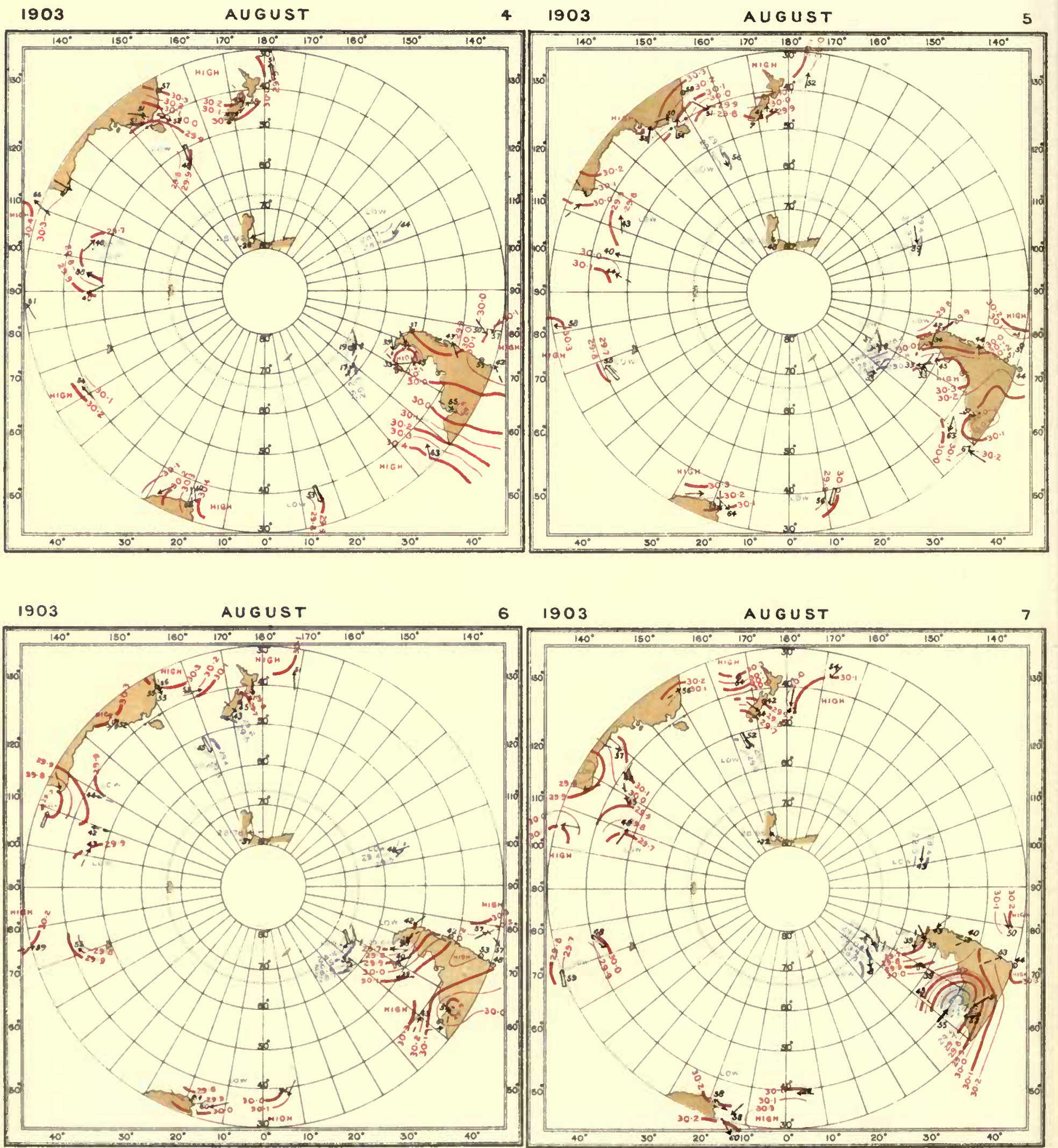
INTERNATIONAL ANTARCTIC CO-OPERATION.

SYNCHRONOUS CHARTS OF SEALEVEL PRESSURE FOR NOON GMT

WITH WINDS AND AIR TEMPERATURES.
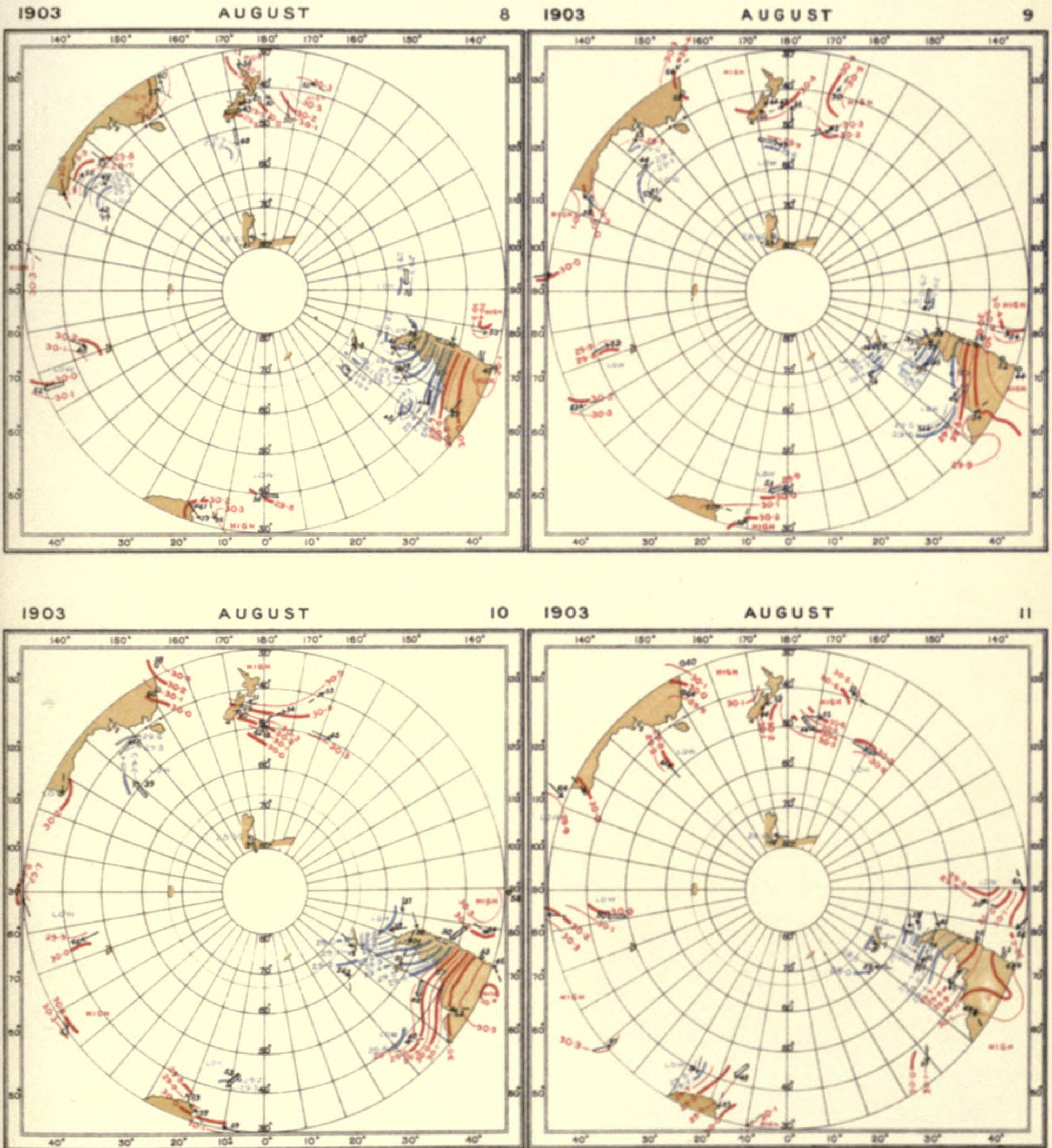


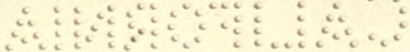

$\because \because:$ : 

INTERNATIONAL ANTARCTIC CO-OPERATION.

SYNCHRONOUS CHARTS OF SEALEVEL PRESSURE FOR NOON G.M.T

WITH WINOS AND AIR TEMPERATURES
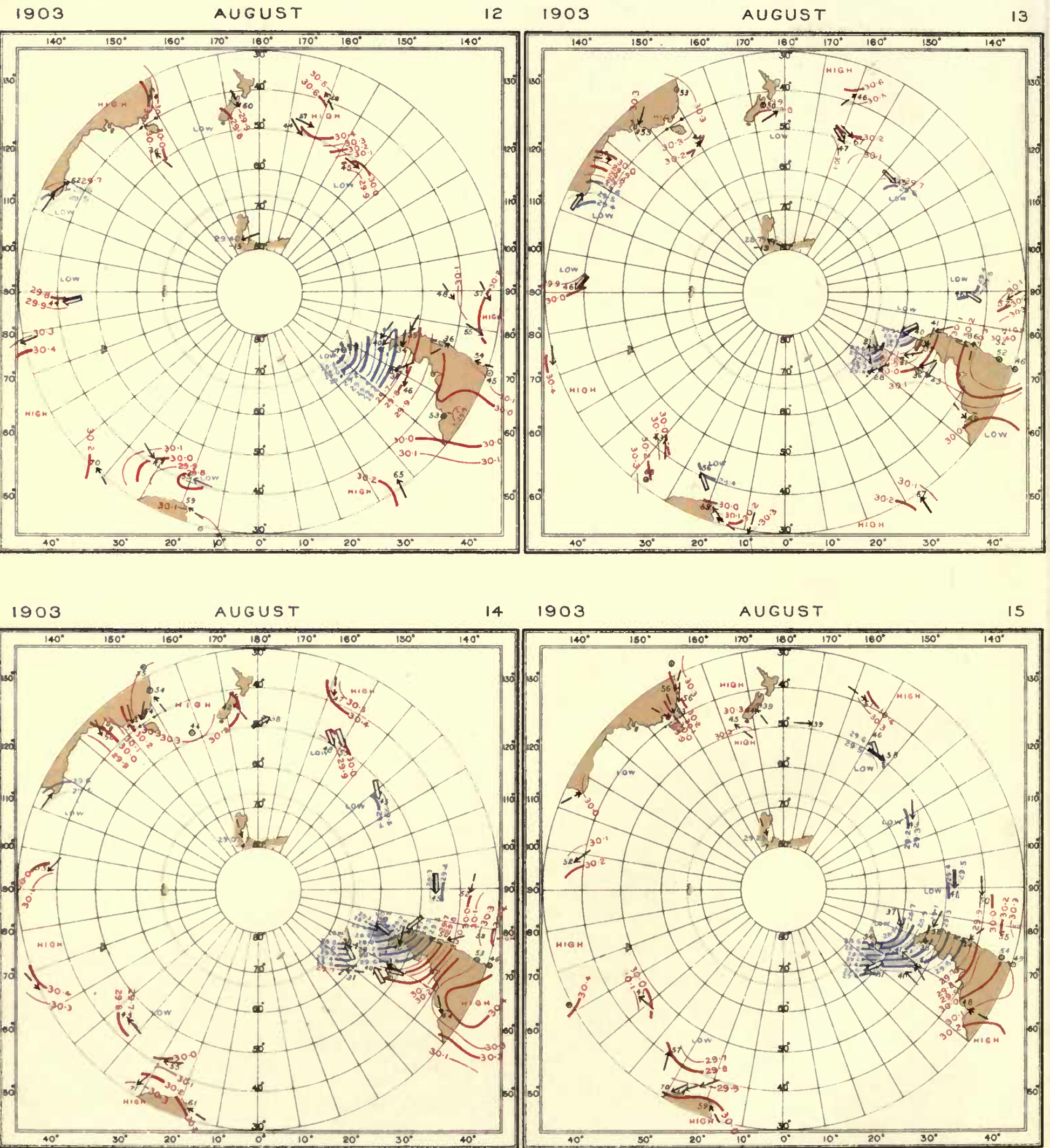
INTERNATIONAL ANTARCTIC COOOPERATION.

SYNCHRONOUS CHARTS OF SEALEVEL PRESSURE FOR NOON GMT

WITH WINDS AND AIR TEMPERATURES.

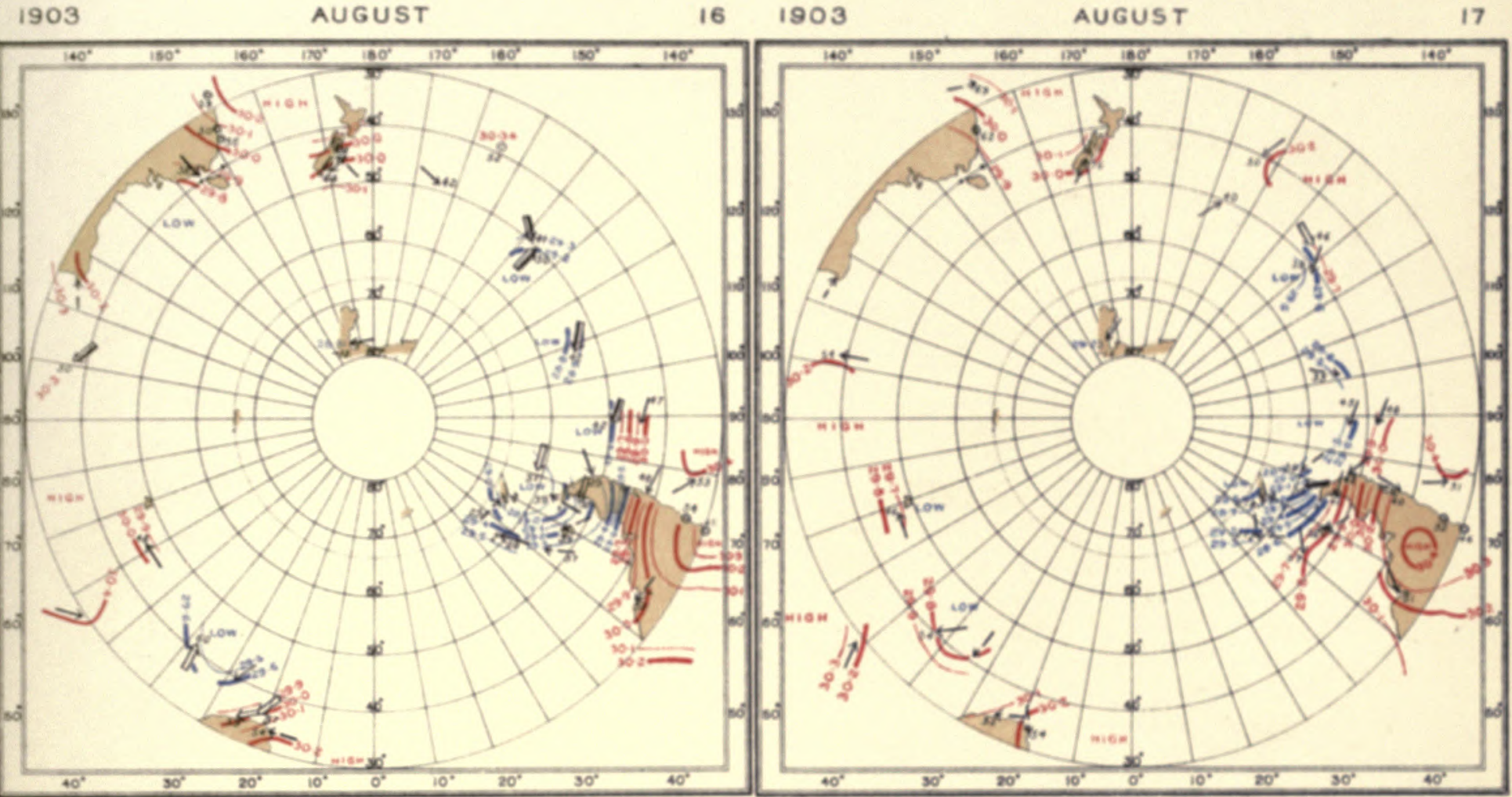

1903

AUGUST

$18 \quad 1903$

AUGUST

19

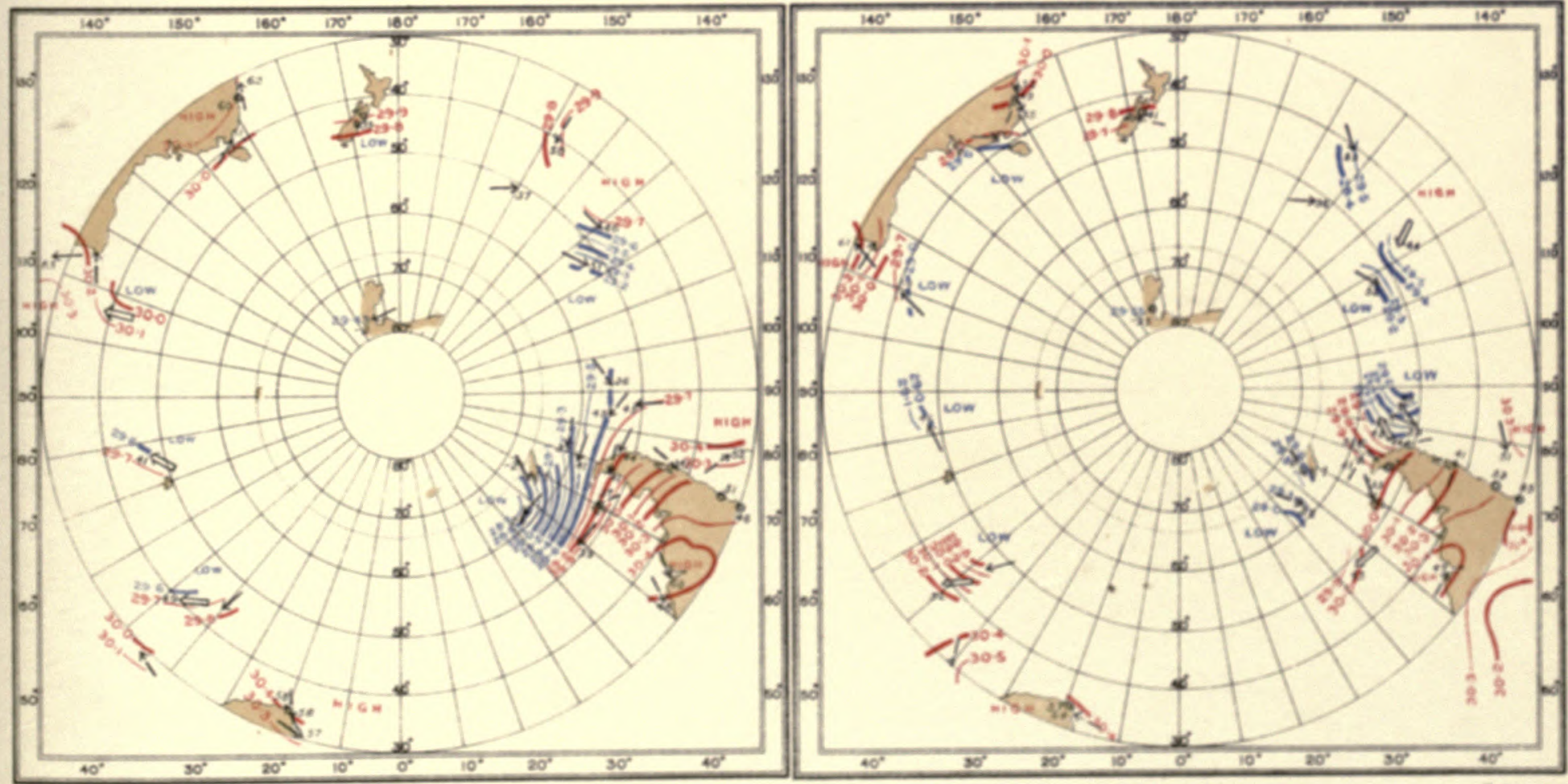




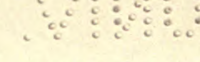

and 


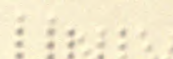

A 40 
INTERNATIONAL ANTARCTIC CO-OPERATION

SYNCHRONOUS CHARTS OF SEALLEVEL PRESSURE FOR NOON GM.T.

WITH WINDS AND AIR TEMPERATURES

1903

$A \cup G \cup S T$

$20 \quad 1903$

$A \cup G \cup S T$

21
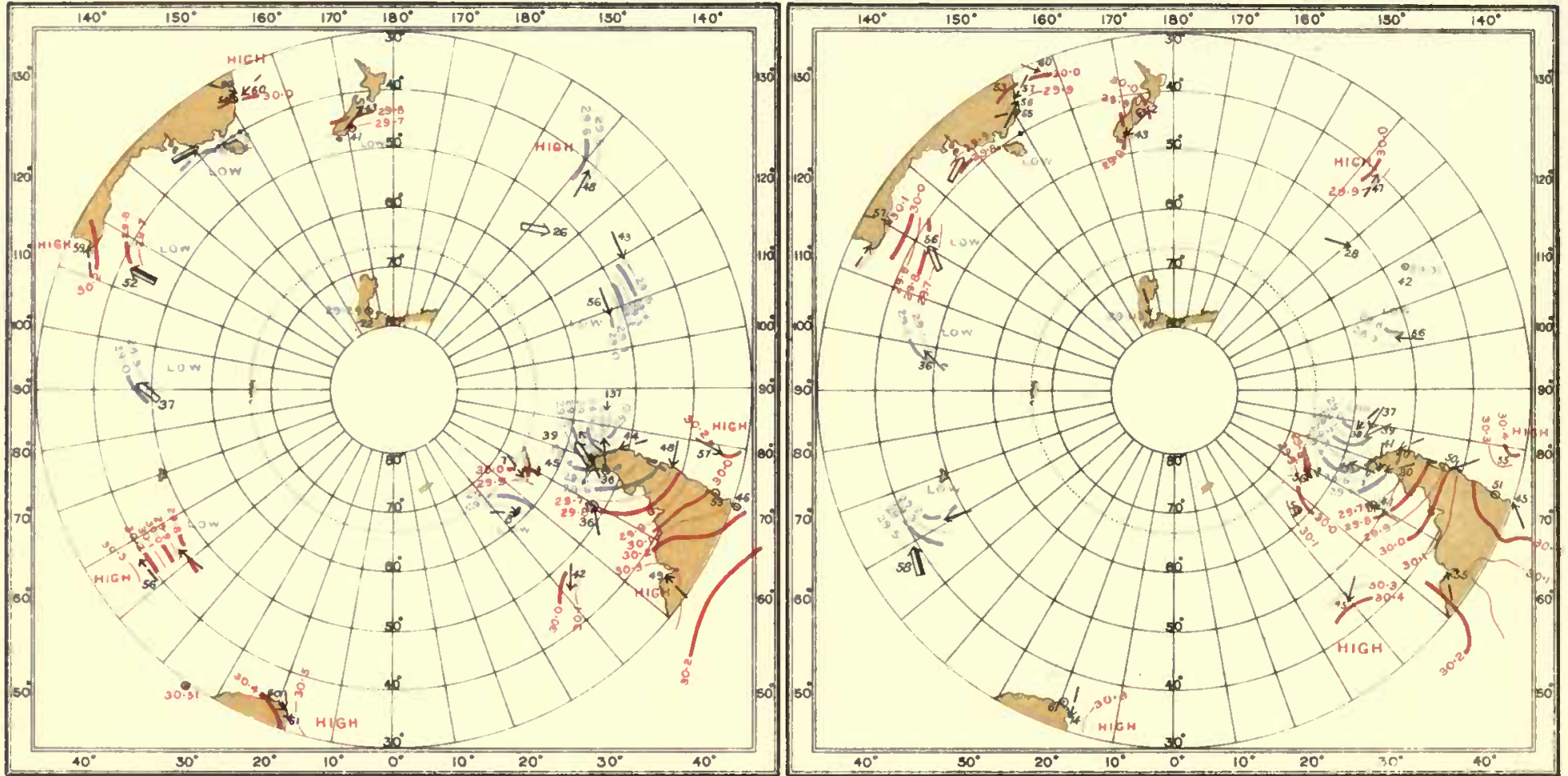

1903

A U G U S T

$22 \quad 1903$

AUG UST

23

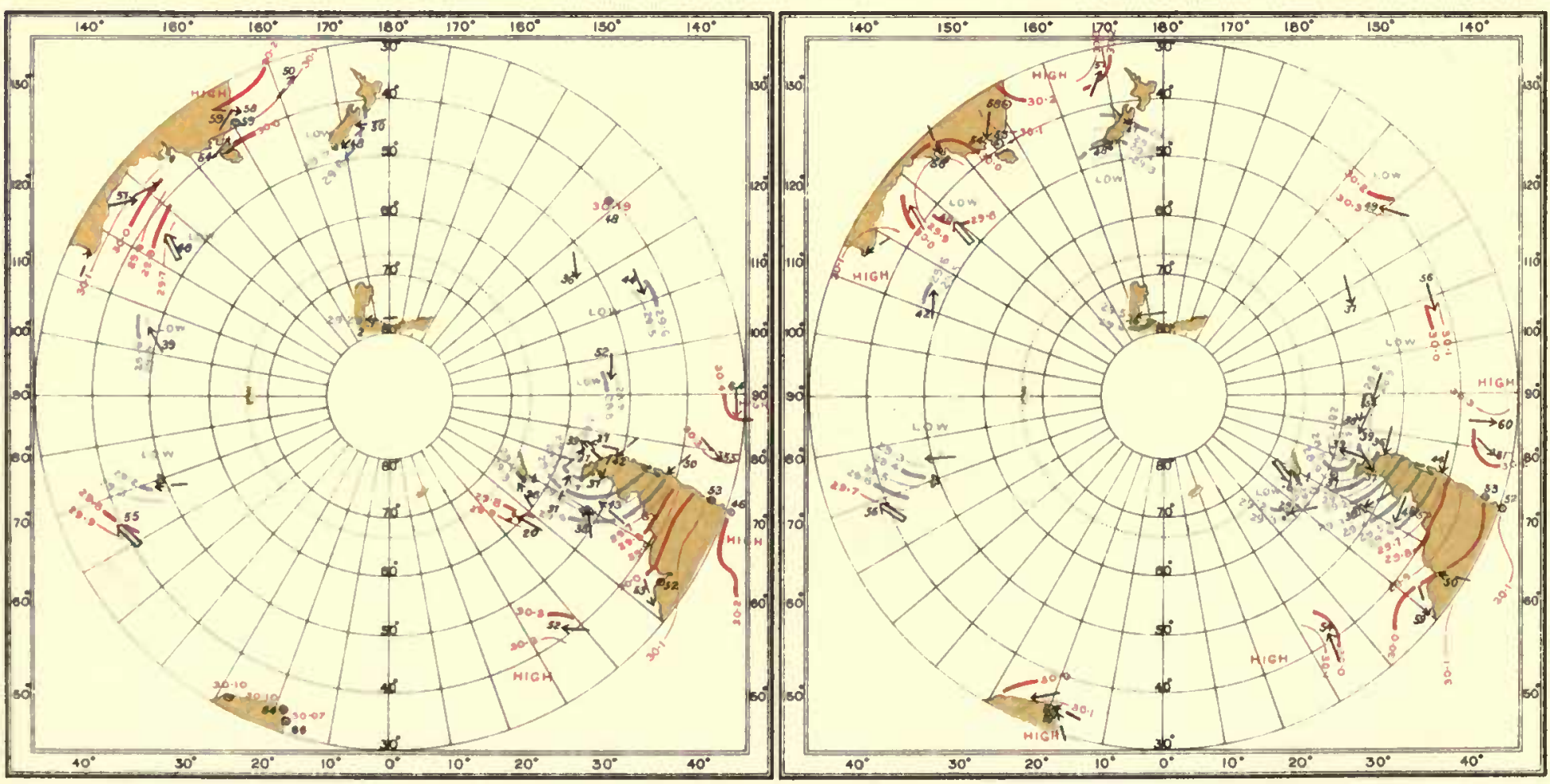


INTERNATIONAL ANTARCTIC CO-OPERATION.

SYNCHRONOUS CHARTS OF SEALEVEL PRESSURE FOR NOON GMT

WITH WINDS AND AIR TEMPERATURES

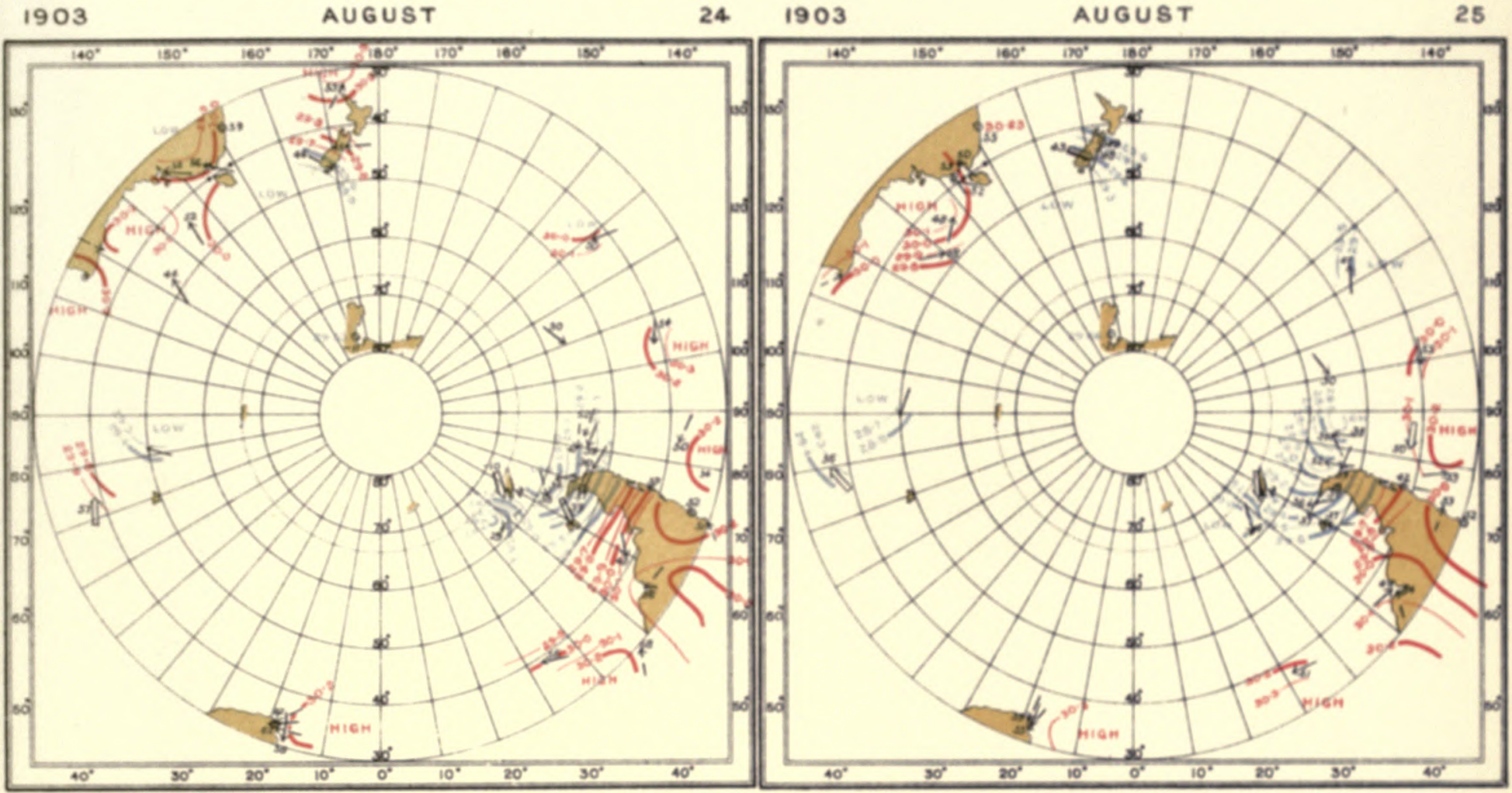

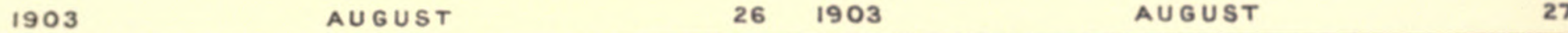

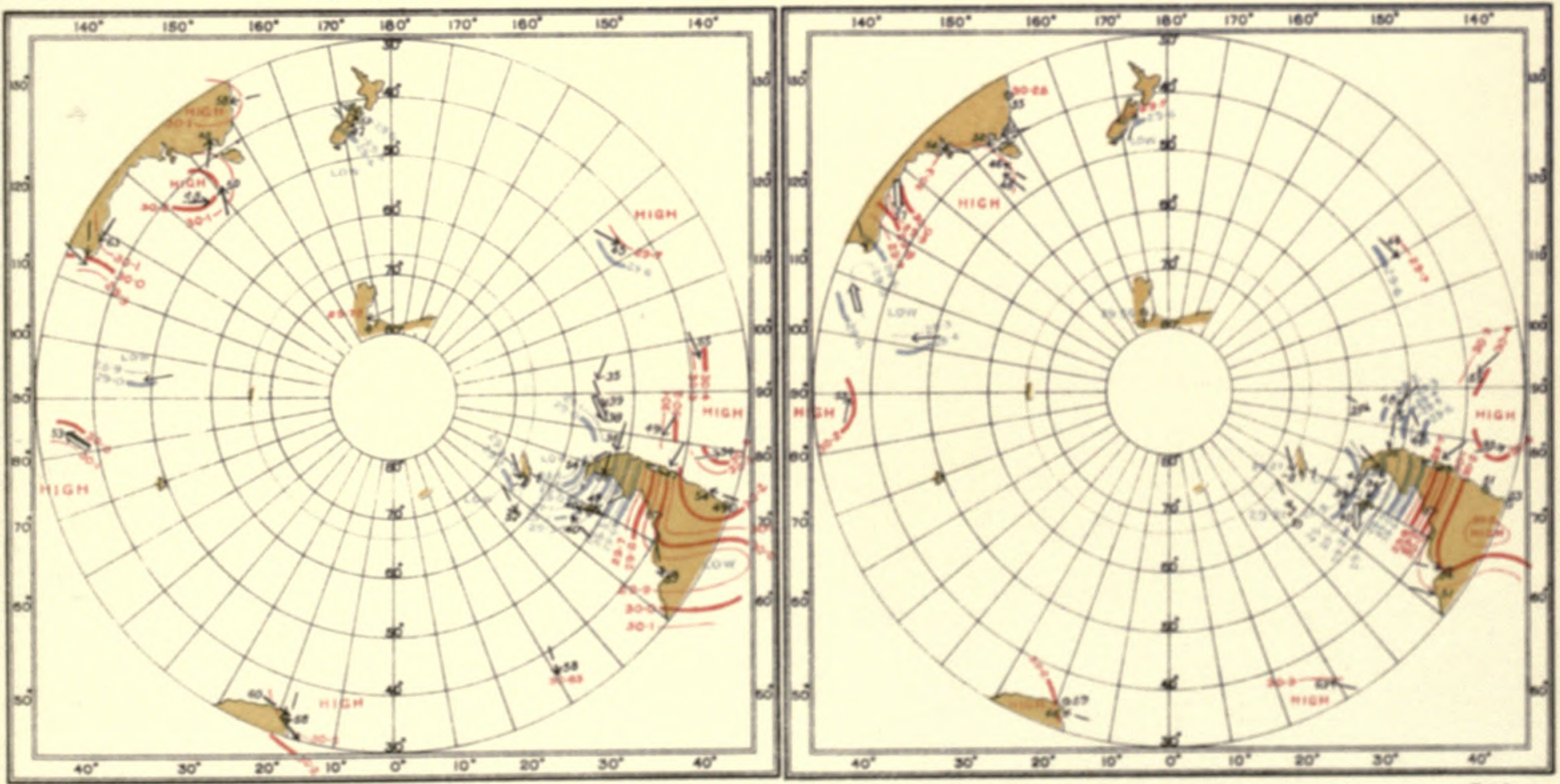


$\because \vdots \vdots$

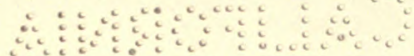

・ 


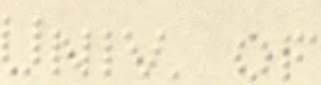

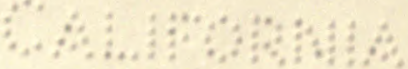


INTERNATIONAL ANTARCTIC COOPERATION

SYNGHRONOUS CHARTS OF SEA-LEVEL PRESSURE FOR NOON GMT

WITH WINDS AND AIR TEMPERATURES

1903

A U G UST

$28 \quad 1903$

A U G U ST

29
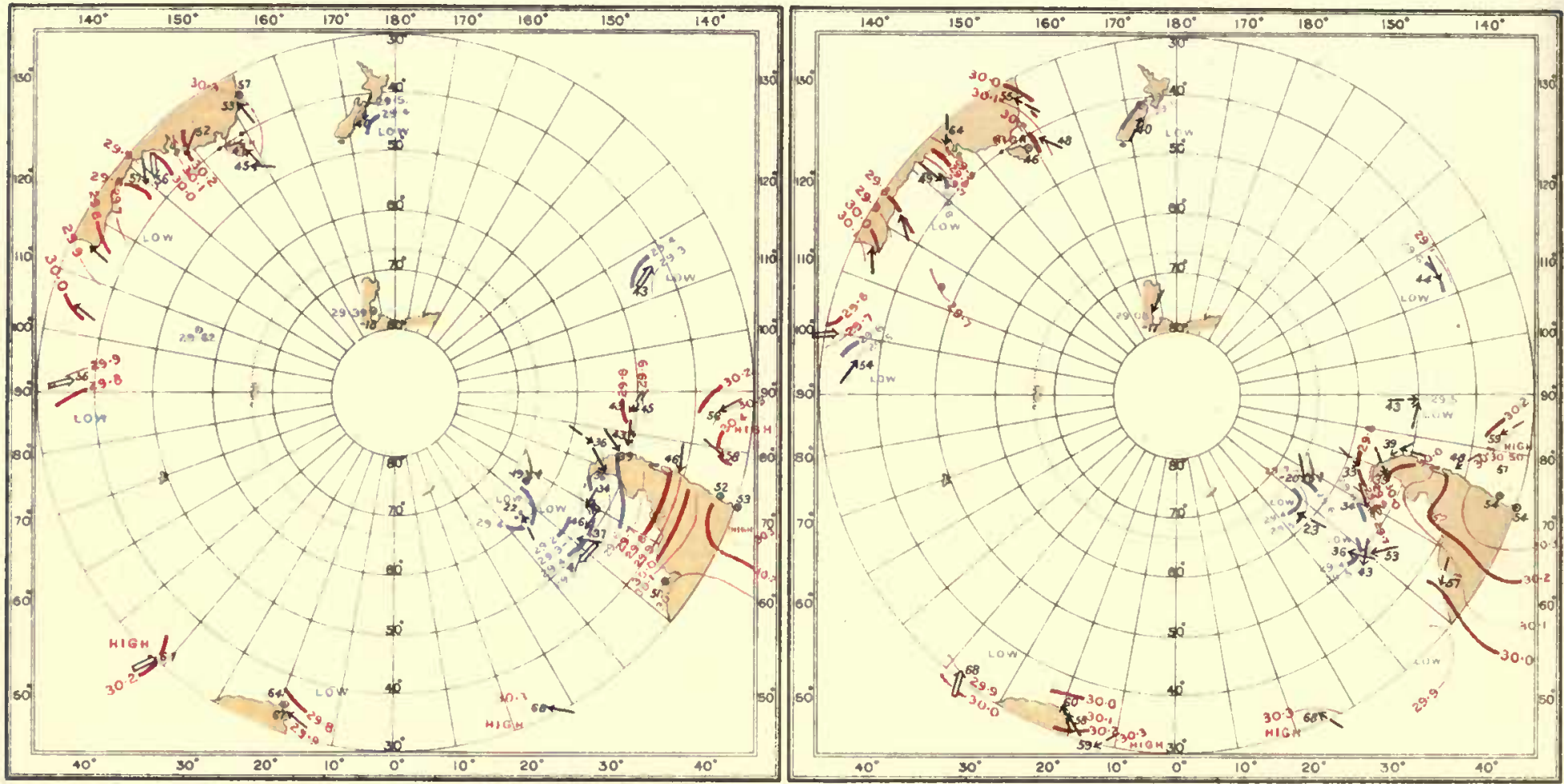

1903

$A \cup G \cup S T$

$30 \quad 1903$

$A \cup G \cup S T$

31

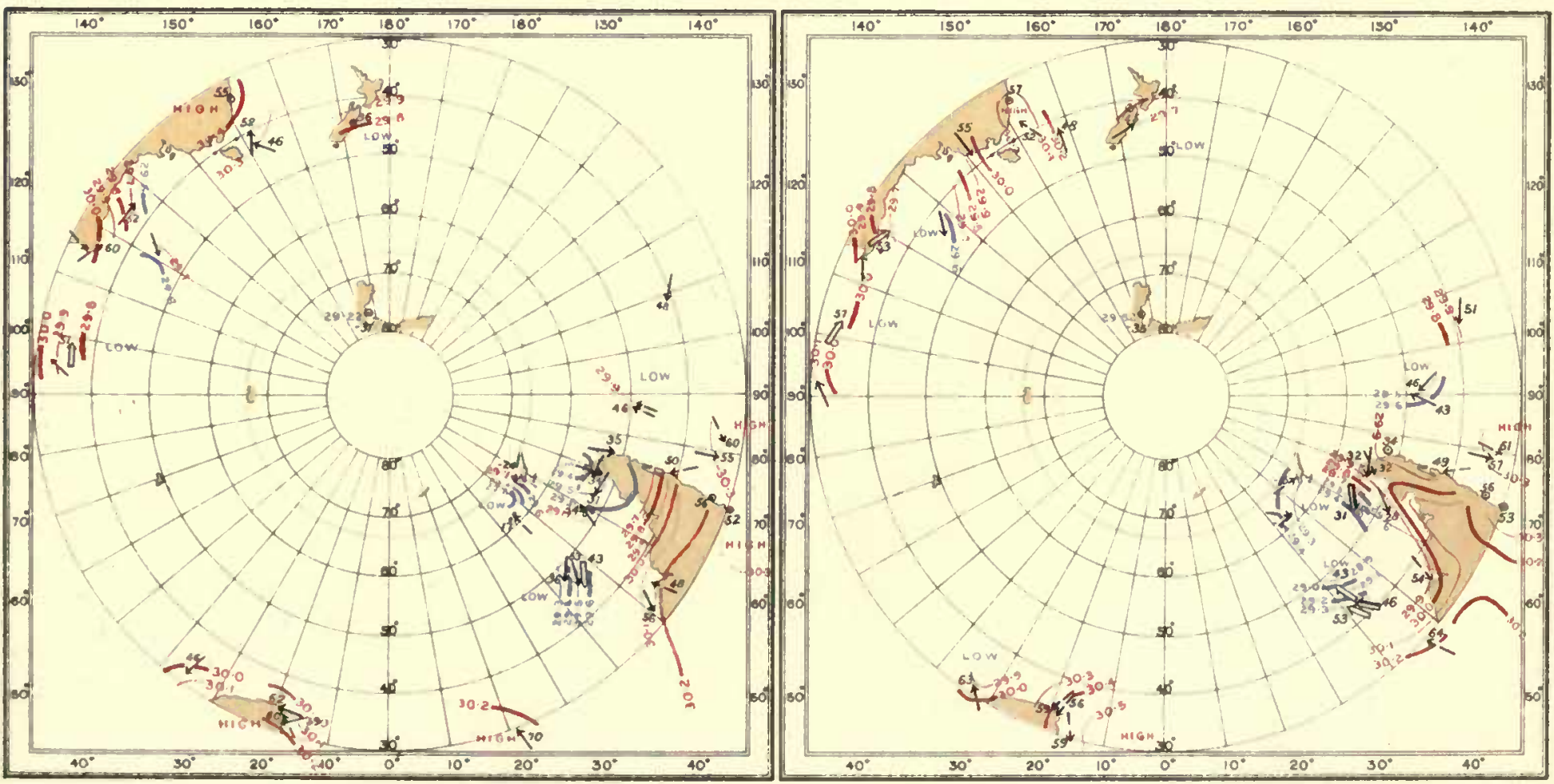


INTERNATIONAL ANTARCTIC CO-OPERATION

SYNCHAONOUS CHARTS OF SEALEVEL PRESSURE FOR NOON GMT

WITH WINDS AND AIR TEMPERATURES
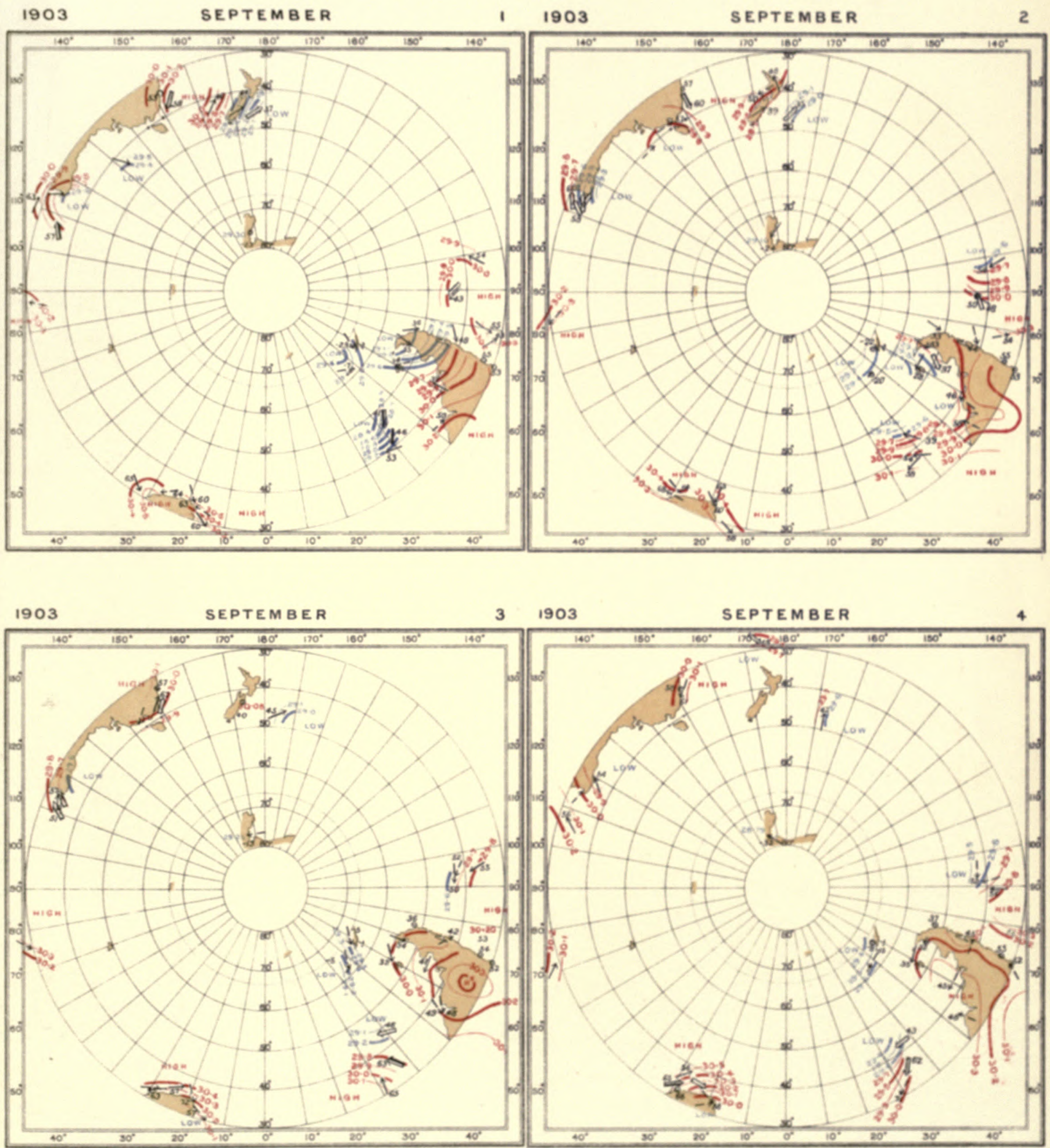


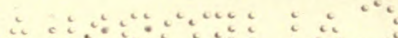


INTERNATIONAL ANTARCTIC CO-OPERATION.

SYNCHRONOUS CHARTS OF SEALEVEL PRESSURE FOR NOON GM.T

WITH WINDS ANO AIR TEMPERATURES
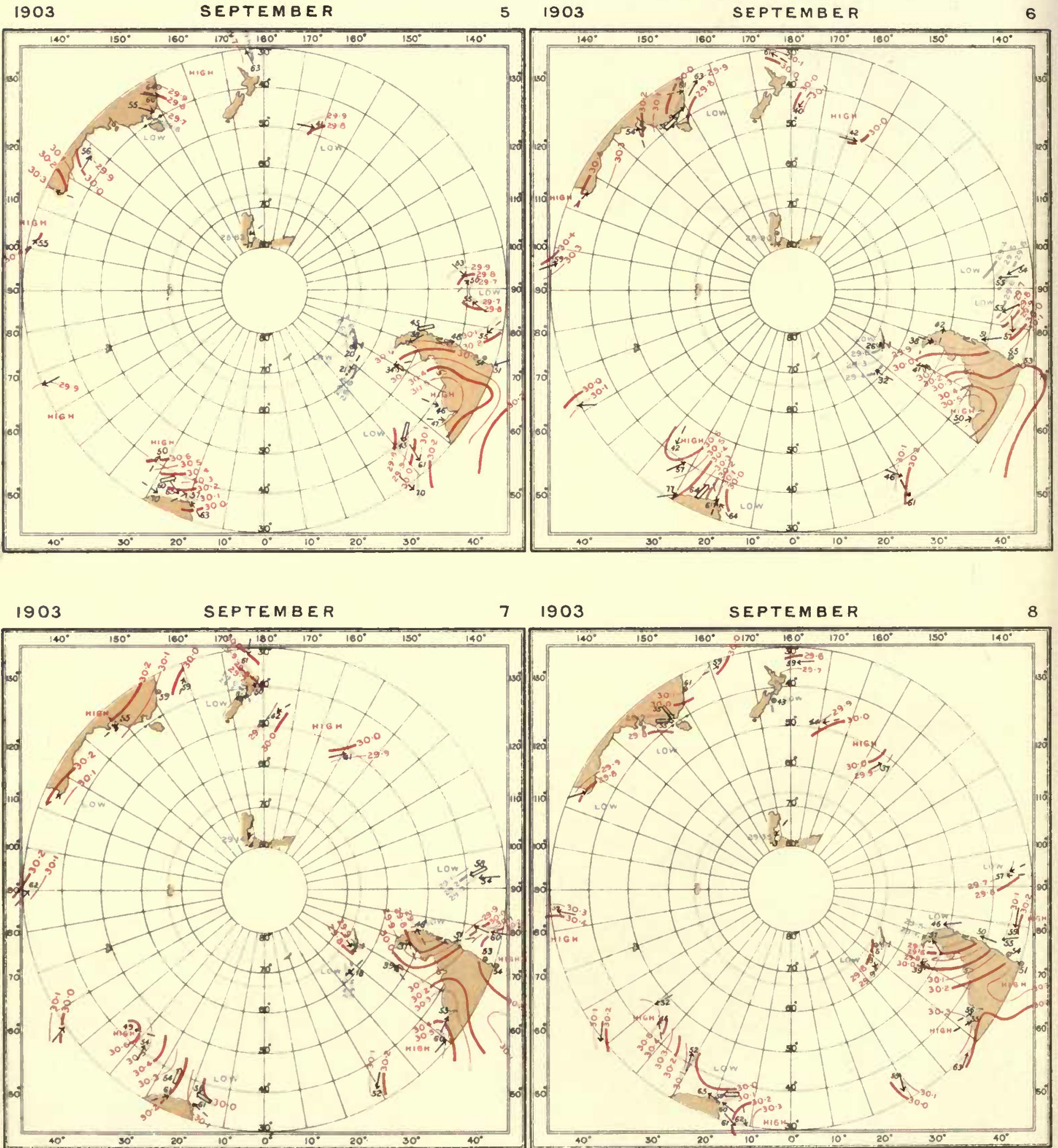
INTERNATIONAL ANTARCTIC COOOPERTION.

,

SYNCHRONOUS CHARTS OF SEA-LEVEL PRESSURE FOR NOON GM.T

WITH WINDS AND AIR TEMPERATURES

1903

SEPTEMBER

$9 \quad 1903$

SEPTEMBER

10

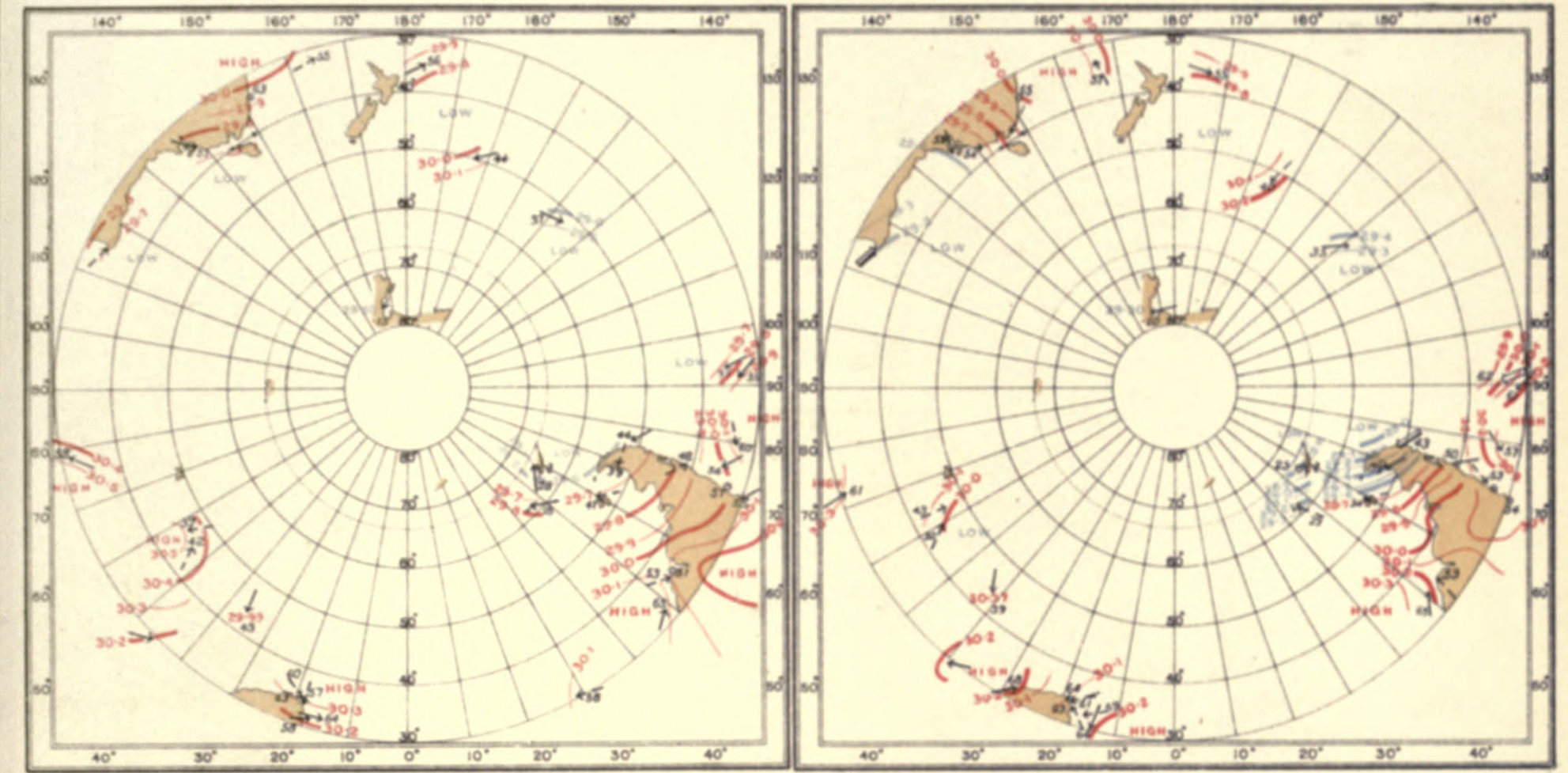

1903 SEPTEMBER

1903

SEPTEMBER

12

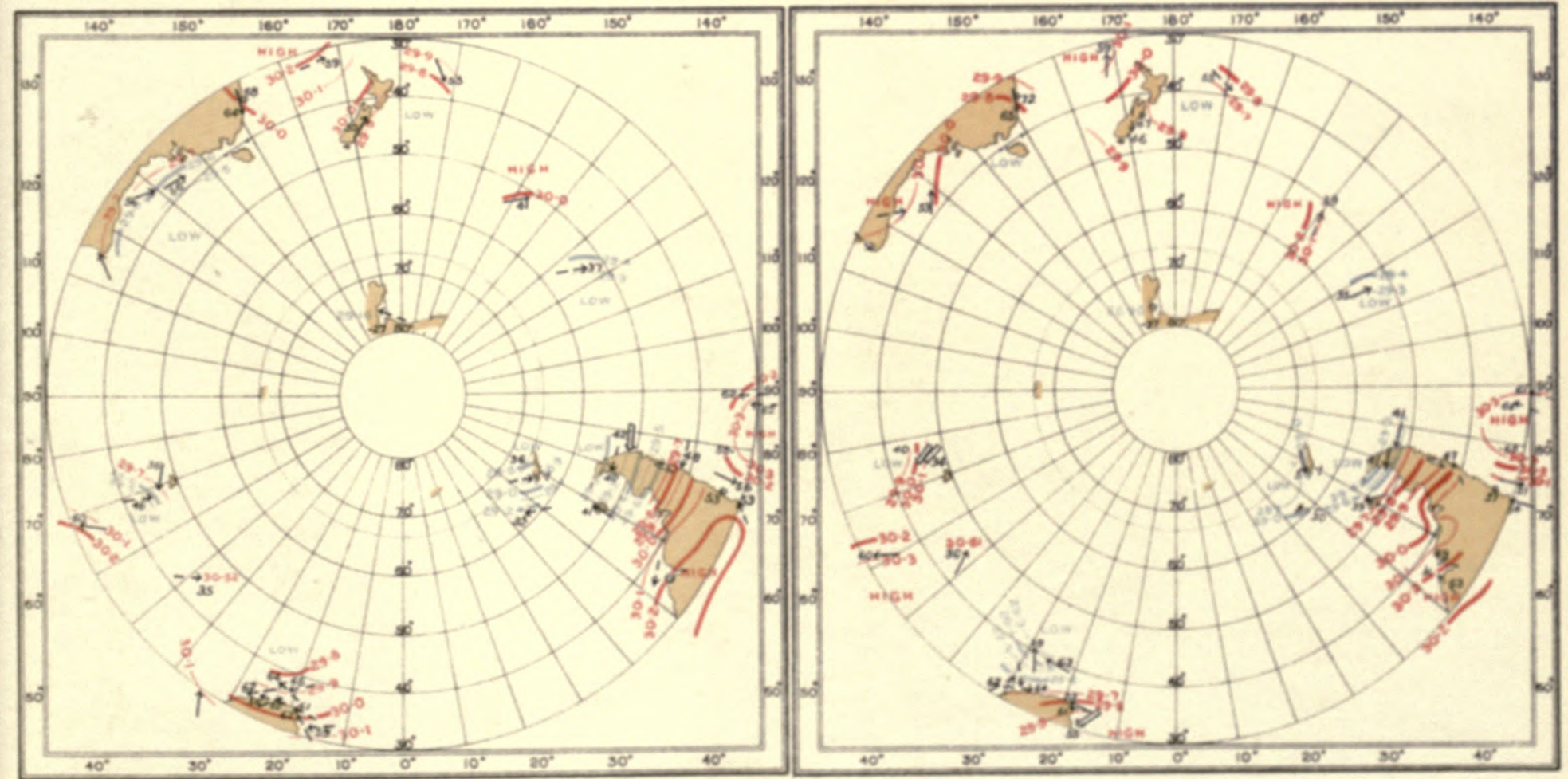


$\because \because$

$\because \because 90 \div$

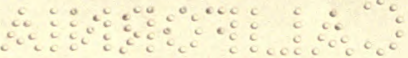


1. 6

a 
INTERNATIONAL ANTARCTIC CO-OPERATION

SYNCHRONOUS CHARTS OF SEALEVEL PRESSURE FOR NOON GM T.

WITH WINDS AND AIR TEMPERATURES
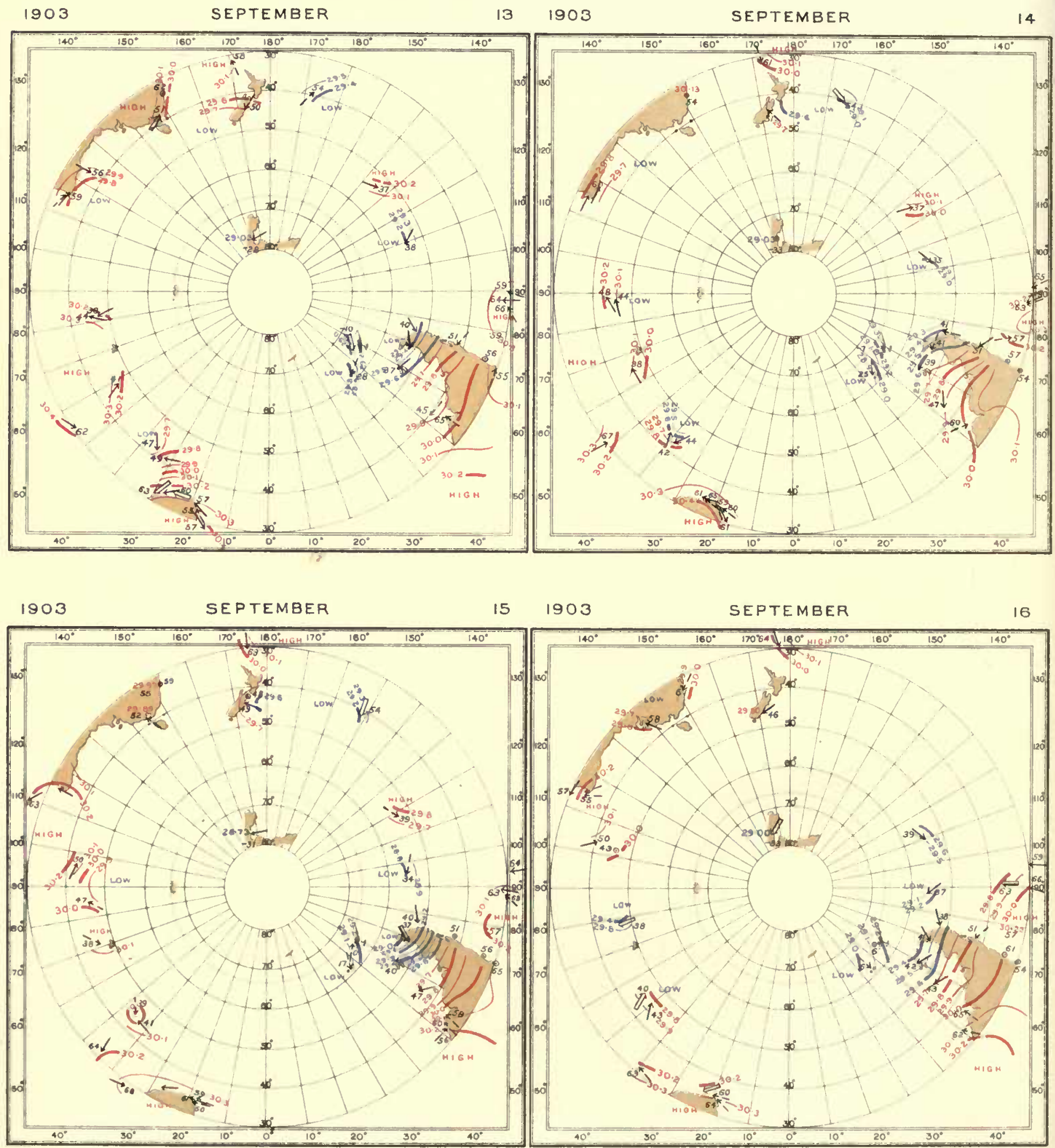
INTERNATIONAL ANTARCTIC COOPERATION.

SYNCHRONOUS CHARTS OF SEALLVEL PRESSURE FOR NOON G.M.T.

WITH WINDS AND AIR TEMPERATURES
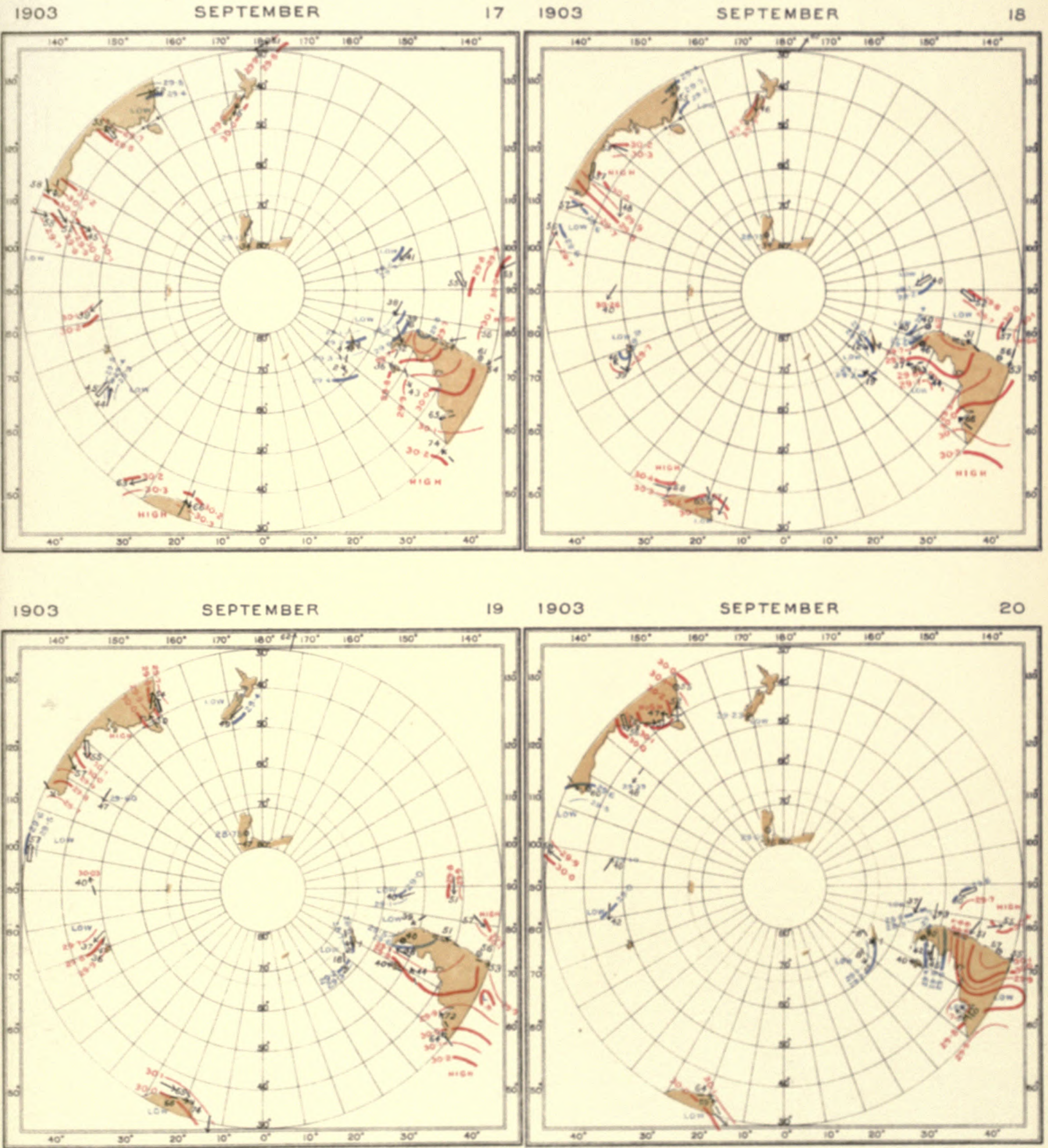
INTERNATIONAL ANTARCTIC CO-OPERATION.

SYNCHRONOUS CHARTS OF SEA-LEVEL PRESSURE FOR NOON G.M.T.

WITH WINOS AND AIR TEMPERATURES.
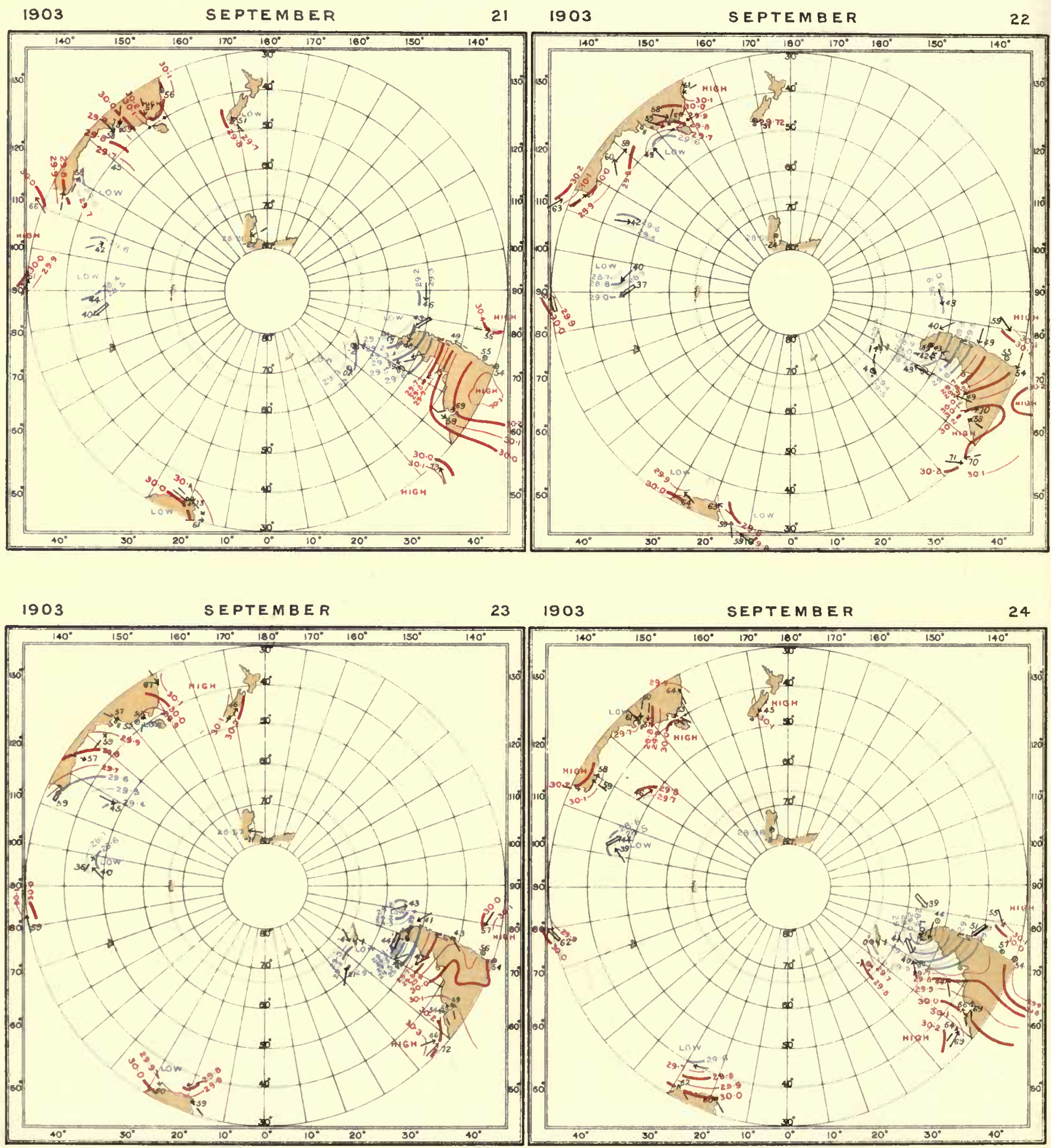
INTERNATIONAL ANTARCTIC CO-OPERATION

SYNCHRONOUS CHARTS OF SEALLEVEL PRESSURE FOR NOON GMT

WITH WINDS AND AIR TEMPERATURES

1903

SEPTEMBER

$25 \quad 1903$

SEPTEMBER

26

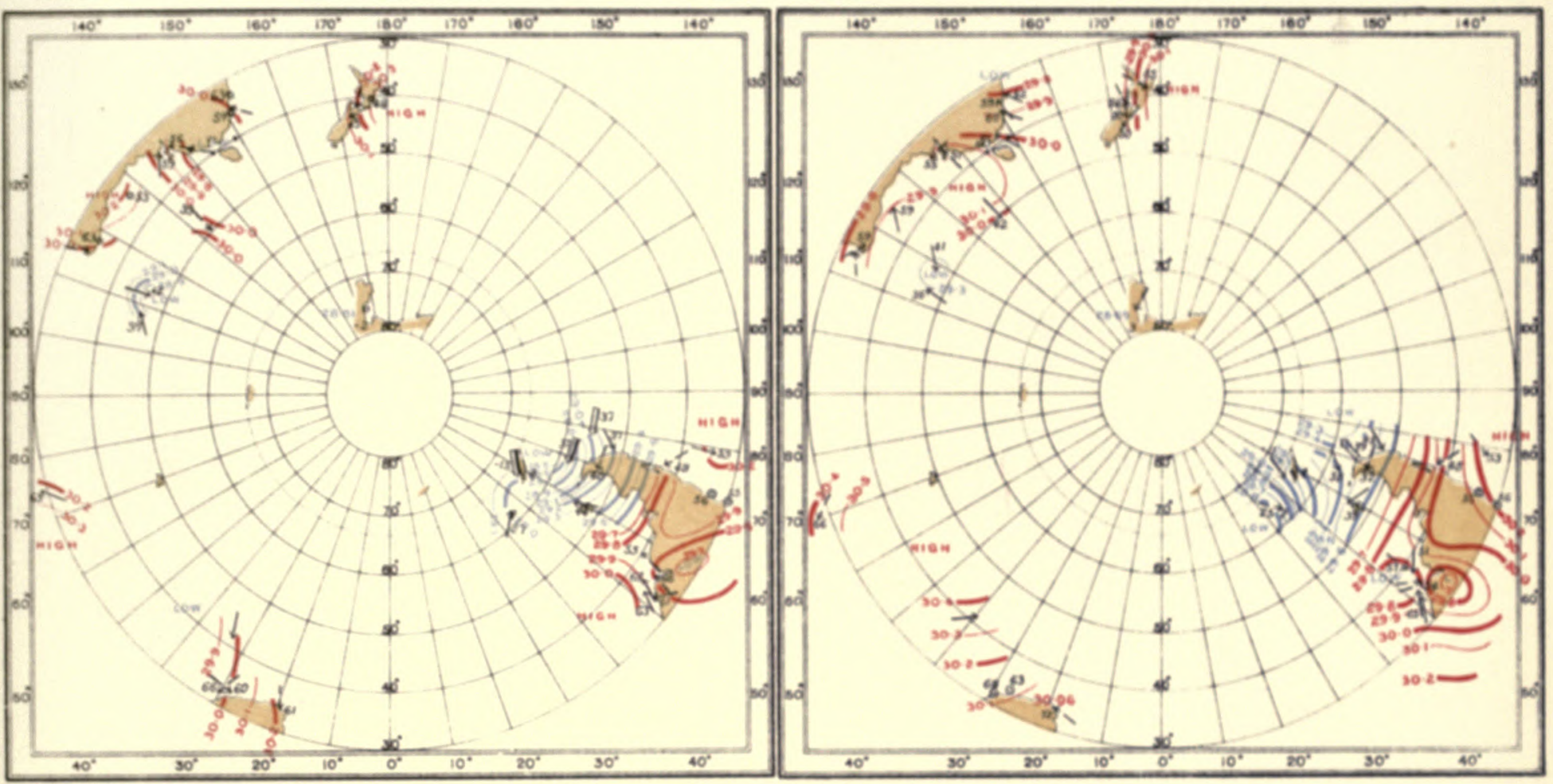

1903 SEPTEMBER
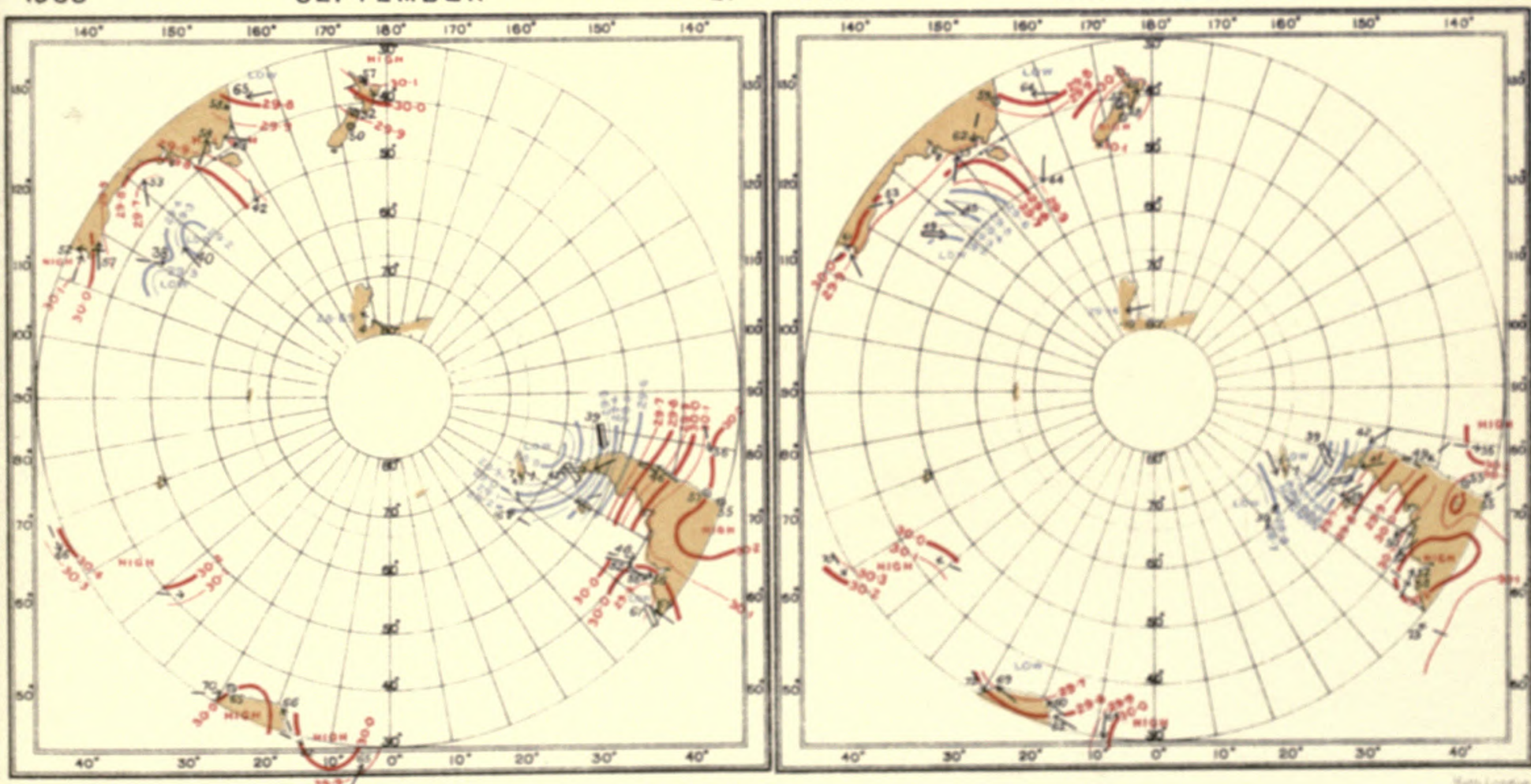
$\because$\begin{tabular}{l}
3 \\
$\because$ \\
\hdashline
\end{tabular}

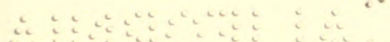




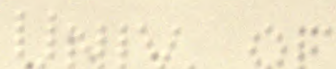

\% 
INTERNATIONAL ANTARCTIC COOPERATION.

SYNCHRONOUS CHARTS OF SEA-LEVEL PRESSURE FOR NOON GMT

WITH WINDS AND AIR TEMPERATURES.

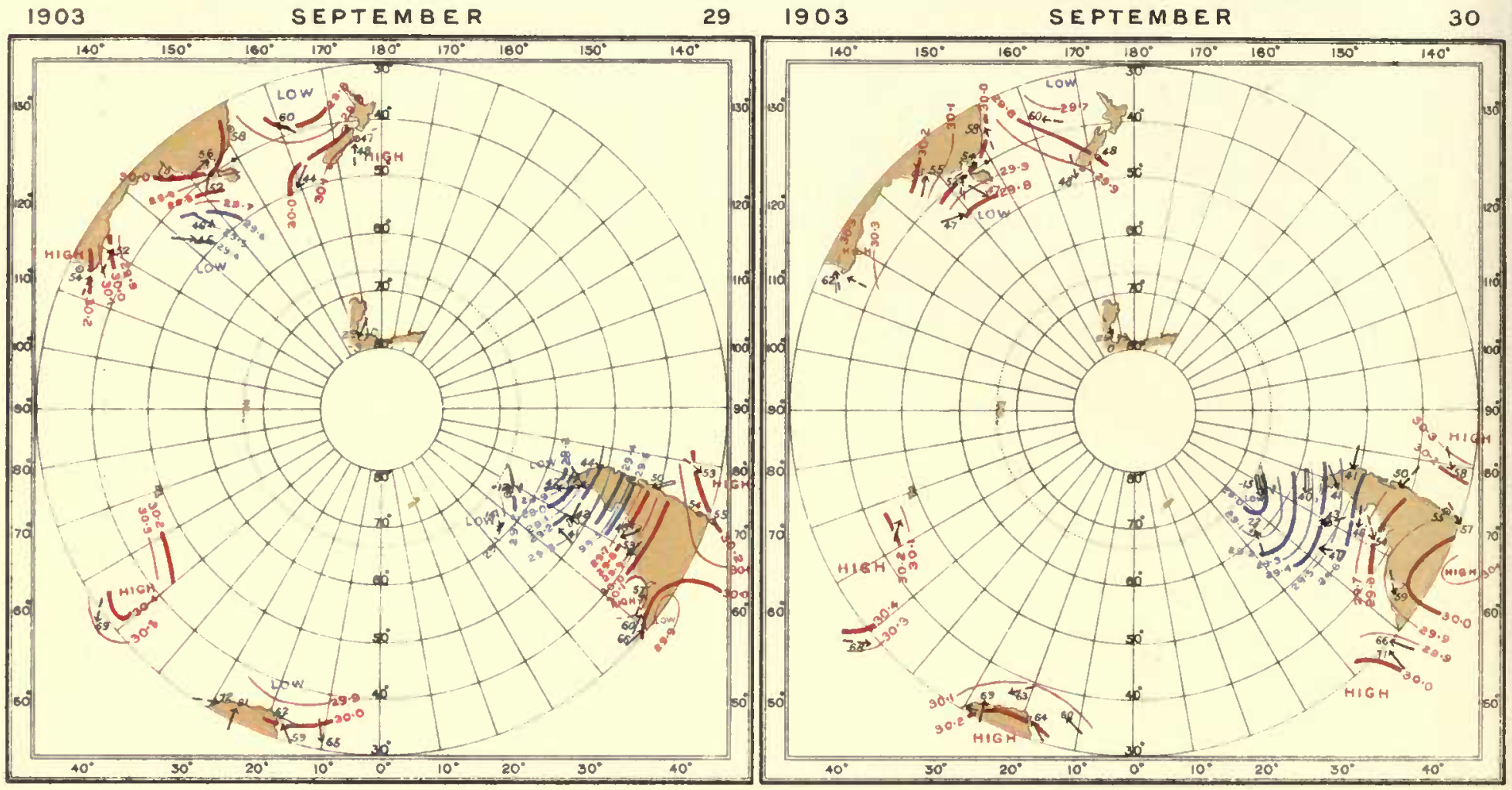

1903 OCTOBER

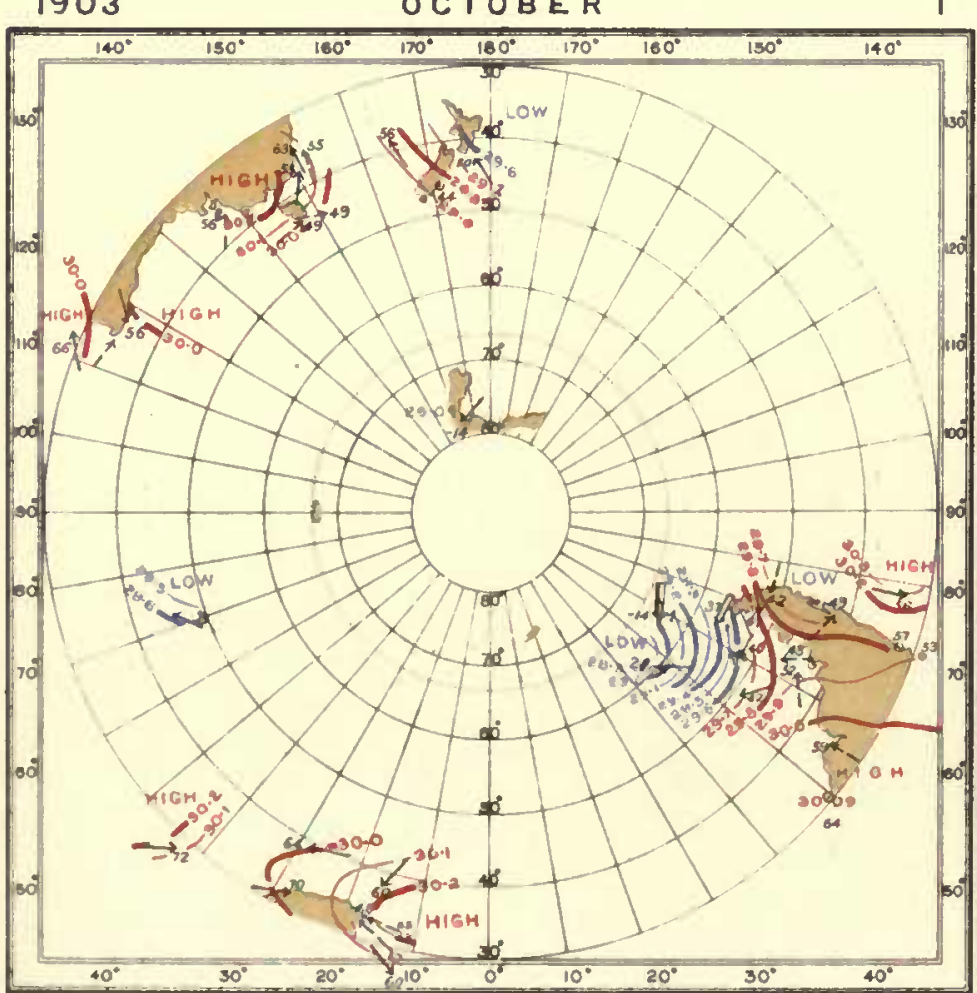

1903

O C TOBER

2

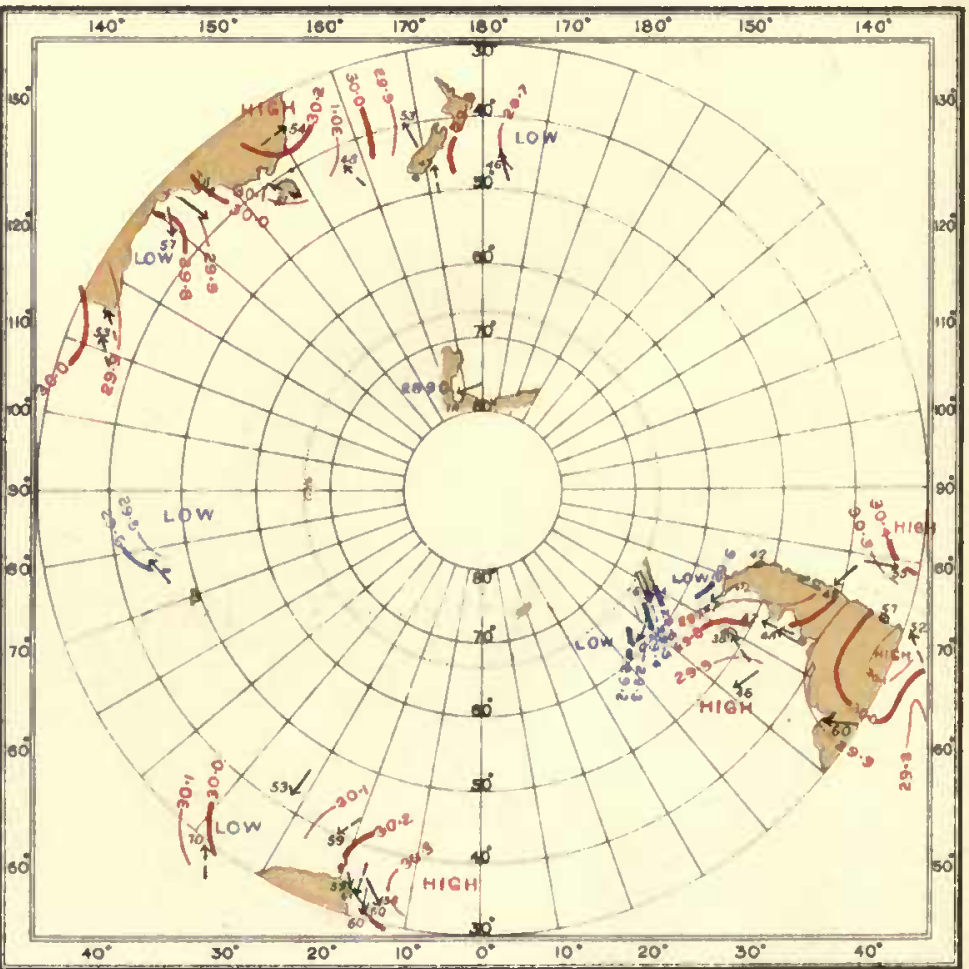


INTERNATIONAL ANTARCTIC CO-OPERATION.

SYNCHRONOUS CHARTS OF SEA-LEVEL PRESSURE FOR NOON GMT.T.

WITH WINDS AND AIR TEMPERATURES

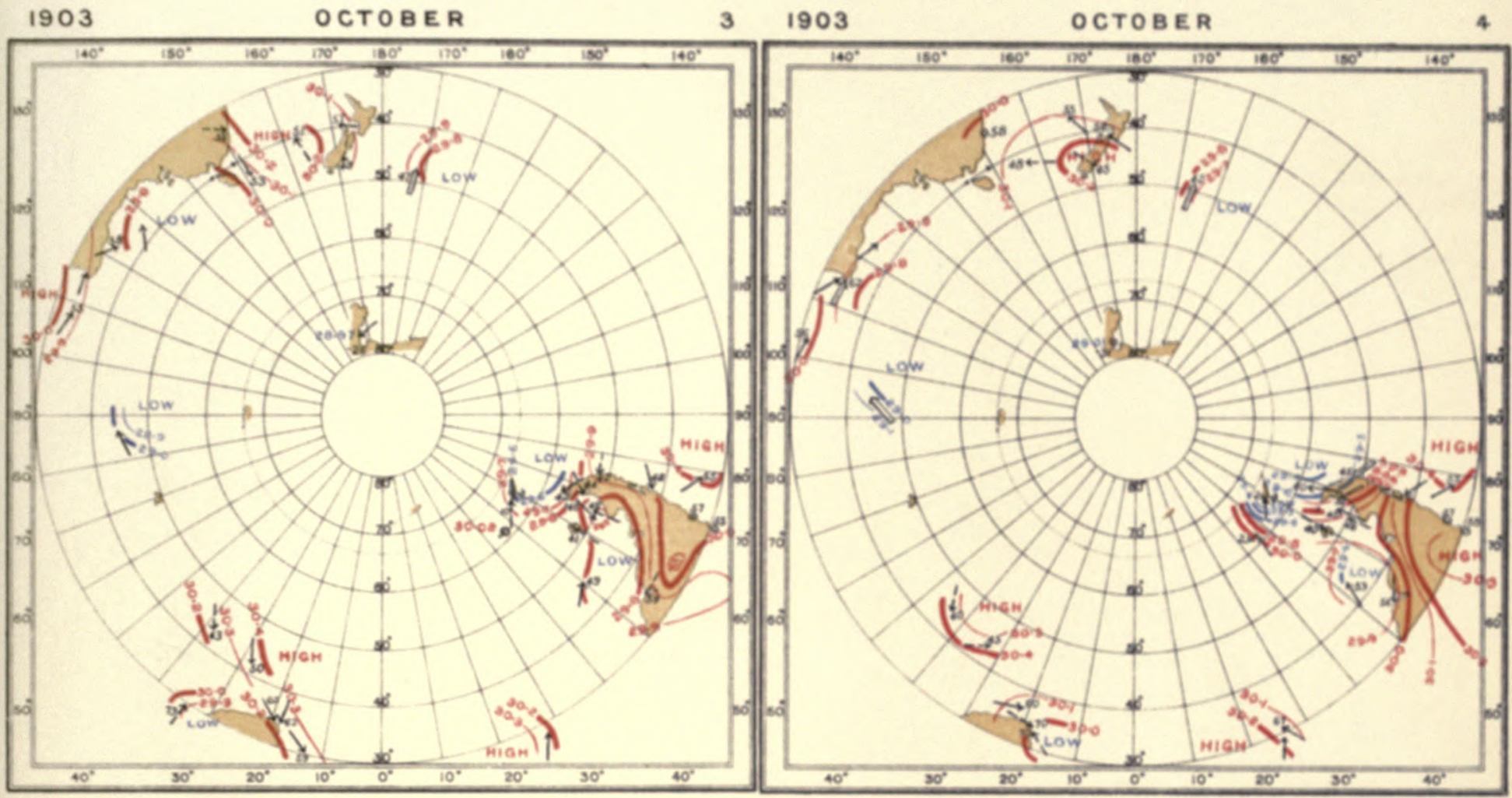

1903 OCTOBER

51903 OCTOBER

6
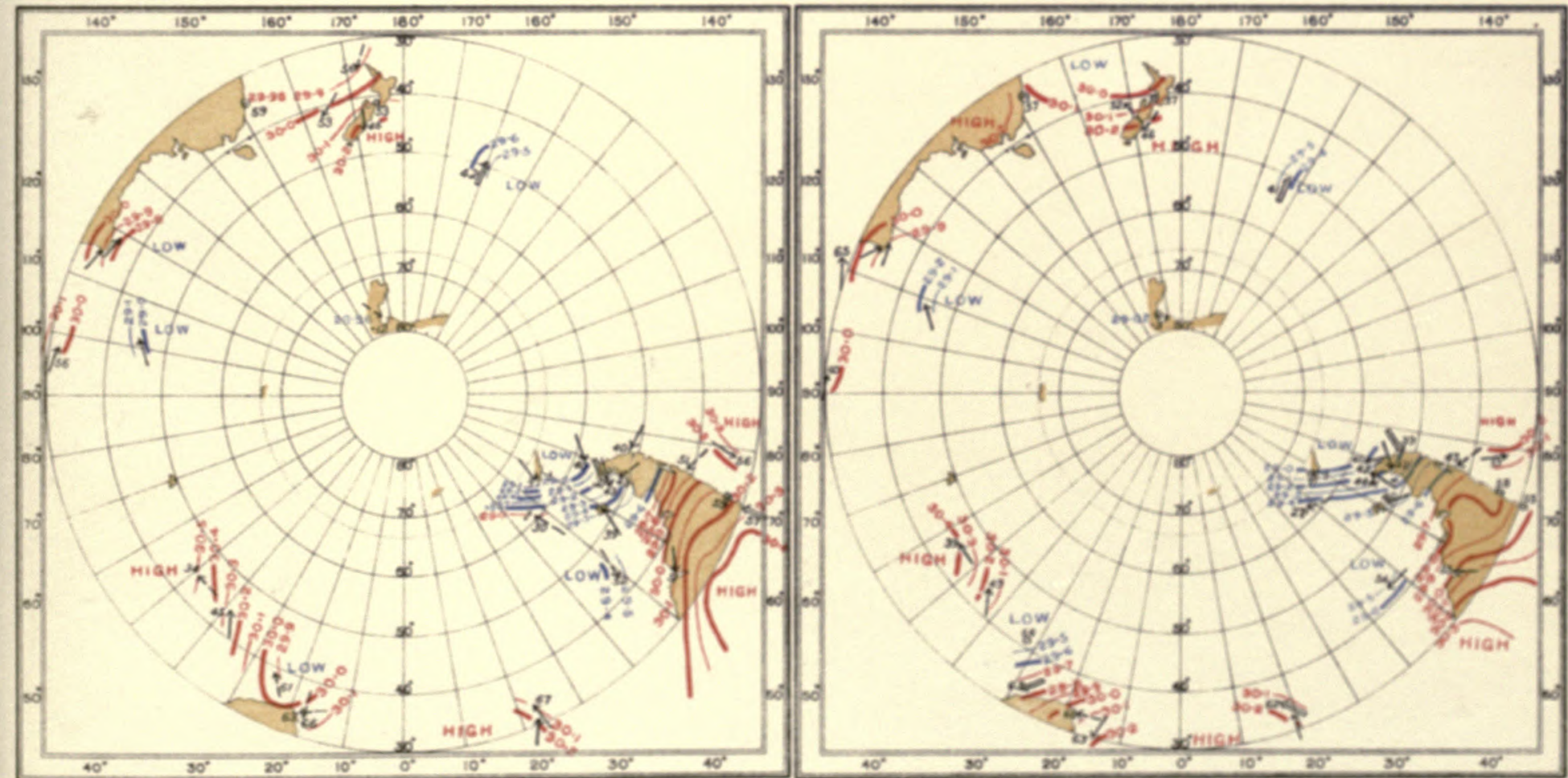
$\because \vdots z^{2}$

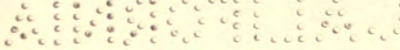




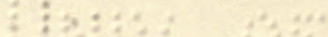

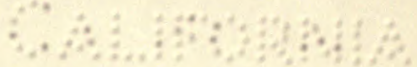


INTERNATIONAL ANTARCTIC CO-OPERATION.

SYNCHRONOUS CHARTS OF SEA-LEVEL PRESSURE FOR NOON G.MT

WITH WINDS AND AIR TEMPERATURES

1903

OCTOBER

$7 \quad 1803$

OCTOBER

8

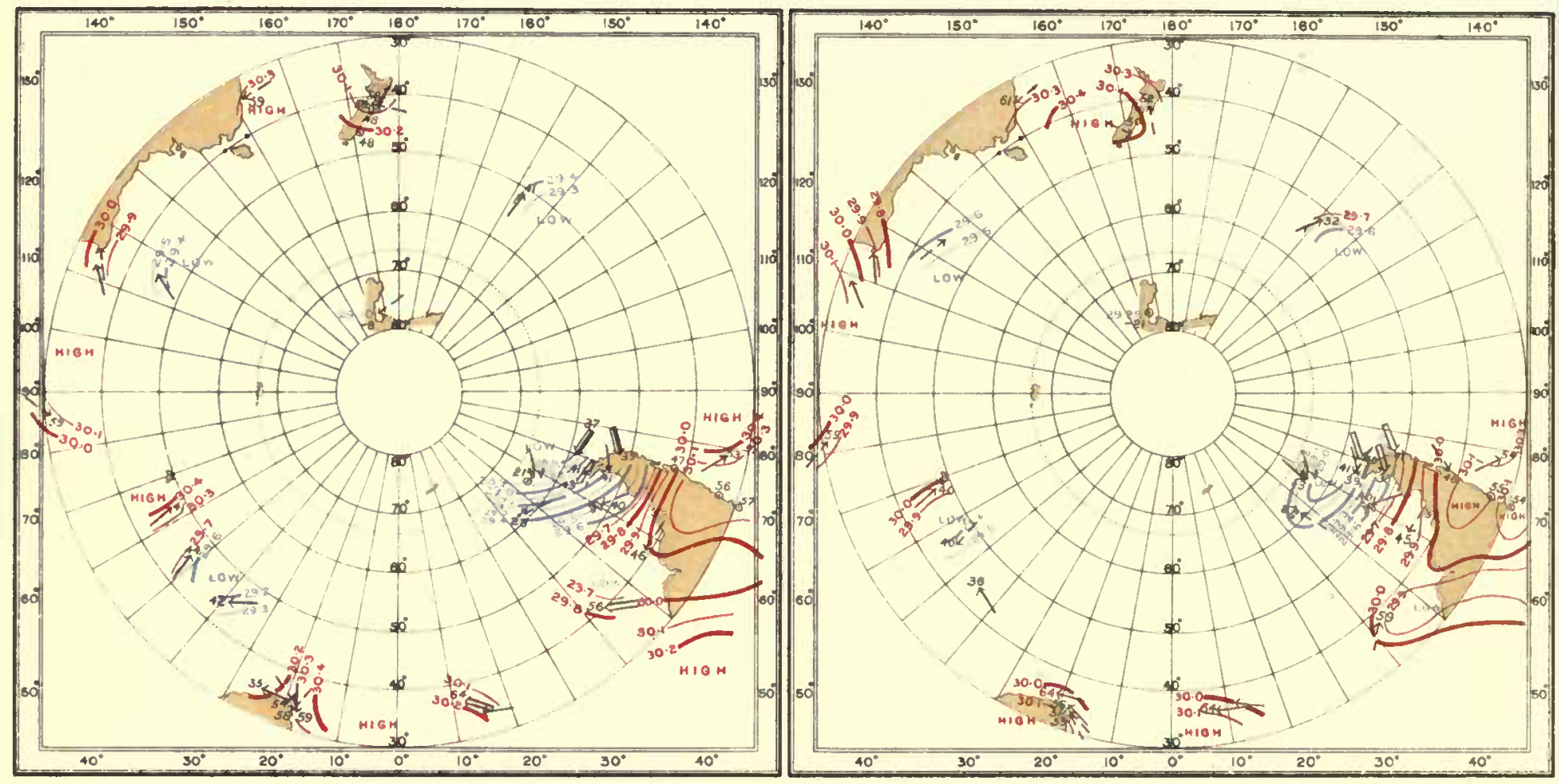

1903 OCTOBER

$9 \quad 1903$

OCTOBER

10
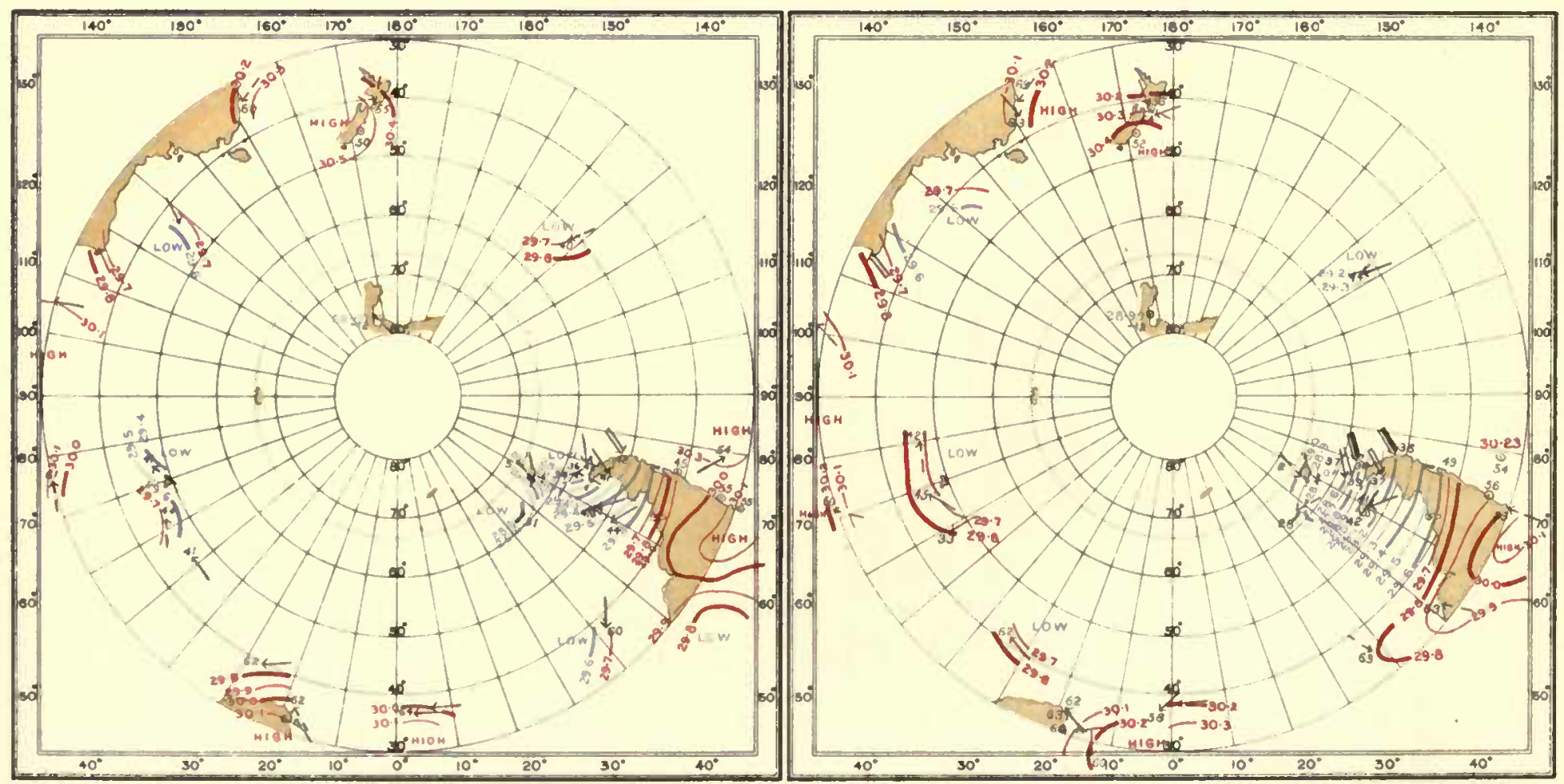
INTERNATIONAL ANTARCTIC CO-OPERATION.

SYNCHRONOUS CHARTS OF SEALLEVEL PRESSURE FOR NOONGMT

WITH WINDS AND AIR TEMPERATURES

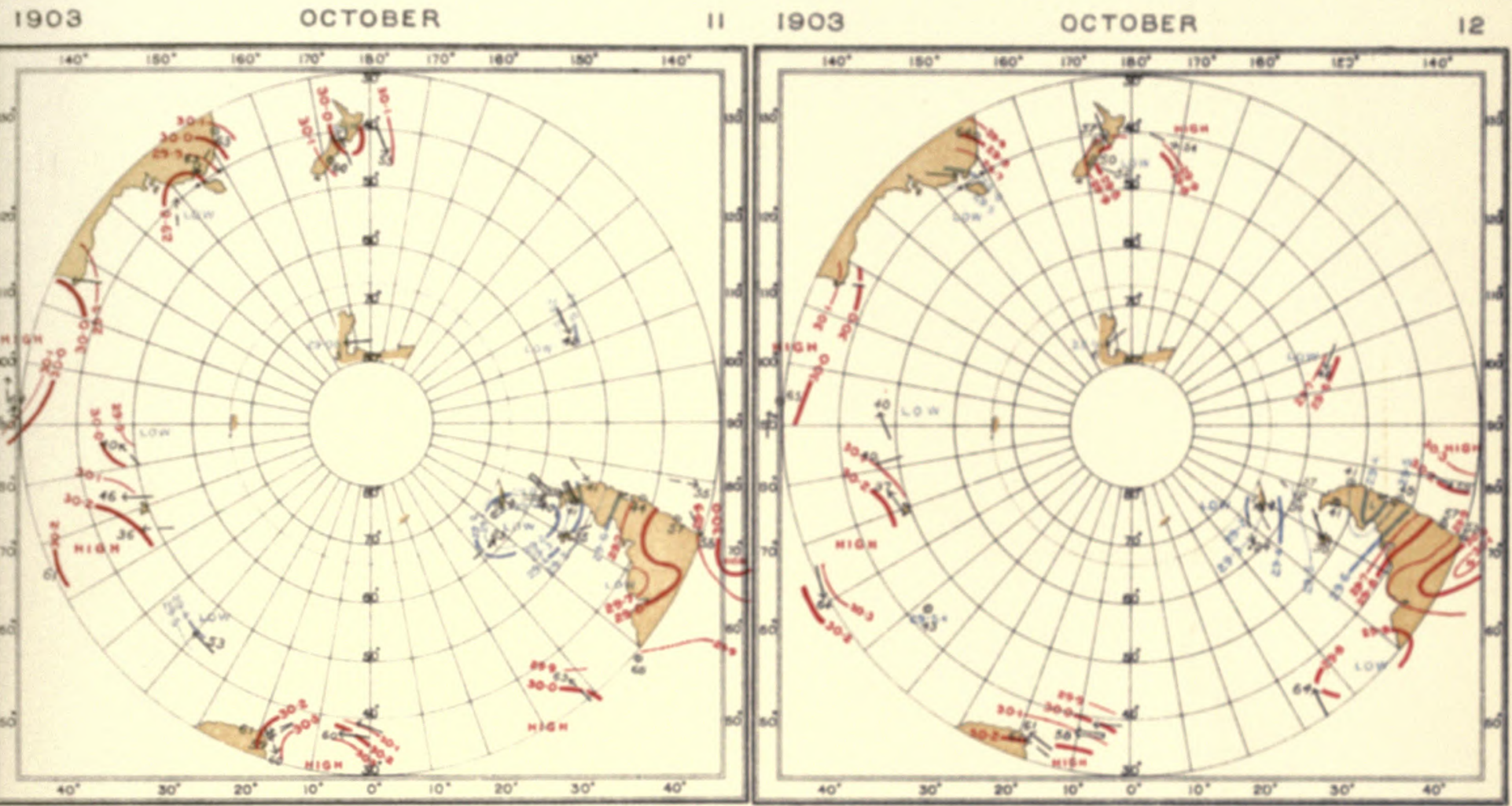

1903

OCTOBER

I3 I9O3 OCTOBER

14

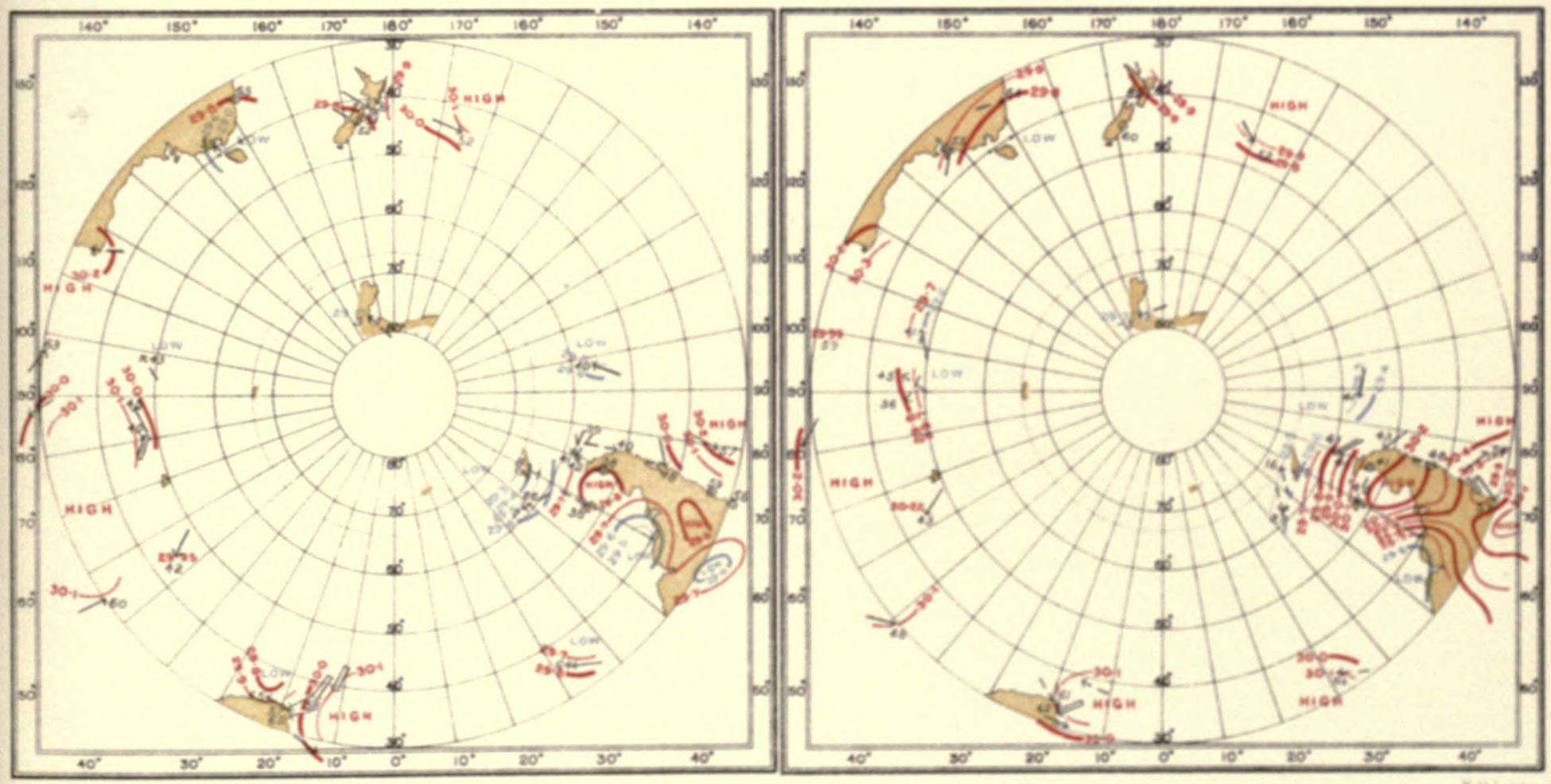


$\therefore \vdots \vdots \vdots \vdots$ 
INTERNATIONAL ANTARCTIC CO-OPERATION

SYNCHRONOUS CHARTS OF SEA-LEVEL PRESSURE FOR NOON GMT WITH WINDS AND AIR TEMPERATURES
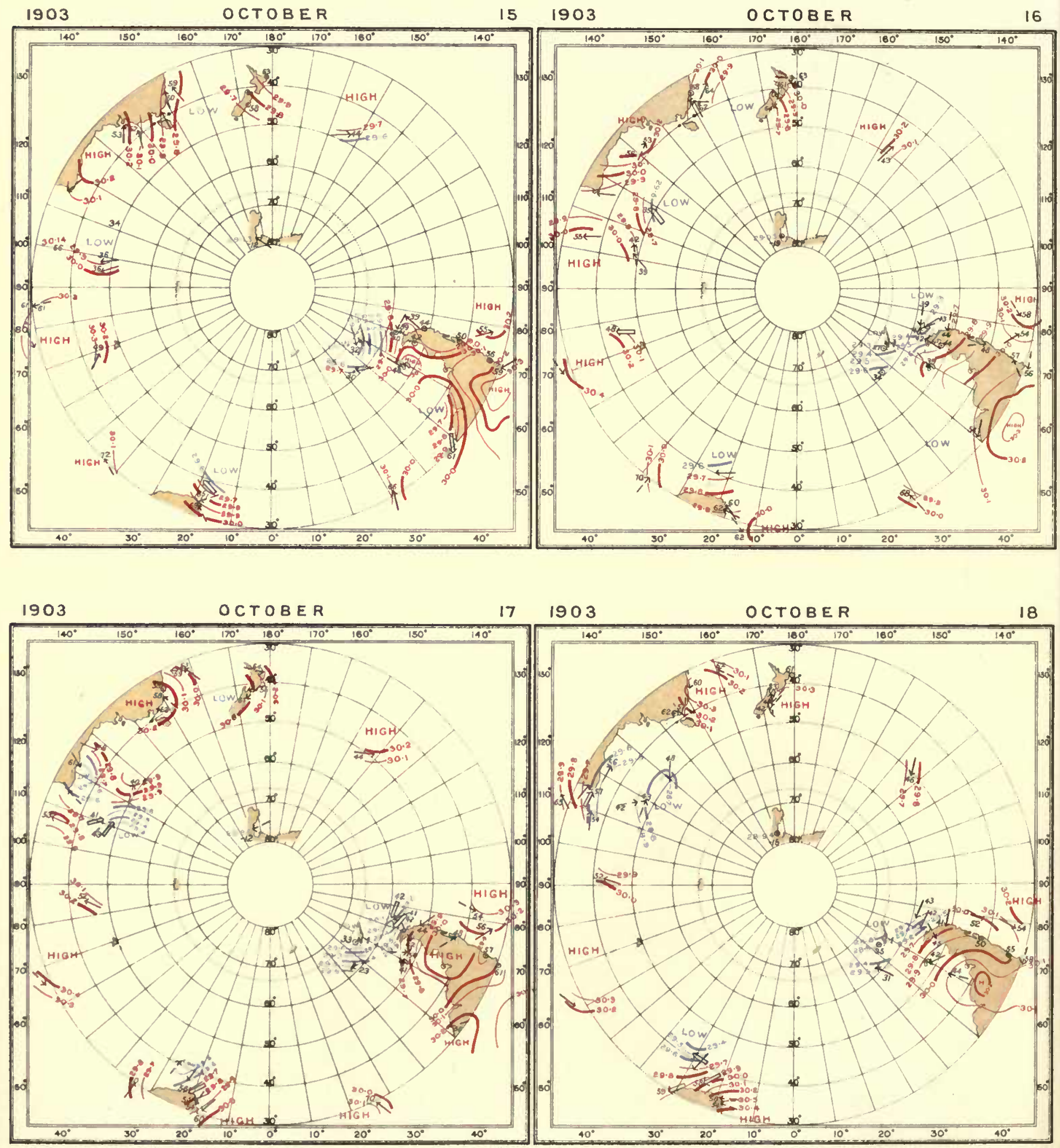
INTERNATIONAL ANTARCTIC COOPERATION

SYNCHRONOUS CHARTS OF SEALEVEL PRESSURE FOR NOON GMT.

WITH WINDS AND AIR TEMPERATURES

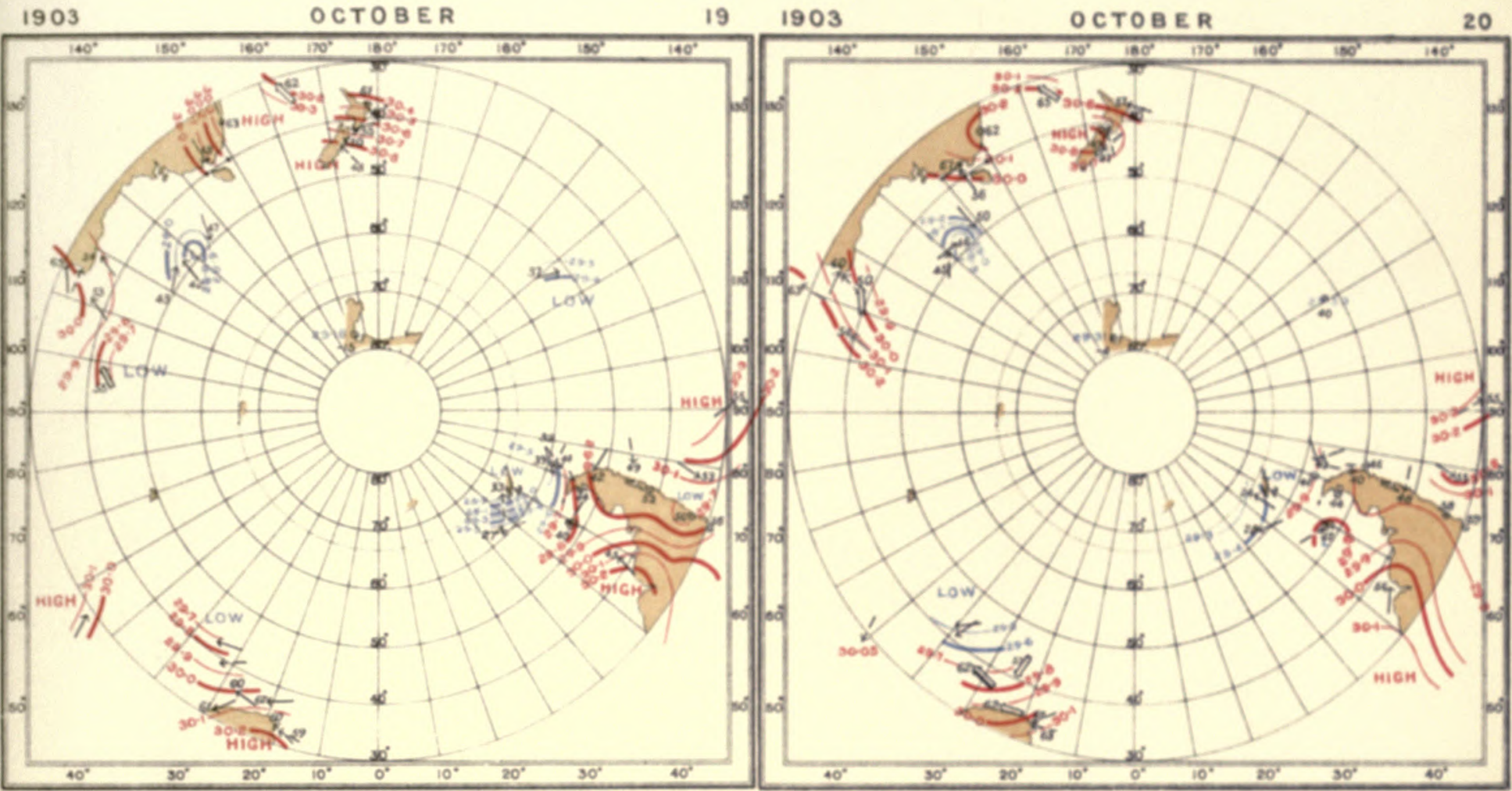

1903

OCTOBER

$21 \quad 1903$

OCTOBER

22

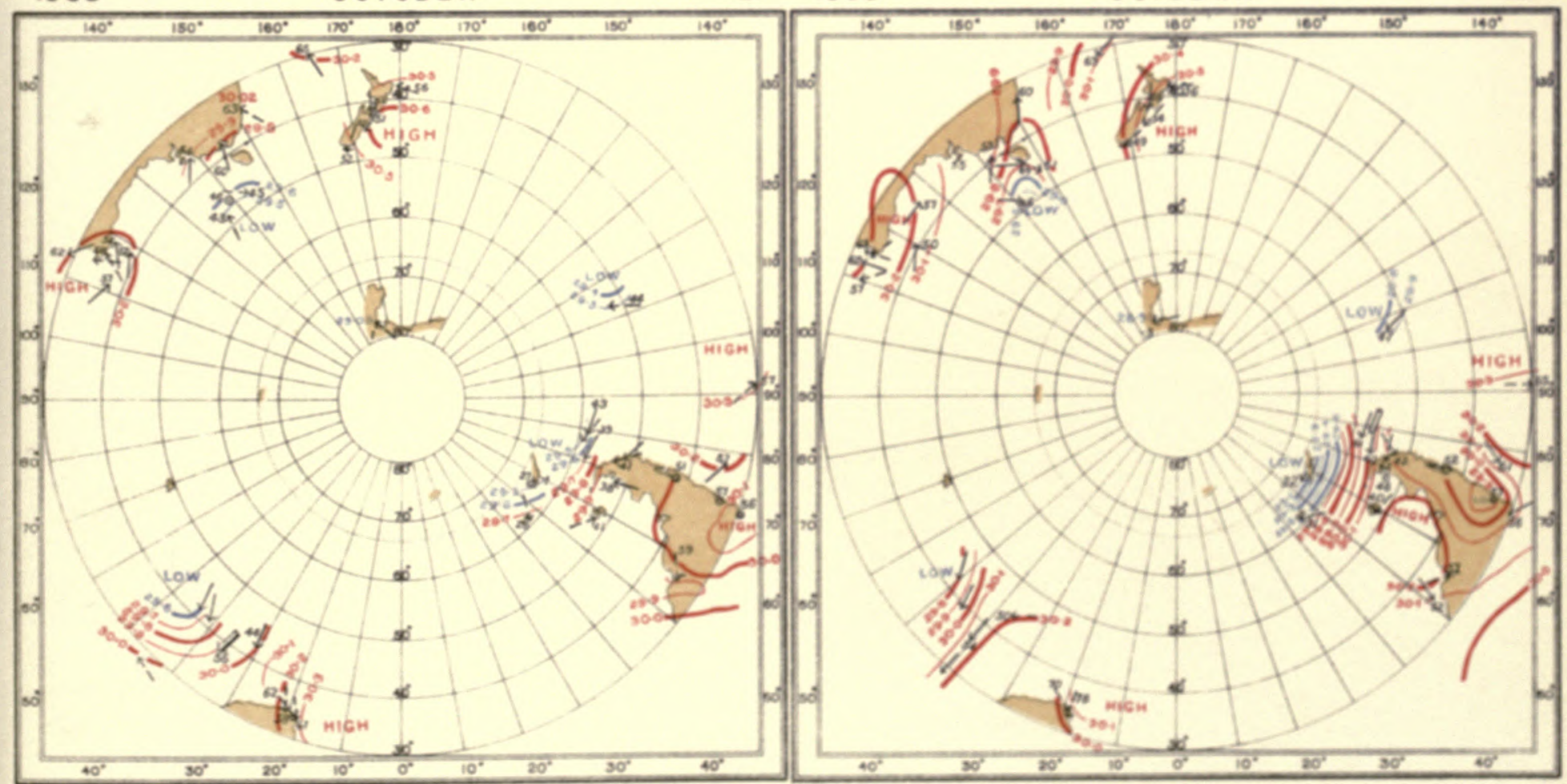


$\because \because \vdots \quad \because \because \vdots \vdots \because \vdots \vdots$

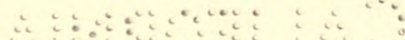

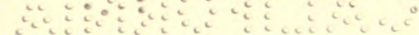


1)

C. A 
INTERNATIONAL ANTARCTIC COOOPERATION.

SYNCHRONOUS CHARTS OF SEA-LEVEL PRESSURE FOR NOON GMT

WITH WINDS AND AIR TEMPERATURES
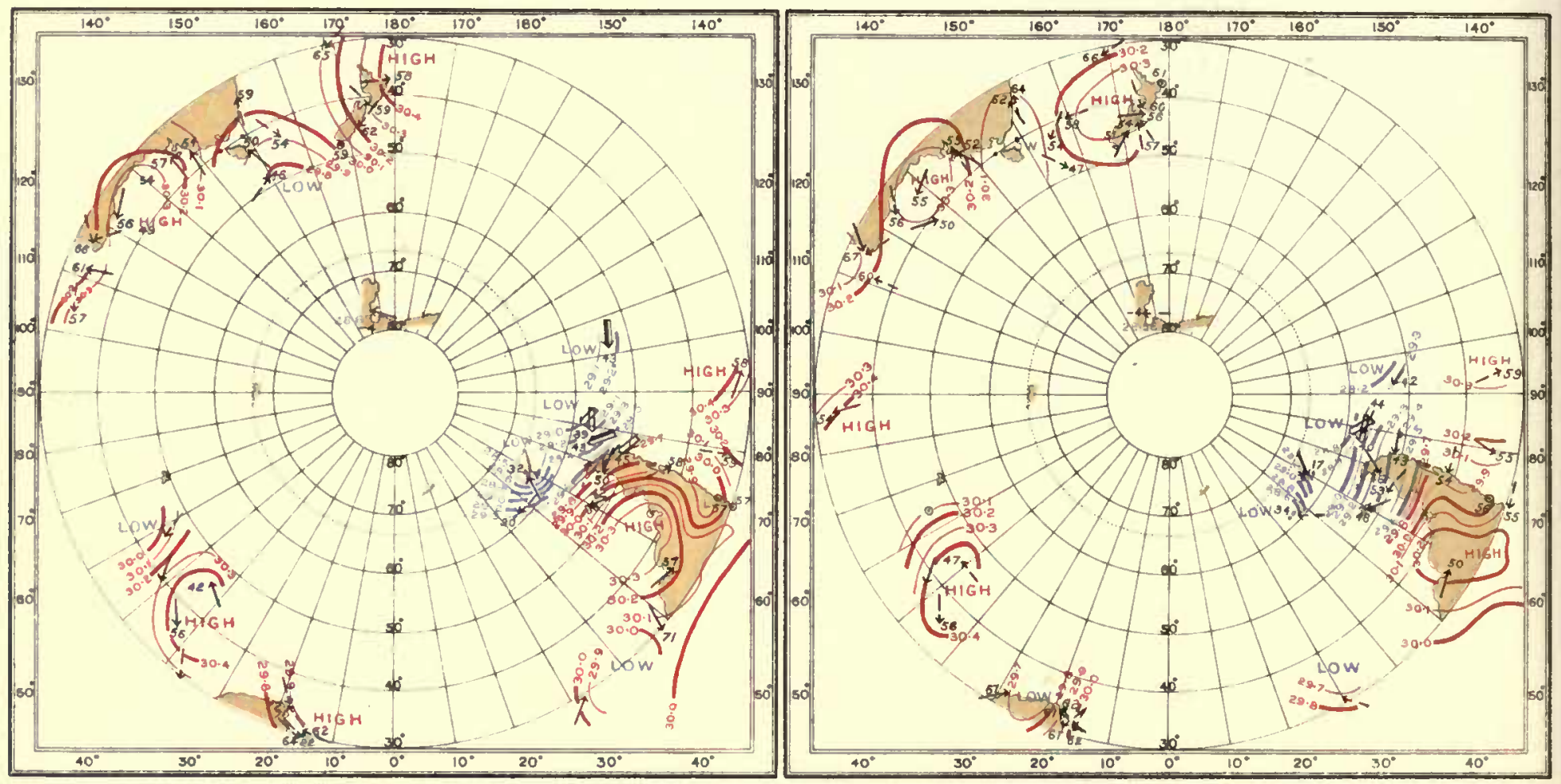

1903

OCTOBER

$25 \quad 1903$

OCTOBER

26
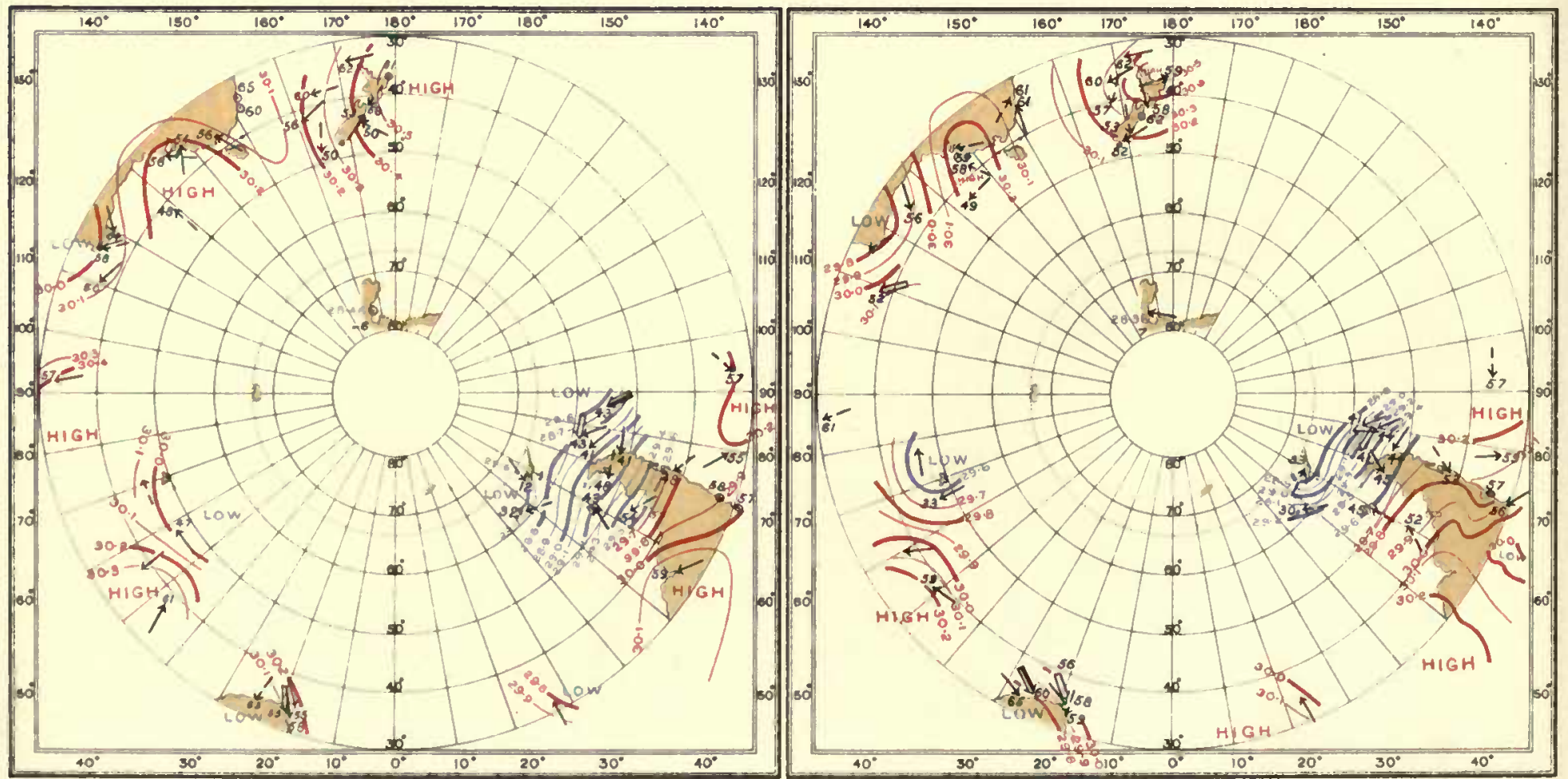
INTERNATIONAL ANTARCTIC COOOPERATION

SYNCHRONOUS CHARTS OF SEALLVEL PRESSURE FOR NOON GMT

WITH WINDS AND AIR TEMPERATURES
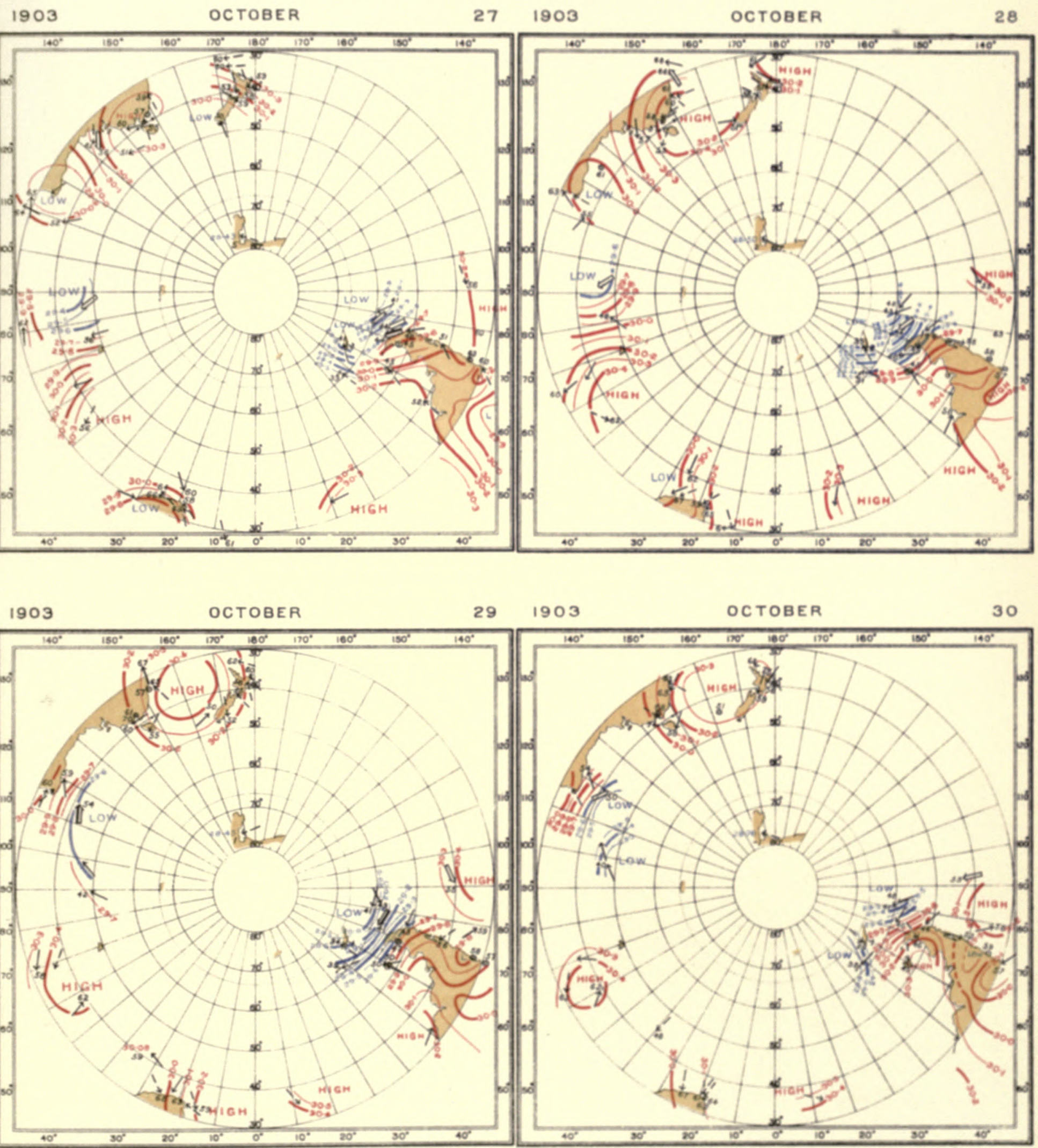
$\because \because$

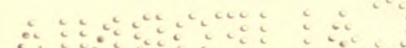

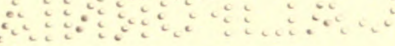




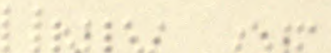

H. 
INTERNATIONAL ANTARCTIC COOPERATION.

SYNCHRONOUS CHARTS OF SEALEVEL PRESSURE FOR NOON GMT

WITH WINDS AND AIR TEMPERATURES

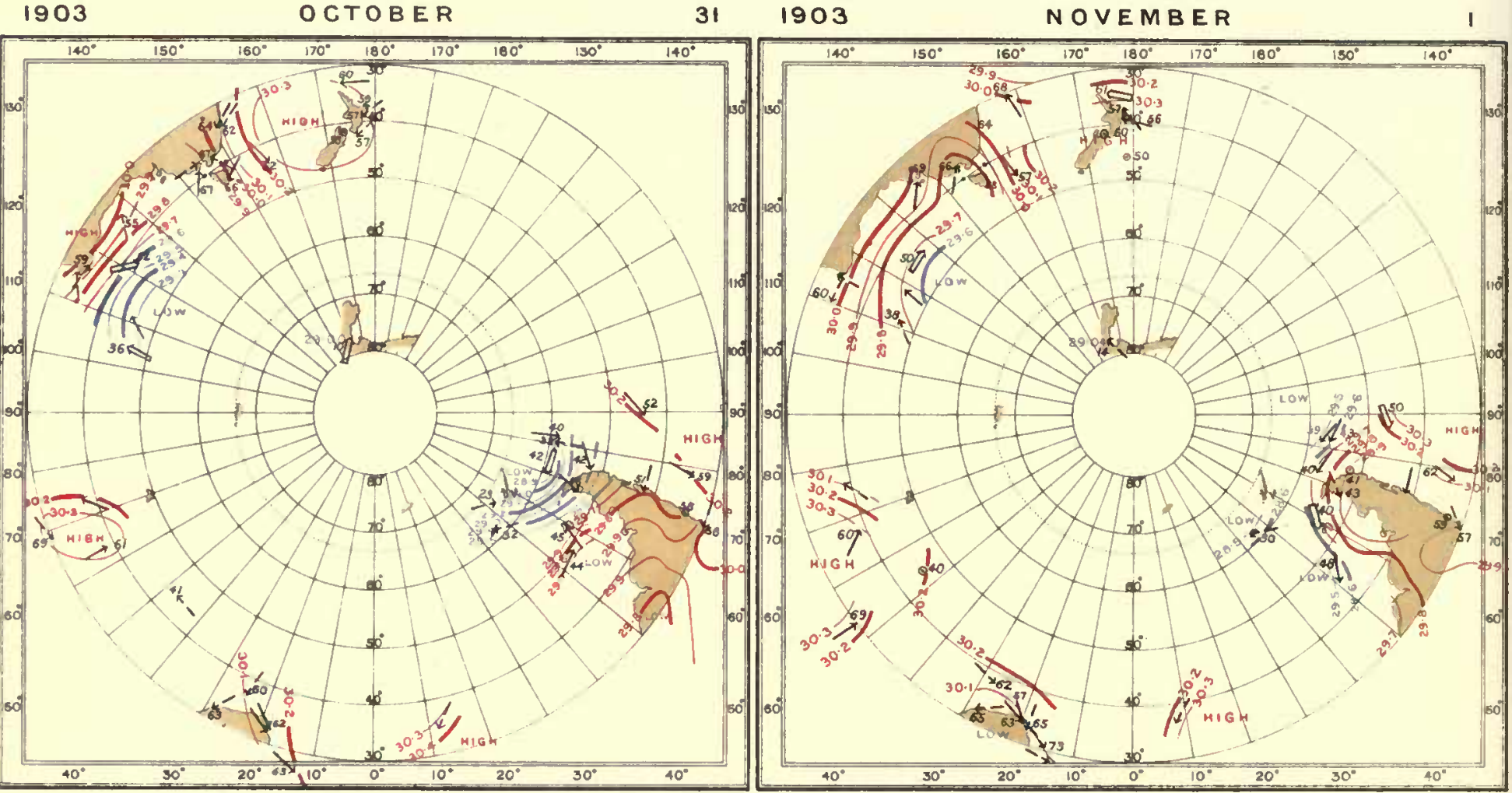

1903 NOVEMBER

21903

NOVEMBER

3

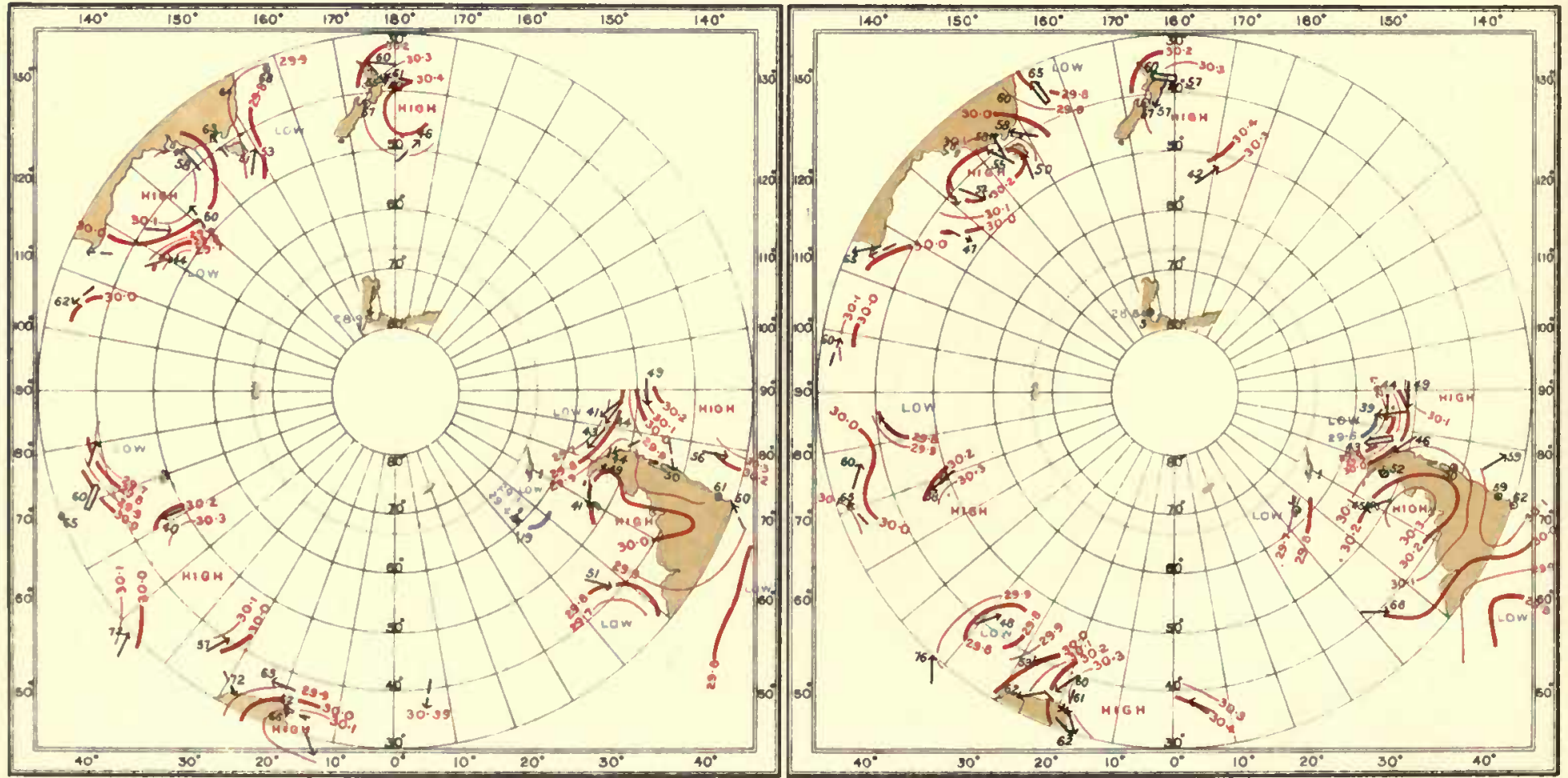


“ํ.

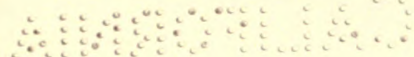


$\vdots \vdots 3,1 \%$ :

, A 
INTERNATIONAL ANTARCTIC CO-OPERATION

SYNCHRONOUS CHARTS OF SEA-LEVEL PRESSURE FOR NOON G.MT

WITH WINDS AND AIR TEMPERATURES.

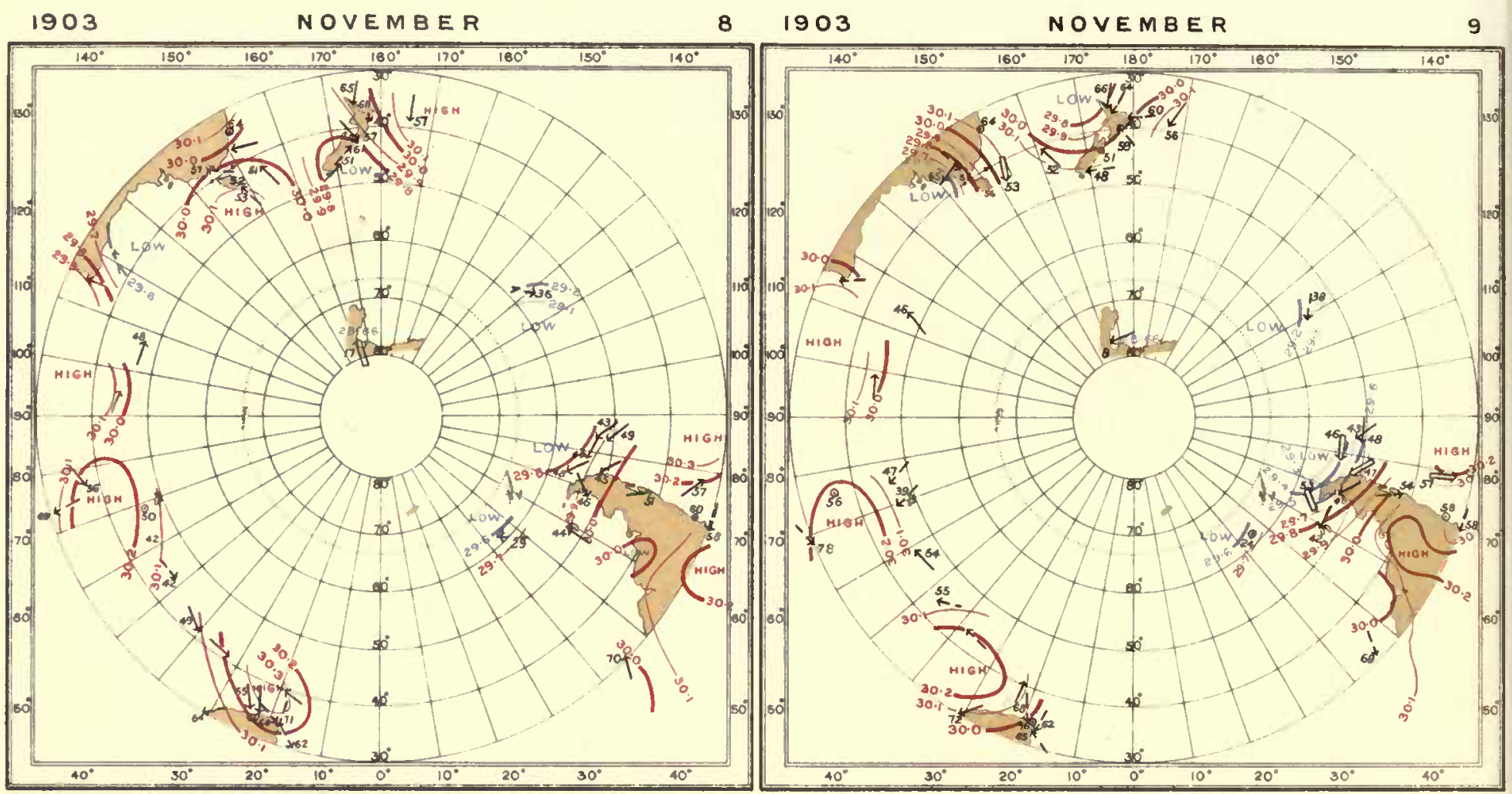

1903 NOVEMBER

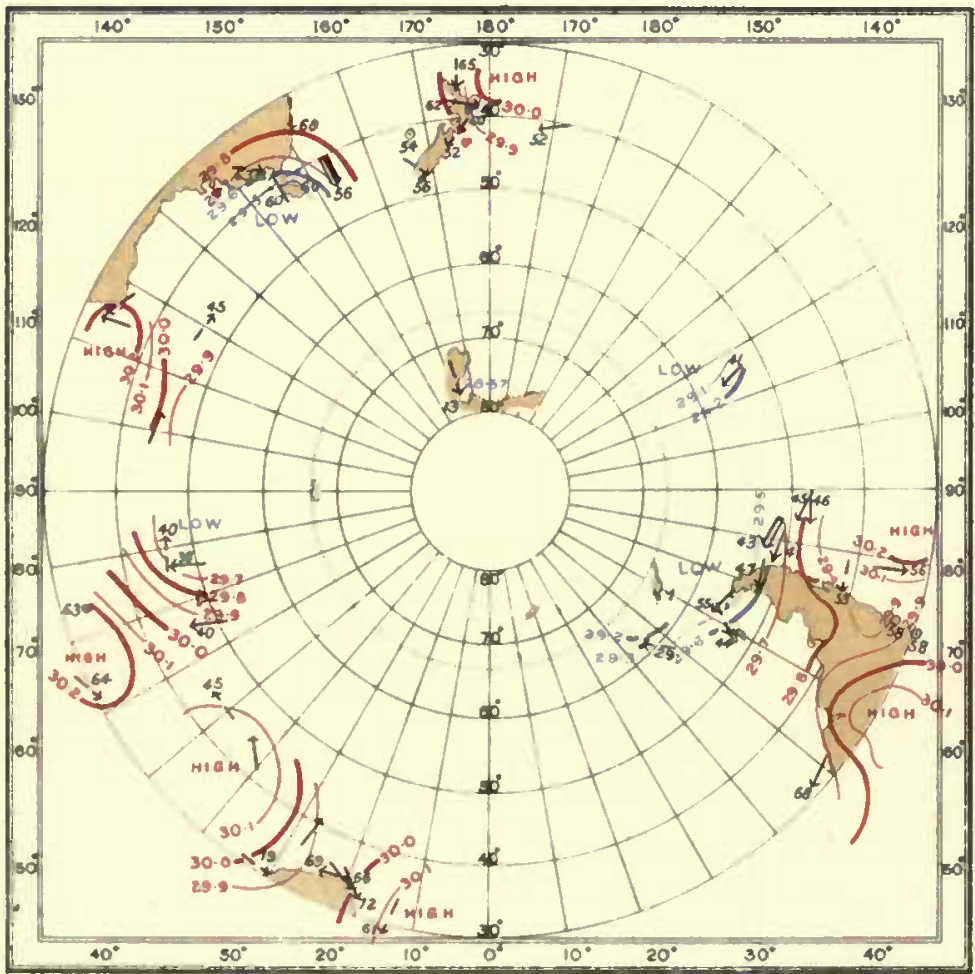

1903

NOVEMEER

II

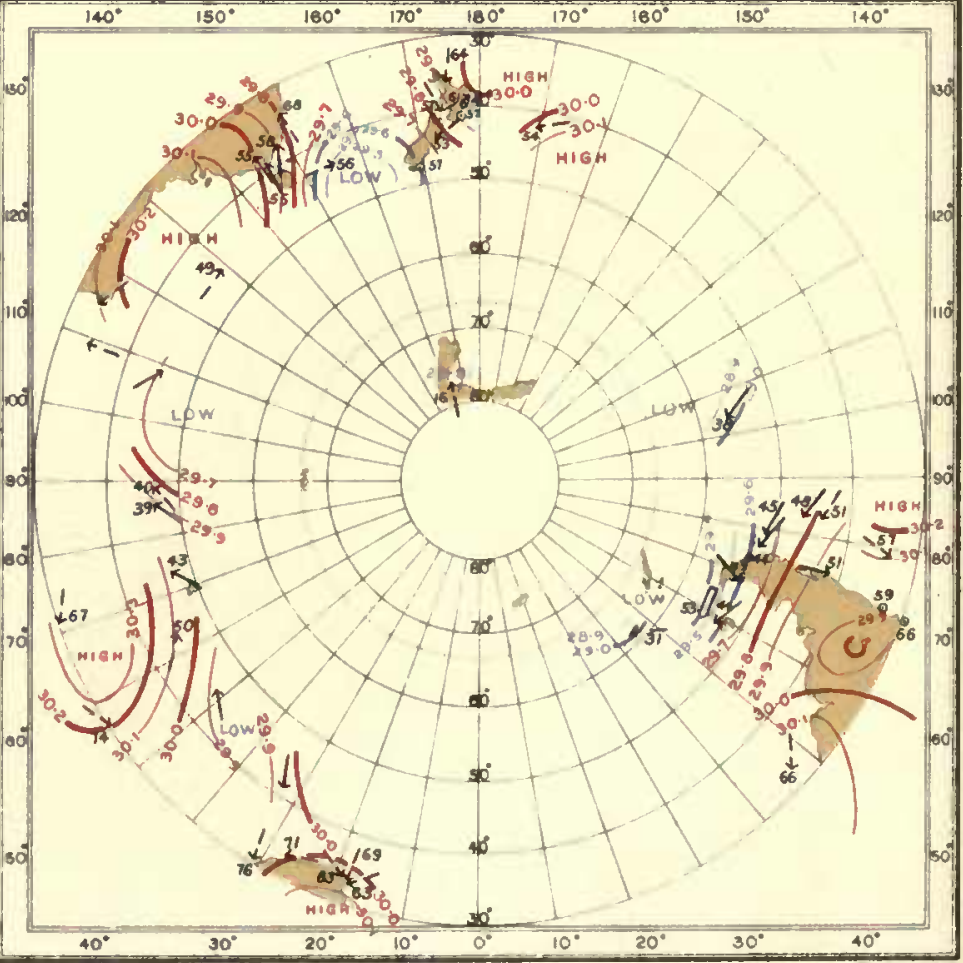


INTERNATIONAL ANTARCTIC COOOPERATION

SYNCHRONOUS CHARTS OF SEALEVEL PRESSURE FOR NOON G.M.T

WITH WINDS AND AIR TEMPERATURES

1903

NOVEMBER

$12 \quad 1903$

NOVEMBER

13

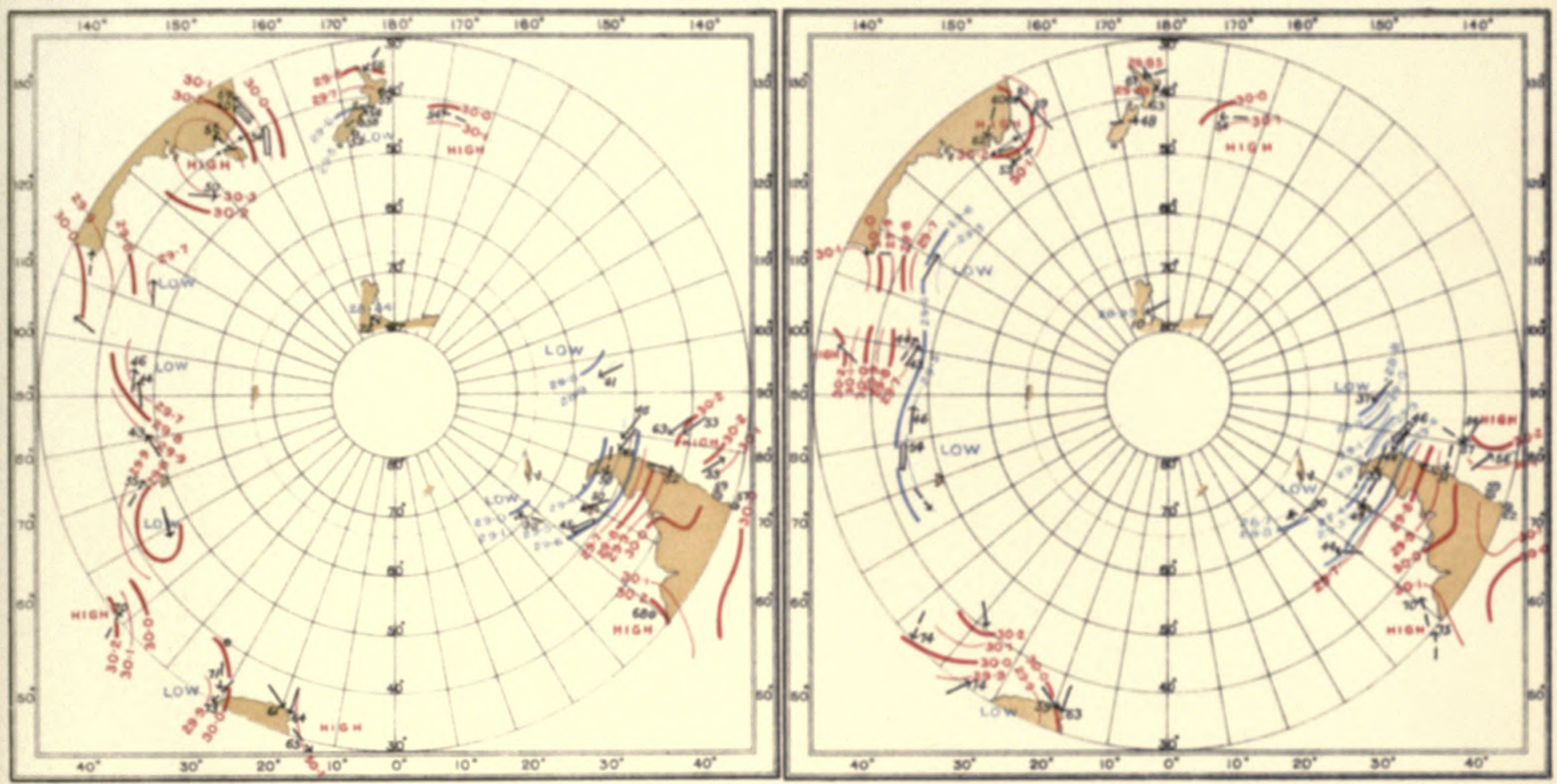

\section{3}

NOVEMBER

$14 \quad 1903$

NOVEM BER

15

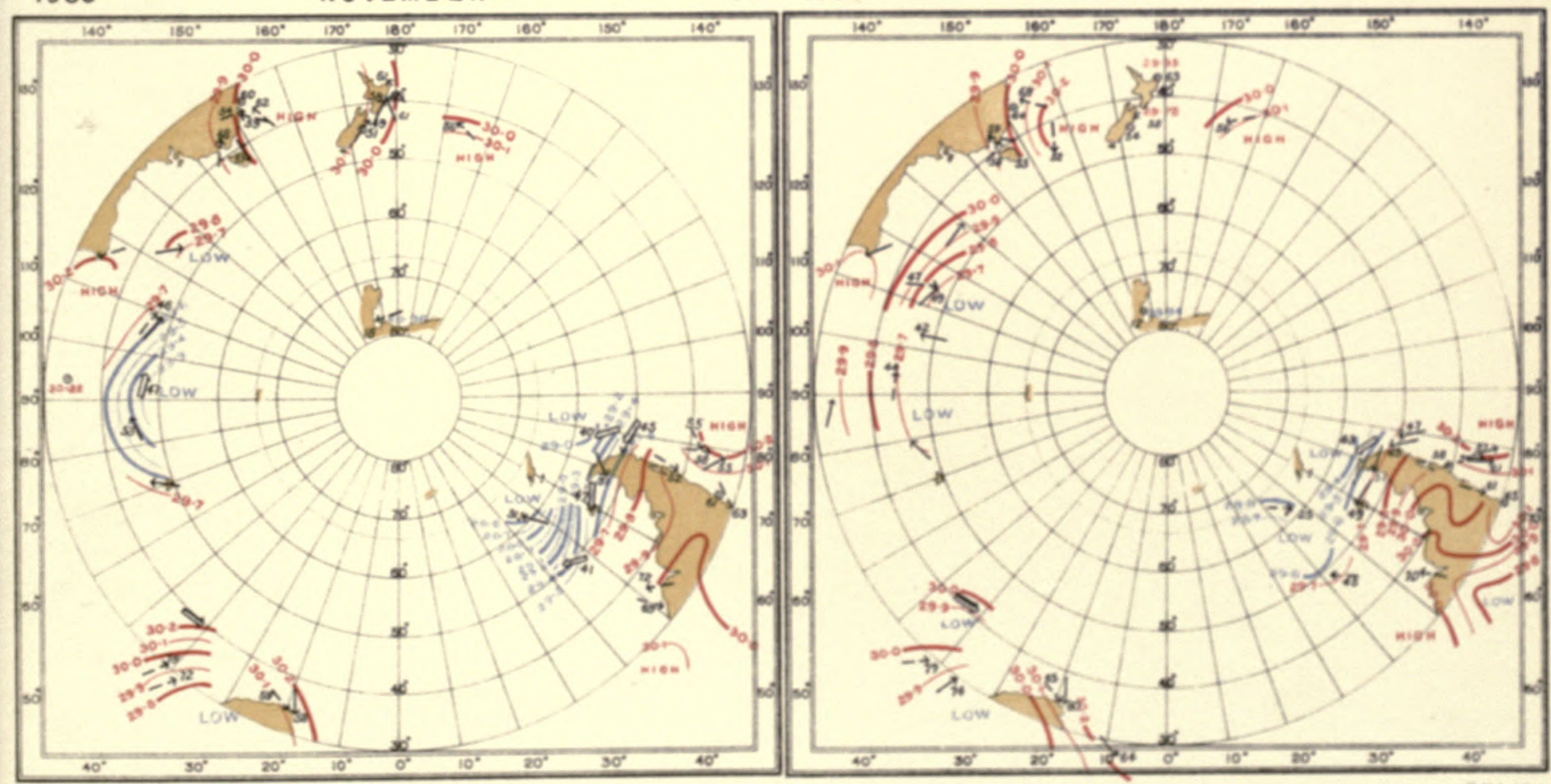


$\because \because \because \quad \because \because \vdots \vdots \vdots \vdots \vdots 0$

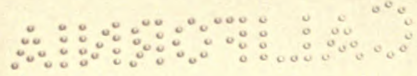


1) $\%$

CA H 
INTERNATIONAL ANTARCTIC COOOPERATION.

SYNGHRONOUS CHARTS OF SEA-LEVEL PRESSURE FOR NOONGM.T

WITH WINDS AND AIR TEMPERATURES

1903 NOVEMBER

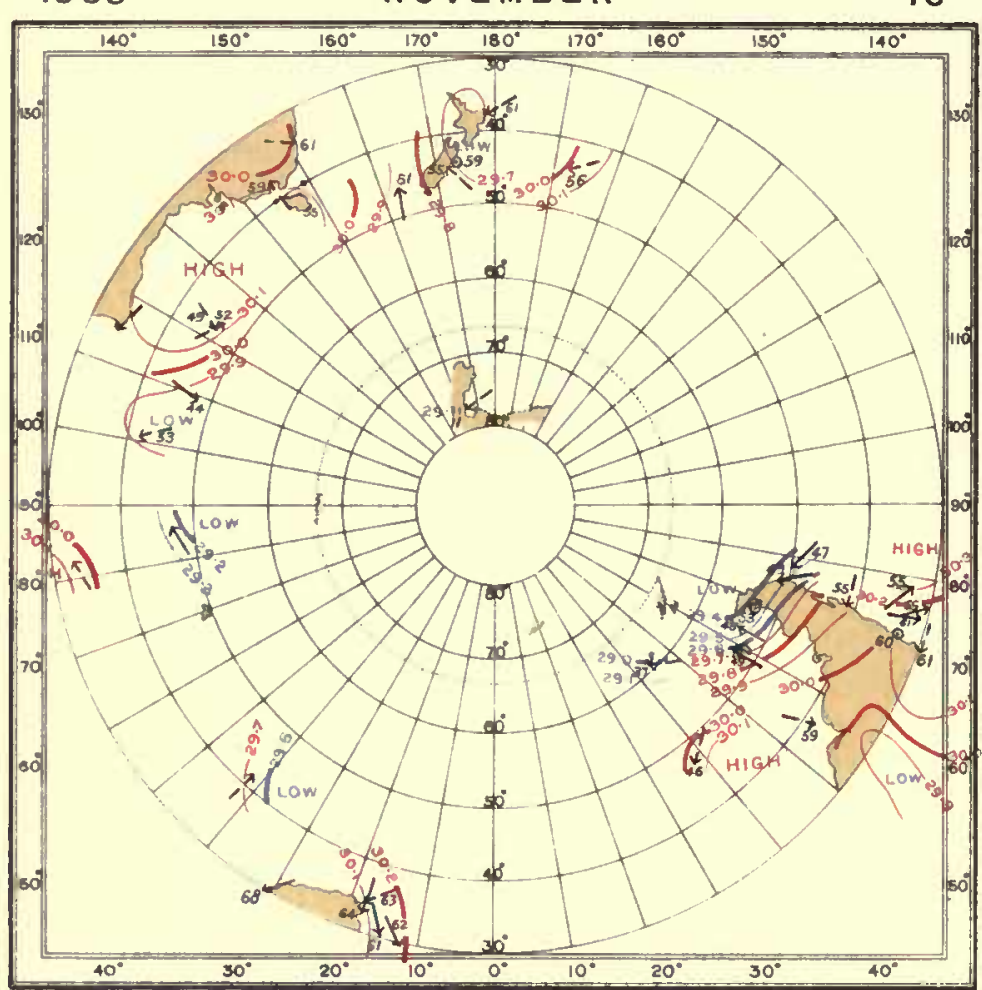

1903 NOVEMBER

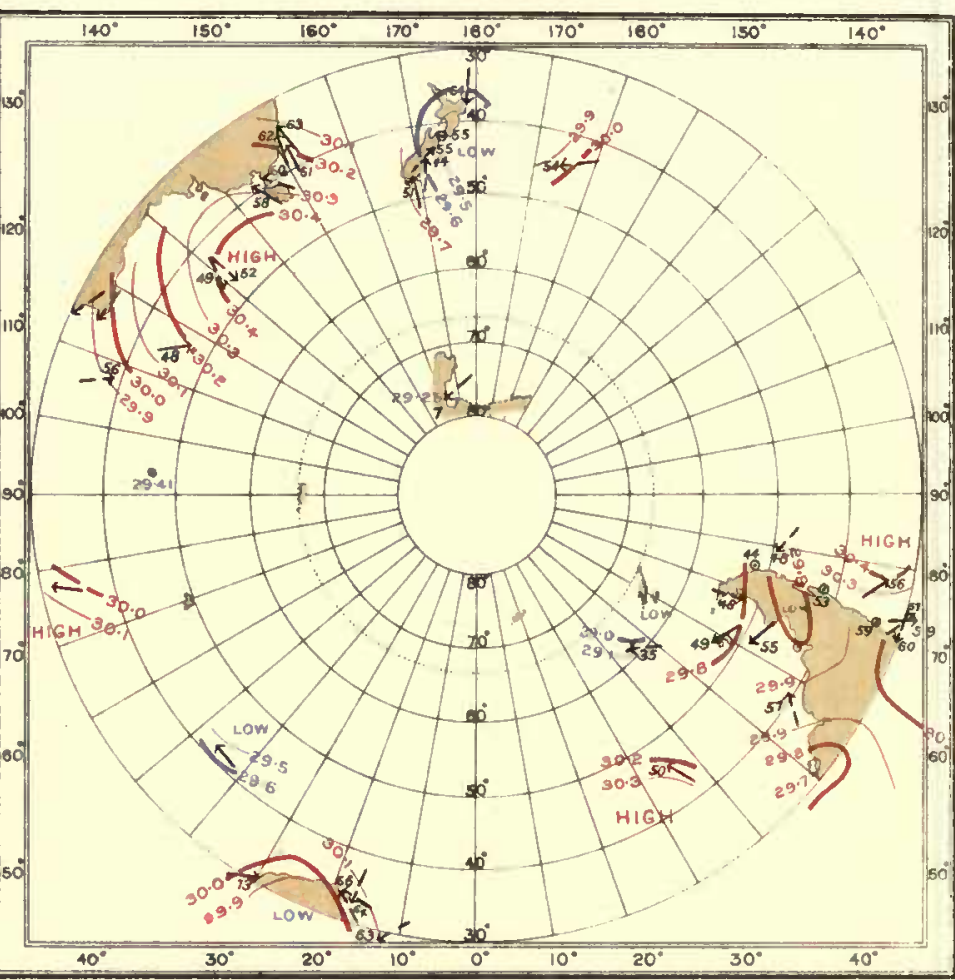

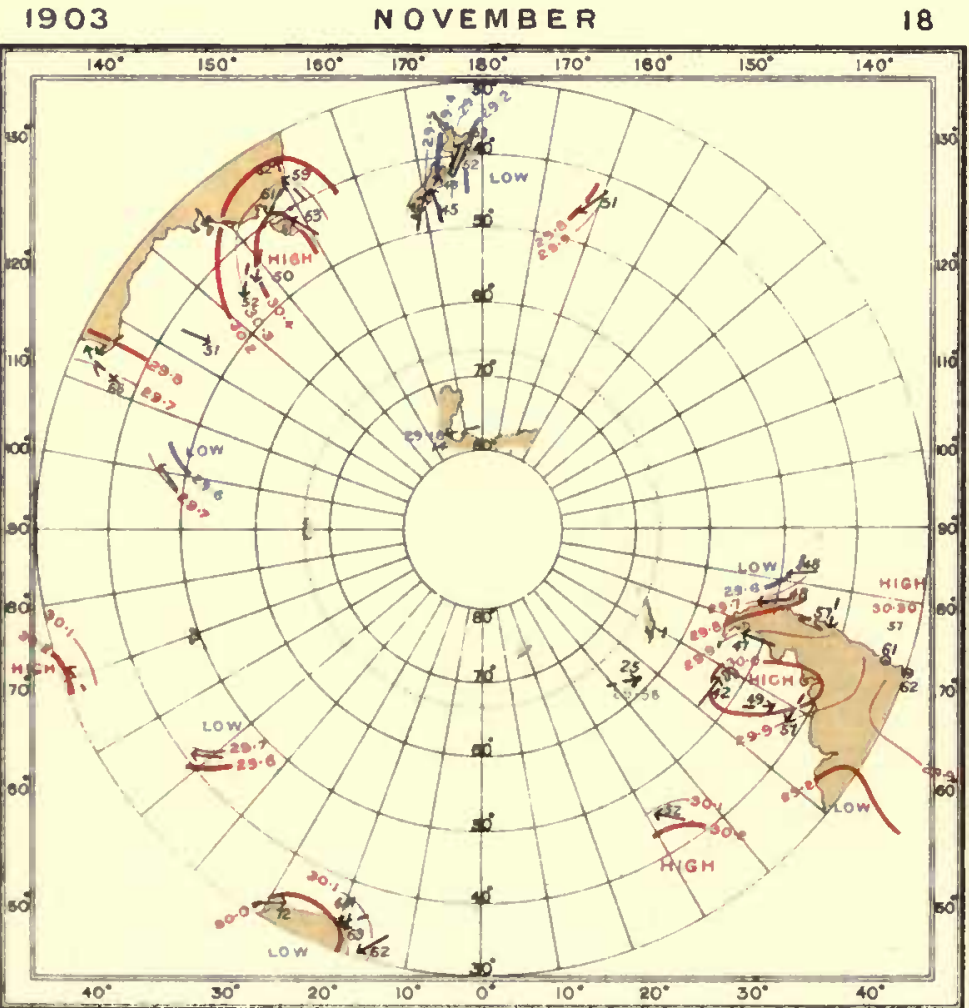

1903

N OVEMBER

19

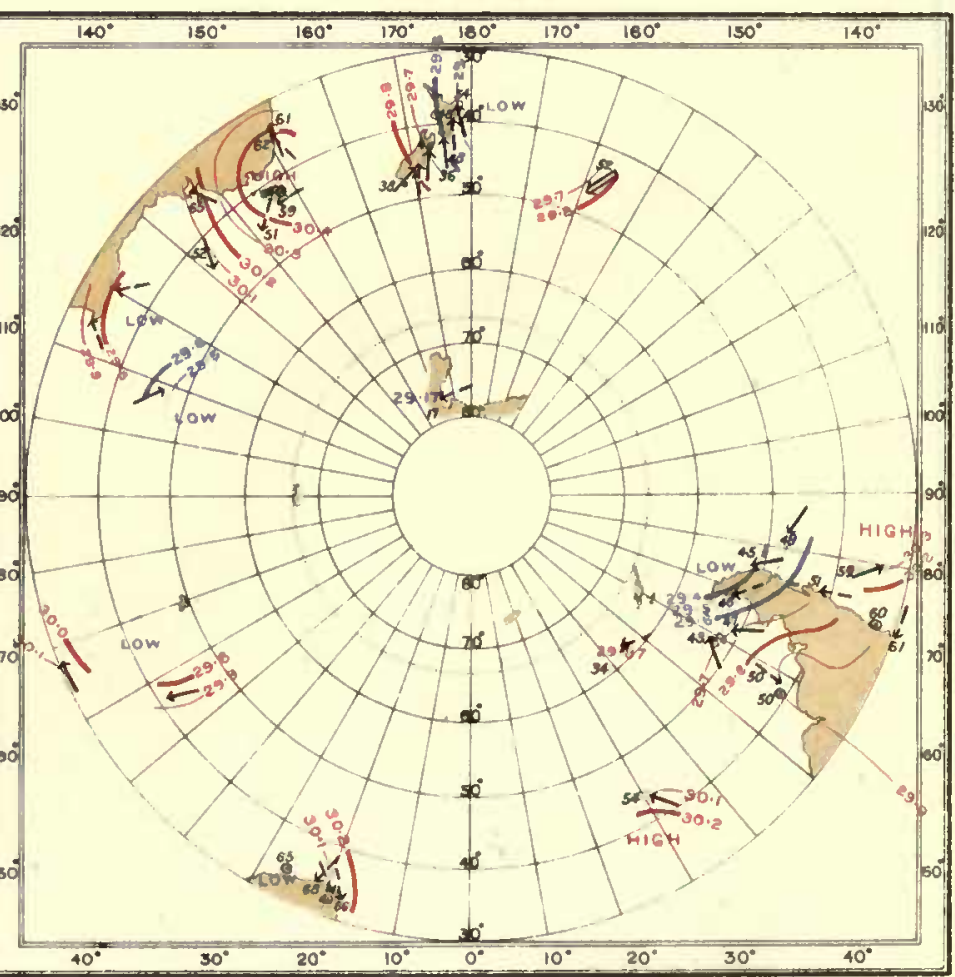


INTERNATIONAL ANTARCTIC CO-OPERATION.

SYNCHRONOUS CHARTS OF SEALLEVEL PRESSURE FOR NOON G.M.T. WITH WINDS AND AIR TEMPERATURES
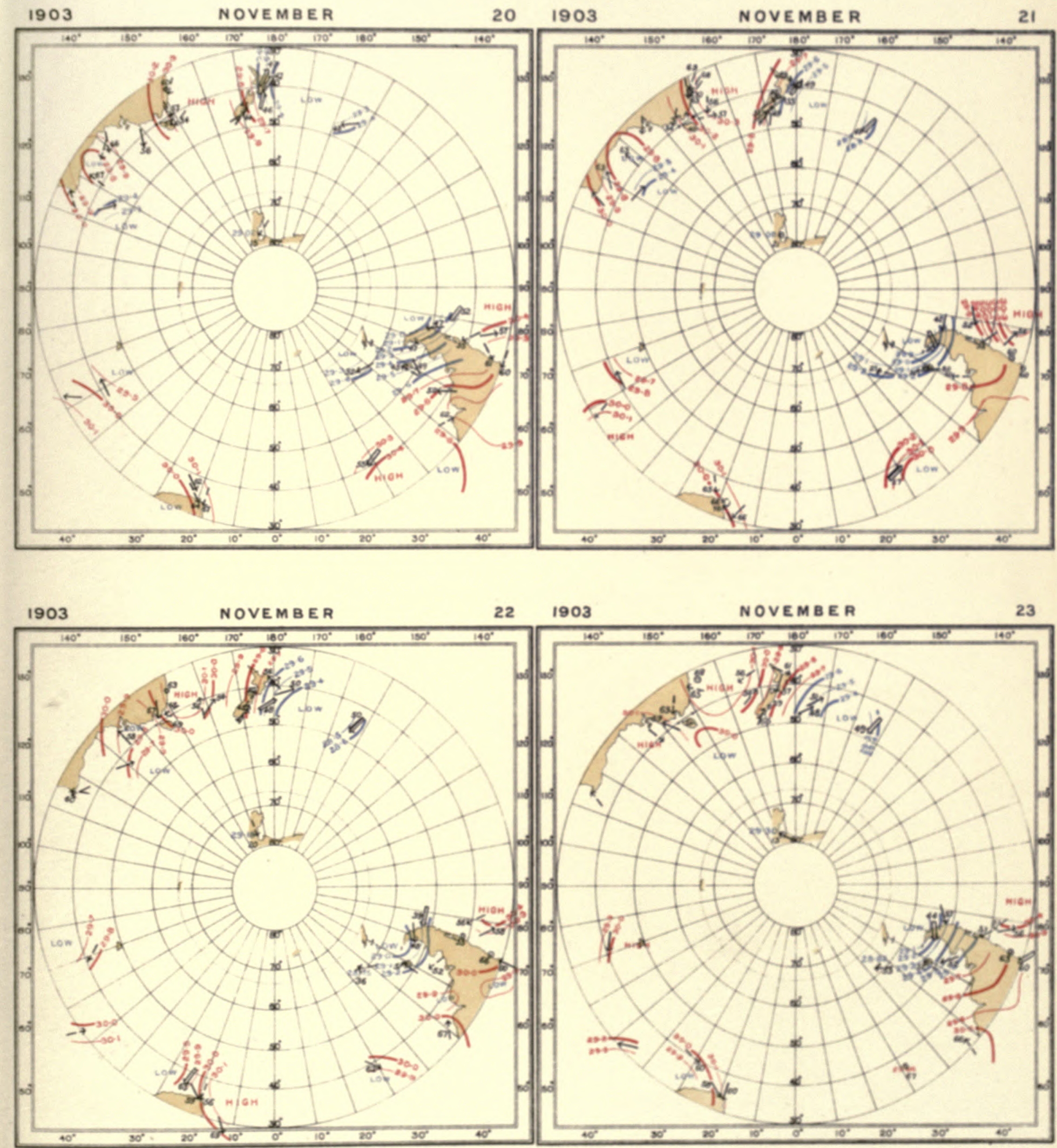
$\because \vdots$

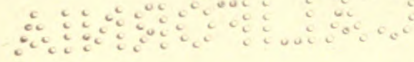


INTERNATIONAL ANTARCTIC CO-OPERATION.

SYNCHRONOUS CHARTS OF SEALLEVEL PRESSURE FOR NOON GM.T

WITH WINDS AND AIR TEMPERATURES

1903

NOVEMBER

$24 \quad 1903$

NOVEMBER

25
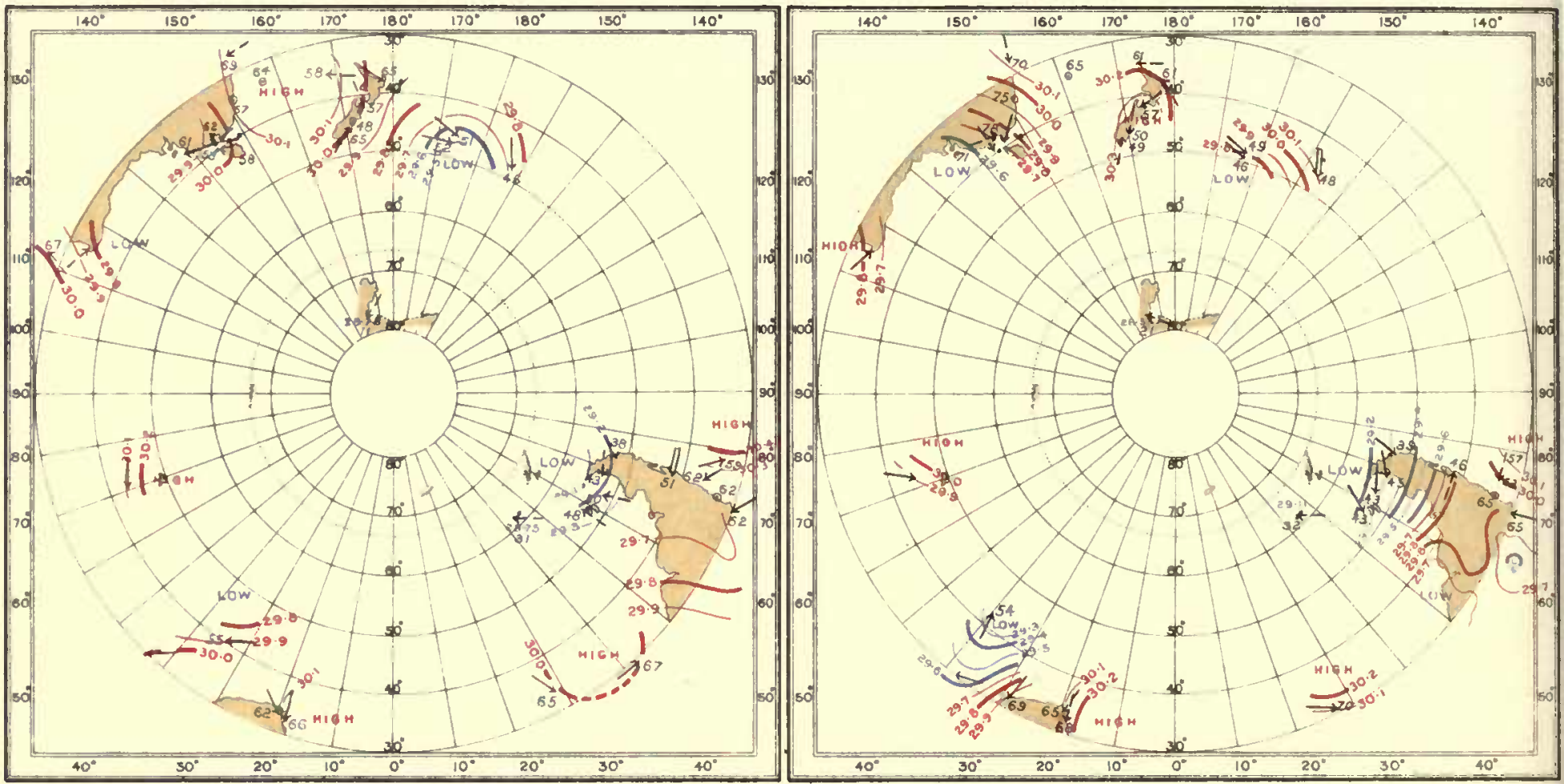

1903

NOVEMBER

$26 \quad 1903$

NOVEMBER

27
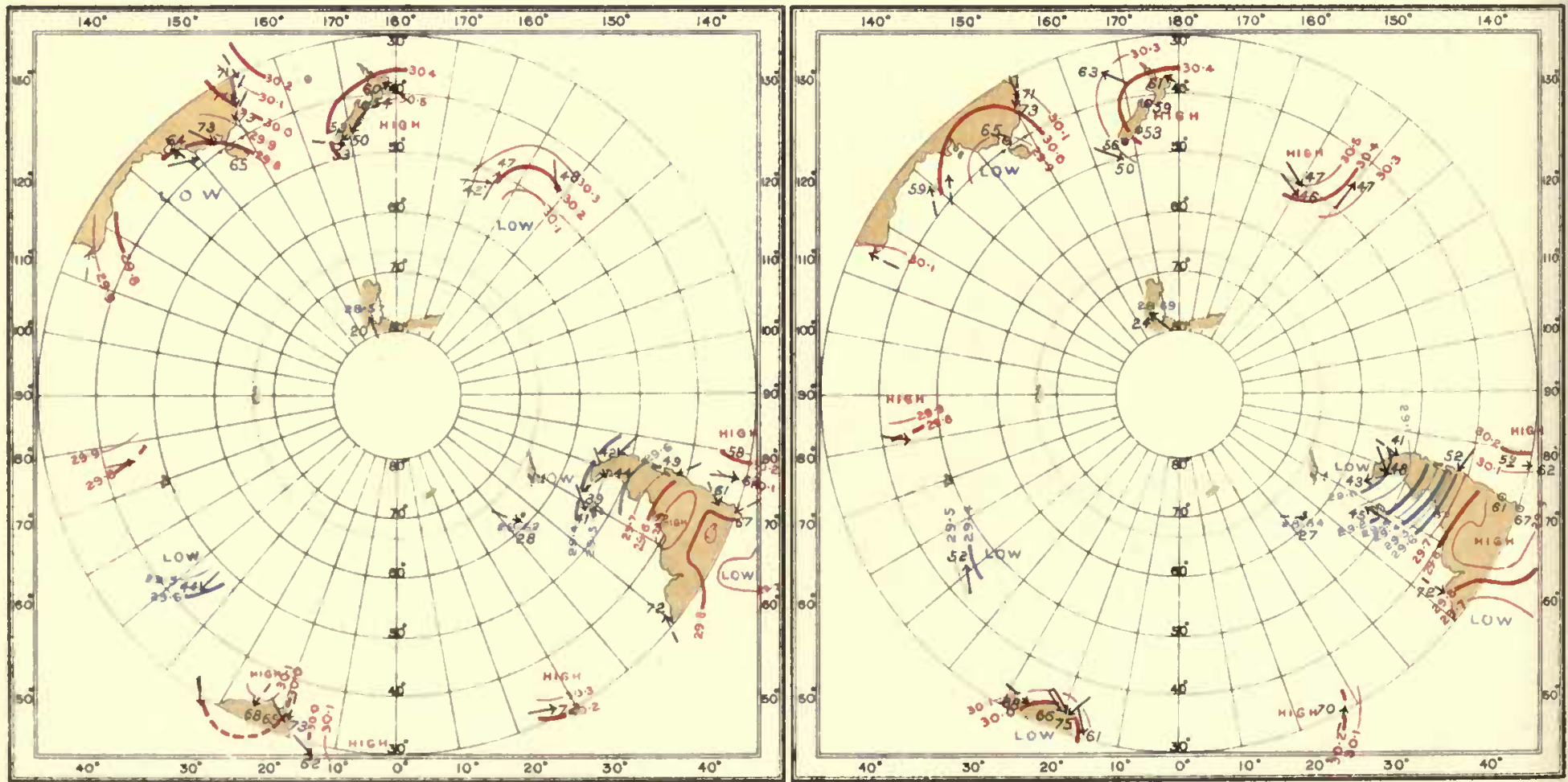
INTERNATIONAL ANTARCTIC CO-OPERATION

SYNCHRONOUS CHARTS OF SEALLVEL PRESSURE FOR NOON GM.T

WITH WINDS AND AIR TEMPERATURES
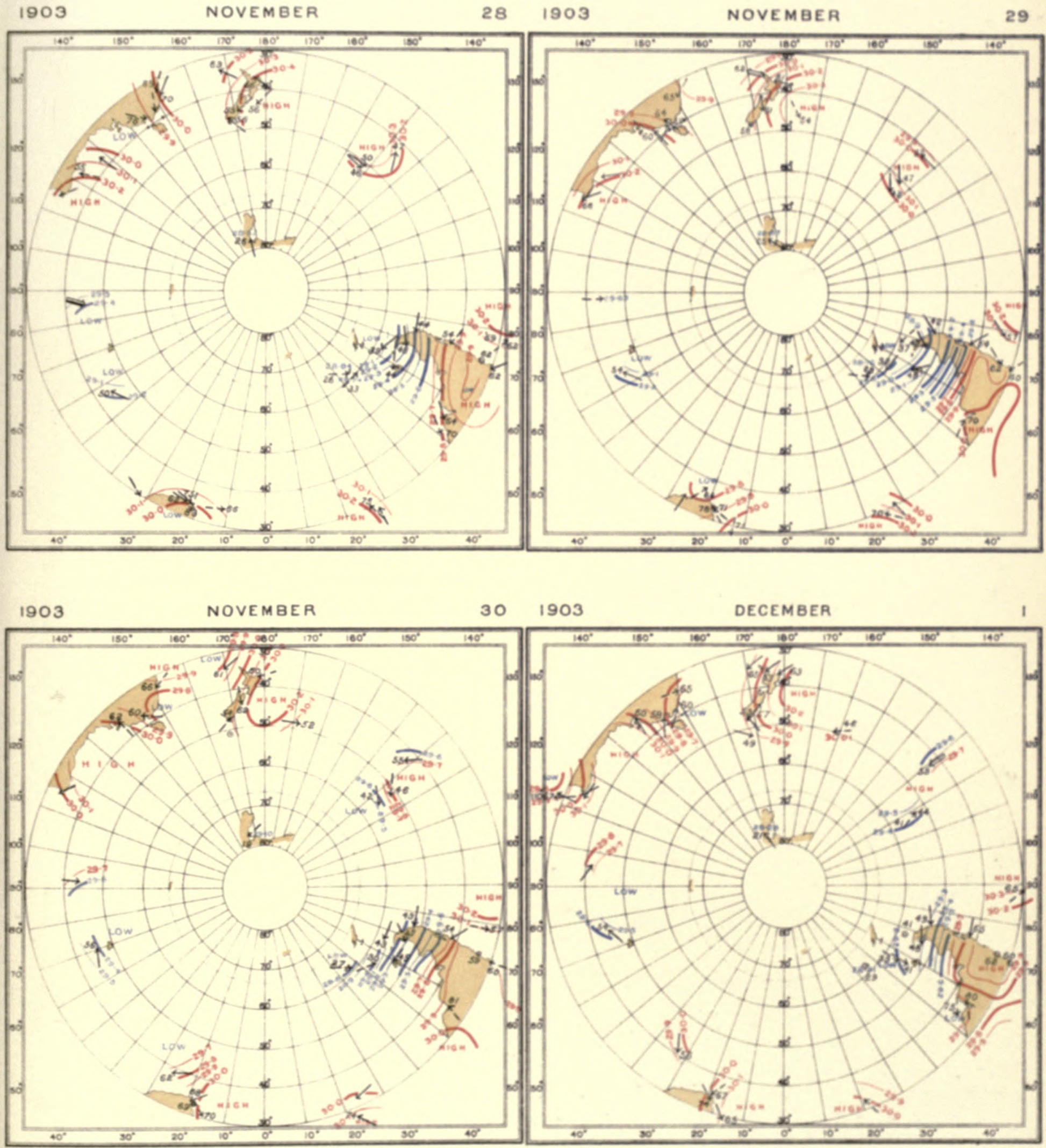
1.to

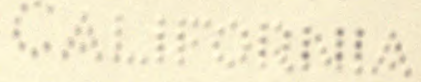



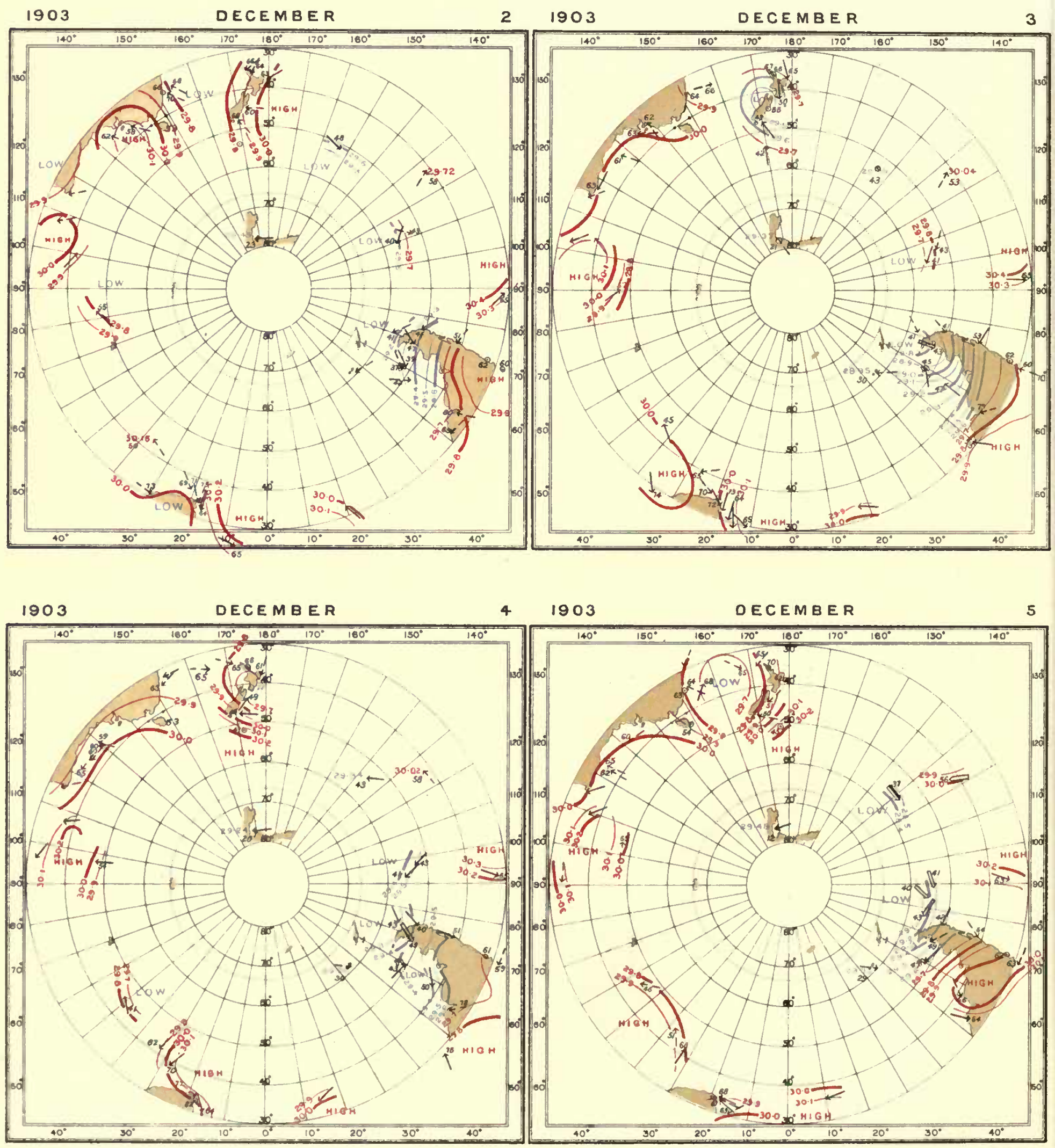
INTERNATIONAL ANTARCTIC CO-OPERATION

SYNCHRONOUS CHARTS OF SEALLEVL PRESSURE FOR NOON GMT

WITH WINDS AND AIR TEMPERATURES

1903

DECEMBER

$6 \quad 1903$

DECEM BE R

7

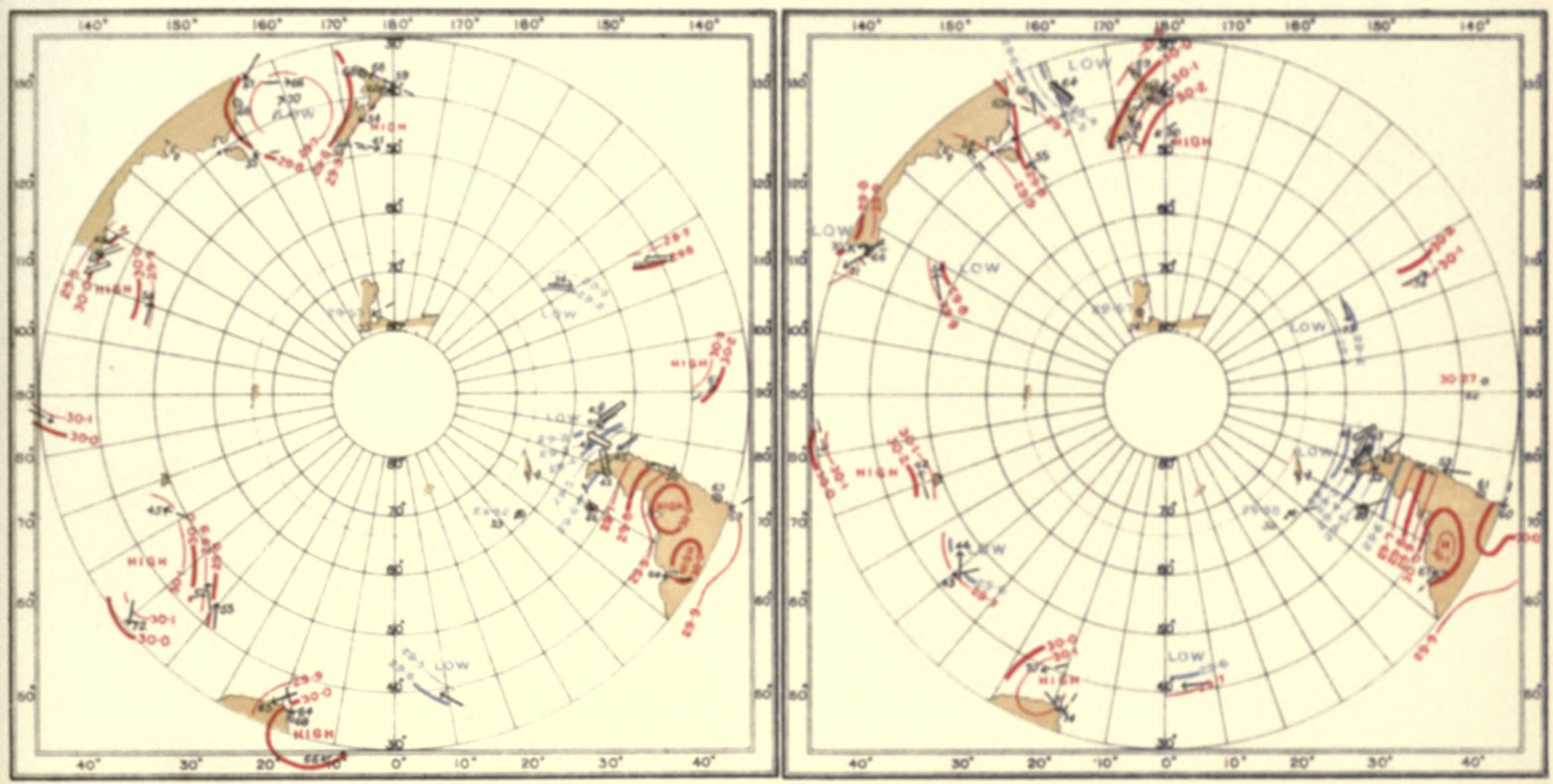

\section{3}

DECEMBER

$8 \quad 1903$

DECEMBER

9

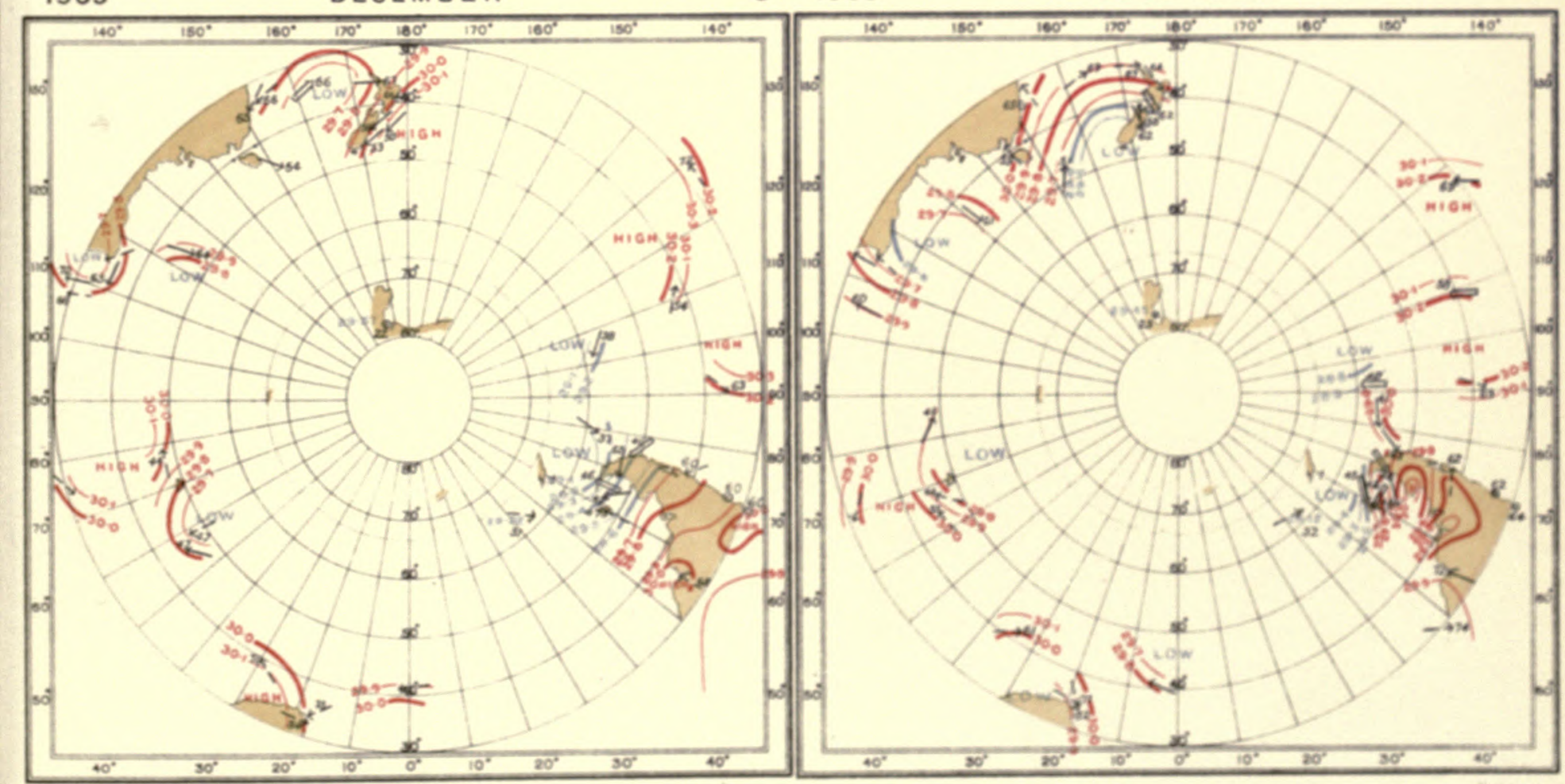


$\because \vdots \vdots=$

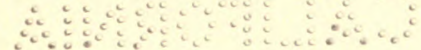


1)

A औकी 
SYNCHRONOUS CHARTS OF SEA-LEVEL PRESSURE FOR NOON GMT

WITH WINDS AND AIR TEMPERATURES

1903

DECEMBER

$10 \quad 1903$

DECEMBER
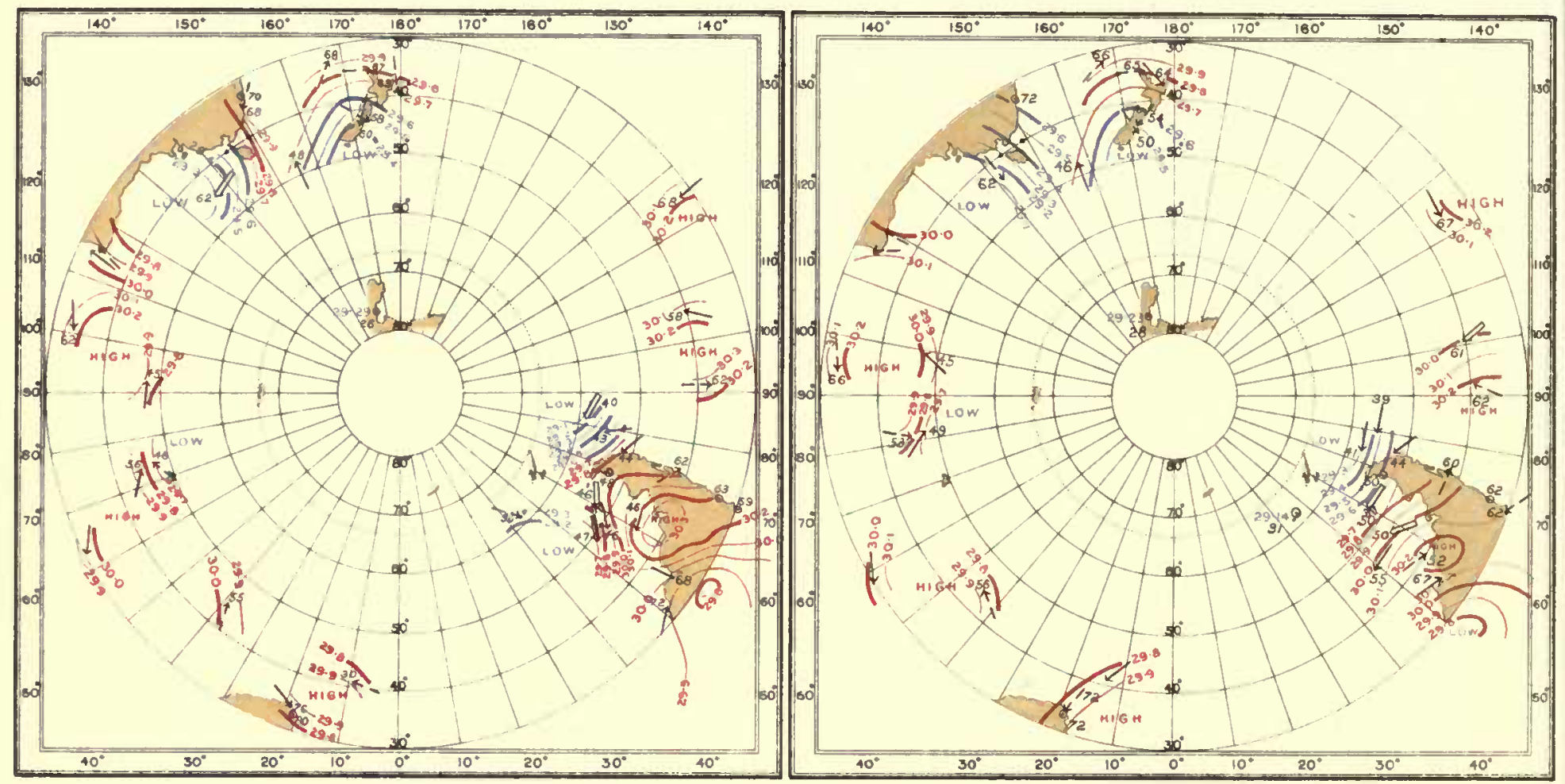

1903

DECEMBER

$12 \quad 1903$

DECEMBER

13
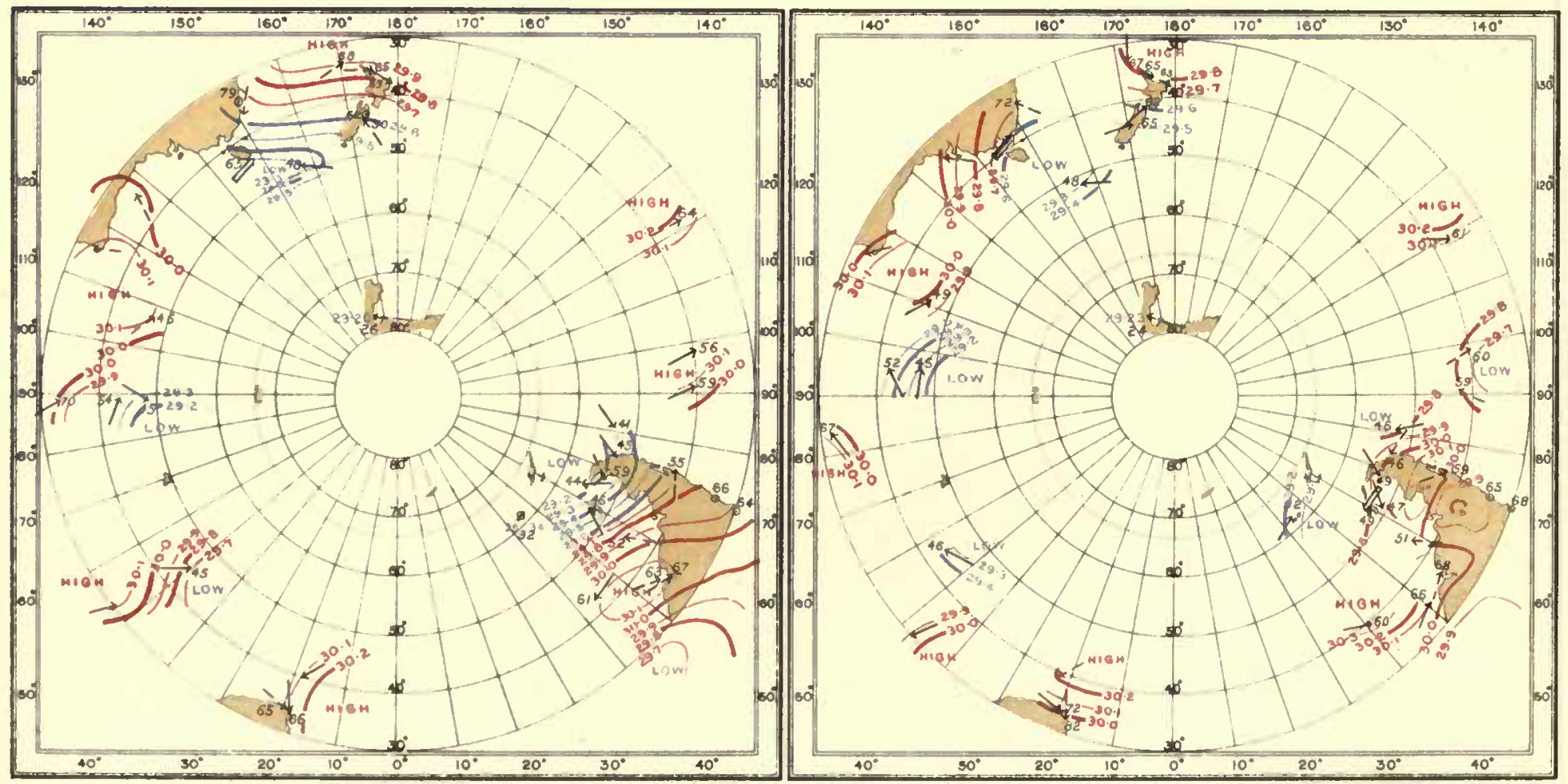

$\because \because \vdots \quad \because \because \vdots \vdots \vdots$

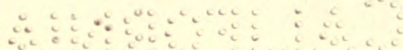




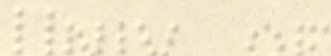

2. A $3: 3,03 \%$ 
INTERNATIONAL ANTARCTIC COOPERATION.

SYNGHRONOUS CHARTS OF SEA-LEVEL PRESSURE FOR NOON GMT.

WITH WINDS AND AIR TEMPERATURES.
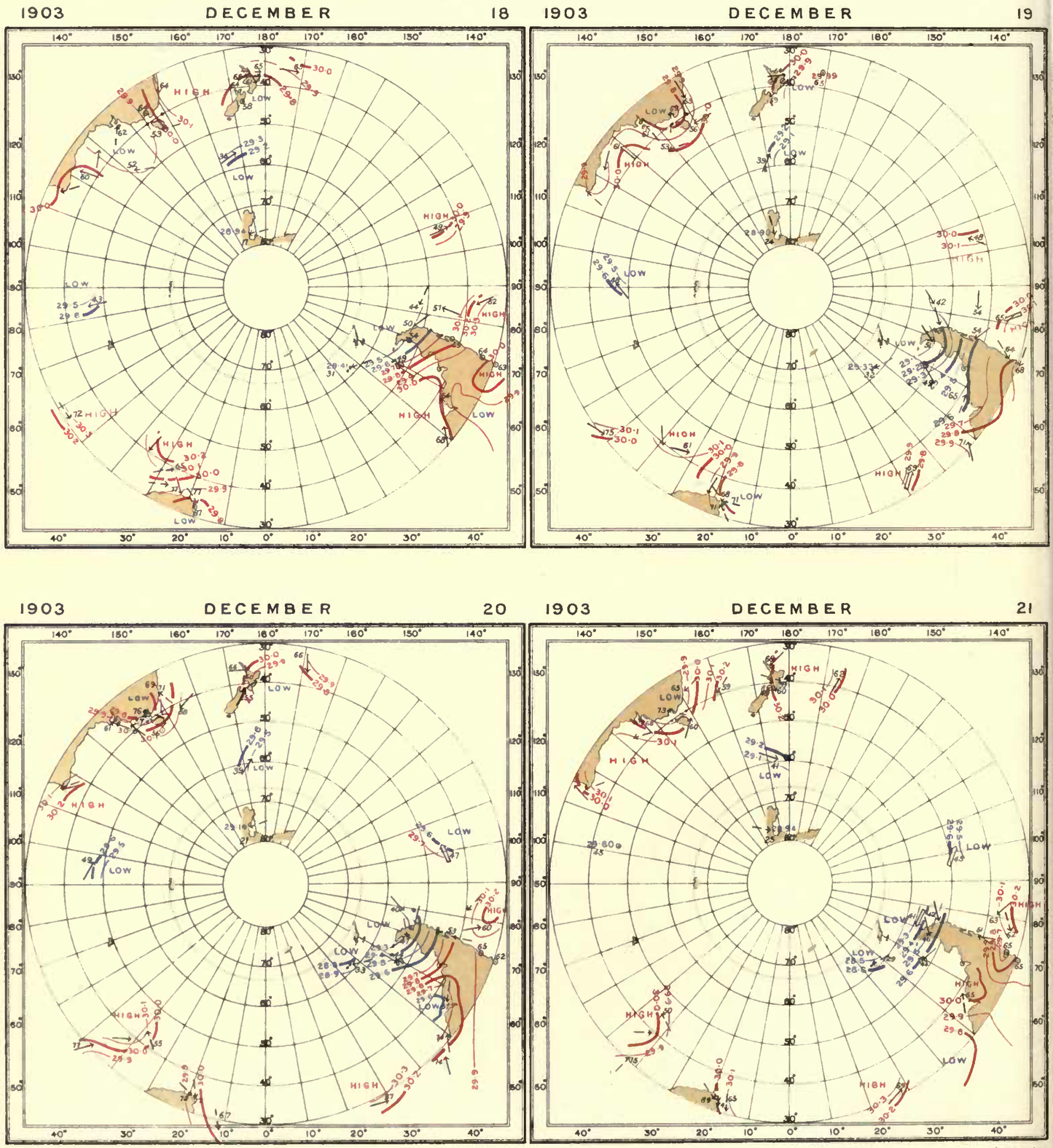


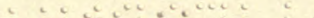

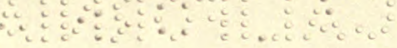


INTERNATIONAL ANTARCTIC CO-OPERATION

SYNCHRONOUS CHARTS OF SEALEVEL PRESSURE FOR NOON G.M.T

WITH WINDS AND AIR TEMPERATURES.

1903 DECEMBER

$26 \quad 1903$

DECEMBER
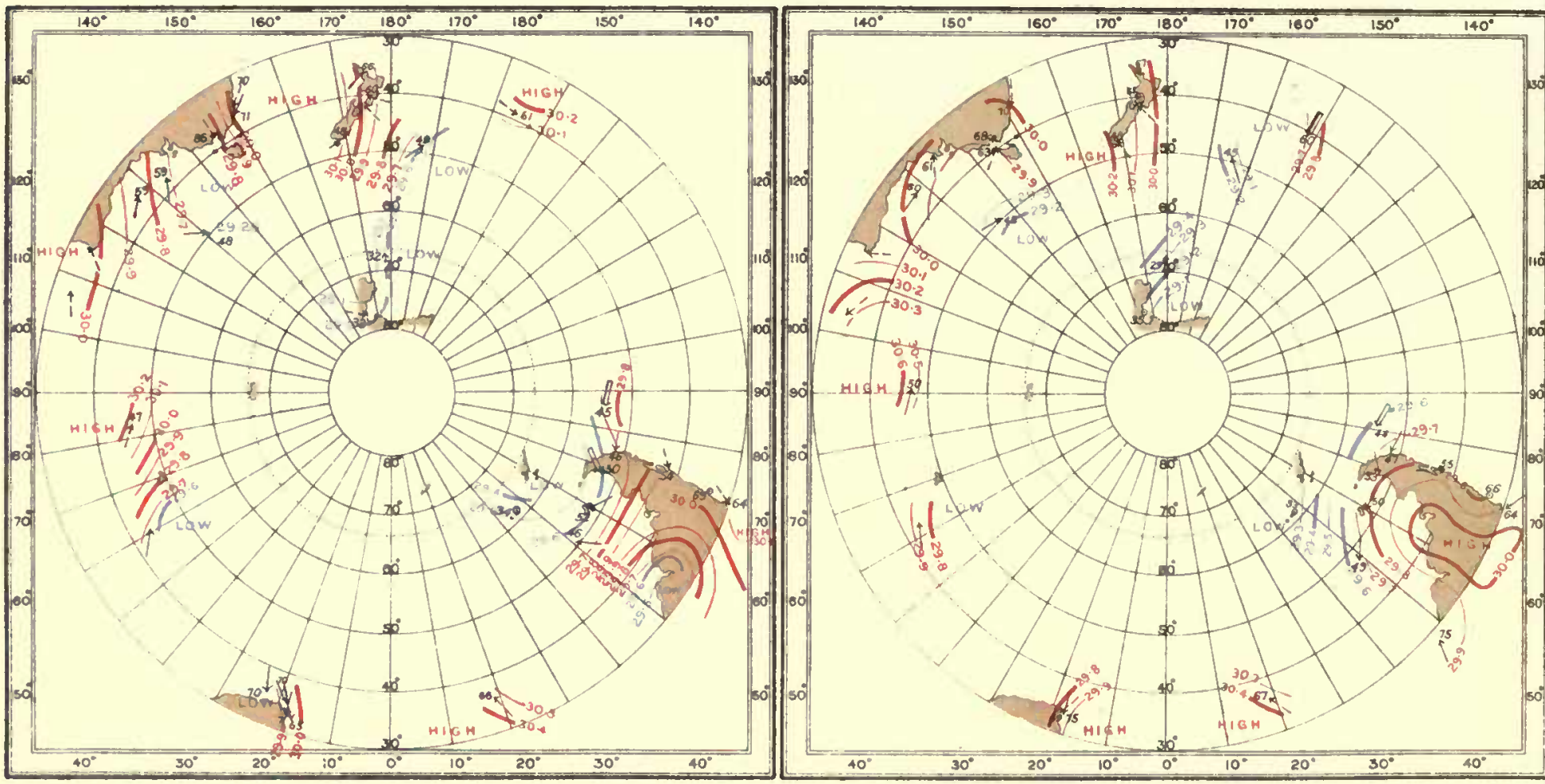

1903

DECEMBER

$28 \quad 1903$

DECEMBER

29

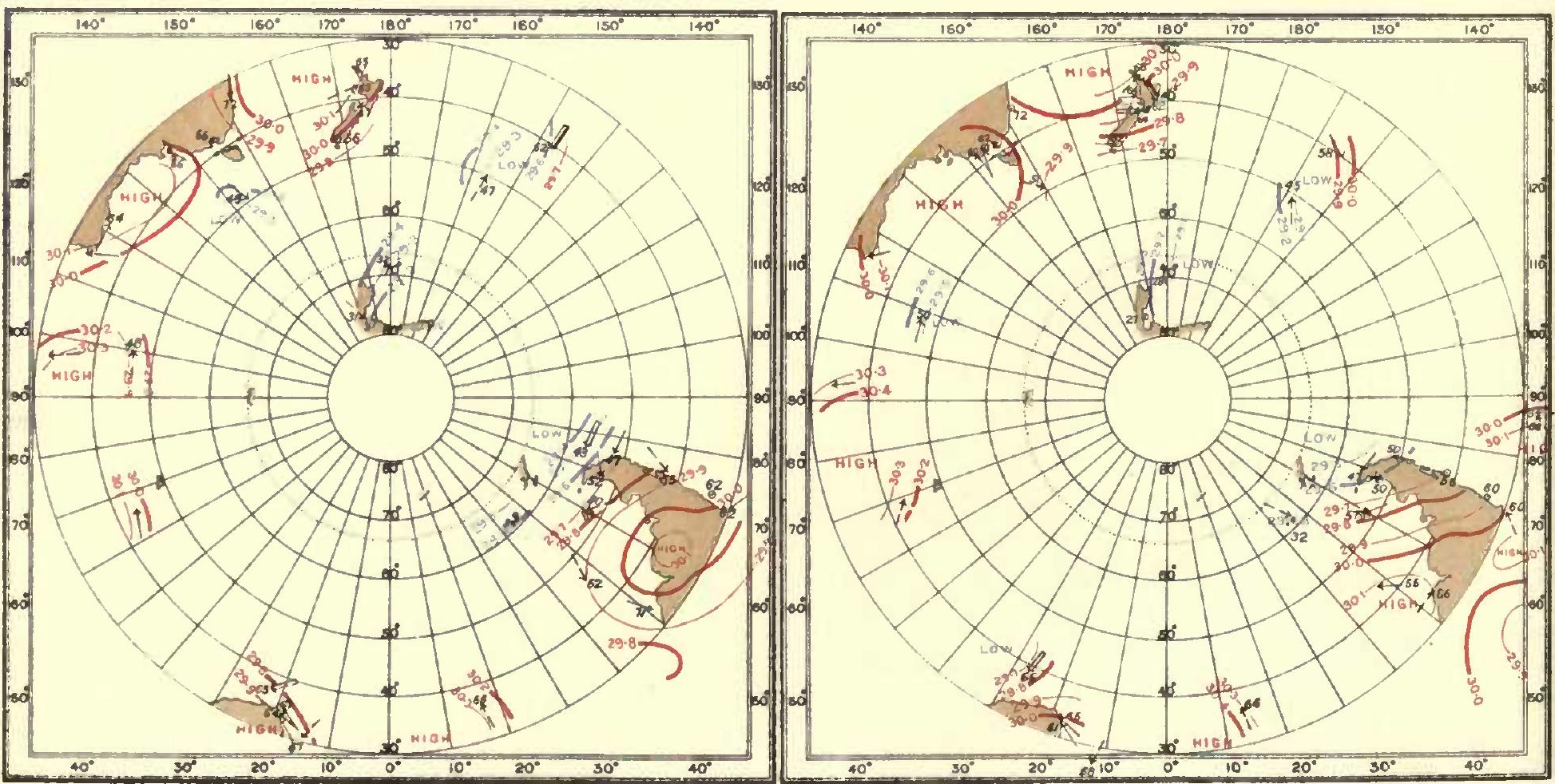


$\because \vdots \vdots \quad \because \vdots \vdots \vdots \vdots \vdots \vdots \vdots \vdots \vdots \vdots 0$

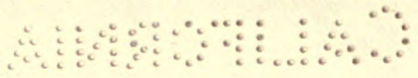


!)

and 
INTERNATIONAL ANTARCTIC CO-OPERATION.

SYNCHRONOUS CHARTS OF SEA-LEVEL PRESSURE FOR NOON G.M.T WITH WINDS AND AIR TEMPERATURES
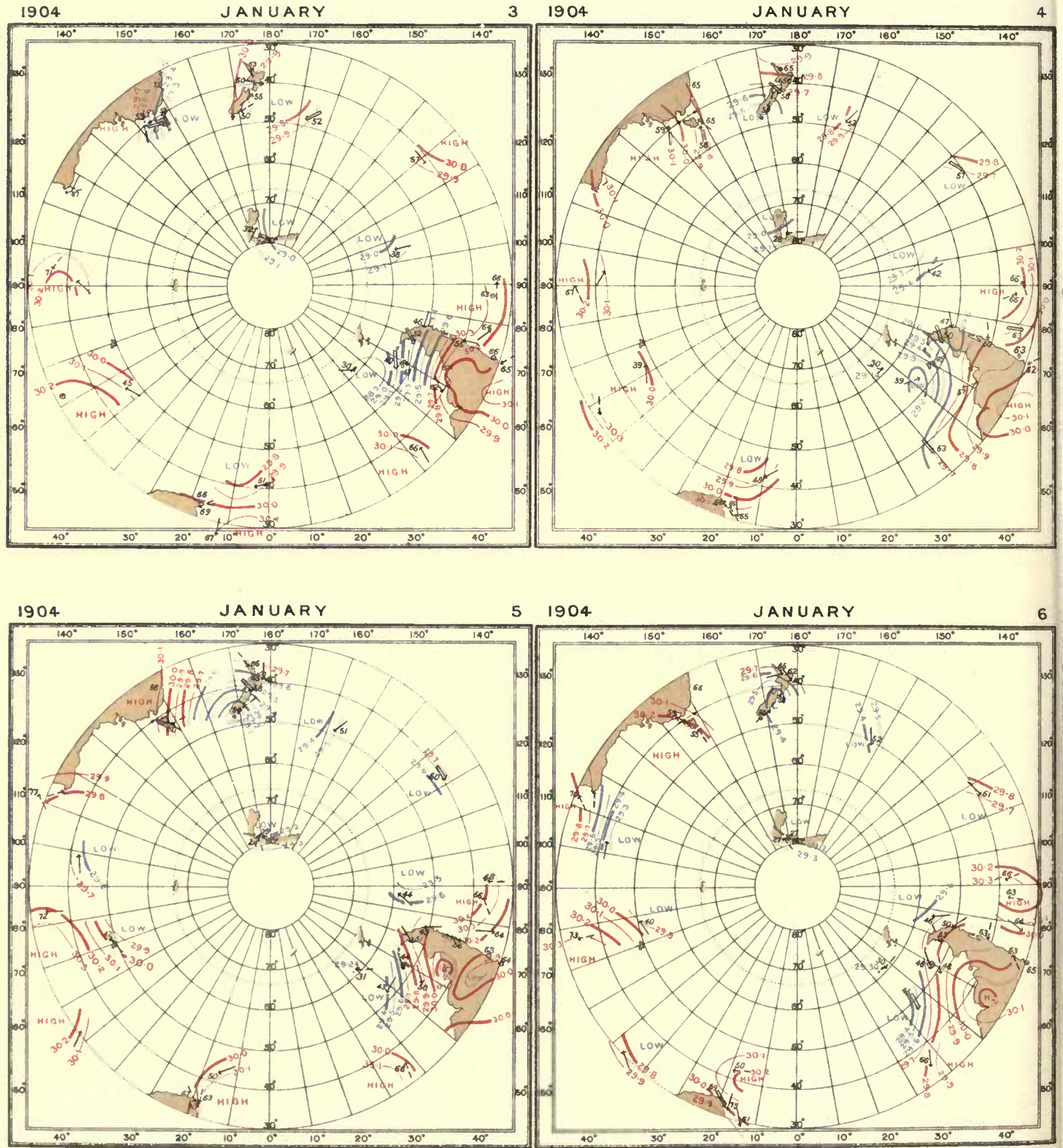


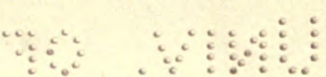

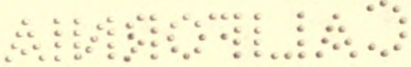



INTERNATIONAL ANTARCTIC COOPERATION.

SYNCHRONOUS CHARTS OF SEA-LEVEL PRESSURE FOR NOON G.M.T

WITH WINDS AND AIR TEMPERATURES.

1904 JANUARY

$11 \quad 1904$

JANUARY

12
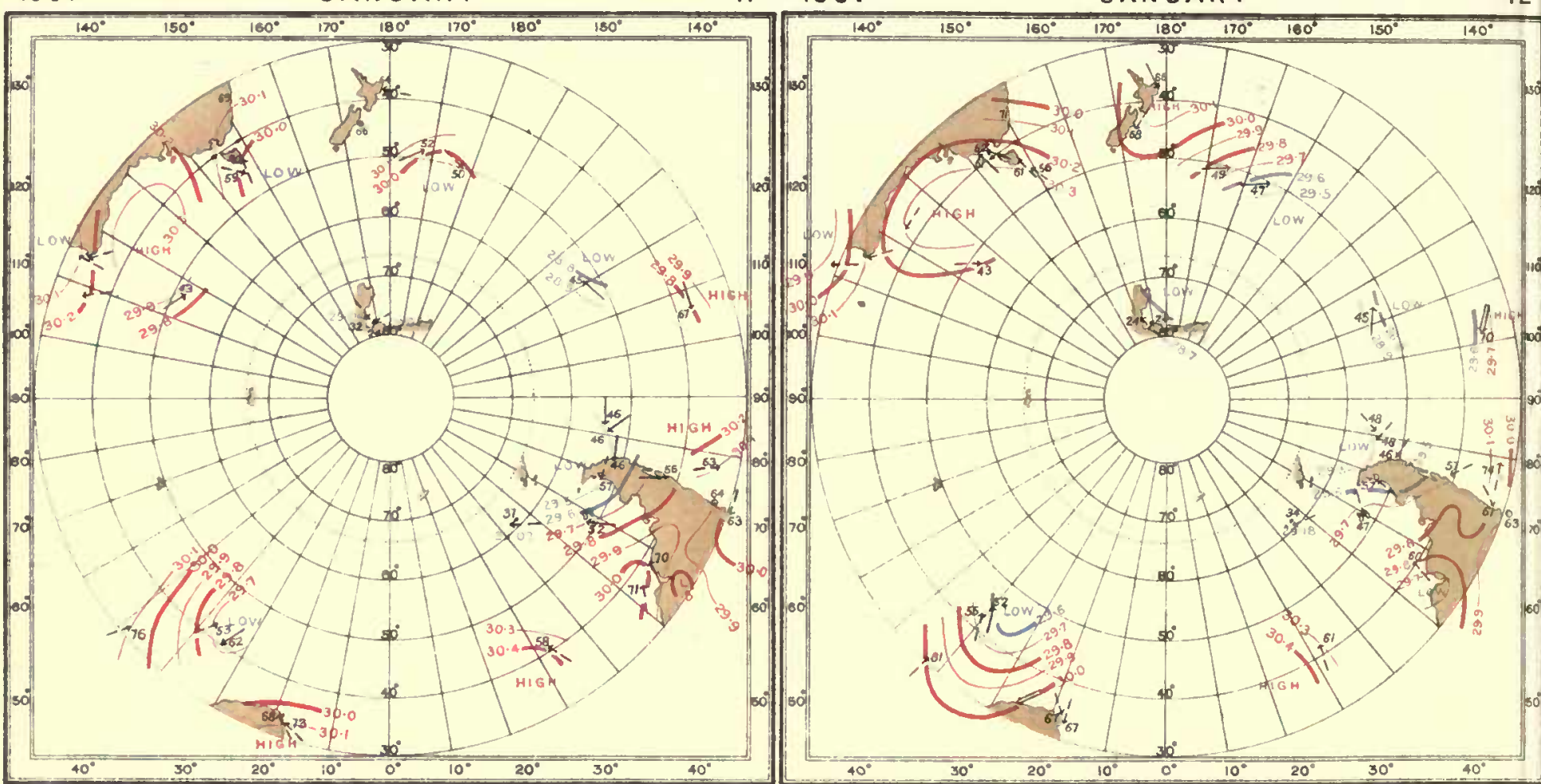

1904

JAN UARY

$13 \quad 1904$

JANUARY

14
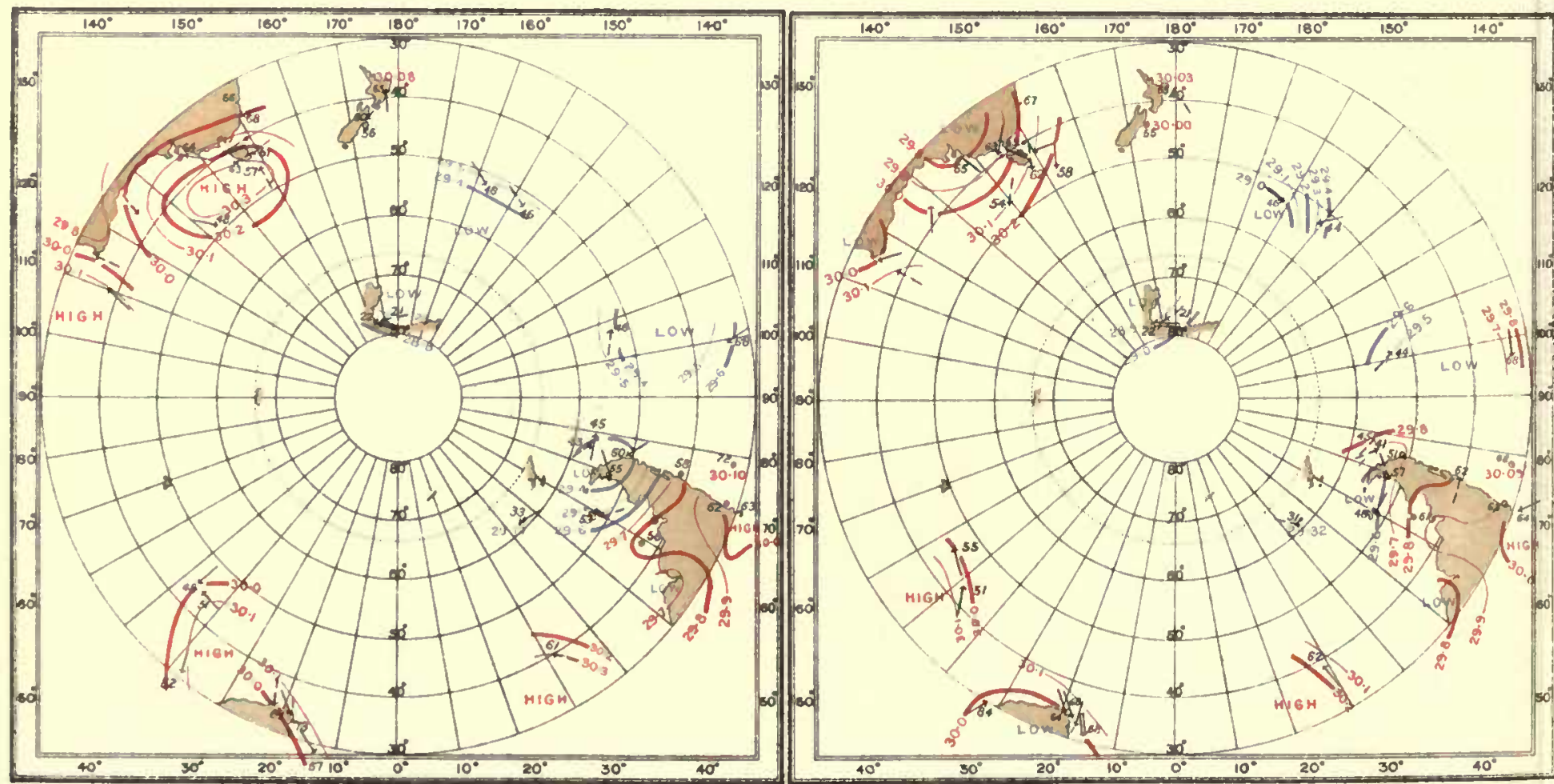
INTERNATIONAL ANTARCTIC COOPERATION.

SYNCHRONOUS CHARTS OF SEA-LEVEL PRESSURE FOR NOONGMT

WITH WINDS AND AIA TEMPERATURES

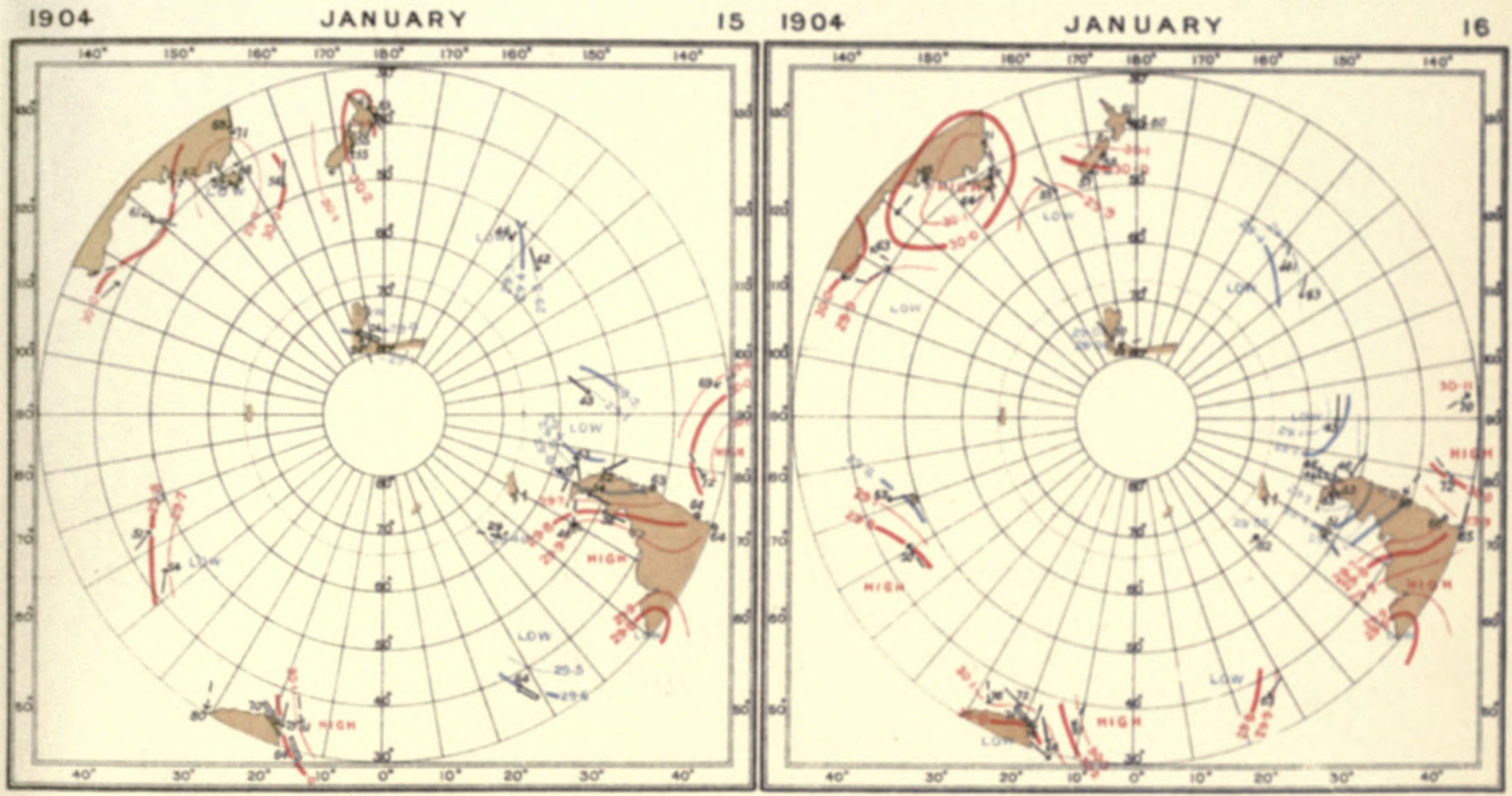

$1904 \quad$ JANUARY

$17 \quad 1904$

J AN UARY

18
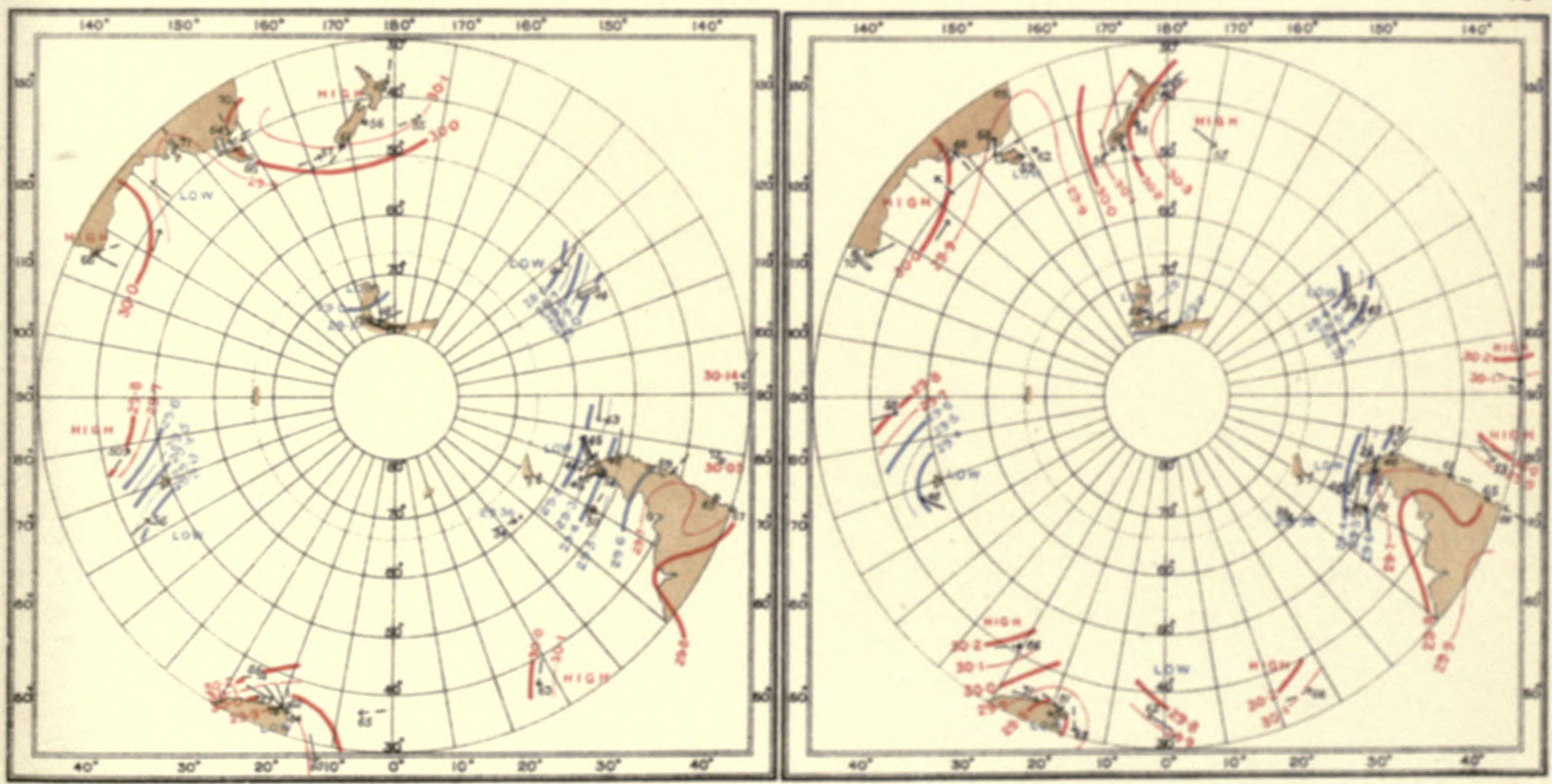
$\therefore \vdots \vdots \because \because \because \because \because \vdots \vdots \vdots \therefore$ 
3.

tat 
INTERNATIONAL ANTARCTIC CO-OPERATION.

SYNCHRONOUS CMARTS OF SEALEVEL PRESSURE FOR NOON G.M.T.

WITH WINDS AND AIR TEMPERATURES
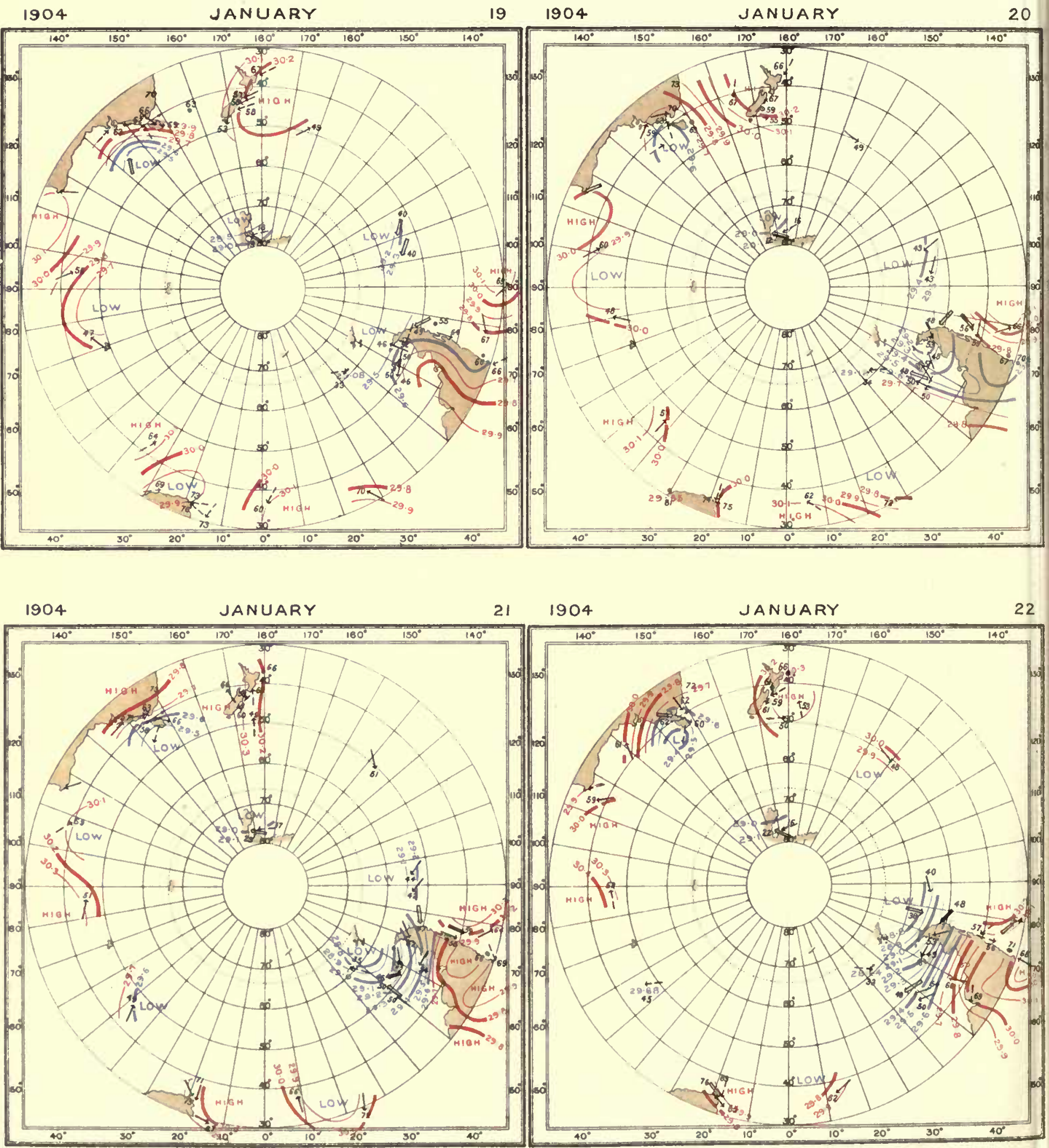
JANUARY $23 \quad 1904$ JANUARY
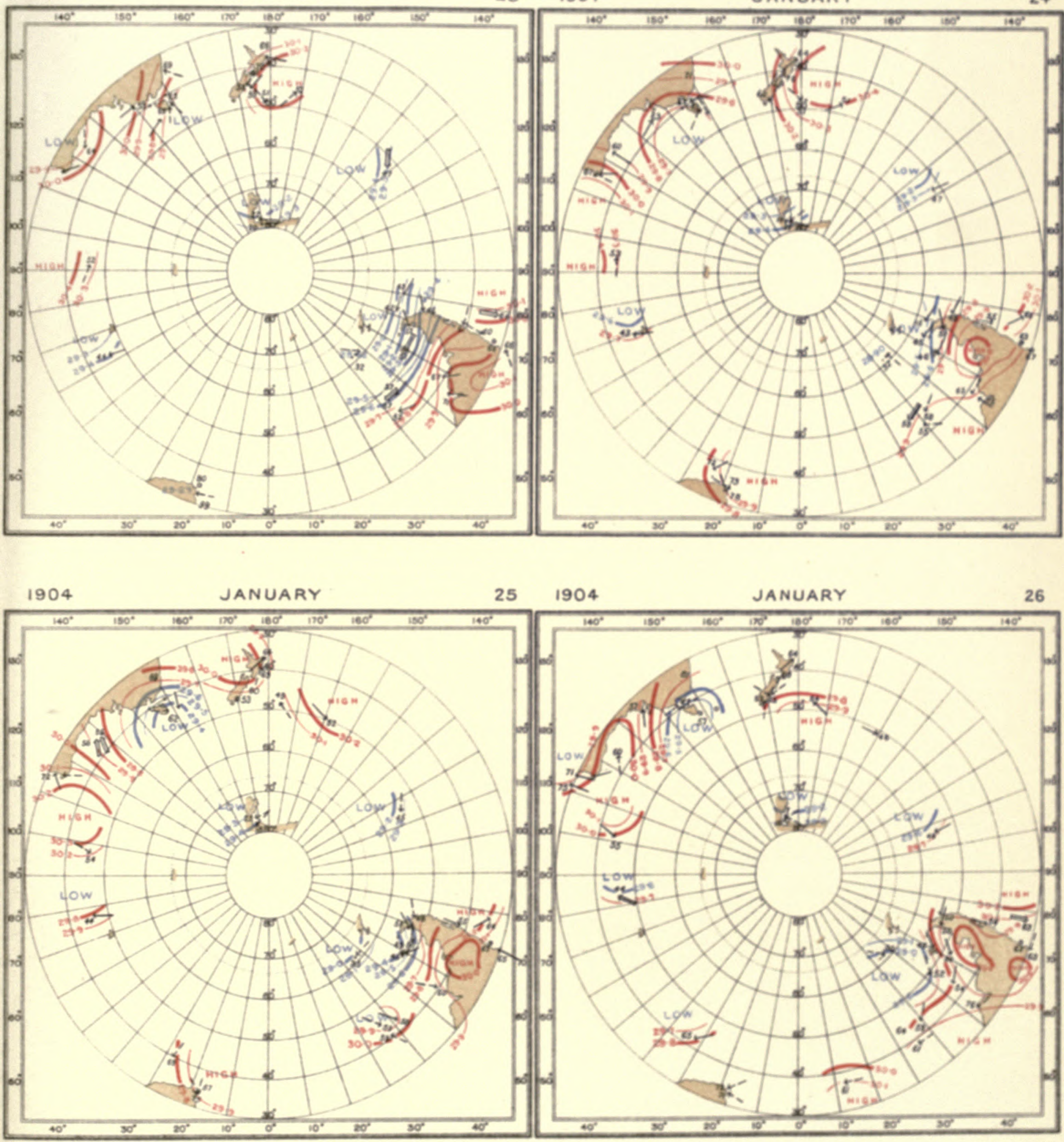
和

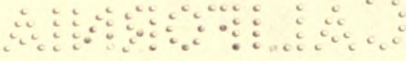


!

a B का 
INTERNATIONAL ANTARCTIC CO-OPERATION

SYNCHRONOUS CHARTS OF SEA-LEVEL PRESSURE FOR NOON G.M.T

WITH WINDS AND AIR TEMPERATURES.
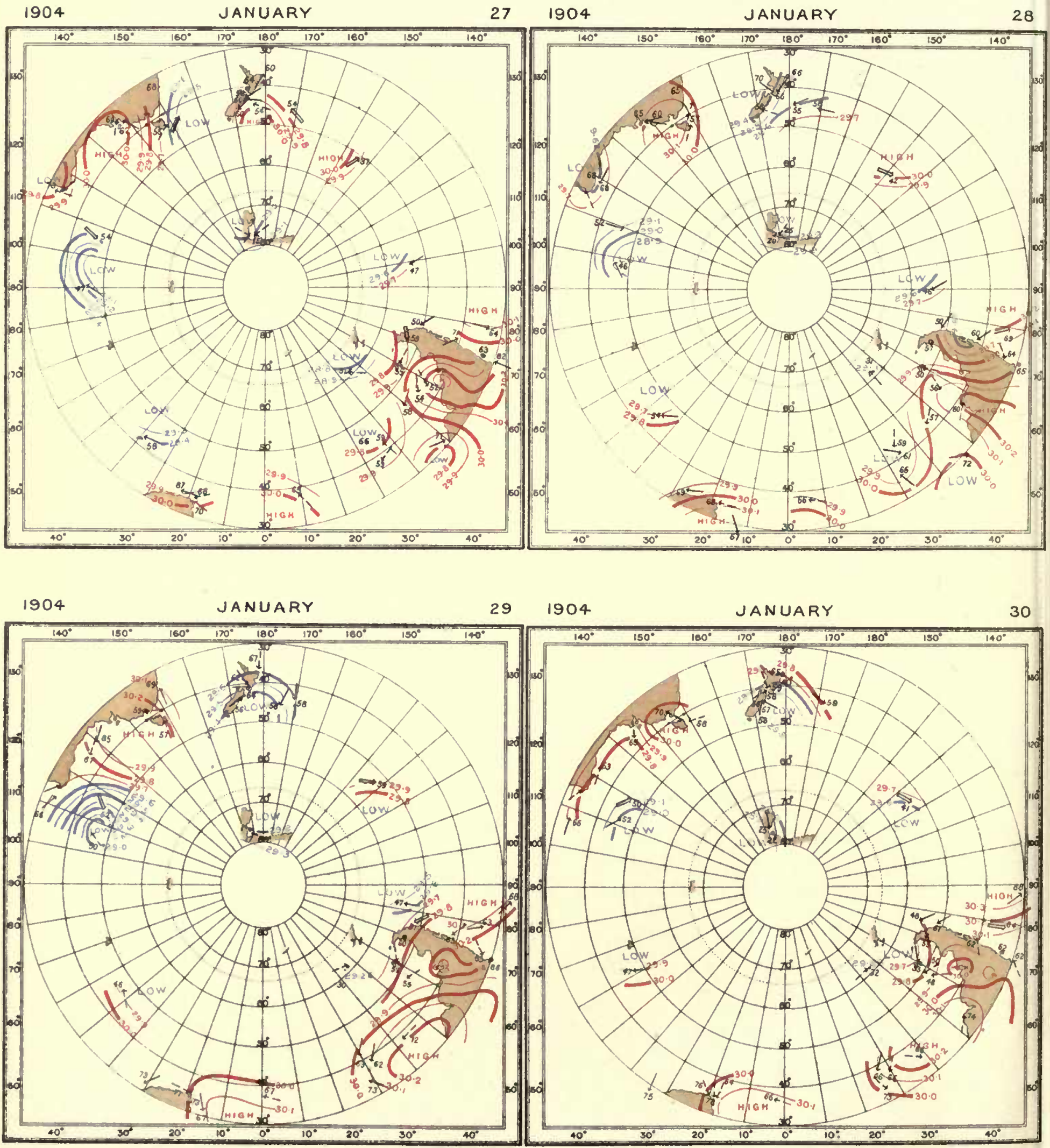
INTERNATIONAL ANTARCTIC COOPERATION.

SYNCHRONOUS CHARTS OF SEA-LEVEL PRESSURE FOR NOON GMT

WITH WINDS AND AIR TEMPERATURES

1904

JANUARY

$31-1904$

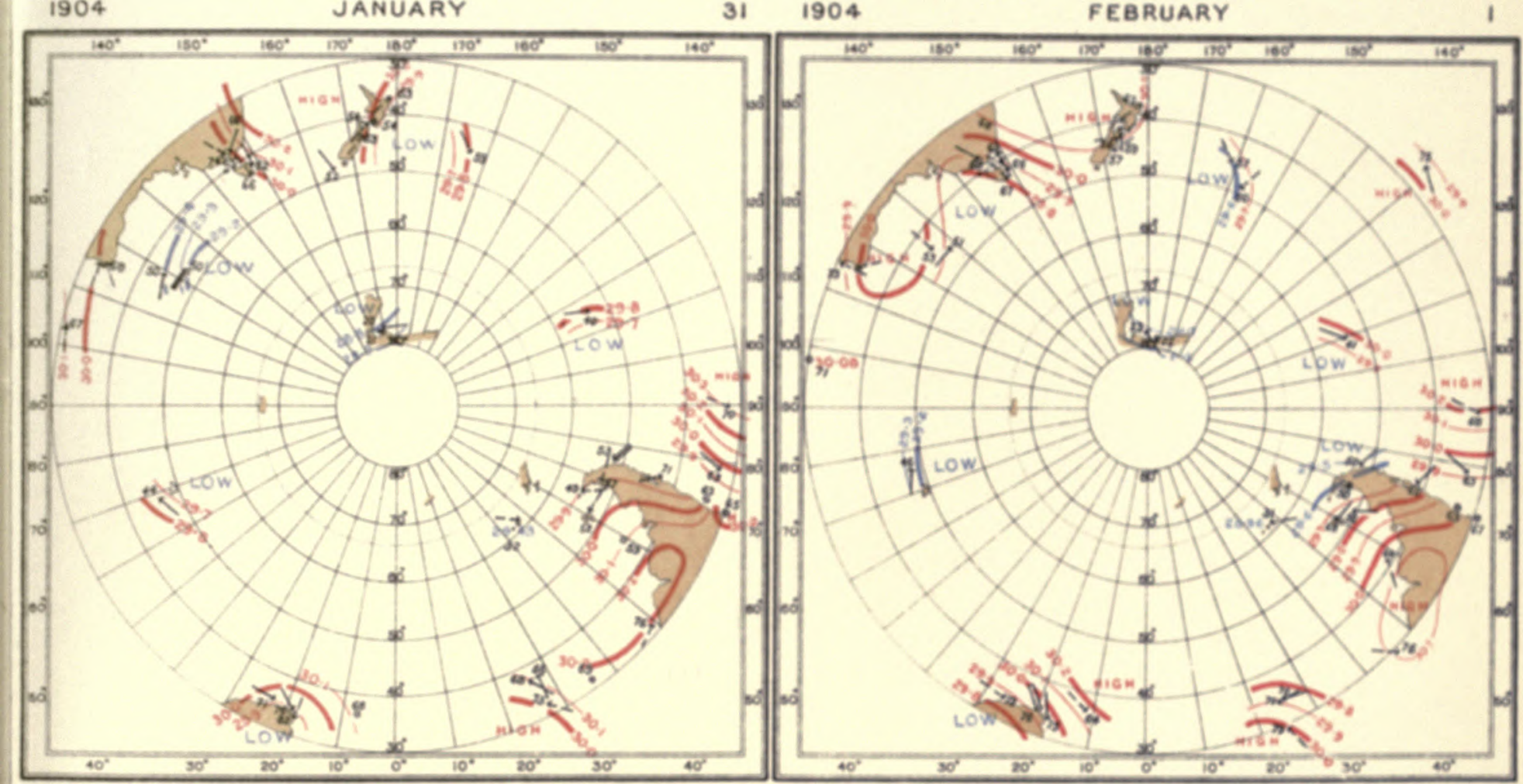

1904 FEBRUARY

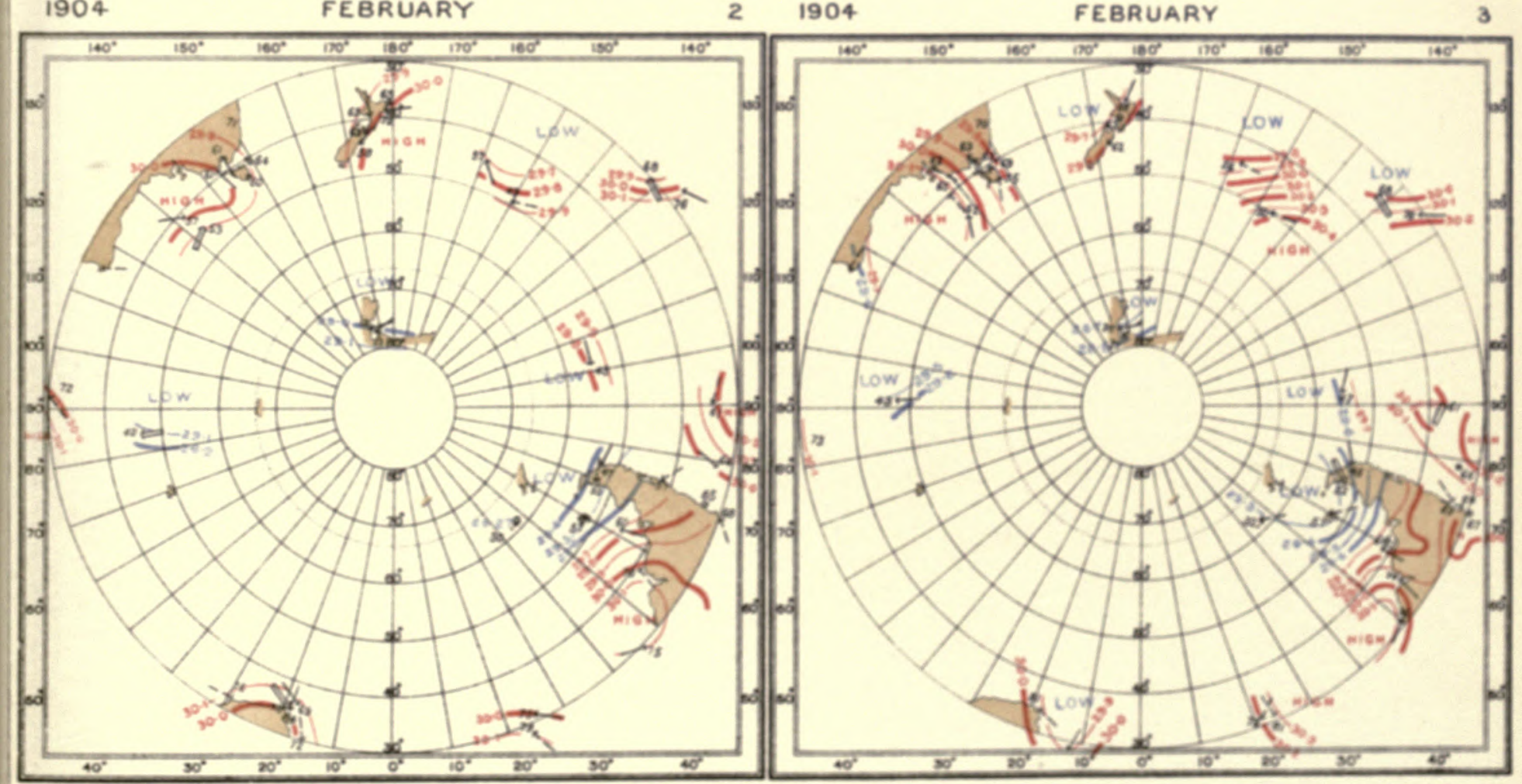


$\because \because \quad \because \vdots \vdots \vdots 00$

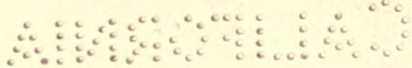



INTERNATIONAL ANTARCTIC CO-OPERATION.

SYNGHRONOUS CMARTS OF SEA-LEVEL PRESSURE FOR NOON G.M.T.

WITH WINDS AND AIR TEMPERATURES

1904

FEBRUARY

$4 \quad 1904$

FEBRUARY

5
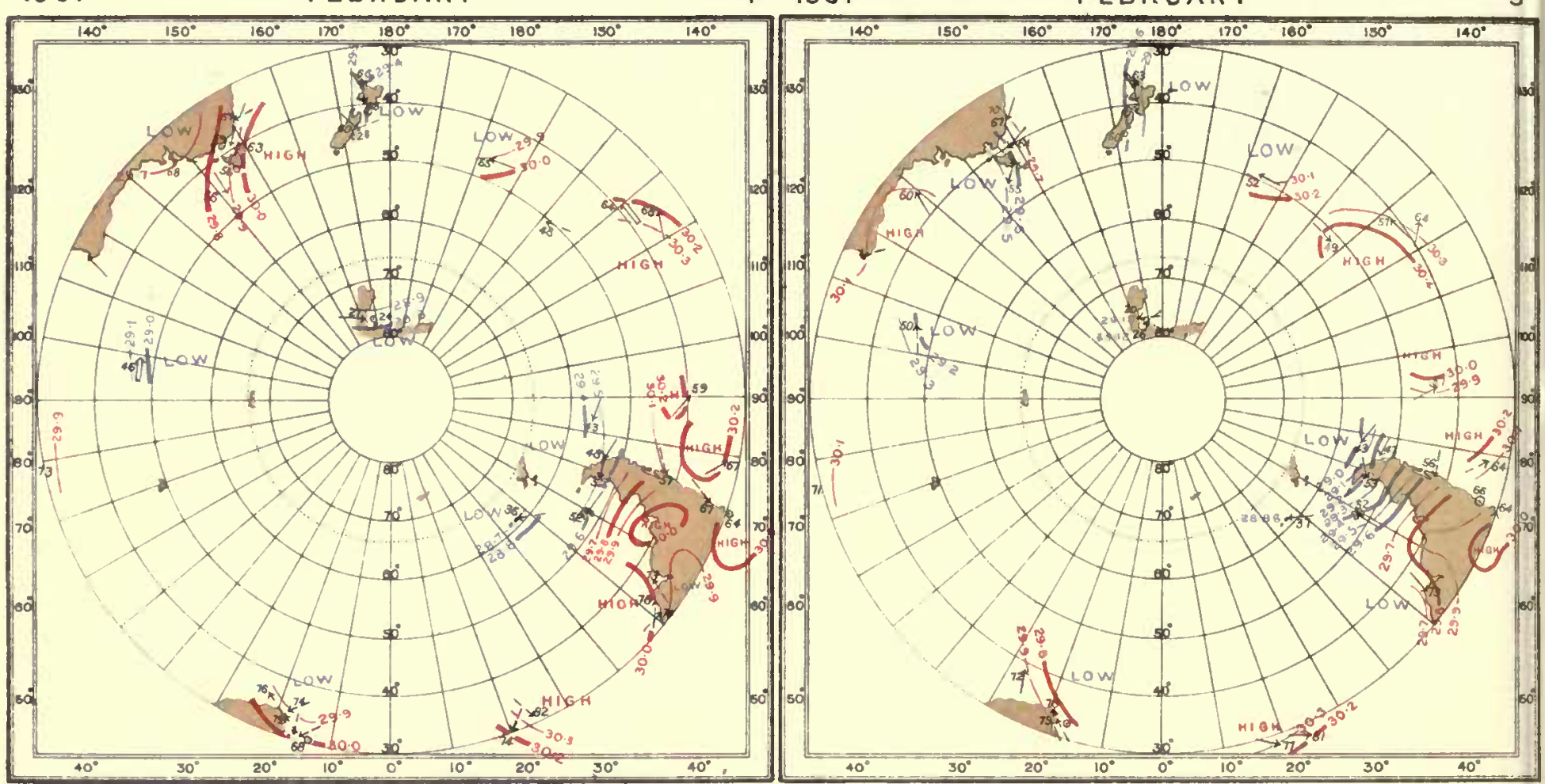

1904

FEBRUARY

$6 \quad 1904$

FEBRUARY

7

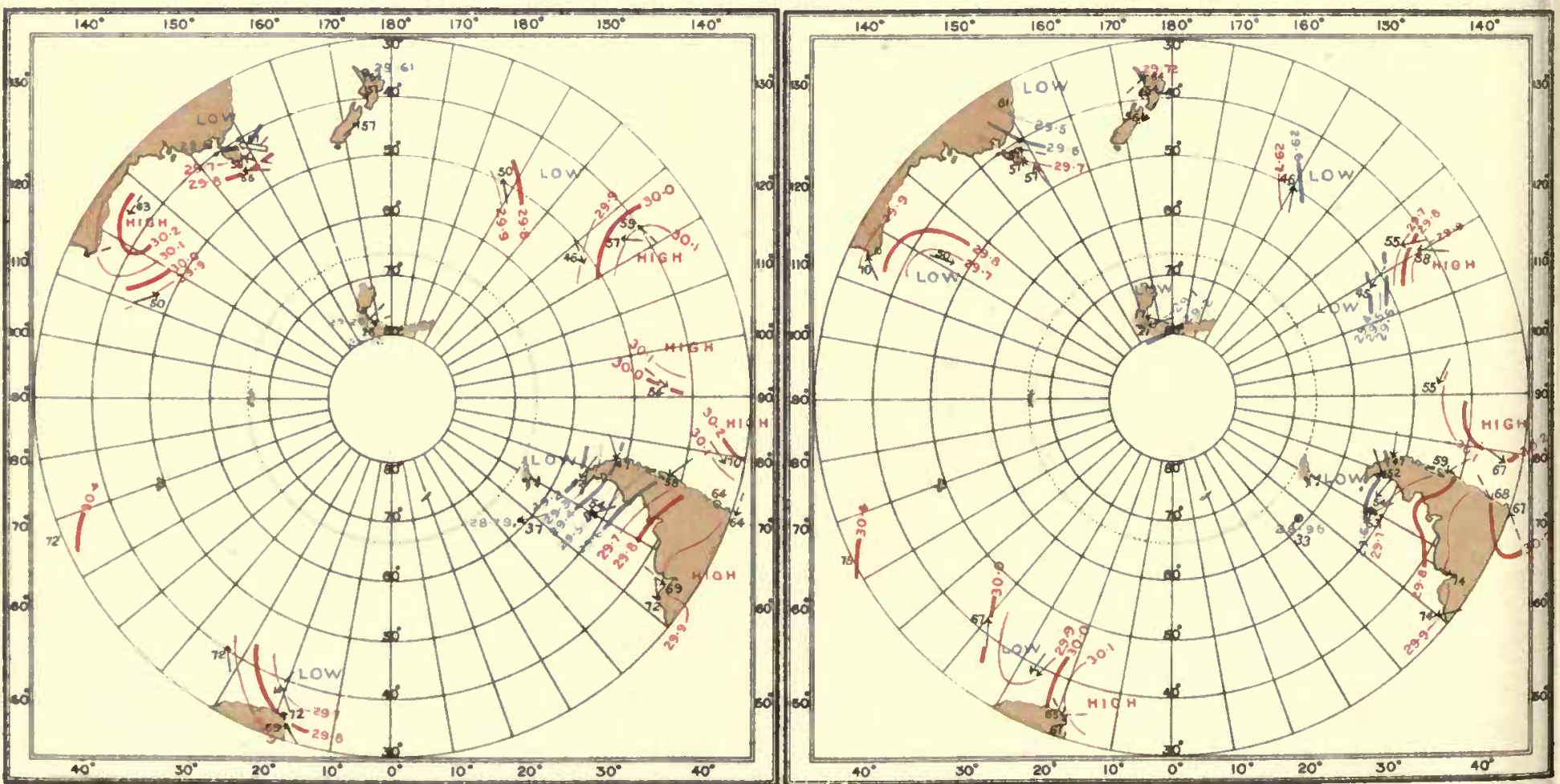


INTERNATIONAL ANTARCTIC CO-OPERATION.

SYNCHRONOUS CHARTS OF SEA-LEVEL PRESSURE FOR NOON G.M.T.

WITH WINDS AND AIR TEMPERATURES.

1904

FEBRUARY

$8 \quad 1904$

FEBRUARY

9
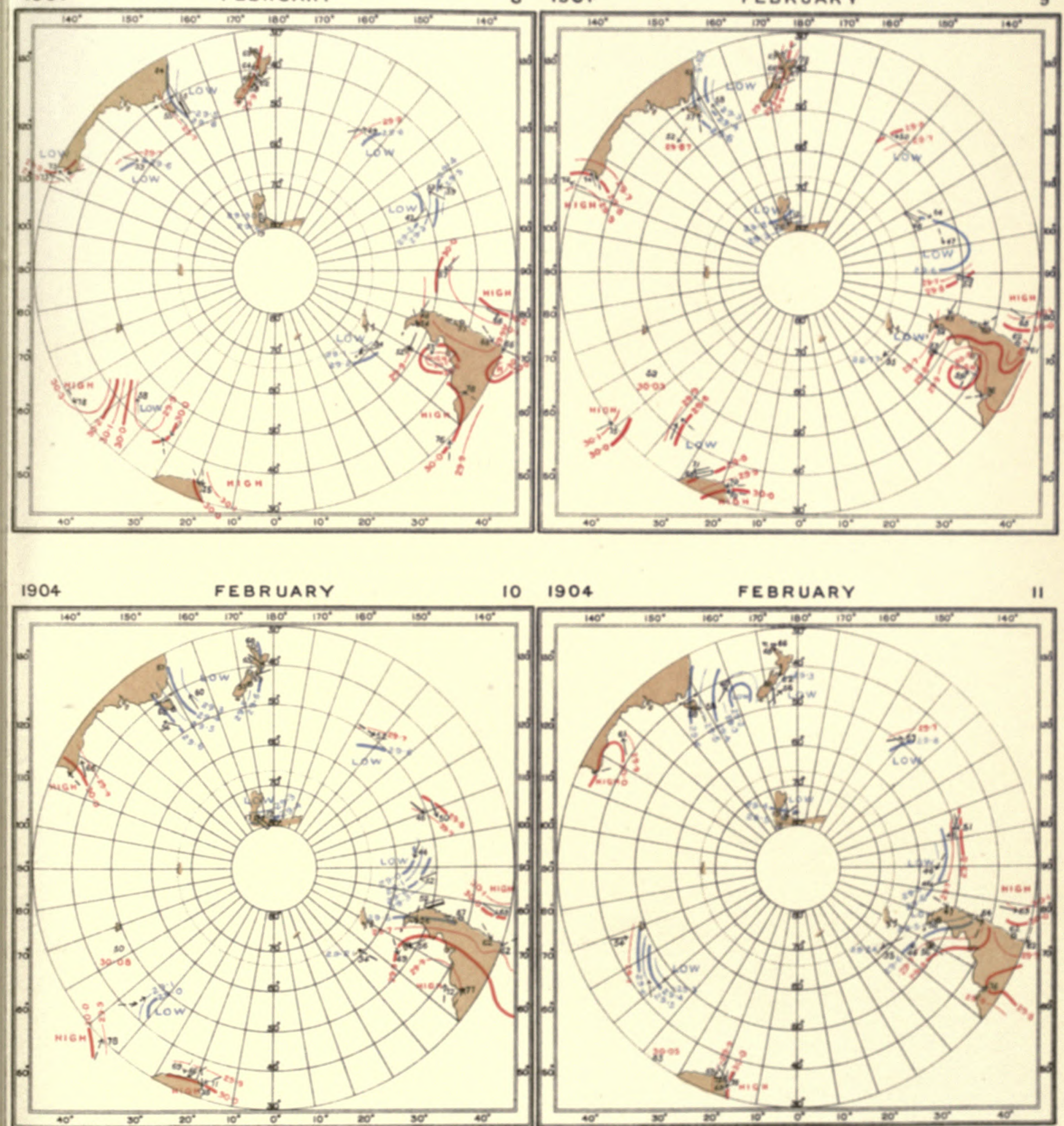

Heth Lotsos 
..

CA S... 
INTERNATIONAL ANTARCTIC CO-OPERATION.

SYNCHRONOUS CHARTS OF SEALEVEL PRESSURE FOR NOON G.M.T

WITH WINDS AND AIR TEMPERATURES.

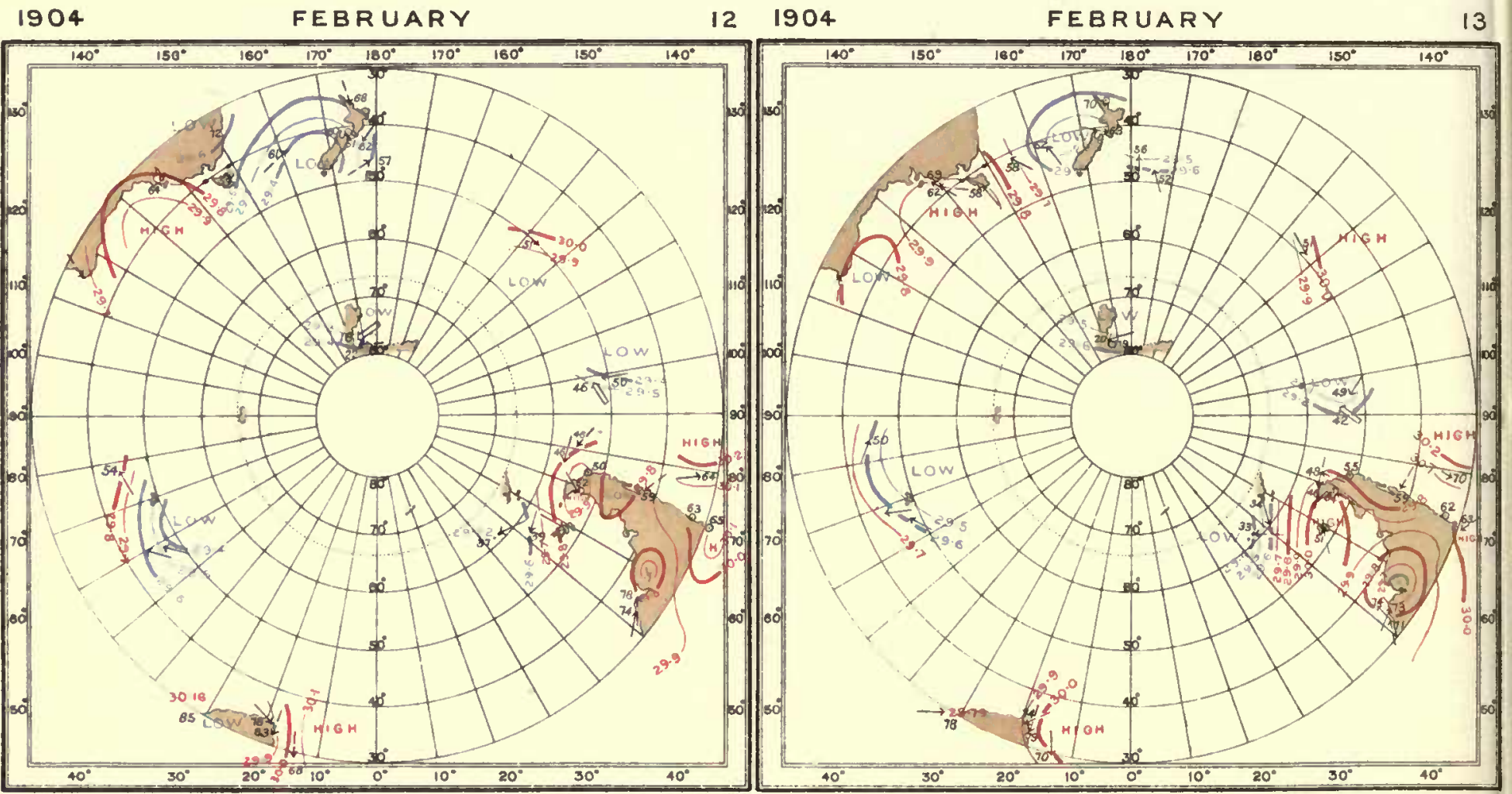

1904 FEBRUARY

$14 \quad 1904 \quad$ FEBRUARY

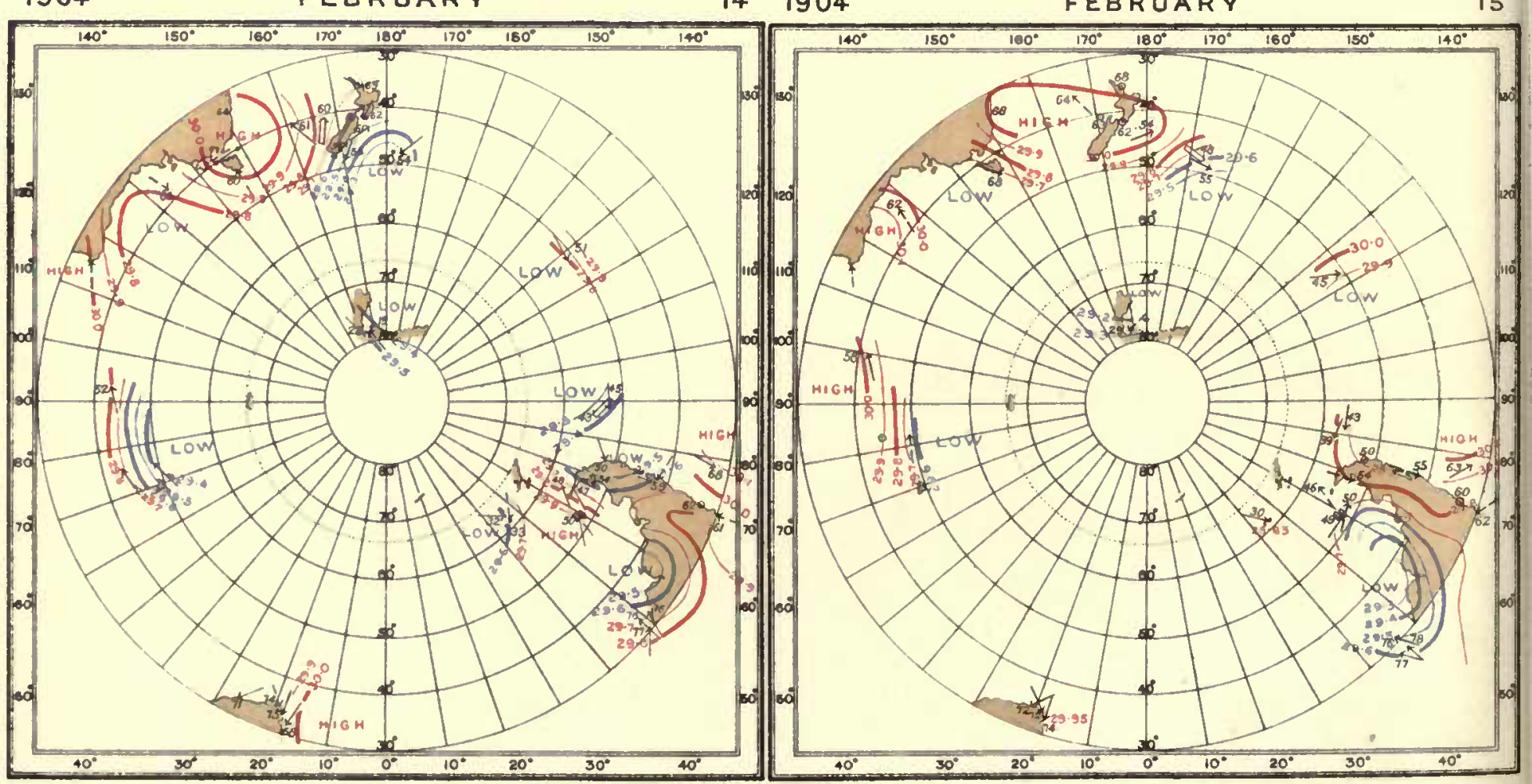


INTERNATIONAL ANTARCTIC CO-OPERATION.

SYNCHRONOUS CHARTS OF SEA-LEVEL PRESSURE FOR NOON GM.T.

WITH WINDS AND AIR TEMPERATURES

1904

FEBRUARY

$16 \quad 1904$

FEBRUARY

17

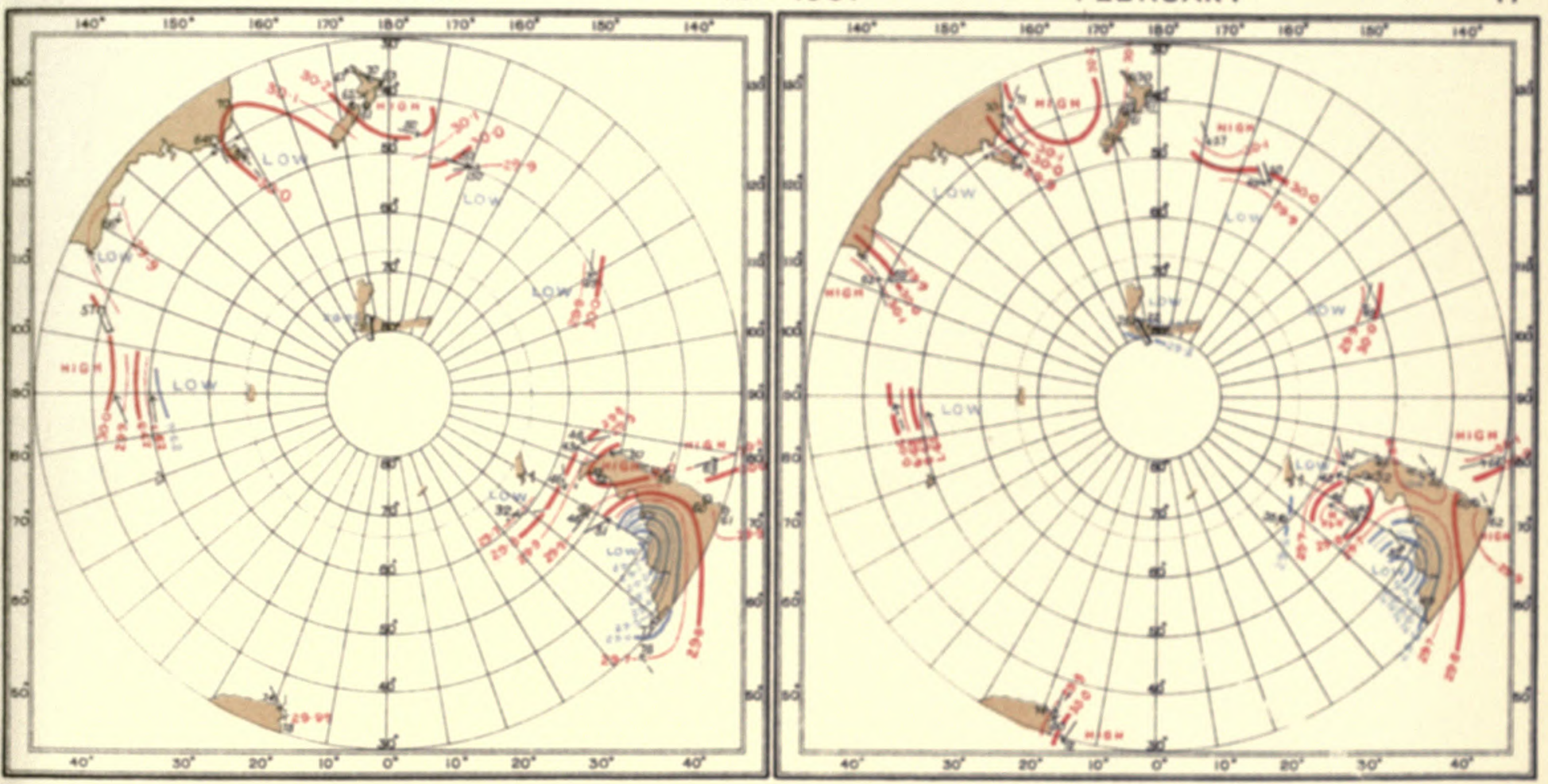

1904 FEBRUARY

$18 \quad 1904$

FEBRUARY

19

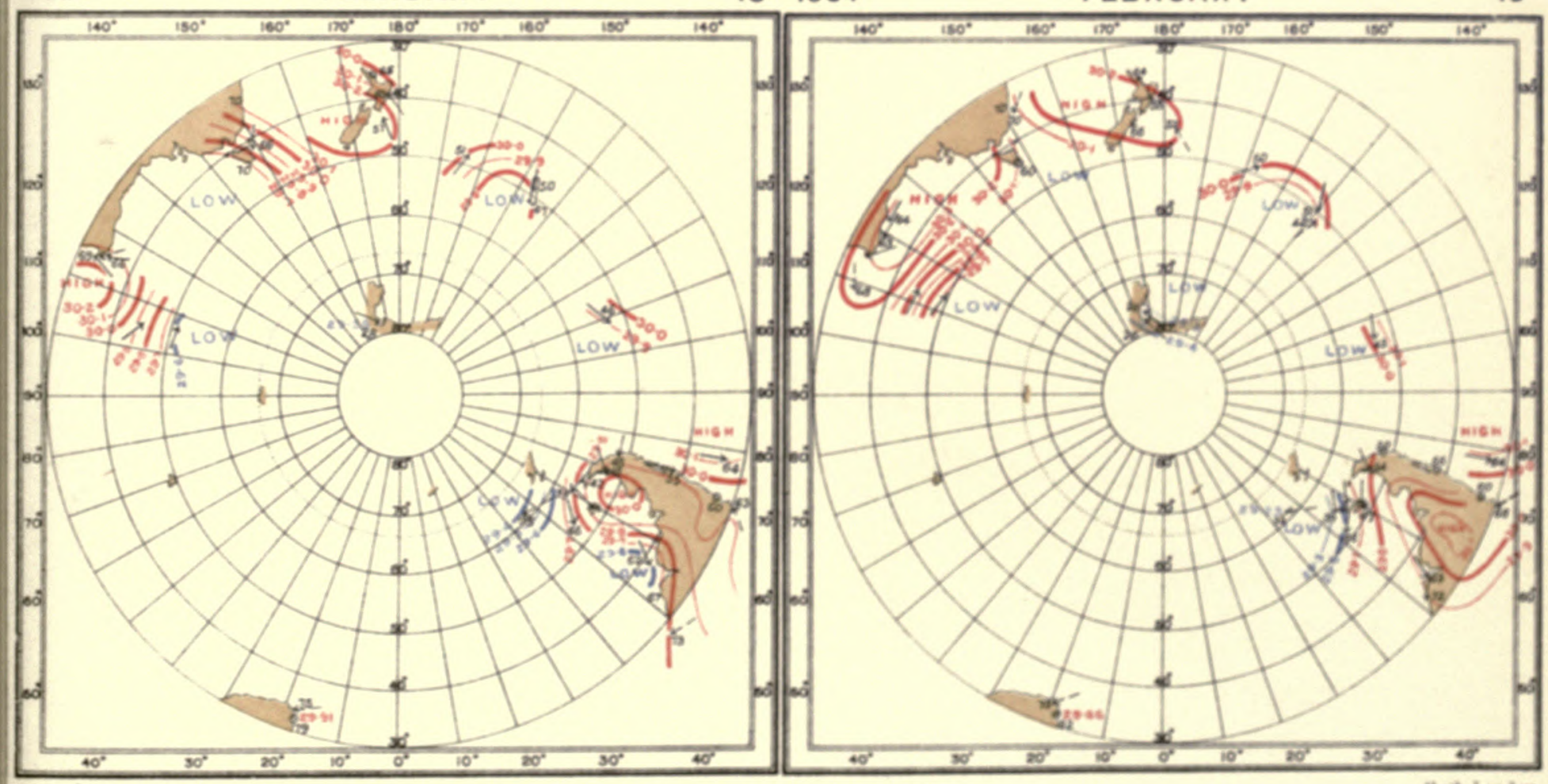


$\because \because \vdots \quad \because \vdots 3$

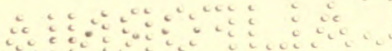


1)

a 
INTERNATIONAL ANTARCTIC COOOPEATION.

SYNCHRONOUS CHARTS OF SEA-LEVEL PRESSURE FOR NOON G.M.T.

WITH WINDS AND AIR TEMPERATURES.

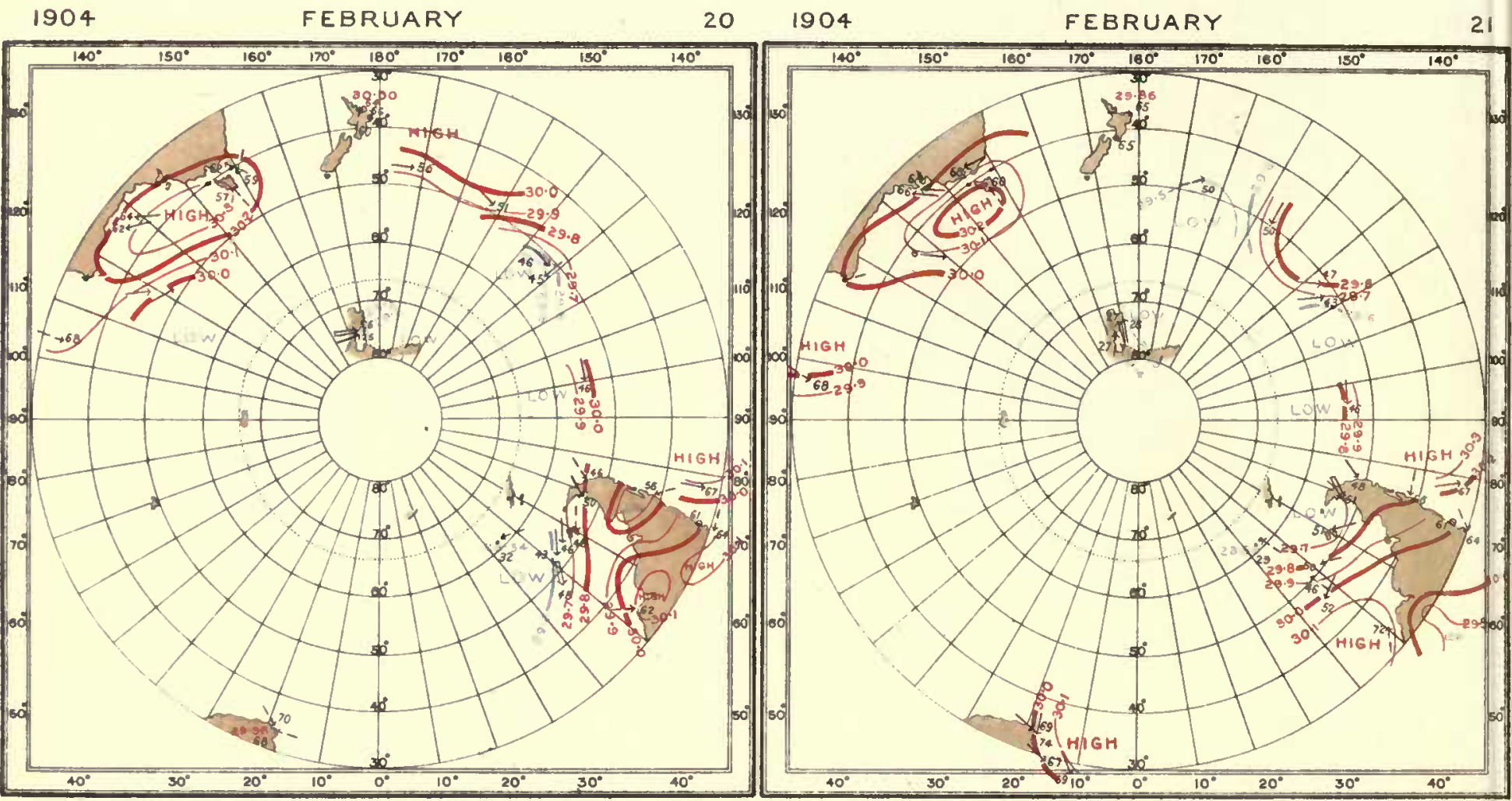

1904 FEBRUARY

$22 \quad 1904$

FEBRUARY

23
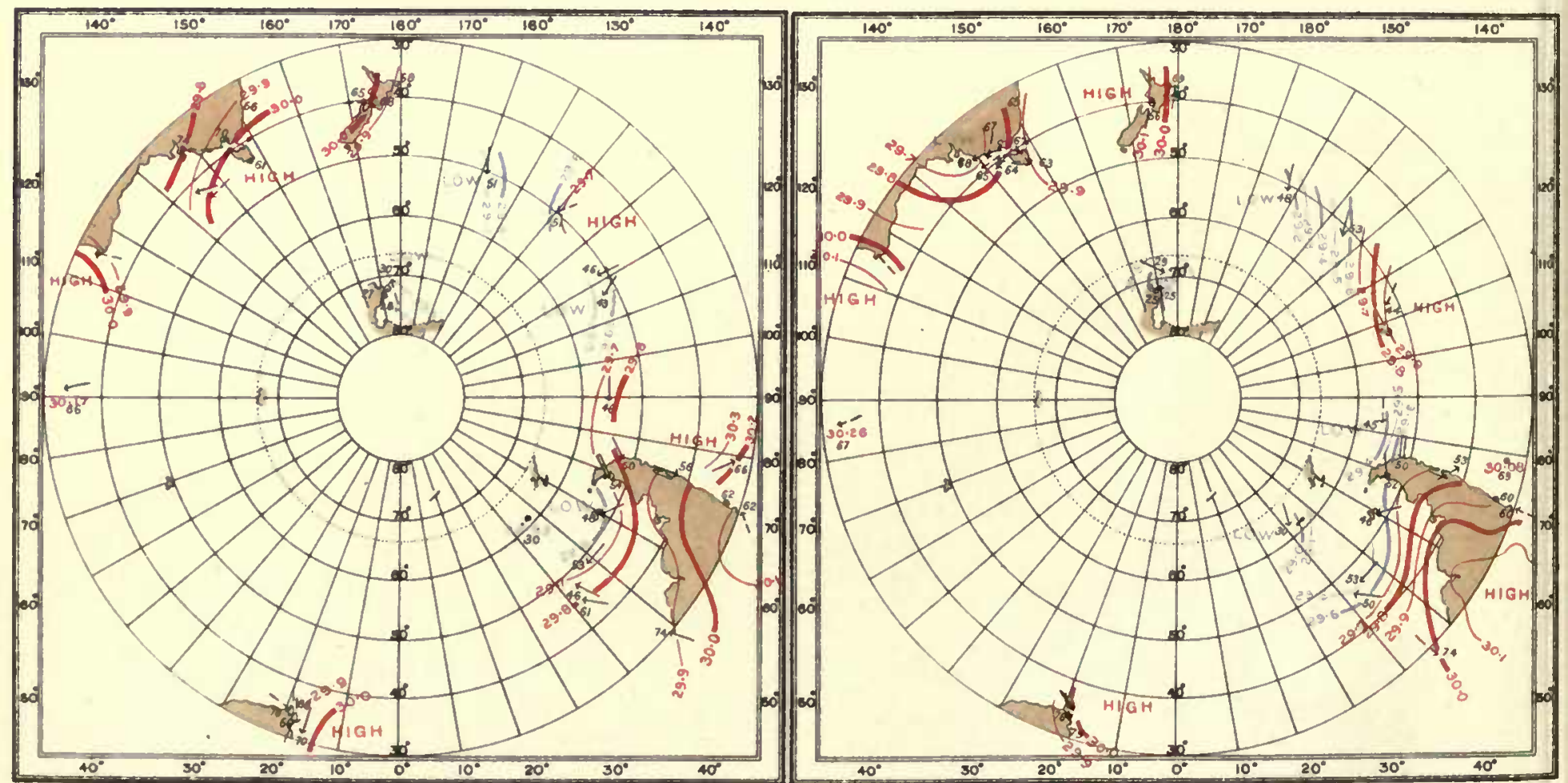
$\because \vdots \vdots \because \vdots \vdots \vdots \vdots \vdots \vdots \vdots \vdots 0$

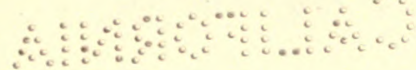




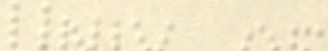

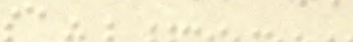

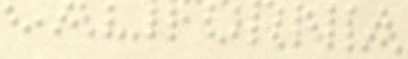


INTERNATIONAL ANTARCTIC CO-OPERATION.

SYNGHRONOUS CHARTS OF SEA-LEVEL PRESSURE FOR NOON G.M.T

WITH WINDS AND AIR TEMPERATURES.

1904 FEBRUARY

$28 \quad 1904$

FEBRUARY

29

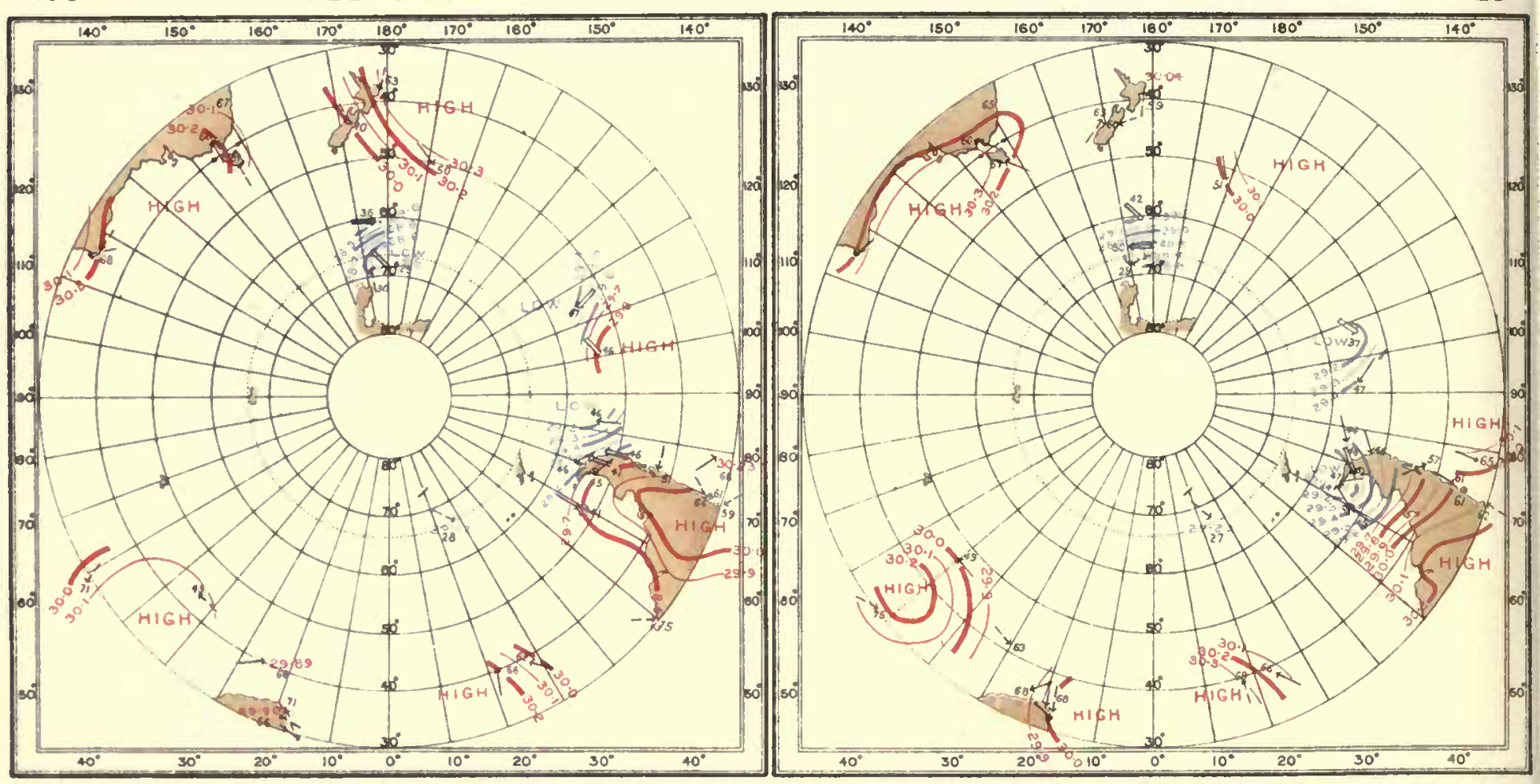

1904

MARCH

$1 \quad 1904$

MARCH

2
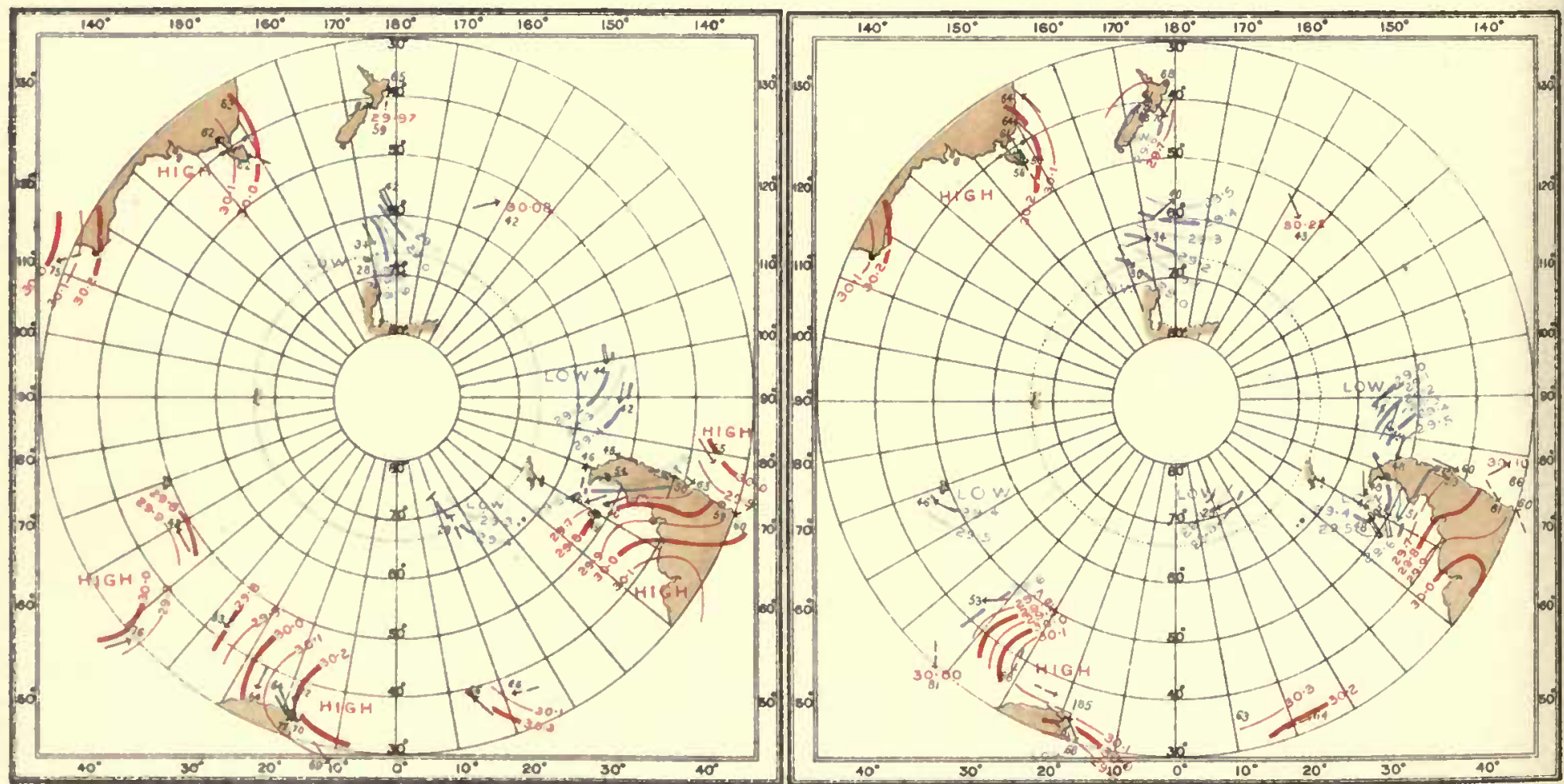
INTERNATIONAL ANTARCTIC CO-OPERATION.

SYNCHRONOUS CHARTS OF SEA-LEVEL PRESSURE FOR NOON GM.T. WITH WINDS AND AIR TEMPERATURES
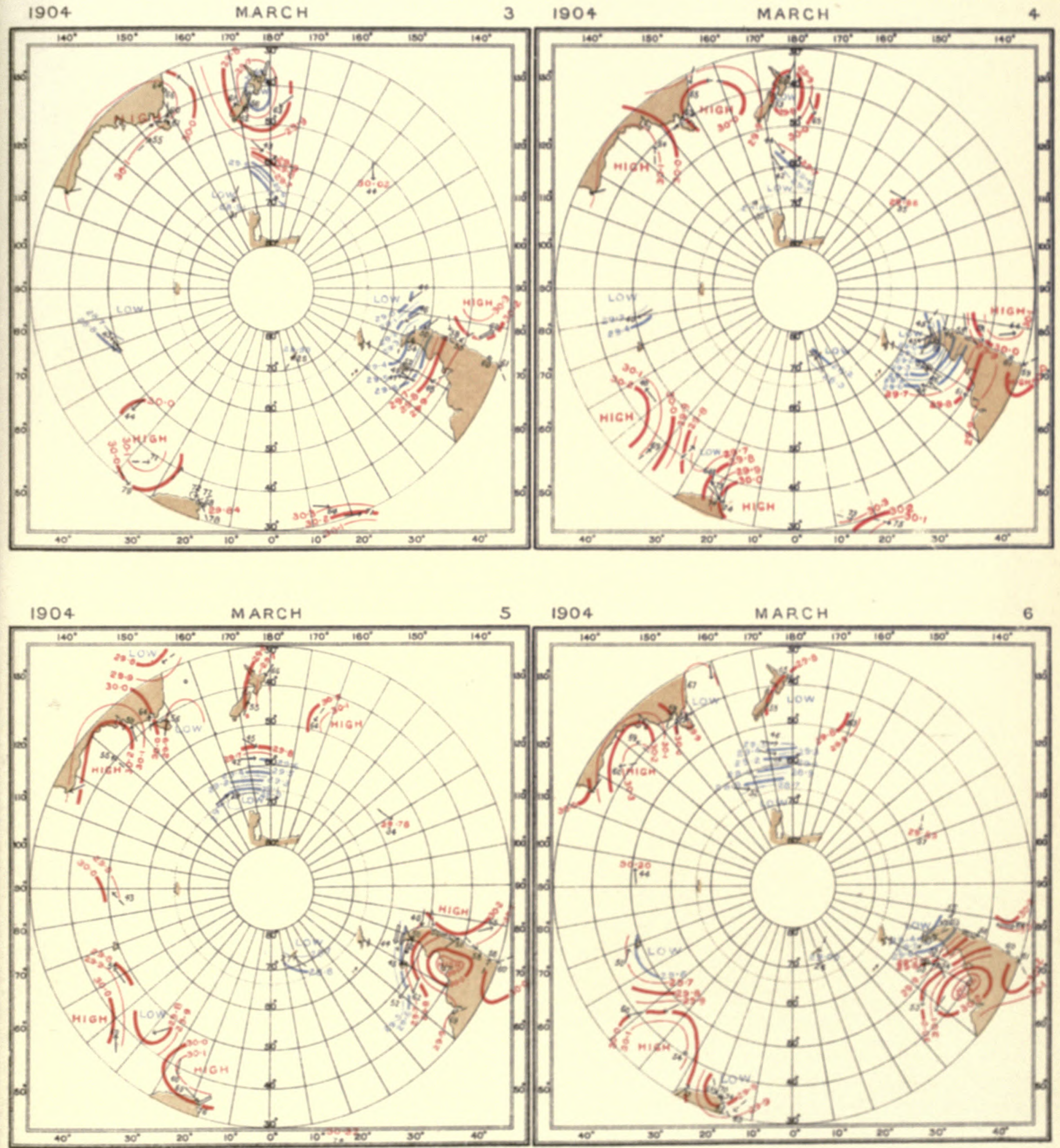
$\because 3$

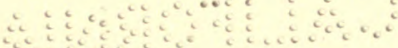


INTERNATIONAL ANTARCTIC COOPERATION.

SYNCHRONOUS CMARTS OF SEA-LEVEL PRESSURE FOR NOON G.M.T

WITH WINDS AND AIR TEMPERATURES.
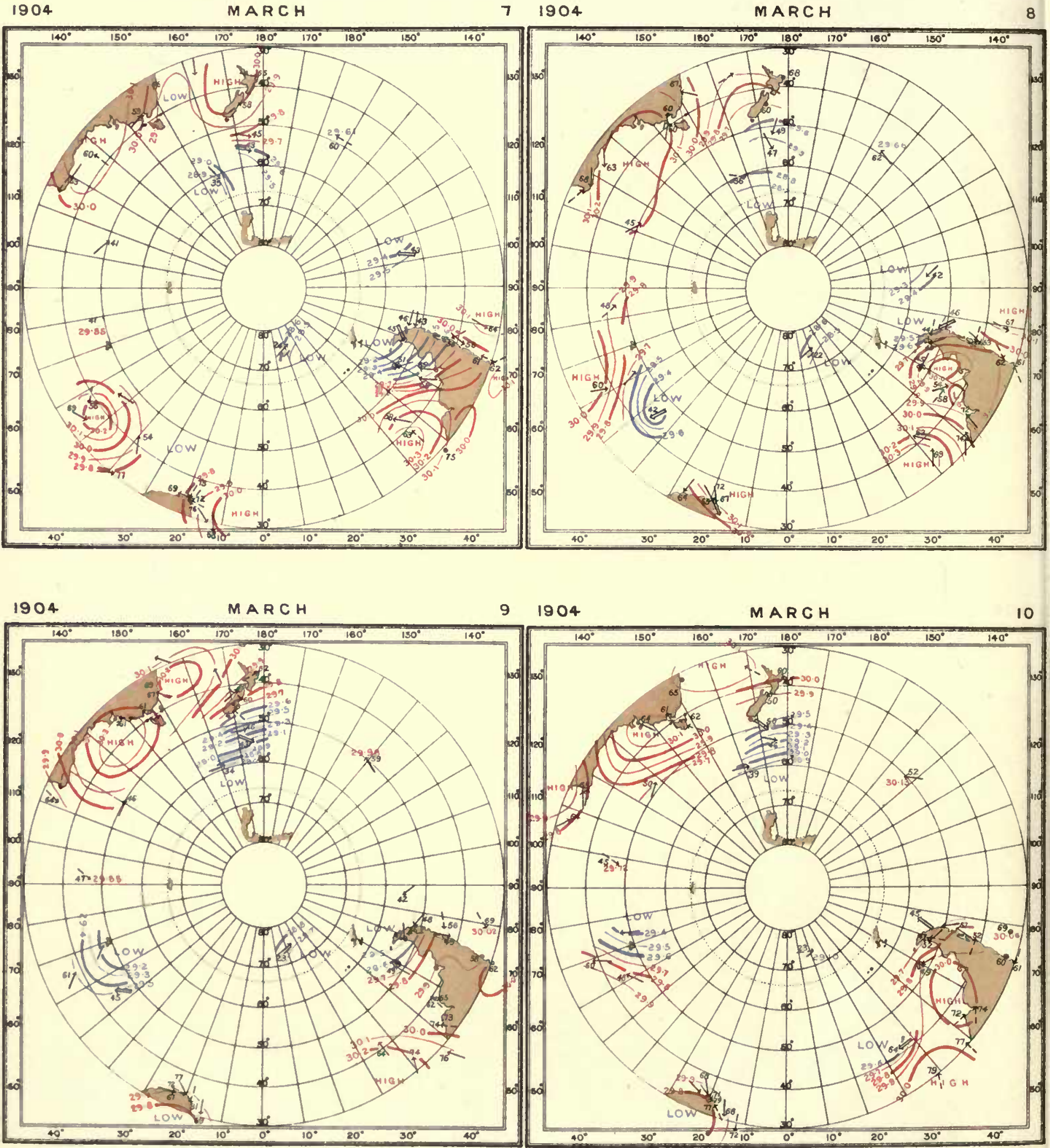
INTERNATIONAL ANTARCTIC CO-OPERATION.

SYNCHRONOUS CHARTS OF SEA-LEVEL PRESSURE FOR NOON GMT.

WITH WINDS AND AIR TEMPERATURES.

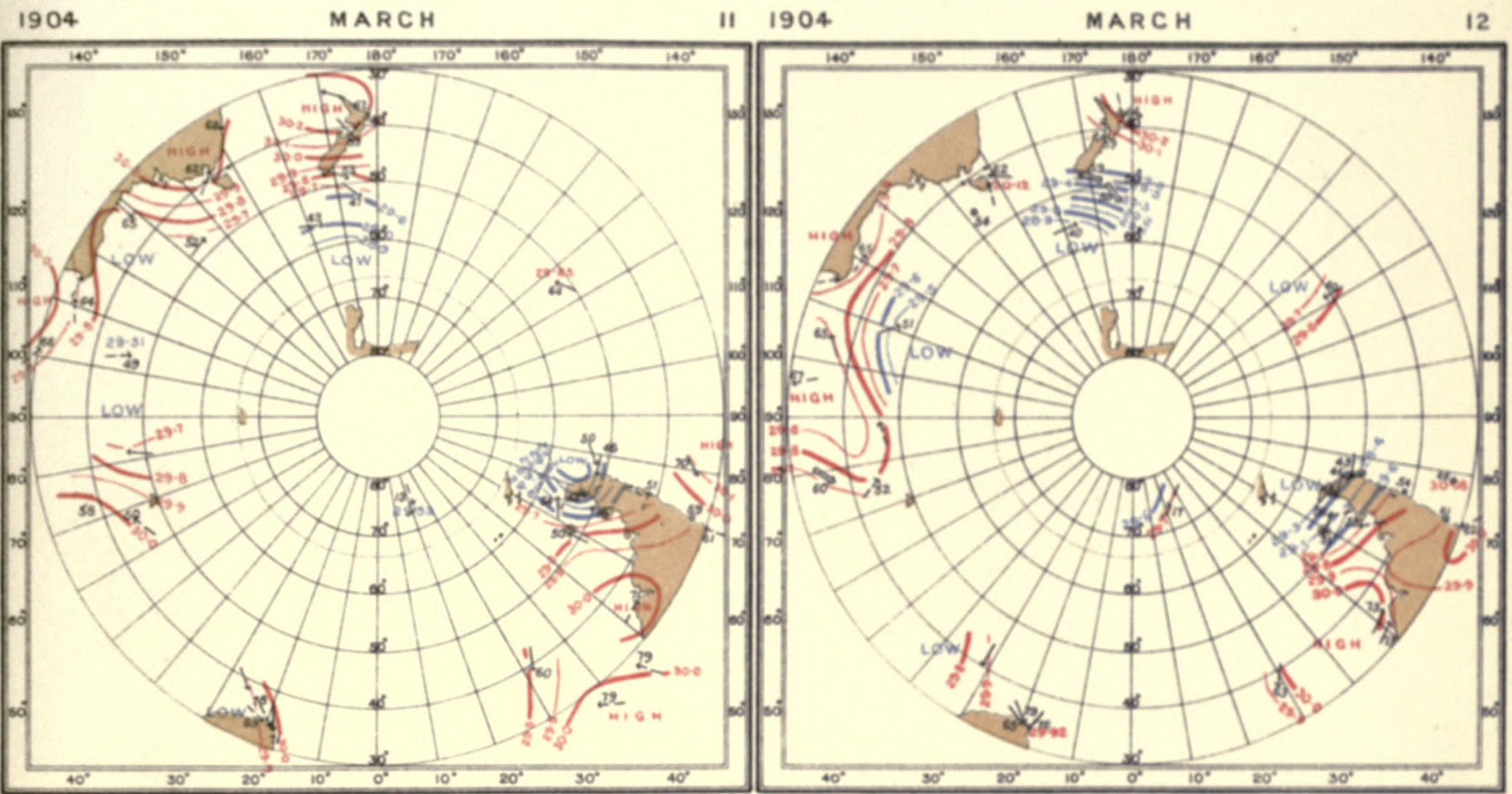

1904

M ARCH

$13 \quad 1904$

MARCH

14
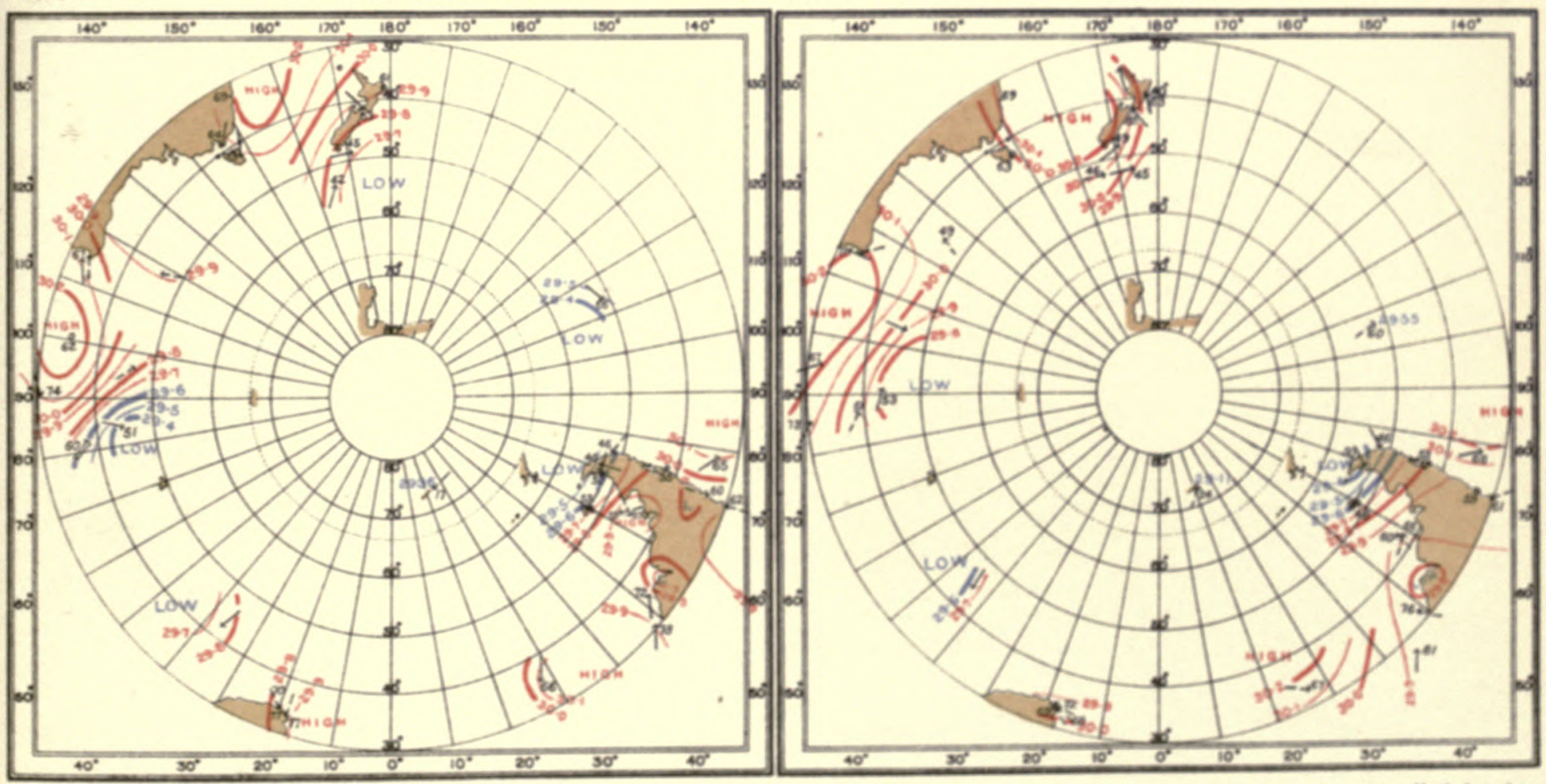

Heth London 
$\because \vdots \vdots \quad \because \vdots \vdots \vdots \vdots \vdots \vdots \vdots \vdots \vdots 0$

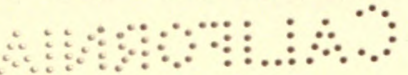


1

to 
INTERNATIONAL ANTARCTIC CO-OPERATION.

SYNCHRONOUS CHARTS OF SEA-LEVEL PRESSURE FOR NOON G.M.T. WITH WINDS AND AIR TEMPERATURES
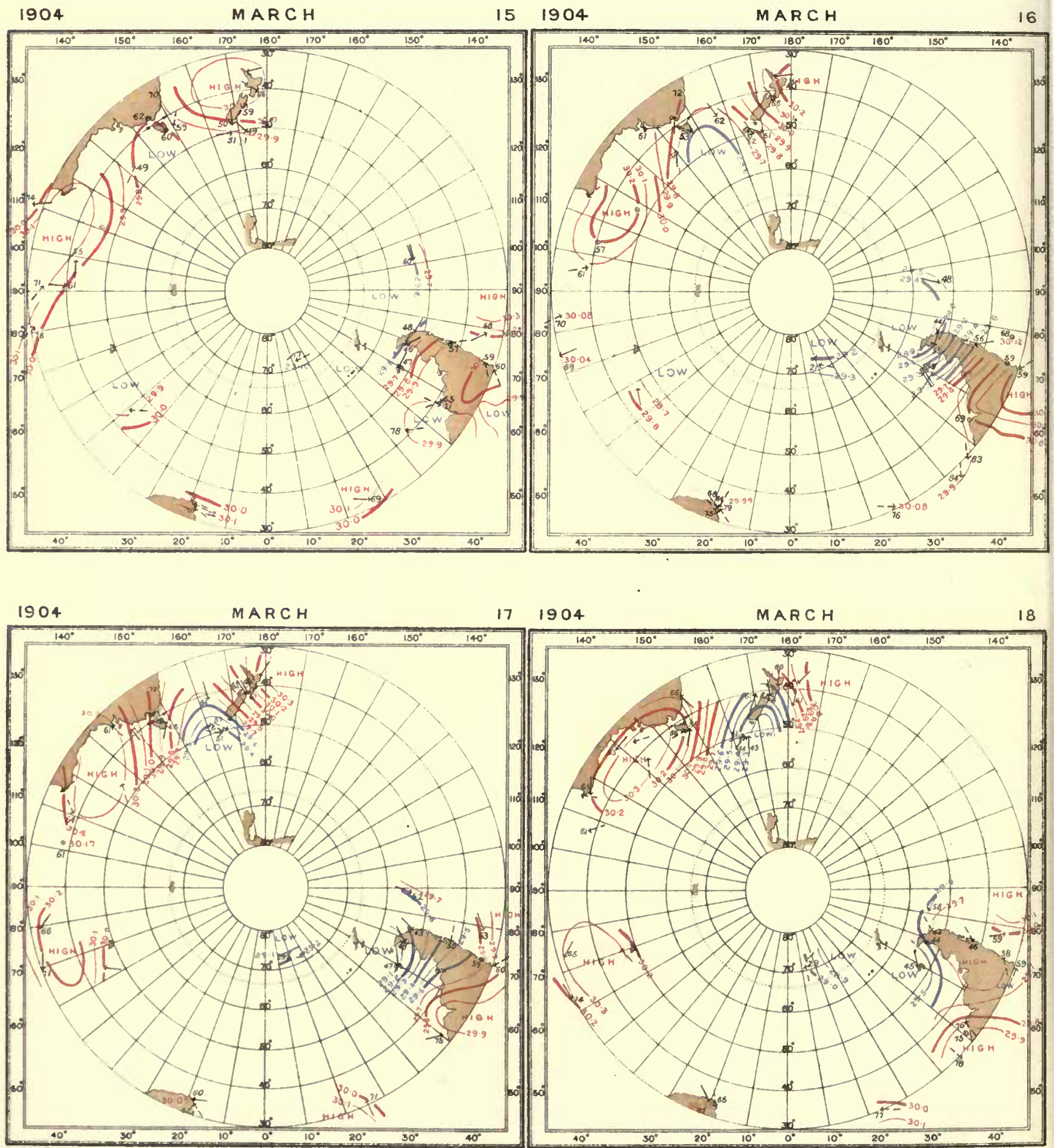
INTERNATIONAL ANTARCTIC CO-OPERATION.

SYNCHRONOUS CHARTS OF SEA-LEVEL PRESSURE FOR NOON GMT

WITH WINDS AND AIR TEMPERATURES

1904 MARCH

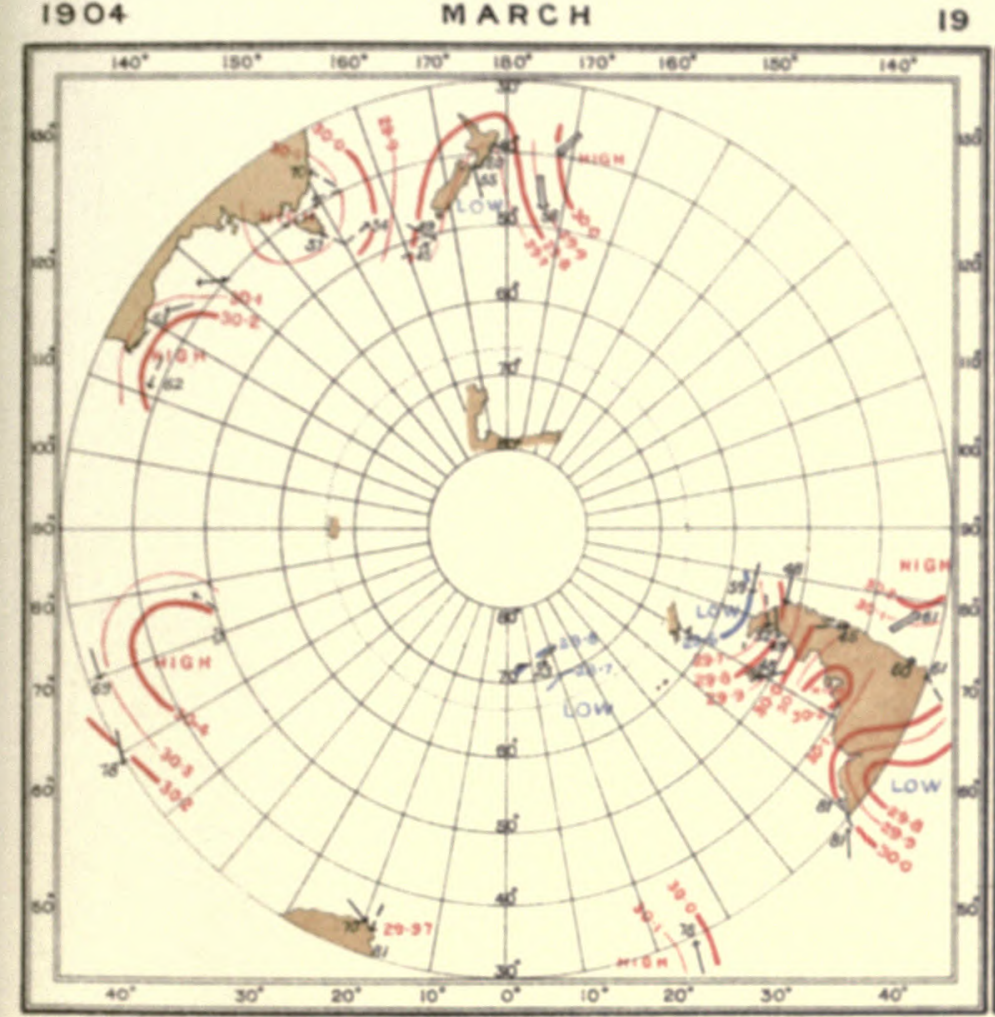

1904

M ARCH

20

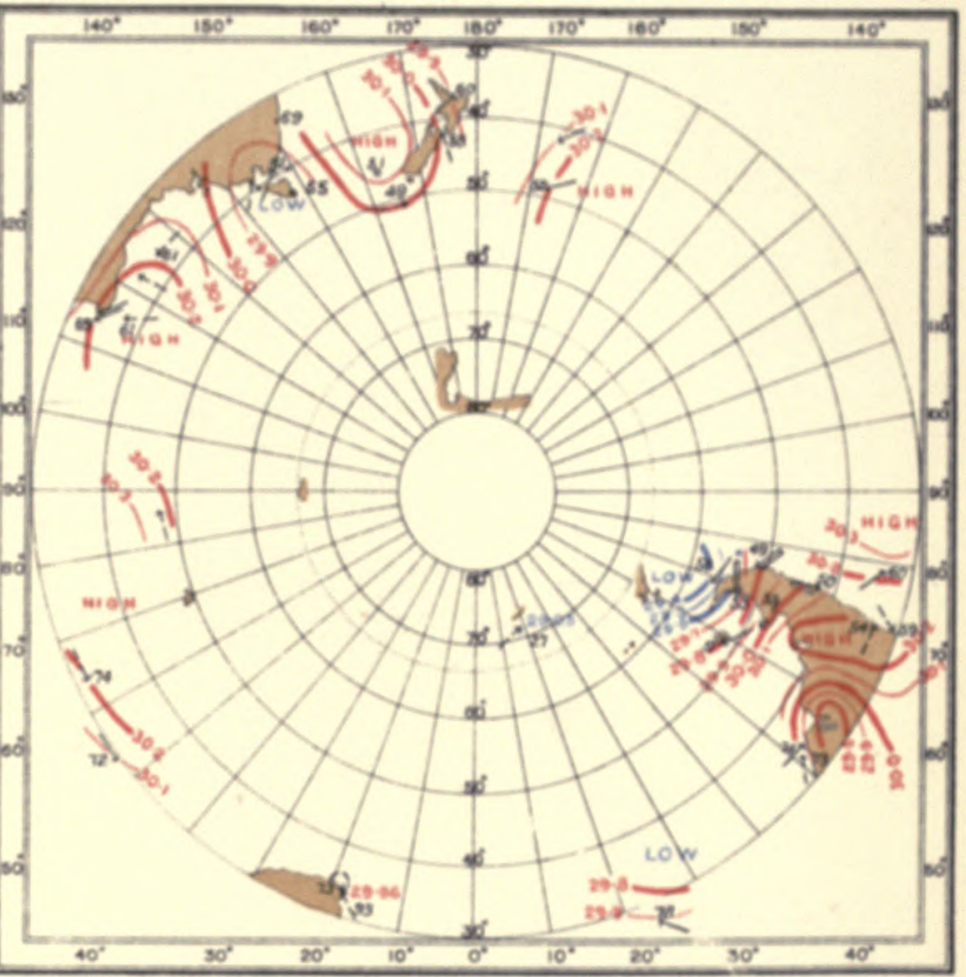

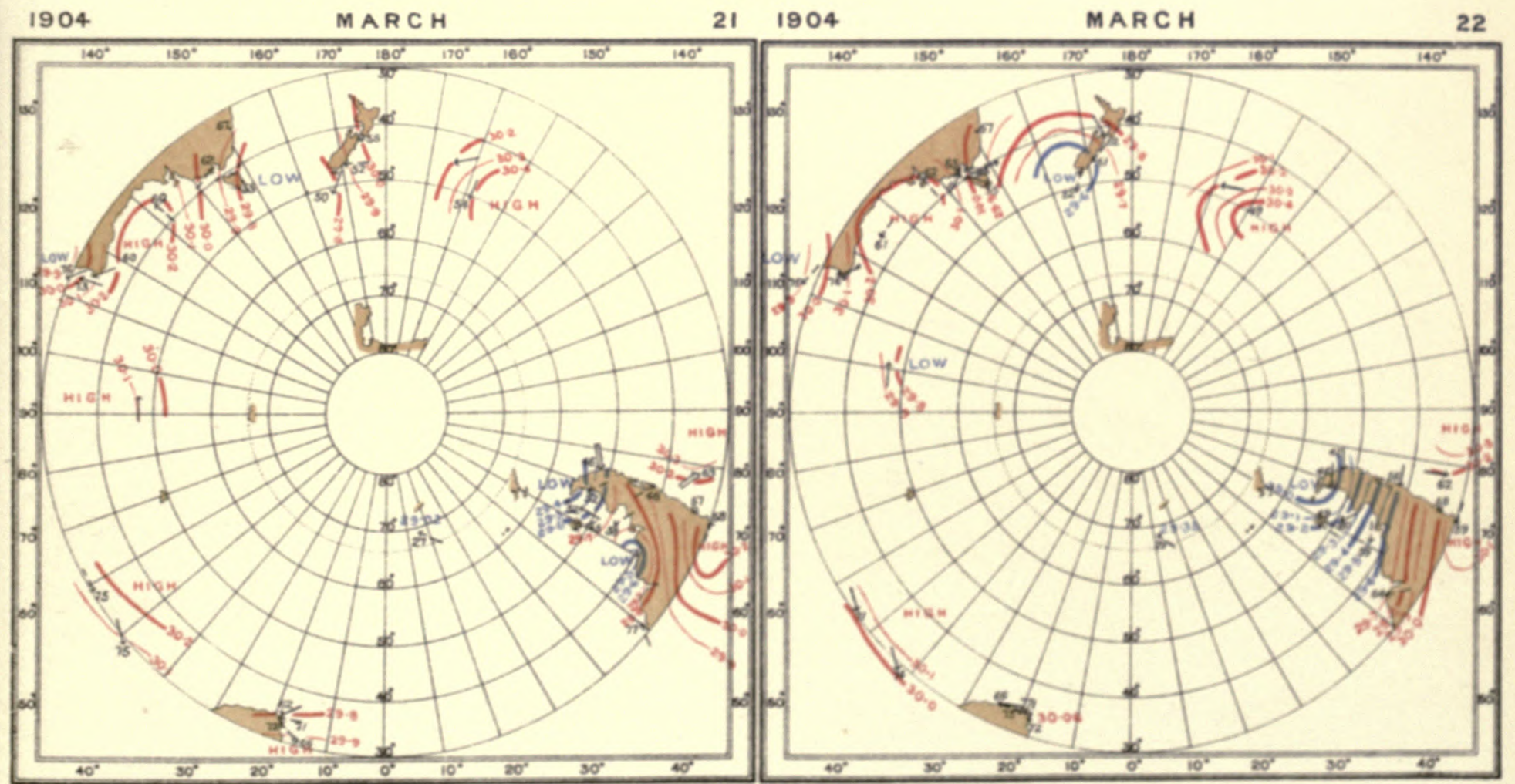


\begin{tabular}{lll} 
& 4 \\
\hdashline & 0
\end{tabular}

a. 

INTERNATIONAL ANTARCTIC CO-OPERATION.

SYNCHRONOUS CMARTS OF SEA-LEVEL PRESSURE FOR NOON G.M.T

WITH WINDS AND AIR TEMPERATURES
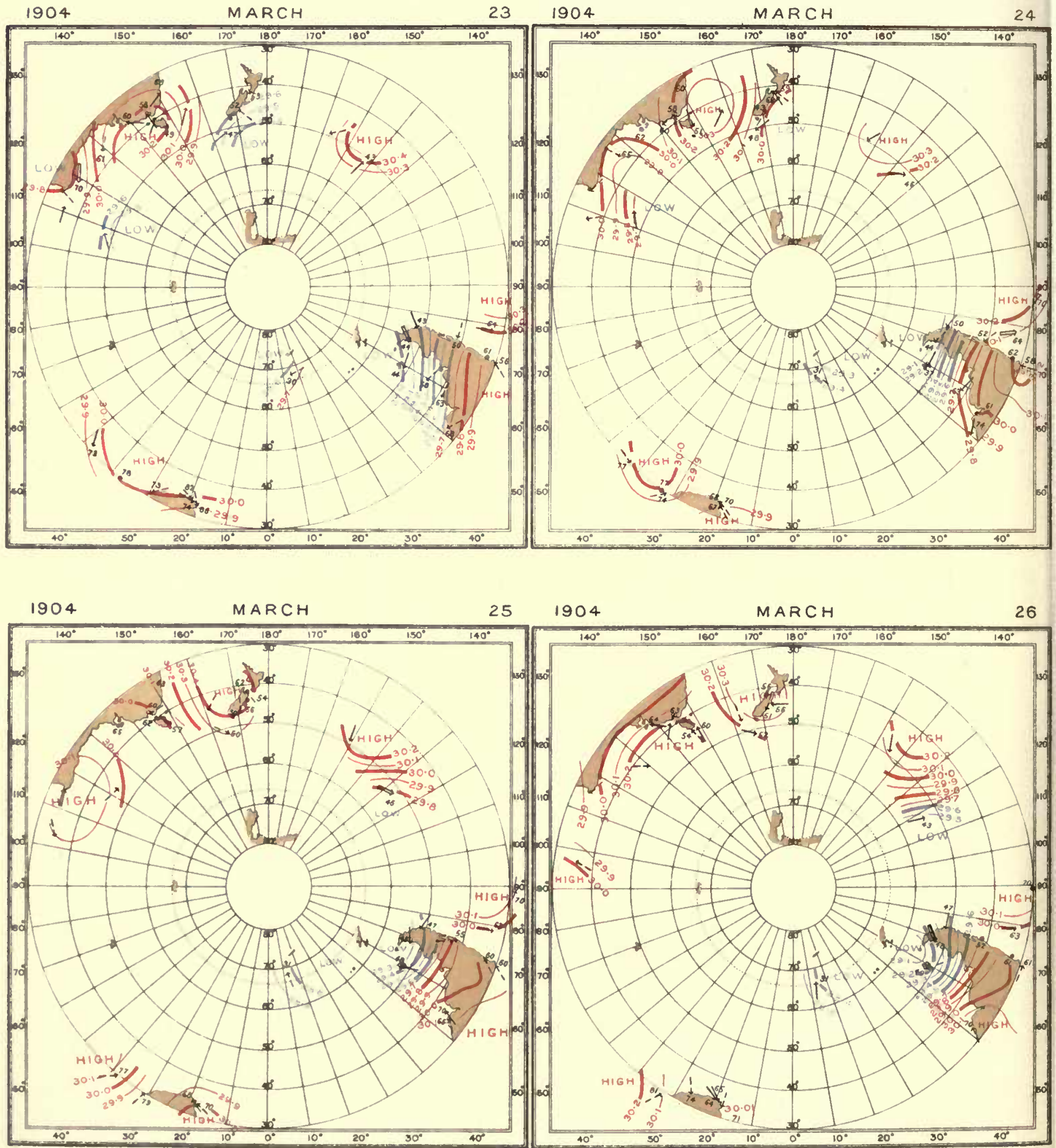
INTERNATIONAL ANTARCTIC COOPERATION.

SYNCHRONOUS CHARTS OF SEALEVEL PRESSURE FOR NOON GM.T

WITH WINDS AND AIR TEMPERATURES

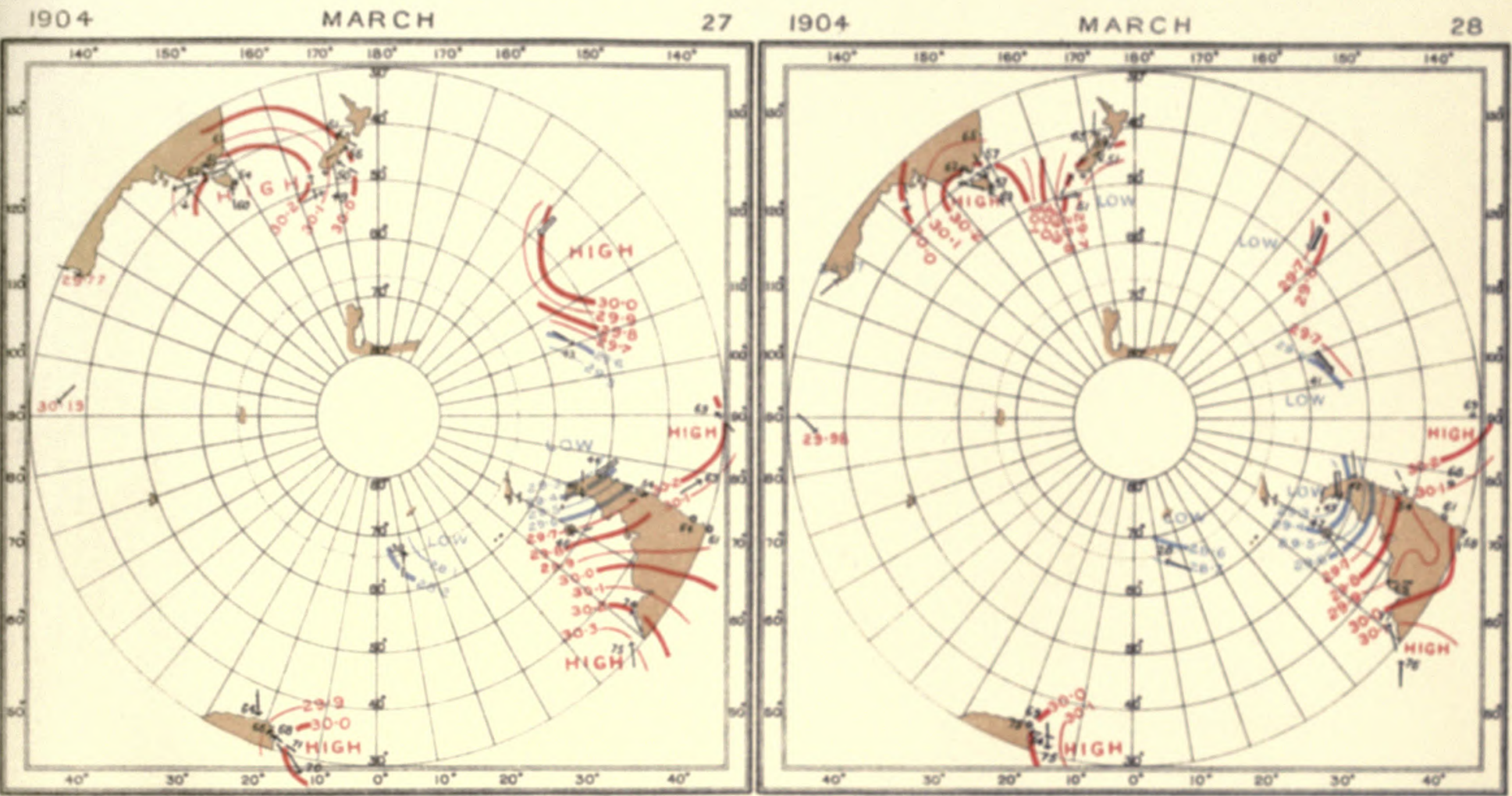

$1904 \quad$ MARCH

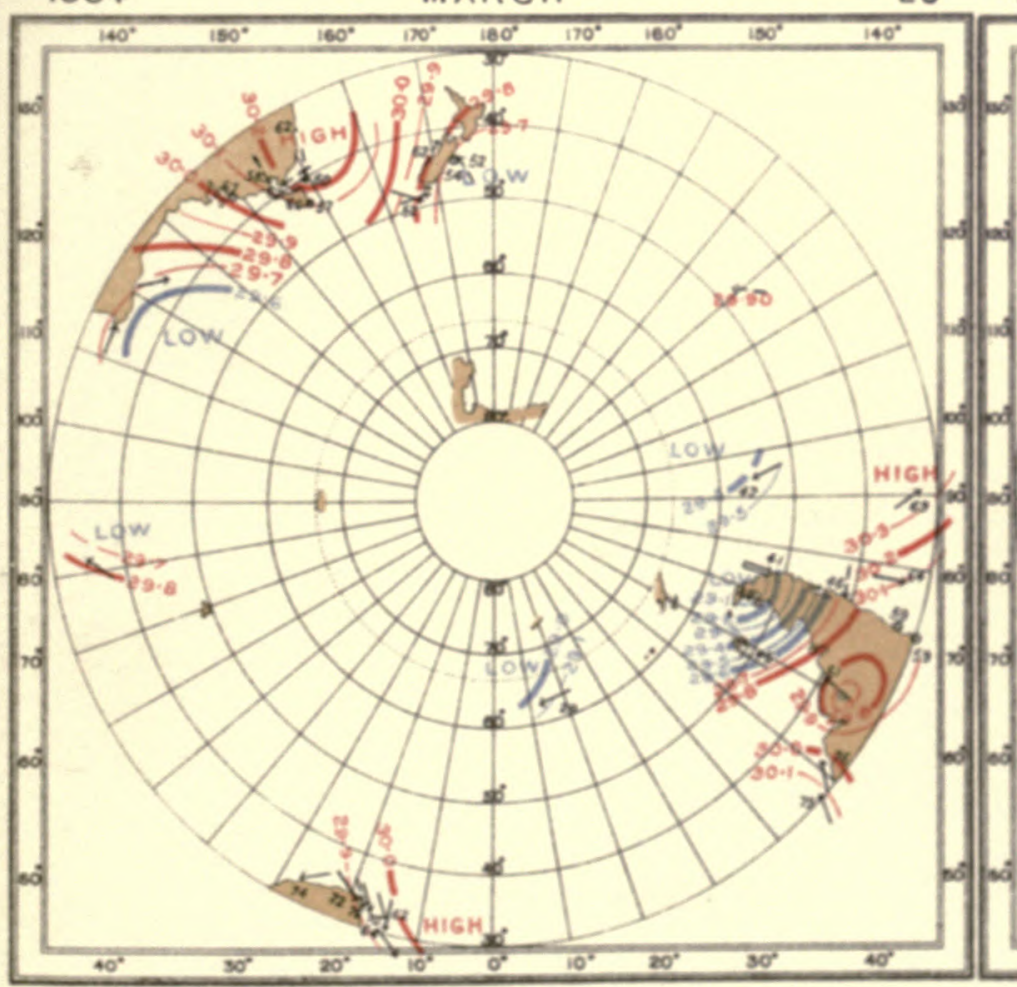

$1904 \quad M A R C H$

30
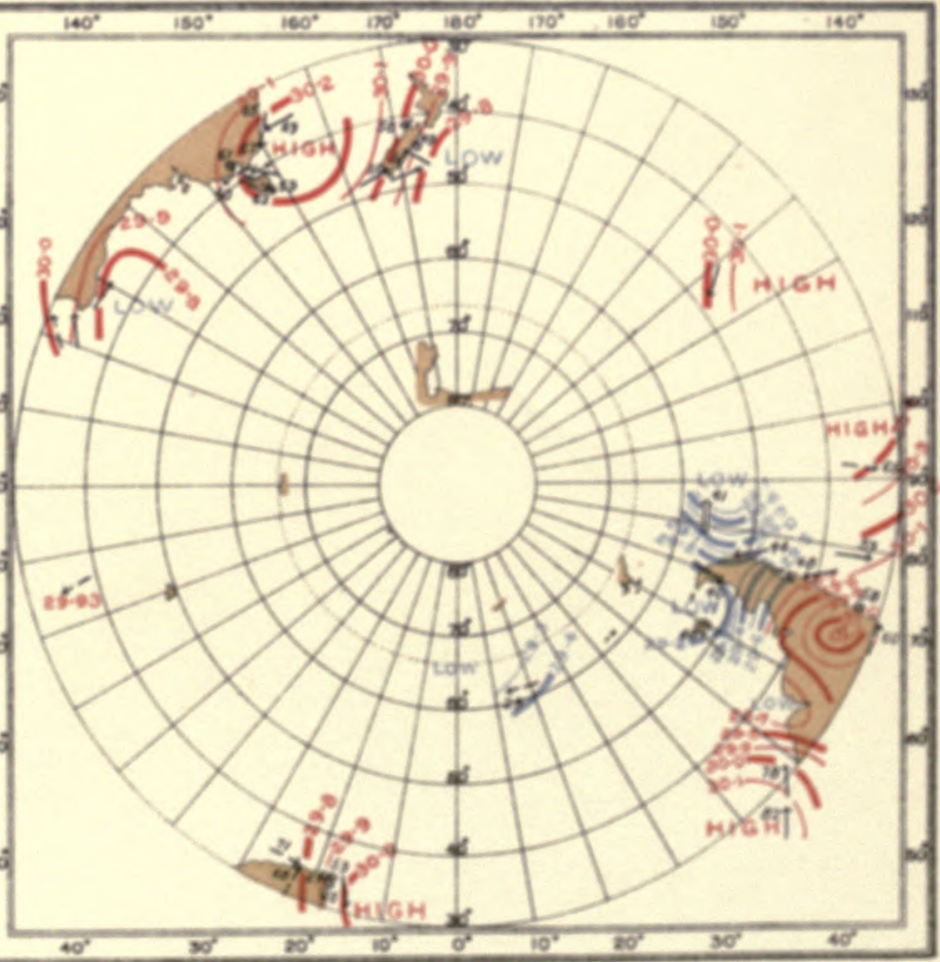
. 
INTERNATIONAL ANTARCTIC COOOPERATION.

SYNCHRONOUS CHARTS OF SEA-LEVEL PRESSURE FOR NOON GM.T

WITH WINDS AND AIR TEMPERATURES.

$1904 \quad$ M ARCH 31
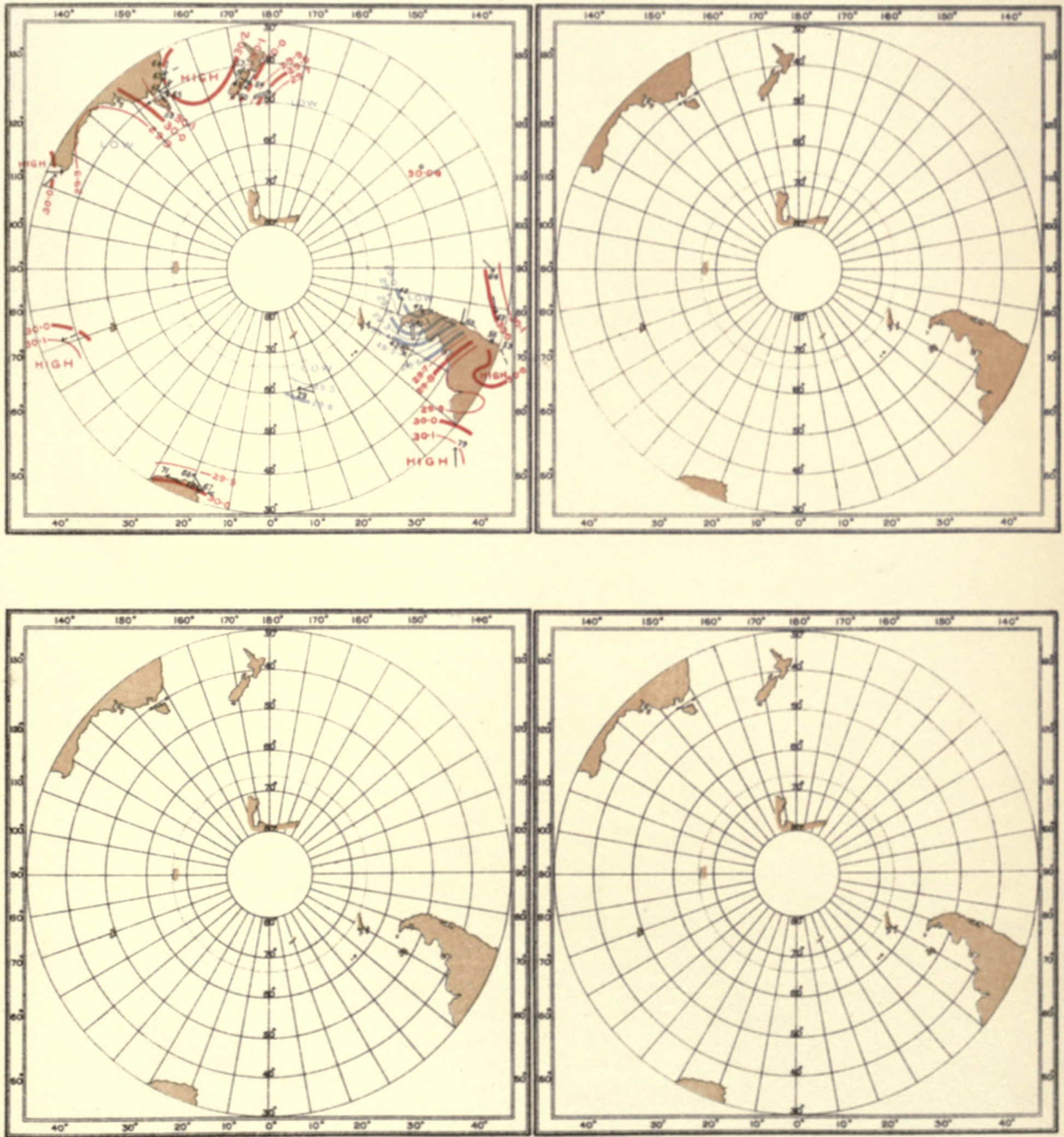
$\because \because \because \vdots$

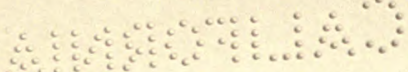


INTERNATIONAL ANTARCTIC CO-OPERATION.

CHARTS OF MEAN SEA LEVEL PRESSURE AND AIR TEMPERATURE.

OCTOBER

NORMAL PRESSURE.

MEAN PRESSURE, NOON, G.M.T. 1901.
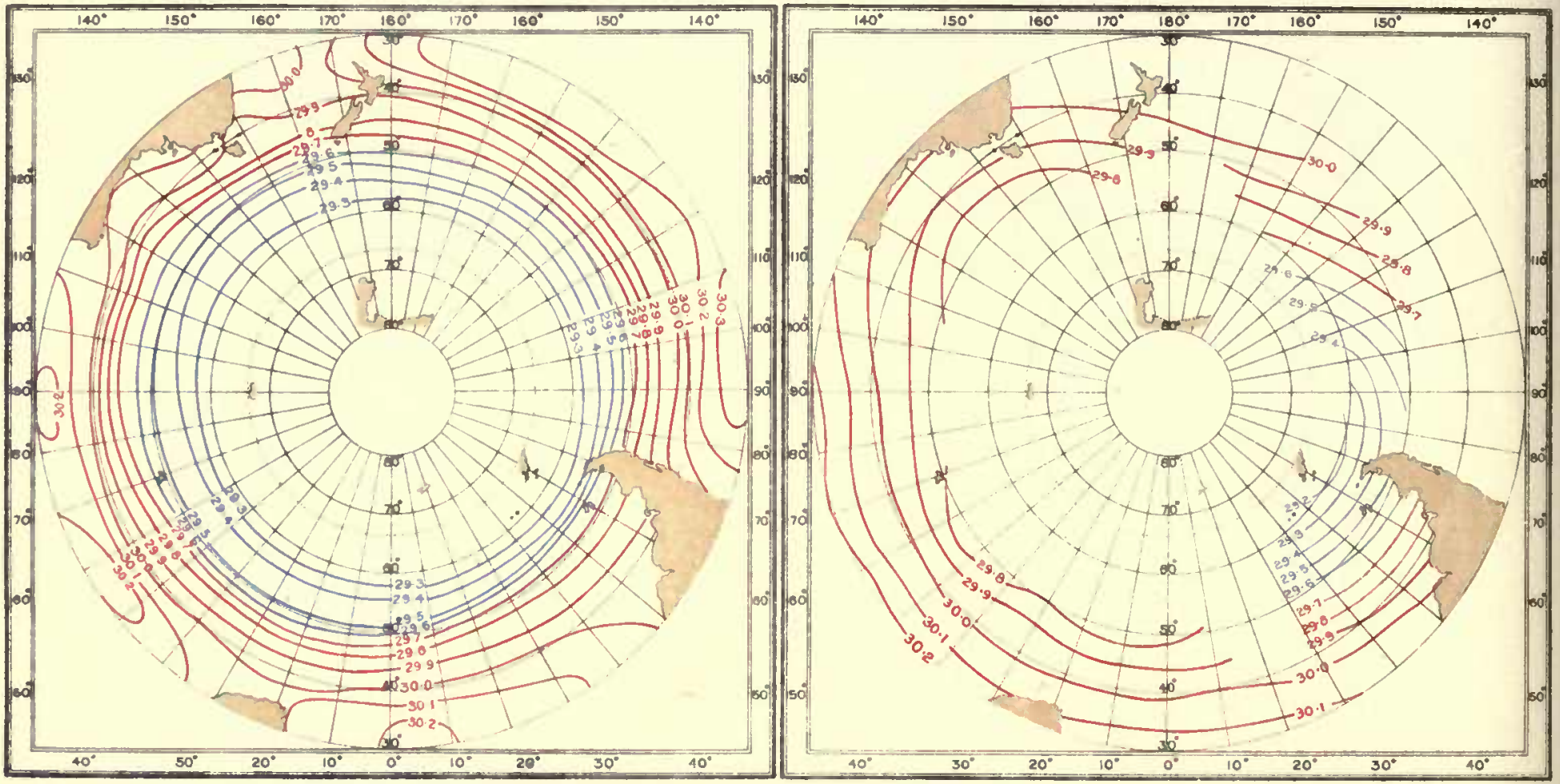

NORMAL AIR TEMPERATURE.

OCTOBER

MEAN AIR TEMPERATURE, NOON, G.M.T. 1901.

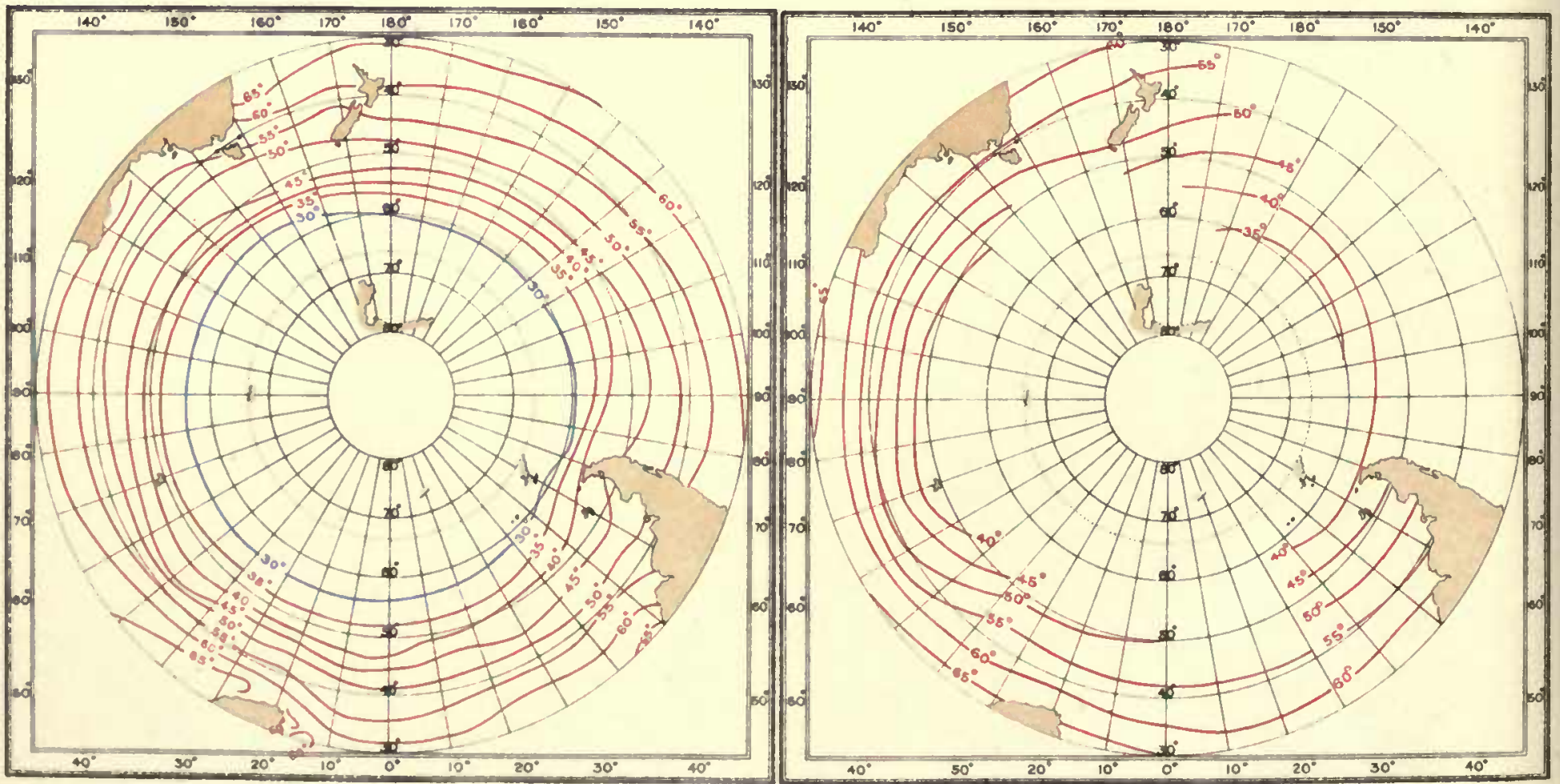


INTERNATIONAL ANTARCTIC CO-OPERATION.

CHARTS OF MEAN SEA LEVEL PRESSURE AND AIR TEMPERATURE.

NOVEMBER

NORMAL PRESSURE.

MEAN PRESSURE, NOON, G.M.T. 1901.

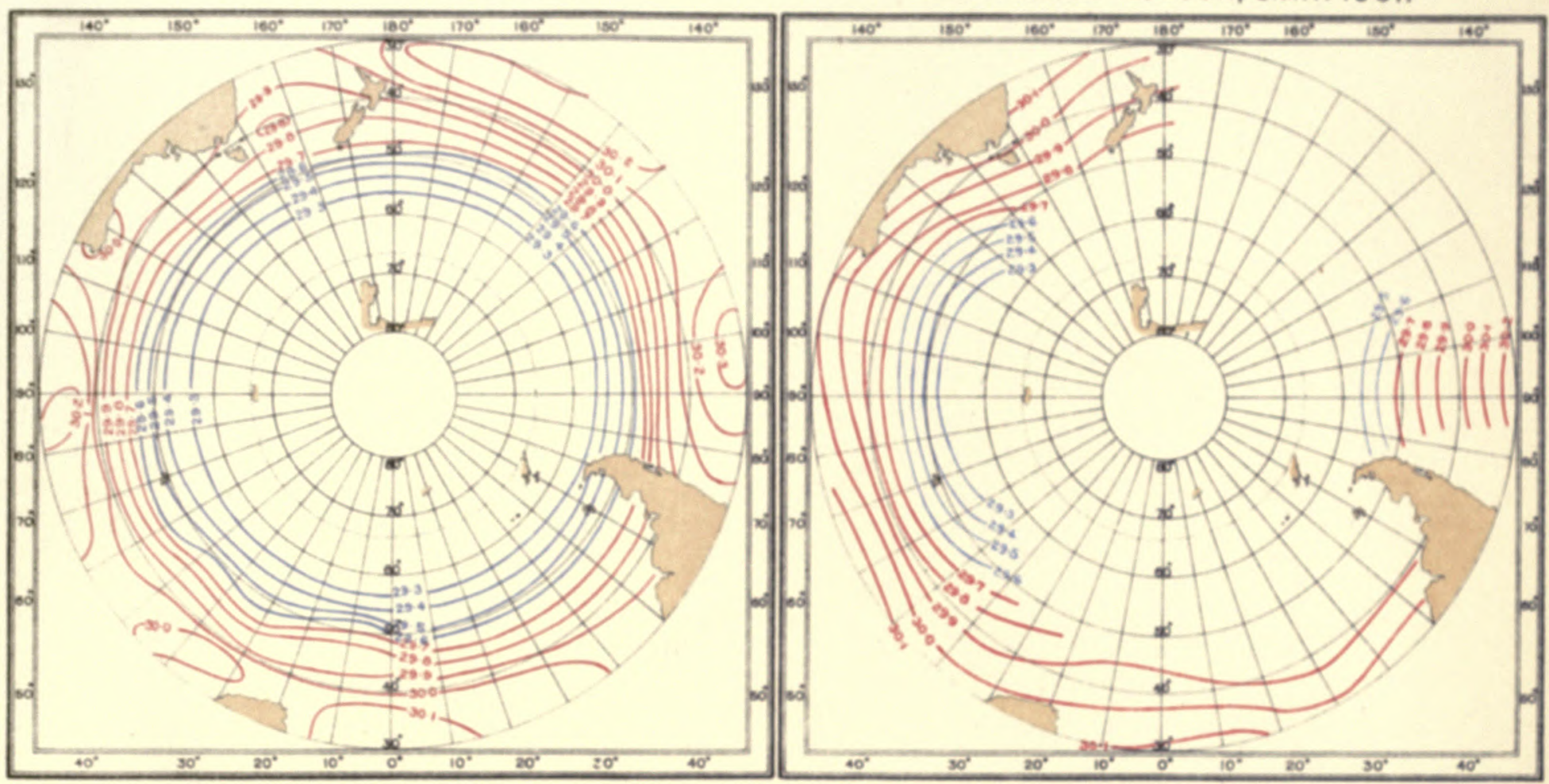

NORMAL AIR TEMPERATURE.

MEAN AIR TEMPERATURE, NOON, G.M.T. I90।
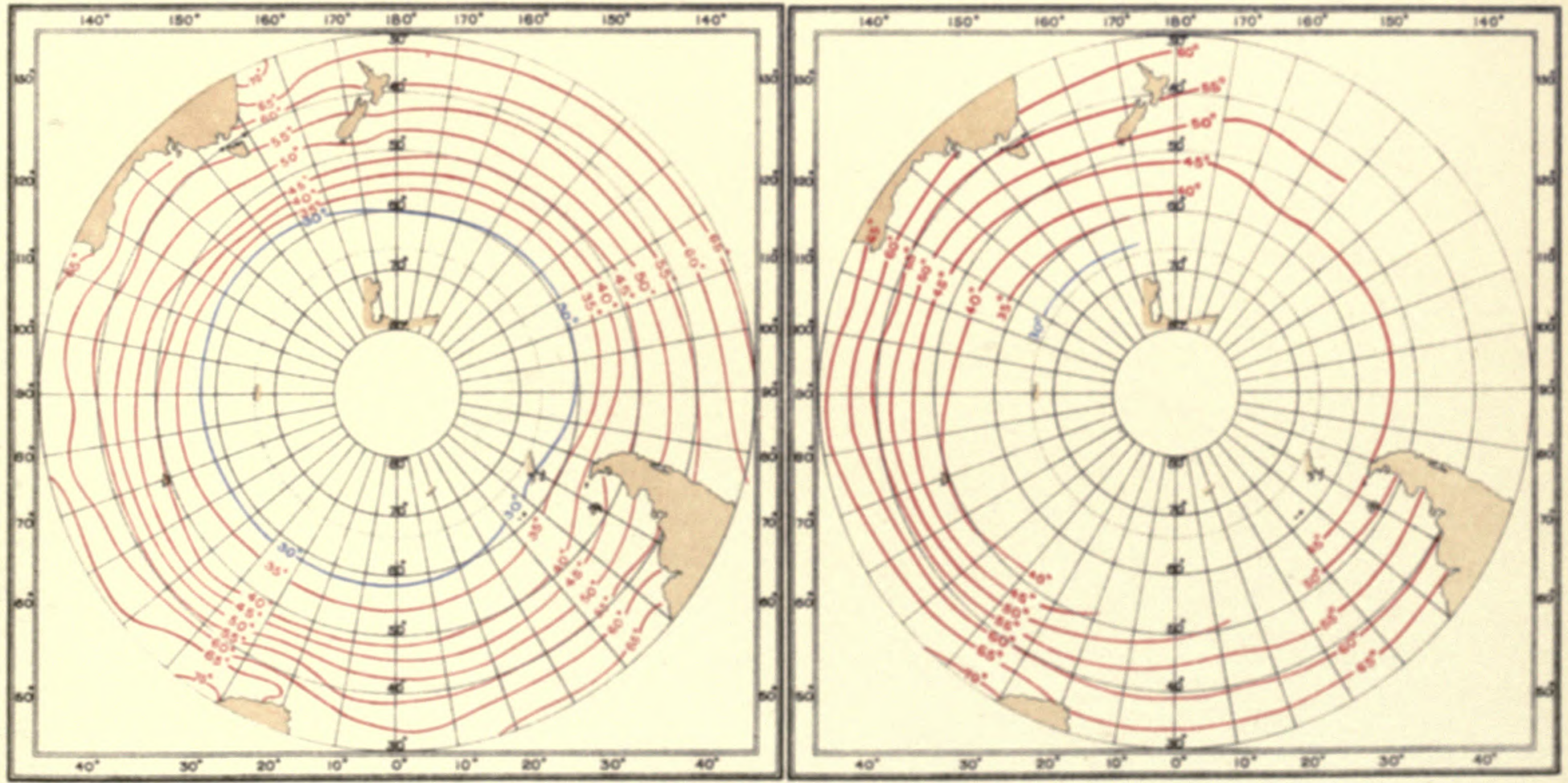

Heth Londen 
$\because \because \quad \because \because \vdots \vdots \vdots \vdots \vdots 0$

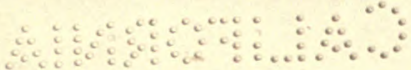


1\%

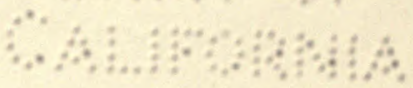


INTERNATIONAL ANTARCTIC CO-OPERATION.

CHARTS OF MEAN SEA LEVEL PRESSURE AND AIR TEMPERATURE.

DECEMBER

NORMAL PRESSURE.

MEAN PRESSURE, NOON, G.M.T. 1901
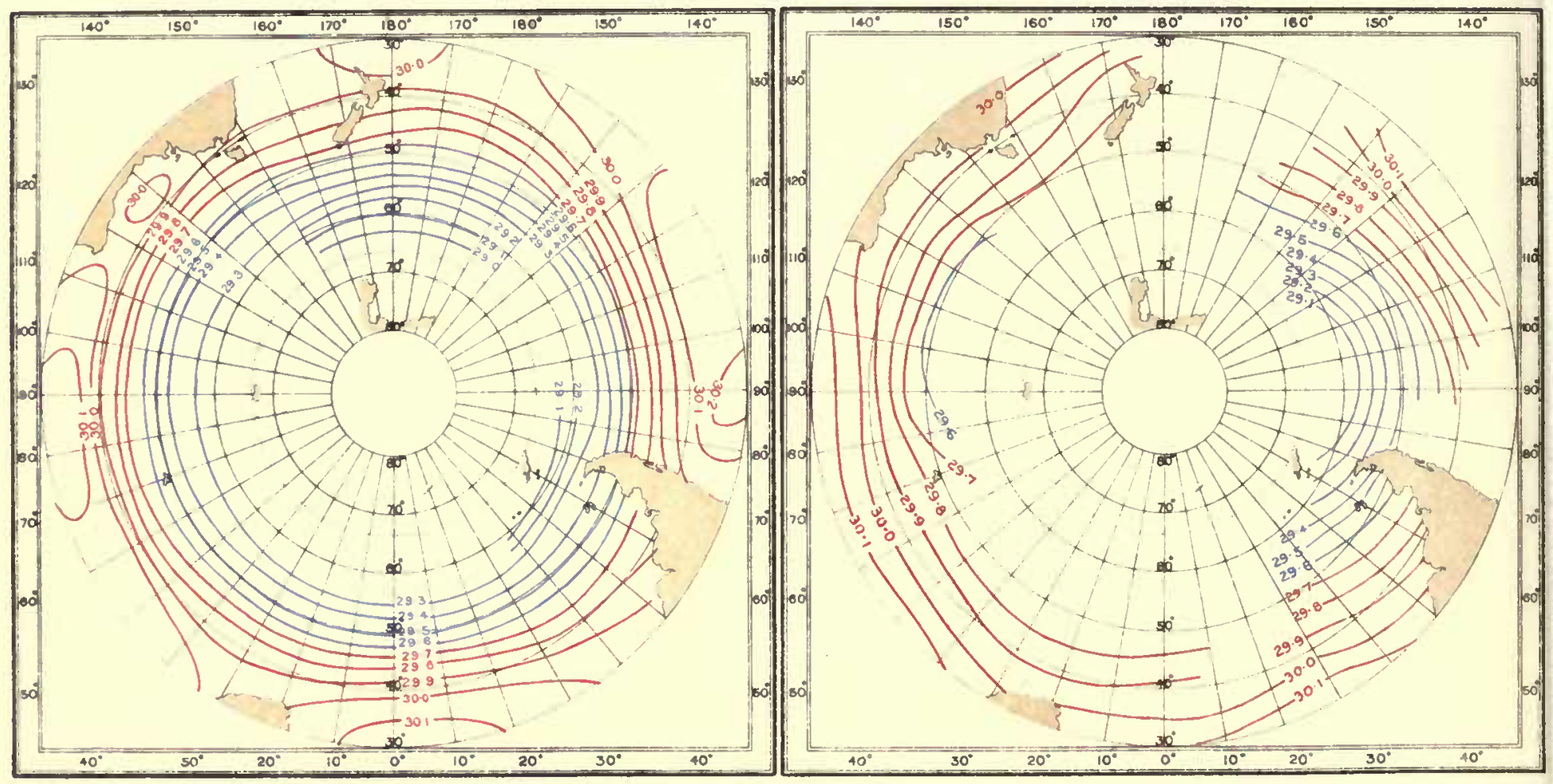

NORMAL AIR TEMPERATURE.

DECEMBER

MEAN AIR TEMPERATURE, NOON, G.M.T. 1901

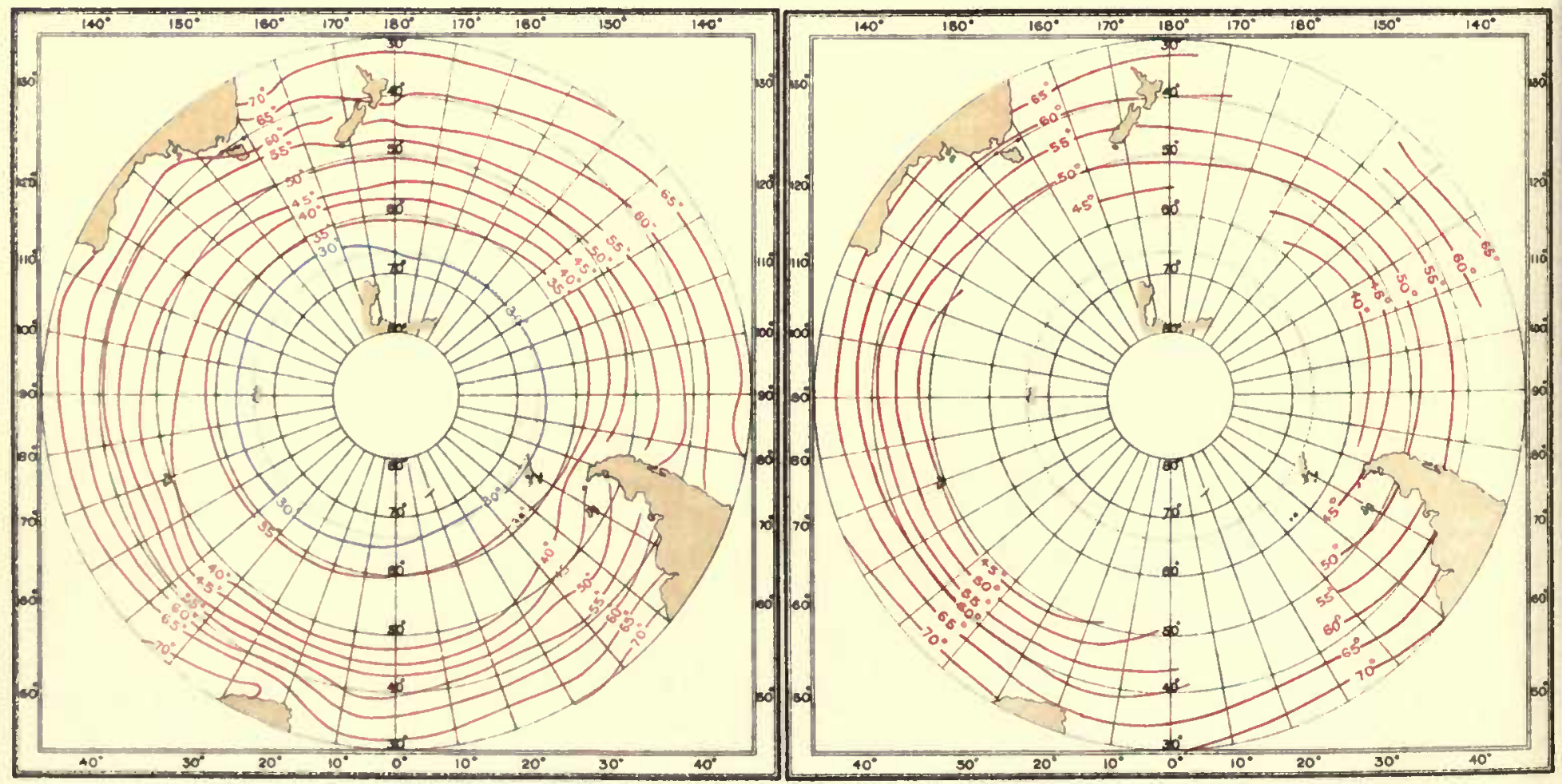


INTERNATIONAL ANTARCTIC CO-OPERATION.

CHARTS OF MEAN SEA LEVEL PRESSURE AND AIR TEMPERATURE.

$J A N \cup A R Y$

NORMAL PRESSURE.

MEAN PRESSURE, NOON, G.M.T. 1902.

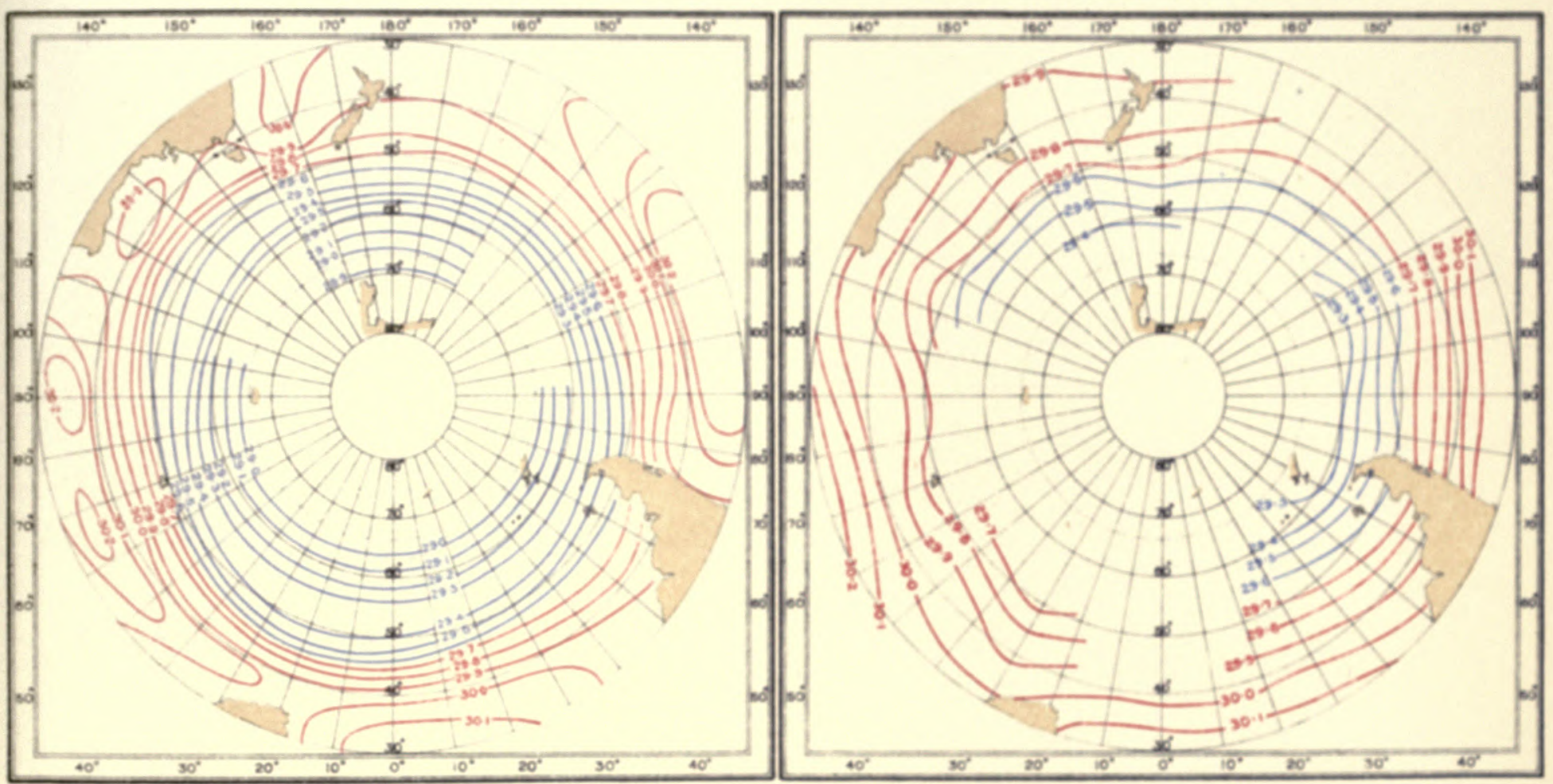

NORMAL AIR TEMPERATURE.

MEAN AIR TEMPERATURE, NOON, G.M.T. 1902.
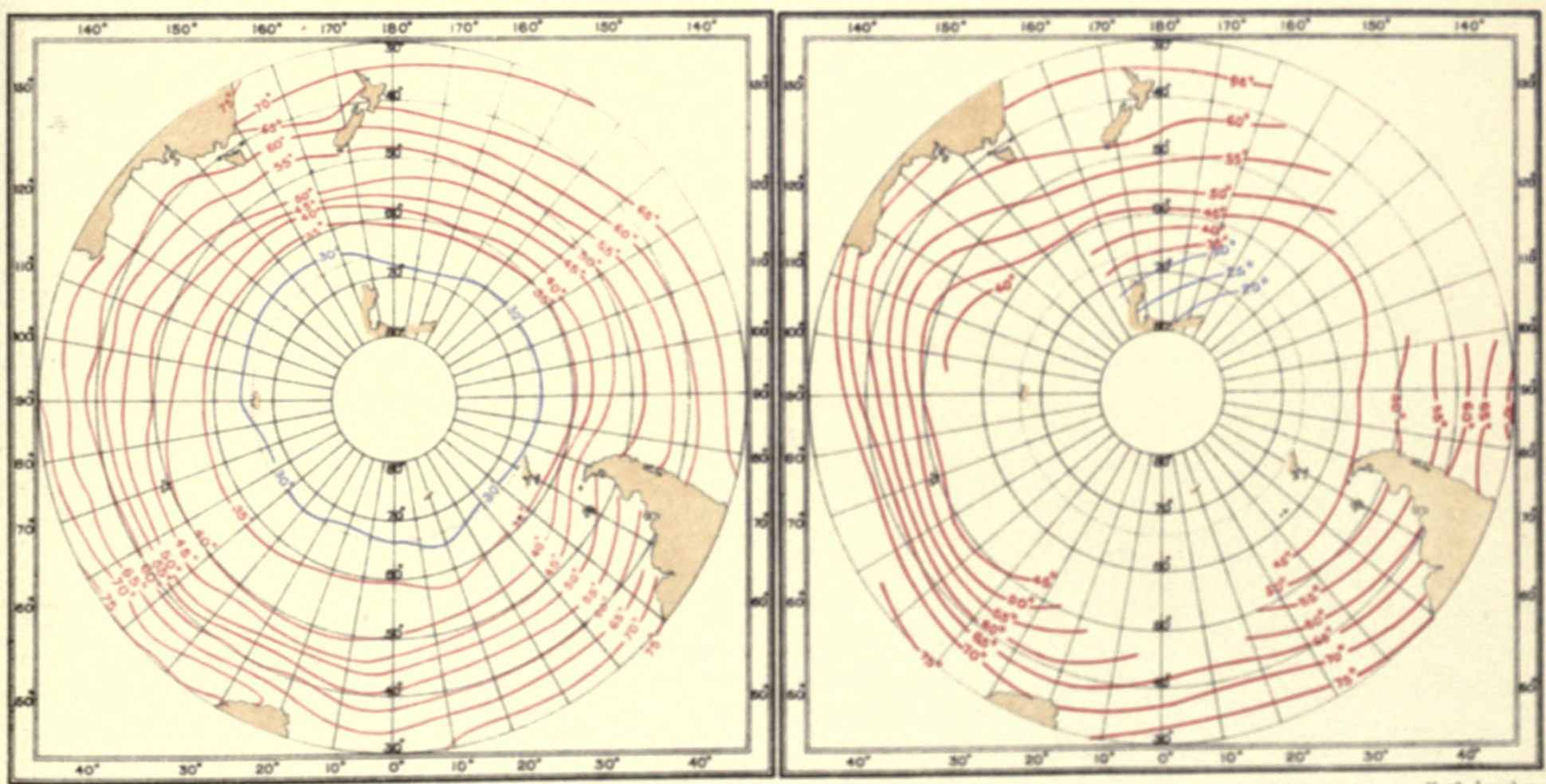

Hure Londet 


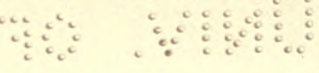

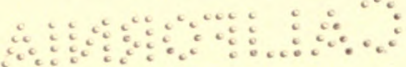


1) $\%$,

WA 


\section{INTERNATIONAL ANTARCTIC CO-OPERATION.}

CHARTS OF MEAN SEA LEVEL PRESSURE AND AIR TEMPERATURE.

FEBRUARY

NORMAL PRESSURE.
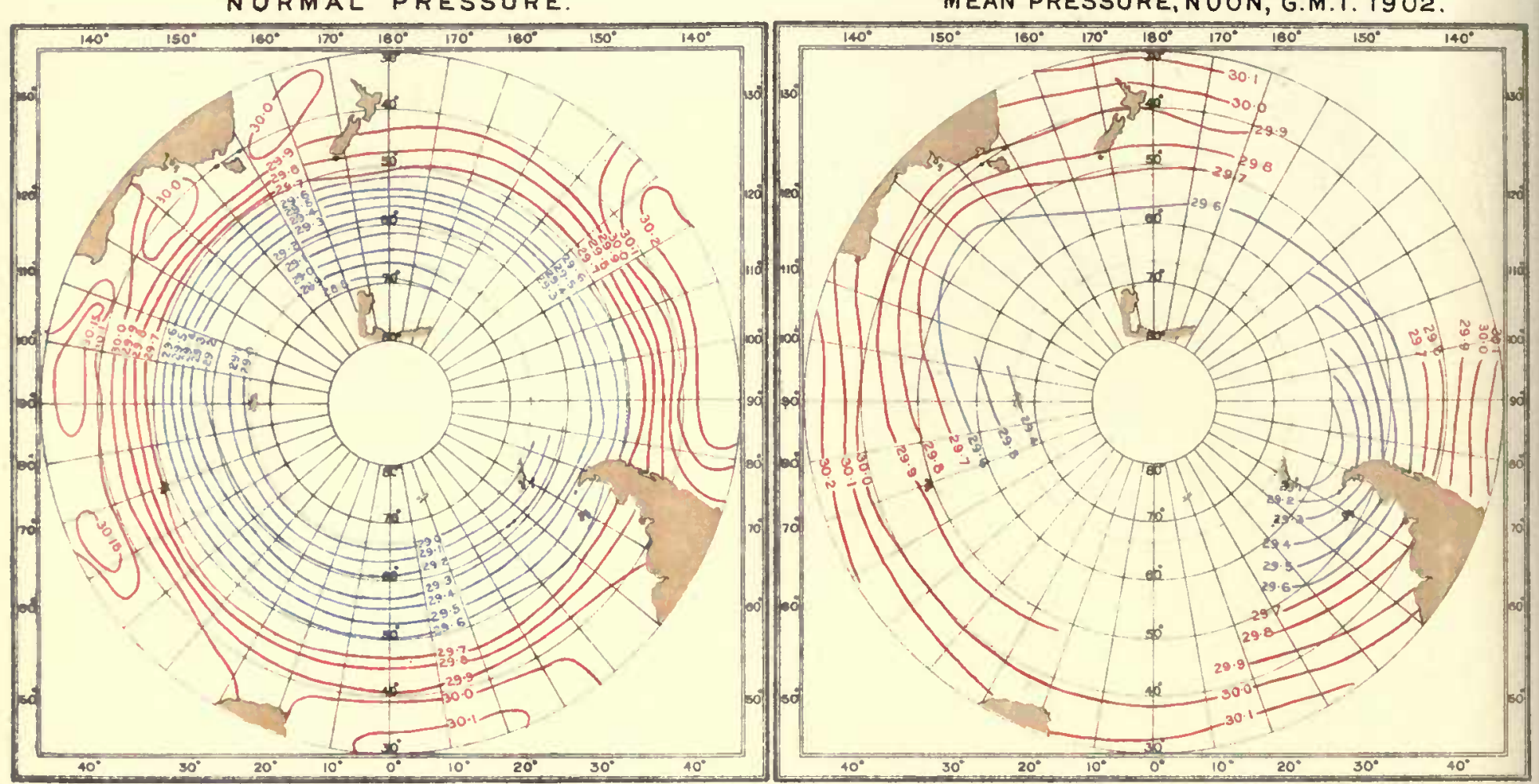

NORMAL AIR TEMPERATURE.

FEBRUARY

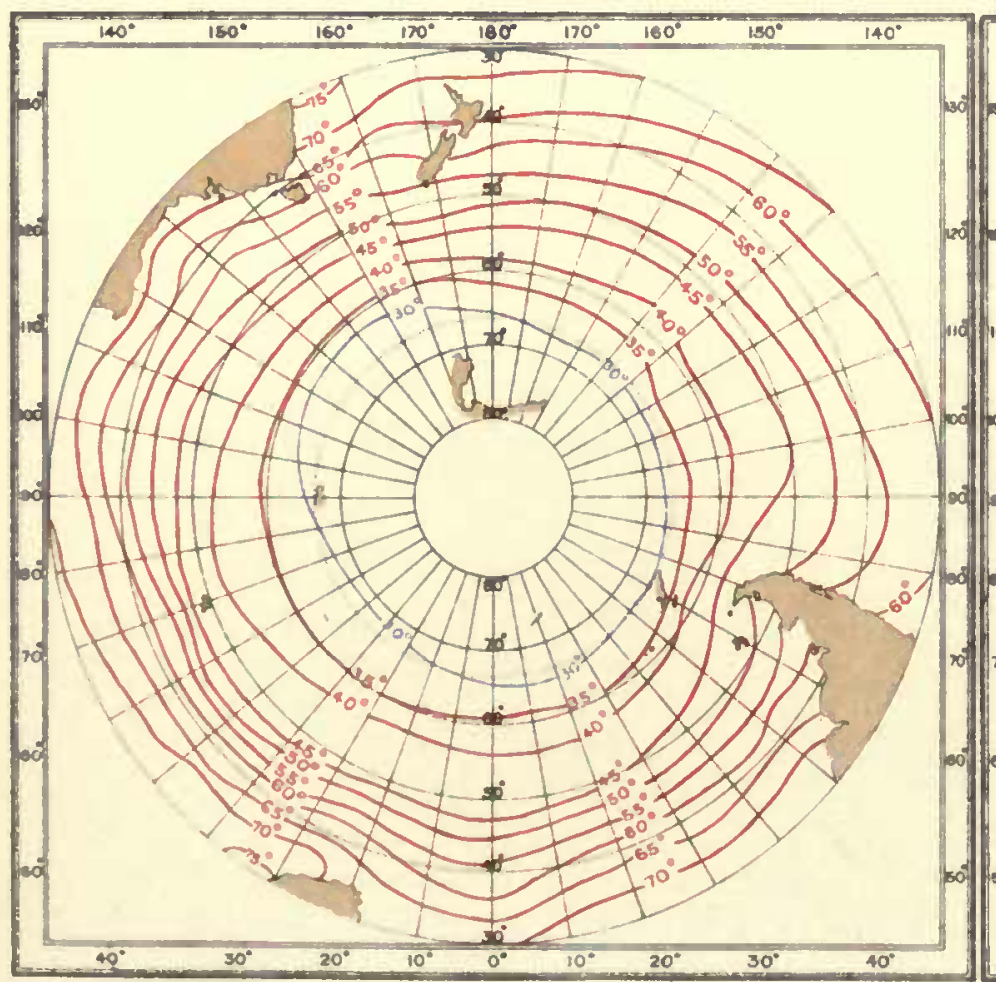

MEAN AIR TEMPERATURE, NOON, G.M.T. 1902.

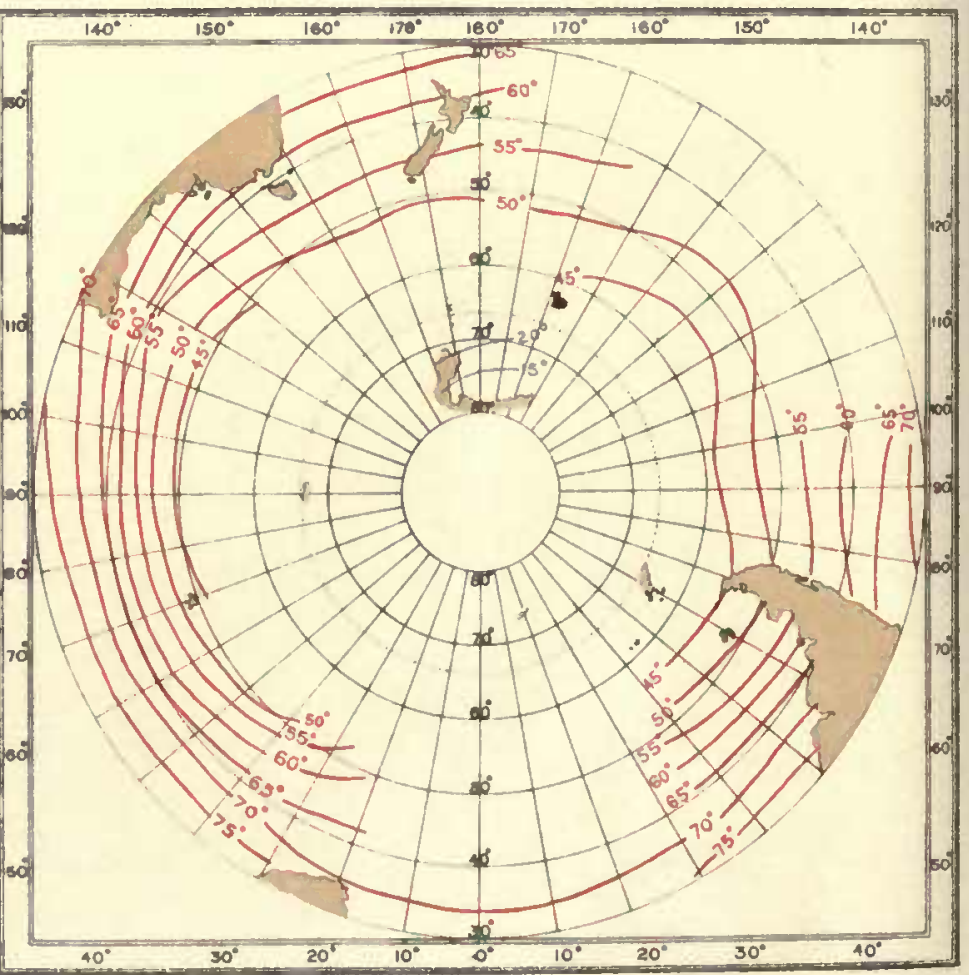


INTERNATIONAL ANTARCTIC CO-OPERATION.

CHARTS OF MEAN SEA LEVEL PRESSURE AND AIR TEMPERATURE,

MARCH

NORMAL PRESSURE.
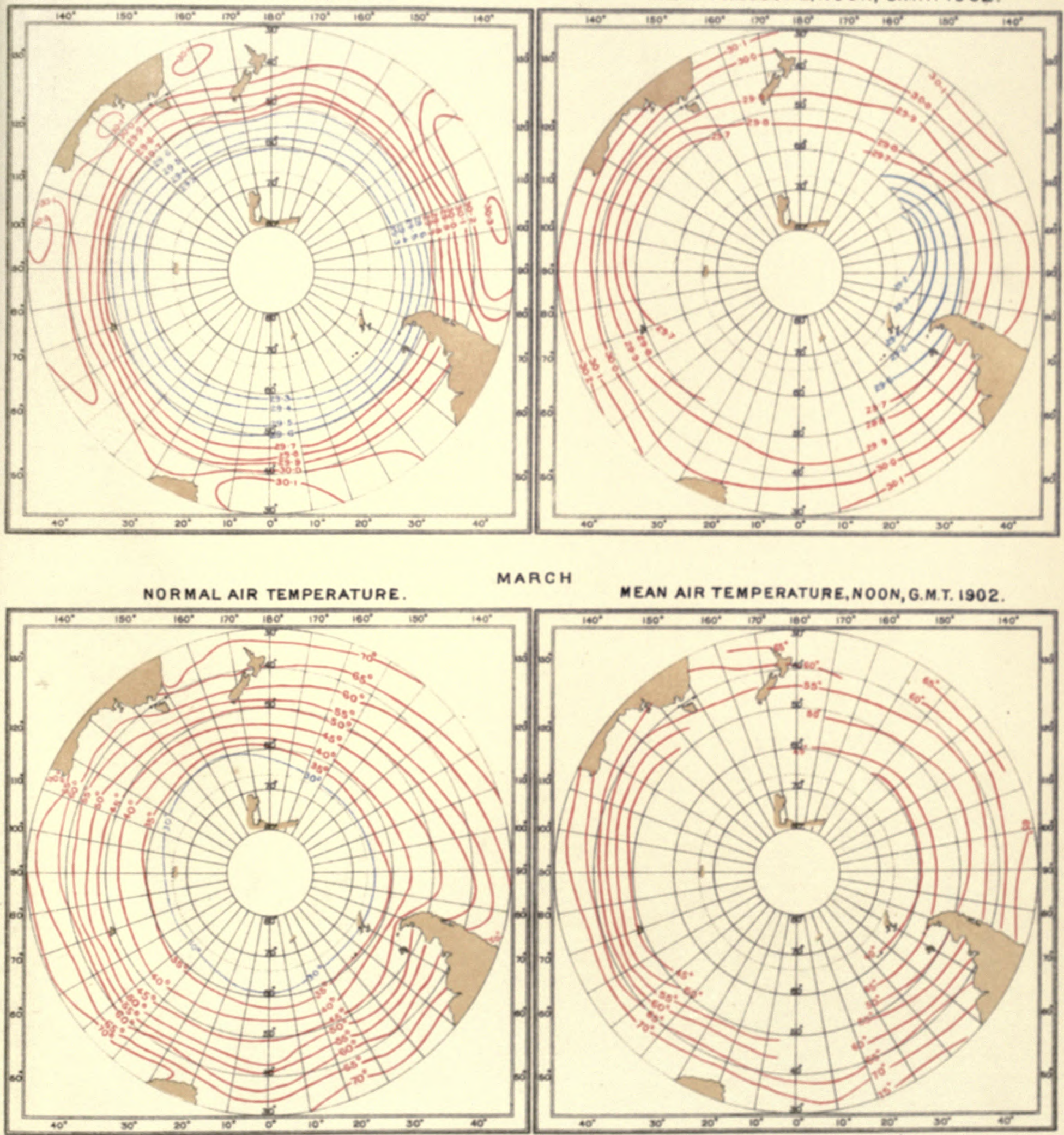

Huth londer 


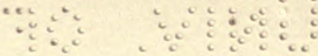

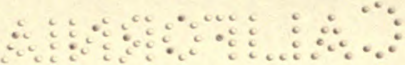


INTERNATIONAL ANTARCTIC CO-OPERATION.

CHARTS OF MEAN SEA LEVEL PRESSURE AND AIR TEMPERATURE.

APR IL

NORMAL PRESSURE.

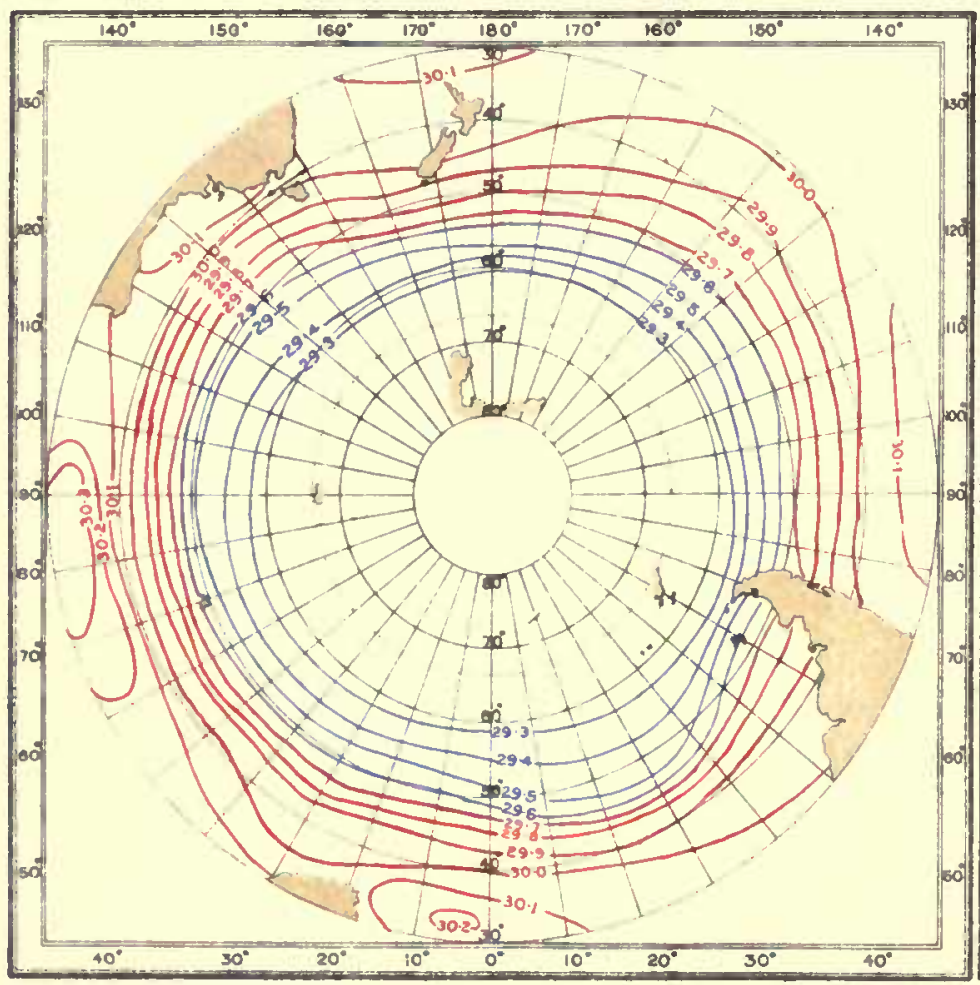

MEAN PRESSURE, NOON, G.M.T. 1902
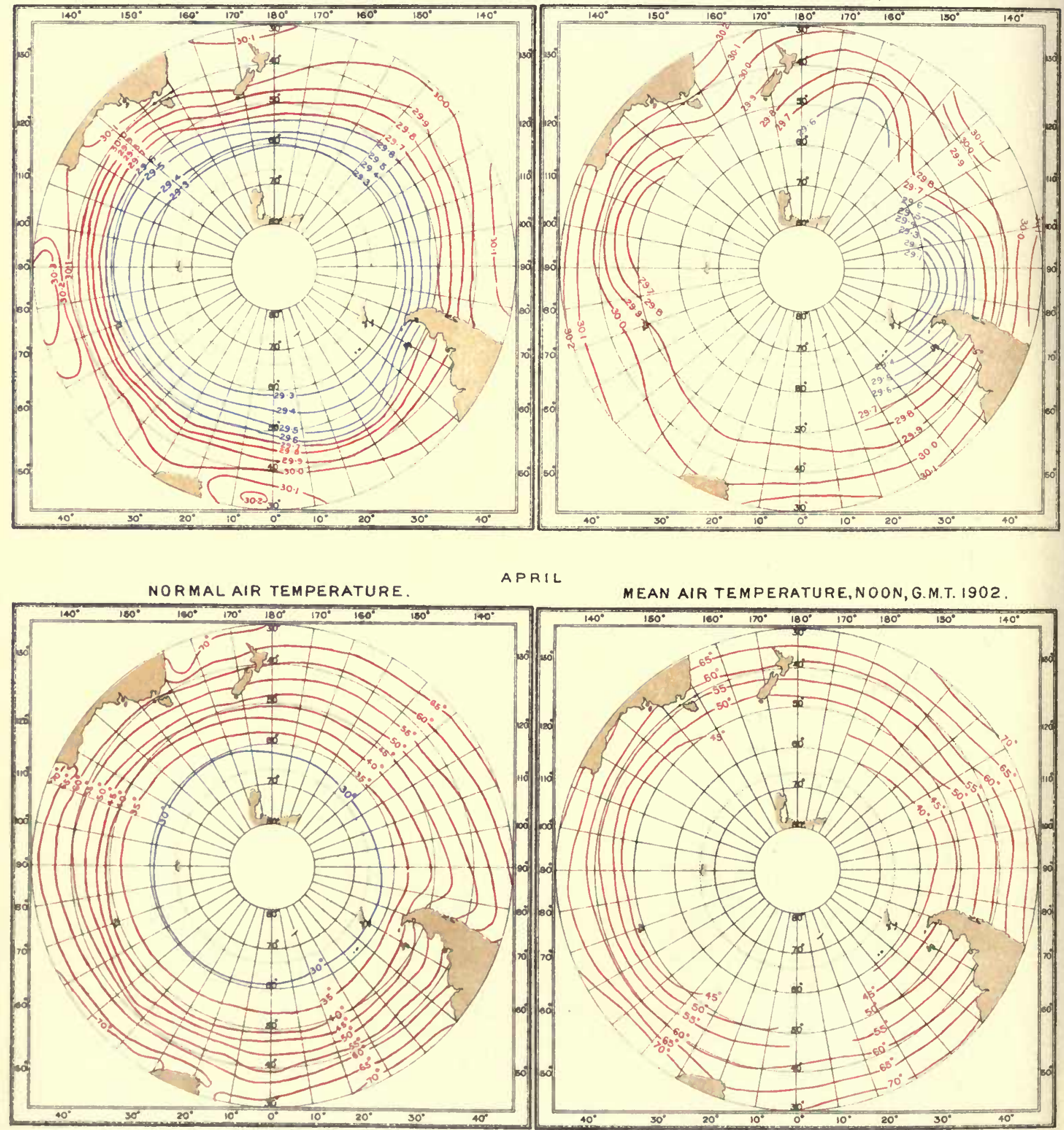

PRIL

MEAN AIR TEMPERATURE, NOON, G.M.T. 1902

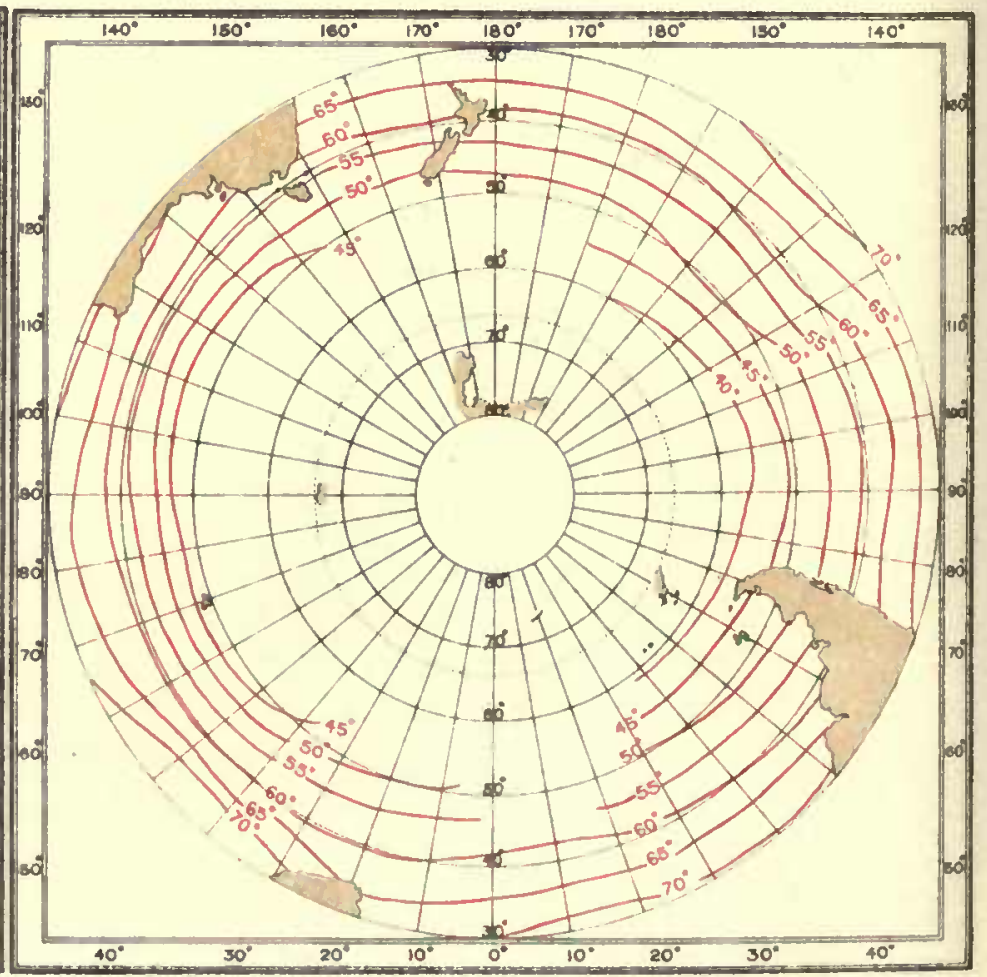


INTERNATIONAL ANTARCTIC CO-OPERATION.

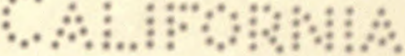

CHARTS OF MEAN SEA LEVEL PRESSURE AND AIR TEMPERATURE.

MA Y

NORMAL PRESSURE.

MEAN PRESSURE, NOON, G.M.T. 1902.
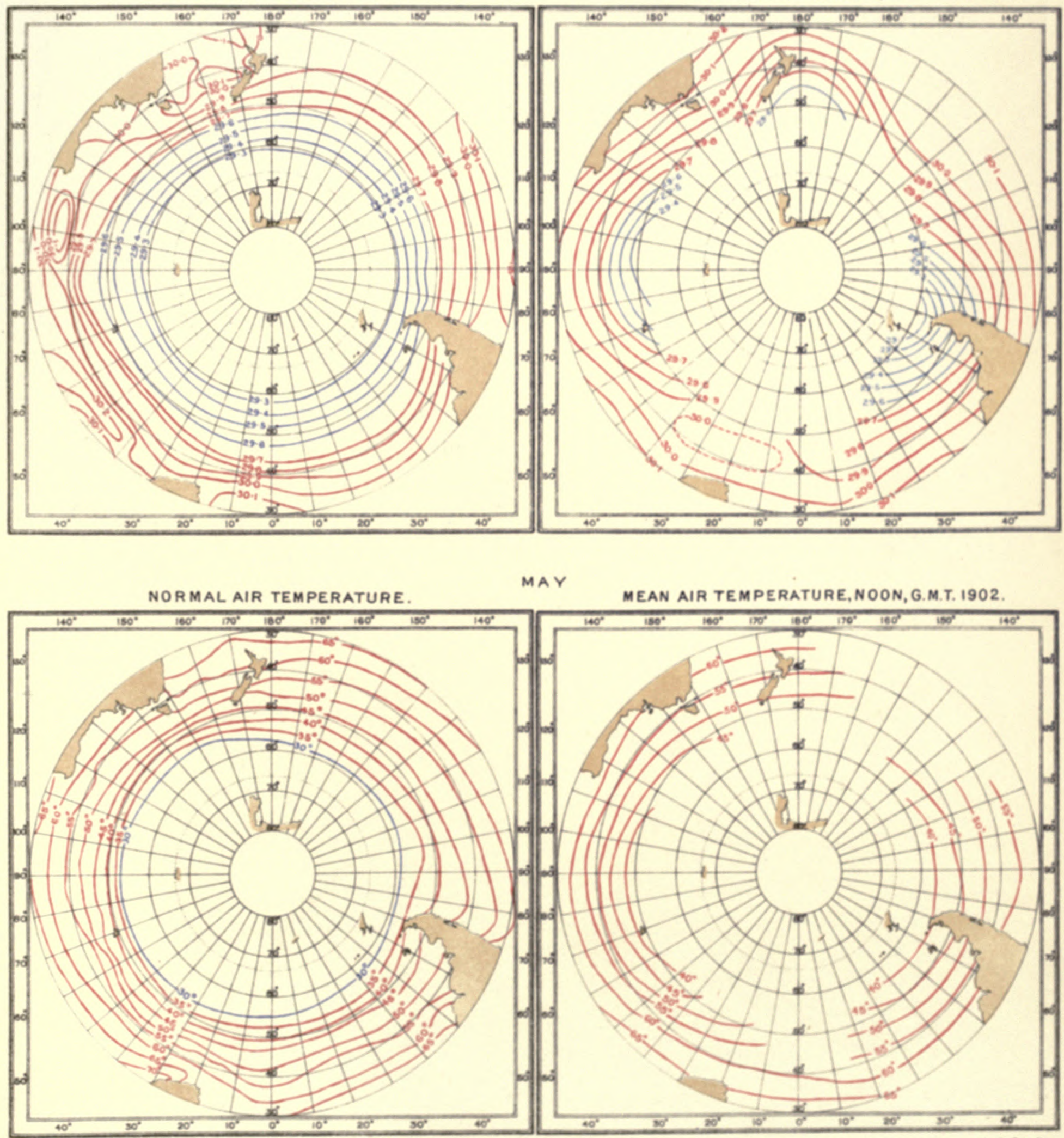


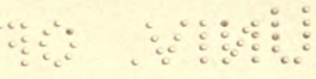

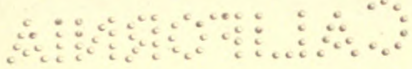




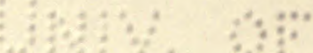

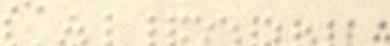


INTERNATIONAL ANTARCTIC CO-OPERATION.

CHARTS OF MEAN SEA LEVEL PRESSURE AND AIR TEMPERATURE.

JUNE

NORMAL PRESSURE.

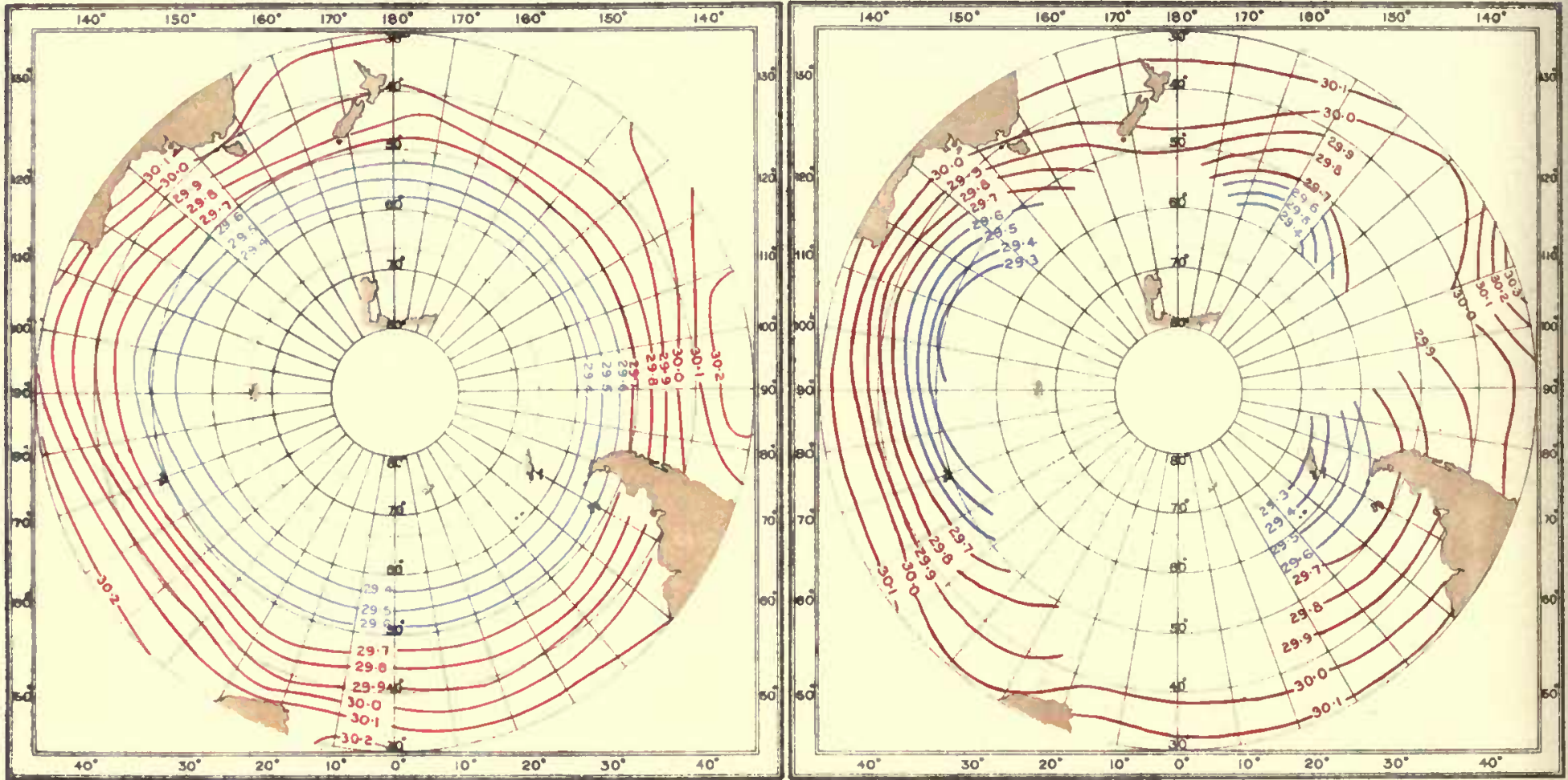

JUNE

NORMAL AIR TEMPERATURE.

MEAN AIR TEMPERATURE, NOON, G.M.T. 1902.

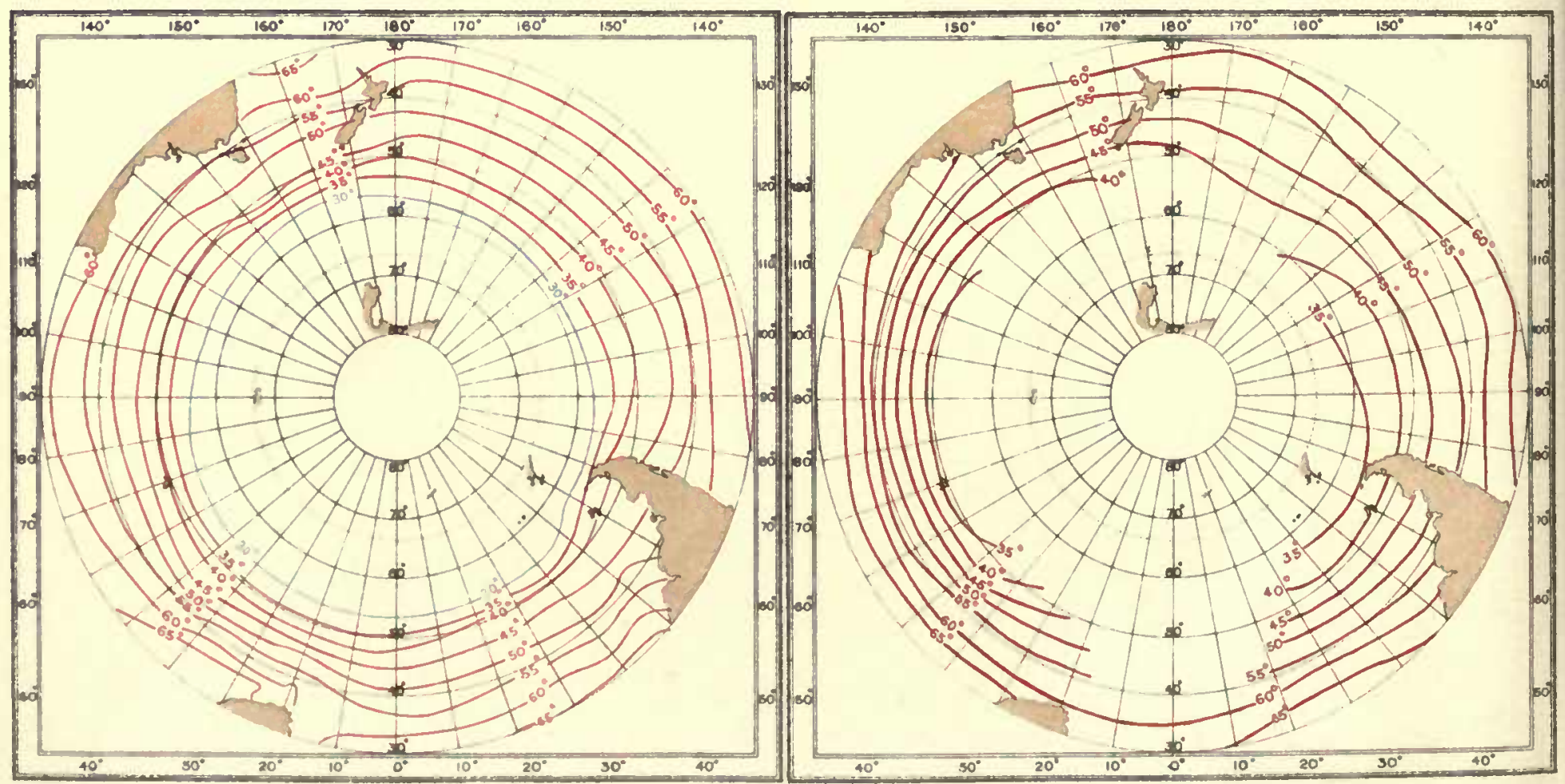


INTERNATIONAL ANTARCTIC CO-OPERATION.

CHARTS OF MEAN SEA LEVEL PRESSURE AND AIR TEMPERATURE.

JULY

NORMAL PRESSURE.

MEAN PRESSURE, NOON, G.M.T. 1902.
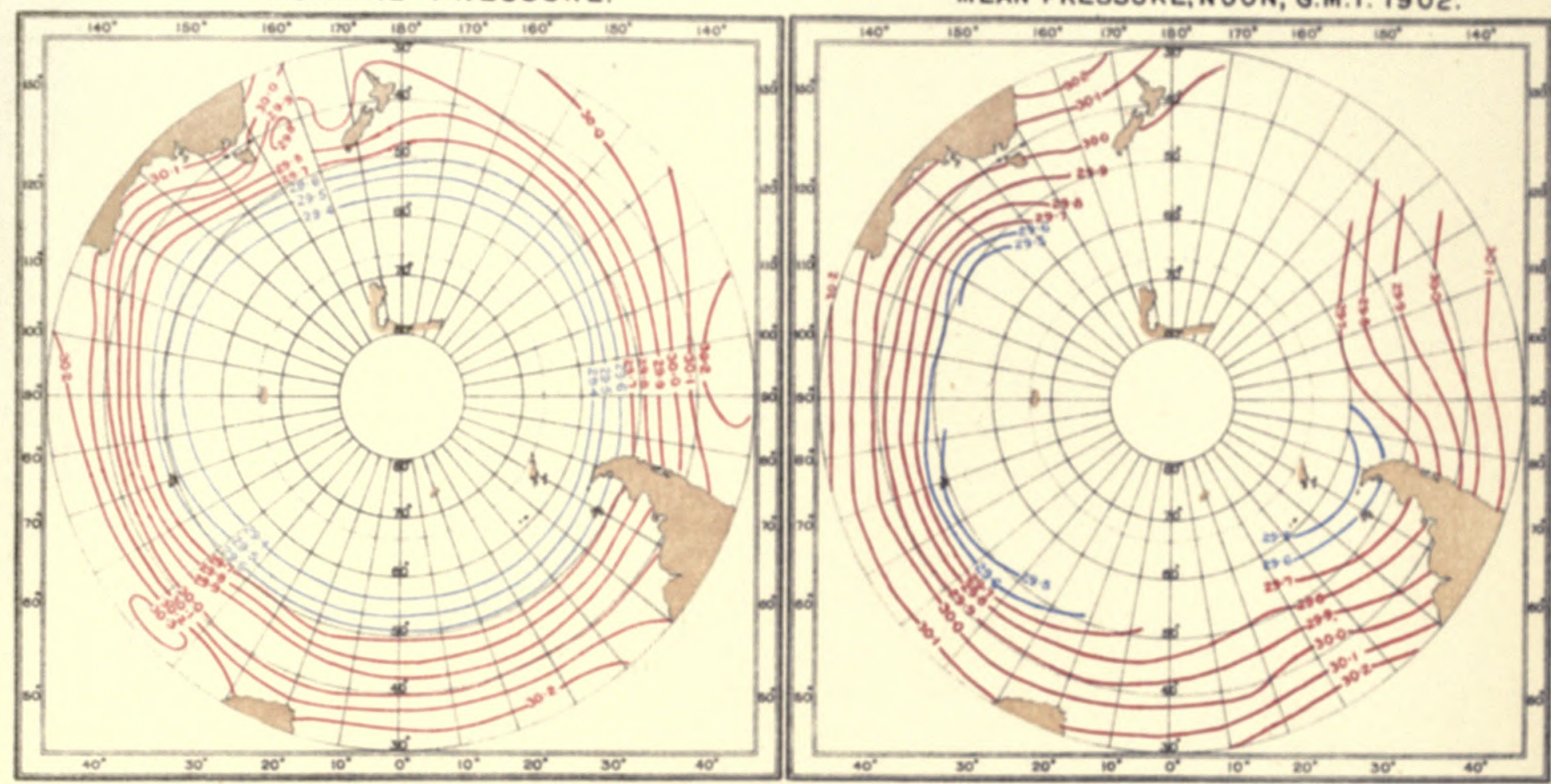

JULY

NORMAL AIR TEMPERATURE.

MEAN AIR TEMPERATURE, NOON, G.M.T. 1902.
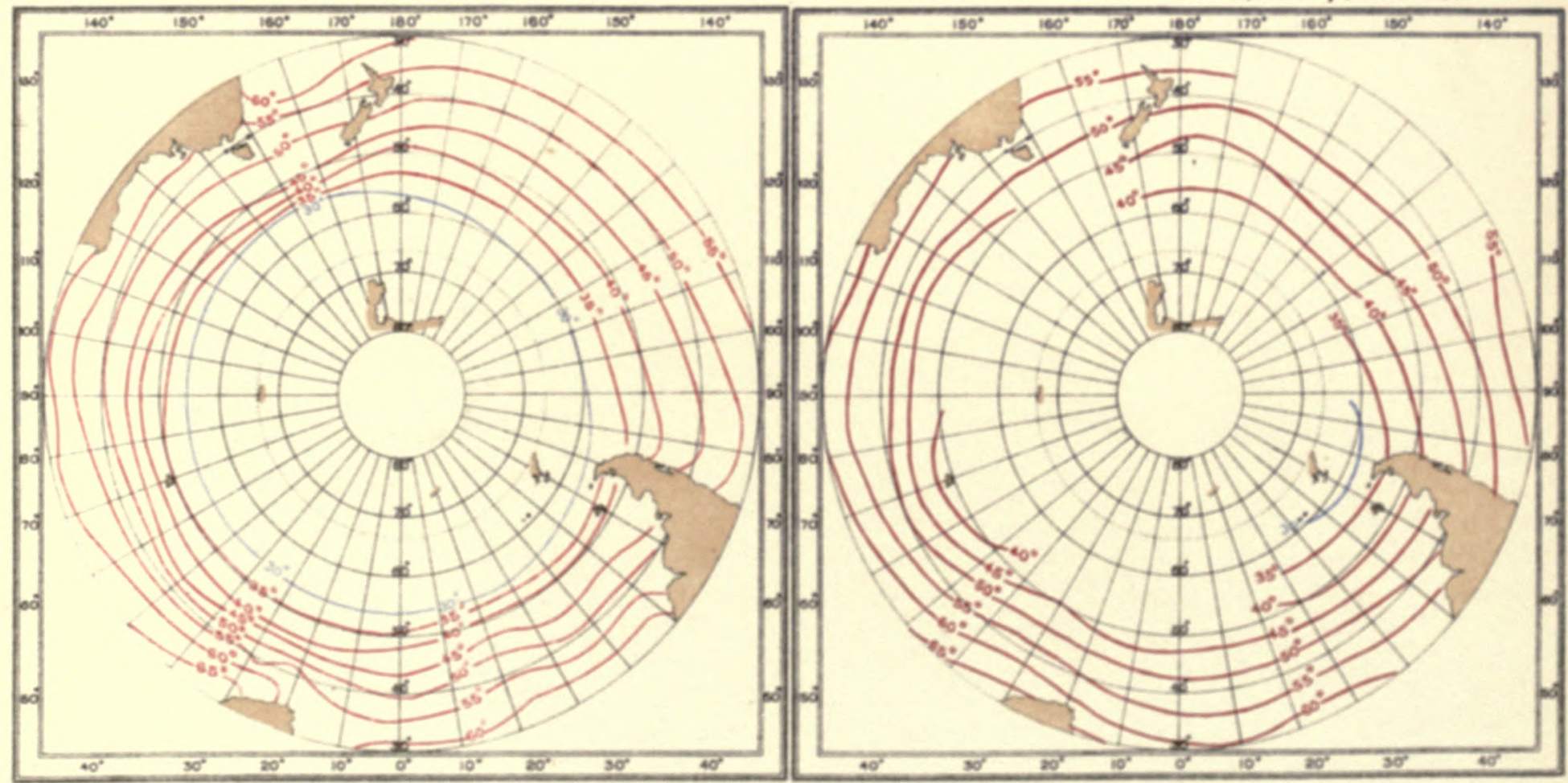


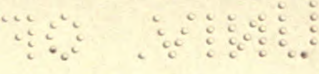

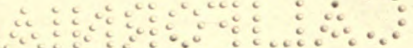




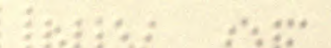

品:

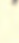


INTERNATIONAL ANTARCTIC CO-OPERATION.

CHARTS OF MEAN SEA LEVEL PRESSURE AND AIR TEMPERATURE.

AUGUST

NORMAL PRESSURE.

MEAN PRESSURE, NOON, G.M.T. 1902.
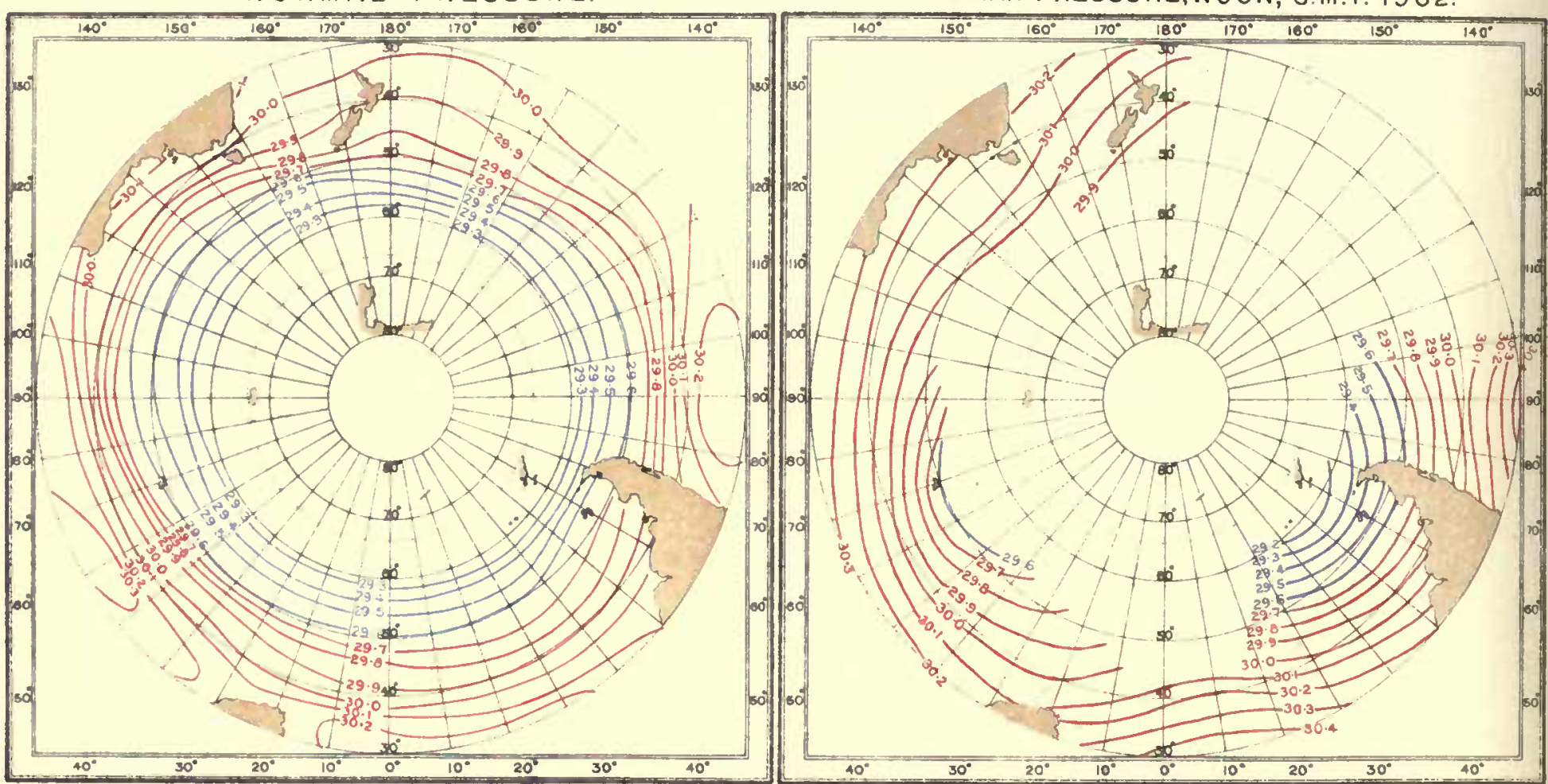

AUGUST

NORMAL AIR TEMPERATURE.

MEAN AIR TEMPERATURE,NOON, G.M.T. 1902.

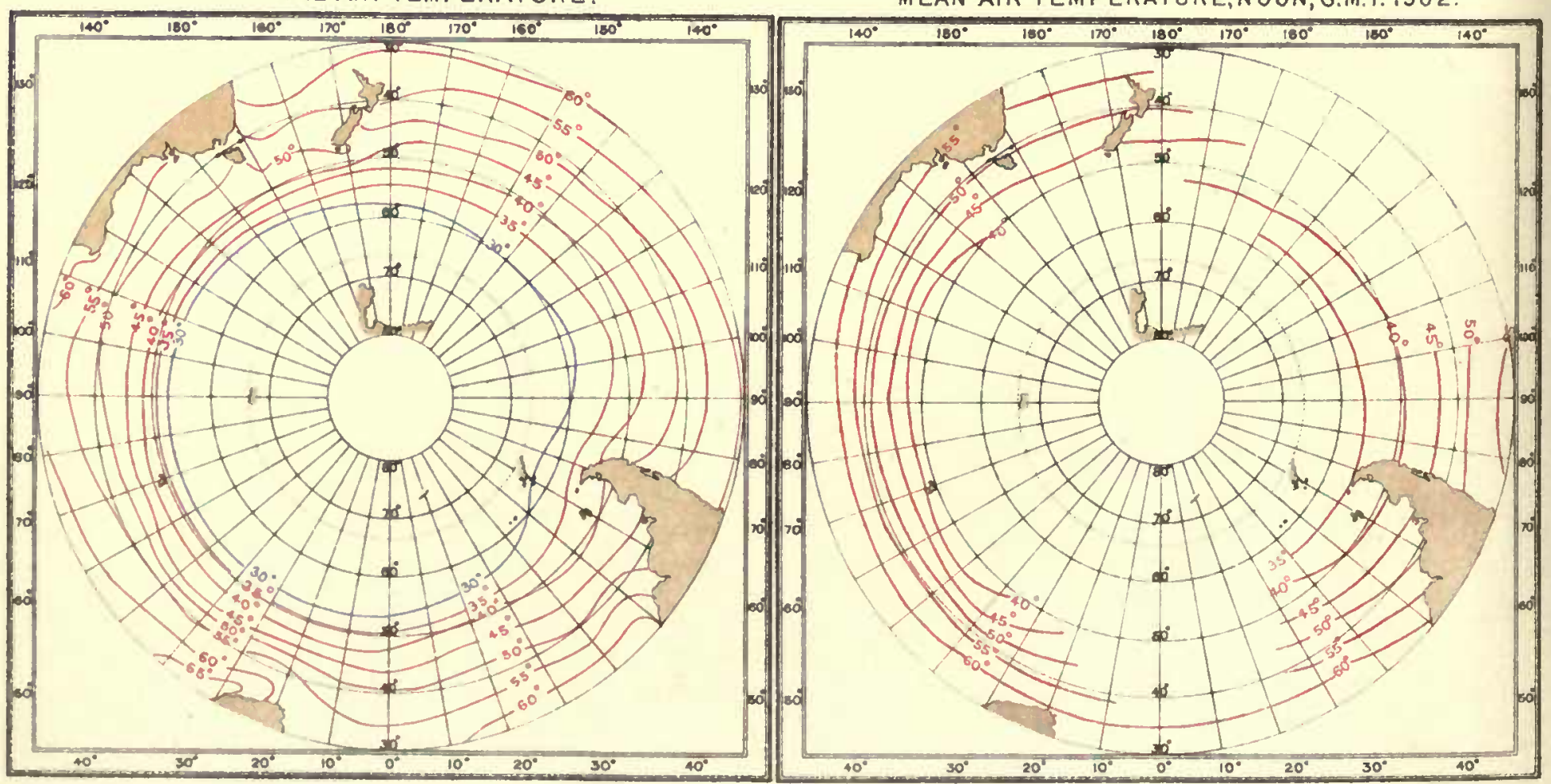


INTERNATIONAL ANTARCTIC CO-OPERATION.

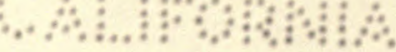

CHARTS OF MEAN SEA LEVEL PRESSURE AND AIRTEMPERATURE.

SEPTEMBER

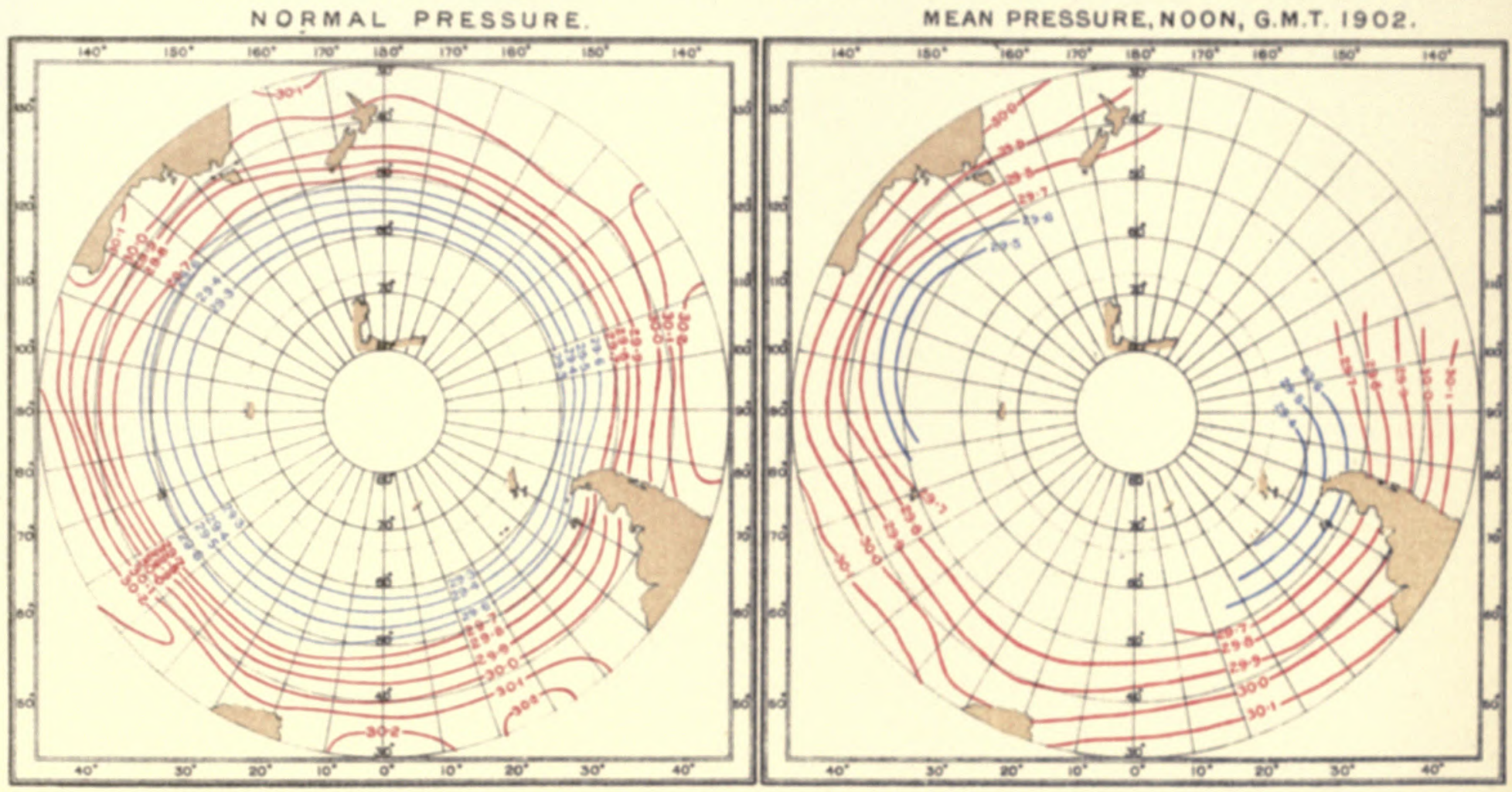

SEPTEMBER

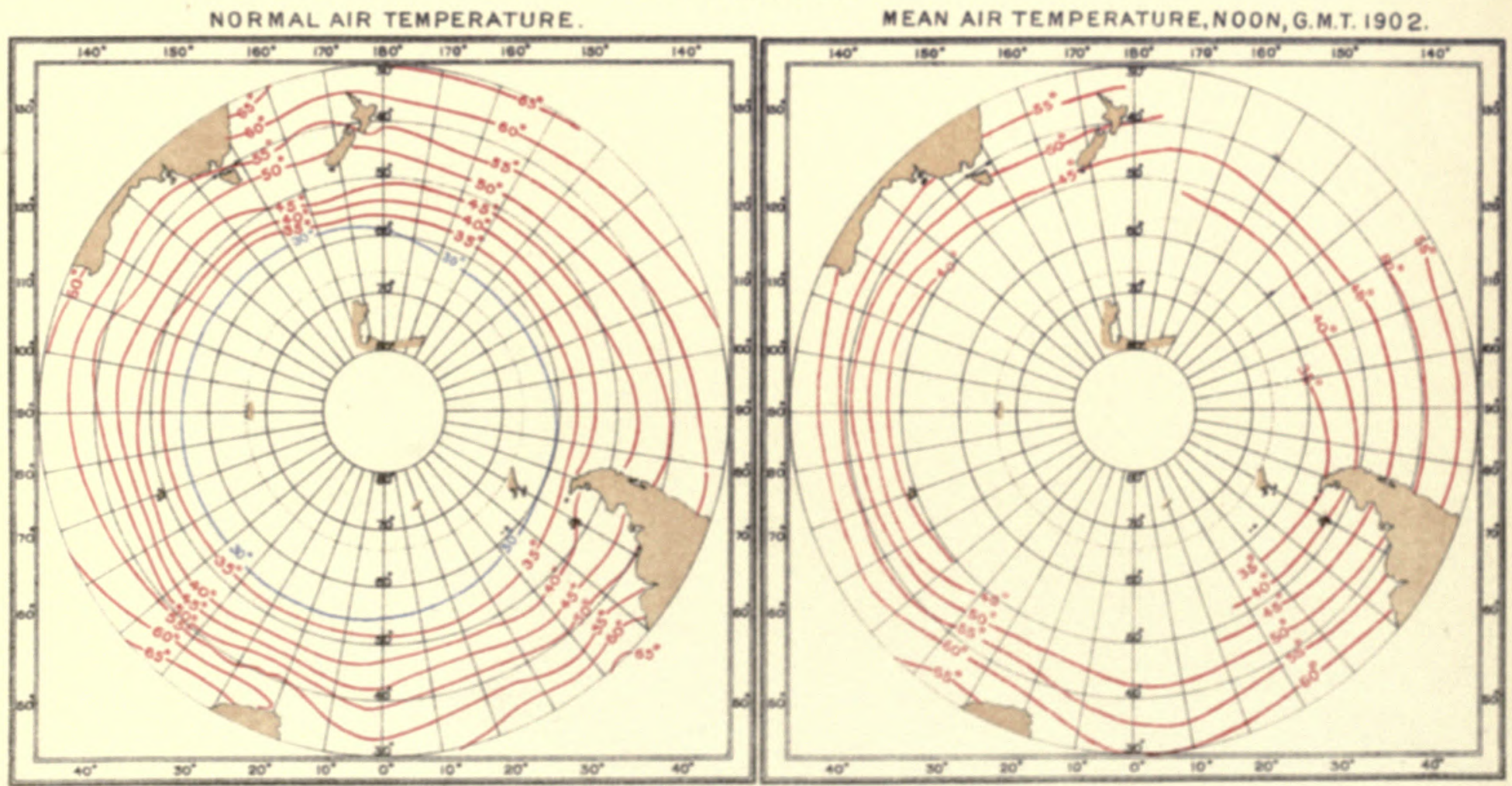




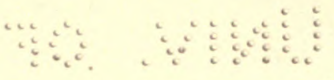

$\therefore \vdots \vdots \vdots \because \vdots \because \vdots \vdots \vdots \vdots \cdots \cdots \cdots$ 
a)

\% A 
INTERNATIONAL ANTARCTIC CO-OPERATION.

CHARTS OF MEAN SEA LEVEL PRESSURE AND AIR TEMPERATURE.

OCTOBER

NORMAL PRESSURE.

MEAN PRESSURE, NOON, G.M.T. 1902.
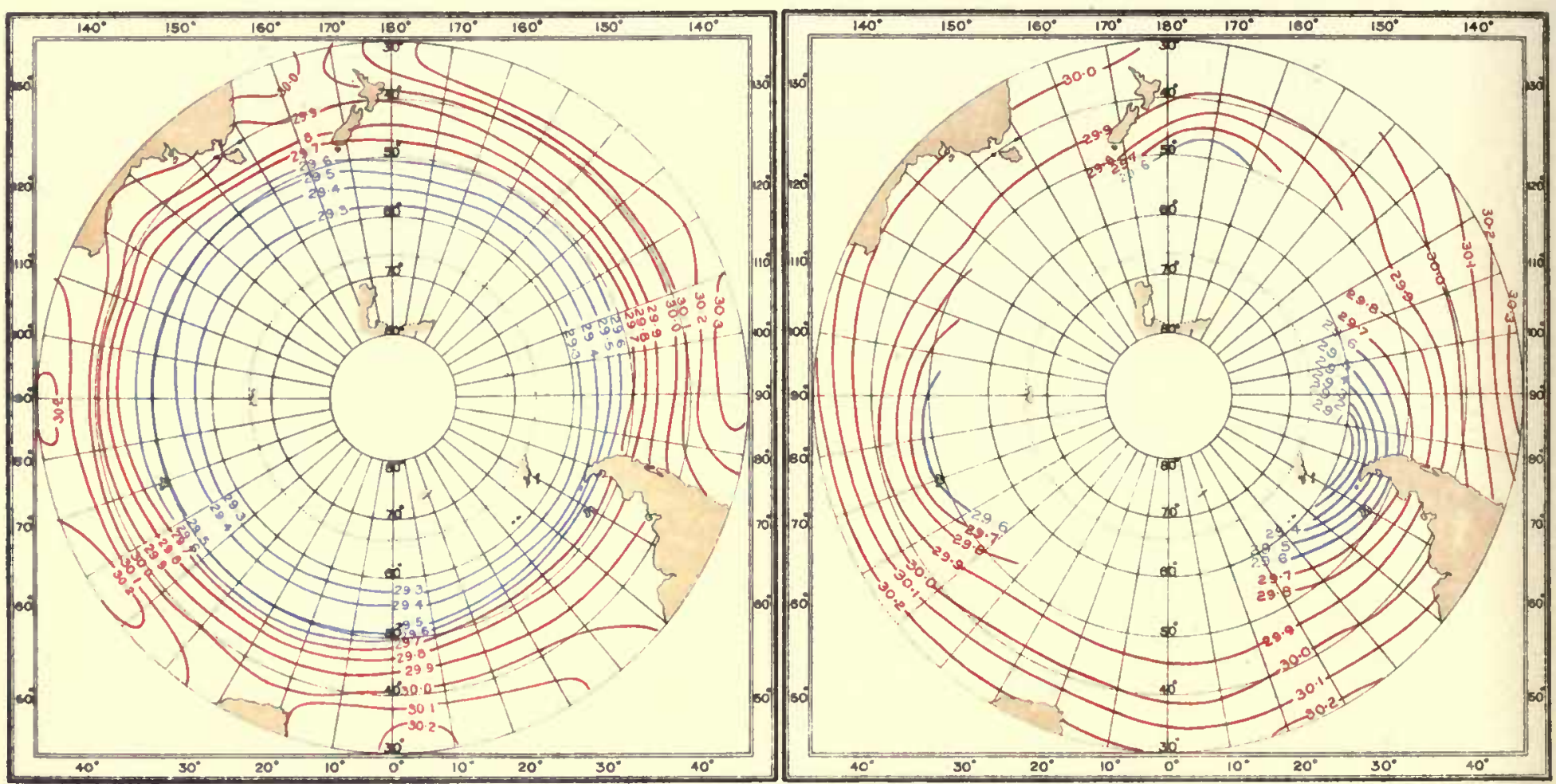

NORMAL AIR TEMPERATURE.

MEAN AIR TEMPERATURE, NOON, G.M.T. 1902.

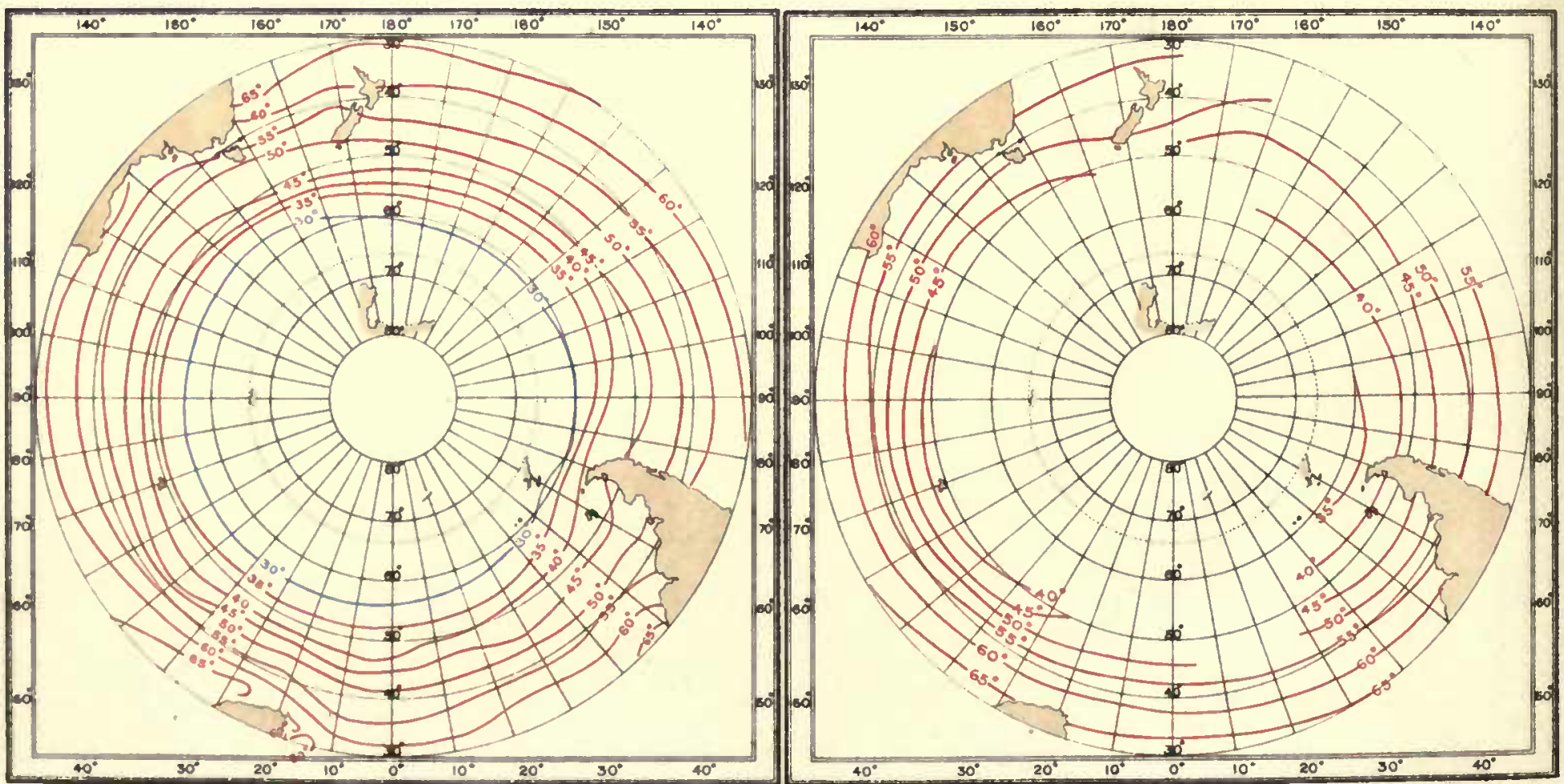


INTERNATIONAL ANTARCTIC CO-OPERATION.

CHARTS OF MEAN SEA LEVEL PRESSURE AND AIR TENPERATURE.

NOVEMBER

NORMAL PRESSURE.

MEAN PRESSURE, NOON, G.M.T. 1902.

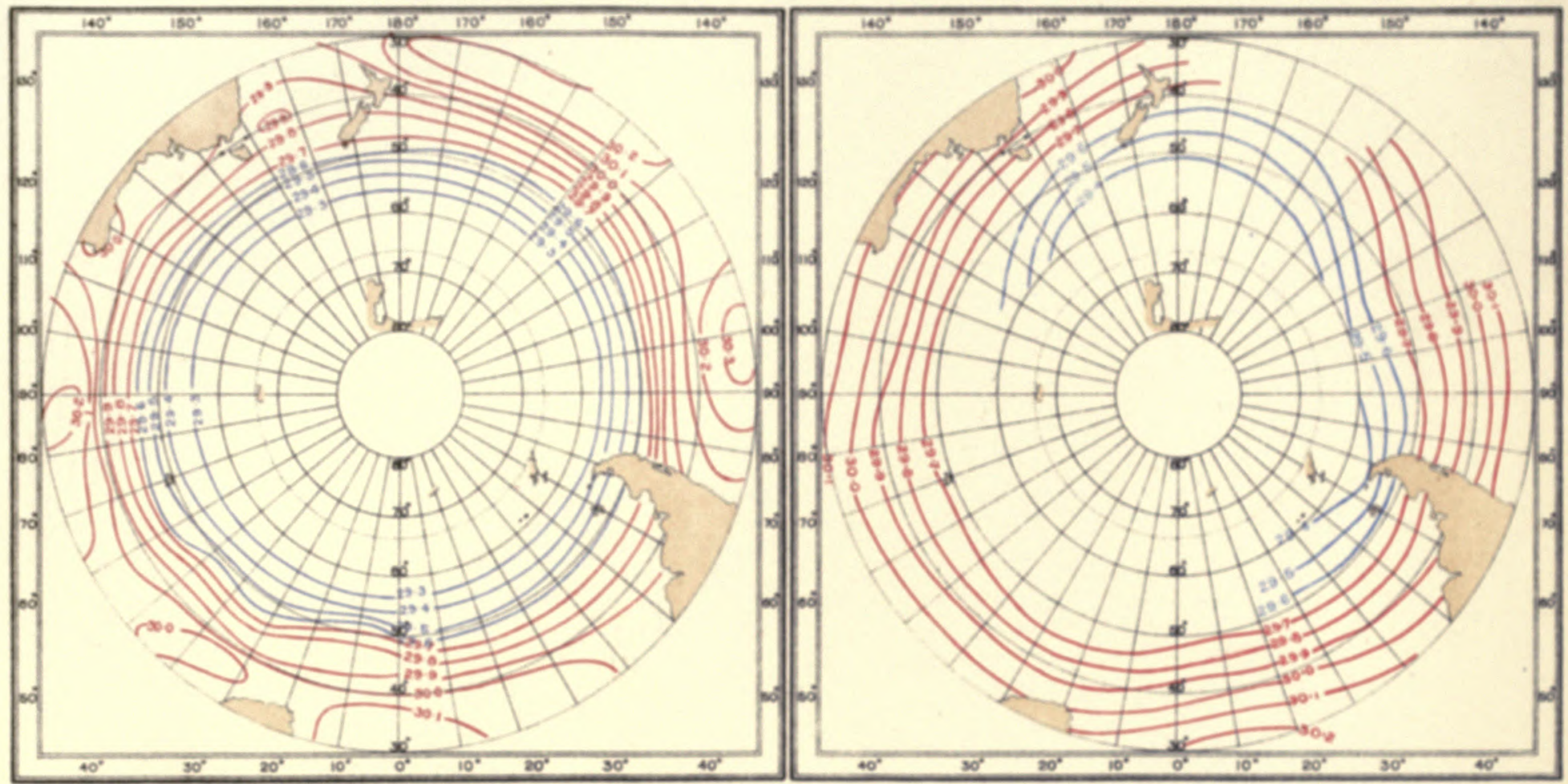

NORMAL AIR TEMPERATURE.

NOVEMBER MEAN AIR TEMPERATURE, NOON, G.M.T. 1902.

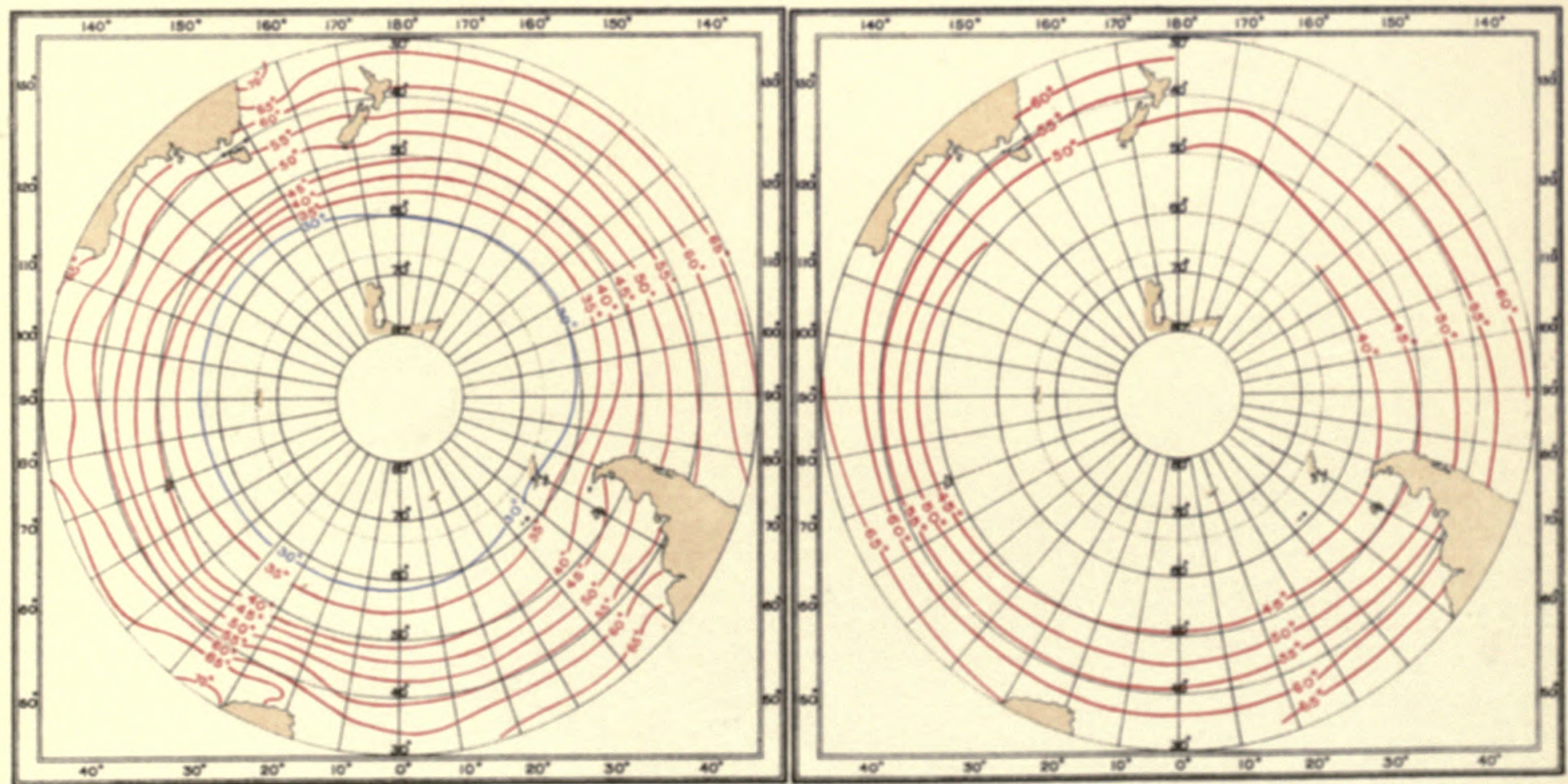

Hith Londor: 
a 
2.8\%

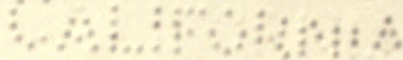


INTERNATIONAL ANTARCTIC CO-OPERATION.

CHARTS OF MEAN SEA LEVEL PRESSURE AND AIR TEMPERATURE.

DECEMBER

NORMAL PRESSURE.

MEAN PRESSURE, MOON, G.M.T. 1902.
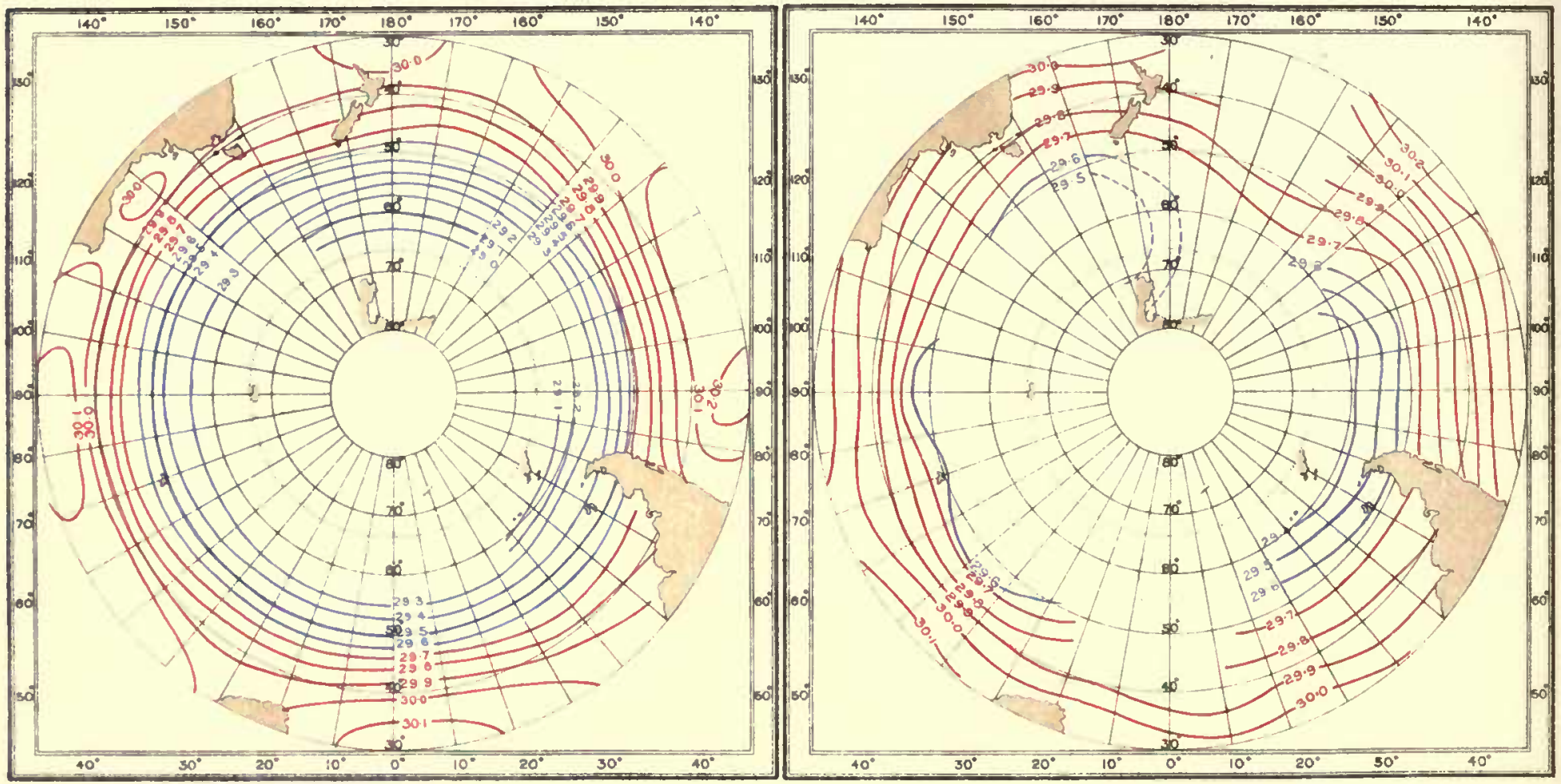

NORMAL AIR TEMPERATURE.

DECEMBER

MEAN AIR TEMPERATURE, NOON, G.M.T. 1902.

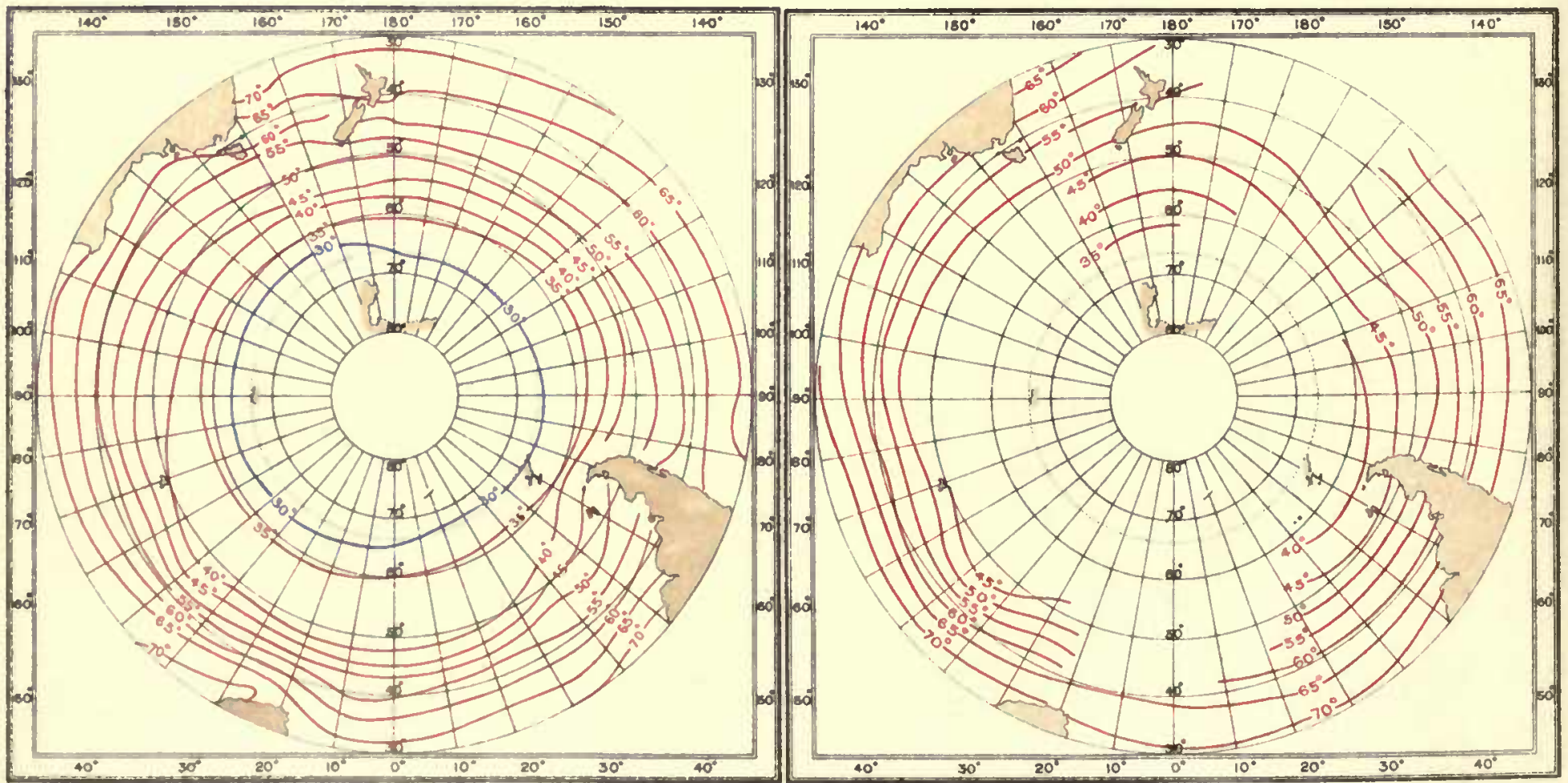


INTERNATIONAL ANTARCTIC CO-OPERATION.

CHARTS OF MEAN SEA LEVEL PRESSURE AND AIR TEMPERATURE.

JANU A RY

NORMAL PRESSURE.

MEAN PRESSURE, NOON, G.M.T. 1903.

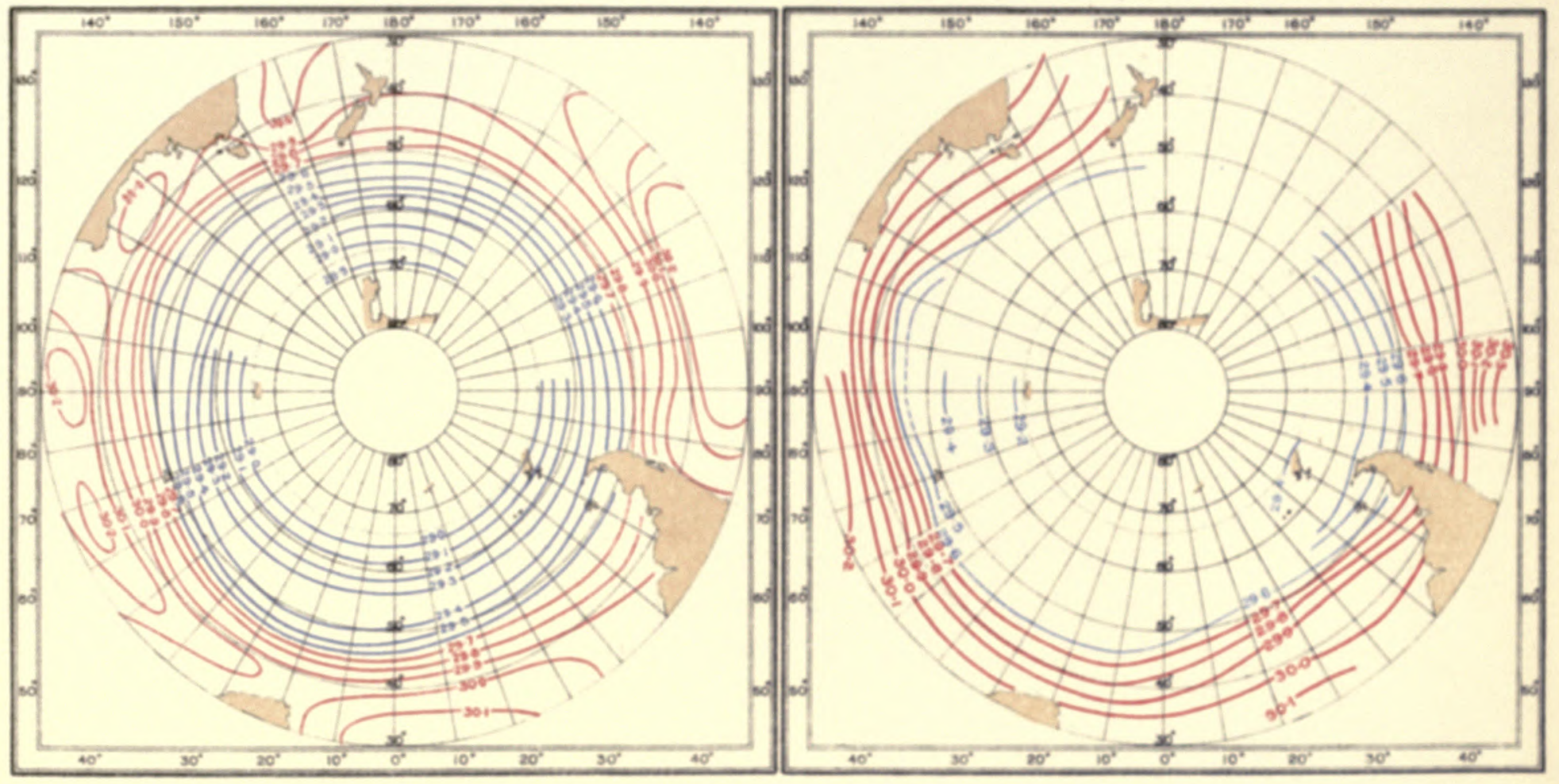

NORMAL AIR TEMPERATURE.

MEAN AIR TEMPERATURE,NOON, G.M.T. 1903.

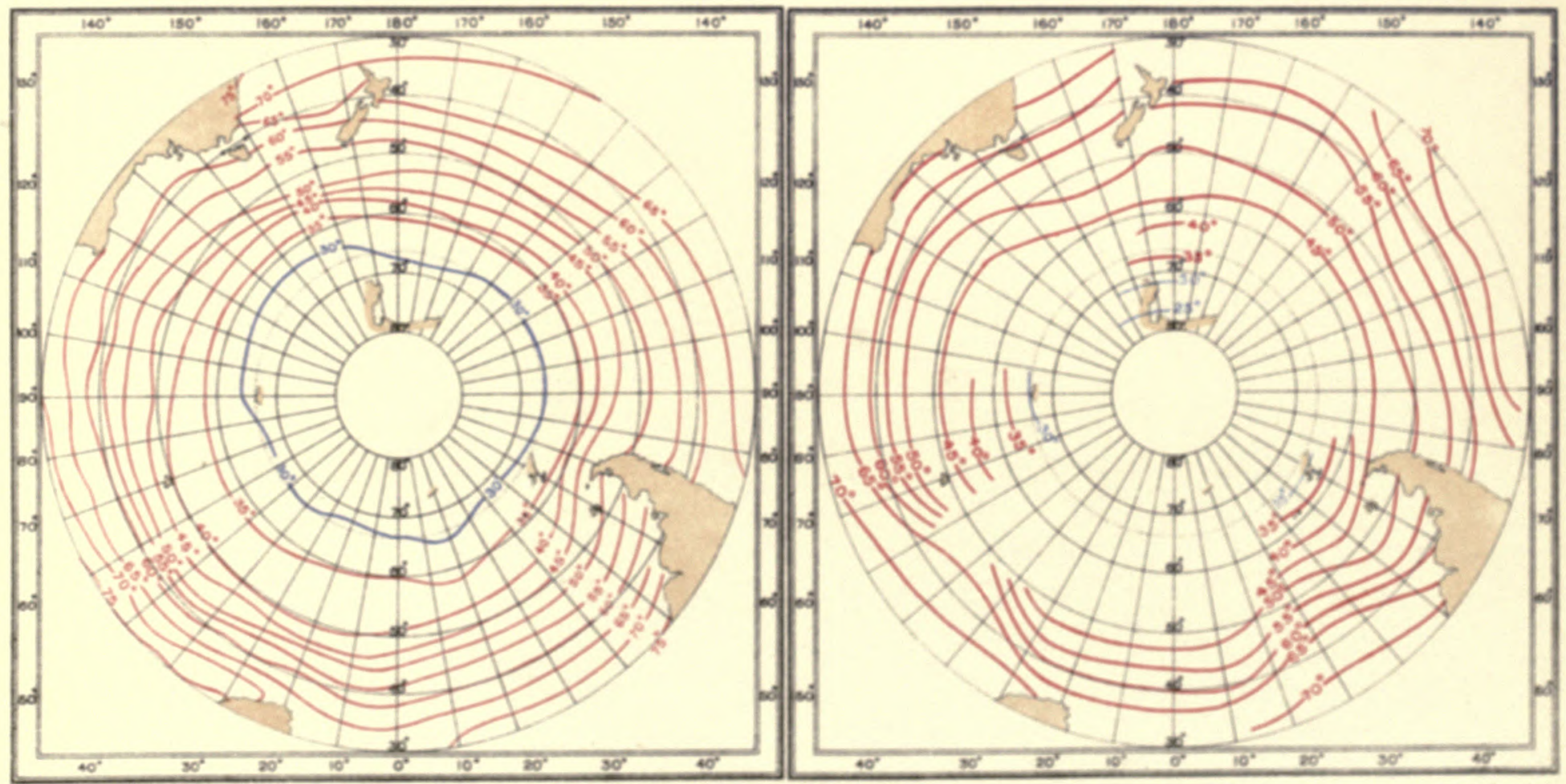


和

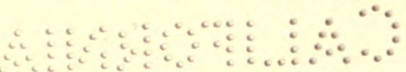


1)

W. 
INTERNATIONAL ANTARCTIC CO-OPERATION.

CHARTS OF MEAN SEA LEVEL PRESSURE AND AIR TEMPERATURE.

FEBRUARY

NORMAL PRESSURE.

MEAN PRESSURE, NOON, G.M.T. 1903
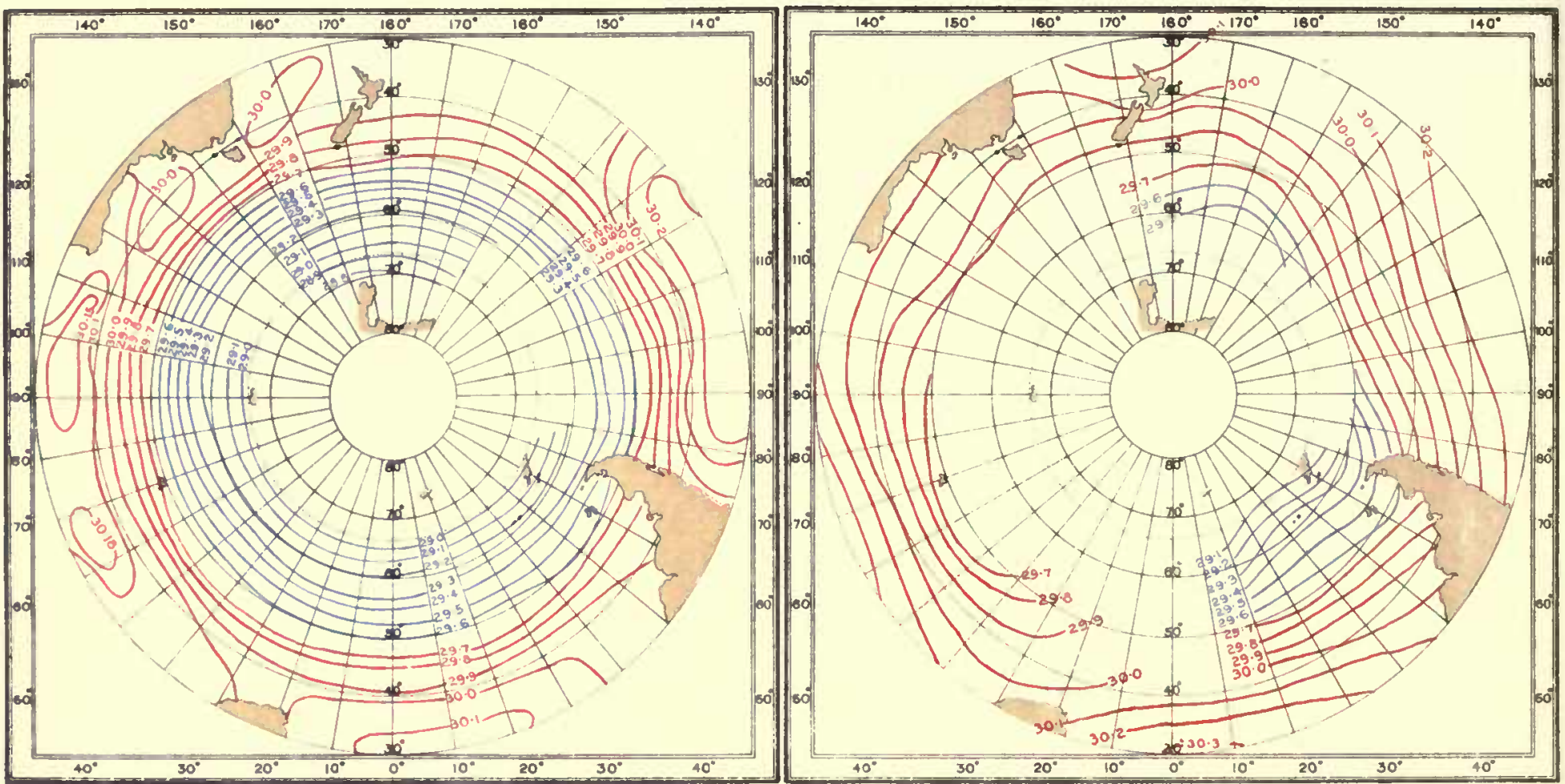

NORMAL AIR TEMPERATURE.

FEBRUARY

MEAN AIR TEMPERATURE, NOON, G.M.T. 1903.

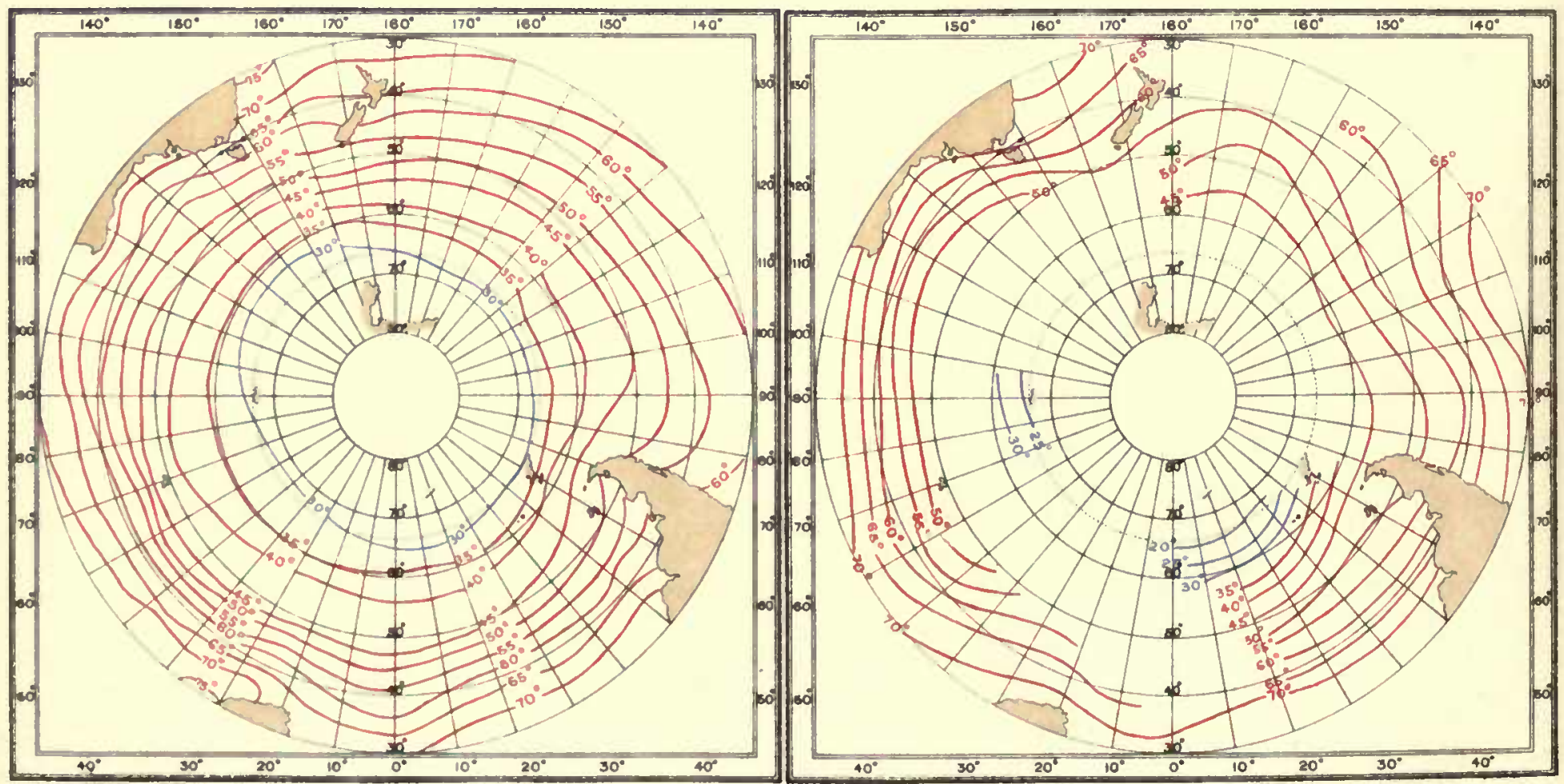


INTERNATIONAL ANTARCTIC CO-OPERATION.

CHARTS OF MEAN SEA LEVEL PRESSURE AND AIR TEMPERATURE.

MARCH

NORMAL PRESSURE.

MEAN PRESSURE, NOON, G.M.T. 1903.

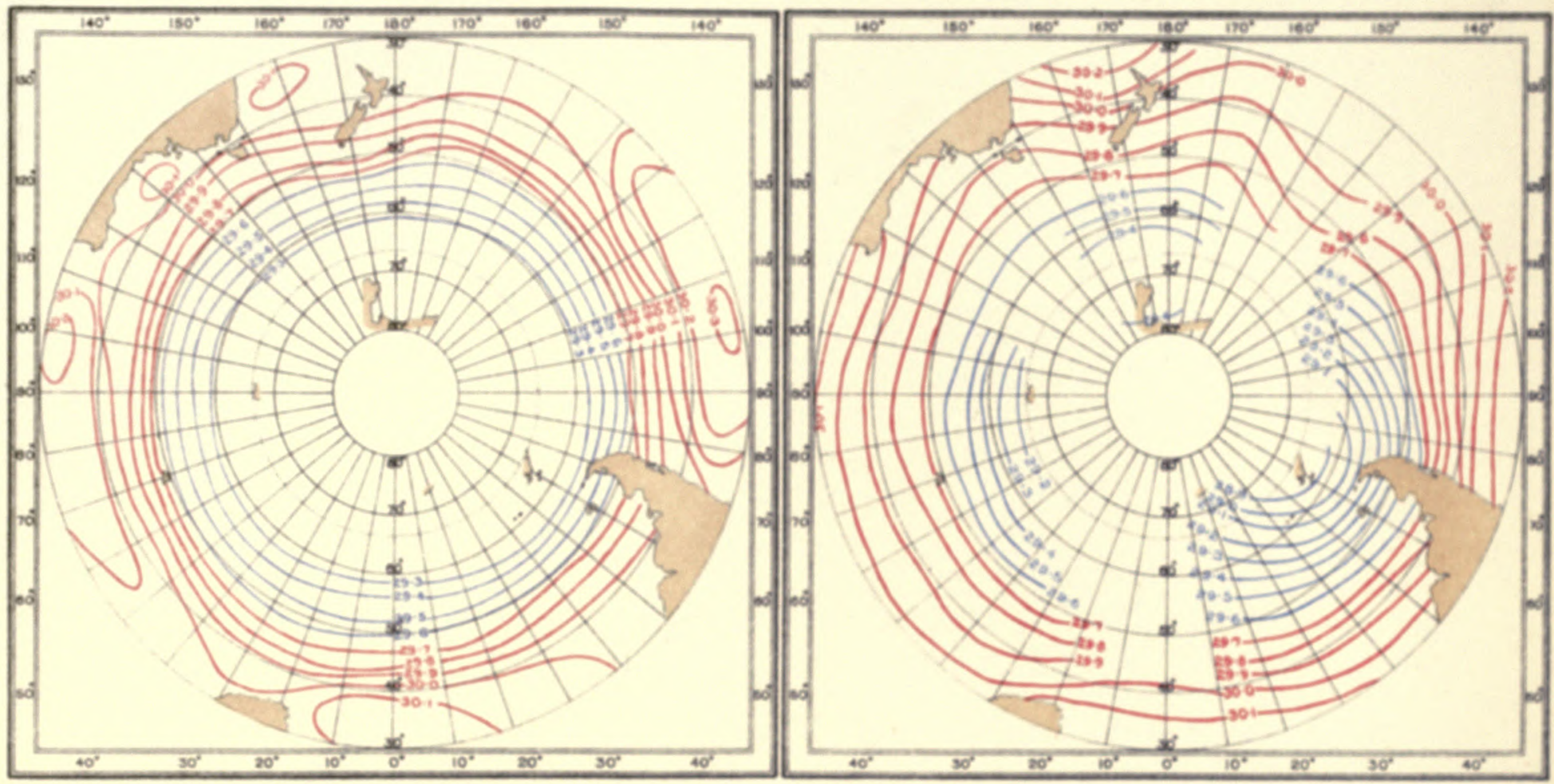

NORMAL AIR TEMPERATURE.

MARCH

MEAN AIR TEMPERATURE, NOON, G.M.T. 1903.

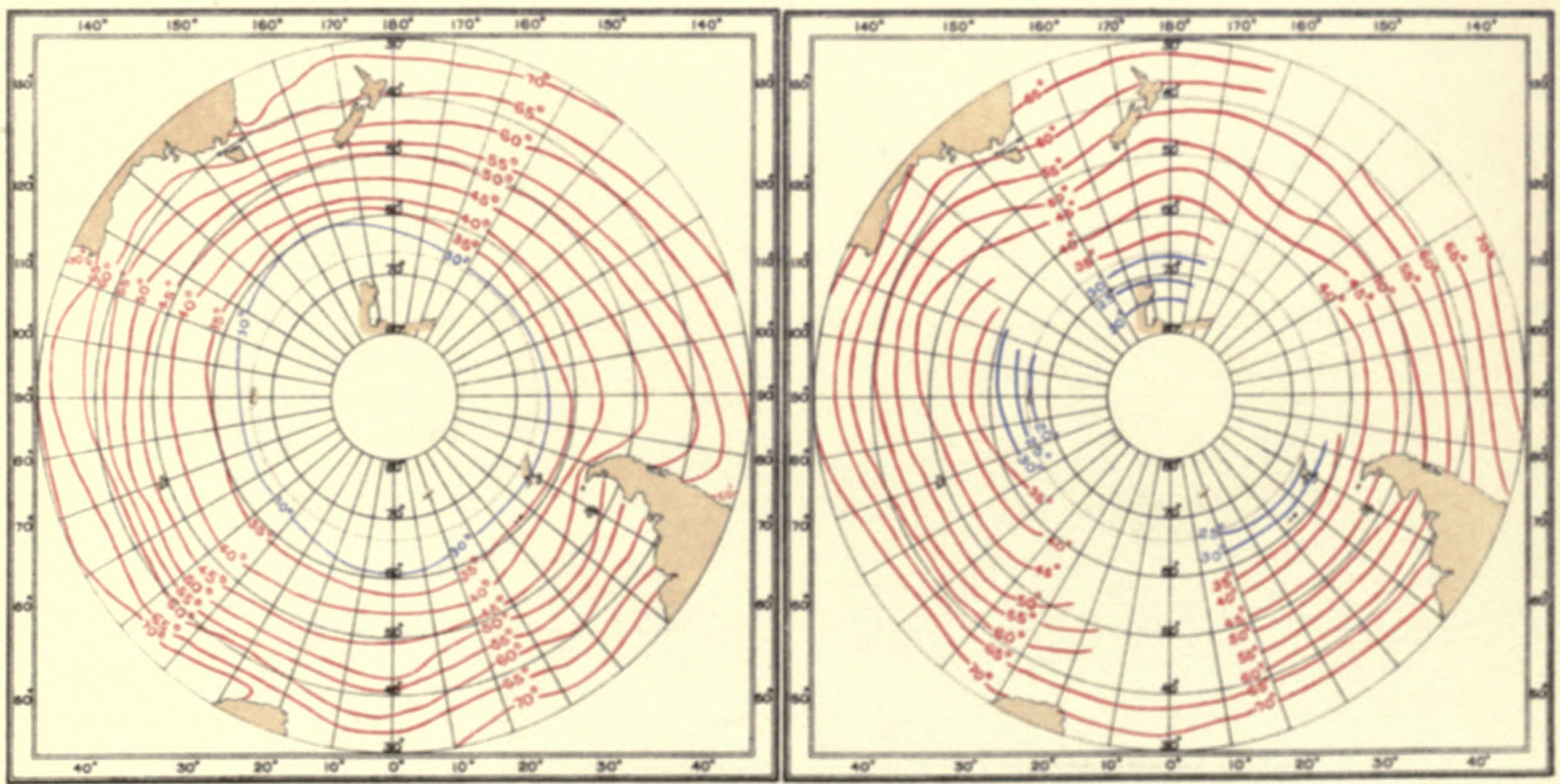

Heth $\operatorname{Londim}$ 


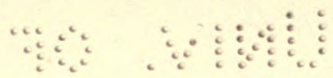

$\therefore \vdots \vdots \because \vdots \because \cdots \vdots \vdots \vdots \cdots \cdots$ 


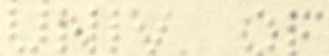

\&... 
INTERNATIONAL ANTARCTIC CO-OPERATION.

CHARTS OF MEAN SEA LEVEL PRESSURE AND AIR TEMPERATURE.

NORMAL PRESSURE.

APRIL

MEAN PRESSURE, NOON, G.M.T. 1903
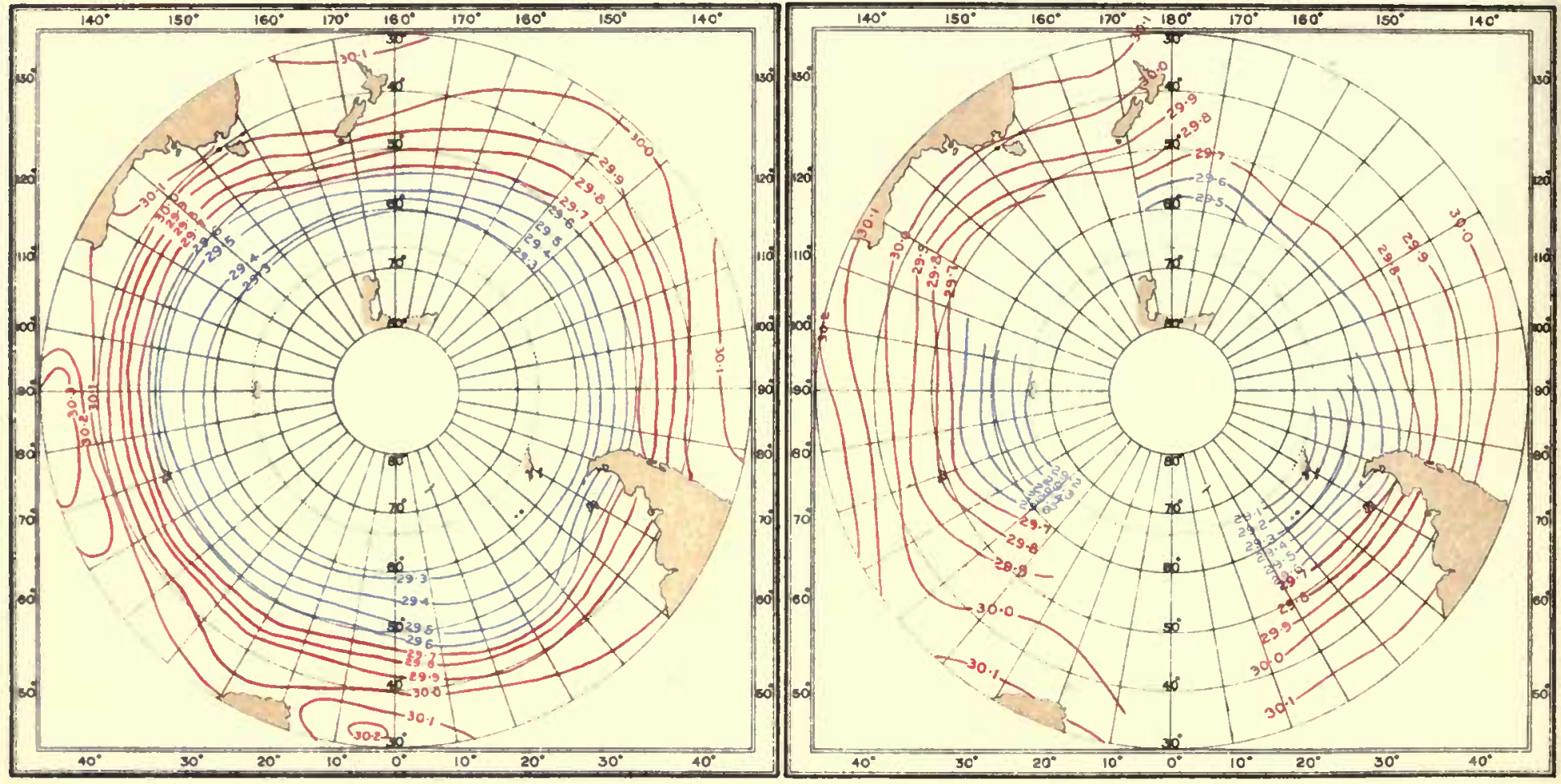

NORMAL AIR TEMPERATURE.

APRIL

MEAN AIR TEMPERATURE, NOON, G.M.T. 1903.

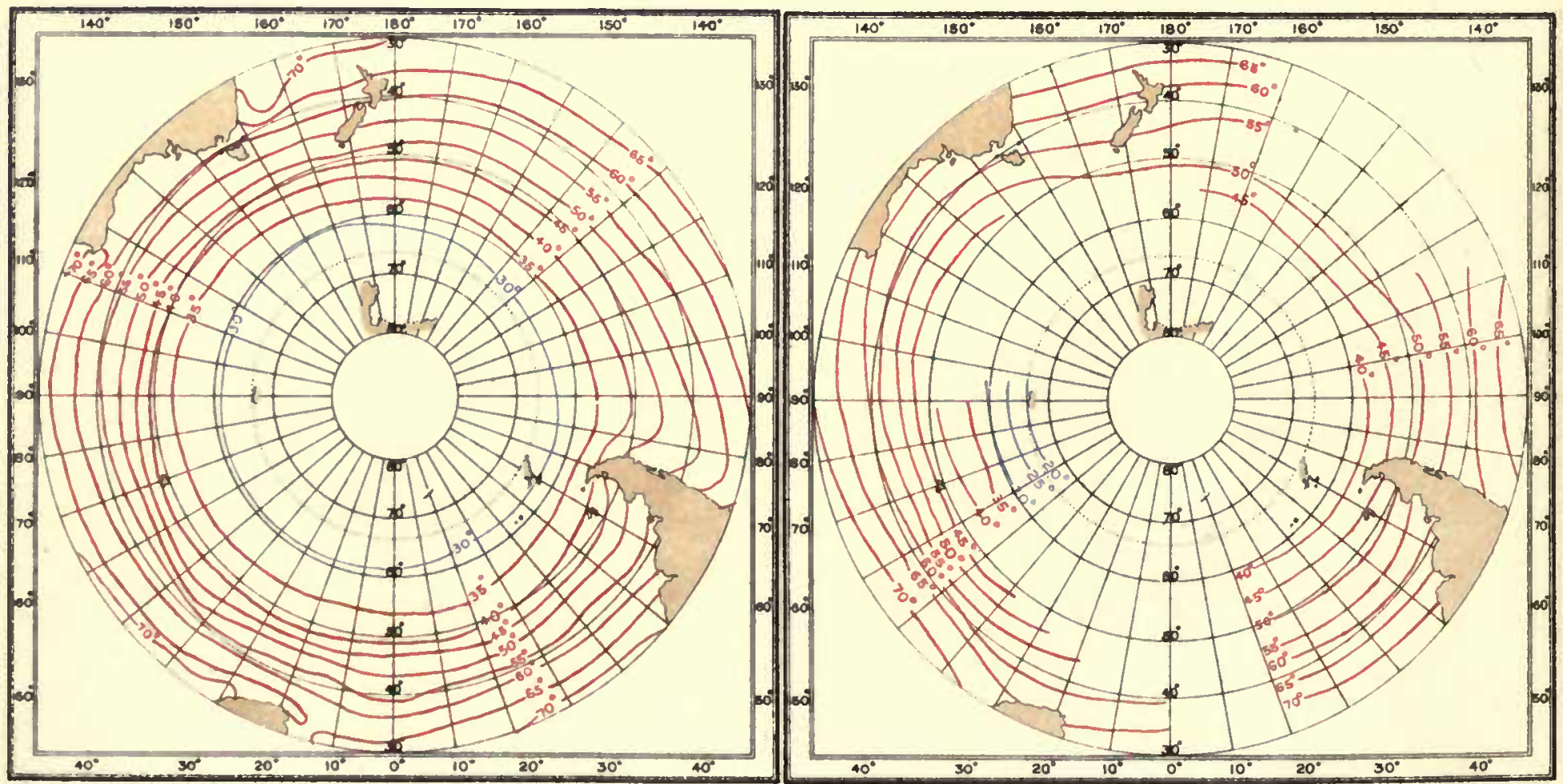


INTERNATIONAL ANTARCTIC CO-OPERATION.

CHARTS OF MEAN SEA LEVEL PRESSURE AND AIR TEMPERATURE.

NORMAL PRESSURE.

MAY

$160^{\circ} \quad 100^{\circ}$ 180 $160^{\circ}$ 16 $160^{\circ} \quad 140^{\circ}$

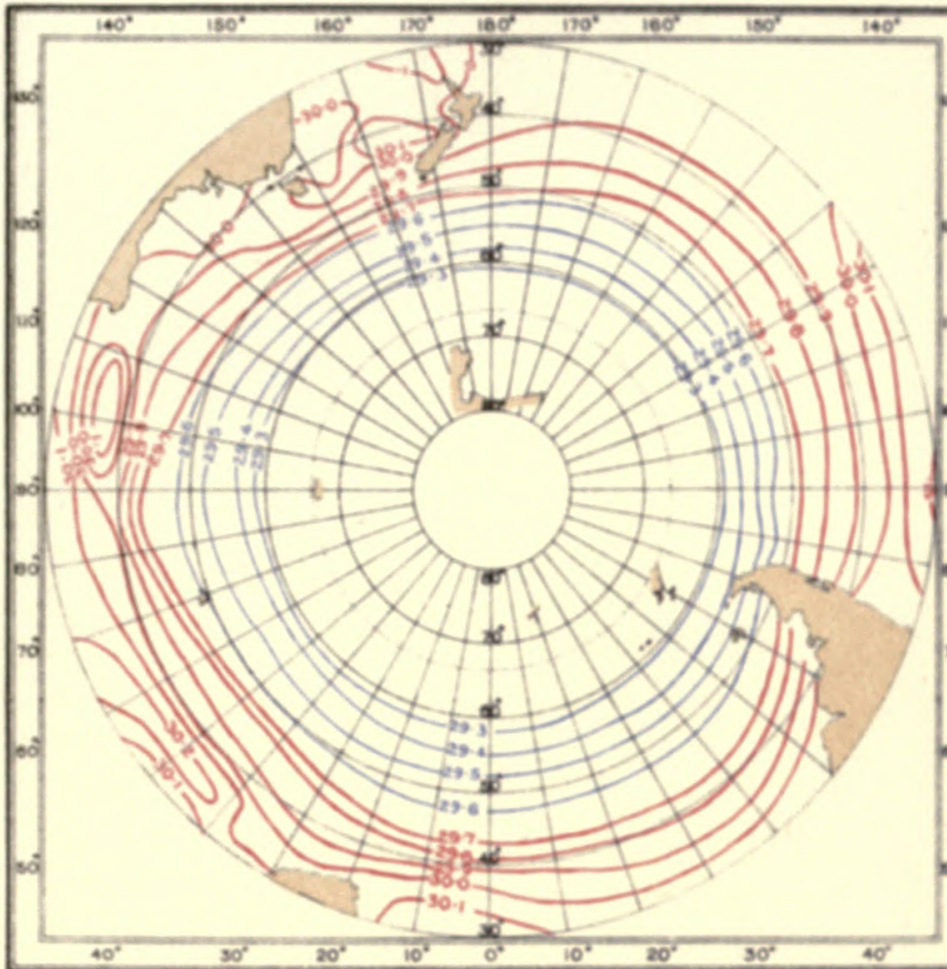

MEAN PRESSURE, NOON, G.M.T. 1903.

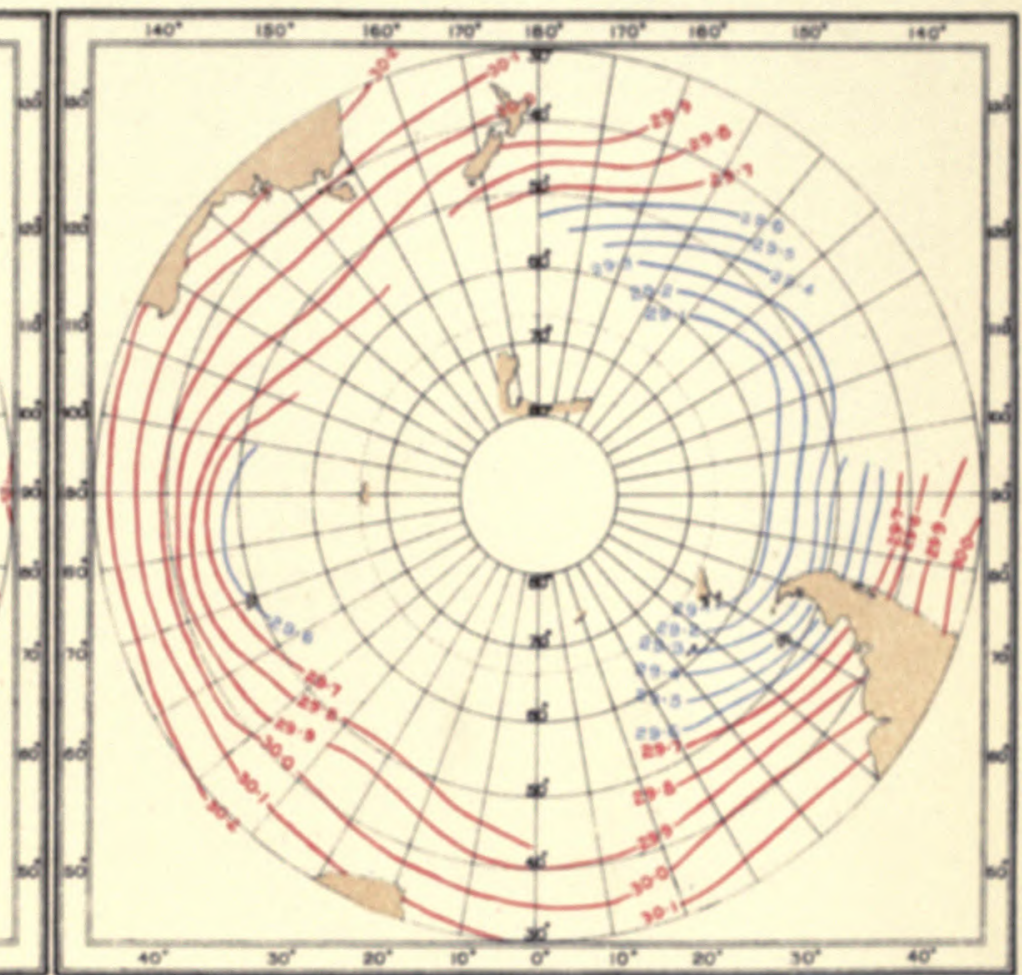

NORMAL AIR TEMPERATURE.

MA Y

MEAN AIR TEMPERATURE, NOON, G.M.T. 1903.

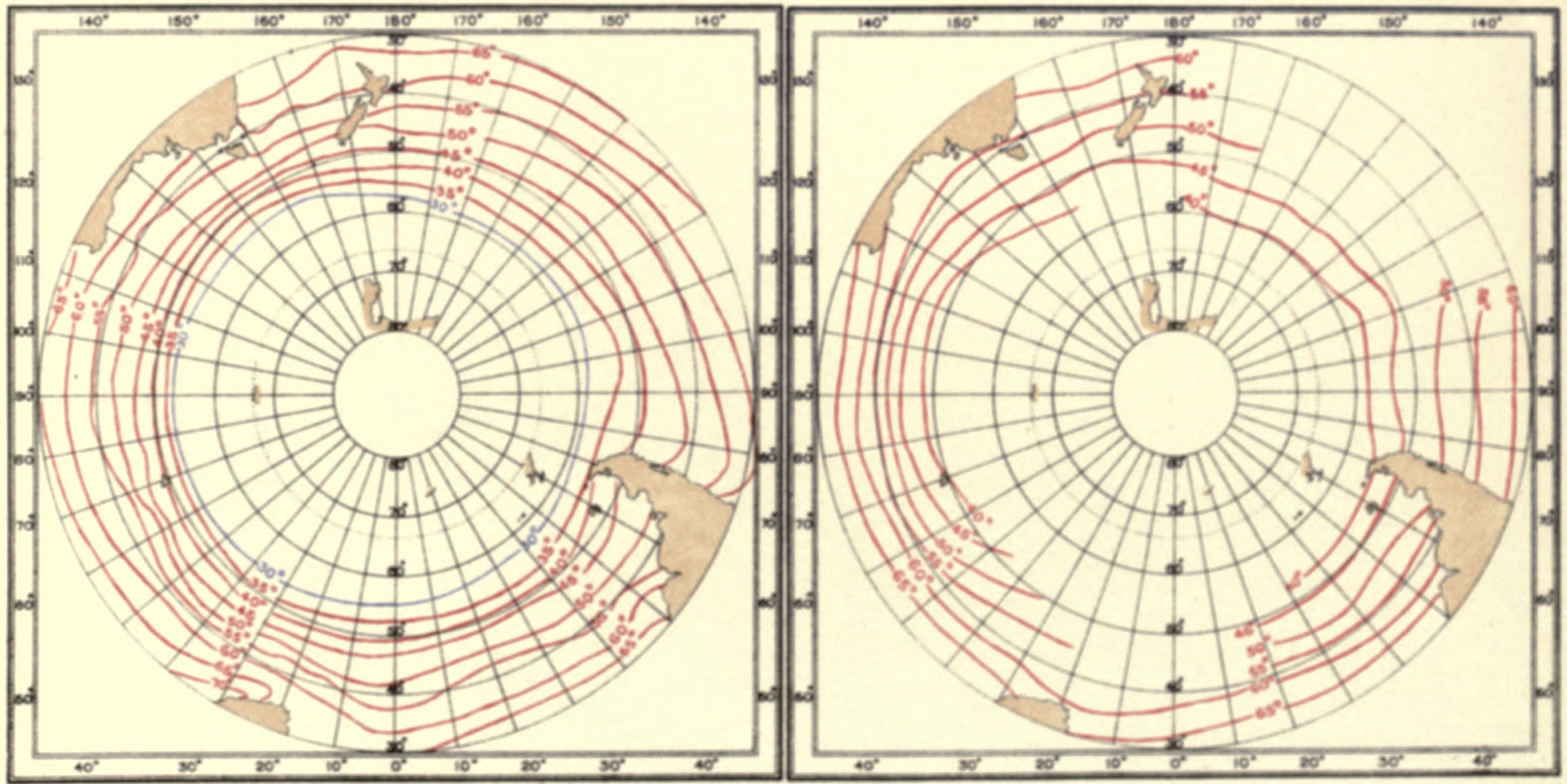




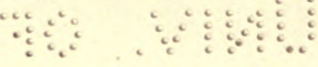

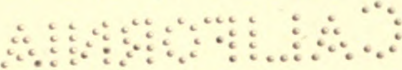




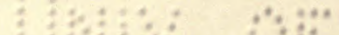

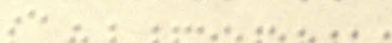

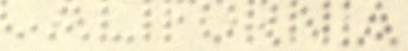


INTERNATIONAL ANTARCTIC CO-OPERATION.

CHARTS OF MEAN SEA LEVEL PRESSURE AND AIR TEMPERATURE.

JUNE

NORMAL PRESSURE.

MEAN PRESSURE, NOON, G.M.T. 1903.
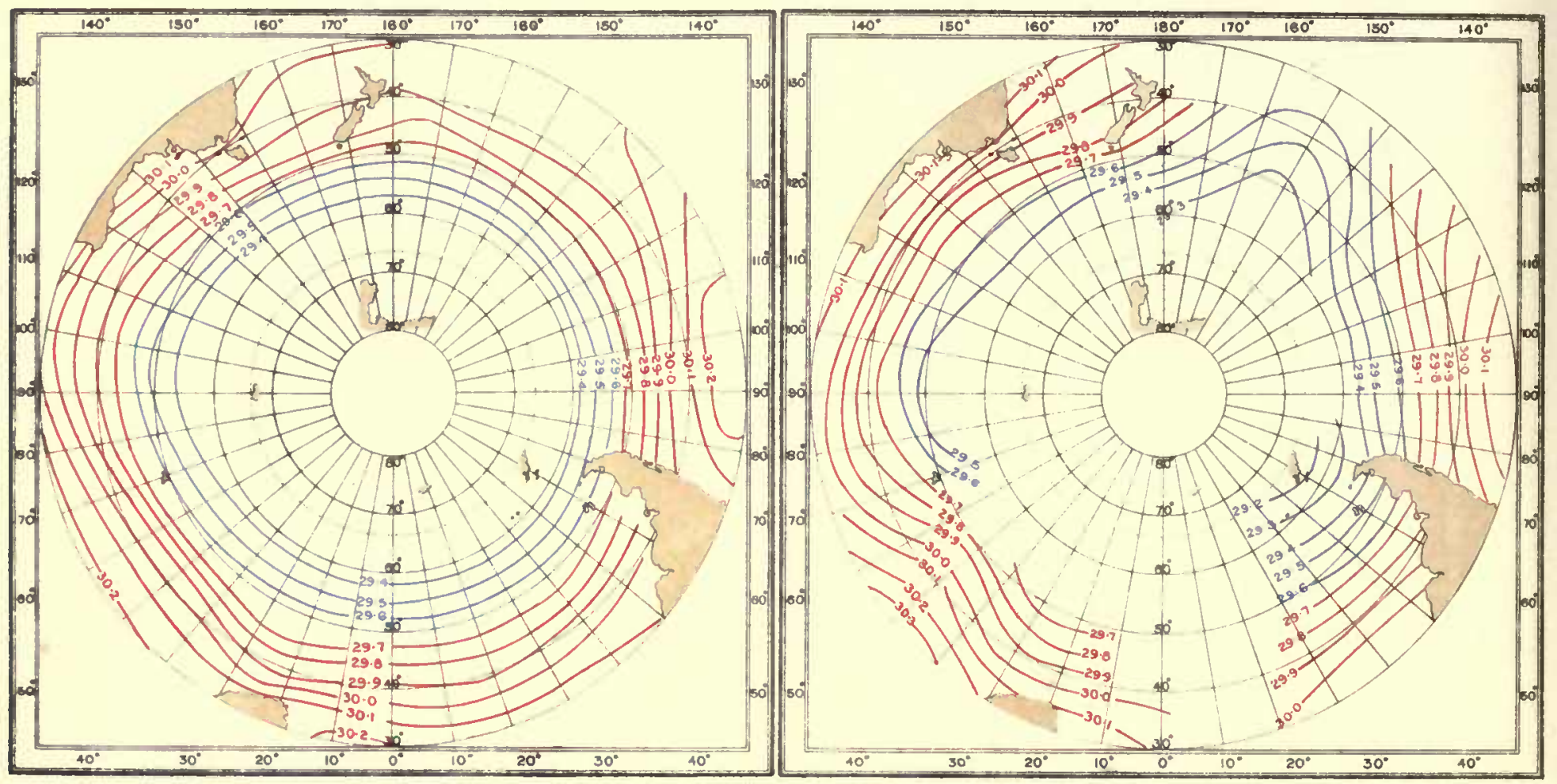

NORMAL AIR TEMPERATURE.

JUNE

MEAN AIR TEMPERATURE, NOON, G.M.T. 1903.

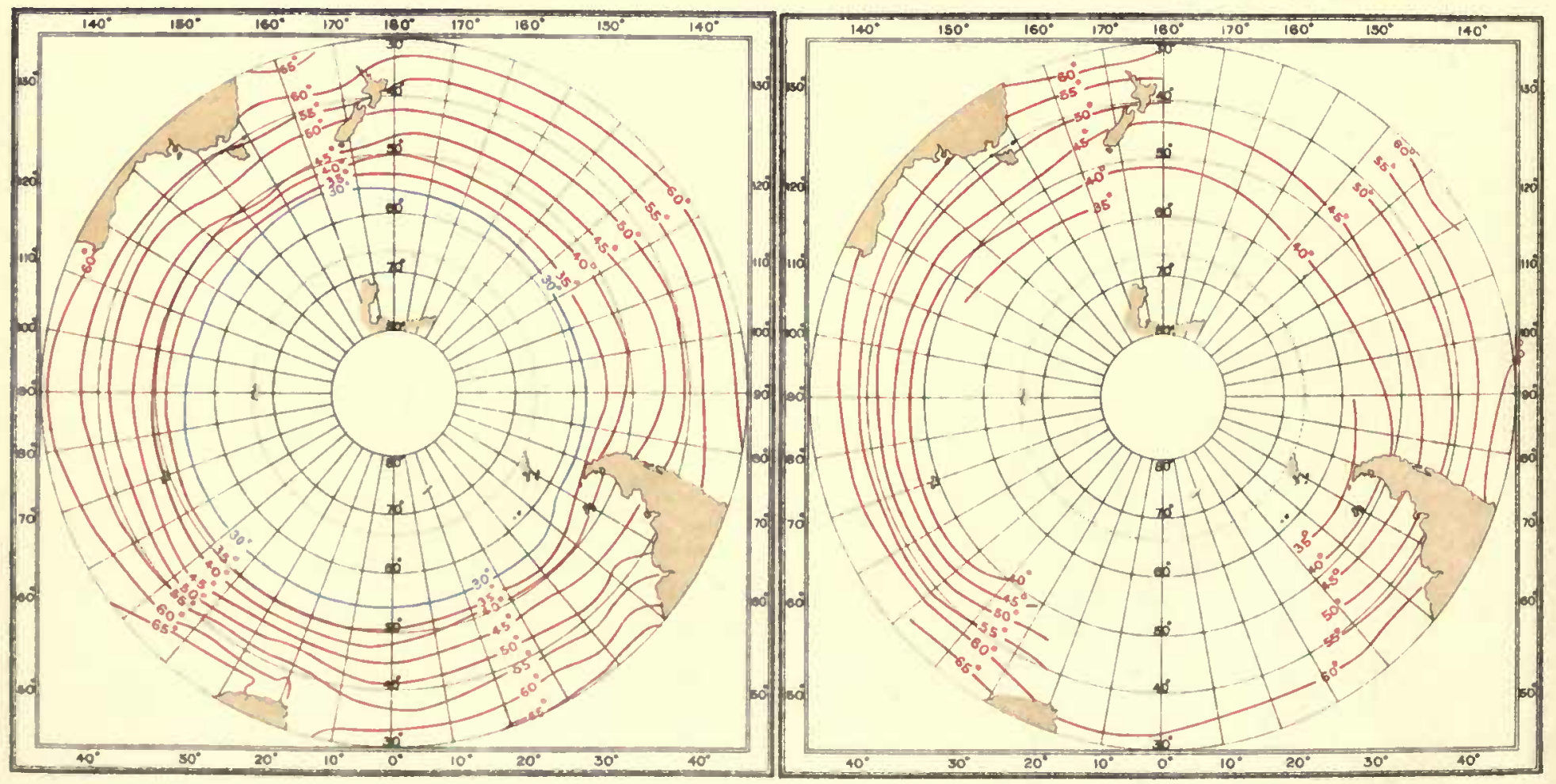


INTERNATIONAL ANTARCTIC CO-OPERATION.

CHARTS OF MEAN SEA LEVEL PRESSURE AND AIR TEMPERATURE.

JULY

NORMAL PRESSURE.

MEAN PRESSURE, NOON, G.M.T. 1903.
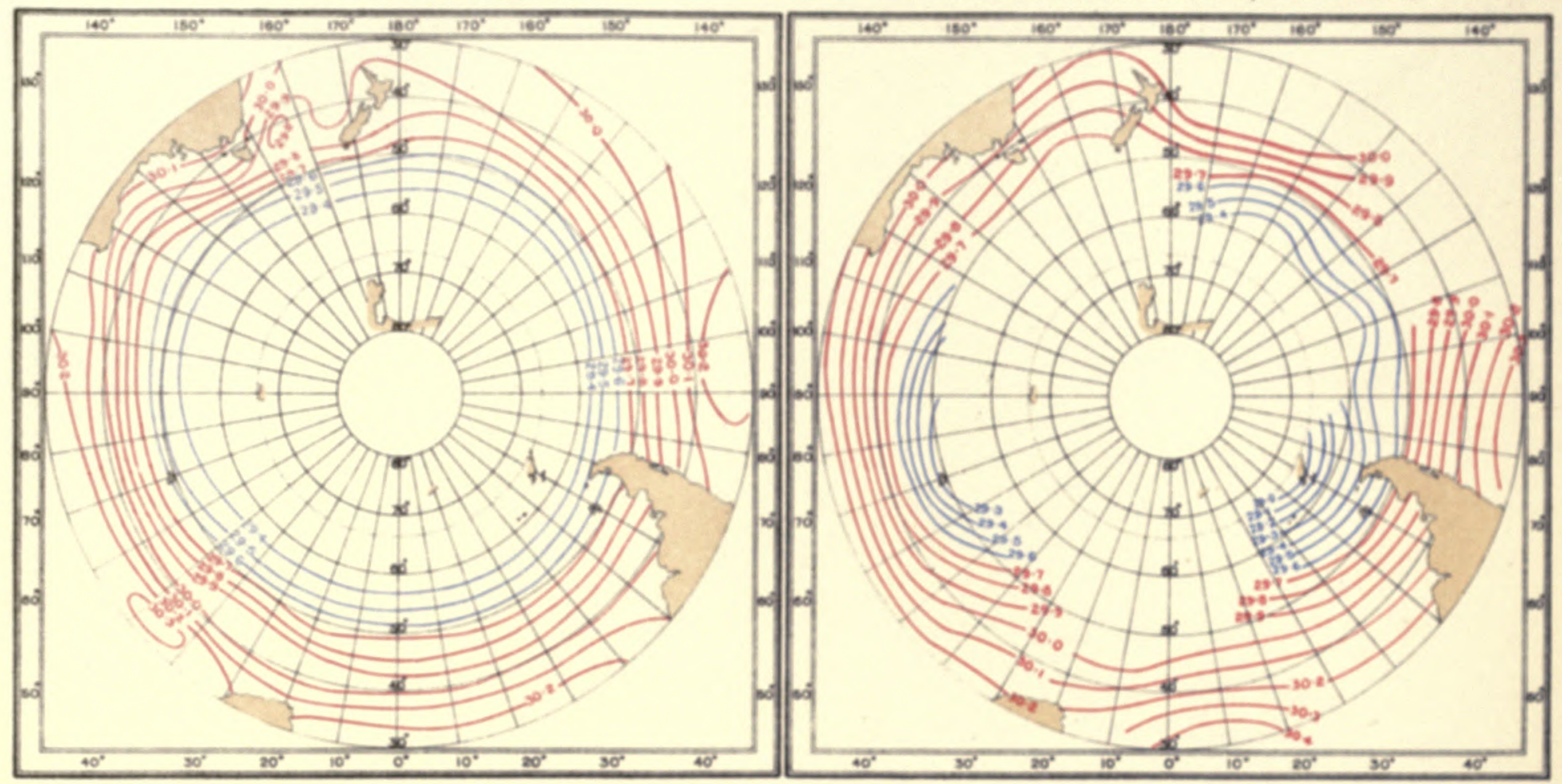

NORMAL AIR TEMPERATURE.

JULY MEAN AIR TEMPERATURE,NOON,G.M.T.1903.

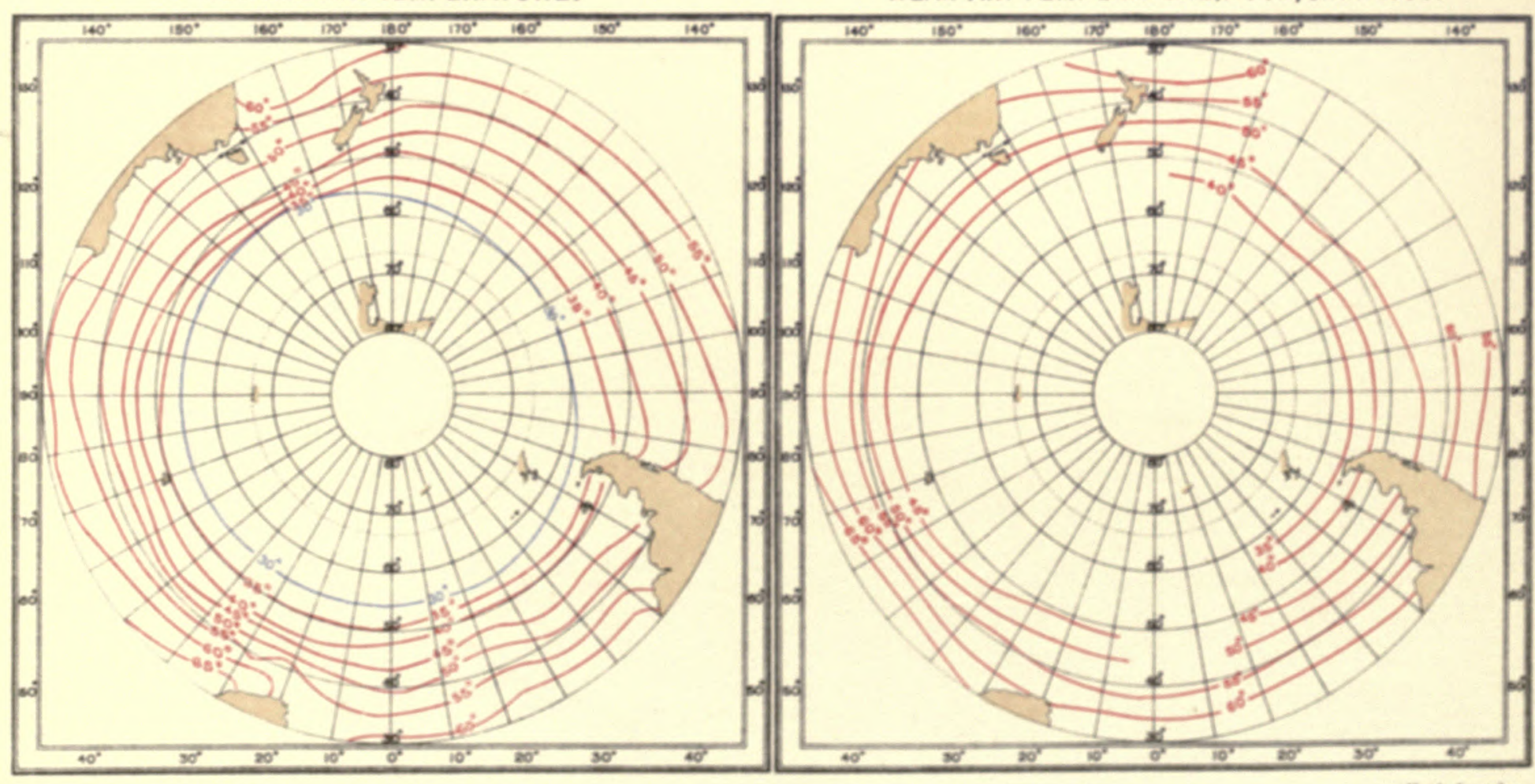


等

a d a 
(1)

conatom 
INTERNATIONAL ANTARCTIC CO-OPERATION.

CHARTS OF MEAN SEA LEVEL PRESSURE AND AIR TEMPERATURE.

$A \cup G \cup S T$

NORMAL PRESSURE.

MEAN PRESSURE, NOON, G.M.T. 1903.

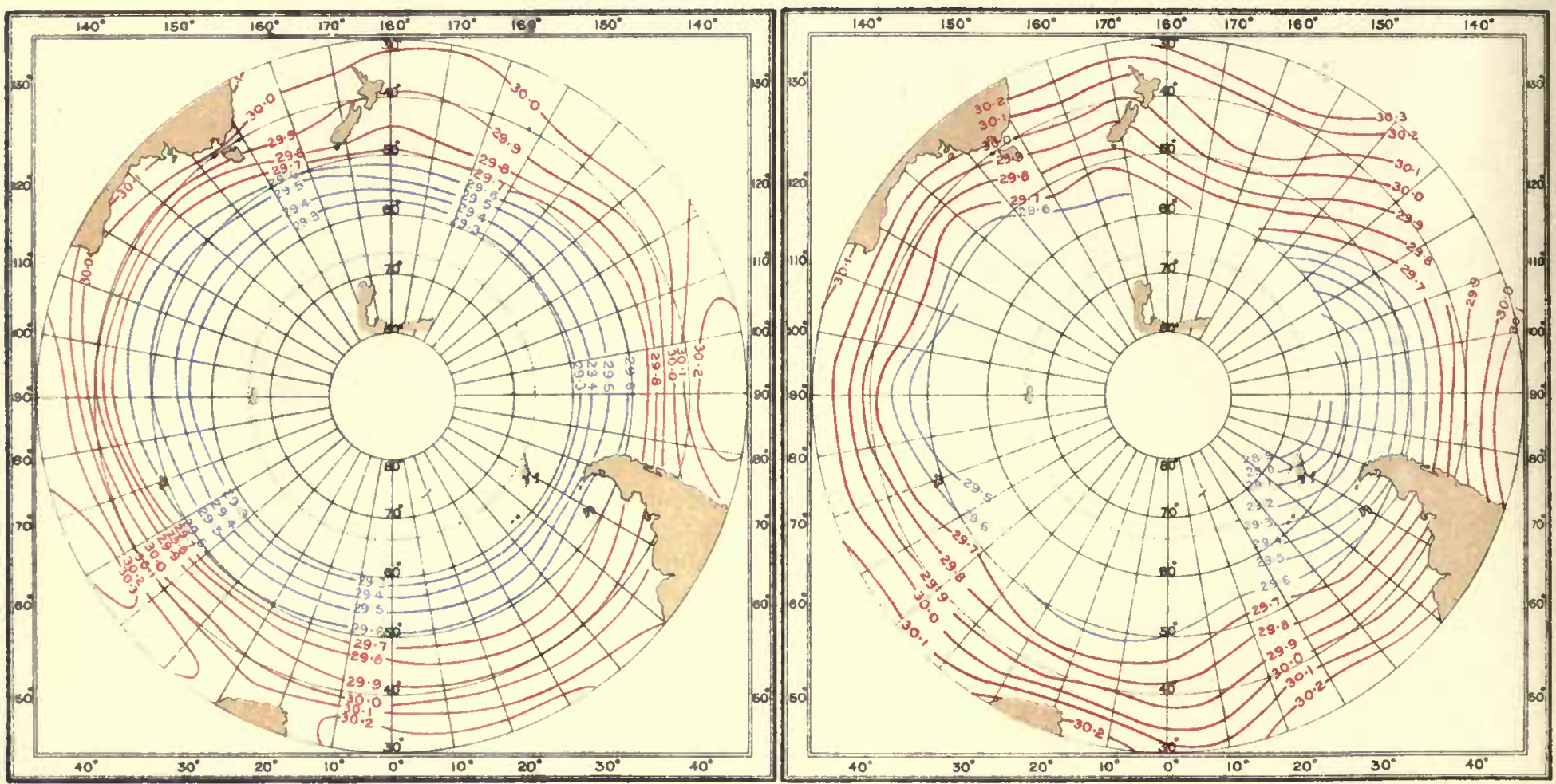

NORMAL AIR TEMPERATURE.

AUGUST MEAN AIR TEMPERATURE,NOON, G.M.T. 1903

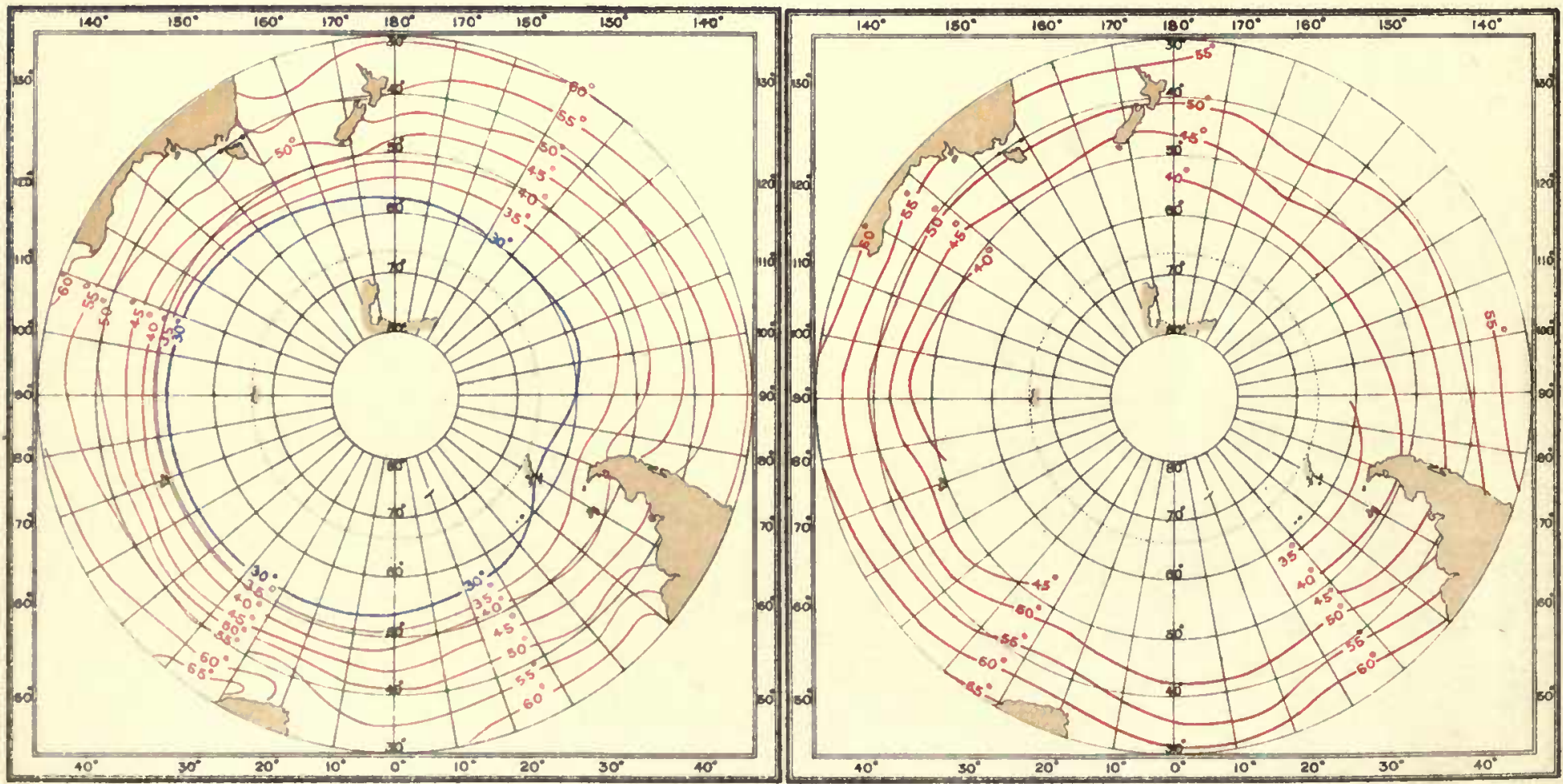


INTERNATIONAL ANTARCTIC CO-OPERATION.

CHARTS OF MEAN SEA LEVEL PRESSURE AND AIR TEMPERATURE.

SEPTEMBER

NORMAL PRESSURE.

MEAN PRESSURE, NOON, G.M.T. 1903.

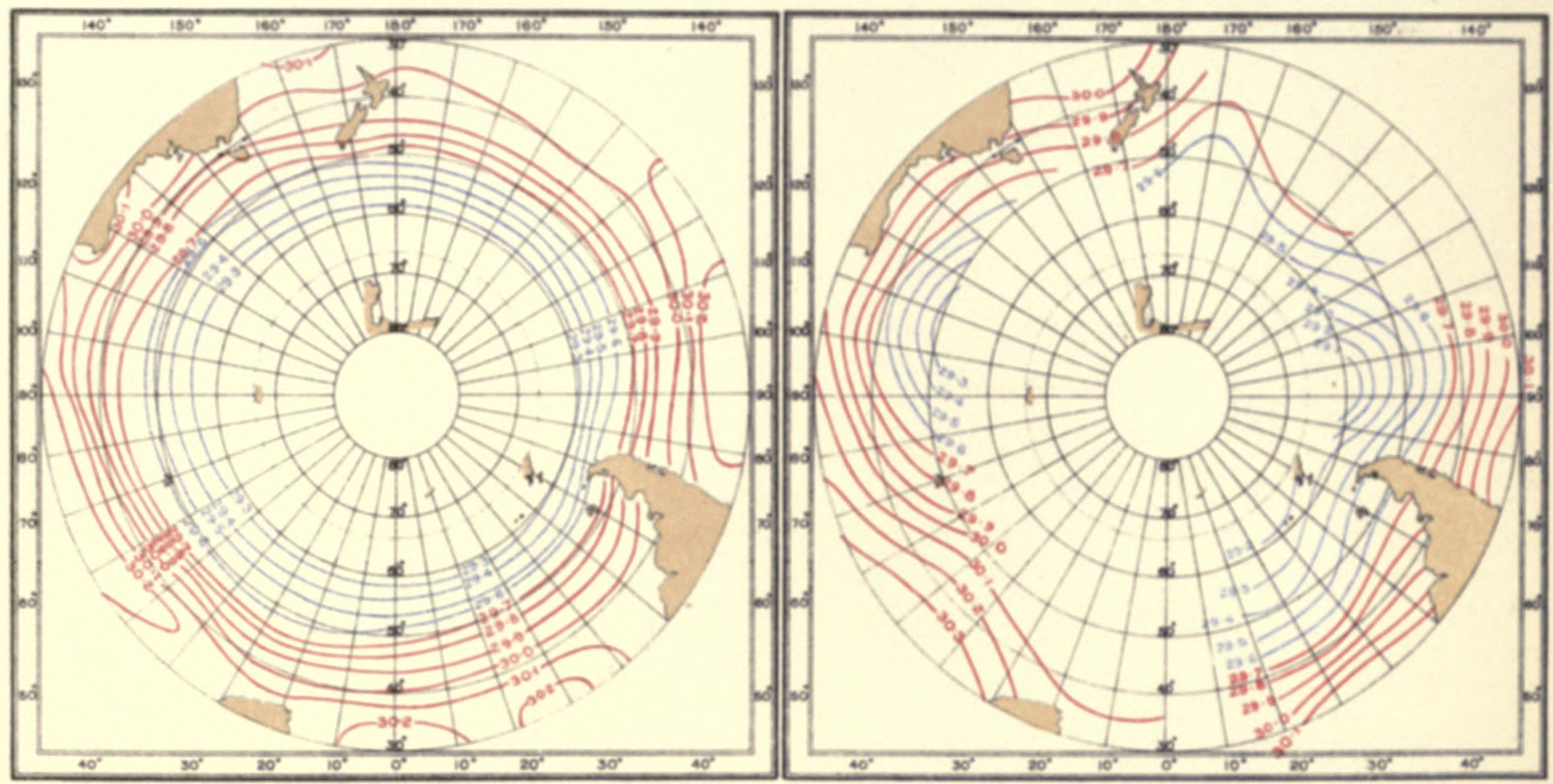

NORMAL AIR TEMPERATURE.

MEAN AIR TEMPERATURE, NOON, G.M.T. 1903.

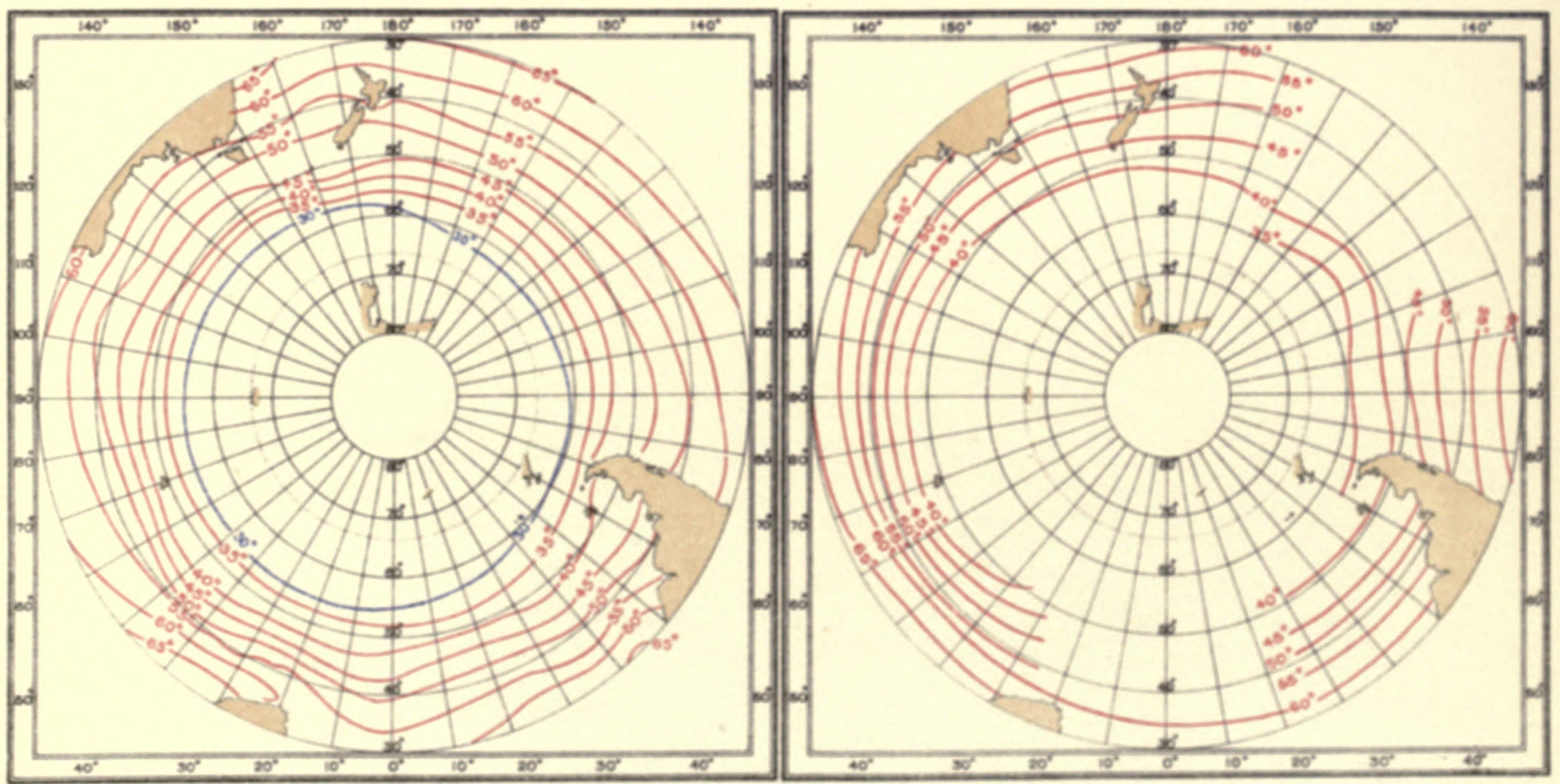




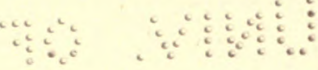

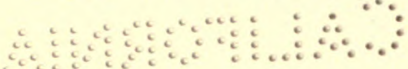




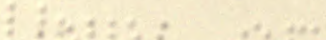

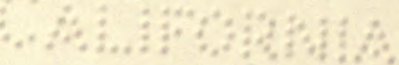


INTERNATIONAL ANTARCTIC CO-OPERATION.

CHARTS OF MEAN SEA LEVEL PRESSURE AND AIR TEMPERATURE.

OCTOBER

NORMAL PRESSURE.

MEAN PRESSURE, NOON, G.M.T. 1903
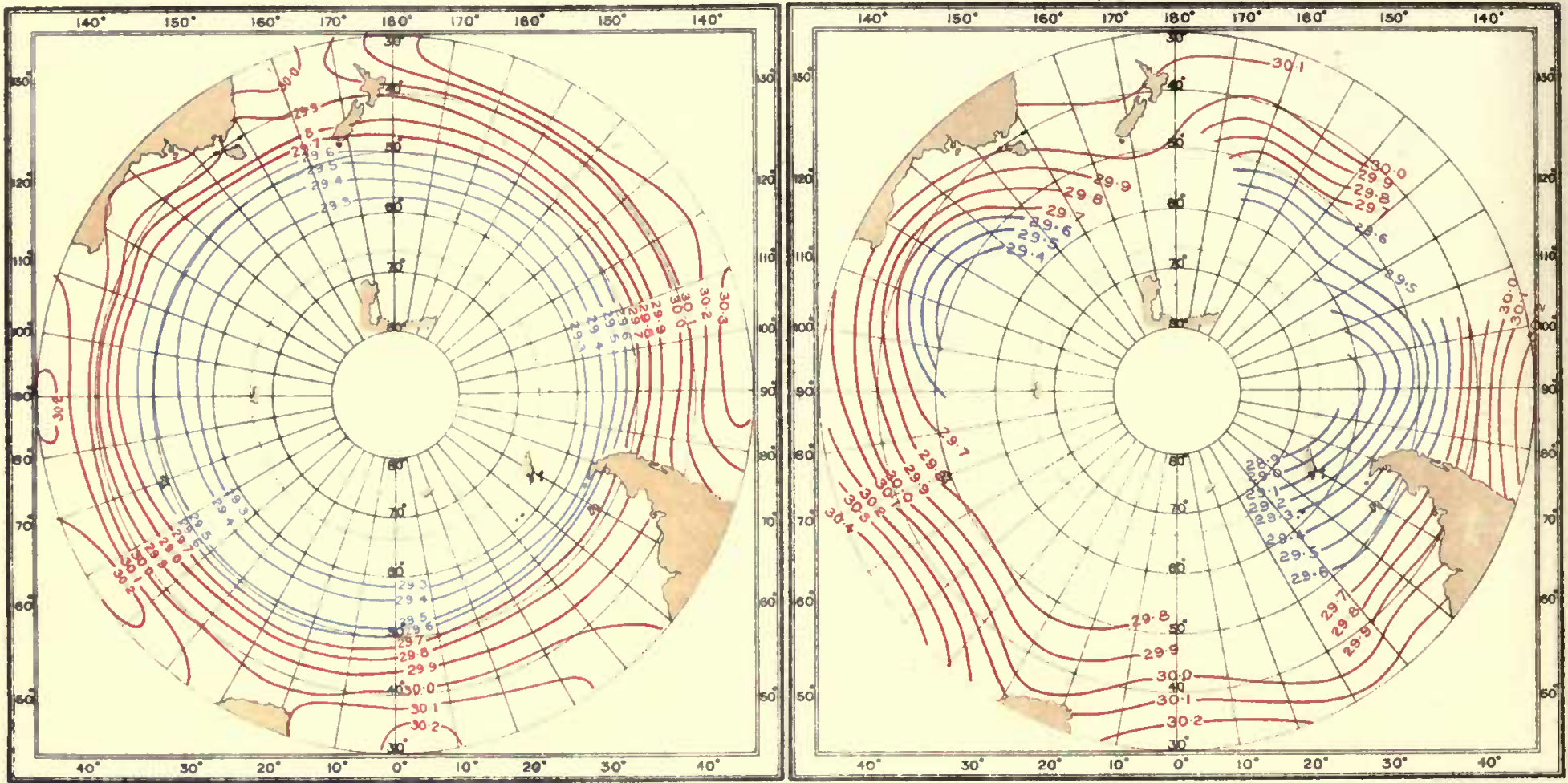

NORMAL AIR TEMPERATURE.

OCTOBER

MEAN AIR TEMPERATURE, NOON, G.M.T. 1903.

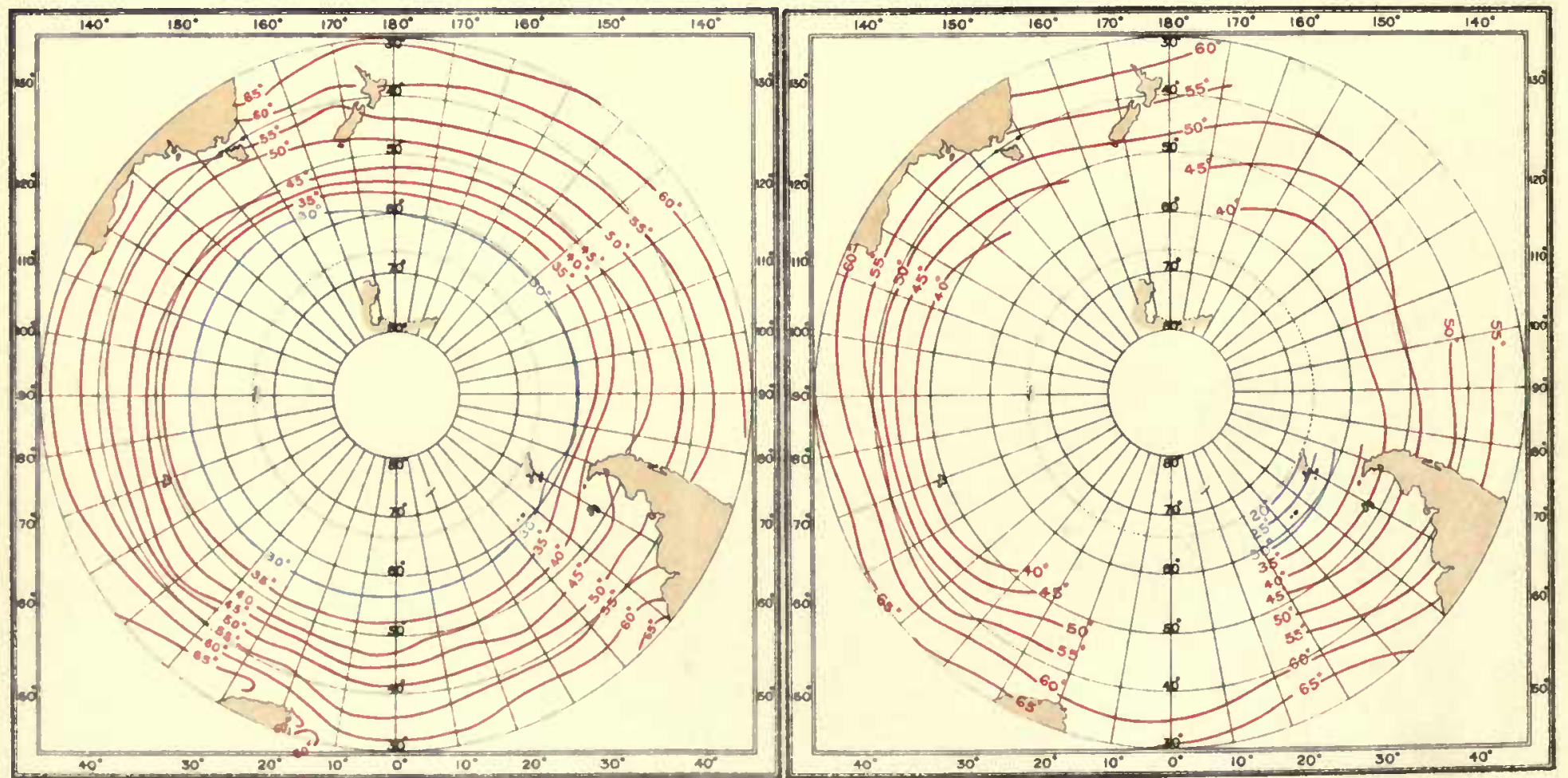


INTERNATIONAL ANTARCTIC CO-OPERATION.

CHARTS OF MEAN SEA LEVEL PRESSURE AND AIRTEMPERATURE.

NOVEMBER

NORMAL PRESSURE.

MEAN PRESSURE, NOON, G.M.T. 1903.
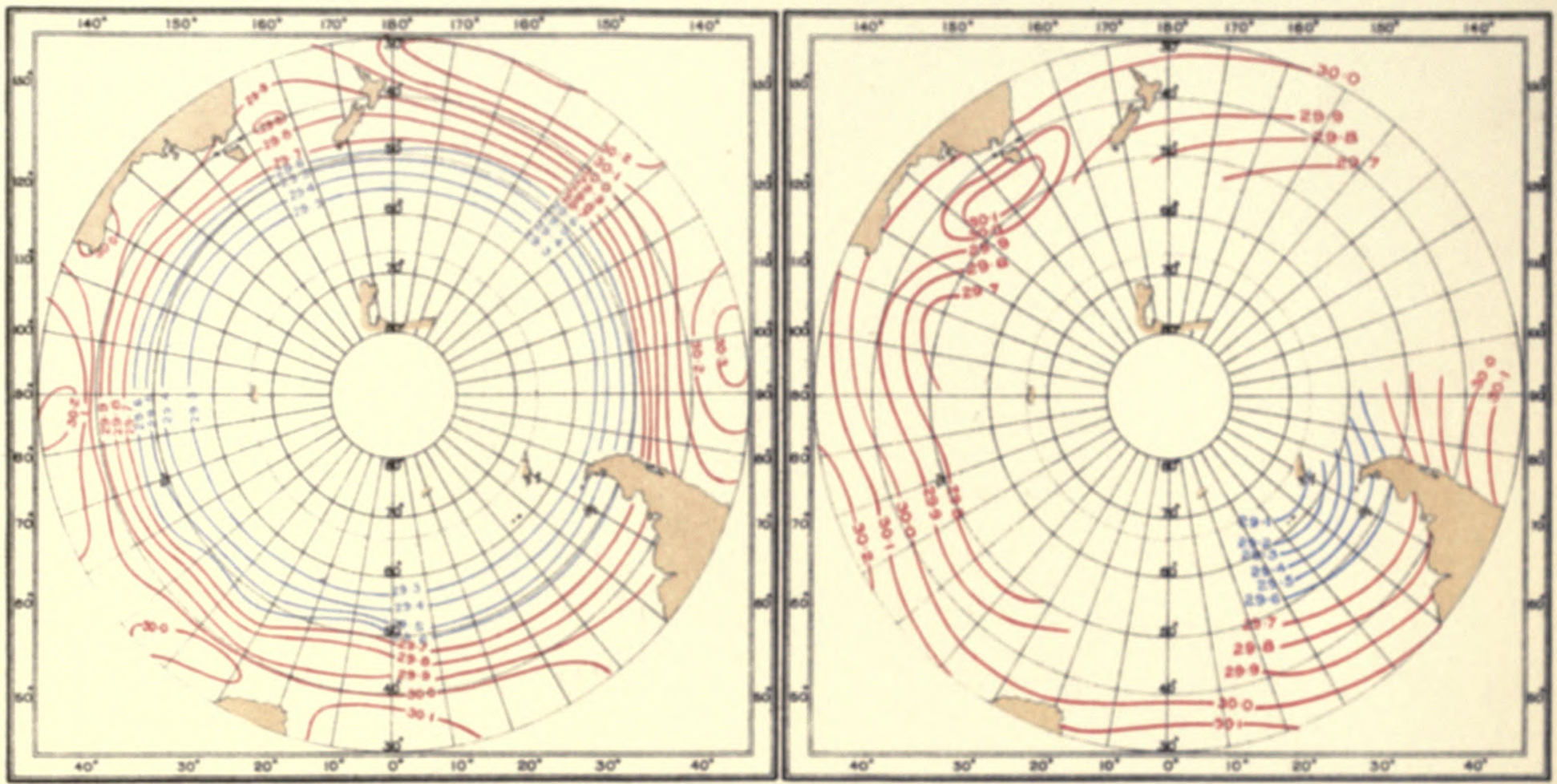

NORMAL AIR TEMPERATURE.

NOVEMBER MEAN AIR TEMPERATURE, NOON, G.M.T. 1903.
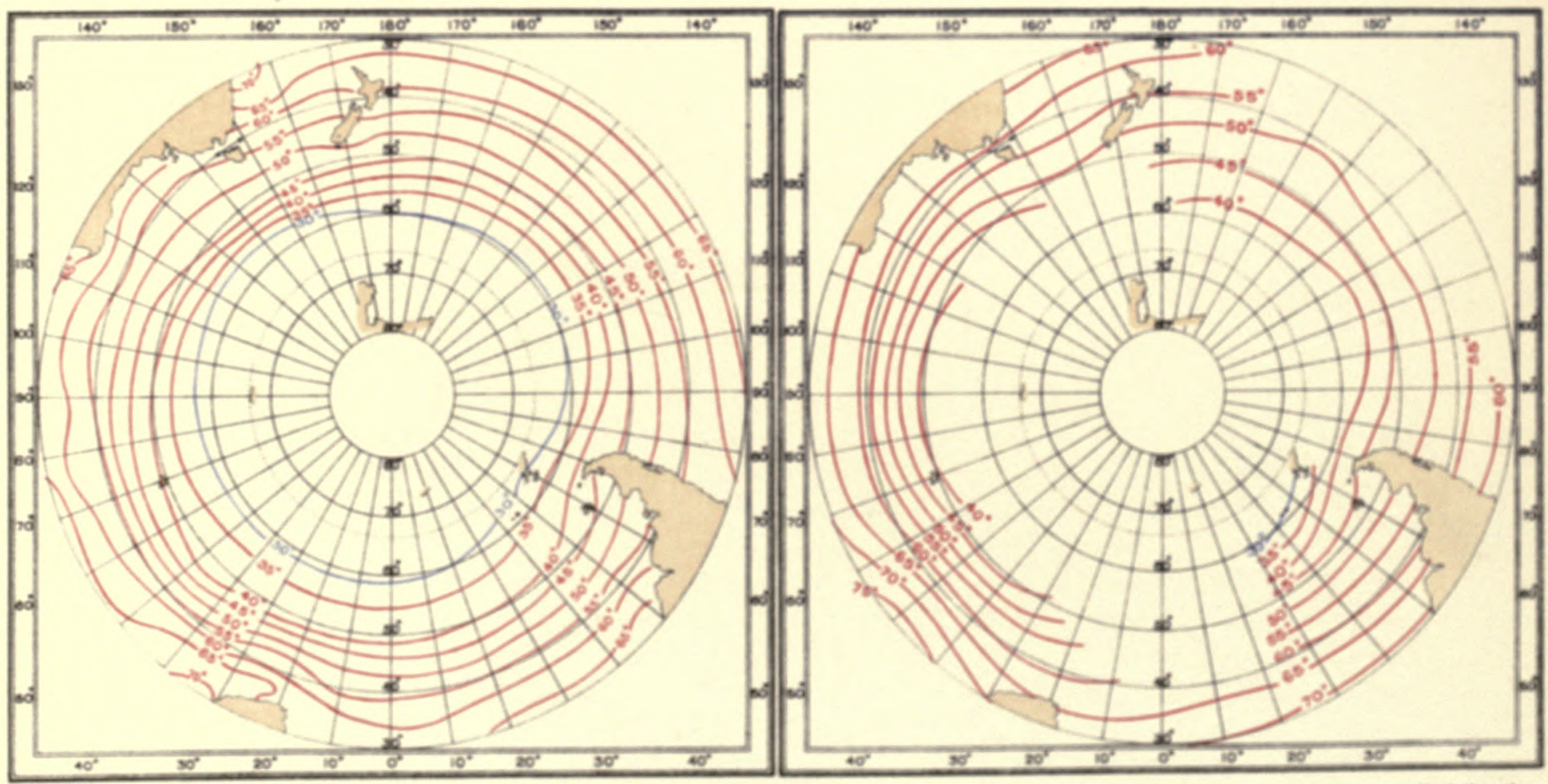

Hath Losdem 
$\because \vdots \vdots$

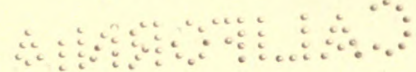



INTERNATIONAL ANTARCTIC CO-OPERATION.

CHARTS OF MEAN SEA LEVEL PRESSURE AND AIR TEMPERATURE.

DECEMBER

NORMAL PRESSURE.

MEAN PRESSURE, NOON, G.M.T. 1903.

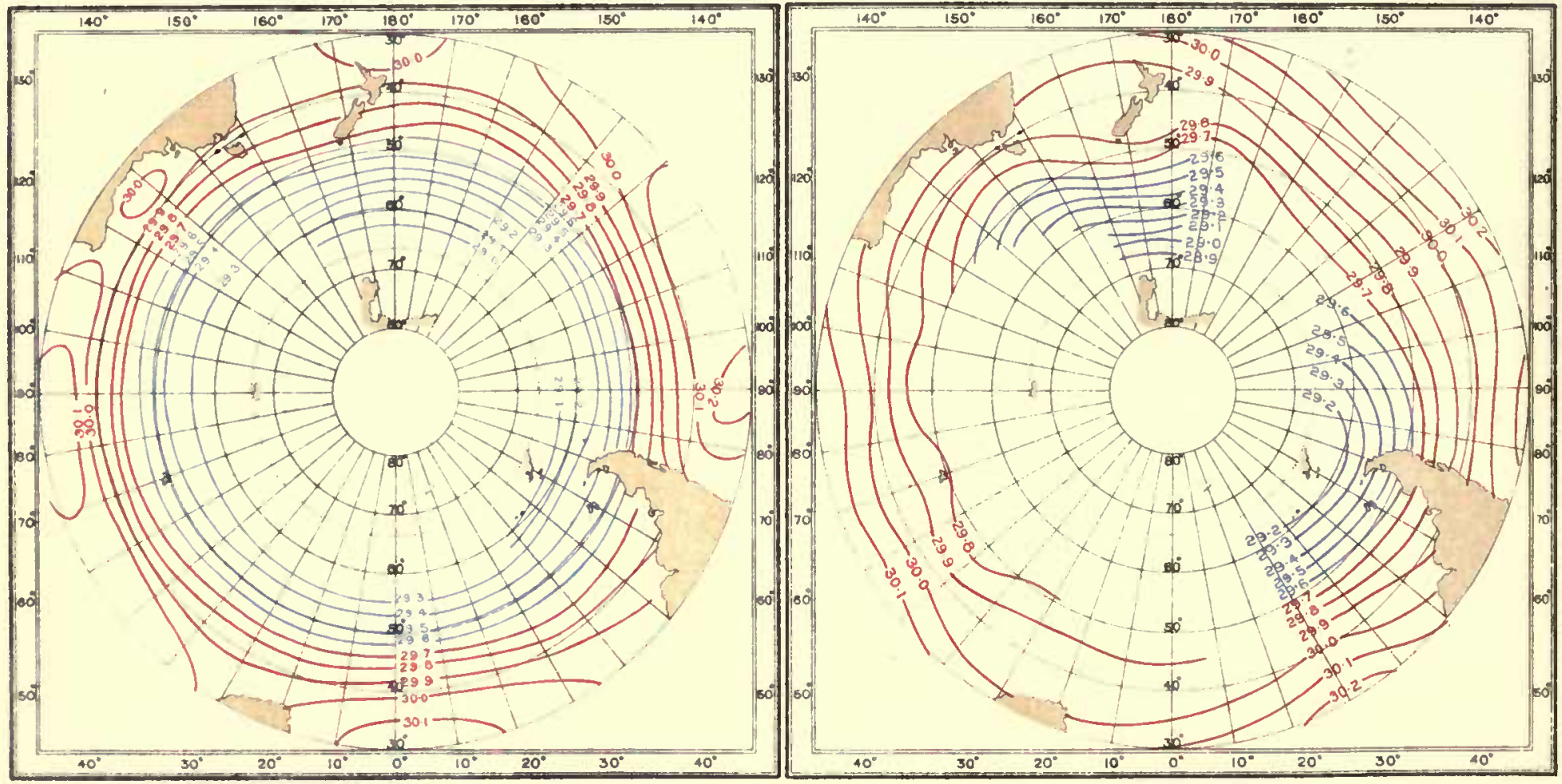

NORMAL AIR TEMPERATURE.

DECEMBER

MEAN AIR TEMPERATURE, NOON, G.M.T. 1903

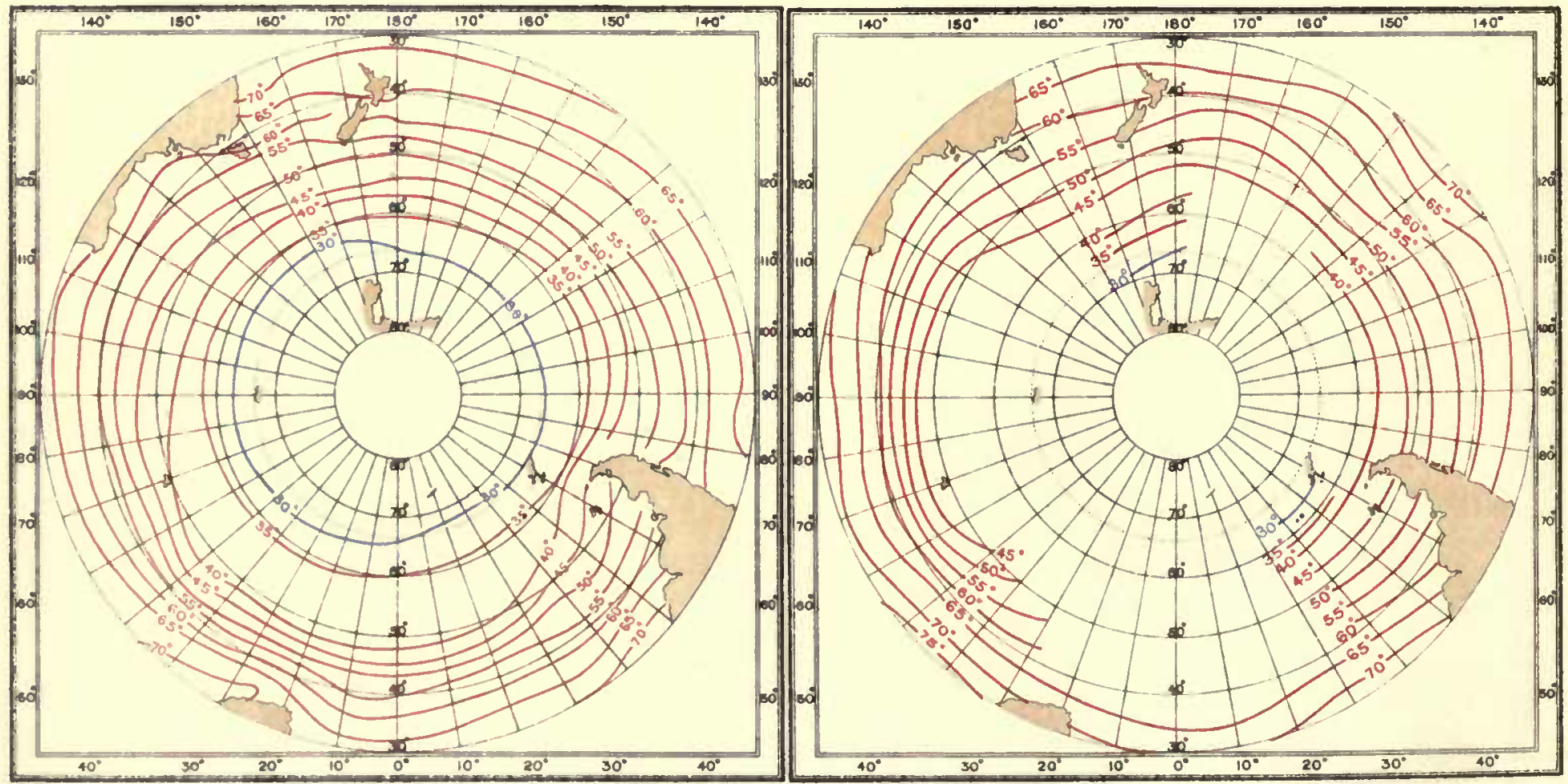


INTERNATIONAL ANTARCTIC CO-OPERATION:

CHARTS OF MEAN SEA LEVEL PRESSURE AND AIR TEMPERATURE.

JANUARY

NORMAL PRESSURE.

MEAN PRESSURE, NOON, G.M.T. 1904.

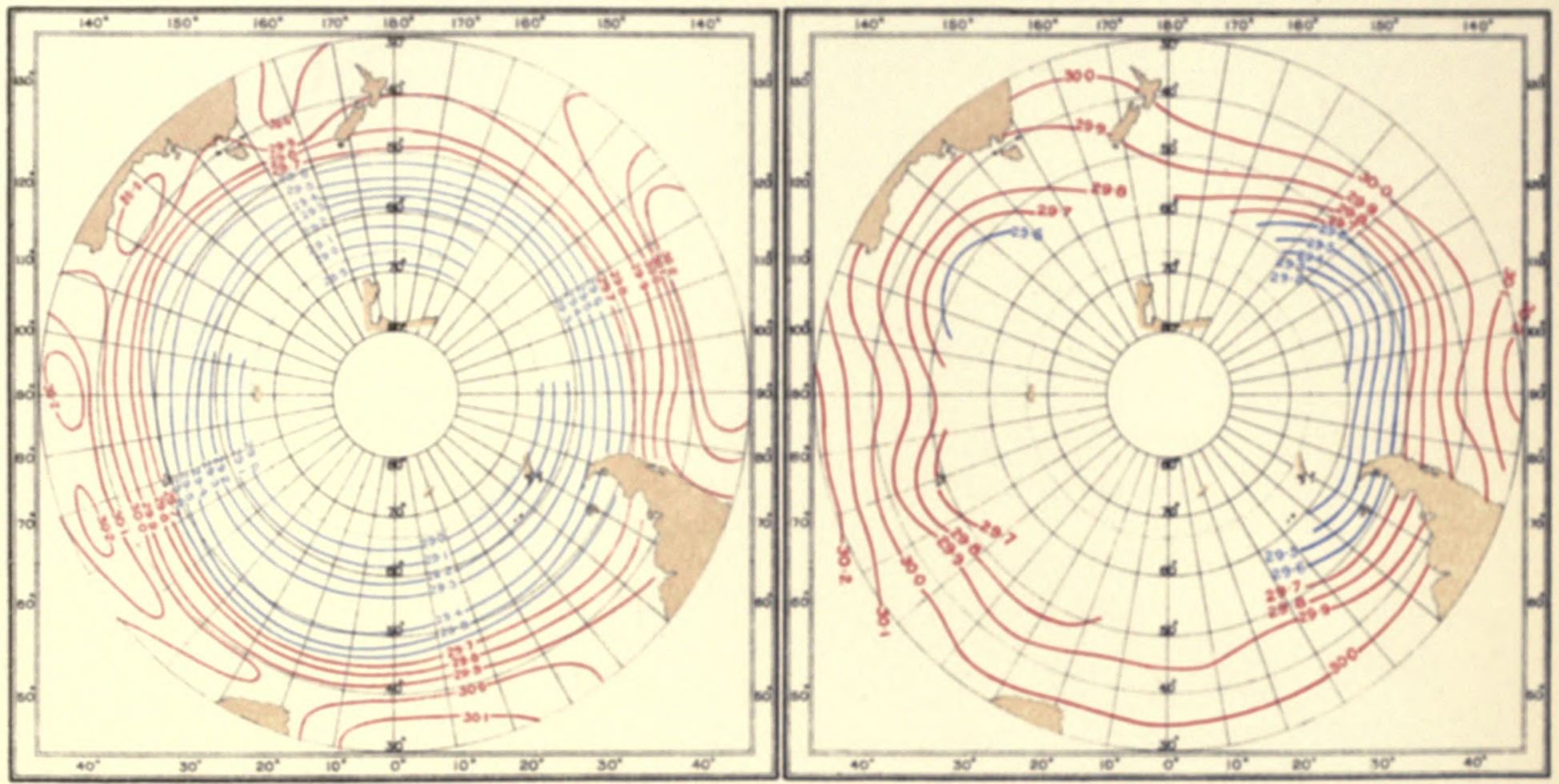

NORMAL AIR TEMPERATURE.

JANUARY MEAN AIRTEMPERATURE, NOON,G.M.T. 1904.

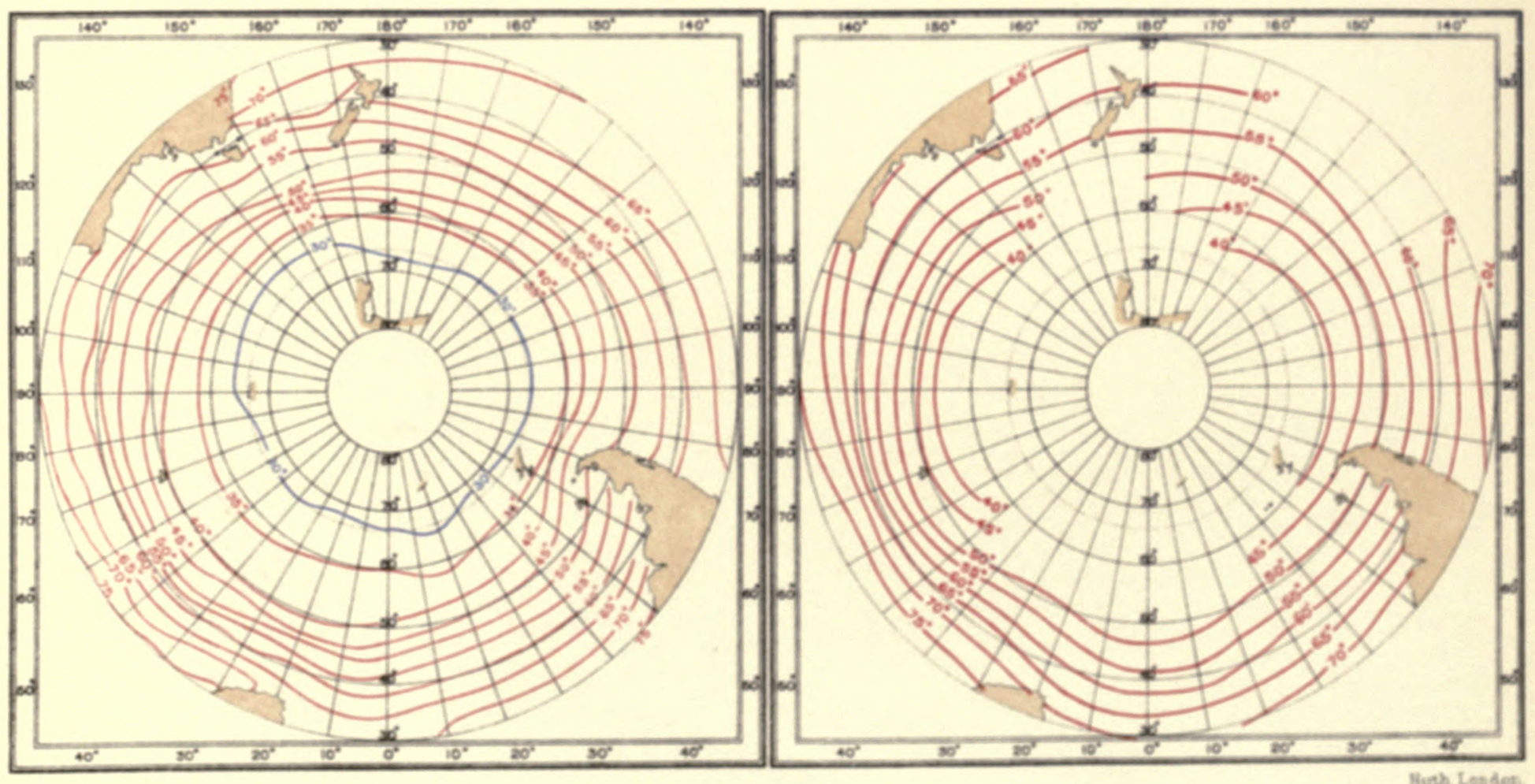


$\because 4 \quad \because 3$

a 
औat

.A 


\section{INTERNATIONAL ANTARCTIC CO-OPERATION.}

CHARTS OF MEAN SEA LEVEL PRESSURE AND AIR TEMPERATURE.

FEBRUARY

NORMAL PRESSURE.

MEAN PRESSURE, NOON, G.M.T. 1904
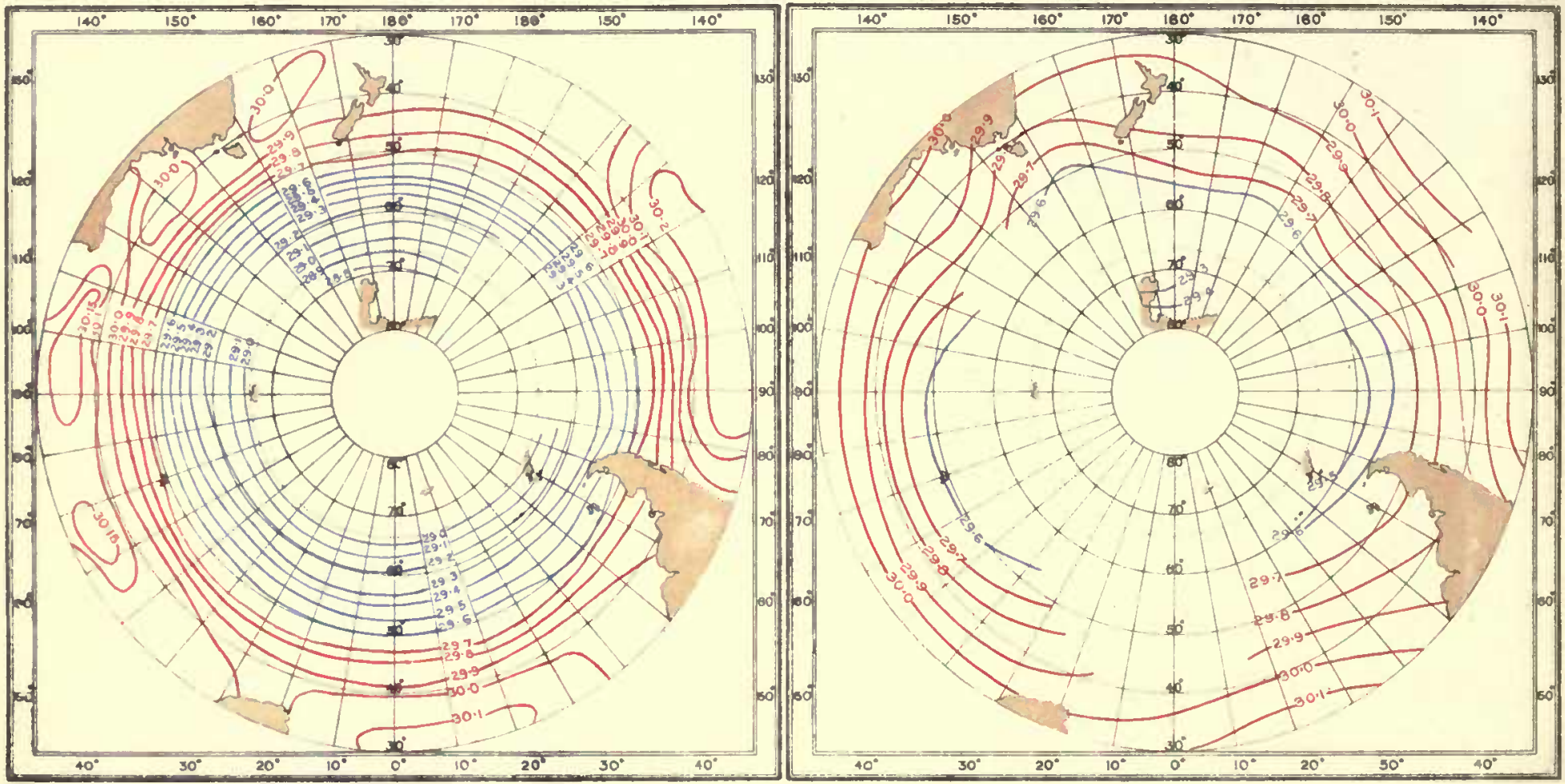

NORMAL AIR TEMPERATURE

MEAN AIR TEMPERATURE,NOON, G.M.T. 1904.

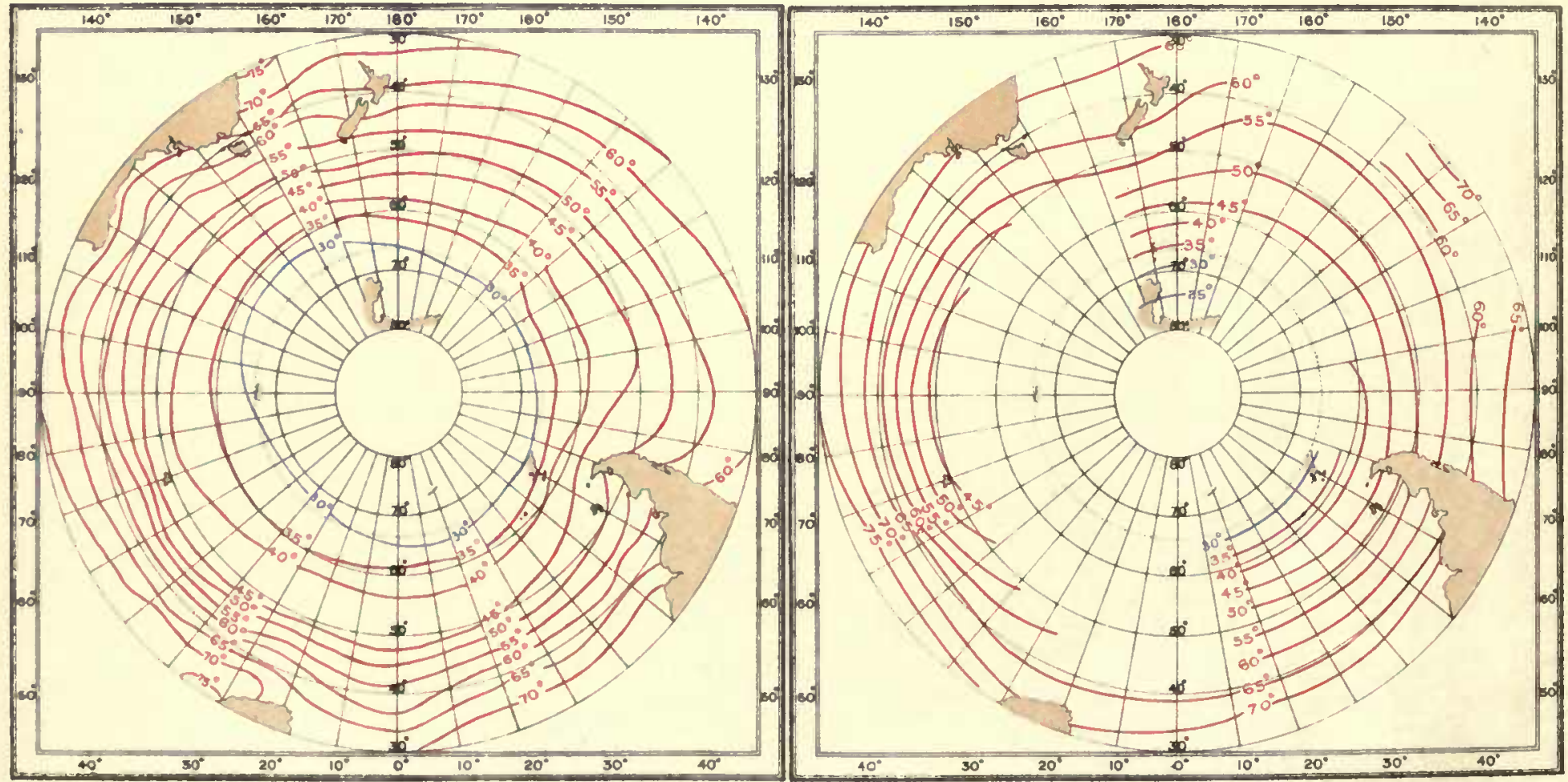


INTERNATIONAL ANTARCTIC CO-OPERATION.

CHARTS OF MEAN SEA LEVEL PRESSURE AND AIR TEMPERATURE.

MARCH

NORMAL PRESSURE

MEAN PRESSURE, NOON, G.M.T. 1904.
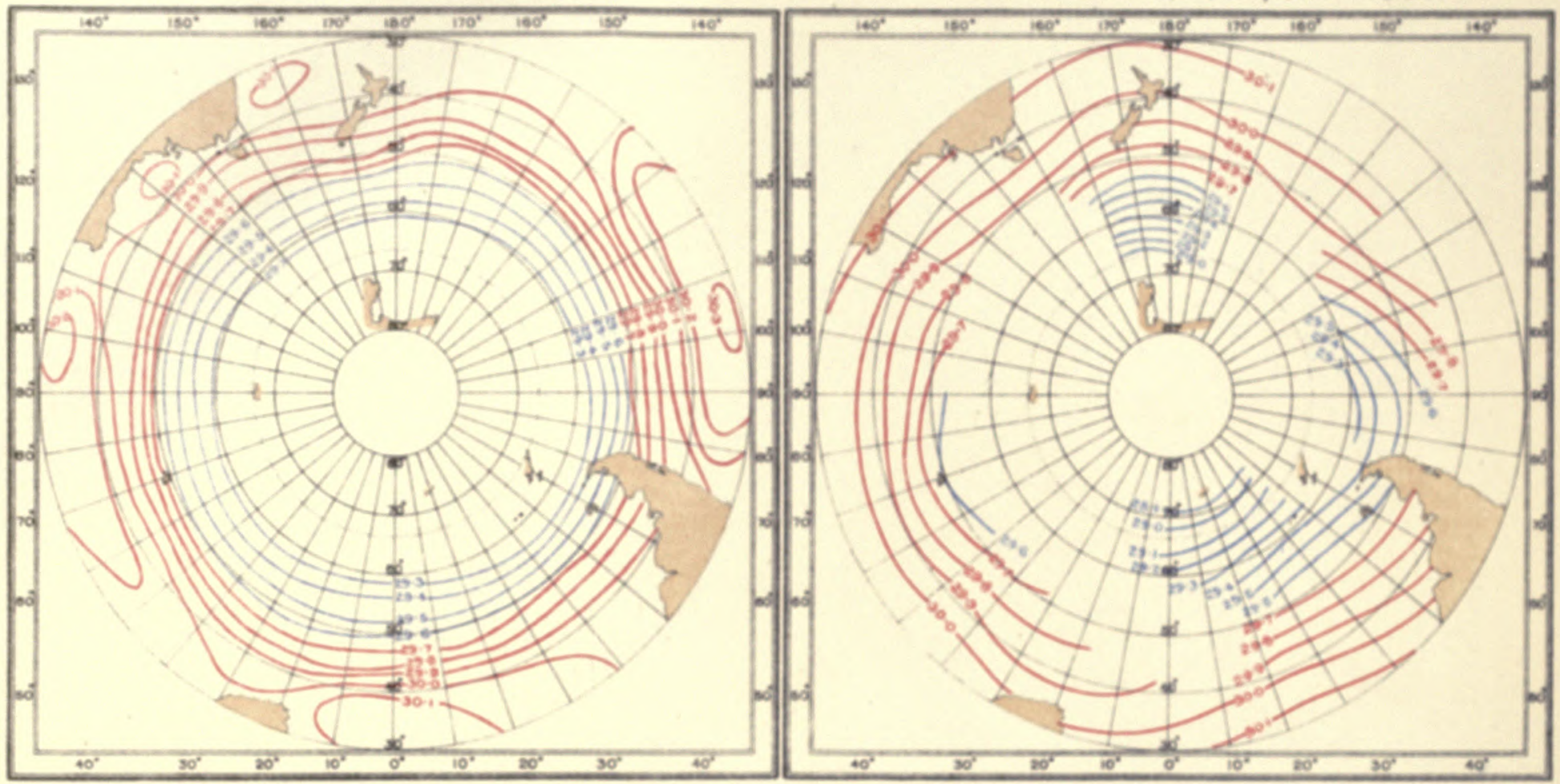

NORMAL AIR TEMPERATURE.

MARCH MEAN AIR TEMPERATURE, NOON, G.M.T. 1904.

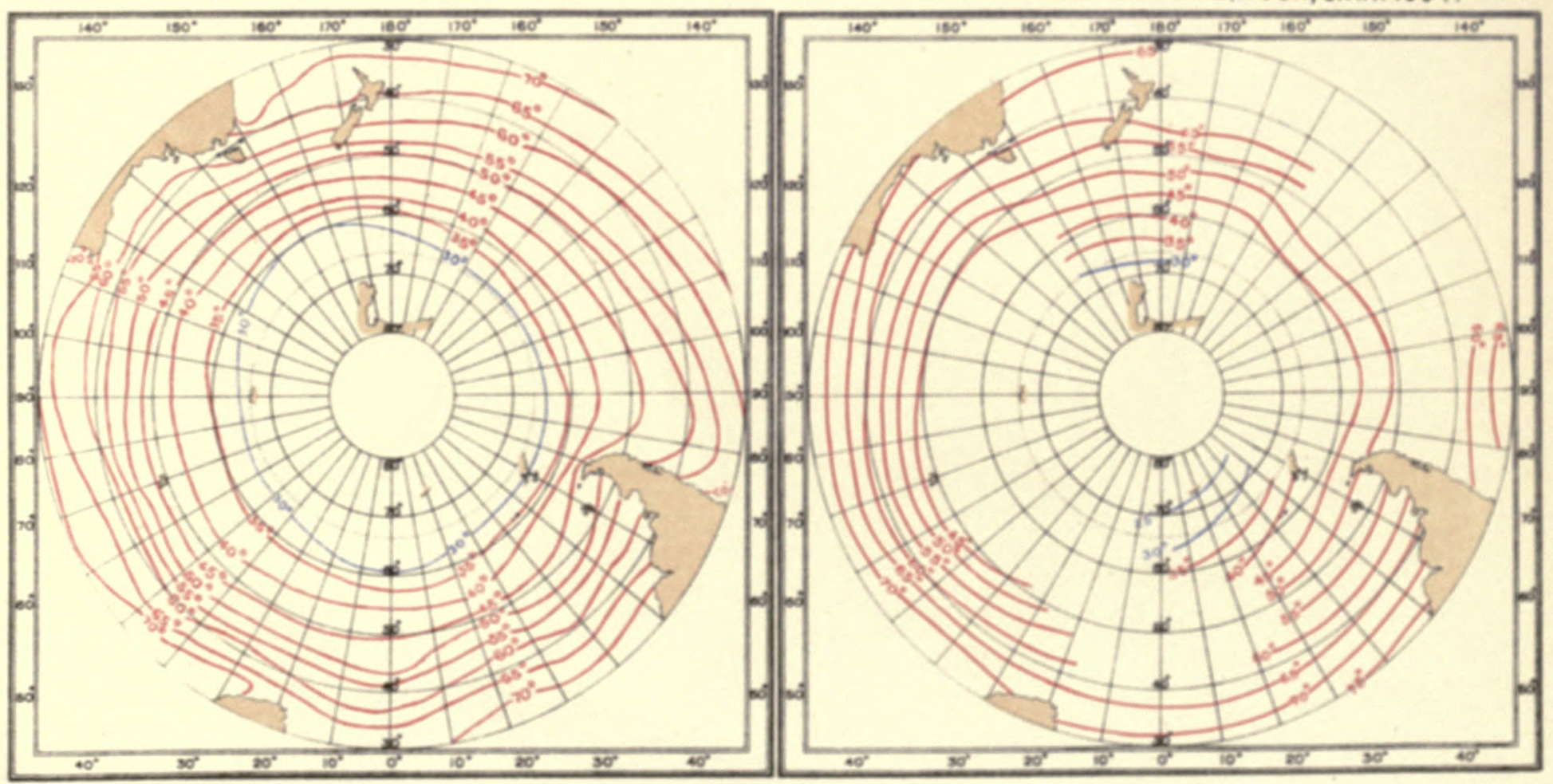


i 




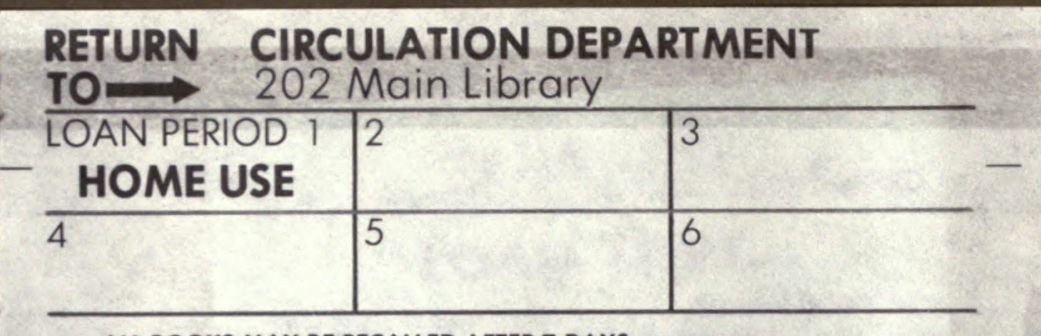

ALL BOOKS MAY BE RECALLED AFTER 7 DAYS

1. month loans may be renewed by calling 642.3405

6. month loans may be recharged by bringing books to Circulation Desk

Renewals and recharges may be made 4 days prior to due date

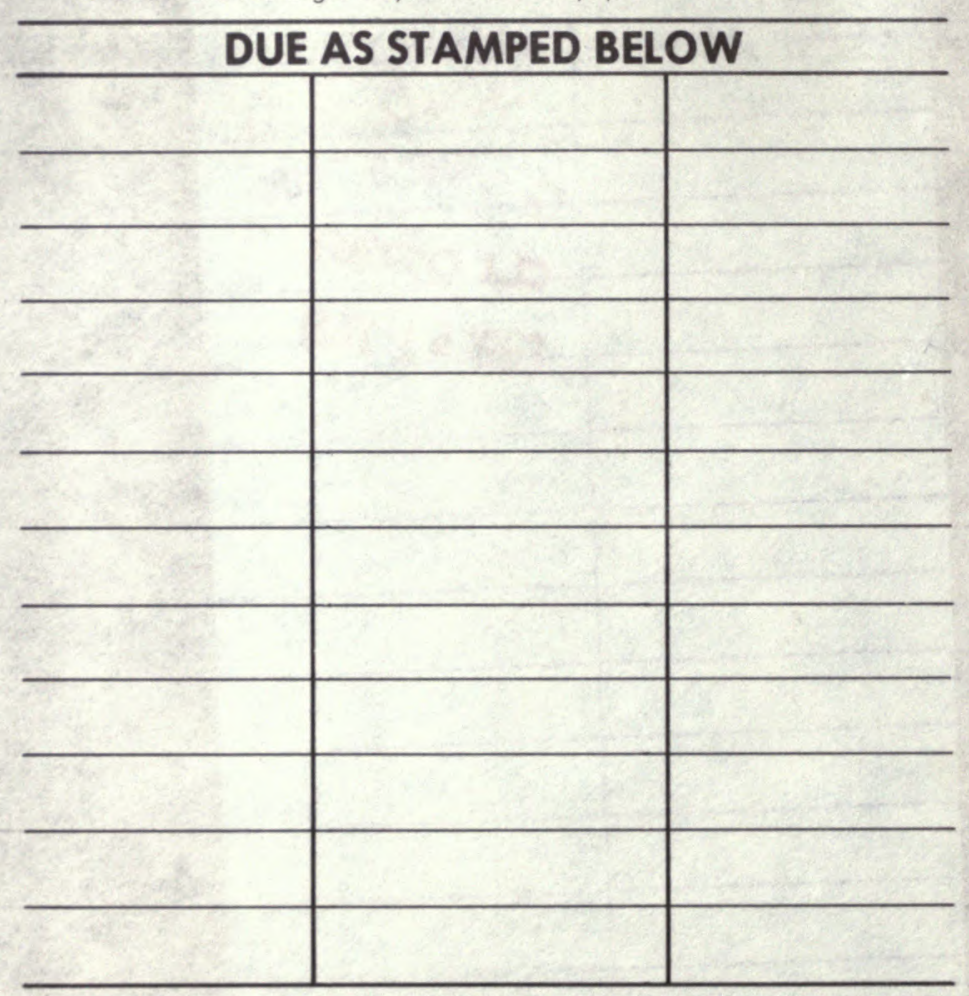

UNIVERSITY OF CALIFORNIA, BERKELEY FORM NO. DD6, 60m, 12/80 BERKELEY, CA 94720 


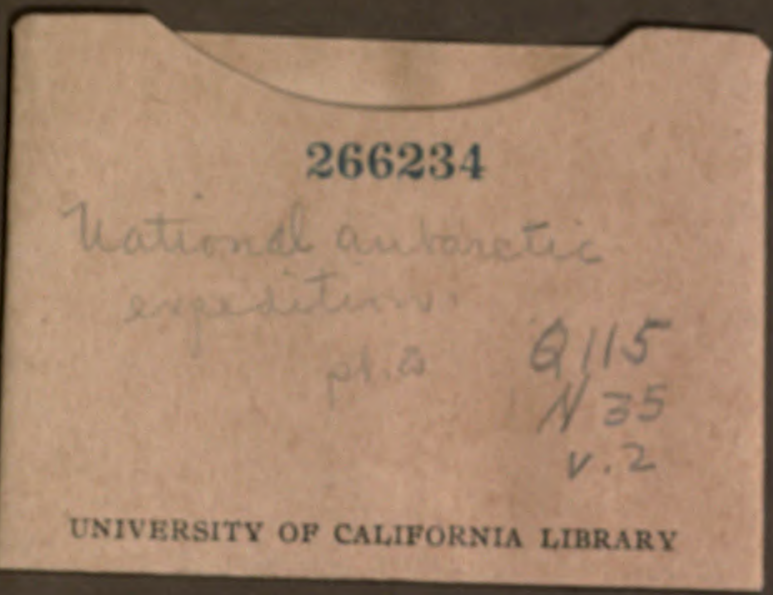


